Título de la tesis:

Análisis multidimensional de la aplicación de Aprendizaje Integrado de Contenidos y Lengua en Educación Física / Multidimensional analysis of the application of Content and Language Integrated Learning in Physical Education

Doctoranda:

Celina Salvador García

Directores de la tesis:

Oscar Chiva Bartoll y María Noelia Ruiz Madrid

Mes y año:

Enero 2019 



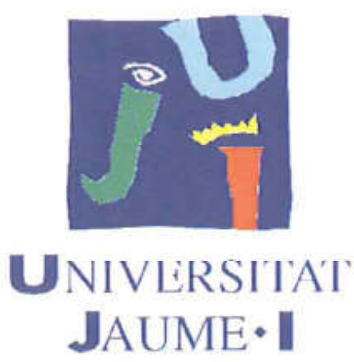

Programa de Doctorado en Educación

Escuela de Doctorado de la Universitat Jaume I

Análisis multidimensional de la aplicación de Aprendizaje Integrado de Contenidos y Lengua en Educación Física

Multidimensional analysis of the application of Content and Language Integrated Learning in Physical Education

Memoria presentada por Celina Salvador García para optar al grado de doctor/a por la Universitat Jaume I

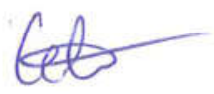

Doctoranda:

Celina Salvador García

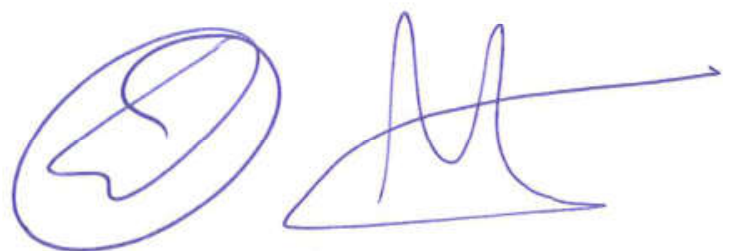

Directores:

Oscar Chiva Bartoll

$M^{a}$ Noelia Ruiz Madrid

Castelló de la Plana, enero 2019. 


\section{Financiación recibida}

Plan de Promoción de la Investigación de la Universitat Jaume I, 2016.

Beca FPI-UJI PRE-DOC (Programa 541-A). 
Tesis por compendio de las siguientes publicaciones:

- Salvador-García, C., Chiva-Bartoll, O., \& Ruiz, N. (2016). Aprendizaje integrado de contenidos y lengua extranjera. Educación física e inglés. En O. Chiva \& M. Martí (Coord.), Métodos pedagógicos activos y globalizadores (pp. 45-64). Barcelona: Graó.

- Salvador-García, C., Chiva-Bartoll, O., \& Isidori, E. (2017). Aprendizaje de un idioma extranjero a través de la Educación Física: una revisión sistemática. Movimento, 23(2), 647-660.

- Salvador García, C., \& Chiva Bartoll, O. (2017). CLIL in teaching physical education: views of the teachers in the Spanish context. Journal of Physical Education and Sport, 17(3), 11301138. DOI: 10.7752/jpes.2017.03174

- Salvador-García, C., Chiva-Bartoll, O., \& Vergaz-Gallego, J. J. (2018). Percepción del alumnado sobre el uso del método AICLE en Educación Física: estudio de caso. Retos: nuevas tendencias en educación física, deporte y recreación, (33), 138-142.

- Salvador-García, C., Chiva-Bartoll, O. \& Colomer, C. The effect of bilingual Physical Education on students' Physical Activity. Things are not always as they seem. Ciencia, Cultura y Deporte, $x x(x x), x x-x x$. (aceptado)

- Salvador-García, C., Chiva-Bartoll, O., \& Capella-Peris, C. Educación física bilingüe: efectos de CLIL sobre los niveles de actividad física. (en revisión)

"Esta tesis dispone de la aceptación de los coautores de las publicaciones que el doctorando/a presenta como tesis y su renuncia expresa a presentarlas como parte de otra tesis doctoral" 

A mi familia, tanto los que están como los que siguen estando. 



\section{Agradecimientos}

Resulta curioso que las primeras palabras de una tesis sean las últimas en ser redactadas, hecho que no obsta para que carezca de sentido. Solo cuando se atisba el destino al cual nos conduce el viaje que emprendimos con esta tesis doctoral, es posible advertir cuántos han colaborado, de una u otra forma, a lo largo del camino. Son incontables las personas que han contribuido a que este trabajo pueda salir adelante $\mathrm{y}$, por tanto, prácticamente imposible mencionarlas a todas. Sin embargo, me siento ante la necesidad de agradecer a todos y todas vuestra ayuda, indispensable, aunque no os lo parezca, para que yo pueda estar acercándome al final de este recorrido.

En primer lugar, me gustaría dar las gracias al profesor Òscar Chiva Bartoll, director de esta tesis doctoral. Sin duda, una de las personas de las que más he podido aprender durante los últimos años. Gracias por dejarme acompañarte y mostrarme en qué consiste el tan apasionante mundo universitario, ha sido todo un privilegio poder contar con tu guía y apoyo. Resulta imposible expresar toda la ayuda que me has brindado, mostrándome el camino a seguir, y siendo el mejor ejemplo posible de trabajo, constancia, tesón y esfuerzo. Por todo ello, no puedo dejar de reconocer la gran admiración que siento. Ojalá la conclusión de este trabajo no sea más que una etapa de un largo viaje en el que podamos continuar compartiendo itinerario.

También, cómo no, es de justicia agradecer a la profesora Noelia Ruiz Madrid su labor de codirección del trabajo y aportación al mismo. Sus sabias palabras y conocimiento han sido de un gran valor para el desarrollo de esta tesis. Todo parece más sencillo cuando alguien con su sensatez y buen hacer respalda y aporta su experiencia para que el trabajo pueda salir adelante. En cualquier empresa es importante estar bien rodeados a fin de llegar a buen puerto, y contar con alguien de su perfil ha posibilitado que los contenidos tratados en este trabajo se mantuvieran en armónico equilibrio.

Por otra parte, es muy importante para mí agradecer al IES El Caminás que nos abriera sus puertas y dejara que dos de sus grupos participaran en nuestra investigación. En especial, quería agradecer su gran labor y dedicación a Emilia Herrera Mor, la profesora que nos brindó la oportunidad de poder ver y estudiar sus clases de educación física. Gracias también a todos 
los alumnos y alumnas, así como sus padres y madres, que han sido partícipes en nuestros estudios. Sin su aportación gran parte de este trabajo no habría sido posible. Igualmente, quiero agradecer a los docentes de educación física que accedieron a participar en nuestro estudio, llenos siempre de ilusión y buenas palabras.

Otras personas a quienes quiero mostrar mi más profundo agradecimiento son todas aquellas cuya colaboración ha sido indispensable para el desarrollo de los diferentes manuscritos que conforman esta tesis. Muchas gracias a Mireia Adelantado, no solo por tu generosidad y respaldo en el trabajo de acelerometría, sino también por tu eterna sonrisa como compañera de área y despacho. Igualmente, agradecer a Edgar Bernad su colaboración, tanto por el material que nos proporcionó, como también por sus explicaciones y tiempo. Gracias también a los profesores y compañeros Emanuele Isidori, Carla Colomer, Carlos Capella y Juan José Vergaz, su labor como co-autores en los respectivos manuscritos ha sido excelente e indispensable para que pudieran salir adelante.

He tenido el privilegio de poder trabajar con el doctor Emanuele Isidori y con la doctora Alessandra Fazio, quienes me acogieron con los brazos abiertos mostrando siempre una gran predisposición y voluntad de colaboración mutua. Gracias por permitirme aprender y trabajar con vosotros, así como por la amabilidad con la que siempre me habéis tratado.

Hago extensivo este agradecimiento al grupo de investigación Endavant que me ha acogido como una más y me ha permitido formarme y aprender en otros campos ajenos a los de esta tesis. También quisiera dar las gracias al grupo de innovación SPIEDA, ya que me ha concedido la oportunidad de poder codearme y aprender de grandes profesionales de la enseñanza de lenguas. Además, me gustaría agradecer a la Universitat Jaume I la formación que me ha proporcionado, y la Beca Predoctoral FPI-UJI que me fue otorgada para la realización de este trabajo, ya que me ha permitido vivir la universidad desde otra perspectiva, pudiendo disfrutar aún más de ella. Pese a que con la conclusión de esta tesis finaliza mi etapa de doctorado, espero que esto no sea un adiós, sino un hasta luego.

Por supuesto, quiero agradecer infinitamente a mi familia su comprensión y apoyo constantes. Son muchísimas las horas que les he quitado pegada al ordenador trabajando. Sin embargo, nunca he recibido una palabra de reproche por su parte, sabían que estaba disfrutando de lo que hacía, y su comprensión y fuerza han sido vitales para mí. Gracias por 
estar ahí incondicionalmente y también a quien ya no está, ojalá hubieras podido ver estas líneas escritas, solo espero que puedas sentirte orgullosa de mí.

En definitiva, a todas las personas que me habéis acompañado en algún momento de mi vida, sea aquí en la otra parte del planeta, todas habéis contribuido a que yo haya podido llegar hasta aquí. Gracias. 



\section{Resumen}

INTRODUCCIÓN. El apartado introductorio justifica la necesidad de analizar el impacto que la aplicación de AICLE (Aprendizaje Integrado de Contenidos y Lengua) acarrea para los actores implicados en el proceso de enseñanza-aprendizaje de la educación física: el profesorado, el alumnado y la propia materia. CONTEXTUALIZACIÓN Y PLANTEAMIENTO DEL TRABAJO. Este apartado delimita el problema de investigación y define los objetivos del trabajo: O.1. Averiguar cuál es el estado de la cuestión en el campo de la educación física mediante el enfoque AICLE. O.1.1. Determinar cuál es el marco teórico particular de la educación física mediante AICLE y concretar sus posibilidades de aplicación. O.1.2. Examinar cuáles son y qué analizan los artículos de mayor impacto que vinculan educación física y enseñanza de lenguas extranjeras. O.2. Investigar cuáles son las percepciones sobre la aplicación de AICLE en educación física de los agentes implicados directamente en su desarrollo. O.2.1. Analizar cómo vive y qué opina sobre AICLE el profesorado de educación física que lo ha aplicado en sus clases. O.2.2. Examinar cómo vive y qué opina el alumnado sobre el uso de AICLE en clase de educación física. O.3. Analizar cómo afecta el uso del enfoque AICLE en las sesiones de educación física. O.3.1. Examinar si la utilización de AICLE en educación implica que se vean alterados los niveles de actividad física del alumnado durante las sesiones en comparación con las sesiones ordinarias de esta asignatura. O.3.2. Conocer si el enfoque AICLE repercute sobre el nivel de actividad física moderada-vigorosa del alumnado y, en caso afirmativo, comprender cómo y por qué. Acto seguido, siguiendo la lógica de tesis doctoral adscrita a la modalidad de compendio de publicaciones, se presentan los distintos manuscritos que componen la investigación, tratando de ofrecer una respuesta clara y ordenada a cada uno de los objetivos planteados a partir del uso de diferentes enfoques metodológicos: cualitativo, cuantitativo y mixto. MARCO TEÓRICO. Dicho apartado enmarca teóricamente la acuciante necesidad social de aprender lenguas, justificando la pertinencia del Aprendizaje Integrado de Contenidos y Lengua en los diferentes niveles y etapas educativas. Seguidamente, se abordan los elementos constitutivos y principales funciones de la asignatura de educación física, para finalizar analizando las convergencias que emergen entre los componentes del referido binomio (AICLE y educación física). PROYECTO DE INVESTIGACIÓN. En él se compendian los diferentes manuscritos que conforman la presente tesis, en consonancia con cada uno de 
los objetivos de investigación planteados. Los dos primeros manuscritos esbozan el marco teórico relativo a la educación física mediante AICLE, el tercero y el cuarto manuscritos se detienen respectivamente en el análisis cualitativo de las percepciones del profesorado y del alumnado. El quinto y sexto analizan el impacto de AICLE sobre los niveles e intensidad de la actividad física realizada en las sesiones y las razones que subyacen. DISCUSIÓN. Con la meta de ofrecer una discusión global este punto contrasta nuestros resultados con los trabajos previos de referencia. En los casos relativos a la percepción del alumnado y del profesorado sobre el uso de AICLE, pese a descubrir matices de gran interés, nuestra investigación va en la línea marcada por el corpus precedente. No obstante, en lo concerniente al tercer objetivo, la presente tesis doctoral plantea un inesperado giro en el guion, mostrando que los niveles de la actividad física que provoca la introducción de AICLE en educación física podrían verse incrementados. Este hecho reviste gran interés y abre una potente línea de investigación para el futuro. CONCLUSIONES. La tesis finaliza con un apartado de conclusiones que concreta la consecución positiva de los diferentes objetivos de estudio. Se ve cumplido así el fin último de esta investigación educativa, dado que aportamos resultados empíricos y puntos de vista novedosos que permitirán mejorar la aplicación del enfoque AICLE en educación física. 


\begin{abstract}
INTRODUCTION. The introductory section justifies the necessity to analyse the impact that CLIL (Content and Language Integrated Learning) has on the main actors of the physical education teaching and learning process: the teachers, the students and the subject.
\end{abstract} CONTEXTUALISATION AND APPROACH OF THE STUDY. This section delimits the research problem and defines the objectives of the work: O1. To find out what the current status of the issue is in the field of teaching physical education through the CLIL approach. O.1.1. To determine the particular theoretical framework of physical education through CLIL and to establish its applicability. O.1.2. To determine which high-impact articles link physical education and the teaching of foreign languages and what exactly they analyse. O.2. To investigate the way the application of CLIL in physical education is perceived by those directly involved in its development. O.2.1. To analyse the day-to-day experience of physical education teachers who have applied CLIL in their classes and what they think about it. O.2.2. To examine students' day-to-day experience of the use of CLIL in their physical education classes and what they think about it. O.3. To analyse how the use of the CLIL approach affects the physical education sessions. O.3.1. To examine whether the use of CLIL in education implies that students' levels of physical activity are altered during the sessions in comparison to the ordinary sessions in this subject. O.3.2. To know whether the CLIL approach affects the level of moderate to vigorous physical activity of students and, if so, to understand how and why it does so. Next, consistent with the format of article thesis (thesis by publication), the six manuscripts that compose this work are listed, attempting to offer a clear and organized response to each of the objectives established. To do so, qualitative, quantitative and mixed methods are used. THEORETICAL FRAMEWORK. This section describes that, according to the literature, there is a clear need to learn languages, therefore, justifying the pertinence of Content and Language Integrated Learning application at different levels and stages in education. Then, we address the elements that physical education consists of as well as its aims. After that, the overlap between CLIL and physical education is examined. RESEARCH PROJECT. This section presents the different manuscripts that go to make up this thesis, in coherence with the research objectives pursued. The first two manuscripts outline the theoretical framework regarding physical education through CLIL; the third and the fourth manuscripts analyse from a qualitative perspective the 
perceptions of teachers and students. The fifth and sixth focus on analysing the effect produced by the use of CLIL on the levels of physical activity displayed in physical education classes as well as the underlying reasons. DISCUSSION. In order to offer a general discussion, this section presents all the results obtained in the manuscripts taken together. Regarding the students' and teachers' perceptions about CLIL, despite some new and interesting nuances found, our research is aligned with the previous literature. However, referring to the third objective, this doctoral thesis makes an unexpected and sharp turn pinpointing that physical activity levels generated by CLIL in the physical education subject might be increased. These findings are of great interest and open a powerful line of research for the future. CONCLUSIONS. The thesis ends with a conclusions section in which we discuss the achievement of the different research objectives. The main aim of this educational research is accomplished since the empirical results and new viewpoints provided will lead toward the improvement of CLIL in physical education. 
Índice

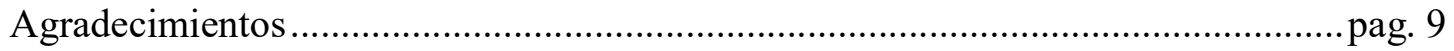

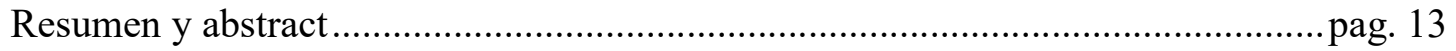

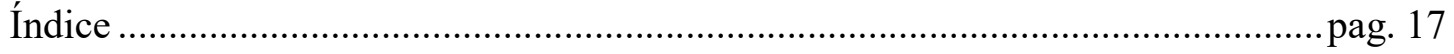

Sumario de tablas y figuras …................................................................................pag. 20

1. Introducción ..................................................................................................................pag. 23

1bis. Introduction ........................................................................................................pag. 28

2. Contextualización y planteamiento del trabajo ...................................................pag. 33

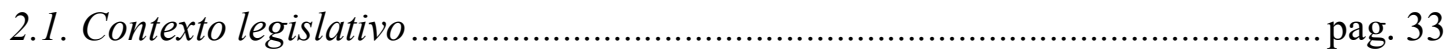

2.1.1. La asignatura de lengua extrajera ..............................................................pag. 34

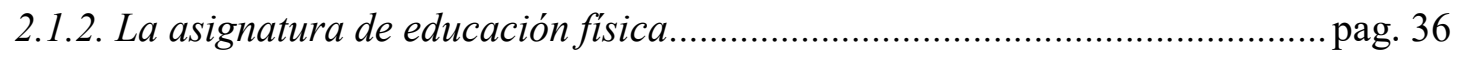

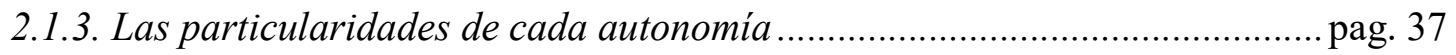

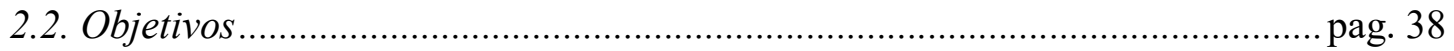

2.3. El compendio de publicaciones ......................................................................... 40

3. Marco teórico .........................................................................................................................pag. 45

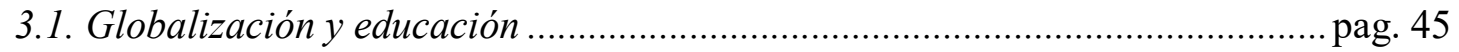

3.2. El aprendizaje de lenguas en un mundo global.................................................. 49

3.3. Competencia comunicativa como respuesta al contexto social ...................... pag. 52

3.4. Aprendizaje Integrado de Contenidos y Lengua .......................................... pag. 54

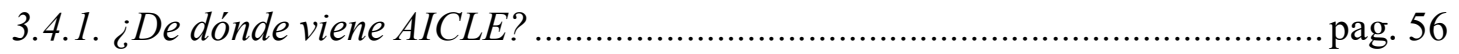

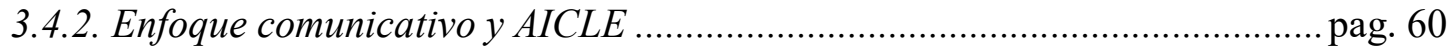

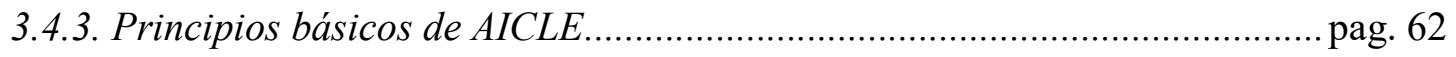

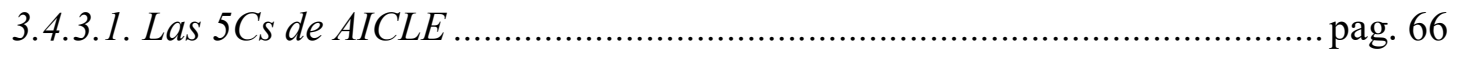


3.4.3.2. La lengua en AICLE. pag. 70

3.4.4. AICLE en diferentes etapas educativas pag. 73

3.4.4.1. Educación infantil pag. 74

3.4.4.2. Primaria pag. 75

3.4.4.3. Secundaria pag. 78

3.4.4.4. Universidad pag. 80

3.4.5. Beneficios de AICLE pag. 83

3.4.6. Críticas hacia AICLE pag. 84

3.5. La educación física. pag. 87

3.5.1. De dónde viene y hacia dónde va la educación física pag. 88

3.5.2. La educación física y el desarrollo integral del alumnado pag. 91

3.5.3. Elementos nucleares de la educación física..... pag. 92

3.5.4. Finalidades de la educación fisica. pag. 98

3.5.5. El proceso de enseñanza-aprendizaje en educación física pag. 100

3.5.6. El futuro de la educación física. pag. 108

3.6. Educación física y AICLE ..... pag. 110

3.6.1. Definiendo la educación física mediante AICLE pag. 111

3.6.2. Convergencias entre educación física y AICLE. pag. 112

3.6.3. Redefiniendo las funciones de la educación física pag. 119

3.6.4. El proceso de enseñanza-aprendizaje en educación física mediante AICLEpag. 122 3.6.5. El rol docente en la educación fisica mediante AICLE. pag. 135

3.6.6. El rol del alumnado en educación física mediante AICLE pag. 138

3.6.7. Investigación en educación física mediante AICLE pag. 140 
4. El proyecto de investigación ................................................................................... pag. 145

4.1. Establecimiento del marco teórico ..................................................................... 146

4.2. Estudio de las percepciones de los principales agentes implicados .............. pag. 195

4.3. Investigación empírica del efecto de AICLE sobre la actividad física del alumandopag. 243

5. Discusión .pag. 289

5.1. Discusión Objetivo 1 pag. 290

5.2. Discusión Objetivo 2 pag. 292

5.3. Discusión Objetivo 3 pag. 295

6. Conclusiones. .pag. 299

6bis. Conclusions. pag. 305

7. Referencias bibliográficas.....................................................................................pag. 311

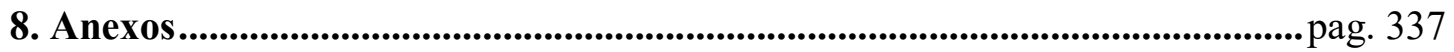




\section{Sumario de tablas:}

Tabla 1. Bloques de contenido área de lengua extranjera

Tabla 2. Bloques de contenido de educación física

Tabla 3. Objetivos y sub-objetivos de investigación

Tabla 4. Las finalidades de la educación física actual

Tabla 5. Bloques de modelos pedagógicos

Tabla 6. Resumen de los estilos de enseñanza

Tabla 7. Elementos de AICLE que dan respuesta a las analogías de los modelos

Tabla 8. Guía para el diseño de tareas equilibradas en educación física mediante AICLE

\section{Sumario de figuras:}

Figura 1. Motivos para aprender lenguas

Figura 2. Objetivos generales de AICLE

Figura 3. Elementos fundamentales de AICLE

Figura 4. Taxonomía revisada de Bloom

Figura 5. Taxonomía de Marzano y Kendall

Figura 6. Matriz de Cummins (2000)

Figura 7. Tríptico del lenguaje (Coyle, Hood y Marsh, 2010)

Figura 8. Analogías y consideraciones pedagógicas de los modelos pedagógicos

Figura 9. Espectro estilos de enseñanza

Figura 10. Aspectos coincidentes entre educación física y AICLE

Figura 11. Estrategias didácticas para la educación física mediante AICLE

Figura 12. Retos del profesorado AICLE según Valdés (2016) 
Figura 13. Situaciones comunicativas en educación física mediante AICLE 



\section{Introducción}

"Change in education is easy to propose, hard to implement, and extraordinary difficult to sustain" (Hargreaves y Fink, 2006, p.6)

Desde la entrada en la democracia nuestro país no ha dejado de sufrir vaivenes relativos a las políticas educativas que han repercutido, entre otras cuestiones, sobre la enseñanza de idiomas y, más recientemente, sobre el uso de diferentes lenguas vehiculares en asignaturas no lingüísticas. Las seis reformas educativas vividas en este tiempo son buena prueba de ello, cada una con sus propias características y múltiples cambios.

Como indican Hargreaves y Fink (2006) en las líneas que encabezan este texto, promulgar cambios en educación es tarea sencilla, pero esto no obsta para que su implementación práctica y su mantenimiento en el tiempo no dejen de ser una empresa compleja y ciertamente ardua. En este momento el aprendizaje de lenguas a través de otros contenidos curriculares es una de las tendencias más extendidas en lo relativo a la enseñanza de idiomas, por lo que conocer las posibles fortalezas, debilidades y limitaciones de esta tendencia es una necesidad que la investigación educativa debe acometer sin vacilación.

Ante la volátil coyuntura de la legislación educativa que nos rige, existe un auge en la implementación del aprendizaje integrado de contenidos y lengua (AICLE). Sin embargo, como concluyen Lagasabaster y Ruiz de Zarobe (2010), pese a que todo indica que su uso está en el camino adecuado, sigue quedando mucho por recorrer. Sin ir más lejos, existe una acuciante necesidad de investigar dicho enfoque ubicando el punto de mira desde las diferentes materias que lo acogen, como es el caso de la educación física (FernándezSanjurjo, Fernández-Costales y Arias-Blanco, 2017). La educación física, al igual que el resto de materias curriculares, encierra multitud de elementos constitutivos en los que conviene reparar y que, bajo ningún concepto deberían verse diluidos por la introducción de AICLE. Sin embargo, aún no se ha demostrado con claridad que la incorporación de dicho enfoque pedagógico, más allá de ser positiva para el aprendizaje de lenguas, no afecta negativamente sobre los rasgos esenciales o intrínsecamente constitutivos de la materia curricular. 
Sin duda, como propone De Miguel (2015), todo trabajo de investigación empírica dentro del terreno educativo debe tener por objeto mejorar la práctica educativa, siendo este uno de los cometidos de la presente tesis doctoral. Siguiendo esta lógica el trabajo que se presenta ofrece evidencias cargadas de significado que nos permitirán comprender qué está ocurriendo en las clases de educación física cuando se adopta el enfoque AICLE. Solo de esta manera sabremos si estamos haciendo las cosas de manera óptima o si existen flancos susceptibles de mejora.

A este respecto, además, la elección de esta temática como objeto de estudio se encuentra ligada a mis motivaciones personales. El deporte y la actividad física siempre han sido partes fundamentales en mi vida. No en vano, mi formación inicial fue la de Maestra con especialidad en Educación Física. Sin embargo, con la intención de seguir formándome y aprendiendo, uno de los cánones que conforman mi propia idiosincrasia, decidí ampliar mi formación hacia el aprendizaje de lenguas siguiendo los pasos de mi madre, mi abuela y mi bisabuela. De este modo, cursé la adaptación al Grado de Educación Primaria con mención en Lengua Inglesa, primero, y el Máster en Comunicación Intercultural y Enseñanza de Lenguas más tarde. El Trabajo de Fin de Máster supuso ya el primer paso, la semilla de la cual nació esta tesis. En él decidí aunar dos de mis grandes aficiones, la educación física y el aprendizaje de lenguas. En particular, dicho trabajo supuso una primera tentativa de análisis sobre las implicaciones del uso del enfoque AICLE en educación física. No obstante, aquel texto originario nos supo a poco $\mathrm{y}$, manteniendo la guía de quienes finalmente han sido mis directores, decidimos apostar por ahondar en el estado de la cuestión y tratar de aportar un pequeño grano de arena a la empresa de descubrir qué subyace a este conjunto de prácticas educativas. De hecho, el problema de investigación que rige este trabajo se centra los entresijos que implica la práctica AICLE en educación física, a fin de dar voz y estudiar las percepciones y la realidad que afecta a los agentes implicados a fin de conocer posibles flancos de mejora.

Este propósito general se concreta en tres objetivos de investigación que son los que guiarán el devenir de esta investigación. A su vez, cada uno de estos objetivos de investigación se divide en otros dos sub-objetivos, descritos en la sección 2 de esta tesis y abordados respectivamente en cada uno de los manuscritos presentados. 
En concreto estos tres objetivos son:

- Objetivo 1. Averiguar cuál es el estado de la cuestión en el campo de la educación fisica mediante el enfoque AICLE.

- Objetivo 2. Investigar cuáles son las percepciones que tienen los actores directamente implicados sobre la aplicación de AICLE en educación física.

- Objetivo 3. Analizar cómo afecta el uso del enfoque AICLE en las sesiones de educación física.

El formato de la presente tesis se adscribe a la modalidad de tesis doctoral por compendio de publicaciones. En base a la lógica de este formato, el trabajo se encuentra dividido en seis apartados. Tras esta introducción, en la que se presenta brevemente el problema de investigación, da comienzo el segundo apartado del texto en el que se expone sucintamente la contextualización y planteamiento del trabajo. A través del mismo se presenta el contexto legislativo relativo al tópico abordado, haciendo especial mención a las dos disciplinas sobre las cuales nos vamos a centrar, la lengua extranjera y la educación física, y a las particularidades propias de la autonomía en la cual se circunscribe el trabajo. Además, en este mismo apartado se explicitan los objetivos planteados en la tesis doctoral y se enumeran las seis publicaciones que tratan de darles respuesta.

El tercer apartado presenta el marco teórico relativo al enfoque AICLE a través del área de educación física. Comenzamos realizando una aproximación general, en la cual partimos del efecto generado por la globalización como fenómeno característico actual. Fruto de dicho fenómeno, emerge en la sociedad una patente necesidad de aprender lenguas, ante la cual la educación debería dar respuesta, para lo que es necesario entender el aprendizaje de lenguas adoptando un enfoque comunicativo. Tras abordar todas estas cuestiones, pasamos a presentar el Aprendizaje Integrado de Contenidos y Lengua (AICLE), un enfoque dual que parece tener el potencial de dar respuesta a la tesitura planteada (Coyle, Hood y Marsh, 2010). En primer lugar, realizamos un breve recorrido por el camino por el que este enfoque pedagógico ha transitado durante sus aproximadamente dos décadas de vida, para continuar exponiendo sus convergencias con el enfoque comunicativo. Seguidamente, exponemos sus principios básicos, así como los elementos nucleares que lo componen. Además, realizamos un breve comentario sobre la aplicación de AICLE en diferentes niveles y etapas educativas 
para terminar, finalmente, exponiendo tanto los beneficios como las críticas que se le achacan.

Posteriormente nos adentramos en la asignatura de educación física, comentando concisamente su historia, los elementos que la conforman, sus finalidades o cómo se desarrolla su proceso de enseñanza-aprendizaje, para finalizar esbozando el futuro que se atisba en dicha materia. Este futuro parece apuntar hacia su posible integración o desarrollo conjunto con otras materias curriculares, por lo que seguidamente se pasa a abordar la imbricación del binomio AICLE-educación física. En este punto, exponemos las definiciones que se han dado a las propuestas realizadas, comentamos las convergencias que emergen entre los componentes del referido binomio, y abordamos los elementos nucleares de la educación física cuando se adscribe al empleo del enfoque AICLE.

El cuarto apartado detalla el proyecto de investigación presentado en esta tesis. En él se especifican secuencialmente los objetivos perseguidos, en coherencia con el desarrollo del trabajo realizado. Junto a cada objetivo, además, se muestran los diferentes manuscritos que conforman la presente tesis. Concretamente se presentan dos manuscritos para dar respuesta a cada uno de los tres objetivos de investigación planteados. De este modo, los dos primeros manuscritos permiten esbozar el marco teórico relativo a la educación física mediante AICLE, los dos siguientes analizan las percepciones de profesorado, por un lado, y alumnado, por otro; y los dos últimos textos se focalizan en analizar el efecto generado por el uso de AICLE sobre los niveles de actividad física mostrado en las sesiones de educación física.

El quinto apartado se destina a realizar una discusión conjunta de los resultados obtenidos, puesto que estos se encuentran expuestos en los diferentes manuscritos y se tratan allí de forma independiente. En este punto, el trabajo pretende presentar una visión global y más general, sustentada en las evidencias empíricas obtenidas, sobre aquello que sucede en las clases de educación física cuando se incorpora el enfoque AICLE. Por último, finalizamos el trabajo con el apartado 6, en el cual exponemos las conclusiones a las que llegamos tras el desarrollo, reflexión y análisis del trabajo realizado.

En conjunto, el presente trabajo nace con la esperanza de dibujar un futuro educativo que preste especial atención a las políticas relacionadas con el aprendizaje de nuevas lenguas en materias no lingüísticas, esencialmente en educación física. Así, se insta a los responsables 
políticos e institucionales, desde el rigor que la investigación educativa nos otorga, a tomar decisiones eficaces en la consecución de objetivos eficientes y equilibrados en el balance entre los recursos invertidos y los resultados obtenidos, así como pertinentes en la apuesta por los principios y valores democráticos y plurales que configuran nuestra identidad social y cultural. 


\section{1bis. Introduction}

"Change in education is easy to propose, hard to implement, and extraordinarily difficult to sustain” (Hargreaves \& Fink, 2006, p.6)

Since our country returned to democracy, it has not ceased to suffer a series of ups and downs regarding educational policies that have had repercussions on, among other things, the teaching of languages and, more recently, on the use of different vehicular languages in nonlinguistic subjects. The six educational reforms that have been implemented during this period, each of them with its own characteristics and numerous changes, are clear proof of this situation.

As pointed out by Hargreaves and Fink (2006) in the quotation heading this text, promoting changes in education is a simple task, but this does not prevent their practical implementation and maintenance over time from being a complex and certainly arduous undertaking. At present, language learning through other curricular content is one of the most widespread trends in language teaching, and thus knowing its possible strengths, weaknesses and limitations is a necessity that educational research must tackle without further hesitation.

While the legislation on education has given rise to a rather volatile situation, there is currently a boom in the implementation of Content and Language Integrated Learning (CLIL). Nevertheless, as Lagasabaster and Ruiz de Zarobe (2010) conclude, although everything seems to indicate that its use is on the right track, there is still a long way to go. Without going any further, there is a pressing need to investigate this approach by placing the spotlight on the different subjects that embrace it, as is the case of physical education (Fernández-Sanjurjo, Fernández-Costales \& Arias-Blanco, 2017). Physical education, like all other curricular subjects, contains a multitude of constitutive elements that need to be taken into account and which under no circumstances should be diluted by the introduction of CLIL. However, it has not yet been clearly demonstrated that the incorporation of such a pedagogical approach, beyond being positive for language learning, does not have a negative effect on the essential or intrinsically constitutive features of the curricular subject. 
Undoubtedly, as proposed by De Miguel (2015), all empirical research work conducted within the field of education must have the improvement of teaching practice as its goal, this being one of the aims of this doctoral thesis. Following this logic, the work presented here offers meaningful evidence that will enable us to understand what is going on in physical education classes when the CLIL approach is adopted. Only in this way will we know whether we are going about things in the best possible way or if there are aspects that can be improved.

In this respect, moreover, the choice of this topic as a subject of study is also linked to my own personal motivations. Sport and physical activity have always been an essential part of my life. Hence, unsurprisingly, my initial training was as a teacher, specialised in physical education. However, with the intention of continuing my training and learning process (one of the canons that make up my own idiosyncrasy) I decided to follow in the footsteps of my mother, my grandmother and my great-grandmother and expand my training towards language learning. Thus, I first took the bridging course required to pursue the Bachelor's Degree in Primary Education, specialised in English, and, later, the Master's Degree in Intercultural Communication and Language Teaching. The Master's Thesis was to be the seed from which this thesis was to stem. In that work I decided to combine two of my great passions, physical education and language learning. Specifically, it was a first attempt to analyse the implications of the use of the CLIL approach in physical education. That original text, however, was not enough and, following the guidance of those who were to end up being my thesis supervisors, I decided to go deeper into the state of the question and try to make my own little contribution to the task of discovering what underlies this set of educational practices. Concretely, the three main objectives of this thesis are:

- Objective 1. To find out what the current status of the issue is in the field of teaching physical education through the CLIL approach.

- Objective 2. To investigate the way the application of CLIL in physical education is perceived by those directly involved in its development.

- Objective 3. To analyse how the use of the CLIL approach affects the physical education sessions. 
This doctoral thesis follows the format known as an article thesis (thesis by publication). Consistent with this format, the thesis is divided into six sections. This introduction, in which the research problem is briefly presented, is followed by the second section, where the contextualisation and approach of the study are outlined. This same section sets out the legislative context related to the topic being addressed, with special emphasis given to the two disciplines on which we are going to focus, foreign language and physical education, together with the particularities of the autonomous region in which the thesis is set. In addition, this second section explains the aims established in the doctoral thesis and lists the six publications that attempt to respond to them.

The third section describes the theoretical framework regarding the CLIL approach through the area of physical education. It begins with a general approximation, which starts out from the effect generated by globalisation as a phenomenon characterising today's world. As a result of this phenomenon, a clear need to learn languages emerges in society and education should respond to this necessity; to do so it is necessary to understand language learning by adopting a communicative approach. After addressing all these issues, the section goes on to present CLIL, a dual approach which seems to have the potential to respond to the situation being dealt with here (Coyle, Hood \& Marsh, 2010). First of all, we take a brief look at the path that this pedagogical approach has followed throughout the approximately two decades of its existence, and then go on to describe the points on which it converges with the communicative approach. Its basic principles are then outlined, together with the core elements it is made up of. Furthermore, we briefly comment on the application of CLIL at different levels and stages of education and finish by commenting on both its benefits and the criticism it has received.

We then turn to physical education by offering a concise history of the subject, the elements that it is made up of, its aims or how its teaching-learning process takes place. This section ends with a forecast of what the future appears to hold for this subject. This future seems to point towards its possible integration or joint development with other curricular subjects, and so we then examine the overlap between CLIL and physical education. At this point the same section presents the definitions that have been put forward for the proposals that have been 
made, comments on the components of this CLIL-physical education binomial, and addresses the core elements of physical education when attached to the use of the CLIL approach.

The fourth section offers details of the research project presented in this thesis. It sequentially specifies the objectives pursued, in coherence with the development of the work carried out. Additionally, each objective is accompanied by the different manuscripts that go to make up this thesis. More specifically, for each of the three research aims to be addressed, two manuscripts are presented in order to respond to them. Thus, the first two manuscripts outline the theoretical framework regarding physical education through CLIL; the next two analyse the perceptions of teachers, on the one hand, and students, on the other; and the last two texts focus on analysing the effect produced by the use of CLIL on the levels of physical activity displayed in physical education classes.

The fifth section contains a discussion of all the results obtained taken together, since in the different manuscripts they are presented and dealt with in an independent manner. At this point the thesis aims to provide an overall, more general view based on the empirical evidence obtained about what happens in physical education classes when the CLIL approach is incorporated into them. Lastly, the thesis ends with section 6, in which we discuss the conclusions reached after developing, reflecting on and analysing the work carried out.

Overall, this work was born with the hope of sketching out an educational future that pays special attention to policies related to the learning of new language in non-language subjects, essentially in physical education. Likewise, based on the rigour conferred by educational research, it also intends to urge political and institutional decision-makers to make efficient and well-adjusted decisions, in terms of striking a balance between the resources invested and the results obtained, while also ensuring they are relevant to the commitment to the democratic and plural principles and values that make up our social and cultural identity. 



\section{Contextualización y planteamiento del trabajo}

En esta sección mostramos la contextualización y planteamiento de la tesis doctoral presentada. Empezamos por el marco legal vinculado al problema de investigación a fin de sustentar los objetivos de estudio y, posteriormente, estar en disposición de definir el planteamiento investigador a seguir.

\subsection{Contexto legislativo}

El contexto educativo actual está sujeto al marco establecido por la legislación vigente. Con este punto de partida, el presente apartado tiene como fin esbozar la situación legislativa que se concreta en los dos campos nucleares que constituyen este trabajo, a saber, las lenguas extranjeras y la educación física. Para ello se aborda el marco legal tanto a nivel estatal como autonómico, haciendo referencia concreta a la Comunidad Valenciana por tratarse del territorio en el que se lleva a cabo el trabajo.

Tal y como viene siendo habitual en las numerosas reformas que han tomado parte en la legislación educativa española de las últimas décadas, el currículum vigente determina las diversas materias que deben ser trabajadas en las diferentes etapas escolares. No obstante, pese a este parcelamiento, se observa una declaración de intenciones por favorecer una visión educativa interdisciplinar tanto en el Real Decreto 126/2014, de 28 de febrero, por el que se establece el currículo básico de la Educación Primaria, como en Real Decreto 1105/2014, de 26 de diciembre, por el que se establece el currículo básico de la Educación Secundaria Obligatoria y del Bachillerato.

A nivel autonómico este hecho también se hace patente a través del reciente Decreto 88/2017 de 7 de julio, del Consell, por el que se modifica el Decreto 108/2014, de 4 de julio, del Consell, por el que se establece el currículo y se desarrolla la ordenación general de la Educación Primaria en la Comunitat Valenciana, que profundiza en la necesidad de incorporar innovaciones didácticas apostando, entre otros, por proyectos interdisciplinarios, tal y como se especifica en el punto 5 del artículo 12 de dicho texto:

"Para fomentar la innovación y promover la autonomía de los centros, la programación didáctica se puede llevar a cabo mediante proyectos específicos, como por ejemplo, trabajo por proyectos, por ámbitos, interdisciplinares, dirigidos a 
mejorar el éxito escolar que aseguren al alumnado la adquisición de las competencias y los objetivos del currículo.” (p. 24841)

Además, el Real Decreto 126/2014 expone que se "otorga a la capacitación para la comunicación en una o más lenguas extranjeras un lugar destacado entre los fines a cuya consecución está orientado nuestro actual sistema educativo" (p. 19394). Mientras que en el Decreto 108/2014 se indica que "la enseñanza y aprendizaje de las lenguas se ha convertido en una línea prioritaria, es fundamental la intervención docente coordinada desde el área o áreas que se aprenden en inglés y el área de lengua inglesa” (p. 16578). De modo que, en este contexto, la integración de varias asignaturas entre las que se encuentre la lengua extranjera parece loable y necesaria.

En el caso del presente trabajo de investigación el foco de interés recae específicamente sobre la combinación de la lengua extranjera con la educación física. Así, pasamos en primer lugar a comentar los elementos más destacados del marco legislativo referente a dicha lengua para, posteriormente, hacer lo propio con el de educación física.

\subsubsection{La asignatura de lengua extrajera}

La lengua extranjera forma parte de las asignaturas troncales del currículo, tanto en Educación Primaria como en Educación Secundaria Obligatoria ${ }^{1}$ y se alude explícitamente a su aprendizaje dentro de los objetivos generales en ambas etapas. Concretamente, el artículo 7 del Decreto 126/2014 que establece los objetivos de la Educación Primaria determina en el objetivo (f) "adquirir en, al menos, una lengua extranjera la competencia comunicativa básica que les permita expresar y comprender mensajes sencillos y desenvolverse en situaciones cotidianas." Por su parte, el artículo 11 del Real Decreto 1105/2014 relativo a la Educación Secundaria Obligatoria establece como objetivo (i) "comprender y expresarse en una o más lenguas extranjeras de manera apropiada".

Resulta interesante comentar que, a lo largo de estos dos decretos, se incide en fomentar el aprendizaje de dicha lengua de manera contextualizada y en el marco de situaciones comunicativas diversas que favorezcan un uso real y motivador de esta, para lo que el juego

\footnotetext{
${ }^{1}$ En esta etapa el currículo diferencia entre primera lengua extranjera, dentro de las materias troncales, y segunda lengua extranjera, que forma parte del bloque de las asignaturas específicas.
} 
y las tareas grupales son establecidos como elementos esenciales. Pese a promover el uso integrado de las destrezas lingüísticas, la asignatura de lengua extranjera presenta diferentes bloques de contenidos separando cada una de estas. En la Tabla 1 pueden apreciarse estos bloques de contenido coincidentes tanto para la etapa de Educación Primaria como para la de Educación Secundaria Obligatoria:

Tabla 1. Bloques de contenido área de lengua extranjera

Bloques de contenido Lengua Extranjera

(Real Decreto 126/2014 y Real Decreto 1105/2014)

Bloque 1. Comprensión de textos orales

Bloque 2. Producción de textos orales: expresión e interacción

Bloque 3. Comprensión de textos escritos

Bloque 4. Producción de textos escritos: expresión e interacción

A pesar de que la asignatura de lengua extranjera constituye una asignatura en sí misma, dada la relevancia que se le otorga al aprendizaje de lenguas, se promueve su introducción en otras áreas. Esta cuestión se refleja en diferentes puntos de la legislación educativa. Por ejemplo, a nivel estatal, el artículo 13 del Real Decreto 126/2014 que atañe al aprendizaje de lenguas extranjeras estipula que "las Administraciones educativas podrán establecer que una parte de las asignaturas del currículo se impartan en lenguas extranjeras sin que ello suponga modificación de los aspectos básicos del currículo regulados en el presente real decreto" ( $\mathrm{p}$. 19358).

Por lo que respecta al ámbito autonómico, con la implantación del Decreto 127/2012, de 3 de agosto, del Consell, por el que se regula el plurilingüismo en la enseñanza no universitaria en la Comunitat Valenciana, todos los centros públicos y concertados incorporan progresivamente al menos un módulo, área o materia de contenido no lingüístico en una lengua extranjera. Además, este mismo texto expone en su artículo número 6 que para reforzar el aprendizaje de la lengua extranjera "los centros organizarán medidas adicionales de coordinación entre el profesorado para la incorporación, en la enseñanza de esta lengua 
extranjera, de materiales de apoyo y refuerzo de contenidos específicos del currículo de áreas, materias o módulos no lingüísticos" (p. 23455).

Por su parte, en la Ley 4/2018, de 21 de febrero, de la Generalitat, por la que se regula y promueve el plurilingüismo en el sistema educativo valenciano, se indica que el tiempo destinado a contenidos en lengua extranjera puede llegar hasta el $25 \%$ de las horas lectivas, contando para ello tanto las horas propias de la asignatura de lengua extranjera como las destinadas a las áreas en las que se utilice esta lengua para vehicular del aprendizaje. En suma, el sistema educativo promueve la incorporación de la lengua extranjera en otras áreas curriculares como medida para favorecer su aprendizaje.

\subsubsection{La asignatura de educación física}

Por lo que respecta a la educación física, esta constituye una de las asignaturas específicas del sistema educativo español, cuestión que significa que su organización puede ser complementada por las administraciones educativas autonómicas. También se alude a esta asignatura dentro de los objetivos generales de la educación en España. En el artículo 7 del Real Decreto 126/2014, el objetivo (k) de la Educación Primaria establece "valorar la higiene y la salud, aceptar el propio cuerpo y el de los otros, respetar las diferencias y utilizar la educación física y el deporte como medios para favorecer el desarrollo personal y social". Por su parte, en el artículo 11 del Real Decreto 1105/2014 el objetivo (k) de la Educación Secundaria Obligatoria incide en

“conocer y aceptar el funcionamiento del propio cuerpo y el de los otros, respetar las diferencias, afianzar los hábitos de cuidado y salud corporales e incorporar la educación física y la práctica del deporte para favorecer el desarrollo personal y social. Conocer y valorar la dimensión humana de la sexualidad en toda su diversidad. Valorar críticamente los hábitos sociales relacionados con la salud, el consumo, el cuidado de los seres vivos y el medio ambiente, contribuyendo a su conservación y mejora."

Así, desde la asignatura de educación física se pretende fomentar el desarrollo de una adecuada competencia motriz que permita al alumnado disponer de un repertorio suficiente de respuestas adecuadas a múltiples situaciones, estando estas vinculadas tanto a las 
actividades físico-deportivas como a la actividad humana en su conjunto. Con este objetivo, el Decreto 108/2014 de la Comunidad Valenciana incide en que la docencia de esta asignatura debería abordarse a través de metodologías activas e inclusivas. Además, en el Decreto 126/2014 se expone cómo el juego constituye un recurso pedagógico imprescindible.

Dado que la educación física es una asignatura catalogada como específica, sus contenidos quedan regulados por la Generalitat Valenciana a través del Decreto 108/2014 para la Educación Primaria y del Decreto 87/2015 para la Educación Secundaria Obligatoria. En ambos casos los conocimientos se estructuran en base a 5 bloques de contenido. Sin embargo, sus nomenclaturas difieren en cierta medida, tal y como puede observarse en la Tabla 2.

Tabla 2. Bloques de contenido de educación física

\section{Educación Primaria}

\begin{tabular}{ll} 
Bloque 1 & Conocimiento y autonomía personal \\
\hline Bloque 2 & $\begin{array}{l}\text { Habilidades motrices, coordinación y } \\
\text { equilibrio. Actividades en el medio } \\
\text { natural }\end{array}$
\end{tabular}

Bloque 3 Expresión motriz y comunicación

\begin{tabular}{lll}
\hline Bloque 4 & Actividad física y salud & Expresión Corporal y comunicación \\
\hline Bloque 5 & Juegos y actividades deportivas & Elementos transversales a la asignatura
\end{tabular}

\subsubsection{Las particularidades de cada autonomía}

A pesar de que las comunidades autónomas tienen transferidas parte de las competencias educativas, la educación que integra lenguas extranjeras a través de un contenido es una práctica común en toda España. Cada comunidad autónoma presenta una realidad lingüística diferente, dado que son varias las que poseen dos lenguas oficiales. Sin embargo, en estos casos, además de promocionar el aprendizaje de sus lenguas propias, también se suele fomentar el aprendizaje de lenguas extranjeras, especialmente el inglés, tal y como ocurre en el caso expuesto de la Comunidad Valenciana. Así, los programas bilingües o plurilingües han proliferado ampliamente en el territorio español (Fernández-Sanjurjo et al., 2017). 
El desarrollo de la enseñanza de contenidos en otra lengua puede variar ampliamente de una comunidad autónoma a otra e incluso entre centros educativos del mismo territorio. Este hecho puede deberse, por ejemplo, a sus propias particularidades, a las asignaturas empleadas o al número de sesiones semanales dedicadas (Merino y Lasagabaster, 2018b). Sin embargo, a menudo, suele emplearse el enfoque AICLE gracias a la heterogeneidad de acercamientos que contempla (Ruiz de Zarobe y Lasagabaster, 2010). Sea como sea, la educación a través de otras lenguas se erige como una realidad en España fruto de lo estipulado en la legislación educativa actual.

Ante esta realidad, la aplicación de AICLE no debería convertirse en una verdad autoevidente sometida al albur de los discursos legislativos dominantes del momento. El estado español y las comunidades autónomas que lo constituyen han realizado un gran esfuerzo por incentivar los programas bilingües/ plurilingües en el ámbito educativo. No obstante, puede apreciarse una desconexión evidente entre el marco legislativo y su puesta en práctica en los centros educativos (Andúgar y Cortina, 2018). Las decisiones y propuestas políticas, así como el desarrollo normativo deberían ir ligados a las aportaciones de la investigación educativa a fin de establecer una política educativa de calidad (Gil y Aznar, 2016). Dado que en este caso la norma (imbricación de lengua y materia no lingüística) ha precedido a la justificación empírica, es necesario articular procedimientos de revisión de las prácticas educativas sustentados en la evidencia científica (Julián, Abarca-Sos, Zaragoza y Aibar, 2016). En esta dirección se encamina el presente trabajo, colocando el foco de atención sobre el enfoque AICLE, particularmente en su aplicación a través de la educación física a fin de indagar si su utilización resulta beneficiosa, inocua o contraproducente para la materia.

\subsection{Objetivos}

El principal problema de investigación abordado en el presente trabajo radica en analizar cómo se desarrolla una práctica AICLE en educación física, así como dar voz y estudiar las percepciones y la realidad que afecta a los agentes implicados a fin de conocer posibles flancos de mejora.

Este propósito general se concreta en tres objetivos de investigación que son los que guiarán el devenir de esta investigación. A su vez, cada uno de estos objetivos de investigación se divide en otros dos sub-objetivos, abordados respectivamente en cada uno de los manuscritos 
presentados. De este modo, los objetivos y sub-objetivos de investigación que constituyen el presente trabajo quedan descritos en la Tabla 3:

Tabla 3. Problema y objetivos de investigación

\section{Problema de investigación}

Dada la revolución que está significando la incorporación del enfoque AICLE en diferentes facetas del proceso de enseñanza-aprendizaje de la educación física, reconocer las percepciones de los agentes implicados a fin de conocer posibles flancos de mejora y analizar los principales efectos de la incorporación de AICLE sobre la asignatura, suponen el problema de investigación de la presente tesis. Esta cuestión se concreta a través de los siguientes objetivos de investigación.

\section{Objetivos de investigación}

O.1. Averiguar cuál es el estado de la cuestión en el campo de la educación física mediante el enfoque AICLE.

- O.1.1. Determinar cuál es el marco teórico particular de la educación física mediante AICLE y concretar sus posibilidades de aplicación.

- O.1.2. Examinar cuáles son y qué analizan los artículos de mayor impacto que vinculan educación física y enseñanza de lenguas extranjeras.

O.2. Investigar cuáles son las percepciones sobre la aplicación de AICLE en educación física de los agentes implicados directamente en su desarrollo.

- O.2.1. Analizar cómo vive y qué opina sobre AICLE el profesorado de educación física que lo ha aplicado en sus clases.

- O.2.2. Examinar cómo vive y qué opina el alumnado sobre el uso de AICLE en clase de educación física.

O.3. Analizar cómo afecta el uso del enfoque AICLE en las sesiones de educación física.

- O.3.1. Examinar si la utilización de AICLE en educación implica que se vean alterados los niveles de actividad física del alumnado durante las sesiones en comparación con las sesiones ordinarias de esta asignatura.

- O.3.2. Conocer si el enfoque AICLE repercute sobre el nivel de actividad física moderada-vigorosa del alumnado y, en caso afirmativo, comprender cómo y por qué.

Para abordar estos objetivos será necesario plantear un marco teórico inicial que delimite y contextualice lo presentado en los sucesivos manuscritos. Posteriormente, a fin de dar respuesta al primer objetivo, en la primera publicación se presenta un recorrido por los fundamentos teóricos de AICLE en educación física, reparando paralelamente en cómo puede esta aplicación implementarse en la práctica diaria. Acto seguido, la segunda 
publicación presenta una revisión sistemática del estado de la cuestión a fin de conocer qué se ha realizado hasta el momento en el campo de la educación física como materia facilitadora para el aprendizaje de otras lenguas. Más adelante, en lo tocante al segundo objetivo, las dos siguientes publicaciones adoptan un proceso de investigación interpretativo de corte cualitativo que indaga en las percepciones de los dos agentes principales de las praxis educativas, a saber, profesorado y alumnado. Así, la tercera publicación se focalizará en atender el punto de vista del profesorado de educación física con experiencia AICLE, mientras que el cuarto manuscrito publicado repara en la perspectiva propia del alumnado que ha recibido clases de educación física mediante AICLE. Por último, el tercer objetivo se aborda mediante dos nuevos textos. El primero de ellos presenta una investigación cuantitativa que compara los niveles e intensidad de la actividad física de las clases en que se aplica AICLE con los niveles de las clases convencionales. El segundo artículo, atendiendo a los inesperados resultados obtenidos en el anterior estudio, aspira a alcanzar un nivel de comprensión más profundo y próximo a través del empleo de métodos mixtos de investigación con una finalidad explicativa (Creswell, Plano Clark, Gutmann y Hanson, 2003). En particular, el estudio analiza la repercusión del empleo de AICLE sobre los niveles de actividad física moderada-vigorosa del alumnado, tratando de descubrir las razones que pudieran subyacer a los resultados obtenidos en el estudio previo.

\subsection{El compendio de publicaciones}

De acuerdo con la normativa vigente para la presentación y defensa de la tesis doctoral del Programa de Doctorado en Educación de la Universitat Jaume I (Aprobado por el Comité de Dirección de la Escuela de Doctorado 3-2018, del 27 de abril de 2018), esta tesis doctoral se presenta acogiéndose a la modalidad de tesis por compendio de publicaciones.

Asimismo, se desarrolla bajo las directrices del Artículo 27 de la Normativa de los estudios de Doctorado, regulados por el RD99/2011, en la Universitat Jaume I relativo al procedimiento y criterios aplicables para la obtención de la mención internacional en el título de doctor (aprobados por el Consejo de Gobierno num.21 de 30 de marzo de 2012), por lo que es un requisito para la obtención de dicho título el estar redactada en dos lenguas diferentes -en este caso español e inglés). 
A continuación, se detallan los seis manuscritos seleccionados para conformar la presente tesis doctoral. Del mismo modo, se enumeran otras publicaciones desarrolladas siguiendo la misma línea de investigación que se han ido generando de un modo paralelo.

Los manuscritos que se incluyen en este documento son:

\section{Manuscrito 1}

Salvador-García, C., Chiva-Bartoll, O., \& Ruiz, N. (2016). Aprendizaje integrado de contenidos y lengua extranjera. Educación física e inglés. En O. Chiva \& M. Martí (Coord.), Métodos pedagógicos activos y globalizadores (pp. 45-64). Barcelona: Graó.

- Editorial Graó, (2016). ISBN: 9788499806761

- La Editorial Graó tiene un índice ICEE de 3.658 en la disciplina "Educación" y ocupa el lugar 3 de 94 editoriales.

\section{Manuscrito 2}

Salvador-García, C., Chiva-Bartoll, O., \& Isidori, E. (2017). Aprendizaje de un idioma extranjero a través de la Educación Física: una revisión sistemática. Movimento, 23(2), 647660 .

- Movimento, (2017). ISSN: 0104-754X

- En JCR 2017 la revista tiene un factor de impacto de 0.257 y en la categoría "Education \& Educational Research" ocupa el lugar 232 de 238 (Q4).

- En SJR 2017 la revista tiene un factor de impacto de 0.23 y en la categoría "Education" ocupa el lugar 692 de 1262 (Q3).

- La revista Movimento aparece evaluada también en:

-MIAR: 10.9 (ICDS 2017)

-CARHUS Plus+ 2017: Grupo C

-LATINDEX: 36 criterios cumplidos

-Ulrichsweb

- La revista Movimento aparece indexada en las siguientes bases de datos: Scopus, Social Science Citation Index, CAB Abstracts, SportDiscus, Veterinary Science Database, DIALNET. 


\section{Manuscrito 3}

Salvador García, C., \& Chiva Bartoll, O. (2017). CLIL in teaching physical education: views of the teachers in the Spanish context. Journal of Physical Education and Sport, 17(3), 11301138 .

- Journal of Physical Education and Sport, (2017). ISSN: 2247-8051

- En SJR 2017 la revista tiene un factor de impacto de 0.284 y en la categoría "Physical Therapy, Sports Therapy and Rehabilitation" ocupa el lugar 101 de 183 (Q3).

- La revista Journal of Physical Education and Sport aparece evaluada también en: -MIAR: 9.7 (ICDS 2017)

-ERIHPlus

-Ulrichsweb

- La revista Journal of Physical Education and Sport aparece indexada en las siguientes bases de datos: Scopus, CAB Abstracts, SportDiscus, Veterinary Science Database, DOAJ

\section{Manuscrito 4}

Salvador-García, C., Chiva-Bartoll, O., \& Vergaz-Gallego, J. J. (2018). Percepción del alumnado sobre el uso del método AICLE en Educación Física: estudio de caso. Retos: nuevas tendencias en educación física, deporte y recreación, (33), 138-142.

- Retos: nuevas tendencias en educación física, deporte y recreación, (2018). ISSN: 1579-1726

- En SJR 2017 la revista Retos: nuevas tendencias en educación física, deporte y recreación tiene un factor de impacto de 0.26 y en la categoría "Education" ocupa el lugar 624 de $1262(\mathrm{Q} 3)$.

- La revista Retos: nuevas tendencias en educación física, deporte y recreación aparece evaluada también en:

-MIAR: 9.7 (ICDS 2017)

-Sello de calidad FECYT

-CARHUS Plus+ 2017: Grup D

-LATINDEX: 36 criterios cumplidos

-DICE

-ERIHPlus

-Ulrichsweb

- La revista Retos: nuevas tendencias en educación física, deporte y recreación aparece indexada en las siguientes bases de datos: Emerging Source Citation Index, Scopus, Fuente Academica Plus, CAB Abstracts, SportDiscus, DOAJ, DIALNET, ISOC. 


\section{Manuscrito 5 (aceptado)}

Salvador-García, C., Chiva-Bartoll, O. \& Colomer, C. The effect of bilingual Physical Education on students' Physical Activity. Things are not always as they seem. Ciencia, Cultura y Deporte, $\mathrm{xx}(\mathrm{xx}), \mathrm{xx}-\mathrm{xx}$.

- Cultura, Ciencia y Deporte (aceptado). ISSN Print 1696-5043 / e-ISSN 1989-7413

- En SJR 2017 la revista tiene un factor de impacto de 0.16 y en la categoría "Physical Therapy, Sports Therapy, Rehabilitation" ocupa el lugar 140 de 175 (Q4).

- La revista Cultura, Ciencia y Deporte aparece evaluada también en:

- REDALYC: Superada

- $\quad$ LATINDEX: $(33 / 33)$

- CNEAI: $18 / 18$

- ANECA: 22/22

- ANEP: Categoría A

- CIRC (2011-12): Categoría B

- Valoración de la difusión internacional (DICE): 14.25

- DIALNET: gB

- $\quad$ MIAR: ICDS 2013 (9.454), 2014 (9.500), 2015 (9.541), 2016 (9.6)

- $\quad$ ARCE 2014 (FECYT): Sello de calidad

- Proceso de indexación en Thompson Reuters (iniciado)

- ERIH PLUS (European Reference Index for Humanities and Social Sciences): Indexada

La revista Cultura, Ciencia y Deporte aparece indexada en las siguientes bases de datos: ISI Web of Science, SCOPUS, EBSCO, INRECS, DICE, LATINDEX, REDALYC, DIALNET, RESH, COMPLUDOC, RECOLECTA, CEDUS,REDINET, SPORTDISCUS, MIAR, PSICODOC, CIRC, DOAJ, ISOC, DULCINEA, SCIRUS, WORLDCAT, LILACS, GTBib, RESEARCH GATE, SAFETYLIT, REBIUN, Universal Impact Factor, Index Copernicus,Genamics, e-Revistas, Cabell's Directory, SJIF, ERIH PLUS, DLP, JOURNALS FOR FREE,BVS, PRESCOPUS RUSSIA, JournalTOCs, Viref, Fuente Académica Plus, ERA

\section{Manuscrito 6 (en revisión)}

Salvador-García, C., Chiva-Bartoll, O., \& Capella-Peris, C. Educación física bilingüe: efectos de CLIL sobre los niveles de actividad física. 
Además, seguidamente se enumeran las referencias de otras publicaciones elaboradas en el marco de esta misma investigación durante el período de realización de la tesis doctoral:

\section{Libro}

Chiva-Bartoll, O., \& Salvador-García, C. (2016). Aprendizaje integrado de Educación Física y Lengua Inglesa. Barcelona: Inde.

\section{Artículos}

Chiva-Bartoll, O., \& Salvador García, C. (2018). Educación Física y pluringüismo: una mirada al futuro inmediato. International Journal of Sports Humanities, 1, 23-32.

Chiva-Bartoll, O, Salvador-García, C. \& Isidori, E. (2018 en prensa). Nuevas miradas de la educación física: implicaciones del enfoque metodológico CLIL. Revista opción, $\mathrm{xx}(\mathrm{xx}), \mathrm{xx}-$ $\mathrm{xx}$.

\section{Comunicaciones}

Salvador-García, C. \& Chiva-Bartoll, O. (2016). AICLE en educación física: un planteamiento para el desarrollo integral del alumnado. En II Congreso Internacional sobre Educación Bilingüe, Córdoba.

Salvador-García, C. \& Herrera-Mor, E. (2017). AICLE en educación física: el caso de un alumno con discapacidad visual. En IV Simposium internacional de primavera educación física y justicia social en poblaciones vulneradas, Valencia.

Salvador-García, C., Herrera-Mor, E., Chiva-Bartoll, O., Ruiz-Madrid, N. \& Salvador-García, F. (2017). AICLE como estrategia de inclusión en educación física: una experiencia. En I Congreso internacional para profesionales de la educación bilingüe, Madrid.

Fazio, A., Salvador-García, C., Chiva-Bartoll, O., Isidori, E. \& Barbatbun, S. (2018). Elearning and ICT in Teaching Physical Education (PE) through CLIL. En The 14th International Scientific Conference eLearning and Software for Education, Bucarest.

Chiva-Bartoll, O., Salvador-García, C. \& Capella-Peris, C. (2018). Sinergias entre aprendizaje cooperativo y educación física con AICLE. En XI Congreso Internacional de Actividades Físicas Cooperativas, Avilés.

Salvador-García, C., Capella-Peris, C., Adelantado-Renau, M. \& García-Antolín, R. (2018). Relación entre la satisfacción del alumnado de educación física bilingüe con los niveles de actividad física alcanzados en las sesiones. En I Congreso internacional sobre metodologías activas, modelos de enseñanza-aprendizaje e investigación en ciencias de la educación y del deporte, Granada. 


\section{Marco teórico}

\subsection{Globalización y educación}

En pleno siglo XXI no resulta complicado entender que el presente período histórico está caracterizado por una evolución social ligada, ineludiblemente, al mundo globalizado que habitamos. La globalización se presenta, a menudo, como rotor de la transformación que está viviendo la sociedad, generando una tendencia "hacia la intensificación de las relaciones globales de interacción e intercambio, (o) la interconexión mundial en los campos de la comunicación social y la armonización transnacional de los modelos y estructuras sociales" (Luzón y Torres, 2016, p. 54). En este sentido, los sistemas sociales están viéndose sujetos a una constante modernización marcada, entre otras cuestiones, por el ritmo que imponen las nuevas tecnologías, puesto que canalizan información de todo tipo permitiendo que casi instantáneamente pueda llegar a cualquier rincón del planeta.

Hoy en día la información es tan rápida como la luz y se encuentra al alcance de cualquiera, motivo por el que es ampliamente reconocido que la nuestra es la sociedad de la información y el conocimiento (Castells, 1999). En este monopolio del saber (Pallarés, Chiva-Bartoll López y Cabero, 2018), la información se encuentra por doquier, incluso es frecuente que en la propia palma de la mano en forma de smartphone o tableta. Y pese a su facilidad de acceso, esta información es más escurridiza que nunca, puesto que tan rápido como llega se volatiliza y olvida dando paso a otra más actualizada. Una vorágine como esta requiere de una breve pausa a fin de recordar que "en medio de esta galaxia digital y del mundo globalizado y repleto de hechos efímeros y modas pasajeras en el que vivimos, es fundamental que dispongamos de una buena educación humana" (Pallarés y Chiva-Bartoll, 2017, p. 55).

La educación se erige como un elemento fundamental para cualquier pueblo, sean cuales sean su lengua, costumbres, valores, normas, religión, etc. De hecho, parafraseando a Gilbert K. Chesterton (1924), la educación es el alma de una sociedad. Sin embargo, pese a su tamaña magnitud y relevancia, los ambientes pedagógicos también se están viendo afectados por la globalización, puesto que dicho fenómeno es "parte del entorno en que se desenvuelve la educación, afectando dimensiones relevantes del contexto en el cual ella opera y al cual debe responder y adaptarse" (Brunner, 2000, p. 13). La acción educativa en ningún caso es sinónimo de prácticas escolares de carácter homogéneo y extrapolable (Pallarés et al., 2018; 
Thoilliez, 2019), más bien al contrario, la educación debe, indefectiblemente, adaptarse al contexto particular en el que se desarrolla, así como velar por amoldarse a las particularidades de los agentes que en ella participan, es decir, discentes y docentes. De este modo, no solo los entornos educacionales, sino todo el hecho educativo se encuentra, en cierto modo, a merced de la pauta marcada por la globalización.

A lo largo de las últimas cuatro décadas las políticas educativas han ido abriéndose paso como asunto global (Grek, 2009; Spring, 2008), abordando diferentes áreas temáticas e incumbiendo a múltiples naciones. Esta pujanza de la educación como constructo global ha derivado en dos vertientes diferenciadas. Por un lado, se encuentran las políticas educativas conjuntas o unificadas, es decir, textos prescriptivos de índole educativa que afectan a una serie de países. En esta categoría, a modo de ejemplo, pueden mencionarse las políticas promovidas por los países de la Organización para la Cooperación y el Desarrollo Económicos (OCDE) que, por ejemplo, comenzó a publicar el Education Policy Analysis en 1996; la Declaración Mundial sobre Educación para todos o, de particular relevancia para el presente trabajo, el Marco Común Europeo de Referencia de las Lenguas.

Por otro lado, puede apreciarse que el lenguaje de la globalización ha irrumpido en los discursos educativos, de manera que los gobiernos y otros grupos de poder tratan de evidenciar la necesidad de que las escuelas se adapten a las demandas de la economía global (Spring, 2008). De esta manera se promueve una educación que, como fin último, forme capital humano ${ }^{2}$ y mejores trabajadores a fin de fomentar el crecimiento económico. Esta cuestión deriva de una perspectiva de globalización capitalista y neoliberal cuyo objetivo es mantener el control del mercado económico (Mejía-Jiménez, 2011). Entrar a valorar la legitimidad de este posicionamiento no es la razón del presente trabajo, sin embargo, nuestra concepción de educación para la globalización se acerca más a la idea propuesta por Pallarés et al. (2018), quienes apuestan por una concepción del aprendizaje entendida como el puro placer de formarse y crecer como personas. En este sentido, aprender para el mundo global permite conocer y reconocer culturas propias y ajenas, crecer y formarse con el resto de la sociedad y, en última instancia, desarrollarse integralmente para alcanzar una vida plena

\footnotetext{
${ }^{2}$ Con el término capital humano hacemos referencia explícita a una cosificación que transforma a las personas en bienes de producción al servicio del sistema capitalista.
} 
mientras se hace frente a las responsabilidades propias como habitantes del mundo, libres y emancipados (Chiva-Bartoll, 2016; Thoilliez, 2019).

Independientemente de los motivos que empujen a cada uno hacia el aprendizaje, lo que resulta innegable es que la educación se fundamenta en lo global y tiende hacia lo global (Çayak y Eskici, 2018; Pallarés et al., 2018). La escuela y las prácticas educativas deben tomar en consideración el contexto propio de cada centro, cada docente y cada estudiante, pero no pueden olvidar el contexto globalizado actual en el que se circunscriben. El mundo cambia y con él también deben hacerlo las praxis educativas a fin de favorecer una buena educación porque "si enseñamos a los estudiantes de hoy como enseñábamos ayer, les estamos privando del mañana” (Dewey, 1944, p. 167). Tomando en consideración la perspectiva social actual, la escuela se encuentra ante una serie de desafíos definitorios del mundo contemporáneo tales como la lucha contra la exclusión, la protección de la equidad o la mejora de la convivencia entre los habitantes que pueblan sociedades cada vez más multiculturales; ante los cuales la educación debe responder. En este sentido, las nuevas condiciones sociales demandan una escuela comprometida con los procesos de transformación y, por tanto, la educación debe mostrarse proclive al cambio y la adaptación. Ante esta tesitura, tal y como sostiene Chiva-Bartoll (2016), uno de los retos que aún quedan pendientes en la esfera educativa radica en la renovación metodológica. Apuntando en la misma dirección, tomamos las palabras de Pallarés et al. (2018), quienes afirman que la escuela

“tendrá que ser capaz de fijar (una serie de reglas de intervención pedagógica) para conseguir las metas educativas exigidas por la sociedad de su momento. Solo así logrará establecer prácticas educativas percibidas como paradigmas coherentes con lo que vive el alumnado fuera de las aulas, unas prácticas entendidas como retos habilitados para ofrecer respuestas a cuestiones particulares sobre qué y cómo enseñar en cada momento de la historia" (p.42)

En definitiva, todo parece indicar que la adaptación de la educación al contexto que encierra todo acto educativo se erige como condición sine qua non a fin de establecer los mimbres que favorezcan su óptimo desarrollo; y para ello, la innovación educativa se erige como estandarte. Múltiples son las reformas educativas propuestas a lo largo de los últimos años 
como fruto del intenso reclamo desde diferentes foros en pos de la innovación y la mejora escolar. No obstante, su puesta en práctica en las aulas ha sido, en no pocas ocasiones, calificada como problemática (Fullan, 2007).

Un interrogante puede surgir en la mente de muchos, ¿cómo puede fallar una propuesta preparada para hacer frente al contexto globalizado? En este punto conviene reparar en la trilogía de registros que cimientan la educación (Pallarés et al., 2018): los administradores vinculados a la norma-, los docentes -representantes de la realidad-, y los expertos -afines a la teoría-. Estos tres elementos interaccionan y su correcta vertebración propicia que el resultado de la tarea educativa sea óptimo. Sin embargo, cualquier desequilibrio entre las tres fuerzas puede acarrear consecuencias equívocas, tal y como ha sucedido a lo largo de los últimos años. Cuando la norma se impone sin haber sido testada empíricamente ni aceptada por una cierta cantidad del profesorado que debe aplicarla, resulta arriesgado confiar en que buenos resultados vayan a obtenerse, por mucho que el planteamiento se adscriba específicamente al contexto. En palabras de Pallarés et al. (2018):

"un desequilibrio desmedido en favor de la dimensión normativa o legal, hasta el punto de cercenar las otras dos dimensiones (expertos y docentes) condena igualmente las políticas de innovación educativa a ser consideradas elementos extraños e impuestos por la Administración, lo que también supone un rechazo o resistencia a incorporarlas a la realidad práctica." (p. 60)

De este modo, no ha sido extraño que durante los últimos años diversas reformas hayan, por un lado, sido propuestas sin que su valía y coherencia hubiera sido suficientemente contrastada por los expertos; y por otro, tenido en cuenta a los docentes que han debido lidiar con planteamientos cuyo lenguaje resultaba incongruente con sus praxis educativas diarias (Dam, 2014). En este punto de incerteza enraíza el presente trabajo, a través del cual intentaremos ahondar en un enfoque metodológico (AICLE) ligado a reformas educativas que han sido propuestas e impuestas sin el suficiente amparo de expertos y docentes. No obstante, antes de abordar los objetivos concretos marcados en el apartado precedente, pasamos, a continuación, a esbozar el contexto que tanta relevancia adquiere en el quehacer educativo, pero estableciendo el punto de atención en las lenguas, por ser su aprendizaje el objetivo nuclear de las reformas implantadas y que vamos a tratar. 


\subsection{El aprendizaje de lenguas en un mundo global}

Pese a que la globalización puede definirse de múltiples maneras, todas ellas coinciden en subrayar su capacidad de creación de un mundo sin barreras en el que la gente se comunica incesantemente (Altan, 2017). Esto ha sido posible gracias al impetuoso avance de las nuevas tecnologías, puesto que dicho factor ha propiciado una mengua en las fronteras internacionales. De esta forma, el intercambio comunicativo resulta cuando menos ágil, dinámico y continuo a la par que sencillo. Como consecuencia de este desenfrenado tráfico informativo, hoy en día existe más que nunca una sensación de conciencia y aprecio hacia la realidad multilingüe en la que habitamos (Larsen-Freeman, 2018).

El nivel de desarrollo que han adquirido las sociedades actuales, fruto de la globalización, demanda que los ciudadanos y ciudadanas sean capaces de comunicarse en distintas lenguas. Por ello, en la actualidad, el mundo está poblado por habitantes plurilingües que posibilitan que las culturas y los países se encuentren férreamente (inter)conectados (Ríos, 2005), de modo que no parece de extrañar que exista una clara propensión al aprendizaje de lenguas. De hecho, ser capaz de hablar en diversos idiomas es una de las metas más perseguidas actualmente, puesto que el enriquecimiento que estos aportan es incuestionable.

Pese a la existencia de más de 7.000 lenguas en el mundo, las 40 más recurrentes son habladas por más de dos tercios de la población mundial y, entre ellas, parece que conocer inglés, español o francés se ha convertido en un componente indispensable de la ciudadanía moderna (Bondarenko, Nasonkin, Shagieva, Kiyanova y Barabanova, 2018). En este sentido, coincidimos con el Marco Común Europeo de Referencia de las Lenguas cuando señala que todas las lenguas y culturas deben ser protegidas y desarrolladas, puesto que todas ellas ostentan gran valor. No obstante, todo indica que la globalización nos aboca hacia un único idioma como medio de comunicación que pueda ser utilizado por todas las personas y, entre otras cuestiones, las ingentes cantidades de dinero empleadas a fin de aprender inglés apuntan hacia la idea de que esta lengua en concreto adquirirá en breve (si no lo ha hecho ya) el estatus de lengua franca (Kaur, 2014).

Tal y como indica Warschauer (2000), se considera que la globalización va ligada con la expansión del inglés como lengua internacional. De hecho, Crystal ya señaló en 1997 que nunca había habido una lengua tan extendida y propagada a nivel mundial, y en las dos 
últimas décadas su poder no ha hecho sino incrementarse. De este modo, la globalización ha traído consigo una sociedad en la que el inglés se comparte entre una infinidad de grupos de hablantes, tanto nativos como no nativos. Por este motivo, el inglés ya no se vincula con una ubicación geográfica o una cultura particulares, sino que cada vez más se concibe como el idioma global (Lamb, 2004; Pennycook, 2017). Por lo tanto, si la lengua inglesa ostenta tal relevancia y se está imponiendo en múltiples áreas, entre las que se encuentra la educación; parece sensato ayudar a empoderar al estudiantado facilitándole su aprendizaje a fin de que también pueda emplearla como herramienta con la que poder imprimir su palabra en el mundo.

Tal y como se ha expuesto, aprender lenguas en el contexto global actual resulta una tarea corriente para la sociedad. Son muchos los especialistas que defienden el aprendizaje de idiomas a fin de mejorar la empleabilidad y las oportunidades de mejora laboral (Alcón, 2011; Leader et al., 2017). Sin embargo, aun siendo razones nada despreciables, conviene recordar que existen otro tipo de motivaciones y argumentos que trascienden el discurso instrumentalista imperante. Sin ir más lejos, aprender lenguas conlleva una renovada apreciación de lo que significa ser humanos, ayudándonos a orientar y enriquecer nuestras vidas hacia una existencia más equilibrada y significativa (Larsen-Freeman, 2018). Desde un enfoque cercano, nos referimos a lo que Pallarés et at. (2018) denominan como la "parte sexy" de la pedagogía, es decir, aquella que se vincula con el placer por aprender que, según subrayan, debe ser impulsado y promovido. Aprender lenguas es un estímulo, un reto y un deleite para muchas personas ${ }^{3}$, pero además de esa motivación puramente intrínseca en lo existencial, pueden rescatarse diversas razones de carácter extrínseco que inciten al aprendizaje de lenguas.

Por ejemplo, la Universidad de Auburn presenta a su alumnado 25 motivos para estudiar lenguas extranjeras ${ }^{4}$. Entre otros motivos se encuentran los que aparecen en la Figura 1:

\footnotetext{
${ }^{3}$ Cada persona tiene gustos diferentes, por lo que no puede aseverarse que aprender lenguas sea un placer para todos. En este sentido, la motivación hacia el aprendizaje de lenguas radica, según Lamb (2004), en diferentes procesos de identificación que son especialmente significativos durante la adolescencia.

${ }^{4} \mathrm{http}$ ///cla.auburn.edu/forlang/resources/twenty-five-reasons/
} 


\begin{tabular}{ll}
\hline $\begin{array}{l}\text { Estudiar } \\
\text { lenguas: }\end{array}$ & $\begin{array}{l}\text { Incrementa las actitudes positivas y disminuye los prejuicios hacia gente } \\
\text { diversa. }\end{array}$ \\
\hline Mejora las habilidades analíticas. & \\
\hline Favorece apreciar más profundamente la cultura propia. & \\
& Incrementa la creatividad. \\
& Ayuda a que el turismo internacional sea más sencillo y placentero. \\
& $\begin{array}{l}\text { Favorece la mejora de habilidades como la resolución de problemas o la } \\
\text { comprensión de conceptos abstractos. }\end{array}$ \\
\hline $\begin{array}{l}\text { Enseña e incita a respetar más al resto de personas al favorecer la } \\
\text { comprensión de la relación entre lengua y naturaleza humana. }\end{array}$ & $\begin{array}{l}\text { Implica adquirir una mayor apreciación por la diversidad cultural. } \\
\text { Abre las opciones de disfrutar del arte, la música, el baile, la moda, la } \\
\text { cocina, el cine, la filosofía, la ciencia... }\end{array}$ \\
$\begin{array}{l}\text { Es parte de la educación liberal puesto que implica ir de la oscuridad y la } \\
\text { reclusión a la claridad y la liberación. }\end{array}$ \\
\hline
\end{tabular}

Figura 1. Motivos para aprender lenguas

Fuente: Adaptado página web Universidad de Auburn (http://cla.auburn.edu/forlang/resources/twenty-fivereasons/)

Independientemente de la razón que estimule a cada persona a enfrentarse al reto de aprender una lengua, lo que parece claro, a tenor de lo expuesto hasta el momento, es que dicho aprendizaje debe desarrollarse tomando en consideración el contexto social. En este sentido, la sociedad del conocimiento no demanda ciudadanos capaces de traducir textos complicados o aprender rápidamente oraciones concretas para una situación particular ${ }^{5}$, sino que requiere hablantes que sean capaces de comunicarse efectivamente en una multiplicidad de situaciones (Warschauer, 2000). Asimismo, como se ha mencionado en el apartado previo, los cambios en la sociedad conllevan cambios en la educación y, hoy en día, la sociedad requiere que el aprendizaje se desarrolle mediante métodos de aprendizaje activos y globalizadores (Chiva-Bartoll, 2016). Este énfasis puesto en el fomento de la capacidad comunicativa, que se caracteriza por la búsqueda de un uso de la lengua funcional y eficaz, y en la participación activa del alumnado, trae como consecuencia que desde hace ya algunos

\footnotetext{
${ }^{5}$ Estas eran las demandas de las cuales emanaron métodos como el grammar translation method o el audiolingual approach
} 
años la didáctica de las lenguas esté abordándose desde el conocido enfoque comunicativo (Spada, 2007); el cual aspira en última instancia a promover la competencia comunicativa del estudiantado, cuestiones que pasamos a precisar en el siguiente apartado.

\subsection{Competencia comunicativa como respuesta al contexto social}

Aprender lenguas no es una actividad novedosa, de hecho, viene realizándose desde tiempos inmemoriales. Sin embargo, tal como se ha argumentado previamente, hoy se trata de una actividad en alza. El aprendizaje de lenguas ha sido un reconocido campo de investigación y muchas son las personas que se han dedicado a su estudio a lo largo de la historia. De hecho, son cuantiosas las teorías y enfoques sucedidos a lo largo de los años entre los que pueden mencionarse, a modo de ejemplo, el grammatical approach, el cognitive approach o el communicative approach ${ }^{6}$ (Lightbown, Spada, Ranta y Rand, 1999; Peter, 1998). Sin embargo, a tenor de la globalización que impera en la actualidad, todo parece indicar que la sociedad demanda ciudadanos y ciudadanas educados para desenvolverse y dar respuesta a demandas y desafíos reales (Chiva-Bartoll, 2016). En el ámbito de las lenguas este fenómeno implica ser poseedores de cierta competencia comunicativa a fin de ser capaces de desenvolverse más o menos eficazmente en las diversas situaciones sociales.

En este mismo sentido se decanta la legislación educativa vigente, mencionada en el apartado 2.1., ya que otorga singular relevancia al empleo de un enfoque comunicativo para la enseñanza-aprendizaje de lenguas, haciendo especial hincapié en el fomento del desarrollo de la competencia comunicativa. Por ejemplo, el objetivo (f) del Real Decreto 126/2014, de 28 de febrero, por el que se establece el currículo básico de la Educación Primaria, establece que el alumnado de dicha etapa educativa debe "adquirir en, al menos, una lengua extranjera la competencia comunicativa básica que les permita expresar y comprender mensajes sencillos y desenvolverse en situaciones cotidianas". Asimismo, tanto en este documento como en el Real Decreto 1105/2014, de 26 de diciembre, por el que se establece el currículo básico de la Educación Secundaria Obligatoria y del Bachillerato, la primera competencia a la que se alude es la competencia en comunicación lingüística.

\footnotetext{
${ }^{6}$ En el presente trabajo emplearemos su voz en castellano, es decir, enfoque comunicativo
} 
De este modo, queda patente que, de acuerdo a la legislación vigente, uno de los objetivos nucleares referentes a la enseñanza-aprendizaje de lenguas radica en favorecer el desarrollo de la competencia comunicativa del alumnado a fin de hacer frente a la sociedad actual.

El término competencia comunicativa lleva más de cuarenta años siendo utilizado (CelceMurcia, 2008), sin embargo, no puede considerarse una expresión inamovible puesto que ha ido evolucionando y adaptándose a lo largo del tiempo. Cuando Hymes (1974) incorporó esta expresión al vocabulario de los y las lingüistas, la competencia comunicativa hacía referencia a la habilidad de saber cuándo hablar, sobre qué hablar, con quién hablar, dónde y de qué manera. Más adelante, Canale y Swain (1980) revisaron el concepto y propusieron un nuevo modelo altamente relevante en el campo de la didáctica de las segundas lenguas y que dividía esta competencia en cuatro componentes: gramatical, discursivo, sociolingüístico y estratégico. No obstante, con el paso de los años el concepto ha continuado siendo motivo de análisis, viéndose revisado tanto por círculos centrados en la lingüística aplicada como por los focalizados en la enseñanza-aprendizaje de lenguas (Byrnes, 2006; Kenning, 2006; Leung, 2005). Posteriormente, Celce-Murcia (2008) propuso ampliar el número de subcompetencias vinculadas a la competencia comunicativa, dividiéndola en seis, a saber: lingüística, socio-cultural, discursiva, interaccional, formulaica (probabilística) y estratégica. Por conformar parte del conjunto 'competencia comunicativa', todas las subcompetencias propuestas deberían verse trabajadas en clase, para lo que conviene prestar atención a cómo se aborda esta cuestión. Autores como Brinton, Snow y Wesche (2003) afirman que la enseñanza de lenguas a través de un contenido, tal y como es el caso de AICLE, resulta una de las fórmulas más efectivas para potenciar la competencia comunicativa en una segunda lengua o lengua foránea, por las características inherentes a estas prácticas educativas.

El término competencia comunicativa se ha visto ligado asiduamente al enfoque comunicativo, puesto que este enfoque educativo persigue como objetivo primordial, tal y como se desprende de su nombre, favorecer el desarrollo de dicha competencia. En este sentido, uno de los principios esenciales de AICLE es su circunscripción al enfoque comunicativo, de hecho, ha sido considerado como un paso más allá de este mismo enfoque puesto que favorece que el alumnado desarrolle su capacidad de comunicarse de maneras que distan de las propuestas por los métodos de aprendizaje de segundas lenguas tradicionales, 
en tanto en cuanto la autenticidad deja de ser opcional y deviene un imperativo (Coyle, Hood y Marsh, 2010; Dalton-Puffer, 2009; DeGraaff, Koopman, Anikina y Westhoff, 2007). De este modo, parece que el enfoque AICLE se erige como una opción válida a fin de desarrollar la competencia comunicativa (Dalton-Puffer, 2009), dando respuesta al cambio social devenido a causa de la globalización, permitiendo al alumnado prepararse para el uso de la lengua que la sociedad le demanda.

Sobre el enfoque AICLE, aplicado desde el área de educación física, se centra el presente trabajo; por lo que a continuación detallamos su concepción, desarrollo, principios, componentes y posibilidades.

\subsection{Aprendizaje Integrado de Contenidos y Lengua (AICLE)}

El enfoque educativo AICLE (Content and Language Integrated Learning (CLIL) en su voz inglesa) ha sido acogido fervorosamente por parte de múltiples de los agentes que se ven implicados, ya sea directa o indirectamente, por su aplicación (Lasagabaster y Doiz, 2016a). Docentes de todas las etapas formativas, alumnado de diferentes edades, legisladores del campo educativo, así como madres y padres de todo el mundo, pero con especial acento en el continente europeo, han recibido su introducción en el panorama educativo con gran entusiasmo. No obstante, mientras que para algunos esta irrupción ha sido recibida como una necesidad imperiosa (Marsh, 2002), para otro sector de población ha sido considerada casi una temeridad (Bruton, 2017). Por ello, en primer lugar, antes de posicionarse al respecto de la pertinencia (o no) de la utilización de AICLE, parece necesario saber exactamente qué implicaciones acarrea su aplicación.

Existe un consenso acerca del término AICLE, considerándolo un paraguas en el que muchas opciones son concebibles (Cenoz, Genesee y Gorter, 2013; Mehisto, Marsh y Frígols, 2008; Pérez-Cañado, 2016). En este sentido, se trata de un vocablo genérico utilizado para describir aquellas praxis educativas en las que se emplea una segunda lengua para la enseñanza de asignaturas curriculares no lingüísticas (Eurydice, 2006). Una de las definiciones más reiteradas es la expuesta por Coyle et al. (2010), que lo describen como "un enfoque educativo dual en el que una lengua adicional se utiliza para aprender tanto un contenido como la lengua en sí” (p.1). Sin embargo, AICLE también se ha identificado, de manera 
general, como una conceptualización "esencialmente metodológica" (Marsh, 2012), o como una "herramienta" cuya esencia radica en la integración (Mehisto et al., 2008).

Diferentes autores han intentado abordar su esclarecimiento de manera más concreta, para lo que ha sido recurrente tratar de acotarlo en base a qué no es, por ejemplo, confrontándolo con metodologías como el Content Based Instruction, Content-Based Language Teaching o los programas de inmersión (Broca, 2016; Cenoz, 2015; Cenoz et al., 2013; Hüttner y Smit, 2014; Lasagabaster y Sierra, 2010; Lyster y Ballinger, 2011). Sin embargo, aún quedan numerosos cabos sueltos con respecto a las implicaciones que subyacen a AICLE y, de hecho, diversas voces critican esta falta de concreción, por ser considerado un término difuso e impreciso (Bruton, 2013). Por ejemplo, AICLE ha sido criticado por ser un concepto ambiguo y confuso, es decir, todo un galimatías en comparación con otros métodos pedagógicos similares (Cenoz et al., 2013). Por este motivo, la siempre atrayente etiqueta AICLE ha sido utilizada en una multiplicidad de praxis cuyas características podían diferir vastamente (Lasagabaster y Sierra, 2010).

En el lado opuesto de la balanza, múltiples de sus valedores han enaltecido esta flexibilidad inherente a AICLE, puesto que favorece su introducción en muy variados contextos, pudiendo involucrar mayor dinamismo y creatividad (Casal, 2016). En este sentido, también se pone en valor su maleabilidad por favorecer la adaptación de los procesos de enseñanzaaprendizaje al contexto particular de cada clase, teniendo en consideración la diversidad característica de las aulas actuales (Coyle et al., 2010; Hüttner y Smit, 2014; Pérez-Cañado, 2016). De este modo, la inicialmente criticada indefinición se torna en un potente estandarte que permite que AICLE se adecue a la multiplicidad de escenarios y agentes (centros educativos, docentes, estudiantes y contextos sociales) que puedan acogerlo.

También debido a su amplitud de miras, otro aspecto que ha generado debate concierne a la lengua de aprendizaje a la que incumbe. Atendiendo a la definición de AICLE expuesta por Coyle et al. (2010), se hace referencia a una "lengua adicional", concepto que también puede resultar ambiguo. Por lo general, dicho término suele aludir a una lengua extranjera escasamente (o nunca) utilizada en el contexto social cercano a los aprendices, de manera que las posibilidades de aprenderla en situaciones no formales se ven ciertamente constreñidas (Pérez, Cañado, 2016; Scott y Beadle, 2014). No obstante, según el Eurydice 
(2006), dicho concepto abarca no solo lenguas foráneas, sino también incorpora aquellas regionales, minoritarias y/o co-oficiales, de modo que la exposición del alumnado a estos idiomas en situaciones ajenas al ámbito escolar puede verse incrementada considerablemente. En el presente trabajo, al igual que Lo y Lin (2015), optamos por adoptar el término "lengua adicional" para referirnos a cualquier lengua que pueda ser empleada en AICLE y que puede variar en función del contexto en que le se aplique, sea esta una segunda lengua, tercera lengua o lengua extranjera.

En cualquier caso, pese a la infinidad de idiomas (foráneos o no) que pueden trabajarse mediante AICLE, el inglés se erige como lengua hegemónica (Fortanet, 2013; Pérez-Cañado, 2016). La inglesa se ha convertido en la lengua más utilizada en campos de prestigio como la ciencia, la política o la economía; cuestión que ha suscitado que el interés por su aprendizaje se haya expandido por todo el mundo. Sin embargo, en lo concerniente a AICLE, resulta más relevante reparar en cómo se implementa, que en la lengua utilizada (Fortanet, 2013). Desde un enfoque AICLE, dicha lengua no es únicamente un producto a aprender, puesto que al mismo tiempo este idioma se emplea para transmitir conocimiento, estimulando entornos de aprendizaje más naturales que favorecen la adquisición lingüística (DaltonPuffer, 2007). En este sentido, AICLE supone dar un paso más en el enfoque comunicativo, puesto que la autenticidad deja de ser opcional, para convertirse en un imperativo (Coyle et al., 2010). Por este motivo, entre otros, conviene reparar cuidadosamente en una adecuada incorporación de AICLE, tal y como se abordará más adelante.

\subsection{1. ¿De dónde viene AICLE?}

El nacimiento de AICLE fue el fruto de la congregación de múltiples circunstancias. Por un lado, cabe destacar su complementariedad con las características de la sociedad actual, globalizada e interconectada. Antes de adentrarnos en la era de la información y la tecnología (Castells, 1999), el aprendizaje se regía por la premisa aprender ahora para utilizar más adelante. Sin embargo, este postulado carece de sentido en un mundo en la que la información está al alcance de la mano, por lo que hoy en día la sociedad se encuentra más vinculada al “aprender mientras se utiliza y utilizar mientras se aprende" (Coyle et al., 2010). Este postulado, de claro trasfondo deweyniano (learning by doing), puede ser entendido tanto en referencia al uso de las nuevas tecnologías como, en este caso, al de las lenguas. En dicho 
contexto, la sociedad demanda un aprendizaje para ya mismo, por lo que cobra sentido aprender una lengua a la vez que esta se está utilizando con un propósito concreto.

También es interesante comentar que, como hemos visto en apartados previos, a nivel continental se apostó decididamente por invertir y apoyar el aprendizaje de lenguas a fin de favorecer una Europa más unida, puesto que esto supondría una mayor facilidad para establecer relaciones laborales y económicas entre los países que integran dicho continente (Eurydice, 2006). Esta cuestión, que de entrada resultó ser un punto básico sobre el que cimentar e instituir un viraje pro-aprendizaje de lenguas, ha permitido atender a otro tipo de motivaciones educativas como promover en el alumnado una mejor comprensión del mundo y sus ciudadanos, tener la oportunidad de abrirse a otras culturas y de crecer integralmente, así como de disfrutar del propio aprendizaje.

Asimismo, resulta pertinente recordar que en múltiples ocasiones el aprendizaje de lenguas ha sido un campo restringido a aquellas personas que ostentaban un determinado poder adquisitivo. Quienes alcanzaban un buen dominio de lenguas eran aquellos que podían, más allá de la escuela, acudir a centros privados, clases particulares, así como realizar cursos o estancias en países extranjeros. Teniendo en cuenta que la educación debe ser una herramienta de igualdad, parecía apropiado establecer medidas ligadas a principios propios de la justicia social y la equidad (Fortanet, 2013), que persiguieran facilitar que todo el alumnado, fuera cual fuera su origen y entorno, tuviera la oportunidad de aprender lenguas adquiriendo un buen nivel de dominio.

Al mismo tiempo, otro de los factores que favoreció el nacimiento de AICLE radica en el hecho de que, de un tiempo a esta parte, se ha desarrollado una tendencia cuantificadora que ha asaltado el mundo de la enseñanza. Con el propósito de poder cuantificar y clasificar de una manera supuestamente objetiva el estado de la educación se han desarrollado informes, tales como el renombrado PISA $^{7}$, que tratan de mesurar y comparar el conocimiento del alumnado. Así, todos los estados sujetos a esta evaluación externa sienten apremio por mejorar sus resultados en diversas áreas, entre las que se encuentra el aprendizaje de lenguas,

\footnotetext{
${ }^{7}$ El Programa para la Evaluación Internacional de Alumnos de la OCDE tiene por objeto evaluar hasta qué punto los alumnos cercanos al final de la educación obligatoria han adquirido algunos de los conocimientos y habilidades necesarios para la participación plena en la sociedad del saber. Para más información ver: http://www.oecd.org/pisa/pisaenespaol.htm
} 
a fin de tratar de evitar los últimos puestos de las clasificaciones. Este factor también parece haber resultado de relevancia para el advenimiento de numerosas iniciativas y reformas educativas a nivel internacional, nacional y autonómico/regional cuyo objetivo reside en favorecer el aprendizaje de lenguas. Dado que resultaba complicado otorgar aún más horas específicas al aprendizaje de idiomas foráneos, la solución por la que se optó en un gran número de casos resultó ser incorporar dicha lengua a aprender en otras asignaturas, es decir, promover e incluso, en algunos casos, prescribir el empleo de AICLE.

En definitiva, AICLE apareció como consecuencia a la suma de diversos factores que se congregaron en Europa y como una manera de acercar y fomentar el plurilingüismo a todos los habitantes de dicho continente. Conviene recordar en este punto que AICLE es considerado un término ciertamente europeo (Roquet, Llopis y Pérez-Vidal, 2016), de modo que este enfoque apareció como tentativa para hacer frente a una necesidad en este contexto determinado y, finalmente, se erigió como una solución pragmática a dicha situación (Marsh 2002). Así, hoy en día, su empleo en múltiples sistemas educativos del viejo continente resulta ya considerablemente habitual (Pladevall y Vallbona, 2016).

Sin embargo, a pesar de poseer raíces eminentemente europeas, es de recibo mencionar el vínculo de AICLE con otros lugares del mundo. Por ejemplo, su creación se nutrió de los programas de inmersión canadienses, en los que la utilización de lenguas adicionales en asignaturas no lingüísticas ya estaba ciertamente extendida (Coyle, 2007). Además, en otras partes del planeta pueden encontrarse iniciativas similares a AICLE, pero ajustadas a sus contextos particulares. Por ejemplo, en los Estados Unidos se presta apreciable atención a la introducción del inglés en otras asignaturas a través del Content Based Instruction debido a la notable cantidad de alumnado que no tiene este idioma como primera lengua, cuestión muy extendida en dicho país, al igual que ocurre en Australia. En el caso de esta segunda nación, existen programas destinados específicamente a estudiantado que no domina la lengua inglesa que se denominan LOTE (Learning Languages Other than English). En estos dos últimos contextos puede apreciarse que la lengua social dominante es la misma que se está aprendiendo, a diferencia de lo que suele ocurrir en entornos europeos.

Pese a poder verse reflejado o compartir características con enfoques, programas o metodologías ajenas al viejo continente, pasamos ahora a comentar cuál fue el origen y los 
primeros pasos de AICLE en el contexto europeo. El origen de este término fue perpetrado por un grupo de expertos formado por miembros de la administración educativa, investigadores y docentes de diversas procedencias durante la década de los 90 (Marsh, 2002), coincidiendo con la publicación del Libro Blanco de la Comisión Europea. Desde aquella primera concepción y esbozo de AICLE, las autoridades educativas europeas han ido dándole paulatinamente más relevancia. A finales de dicha década se creó un grupo multidisciplinario destinado a concretar sus características clave y compartir experiencias sobre su utilización. Además, se diseminó una definición más clara de qué era AICLE y se proyectó un plan estratégico que vio la luz y se puso en marcha en el año 2001, coincidiendo con la celebración del año europeo de las lenguas. Este momento supuso un punto de inflexión, de manera que el número de investigaciones sobre este enfoque se vio incrementada exponencialmente durante los años siguientes (Fortanet, 2013). Así mismo, en el 2004 el término AICLE ya fue incluido en la publicación Promover el aprendizaje de idiomas y la diversidad lingüística Plan de acción 2004-2006 de la Comisión Europea, siendo presentado como una manera efectiva de aprender lenguas. Un año después, el Consejo Europeo decretó que AICLE debía ser adoptado en toda la Unión Europea (Comisión Europea, 2005), y a partir del año 2007 comenzaron a organizarse congresos y simposios específicos, destinados a compartir experiencias y discutir políticas educativas al respecto.

A nivel estatal, es reseñable la propagación progresiva de AICLE por prácticamente todas las autonomías, sin importar si estas poseen lenguas cooficiales o no. La introducción de AICLE en España puede datarse en el curso 2004/2005, con el establecimiento de dos proyectos piloto, uno en la Región de Madrid y otro en las Islas Baleares (Eurydice, 2006). Desde aquel momento, el interés por dicho enfoque como fórmula para incrementar el conocimiento y dominio de diversos idiomas ha ido aumentando con el paso de los años. Dos de las comunidades autónomas donde más firmemente y con mayor premura caló este enfoque son la madrileña y la andaluza, mediante sus respectivos planes plurilingües. Sin embargo, limitarse a la mera mención de estos dos territorios no resulta fiel a la realidad actual, puesto que son numerosas las autonomías que han decretado la inclusión del bilingüismo o plurilingüismo en sus centros educativos. 
En definitiva, la irrupción de AICLE fue potente y apasionada, e incluso dicho enfoque llegó a ser considerado por algunos como la solución definitiva a un deficitario nivel de dominio de lenguas extranjeras (Pérez-Vidal, 2015). No obstante, este inicial entusiasmo fue decayendo mientras diversas voces críticas comenzaban a hacerse oír (Bruton, 2011, 2013, 2015; Cenoz et al., 2013; Paran, 2013; Pérez-Cañado, 2011, 2012). Tal y como lo describe Pérez-Cañado (2017), AICLE se vio sumido en el "efecto péndulo", ya reincidente en la historia de la didáctica de las lenguas extranjeras, de forma que era aclamado por un sector a la vez que desaprobado por otro.

En el punto actual parece que la situación con respecto a AICLE se encuentra ante una disyuntiva. Por lo tanto, parece necesario investigar qué se esconde tras de él a fin de conocerlo mejor e indagar en sus puntos fuertes y débiles. En este sentido se encamina el presente trabajo, que tiene por objetivo arrojar un poco más de luz sobre el impacto que pueda implicar la utilización de AICLE, concretamente en el campo de la educación física, de manera que pueda aportar su pequeño grano de arena a los estudios que ya se han realizado o que aún se están desarrollando con este cometido.

\subsubsection{Enfoque comunicativo y AICLE}

Para seguir conceptualizando el enfoque AICLE resulta interesante ampliar la perspectiva e incidir en su ligazón con la competencia comunicativa, así como su relación con el enfoque comunicativo. Convenimos recordar que el objetivo capital del enfoque comunicativo radica en propiciar situaciones comunicativas reales a fin de favorecer que el alumnado pueda desarrollar la capacidad de comunicarse efectivamente, primando el sentido comunicativo general ante la corrección gramatical. Por este motivo, Lasagabaster y Sierra (2010) manifiestan que el contexto educativo debe ser motivante para el estudiantado y, por ende, sería más que apropiado proponer situaciones de aprendizaje en las que los discentes se hallen interesados. Este razonamiento emana de las múltiples investigaciones que han concluido que el aprendizaje lingüístico suele ser más exitoso cuando se desarrolla con fines comunicativos e involucra situaciones sociales significativas y desarrolladas en un contexto particular (Celce-Murcia, 2008; De Graaff et al., 2007). Sin embargo, siguiendo a Dörnyei (2009), conviene reparar en el hecho de que proponer actividades comunicativas en las que el aprendizaje de la lengua se plantea de manera implícita no tiene porqué ser garantía 
suficiente para un óptimo aprendizaje de la misma. De hecho, este autor declara que existe la necesidad de introducir, en ciertas ocasiones, una enseñanza más explícita, cuestión que puede verse incorporada en AICLE a través de los objetivos lingüísticos que dicho enfoque plantea.

Por otro lado, resulta interesante incidir en el rol adquirido por los diferentes actores (alumnado y profesorado) que toman parte en el proceso de enseñanza-aprendizaje. Por lo que respecta al alumnado, el enfoque comunicativo aboga por otorgarle el papel protagonista de todo el proceso (Dörnyei, 2009). De este modo, adquieren el rol de actores principales de su aprendizaje, ganando mayor responsabilidad con respecto a su aprendizaje (Richards y Rodgers, 2001; Savignon, 2003) y postulándose como participantes activos de la acción que se sucede en clase. Por su parte, el profesorado adquiere un rol secundario en el que su máximo propósito es guiar al alumnado a fin de facilitar su aprendizaje, de modo que sus tareas consisten en proponer situaciones que promuevan la comunicación y motiven al estudiantado, así como hablar menos y escuchar más (Breen y Candlin, 2001; Deckert, 2004). Estas cuestiones parecen concordar con la perspectiva del enfoque AICLE puesto que Coyle et al. (2010) estipulan que dicho enfoque pedagógico se rige por los principios del aprendizaje socio-constructivista. Por este motivo, Van Kampen, Meirink, Admiraal y Berry (2017) aseveran que este enfoque se caracteriza por ubicar al alumnado en el centro de la praxis educativa. De hecho, en este mismo sentido, Ting (2011) expone que gracias a AICLE los docentes prestan mayor atención a la planificación, cómo emplean la lengua, cómo introducen los contenidos, cuáles son las experiencias previas del alumnado o a la necesidad de introducir estrategias de andamiaje. Aspecto al que también aluden Kashiwagi y Tomecsek (2015), quienes concluyen que la utilización de AICLE conlleva la alteración del estilo docente a fin de optar por métodos y actividades más centradas en el alumnado.

De esta forma, puede apercibirse cómo la literatura avala la tesis de que AICLE se erige como un paso más allá del enfoque comunicativo, favoreciendo, consiguientemente, el desarrollo la competencia comunicativa del alumnado (Coyle et al., 2010; Dalton-Puffer, 2009; De Graaff et al., 2007). 


\subsubsection{Principios básicos de AICLE}

Una vez esbozados la historia y desarrollo de AICLE, así como su entroncamiento con el enfoque comunicativo, pasamos a comentar los principios básicos que rigen dicho enfoque metodológico. Como ya se ha hecho explícito en apartados anteriores, AICLE puede considerarse un paraguas amplio que comprende multiplicidad de modelos, es decir, no existe una única manera unívoca de emplearlo, sino que puede ser adaptado a cada contexto particular y presentar objetivos variables (Coyle et al., 2010). Pese a esta apertura de miras, existen una serie de características comunes que deben estar presentes, ineludiblemente, en cualquier propuesta que acometa su aplicación.

Para empezar, resulta interesante recordar que AICLE encuentra sus raíces en principios vinculados a la justicia social y la equidad (Fortanet, 2013), de manera que hacer un uso elitista o segregado del mismo carecería de sentido. Este enfoque, tal y como ya se ha expuesto, apareció como una forma de favorecer que todo el alumnado, indistintamente de su procedencia social o poder adquisitivo, pudiera gozar de la oportunidad de aprender lenguas. Diversas voces han criticado que, en determinadas ocasiones, AICLE haya podido perder su función equitativa (Bruton, 2015, Cenoz et al., 2013). No obstante, dado su origen, este enfoque debe estar al alcance de cualquiera y no debería verse limitado a grupos particularmente seleccionados por poseer unas determinadas características como, por ejemplo, presentar mejores resultados académicos (Bruton, 2011; 2015).

En otro orden de aspectos, los centros educativos encuentran en la promoción del desarrollo integral del alumnado uno de sus objetivos principales. En este sentido, tal y como plantea Delors (1996), la educación no consiste solo en aprender a conocer, sino también en aprender a hacer, aprender a vivir y aprender a ser para que el estudiantado sea consciente, desde una perspectiva crítica, del mundo en el que habita, la sociedad que le rodea y la realidad multilingüe en la que vive. AICLE entronca con este cometido $\mathrm{y}$, de hecho, puede devenir una poderosa herramienta en la adquisición de una mayor comprensión intercultural, puesto que permite descubrir y valorar otras culturas, tradiciones, valores y comportamientos (Coyle, Holmes y King, 2009), al mismo tiempo que posibilita que el alumnado pueda mostrar sus críticas y opiniones sobre el mundo y la sociedad, dejando su impronta, a través de diversos idiomas. 
Así mismo, AICLE presenta una concordancia clara con los principios del aprendizaje socioconstructivista (Coyle et al., 2010), puesto que la praxis educativa gira en torno al alumnado, que adquiere el rol de actor principal de su propio aprendizaje. De este modo, los docentes que emplean AICLE prestan mayor atención a cómo se expresan, cuáles son los conocimientos y experiencias previas de los discentes, así como a la necesidad de utilizar estrategias de andamiaje para garantizar o, como mínimo, favorecer un aprendizaje eficaz (Ting, 2011). Además, puesto que se sustenta en el enfoque comunicativo, AICLE también se muestra en sintonía con las actuales teorías propias del campo de la didáctica de las lenguas, apuntaladas sobre un posicionamiento ecléctico que otorga relevancia tanto al significado como a la forma del acto comunicativo (Villanueva, 2007).

Siguiendo Coyle (2007), la implantación de AICLE debe encontrarse más o menos sujeta, en función de las características del modelo adoptado, a una serie de objetivos generales (Figura 2) como son:

\begin{tabular}{|c|c|}
\hline \multirow{8}{*}{$\begin{array}{l}\text { Objetivos } \\
\text { generales AICLE }\end{array}$} & Desarrollar habilidades comunicativas interculturales. \\
\hline & Preparar para el internacionalismo. \\
\hline & $\begin{array}{l}\text { Ofrecer la oportunidad de aprender un contenido a través de diferentes } \\
\text { perspectivas. }\end{array}$ \\
\hline & Tener acceso a la lengua y terminología propias de un determinado campo. \\
\hline & Mejorar la competencia general de la lengua de aprendizaje. \\
\hline & Desarrollar las destrezas de comunicación oral. \\
\hline & Diversificar los métodos y formas empleados en clase. \\
\hline & Aumentar la motivación del alumnado. \\
\hline
\end{tabular}

Figura 2. Objetivos generales de AICLE

Fuente: Adaptado de (Coyle, 2007)

Todos estos propósitos pueden ser alcanzados mediante una adecuada utilización de AICLE que, necesariamente, deberá encontrar un equilibrio entre contenido y lengua. Conviene recordar que para considerar que el uso de este enfoque está siendo adecuado y exitoso, el contenido no lingüístico debe ser aprendido (Dalton-Puffer, 2007). Para ello, el rol docente 
adquiere gran relevancia puesto que en sus manos queda adaptar la praxis educativa para conseguir no solo este aprendizaje, sino también favorecer la adquisición de la lengua (Coyle et al., 2010). Por este motivo, el empleo de AICLE implica el establecimiento de objetivos de dos naturalezas: por un lado, los relativos a la materia no lingüística y, por otro, los relativos a la lengua de aprendizaje, que deberán ir más allá de la gramática y el léxico pasando a estar relacionados con las competencias comunicativas que demanda la sociedad actual (Marsh, 2012).

Además, existen una serie de elementos fundamentales que favorecen que el uso de AICLE sea exitoso y, por tanto, deberían ser inherentes a su aplicación. Estos quedan expuestos en la Figura 3 (Mehisto et al., 2008): 


\section{Enfoque múltiple}

- Apoyo al aprendizaje de lengua en clases sobre un contenido.

- Apoyo al aprendizaje de un contenido en clase de lengua.

- Integración de varias asignaturas.

- Organización del aprendizaje a través de temas y proyectos transversales.

-Apoyo a la reflexión sobre el proceso de aprendizaje.

\section{Ambiente de aprendizaje seguro y enriquecedor}

- Uso de discursos y actividades rutinarias.

- Exposición a la lengua y el contenido a lo largo de toda la clase.

- Adquisición de seguridad en el alumnado para experimentar con la lengua y el contenido.

-Empleo de centros de aprendizaje en clase.

- Guía para poder acceder a materiales auténticos y ambientes de aprendizaje reales.

- Incremento de la conciencia lingüística del estudiantado.

\section{Autenticidad}

- Concesión de oportunidades para que el alumnado pida la ayuda lingüística que pueda necesitar.

- Adaptación máxima a los intereses de los discentes.

-Establecimiento regular de las conexiones entre el aprendizaje y la vida del estudiantado.

- Conexión con otros hablantes de la lengua AICLE.

- Uso de materiales anacrónicos procedentes de los medios de comunicación y otros recursos.

\section{Aprendizaje activo}

-El alumnado comunica más que el docente.

- El estudiantado ayuda al establecimiento de los objetivos sobre el contenido, la lengua y las habilidades de aprendizaje.

- Los discentes evalúan su progreso en referencia a los objetivos de aprendizaje.

- Promoción de trabajo cooperativo.

- Negociación de los significados de la lengua y el contenido con el estudiantado.

-Actuación de profesorado como facilitador del aprendizaje.

\section{Andamiaje}

- Construcción del aprendizaje en base a los conocimientos previos, habilidades, actitudes, intereses y experiencias del alumnado.

- Reutilización de la información de manera entretenida.

-Atención a los diferentes estilos de aprendizaje.

- Fomento del pensamiento crítico y creativo.

-Estímulo al estudiantado para que salga de su zona de confort.

\section{Cooperación}

- Planificación de cursos/sesiones/temas coordinadamente entre docentes AICLE y noAICLE.

- Involucramiento de los padres y madres para conocer qué es AICLE y como apoyar a sus hijos e hijas.

- Involucramiento de la comunidad local, autoridades y empresas. 
Todos estos elementos favorecen una adecuada introducción del enfoque AICLE, permitiendo enriquecer además la práctica educativa de un modo razonable. En definitiva, pese a su holgura y flexibilidad, son diversos los elementos fundamentales comunes a cualquier iniciativa AICLE, tales como los mencionados en las líneas precedentes. No obstante, para poder granjearse un derecho legítimo y fundado a nivel pedagógico, AICLE debe establecer un marco de acción ajustado y definido, que a su vez se encuentre sustentado en una teoría rigurosa (Coyle, 2007). En este sentido, la aplicación de este enfoque solía apuntalarse en cuatro principios básicos (contenido, comunicación, cultura y conocimiento) a los que con el paso del tiempo se les ha sumado un quinto componente (competencias) (Attard, Walter, Theodorou y Chrysanthou, 2015), tal y como se aborda a continuación.

\subsubsection{Las 5Cs de AICLE}

Las 5Cs de AICLE conforman un marco teórico y metodológico ciertamente conocido y empleado. En un inicio, Marsh (2006) propuso cuatro pilares básicos sobre los que las iniciativas AICLE podían descansar para dotar a sus prácticas educativas de coherencia y sentido con respecto a dicho enfoque. Estos cuatro elementos eran el contenido, la comunicación, la cultura y el conocimiento. Sin embargo, con el advenimiento de la tendencia orientada hacia la formación de alumnado competente que impera en la educación europea actual (Comisión Europea, 2005; Eurydice, 2002), la adición de una quinta C relativa a las competencias que debían ser adquiridas a través de las prácticas AICLE no se hizo esperar (Attard et al., 2015). Así, estos cinco elementos nucleares establecen las líneas básicas a las que el profesorado que se acoja a AICLE debe atenerse. Seguidamente pasamos a comentar brevemente cada uno de estos componentes.

El contenido hace referencia a la esencia básica de la asignatura que acoge el uso de AICLE. Este es el elemento nuclear de toda la acción, puesto que se trata de la esencia misma sobre la cual gira todo el proceso de enseñanza-aprendizaje. El contenido es aquello que le da sentido a la práctica educativa y establece los cimientos básicos vinculados a los conocimientos previos del alumnado sobre los cuales se irán construyendo sus nuevos saberes. 
Por su parte, la comunicación alude al uso que se le da a la lengua en clase. A través de una perspectiva AICLE, la lengua empleada para establecer dicha comunicación es, al mismo tiempo, la lengua que se está aprendiendo. Este factor favorece que el idioma que se está aprendiendo adquiera mayor significatividad, puesto que se le está dando un uso real y próximo al alumnado. Otro aspecto de relevancia relativo a la comunicación radica en el necesario incremento que debe sufrir el tiempo de habla del estudiantado. Dado que uno de los objetivos de AICLE consiste en favorecer el intercambio comunicativo para desarrollar las destrezas comunicativas, es conveniente crear múltiples ocasiones que fomenten y animen a hablar e interaccionar a los discentes.

Hoy en día las competencias han adquirido una alta relevancia a nivel educativo, puesto que atañen a la utilización de conocimientos para poder hacer frente de manera exitosa a situaciones concretas. En este sentido, las competencias ponen de manifiesto aquello que el alumnado puede hacer gracias a su aprendizaje y, por tanto, desde un planteamiento AICLE, hacen referencia tanto a los nuevos saberes relativos al contenido como a la lengua. En definitiva, este tercer pilar de AICLE, relativo a las competencias, acarrea la puesta en práctica del resto de elementos.

En alusión a la cultura (también referida como comunidad por Watanabe, Ikeda e Izumi (2011), resulta interesante recordar su estrecha relación con el aprendizaje en general y el de lenguas en particular desde un posicionamiento socio-constructivista (Bruner, 1984; Villanueva, 2002; Vygotsky, 1989), en tanto que la cultura es un factor capital para acceder al sentido completo de la comunicación. Así mismo, la cultura en AICLE implica la adquisición de una mayor conciencia sobre la propia y el establecimiento de relaciones de esta con las ajenas, no solo relativa al contenido tratado, sino también aquella vinculada a la lengua de aprendizaje.

Por último, el conocimiento se refiere a la formación de conceptos y la construcción de nuevos significados. Para ello, el alumnado debe crear sus propias interpretaciones relativas a la combinación y relación de los cuatro pilares ya descritos, cuestión que implica el trabajo y desarrollo de sus habilidades cognitivas. Desde una perspectiva AICLE conviene prestar mucha atención a cómo se acometen las cuestiones más abstractas, complejas y analíticas, teniendo en cuenta las demandas lingüísticas que se ven involucradas en dicho proceso. 
El hecho de utilizar una lengua que no se domina para abordar un contenido concreto acarrea, necesariamente, el uso de demandas cognitivas de nivel elevado por parte del alumnado (Cenoz et al., 2013; Fortanet, 2013). Pese a lo provechoso que puede resultar la promoción de este tipo de razonamientos, conviene ser cuidadosos en cómo se aborda esta cuestión, puesto que una secuenciación que no pase progresivamente de demandas menos exigentes a otras de mayor calado y/o tenga en cuenta cuestiones referentes a la didáctica de la lengua podría entorpecer el aprendizaje (Marsh, 2012; Roussel, Joulia, Tricot y Sweller, 2017). En este sentido, la taxonomía de Bloom revisada por Anderson et al. (2001) sobre las habilidades y procesos del pensamiento o la taxonomía de Marzano y Kendall (2007) sobre objetivos educativos pueden ofrecer un marco guía de gran utilidad práctica, puesto que establecen diferentes niveles de procesamiento cognitivo a los que puede enfrentarse el alumnado. La taxonomía revisada de Bloom (Figura 4) ha sido recurrentemente vinculada con el enfoque AICLE (Meyer, 2010), siendo una herramienta que presenta un espectro de seis demandas cognitivas que van desde las más sencillas a las más exigentes separándolas en dos grandes grupos: Low Order Thinking Skills (LOTS) y High Order Thinking Skills (HOTS). Por su parte, la taxonomía de Marzano y Kendall (2007) constituye una alternativa que permite discernir entre la naturaleza del contenido y el nivel de procesamiento al que se quiere llegar (Figura 5). En este caso se diferencian también seis niveles de procesamiento, pero referidos a tres sistemas (cognitivo, metacognitivo y self). Además, a estos se añaden tres dominios del conocimiento tales como la información (qué se conoce), los procedimientos mentales y los procedimientos psicomotores (ambos referidos a cómo se conoce). 


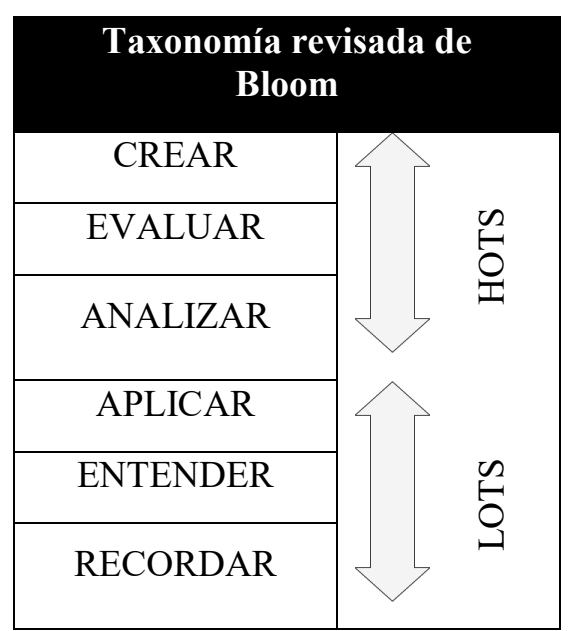

Figura 4. Taxonomía revisada de Bloom

Fuente: Adaptada de Ahmed, Anwar, Wajahat, Edriss y Abdurahen (2014, p.12)

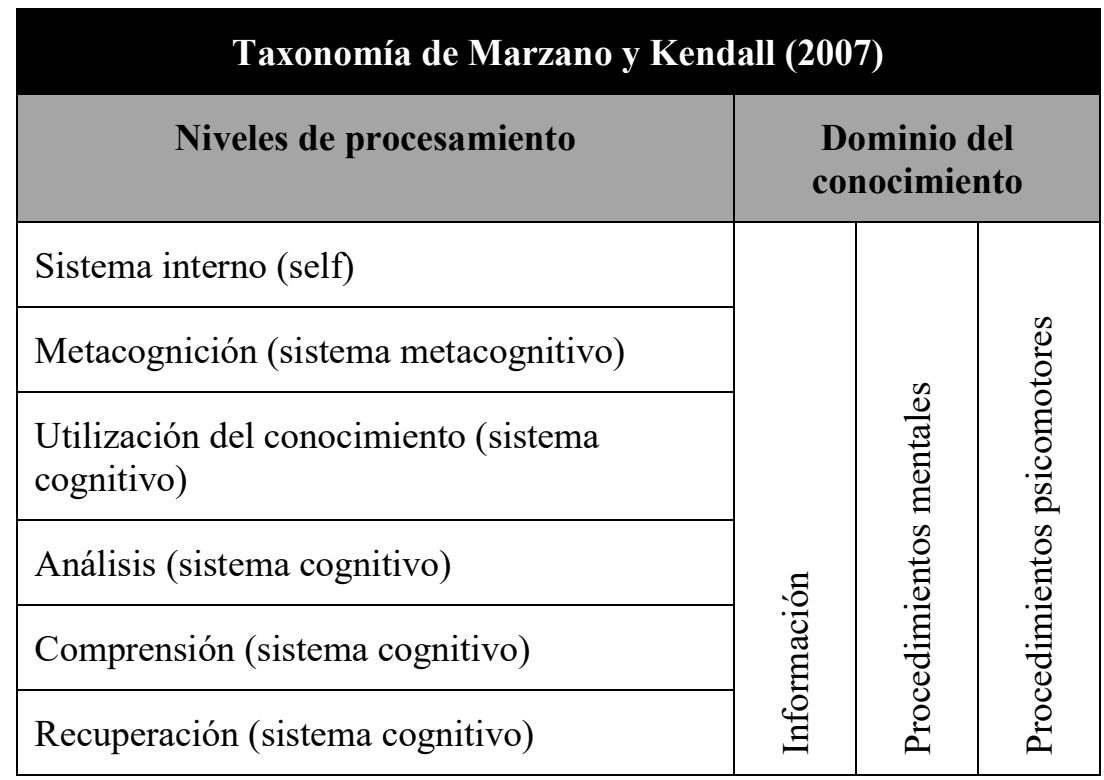

Figura 5. Taxonomía de Marzano y Kendall

Fuente: Adaptada de Marzano y Kendall (2007)

Sin embargo, la relevancia en lo concerniente al conocimiento no reside en la selección de una u otra taxonomía, sino en la identificación de los procesos cognitivos inmiscuidos en cualquier proceso AICLE y su adaptación a la naturaleza del estudiantado implicado (Coyle et al., 2010). Mediante cualquiera de estas taxonomías, los docentes pueden determinar qué niveles de implicación cognitiva y de conocimiento van a plantear al alumnado. Esta decisión debe acometerse, para que se produzca un aprendizaje significativo, partiendo de las 
habilidades, las actitudes, los intereses y las experiencias previas del alumnado (Bruner, 1984; Coyle, 2015).

\subsubsection{La lengua en AICLE}

Una vez esbozados los cinco pilares elementales de AICLE, el foco de atención se deposita, a continuación, en el papel concreto que juega la lengua en este enfoque metodológico. La lengua es un elemento clave en la comunicación del ser humano y deviene esencial para el aprendizaje (Bruner, 1984; Vygotsky, 1989), motivo por el cual su adquisición es una de las mayores preocupaciones de padres y madres con descendientes en edad escolar.

A nivel general, puede afirmarse que la lengua constituye uno de los objetivos esenciales que deben ser desarrollados en las primeras etapas educativas. Por ejemplo, el alumnado a lo largo del período de educación obligatoria está constantemente aprendiendo lengua, puesto que este suele ser el medio de comunicación predominante tanto en contextos sociales como académicos. De hecho, en el ámbito escolar, la lengua es el medio de instrucción con respecto a contenidos de muy diversa índole y, particularmente, en la fase de educación infantil es cuando el alumnado comienza a adquirir nociones de lectura y escritura en su primera lengua, por ejemplo. Sin embargo, tal y como expone la vigente ley educativa (LOMCE 8/2013), la competencia lingüística debe ser desarrollada a lo largo de los doce años de escolarización obligatoria y a través de todas las áreas del currículo, inmiscuyendo dicha competencia tanto a la o las lenguas oficiales como a otras extranjeras.

En lo relativo a las segundas o terceras lenguas, así como las foráneas ${ }^{8}$, de un tiempo a esta parte, estas solo solían incorporarse en la escuela una vez que el alumnado ya poseía un cierto dominio de la lengua materna, y se hacía introduciendo el nuevo idioma como asignatura en particular. Los cambios sucedidos en las teorías concernientes a la didáctica de las lenguas han generado que hoy en día esto sea cosa del pasado. Ahora se promueve el tratamiento integrado de lenguas y, para facilitar el aprendizaje de otros idiomas, se procura aprovechar el conocimiento que el alumnado atesora con respecto a su primera lengua (Cambra, 2011). Si bien es cierto que estos idiomas adicionales se mantienen como materias por sí mismas, no es menos cierto que están viéndose incorporados, además, en otras áreas curriculares.

\footnotetext{
${ }^{8}$ Dependiendo del contexto, la lengua a aprender mediante AICLE puede ser cualquiera de estas.
} 
Aprender una lengua como fin último o aprenderla mientras se utiliza con otro propósito en mente son procesos que difieren asazmente, por ello conviene ser conscientes de qué o cuál es la lengua utilizada en AICLE y cómo se acomete su aprendizaje.

Cuando un idioma que no se domina es empleado como medio de instrucción, el esfuerzo cognitivo al que se ve sujeto el alumnado se incrementa (Cenoz et al., 2013; Fortanet, 2013). Siguiendo a Cummins (2000), a nivel lingüístico pueden diferenciarse dos tipos de habilidades comunicativas, las Basic Interpersonal Communication Skills (BICS) y las Cognitive Academic Language Proficiency (CALP). Mientras las BICS hacen referencia a habilidades de comunicación básica, con gran dependencia del contexto y con una demanda cognitiva limitada, las CALP involucran términos más abstractos, contextos ajenos y, por ende, niveles de pensamiento de un estamento superior. A menudo las segundas se ven involucradas en situaciones académicas, tales como las propuestas por AICLE. Sin embargo, es oportuno recordar que la lengua utilizada en AICLE, pese a no ser dominada por el estudiantado, debe permitir un pertinente aprendizaje del contenido, puesto que este es el eje central de la praxis educativa (Dalton-Puffer, 2007). Por este motivo, conviene pasar progresivamente del uso de BICS al de CALP para que el nuevo conocimiento relativo al contenido vaya progresando en dificultad simultáneamente a la incorporación de elementos lingüísticos de mayor complejidad.

Así, las prácticas adscritas a AICLE deberían hallar un equilibrio entre contenido y lengua (Coyle et al., 2010). A fin de favorecer la adquisición exitosa de ambos elementos, las actividades deben ser presentadas como retos cognitivos adaptados al nivel del alumnado mediante una secuenciación lógica, que incorpore medidas de andamiaje tales como apoyos contextuales y lingüísticos para, progresivamente, ir aumentando el nivel de complicación y retirando dichas ayudas.

En este sentido, la matriz de Cummins (2000) (Figura 6) puede ser tomada como herramienta de guía, puesto que plasma de manera clara la progresión que deberían seguir las actividades, teniendo en cuenta las dificultades a las que se enfrenta el estudiantado que no domina la lengua vehicular. De este modo, la secuenciación propuesta debe comenzar por demandas que se encuentren en el cuadrante 1 presentando tareas sencillas y con apoyos contextuales abundantes, tanto a nivel lingüístico como cognitivo, vinculadas con los conocimientos y 
experiencias previos del alumnado. En este punto las demandas lingüísticas predominantes deben ser las BICS. Seguidamente, se debe pasar al cuadrante 2, en el que la demanda cognitiva se ve incrementada, aludiendo en la mayoría de ocasiones a la introducción de nuevos conceptos relativos al contenido, aunque manteniendo el nivel de complicación lingüística empleando la lengua que el estudiantado ya conoce. Por último, se introducen las tareas que se encuentran en el cuadrante 3 , que no solo incorporan nuevos aspectos relativos al contenido, sino también a la lengua, pasando en este momento a incorporar las CALP, propias ya de un lenguaje académico más complejo. Las tareas con alta demanda lingüística (cuadrante 4) únicamente serían apropiadas en momentos concretos en los que se requiriera de una práctica centrada en la forma de la lengua por ser esta un requisito para progresar en el aprendizaje (Coyle et al., 2010).

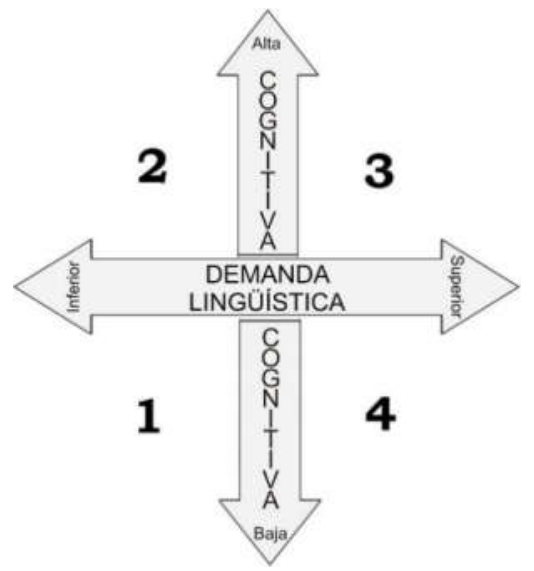

Figura 6. Matriz de Cummins (2000, p. 43)

Otro elemento de ayuda en lo concerniente a la lengua empleada en AICLE reside en el tríptico del lenguaje propuesto por Coyle et al. (2010), que evidencia los diferentes usos que se le da a la lengua a través de este enfoque (Figura 7). Estos autores determinan tres naturalezas distintas: (1) la lengua de aprendizaje, que hace referencia a aquella que posibilita el acceso a los conceptos y habilidades propias del contenido trabajado; (2) la lengua para el aprendizaje, que es la necesaria para funcionar en un entorno regido por la lengua adicional, por ejemplo para realizar preguntas o debatir; y (3) la lengua a través del aprendizaje, que es la referida al lenguaje que emerge sin una planificación previa fruto de la interacción y las actividades desarrolladas en clase. 


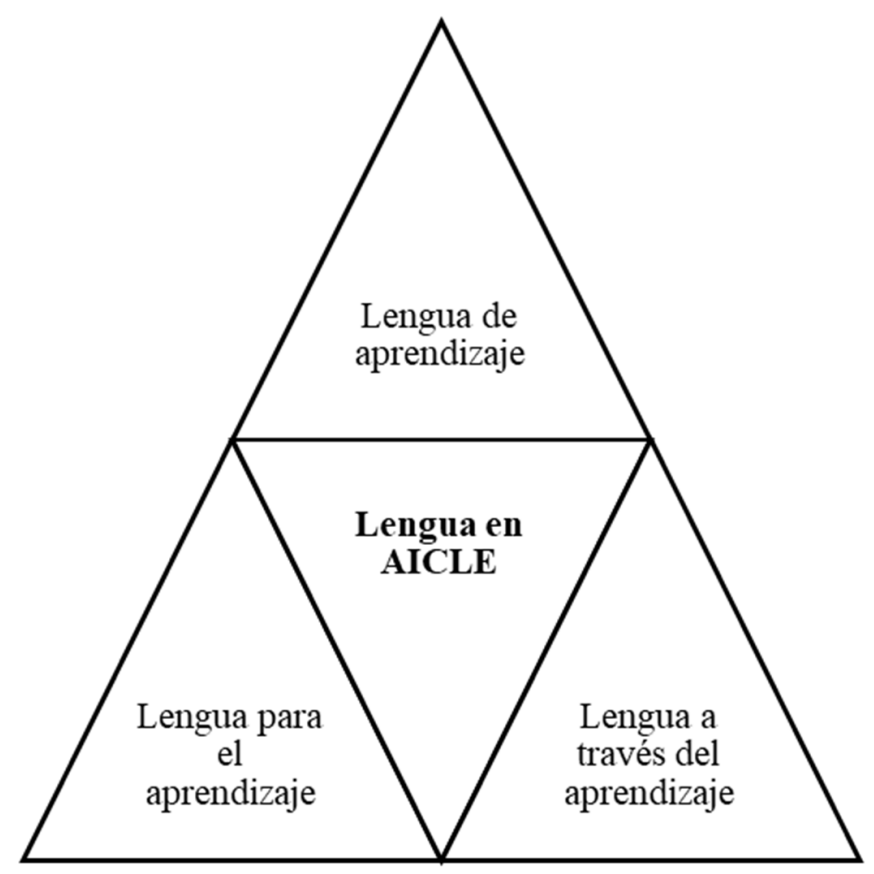

Figura 7. Tríptico del lenguaje (Coyle et al. 2010. p. 36)

En definitiva, la lengua desde un enfoque AICLE adquiere, si cabe, mayor relevancia por la consideración singular que se le da. Gracias a este tratamiento y deferencia, el estudiantado adquiere consciencia de que la nueva lengua aprendida también puede ser empleada como medio de comunicación, cuestión que entraña mayor dificultad de comprensión que cuando este idioma se estudia solo como materia aislada (Fortanet, 2013). Por este motivo, Coyle et al. (2010) destacan la importancia que atesora la interacción en situaciones regidas por AICLE, dado que es mediante su uso efectivo y real como el alumnado le otorga mayor significatividad a la lengua y, por tanto, también a su aprendizaje.

\subsubsection{AICLE en diferentes etapas educativas}

A lo largo de los puntos precedentes se han expuesto las principales características del enfoque AICLE. Su planteamiento responde a un enfoque amplio y flexible que puede ser utilizado en prácticamente cualquier etapa educativa, pudiendo abarcar desde la educación infantil, previa a la escolarización obligatoria, hasta la misma universidad, formando parte ya de la educación post-obligatoria (Pérez-Cañado, 2016). Sin embargo, es cierto que, a menudo, este enfoque pedagógico ha sido asociado con mayor ahínco y vehemencia a las primeras etapas educativas, esencialmente con la educación primaria y secundaria (Fortanet, 
2013), quizás por tratarse de períodos de escolarización preceptivos. Pese a poder introducir AICLE en múltiples momentos formativos, su implementación requiere, necesariamente, una adaptación a cada contexto particular, así como ser conscientes de que su uso en diferentes etapas podría acarrear consecuencias diversas.

A continuación, se comenta la utilización de AICLE diferenciando entre varias de las etapas educativas en las que se ha implementado, a fin de percibir qué entraña su uso en función del momento formativo en el que se incorpora. Primero se mencionan algunas consideraciones relevantes sobre cada período en concreto y, posteriormente, se hace referencia a algunas investigaciones circunscritas a estos estadios, sin ánimo de hacer una revisión exhaustiva, sino de aportar una perspectiva general de la situación.

\subsubsection{Educación infantil}

La etapa de educación infantil se caracteriza por las particularidades de su alumnado, que aún no domina su primera lengua y se encuentra en un estadio de desarrollo psicosocial inicial. La introducción de una lengua adicional puede resultar confusa para los párvulos, motivo por el cual suele apostarse por su incorporación a través de juegos y actividades de carácter lúdico. Habitualmente los programas desarrollados en esta etapa educativa se conocen como "modelos de inmersión" (Coyle et al., 2010) y suelen enfocarse hacia la estimulación de los discentes mediante actividades vinculadas a la acción como ahora juegos, canciones o dibujos.

Las investigaciones centradas en el estudio de la incorporación de otras lenguas en la etapa de educación infantil son un campo todavía inmaduro, especialmente si se trata de la incorporación de idiomas que no se encuentran en el contexto cercano del alumnado (Palviainen, Protassova, Mård-Miettinen y Schwartz, 2016). No obstante, el estudio del bilingüismo en este período parece estar desarrollándose poco a poco. Muestra fehaciente de ello se encuentra en la reciente publicación de un monográfico especial de la prestigiosa revista científica International Journal of Bilingual Education and Bilingualism, dedicado íntegramente al bilingüismo en edad preescolar y abarcando múltiples contextos socioculturales (Schwartz y Palviainen, 2016). De esta publicación son diversos los estudios que pueden resultar de interés con respecto a la temática que nos ocupa, puesto que abordan, por ejemplo, el impacto de las políticas educativas relativas al aprendizaje de lenguas en la etapa 
de educación infantil (Curdt-Christiansen y Sun, 2016), la relevancia de la colaboración de las familias con las escuelas infantiles en lo tocante al aprendizaje de idiomas (Bergroth y Palviainen, 2016), o un acercamiento cualitativo a las prácticas bilingües de cinco docentes en diferentes contextos (Palviainen et al., 2016). A través de estos textos pueden extraerse algunas conclusiones relativas a la enseñanza bilingüe en educación infantil como ahora propuestas de modificación de los modelos bilingües actuales o la demanda de formación específica para la etapa de infantil, dada la gran relevancia que ostenta el profesorado a fin de ofrecer una óptima práctica educativa.

Al margen de esta publicación particular, otras investigaciones relativas a la introducción de una lengua adicional en el período preescolar atienden a las perspectivas y vivencias concretas de docentes de esta etapa educativa (Fleta, 2016; Palviainen y Mard-Miettinen, 2015; Tenolahti, 2017), subrayando la necesidad de utilizar estrategias de andamiaje en los procesos de enseñanza-aprendizaje y métodos que favorezcan prácticas activas así como facilitar formación específica a los estudiantes universitarios. Estos estudios se acometen también desde aproximaciones cualitativas, por lo que parece vislumbrarse cierta carencia en lo concerniente a perspectivas cuantitativas y que persigan una mayor generalización de los resultados obtenidos. Del mismo modo, se percibe un vacío en lo relativo a otros agentes implicados en las praxis bilingües tales como los discentes, sus padres y madres o representantes de la administración educativa.

\subsubsection{Primaria}

En España la etapa de educación primaria está compuesta por seis cursos académicos, comprendiendo alumnado de 6 a 12 años de edad. Este momento evolutivo de los infantes está ligado a una gran cantidad de cambios, no solo a nivel físico, sino también a nivel psicológico. De este modo, el aprendizaje de una lengua adicional no debería acometerse de la misma manera con estudiantado de primer curso que con aquellos que se encuentran en su último año en la escuela. Además, el nivel de dominio de la primera lengua del alumnado también presenta una diferencia importante, cuestión que inevitablemente es relevante en el aprendizaje de otros idiomas (Ríos, 2005).

Siguiendo a Coyle et al. (2010), son múltiples los modelos de AICLE que se pueden implementar a lo largo de la educación primaria. En función del uso que se le otorgue a la 
lengua meta, dichos autores presentan tres modelos que van de menor a mayor relevancia de dicho idioma: (1) creación de confianza e introducción a los conceptos clave, (2) desarrollo de conceptos clave y autonomía del alumnado, y (3) preparación para el programa AICLE a largo plazo. Asimismo, conviene tener presente que los modelos o programas aplicados no solo difieren con respecto al nivel de utilización de la lengua meta, sino que ineludiblemente deben considerar y adaptarse al contexto particular propio de la escuela.

Otro aspecto digno de mención en esta etapa formativa y que ha generado ciertas controversias radica en la determinación del momento óptimo para introducir AICLE (Coyle et al., 2010). Por un lado, algunos autores aseveran que cuanto antes se introduzca la lengua adicional su aprendizaje será más natural y, por ende, mejor (Álvarez-Diez, 2010; Cenoz, 2003; Horwitz, 1987, 1988). Por otro lado, sin embargo, diversas voces temen que la introducción de otra lengua en una fase temprana pueda resultar improductiva (Lorenzo, Casal y Moore, 2009; Pérez-Cañado, 2012) o incluso contraproducente, ya no solo para el aprendizaje de la lengua meta, sino también para la lengua materna (Goorhuis-Brouwer y de Bot, 2010; Muñoz, 2003; Nikolov y Djigunović, 2006). A pesar de ello, actualmente la legislación educativa está acotando cada vez más el momento concreto en el cual debe incorporarse el aprendizaje de otras lenguas en los centros educativos, de modo que su introducción resulta prescriptiva y queda sujeta a la voluntad de instancias educativas superiores.

A fin de tomar conciencia sobre el estado de la cuestión en dicha etapa educativa, conviene subrayar que a lo largo de los últimos años el número de estudios focalizados en estudiar las implicaciones que subyacen a la incorporación de AICLE en educación primaria se ha visto incrementado de manera considerable, abordándose a través de diferentes paradigmas e involucrando a diferentes agentes. Por ejemplo, Coral, Lleixà y Ventura (2018) analizaron los resultados obtenidos por 1175 escuelas de educación primaria en exámenes de índole estatal, encontrando que aquellas escuelas que habían desarrollado programas AICLE presentaban unos resultados ligeramente superiores en la competencia en lengua inglesa a aquellos centros en los que no se habían desarrollado iniciativas de este tipo. Por otra parte, dirigiendo el foco de atención sobre las diferentes habilidades lingüísticas del alumnado en lo tocante a la lengua meta, Papadopoulos y Theodoglou (2017) desarrollaron un estudio 
tomando medidas pre-test y post test cuyos resultados se complementaron con el diario del profesor y con diversas entrevistas. Los autores concluyeron que las habilidades de comprensión tanto oral como escrita del alumnado habían sido desarrolladas gracias a la utilización de AICLE. En la misma dirección se ubica el estudio de Pladevall (2016), quien indica que la comprensión oral se ve mejorada gracias al uso de AICLE, especialmente en el alumnado cuyas calificaciones globales son menores.

En lo que concierne a la expresión oral, Morilla-García (2017) llevó a cabo un estudio comparativo combinando las metodologías cualitativa y cuantitativa concluyendo que la introducción de técnicas para la aplicación de inteligencia emocional en contextos AICLE generaba una mejora en la producción oral del alumnado. Asimismo, en relación al efecto que la incorporación de un programa AICLE pueda causar sobre la primera lengua del alumnado, Nieto (2018) asevera que, pese a que el uso de la lengua madre quedaba limitado al 25\% del tiempo académico, la capacidad de comprensión lectora del alumnado no se vio disminuida, posiblemente por la transferencia entre lenguas generada. De manera similar, la investigación presentada por Merisuo-Storm (2006) también se centraba en analizar las habilidades relacionadas con la lengua madre del alumnado y, al igual que la anterior, sus resultados no evidenciaron diferencias significativas entre el grupo AICLE y el grupo noAICLE. Sin embargo, la autora señala que el alumnado AICLE mostraba una actitud más positiva hacia el aprendizaje de lengua que el grupo control.

Pese a que resultados halagüeños como los hasta ahora presentados son los predominantes, también pueden encontrarse otros que no son tan optimistas (Pérez-Cañado, 2018b). En este sentido pueden comentarse publicaciones que apuntan hacia la idea de que el empleo del enfoque AICLE podría acarrear consecuencias negativas. En este caso, un ejemplo radica en la investigación desarrollada por Pladevall y Vallbona (2016). Este estudio, realizado durante dos años, analizó los efectos de AICLE sobre las habilidades receptivas del estudiantado, que, según un análisis intra-grupo, mejoraron tanto en el grupo AICLE como en el noAICLE. Sin embargo, al llevar a cabo comparaciones inter-grupo se aprecia, por un lado, que no había diferencias en los resultados concernientes a la comprensión escrita y, por el otro, que el grupo no-AICLE presentaba mejores resultados que el grupo AICLE en relación a la comprensión oral. Por su parte, Fernández-Sanjurjo et al. (2017) desarrollaron un estudio 
sobre AICLE desarrollado en el área de ciencias naturales y, de acuerdo con sus resultados, el alumnado que recibió las clases en su primera lengua obtuvo resultados ligeramente superiores que aquellos con los que se utilizó AICLE.

\subsubsection{Secundaria}

Colocando ahora el foco de atención sobre la etapa de educación secundaria, es interesante comenzar recordando que el alumnado, una vez alcanzado este estadio formativo, comienza a ver modificadas sus motivaciones fruto de la fase psicoevolutiva en la que se encuentra. De este modo, en muchas ocasiones, el aprendizaje de otra lengua deja de ser visto como una mera anécdota o diversión para pasar a ser un objetivo de relevancia para su devenir futuro (Coyle et al., 2010; Salvador-García, Chiva-Bartoll y Vergaz, 2018).

Por otro lado, la organización de los centros de educación secundaria difiere notablemente con respecto a la de una escuela primaria. Los institutos están formados por departamentos que deberían coordinarse para favorecer una óptima introducción de AICLE, aportando coherencia y significatividad a las praxis de diferentes áreas (Lorenzo et al., 2009). La colaboración referente a AICLE facilita el desarrollo de buenas prácticas puesto que tiene en cuenta tanto el contenido como la lengua, favoreciendo una buena planificación de ambas cuestiones y creando el mejor escenario posible para favorecer el aprendizaje de ambos. Sin embargo, en la práctica, dicha coherencia y coordinación interdepartamental no siempre se alcanza (Merino, 2016).

Coyle et al., (2010) presentan también diversos modelos de introducción de AICLE para la etapa de secundaria, que entrañan mayor complejidad que aquellos propuestos para el período formativo precedente. En este caso, los modelos expuestos son: (1) educación escolar dual, (2) educación bilingüe, (3) aproximación interdisciplinar, (4) proyectos basados en el lenguaje y (5) dominio específico vocacacional de AICLE. No obstante, conviene recordar que su introducción de manera pura puede resultar una utopía (e incluso paradójicamente un error) dado que cada centro educativo es particular y, por tanto, dichos modelos deben adaptarse ineludiblemente a su situación singular.

A tenor de una buena parte de la literatura, la implementación de AICLE se relaciona con una mejora de la competencia lingüística en la lengua meta del alumnado (Lancaster, 2018; 
Pérez-Cañado, 2018a; 2018b), particularmente en las habilidades receptivas (Pérez-Cañado, 2012; Prieto-Arranz, Fabra, Calafat-Ripoll y Catrain-González, 2015; Ruiz de Zarobe, 2011), tanto en educación primaria como secundaria. Sin embargo, en esta segunda etapa parece que también puede contribuir en la mejora de habilidades de expresión tanto oral como escrita. Por ejemplo, Pérez-Cañado y Lancaster (2017) realizaron un estudio de un caso con el objetivo de analizar el impacto de AICLE sobre las habilidades de comprensión y expresión concluyendo que, en contraposición a lo previsible, fueron las habilidades productivas las que más positivamente se vieron afectadas. En la misma dirección apuntan Gallardo del Puerto y Gómez-Lacabex (2017), quienes llevaron a cabo un estudio cualitativo mediante el cual concluyeron que los estudiantes AICLE eran capaces de producir narraciones orales más densas y ricas caracterizadas por presentar mejores niveles de contenido, vocabulario, gramática y fluidez. Además, según Llinares y Whittaker (2007), AICLE también contribuye en la utilización de registros lingüísticos más adecuados tanto en la expresión oral como escrita. En lo que concierne a la redacción de textos Whittaker, Llinares y McCabe (2011) realizaron una investigación en la que recogieron producciones escritas de la asignatura de historia (realizada mediante AICLE) de los mismos estudiantes durante cuatro años. Tras observar el progreso en la capacidad de expresarse de forma escrita del alumnado, los autores concluyeron que los contextos AICLE son adecuados para desarrollar el discurso escrito del estudiantado. Por su parte, Corral y González (2018) realizaron un estudio comparativo entre un grupo AICLE y otro no-AICLE realizando un análisis de error de los textos redactados por los discentes de ambos grupos. Según los resultados obtenidos, el alumnado AICLE utilizaba menos recurrentemente su lengua materna como recurso para resolver su falta de competencia en la lengua meta a la hora de escribir.

Un aspecto que ha aglutinado un cierto número de investigaciones radica en el efecto que el uso de AICLE puede generar sobre la primera lengua del alumnado. En este sentido, Merino y Lasagabaster (2018a) desarrollaron un estudio longitudinal en un contexto bilingüe comparando un grupo AICLE con otro no-AICLE. Estos autores concluyeron, por un lado, que no había diferencias entre grupo control y experimental con respecto a las dos lenguas oficiales y, por otro, que la competencia en lengua inglesa del alumnado AICLE era significativamente mayor. Otro aspecto que ha sido motivo de análisis, aunque en menor medida, es la afectación que puede sufrir el contenido trabajado mediante AICLE (Duran- 
Martínez, 2018; Pérez-Cañado, 2018b). A modo de ejemplo, pueden comentarse las investigaciones realizadas por Surmont, Struys, Van Den Noort y Van De Craen (2017) y Ouazizi (2016). En ambos casos se han obtenido resultados positivos con respecto al contenido de matemáticas trabajado a través de AICLE, puesto que el alumnado de los grupos AICLE obtuvo resultados significativamente mejores que los grupos no-AICLE.

No obstante, también en educación secundaria pueden encontrarse estudios que apuntan hacia una versión ciertamente equívoca de AICLE (Pérez-Cañado, 2018b). Por ejemplo, Bergroth (2006) realizó un estudio cuantitativo a fin de analizar el impacto de AICLE sobre la primera lengua del alumnado, así como sobre el contenido trabajado mediante dicho enfoque pedagógico, concluyendo que de sus resultados no se desprende ninguna diferencia entre los grupos AICLE y no-AICLE en estas variables. En la misma línea apunta el estudio perpetrado por Admiraal, Westhoff y de Bot (2006), puesto que en su caso AICLE tampoco generó diferencias ni en la primera lengua del alumnado ni en el aprendizaje de las asignaturas involucradas (historia y geografía).

Una visión más obscura de AICLE es la que se desprende de estudios como el de Rallo y Jacob (2015). Estos autores centraron su investigación en el desarrollo de la pronunciación y la fluidez comparando alumnado AICLE con no-AICLE y concluyeron que, tras dos años de intervención, no se obtuvieron diferencias significativas entre los dos grupos en ninguna de las dos variables, de forma que del estudio se desprendía que dicho enfoque pedagógico no generaba mejoras en la expresión oral del estudiantado. Por su parte, el estudio desarrollado por Piesche, Jonkmann, Fiege y Keßler (2016) mostró que el alumnado que había realizado las clases de ciencia en su primera lengua obtuvo mejores resultados que el alumnado que había llevado a cabo las clases mediante AICLE, infiriendo que los peores resultados obtenidos eran consecuencia del uso de este enfoque pedagógico.

\subsubsection{Universidad}

Por último, pasamos a comentar la incorporación de AICLE en la etapa de educación superior, haciendo referencia en concreto a la universidad. Si bien es cierto que, como se ha comentado, históricamente AICLE se ha vinculado más a la educación primaria y secundaria (Roquet et al., 2016), esto no ha resultado un impedimento para su progresiva incorporación en las aulas de educación superior. Su eclosión en este nivel educativo se sustenta en 
razonamientos que difieren en cierta medida con los relativos a períodos formativos previos y se acogen a la imparable evolución que está sobrellevando el contexto universitario.

Hoy en día, las universidades buscan con ahínco medidas que favorezcan su internacionalización, para lo que se esmeran por cumplir diversos de los objetivos planteados por la European Higher Education Area (EHEA) (Greere y Räsänen, 2008), como ahora atraer a un mayor número de estudiantes internacionales, mejorar el perfil de la universidad promocionando su calidad como institución, favorecer las relaciones de colaboración internacional entre estudiantes, profesorado y empresas de diversa envergadura, favorecer el trabajo conjunto (networking) a nivel académico, investigador y profesional; y desarrollar habilidades interculturales. Con el cometido de cumplir con todos estos propósitos, la incorporación de AICLE resulta un factor clave, puesto que implica la utilización de otras lenguas en las aulas, dando cabida a estudiantes foráneos que no dominan la lengua natural del lugar (Pedrosa, 2016). Asimismo, simultáneamente se forma al alumnado propio para que pueda aprovechar con mayor garantía posibles estancias en otros centros.

En lo tocante al estudiantado, se percibe una tendencia a considerar que el mero conocimiento de la lengua materna no es suficiente para alcanzar expectativas profesionales de nivel elevado. En este sentido, se suele considerar que, para poder acceder a mejores puestos de trabajo a escala internacional, resulta básico el desarrollo de habilidades lingüísticas y culturales (Fortanet, 2013). Por tanto, para el alumnado la incorporación de AICLE ostenta gran valor, puesto que favorece la consecución de niveles de experto en el campo de estudio a la vez que se desarrollan competencias lingüísticas y comunicativas propias al terreno académico y profesional, generando procesos de enseñanza-aprendizaje más significativos (Pedrosa, 2016).

Coyle et al. (2010) diferencian tres modelos de aplicación de AICLE para el nivel universitario, a saber, (1) educación plurilingüe, (2) AICLE y (3) cursos de contenido con lenguaje incorporado. No obstante, existen voces que prefieren utilizar otros términos como ICLHE (Integrating Content and Language in Higher Education) o EMI (English Medium Instruction) (Dearden 2015; Doiz, Lasagabaster y Sierra, 2013) en esta etapa formativa. En este sentido se alega que en el período universitario la balanza se inclina más hacia el contenido que hacia la lengua, cuestión que podría contravenir las características propias de 
AICLE (Pérez-Vidal, 2015). Además, otro argumento a favor de promulgar el término ICLHE radica en que este posibilitaría tener una perspectiva más internacional de la enseñanza de contenidos mediante una lengua adicional, puesto que AICLE es considerada una expresión ciertamente europea (Roquet et al., 2016).

Sea cual sea el término empleado para designar aquellas praxis en las que se utilice una lengua adicional para enseñar una materia universitaria, la importancia reside en su adecuada implementación. Con el fin de tratar de promocionar no solo el uso de AICLE sino también su correcta introducción en las aulas, son múltiples los grupos de investigación y seminarios de formación permanente que han advenido en los centros de educación superior. Por lo que se refiere a nuestro contexto más cercano, el seminario SPIEDA de la Universitat Jaume I se encamina a promover como innovación educativa el uso del inglés en la docencia universitaria. Del mismo modo, sin ir mucho más lejos, los grupos de investigación GRAPE y TALIS de la Universitat Jaume I y la Universitat de València respectivamente, recogen entre sus líneas de investigación el estudio del enfoque AICLE.

Fruto de investigaciones perpetradas por grupos o investigadores interesados en esta línea de trabajo, existen también diversas publicaciones sobre AICLE en educación superior. Por ejemplo, Campagna y Pulcini (2014) describen el panorama general relativo a los programas desarrollados en lengua inglesa en las universidades italianas, mientras que Chaplier (2013) hace lo propio con Francia. Por su parte, McDougald (2017) y Taillefer (2013) proponen, en base a sus respectivas investigaciones, cómo integrar contenidos y lengua adelantando que no existe ninguna "receta secreta" para un éxito asegurado (McDougald, 2017, p 13). Sánchez-Pérez y Salaberri (2017), en cambio, se centran en las necesidades de formación del profesorado, quienes mostraron mayor interés por mejorar sus habilidades comunicativas que en la metodología. Además de esta literatura, de índole más puramente científico, pueden encontrarse publicaciones de ámbito más divulgativo que se adentran en la implementación de AICLE a nivel universitario como son las obras de Fortanet (2013) o Lasagabaster y Doiz (2016b) en las cuales se esboza el panorama general en España y se exponen diversas experiencias respectivamente. Recientemente además se ha creado una asociación 
internacional que aúna a investigadores e investigadoras en el campo de ICLHE (ICLHE international association $)^{9}$.

\subsubsection{Beneficios de AICLE}

Como hemos descrito hasta el momento el empleo de AICLE no está exento de polémica. Existen tanto defensores como detractores de su uso, por lo que, a fin de adoptar una postura plenamente informada, parece necesario reparar tanto en las virtudes como en los defectos que se le achacan. Comenzamos, así pues, comentando los beneficios que, mediante una adecuada implementación, subyacen al enfoque AICLE.

Para empezar, conviene recordar que AICLE es un enfoque pedagógico abierto y flexible, un paraguas en el que múltiples opciones son concebibles (Cenoz et al., 2013; Mehisto et al., 2008; Pérez-Cañado, 2016). Dada esta apertura de miras, tal y como se ha comentado en apartados precedentes, AICLE se convierte en un enfoque que, ineludiblemente, debe adaptarse al contexto particular en el que se desarrolla y que puede variar ostensiblemente dada la diversidad inherente al escenario social actual (Coyle et al., 2010; Hüttner y Smit, 2014; Pérez-Cañado, 2016). De este modo, dicha capacidad de adaptación al ambiente se erige como uno de los baluartes de este enfoque pedagógico.

Asimismo, fruto también de su maleabilidad, AICLE puede ser adoptado desde múltiples asignaturas pertenecientes a muy diversos campos, por lo que no se cierra a ninguna posibilidad y deja que cada centro sea el que elija desde qué materia es más apropiado implementarlo (Merino, 2016). Además, resulta interesante reparar en su capacidad de imbricación con diferentes metodologías. Gracias a esa flexibilidad AICLE puede aplicarse en conjunción con otros métodos pedagógicos tales como el aprendizaje-servicio (Porto, Houghton y Byram, 2017; Rauschert y Byram, 2018), el aprendizaje cooperativo (Casal, 2016; Karimi, Lotfi y Biria, 2017; Pastor, 2011; Pistorio, 2010), la gamificación (Jauregui y Melchor-Couto, 2017; Pitura y Chmielarz, 2017; Ricardo, 2017) o la flipped classroom (Capone, del Sorbo y Fiore, 2017; Nanclares y Rodríguez, 2016; Rodríguez-Merayo y Cebrián-Bernat, 2018); de modo que las aportaciones de ambas casuísticas se adhieren, otorgando a la práctica pedagógica mayor enriquecimiento.

${ }^{9}$ www.iclhe.org 
Otro beneficio subyacente a AICLE radica en su promoción de la equidad y la inclusión social (Fortanet, 2013). De hecho, tal y como se ha comentado con anterioridad, uno de los objetivos primigenios de AICLE consistía en favorecer que todas las personas, independientemente de su origen y entorno social, tuvieran más opciones de aprender una lengua adicional (Coyle et al., 2010; Marsh, 2002). Además, a tenor de los resultados obtenidos por diferentes estudios, AICLE se asocia con múltiples beneficios vinculados a la competencia lingüística (Coral el al., 2018; Lancaster, 2018; Pérez-Cañado, 2018a; 2018b) tales como una mejora, especialmente, en las habilidades de comprensión escrita y de comprensión oral (Gallardo del Puerto y Martínez-Adrián, 2013; Navarro y García, 2018; Pérez-Cañado, 2012; Pladevall, 2016; Prieto et al., 2015). Además, también se le atribuyen beneficios en la adquisición de vocabulario y en la competencia escrita del alumnado (Corral y González, 2018; Marsh, Pérez-Cañado y Ráez-Padilla, 2015; Whittaker et al., 2011) así como en su capacidad de expresión oral (Gallardo del Puerto y Gómez-Lacabex, 2017; Morilla-García, 2017; Pérez-Cañado y Lancaster, 2017). A tenor de estos resultados, Merino (2016), subraya tres beneficios propios de AICLE: (1) la proporción de más input en la lengua meta, (2) el uso de la lengua con un sentido explícito en clase y (3) el uso dinámico y real que se le da a la lengua. Este tercer elemento se halla más próximo a procesos de aprendizaje naturales $\mathrm{y}$, por tanto, más vinculados a la adquisición ${ }^{10}$ que al aprendizaje de la misma (Coyle et al., 2010).

Por último, otro de los beneficios que, a tenor de diversos estudios, se asocia con AICLE es el aumento de la motivación por parte del alumnado. Parece que el uso de este enfoque pedagógico genera en el estudiantado un mayor deseo por entender y usar el contenido estudiado que les lleva a presentar, a su vez, una mayor motivación hacia el aprendizaje de la lengua (Lasagabaster y Doiz, 2016a; Mehisto et al., 2008; Navarro y García, 2018; Scott y Beadle, 2014).

\subsubsection{Críticas hacia AICLE}

A pesar de haberse vinculado con múltiples beneficios, AICLE también ha sido motivo de críticas en diversos foros tal y como se ha mencionado anteriormente. La incursión del bilingüismo en las aulas nació a raíz de un interés educativo. Sin embargo, ha terminado por

\footnotetext{
${ }^{10}$ Son más conocidos en su voz inglesa -learning vs acquisition-. Para más información ver Krashen (1981).
} 
convertirse en un tema también de índole política, hecho que ineludiblemente genera defensores y detractores dogmáticos que, en el peor de los casos, se guían más por intereses partidistas que por razones estrictamente pedagógicas. Como consecuencia de este movimiento, pueden encontrarse reproches de orden público hacia el bilingüismo, tal y como puede comprobarse en informes como el publicado por el Observatorio por la Educación Pública $^{11} \mathrm{o}$ en artículos periodísticos ${ }^{12}$ en los que sindicatos y parte del profesorado cuestionan la introducción del bilingüismo en las aulas. Sin embargo, el interés del presente trabajo reside en las razones más puramente académicas y hechos contrastados e investigados que pasamos a comentar.

Así, a la desaprobación expuesta por diversos sectores sociales se suma la exhibida por parte de diferentes expertos en la materia. Tal y como ya se ha manifestado en el presente trabajo, autores como Bruton (2013), Cenoz et al. (2013) o Paran (2013), arremeten contra la (in)definición de AICLE, considerándola ambigua, imprecisa y provechosamente vaga. Supuestamente, una definición de este calado debería facilitar la comprensión de qué es AICLE en lugar de llevar a una confusión terminológica (Bruton, 2015) en la que tanta flexibilidad parece carecer de sentido, dado que la poca concreción no hace más que dificultar su puesta práctica (Scott y Beadle, 2014).

Por otro lado, parece que el hecho de que la implementación práctica de AICLE (debido a imposiciones de ámbito legislativo) precediera a su confrontación empírica juega en favor del sector más crítico con este enfoque (Coyle et al., 2010). Tal y como se ha comentado en el punto 3.4.4, múltiples estudios han sido realizados en un intento de desvelar qué se esconde detrás de este enfoque pedagógico. Sin embargo, según autores como Bruton (2013), la mayoría de los resultados obtenidos son fruto de un intento intencionado de hacer ver que las políticas educativas implantadas generaban efectos positivos $\mathrm{y}$, por tanto, estaban marcadamente influenciados (Pérez-Cañado, 2016). Así, pese a estas tentativas de subrayar las bondades de AICLE a través de la presentación de resultados aparentemente alentadores,

\footnotetext{
${ }^{11}$ Para ver el informe entrar en el link: http://oxep.org/?p=504

${ }^{12}$ Un ejemplo puede encontrarse en el diario El País https://elpais.com/politica/2017/10/06/actualidad/1507284770 581444.html otro ejemplo del diario El Pais https:/elpais.com/sociedad/2018/12/05/actualidad/1544011044_830446.html
} 
autores como Bruton (2011; 2013) o Paran (2013) los consideran carentes de validez, credibilidad, coherencia empírica y objetividad.

En otro orden de aspectos, siguiendo a Mehisto et al. (2008), desarrollar buenas prácticas mediante AICLE no es tarea sencilla de por sí. Además, consecuencia de su vaporosa definición, esta cuestión puede verse aún más dificultada al sumársele factores como la falta de unas directrices claras para su implementación (Scott y Beadle, 2014). Asimismo, resulta conveniente reparar en la cantidad de tiempo que supone para los y las docentes enfrentarse a un reto como es la aplicación práctica de AICLE (McDougald, 2015). Por un lado, el incremento de tiempo dedicado a programar las sesiones además de preparar o adaptar materiales resulta ciertamente significativo (Mehisto et al., 2008). Por otro lado, puesto que AICLE hace referencia tanto al aprendizaje de un contenido como al de un idioma, resulta evidente que el profesorado deberá no solo ser capaz de comunicarse eficazmente en la lengua meta, sino también de facilitar que el alumnado desarrolle su competencia lingüística (Scott y Beadle, 2014). De este modo, la implementación de AICLE requiere, ineludiblemente, de una buena formación docente, especializada y que tome en consideración aspectos pedagógicos vinculados a la lengua (Coyle, 2007; De Graaff et al., 2007; Fortanet, 2013). Por lo tanto, resulta necesario que el profesorado esté bien formado a fin de garantizar una óptima planificación y puesta en práctica de AICLE. En definitiva, la introducción de este enfoque pedagógico supone para el profesorado un incremento del tiempo dedicado tanto a la programación como a la formación, un tiempo que quizás no todos los y las docentes estén dispuestos a dedicar (Banegas, 2012; Pena y Porto, 2008).

Además de la mayor dedicación que AICLE requiere al profesorado, también parece que su uso implica que la praxis educativa se vea dilatada y propicie la concreción en los elementos básicos del contenido (Dalton-Puffer, 2009; Harrop, 2012). Atendiendo a Merino (2016), aprender un contenido mediante una lengua adicional conlleva una mayor complejidad y esfuerzo por parte del alumnado. Este hecho se ve corroborado por Roussel et al. (2017), quienes aludiendo a la teoría de la carga cognitiva aseveran que la enseñanza mediante una lengua que no se domina a menudo incurre en una cierta deficiencia en el proceso comunicativo. Por lo tanto, todo parece indicar que el alumnado bajo prácticas AICLE debe enfrentarse ante un proceso se enseñanza-aprendizaje más complejo. Por este motivo, parece 
arriesgado afirmar que pueda aprenderse lo mismo en una clase cuya la lengua vehicular es una lengua adicional en comparación con otra en la que se utiliza la lengua materna del estudiantado (Bruton, 2013).

Como consecuencia a esta dificultad comunicativa, diversos autores señalan que los contenidos de la materia que acoge AICLE podrían verse afectados. De hecho, según Merino (2016), una posible disminución de los contenidos a aprender se erige como una de las mayores críticas hacia este enfoque pedagógico, subrayando que la pérdida de contenidos sería un precio demasiado alto que no valdría la pena pagar, por mucho que el aprendizaje de lengua se viera favorecido.

Cómo afecta AICLE al contenido de la asignatura no lingüística es un tema que preocupa a muchos docentes, padres, madres e investigadores (Dalton-Puffer, 2011). Sin embargo, la mayoría de investigaciones desarrolladas han sido realizadas desde el campo de la lingüística y en ausencia de evaluaciones normalizadas del contenido (Merino, 2016). Por este motivo, a fin de continuar descubriendo qué es realmente AICLE y qué consecuencias conlleva su implantación en los centros educativos y las prácticas de enseñanza-aprendizaje, existe una necesidad apremiante de continuar investigando (Merino, 2016; Pérez Cañado, 2016).

Tal y como se ha mencionado en apartados anteriores AICLE comenzó a irrumpir en las aulas españolas hace ya más de una década. De este modo, parece que tras un cierto tiempo de aplicación el punto actual resulta ciertamente indicado para poder analizar y valorar si su implementación está generando los frutos esperados (Pérez-Cañado, 2016). Asimismo, parece un momento adecuado también para que los especialistas de las diferentes asignaturas que acogen AICLE entren a valorar su desarrollo. En un intento de cubrir este nicho se dirige el presente trabajo, depositando el foco de atención en una materia en concreto, la educación física, sobre la cual pasamos a discutir a continuación.

\subsection{La educación física}

El presente apartado tiene por objetivo presentar la educación física como materia del currículo escolar a fin de poder comprender, desde el conocimiento de su contexto y características propias, qué implicaciones puede tener el enfoque AICLE en la misma. Dada su idiosincrasia motriz y eminentemente procedimental, que la diferencia diametralmente del 
resto de asignaturas curriculares, es importante para centrar el presente trabajo conocer cuáles son sus pilares y rasgos definitorios.

\subsubsection{De dónde viene y hacia dónde va la educación física}

La escuela y la educación se hallan sujetas a las condiciones sociales que las envuelven. La educación física no se muestra ajena a esta corriente y, de hecho, en palabras de Lleixà (2017) "una mirada a la Educación Física en el momento presente nos muestra su inquietud por adaptarse a las necesidades de la sociedad del siglo XXI y dar respuesta a diferentes problemáticas propias de esta época” (p. 2). Así, puede verse cómo la educación física presenta una firme voluntad por ayudar al alumnado a formarse integralmente. En este caso, la formación afecta tanto al conocimiento teórico como al conocimiento práctico que, a diferencia del resto de materias, proviene de la experiencia del movimiento.

Hoy en día, la educación física se erige como una asignatura más del sistema educativo, con los mismos derechos y deberes que el resto de las materias. No obstante, la percepción social de ese constructo llamado educación física no siempre ha ostentado esta misma potestad (Kirk, 2010; Martos, Tamarit y Torrent, 2016). De hecho, hasta no hace tanto, la educación física no formaba parte del sistema escolar. Por este motivo, parece pertinente comenzar el presente apartado haciendo un breve repaso a cómo se ha ido trazando su línea de vida, desde la llegada de algo parecido a la educación física al sistema educativo hasta la educación física que conocemos hoy en día.

Fue en el siglo XIX cuando, tras un largo proceso de pruebas, una asignatura vinculada con el movimiento aterrizó en el sistema educativo español. En aquel momento la gimnasia militar y acrobática ostentaban gran popularidad, motivo por el cual aquella asignatura poseía unas características marcadamente analíticas y de corte militar (Devís, 2018), de modo que los discursos de educación física orientados al rendimiento eran claramente predominantes (Tinning, 1996). A finales de este siglo y principios del siguiente, aún enmarcado en esta misma orientación, sobrevino el movimiento higienista (Cañellas y Torán, 1975), que catapultó a la gimnasia sueca gracias a su potencial valor terapéutico. Esta consistía en proporcionar una instrucción simultánea a una gran cantidad de estudiantes aplicando las tablas gimnásticas suecas, de forma que primaba un sistema analítico (Zagalaz, 2001). Sin embargo, otros movimientos y escuelas de diferentes índoles surgidos en aquella época 
también influenciaron, en mayor o menor medida, a la educación física de comienzos del siglo XX (Buscà, 2005). Por ejemplo, la escuela alemana se caracterizaba por sus rígidos planteamientos de los ejercicios, en los que tiempo, lugar, material y ejecución estaban férreamente cerrados. La escuela francesa, por su parte, proponía ejercicios globales plagados de acrobacias y motivos militares concebidos con fines estéticos y utilitarios a fin de preparar a la persona para prestar servicios al Estado (Piernavieja, 1960). En cambio, la escuela inglesa trataba de inculcar en el alumnado los sentidos de honradez y de juego limpio mediante las actividades atléticas y los juegos deportivos (Pérez-Ramírez, 1993).

A mediados del siglo XX, en medio de esta conjunción de posicionamientos, la educación física se vio comprometida por una doble crítica. Por un lado, prevalecía la idea de educación de carácter esencialista que, al hallarse vinculada a asignaturas de corte científico y eminentemente cognitivo, relegaba a aquellas alejadas a dicho campo, como la educación física, a un segundo plano. Por otro lado, esta asignatura también se vio sujeta a ataques provenientes de filósofos de tradición analítica, puesto que desde su concepción de educación racionalista tampoco había lugar para la educación física. Sin embargo, estos pensadores sí aceptaban que las actividades propias de la educación física podían tener un cierto valor instrumental (Devís, 2018). Quizás a raíz de estas críticas, la educación física empezó a evolucionar hacia una versión convergente con las tendencias propias de la educación física actual. En este sentido, un grupo de filósofos de la época comenzó a presentar justificaciones alegando por qué la educación física era intrínsecamente valiosa, incidiendo en que su aporte no residía tanto en el conocimiento teórico sino en el práctico, en la capacidad de moverse y el entendimiento de la acción; involucrando, por tanto, formas racionales de conocimiento. Por ejemplo, Arnold (1979) estructuró una teoría cimentada en tres pilares: (1) educación sobre el movimiento, referida al cuerpo teórico de la asignatura compuesto por contenidos provenientes de la fisiología, la historia o la filosofía del deporte; (2) educación a través del movimiento, cuyo propósito era instrumental y promocionaba fines y valores funcionales; y (3) educación en movimiento, basado en la experiencia propia, que requería, ineludiblemente, de conocimiento y comprensión de la misma.

De este modo, empezaron a generarse discursos alternativos a aquella primera forma de entender y practicar la educación física, adquiriendo, en ese momento, una mayor orientación 
hacia la participación (Tinning, 1996). De esta manera, la importancia comenzaba a residir en que la educación física contribuyera a la formación integral del alumnado (Kirk y MacDonald, 1998; López-Pastor, Brunicardi, Arribas y Aguado, 2016). Esta nueva concepción de la asignatura entronca con los cambios sociales que fueron sucediéndose. En este sentido, la sociedad de hoy plantea nuevos retos, ante los que la educación física puede y debe contribuir a fin de favorecer una formación holística del estudiantado.

Como se ha podido observar, los contenidos que aborda la educación física han ido evolucionando a lo largo de sus días. Las distintas perspectivas, movimientos y escuelas han ido moldeándolos durante su historia. Así, hoy, estas influencias aún pueden percibirse, por ejemplo, en los bloques de contenido que la conforman. Pese a no coincidir plenamente entre las etapas de educación primaria y secundaria a las que nos hemos referido en el apartado 2.1.2., pueden diferenciarse una serie de ejes fundamentales como:

- Condición física i salud. Centrado en fomentar la adquisición de hábitos de práctica física regular, de higiene, posturales y de alimentación, así como la adopción de actitudes críticas ante prácticas sociales no saludables.

- Juegos y deportes. Utiliza estos elementos como recurso pedagógico como medio para desarrollar las relaciones sociales, la colaboración, la cooperación, la resolución de conflictos, el cumplimiento de las reglas o el respeto.

- Expresión corporal. Persigue el desarrollo físico, psíquico y emocional del alumnado a través del movimiento y de la experimentación con diferentes recursos expresivos para que el alumnado sea capaz de expresarse y comunicarse.

- Actividades en el medio natural. Se centra en facilitar que el alumnado descubra y practique actividades en la naturaleza, que adquiera hábitos de cuidado y respeto hacia la misma y que promueva acciones para su mejora y conservación.

- Habilidades motrices. Incide en el desarrollo de las habilidades motrices que permitan al alumnado abordar otros contenidos más complejos vinculados tanto a la actividad física como a su vida cotidiana.

Actualmente la educación física se ha ganado a pulso un lugar en el sistema educativo. Sin embargo, aún hay sectores que siguen considerándola una asignatura de menor valía (Kirk, MacDonald y O’Sullivan, 2006; Sparkes, Templin y Schempp 1993; Stroot y Ko, 2006). Por 
este motivo, parece apropiado pasar, seguidamente, a justificar su existencia dejando evidencia de por qué se erige como una asignatura con valor propio que contribuye a la formación integral del alumnado.

\subsubsection{La educación física y el desarrollo integral del alumnado}

La educación física, en su concepción actual, ha adquirido un estatus propio como asignatura gracias al gran potencial y valor educativo que encierra (Arnold, 1991; Fraile, 1995; Kirk, 1988; López-Pastor, et al., 2016). Aunque en un momento inicial los discursos vinculados a esta materia se vieran dirigidos únicamente a su visión más tecnicista, mecanicista, acultural y acrítica; la realidad de hoy dista mucho de aquel enfoque. Pese a que en el currículum actual aún se atisban vestigios de este modelo (Sosaoga, 2017), el currículum que implementa el docente de educación física suele asentarse en la idea de proporcionar aprendizajes que fomenten la socialización del alumnado. Así, son numerosos los autores que subrayan la capacidad de la educación física de incidir directamente sobre cuestiones tan relevantes como la cooperación, el respeto, la resolución de conflictos o la identificación y aprecio de la diversidad individual, social y cultural (Hellison, 2011; Monzonís y Capllonch, 2014; Pennington, Prusak y Wilkinson, 2014; Teck Koh, Wen Ong y Camiré, 2014).

Además, la educación física tiene mucho que aportar con respecto al bagaje personal del alumnado. De hecho, uno de los objetivos que persigue radica en favorecer que el alumnado sea capaz de interactuar con y en la sociedad que le envuelve. Para ello, es necesario dotar a los niños y niñas de aprendizajes que les permitan conocerse mejor a sí mismos y a los que les rodean, así como entender y aceptar que cada persona tiene unas capacidades diferentes, pudiendo ser estas tanto de carácter físico como cognitivo o emocional. De este modo, todas las personas, también aquellas que están vulneradas socialmente, pueden lograr beneficiarse de la educación física (Devís y Peiró, 2002).

Por otro lado, la educación física se instala como una asignatura de lo más apropiada para proporcionar al alumnado experiencias múltiples y variadas cuyo punto de convergencia se encuentra en el cuerpo y el movimiento, pero que a su vez tratan de favorecer el desarrollo cognitivo del estudiantado. La enseñanza de la educación física 
"busca una implicación cognitiva que favorezca la toma de decisiones, persigue modelos de actuación que muestren la aplicabilidad en situaciones de práctica real, potencia aprendizajes cooperativos y aprendizajes entre iguales y pone especial énfasis en los valores que se desprenden de la práctica” (Lleixà, 2017, p. 2).

En este sentido, la gama de actividades que atañen a esta asignatura tiene como eje vertebrador un conocimiento práctico que se articula con el conocimiento teórico (Almond, 1989; Breivik, 2014). Conviene enfatizar que este conocimiento práctico debe ser entendido de manera que implique no solo la capacidad de una persona de hacer algo, sino también de ofrecer una explicación sobre cómo lo llevó a cabo (Arnold, 1991). Dicho tipo de conocimiento práctico es al que aspira la educación física.

En suma, la educación física tiene el potencial de proporcionar al estudiantado una práctica educativa holística que favorece aprendizajes no solo físicos, sino también sociales, personales y cognitivos (Dyson, Griffin y Hastie, 2004; Kirk y MacDonald, 1998). Además, girando siempre en torno al eje vertebrador conformado por la dimensión motriz encuentra, como fin último, guiar al alumnado hacia una vida auténtica (educación intelectual), buena (educación moral) y feliz (educación sentimental).

\subsubsection{Elementos nucleares de la educación física}

Tras esbozar la aportación con la que la educación física puede contribuir en la formación integral del alumnado pasamos, seguidamente, a comentar algunos de los rasgos más característicos de esta materia. Como hemos observado a lo largo de las páginas precedentes, la educación física ha ido modulándose a lo largo de los años y se ha visto sometida a disputas entre grupos que la percibían desde posicionamientos o ideologías enfrentadas. De hecho, aún hoy, la educación física está continuamente redefiniéndose con objeto de dar sentido a su existencia y contribución en la formación del alumnado, porque, como dicen McEvoy, Heikinaro-Johansson y MacPhail (2017), la concepción de lo que es la educación física se construye socialmente, en base a unos contenidos y unas finalidades que pueden ir cambiando. Actualmente, por tanto, pueden existir también diversas ópticas e interpretaciones de lo que representa la educación física, ni mejores ni peores, únicamente diferentes. Por este motivo, en el presente apartado presentamos los que, desde nuestro punto de vista, son los pilares que sustentan nuestra propia concepción de la educación física. 
Si bien otros elementos podrían ser incorporados o alguno de los propuestos podría eliminarse, los cuatro pilares que pasamos a comentar son: el socioconstructivismo, por ser sus principios preceptos básicos en el planteamiento de la educación física actual (Dyson et al., 2004); su vínculo con la pedagogía crítica, puesto que impregna a la asignatura con ese cariz de preocupación y acción con respecto a la sociedad (López-Pastor, 2002); el juego, por ser una herramienta fundamental y recurrente de la asignatura (Gil y Chiva-Bartoll, 2014); y la motivación que por lo general suscita, puesto que se erige como uno de los motores principales de la educación física a la hora de facilitar el aprendizaje del alumnado (Biddle, 2003).

\section{Aprendizaje socioconstructivista}

El primer elemento característico al que aludimos hace referencia a los principios socioconstructivistas del aprendizaje que rigen la educación física actual. Siguiendo a Dyson et al. (2004), puede afirmarse que esta asignatura se ubica en un posicionamiento socioconstructivista del aprendizaje en tanto en cuanto se sirve de los tres pilares que cimientan esta perspectiva, a saber: alumnado activo, alumnado creativo y alumnado social.

Por lo que respecta al alumnado activo, la educación física debe velar por favorecer la adquisición de conocimientos de carácter práctico. Como se ha mencionado previamente, este conocimiento práctico se adopta desde la perspectiva propuesta por Arnold (1991), quien esgrime que las tareas deben ser realizadas de manera intencional a fin de alcanzar un nivel mínimo de competencia que capacite al estudiantado a poder justificar la acción que se ha llevado a cabo. Desde esta visión de conocimiento práctico se huye de la función imitadora del estudiante con el objetivo de que sea un practicante inteligente, cabal y capaz de usar el raciocinio en las diferentes actividades propuestas; es decir, que posea un rol activo tanto en lo físico como en lo cognitivo.

En lo concerniente al alumnado creativo, conviene recordar que este pilar se sustenta en la premisa de que los nuevos conocimientos se adquieren cimentándose sobre los saberes que los discentes ya poseían (Bruner, 1984; Vygotsky, 1989). En este sentido, las experiencias prácticas que ofrece la educación física deben facilitar que el estudiantado realice conexiones, busque estructuras o patrones conectables entre ellos, así como a otras actividades físicas más amplias o a actividades propias de la vida cotidiana (Devís y Molina, 2004). De este 
modo, desde la educación física hay que facilitar el sentido a las prácticas físicas, por ejemplo, asociándolas a contextos de práctica más generales con los que el alumnado pueda establecer conexiones significativas.

Por último, en referencia al alumnado social, la educación física, gracias a su naturaleza, implica, necesariamente, la interacción del estudiantado con sus compañeros y el docente. De este modo, son cuantiosas las oportunidades que se generan de aprender con y del resto, sacando provecho de lo que Vygotsky (1989) denomina la Zona de Desarrollo Próximo ${ }^{13}$. Mediante esta, el alumnado es capaz de lograr mayores cotas de conocimiento, inalcanzables por sí solo, gracias a su interacción con sus compañeros y docentes, dado que estos pueden adoptar el rol de facilitadores de su aprendizaje.

En suma, la educación física desde una concepción socioconstructivista se construye, tomando las ideas de Dyson et al. (2004), sobre tres pilares:

- Otorgarle al alumnado el rol de actor principal, involucrándole en la toma de decisiones y resolución de problemas.

- Basarse en los intereses y saberes previos del estudiantado a fin de que pueda crear su propia conceptualización sobre lo aprendido.

- Apostar por la interacción social como elemento nuclear del aprendizaje.

\section{Pedagogía crítica desde la educación física}

El segundo de los cuatro elementos en los que centramos el presente apartado hace referencia a la pedagogía crítica. Pese a que esta perspectiva pedagógica no se vinculaba con la educación física primigenia, el pensamiento crítico lleva siendo asociado a esta asignatura desde finales del siglo pasado. Entre otros, se encuentran evidencias de esta corriente en los textos publicados por Fernández-Balboa (1999), Felis, Martos y Devís, (2018), Fraile (2004), López-Pastor (2002), Lorente y Martos (2018), McBride (1991) o McBride, Gabbard y Miller (1990).

\footnotetext{
${ }^{13}$ La Zona de Desarrollo Próximo es según Vygotsky (1989) "la distancia entre el nivel real de desarrollo, determinado por la capacidad de resolver independientemente un problema, y el nivel de desarrollo potencial, determinado a través de la resolución de un problema bajo la guía de un adulto o en colaboración con otro compañero más capaz" (p. 133). En otras palabras, se trata del concepto que explica la diferencia entre lo que un niño o niña es capaz de realizar por sí mismo y lo que es capaz de conseguir gracias a la guía de otra persona.
} 
El uso de un razonamiento crítico puede quedar definido como la capacidad de toma de decisiones sobre actividades y/o retos de manera racional y fundada (McBride, 1991). De esta manera, una educación física apoyada en la pedagogía crítica requiere el uso de un acercamiento al aprendizaje en el que el alumnado deba enfrentarse a una disonancia cognitiva $\mathrm{y}$, además, implique su participación en los procesos de evaluación, análisis y diagnóstico (Mawer, 2003). En función a lo descrito, parece evidente el vínculo que se establece entre pedagogía crítica y los principios socioconstructivistas comentados unas líneas más arriba, poniendo especial acento en la figura del alumnado como agente activo de su aprendizaje. Así, cuando desde la educación física se propone la implicación cognitiva del estudiantado mediante su participación y toma de decisiones, se le está demandando que haga uso de su capacidad crítica para que, en última instancia, potencie su autonomía y capacidad de emancipación (Felis et al., 2018).

Siguiendo a López-Pastor (2002) y Rodríguez-Rojo (1997), cuando una asignatura, la educación física en este caso, adopta un posicionamiento crítico, se pregunta por los fines, los valores y el para qué de su acción. En respuesta a estas cuestiones, la educación física no puede permanecer ajena a la sociedad que rodea a la práctica educativa, de hecho, debe mostrarse preocupada por los temas sociales vinculados a sus objetivos y contenidos. La educación física debe ayudar a fraguar valores democráticos en su alumnado con objeto de aportar su granito de arena en la consecución de un mundo más humano, más justo e igualitario habitado por personas más pacíficas, felices y respetuosas (López-Pastor, 2002).

El papel del profesorado de educación física adquiere especial valor a la hora de incorporar una perspectiva crítica en las sesiones. En este sentido, sus decisiones con respecto a cómo afrontar el proceso de enseñanza aprendizaje devienen trascendentales. Por ejemplo, autores como McBride et al. (1990) sugieren que el espectro de los estilos de enseñanza propuesto por Mosston y Assworth (1993), que abordaremos más adelante, puede ser utilizado a fin de favorecer el pensamiento crítico entre el alumnado, especialmente aquellos estilos más centrados en los discentes. Independientemente de la manera en que se afronte la introducción del pensamiento crítico desde la educación física, lo que parece claro es que el objetivo último que se persigue radica en favorecer que se generen nuevas actitudes, valores, 
juicios y sentimientos en el estudiantado, en relación a la propia persona y la sociedad que le rodea.

\section{El juego y la educación física}

Otro de los elementos más definitorios de la educación física radica en la presencia del juego como herramienta indispensable. Siguiendo a Huizinga (1954), el juego puede definirse como una acción o una actividad voluntaria, que se lleva a cabo acotada en unos ciertos límites temporales y espaciales. Además, posee un reglamento libremente consentido pero absolutamente imperioso, puesto que, siguiendo a Suits (1967), el juego se concibe como una actividad atrayente en la que se persigue un objetivo, pero para poder alcanzarlo deben seguirse una serie de reglas previamente estipuladas. Asimismo, el juego va siempre ligado a un sentimiento de tensión y alegría, de manera que se establece como uno de los máximos exponentes de lo lúdico.

En el terreno propio de la educación física, el juego se erige como uno de los recursos más recurrentes por su capacidad de ayudar al alumnado a incrementar su conocimiento sobre el mundo físico (Gil y Chiva-Bartoll, 2014), a la par que fomenta un aprendizaje de carácter espontáneo, natural y significativo. De hecho, incluso algunos discursos críticos con el juego ensalzan su uso educativo, gracias a su potencial como herramienta socializadora (Hirst, 1974; Hirst y Peters, 1970). Además del mencionado beneficio que el juego genera en las habilidades sociales del alumnado, como consecuencia de la emulación de lo que sucede en la realidad, García-Puchades y Chiva-Bartoll (2018) subrayan tres justificaciones más por las que el juego se ha erigido tradicionalmente como un recurso de gran valor para la educación física. Su justificación funcional hace referencia a la capacidad del juego de ayudar al estudiantado a formarse como persona, independientemente del orden social establecido. $\mathrm{Su}$ justificación vivencial defiende que el juego puede ser educativamente valioso por sí mismo, puesto que ayuda a poner en marcha un razonamiento práctico y un tipo de comprensión que difícilmente se encuentra en otras disciplinas y, por tanto, debe estar presente en la escuela por derecho propio. Por último, la justificación vitalista reivindica la necesidad inherente del ser humano de jugar por jugar.

De este modo, parece clara la pertinencia y posibilidades que genera el uso del juego en el marco de la educación física. Siguiendo con García-Puchades y Chiva-Bartoll (2018), se 
plantea la posibilidad de establecer el juego como un movimiento pedagógico propiamente, demostrando así la relevancia que este recurso ostenta para el área. En suma, el juego se establece como elemento imprescindible de la educación física, siendo una de sus marcas más definitorias.

\section{Motivación hacia la educación física}

El último de los aspectos característicos que subyacen al área de la educación física y al cual hacemos alusión radica en la motivación del alumnado hacia la asignatura. El fenómeno motivacional ha sido ampliamente estudiado y parece clara su vinculación con el aprendizaje (Deci, Vallerand, Pelletier y Ryan, 1991; Ryan y Deci, 2000). También en el área de educación física son cuantiosos los estudios desarrollados vinculados a la motivación de los y las estudiantes, por ejemplo, analizando su actitud hacia el currículum, los enfoques, estilos o tareas utilizados por el profesorado, así como hacia innovaciones propuestas en el área (Dyson, 2006). Sin entrar en aspectos tan concretos parece que, en general, el estudiantado presenta una motivación considerablemente positiva hacia el área de educación física, independientemente del sexo y la edad (Biddle, 2003; Carlson, 1995; Chedzoy y Burden, 2009; Dismore y Bailey, 2004; Groves y Laws, 2000; Hernando, 2015; Rikard y Banville, 2006; Subramaniam y Silverman, 2007). Pese a que cada estudiante es diferente y no todos y todas comparten esta misma idea, a menudo suelen vincular la educación física con conceptos como diversión y entretenimiento (Coulter y Ní Chróinín, 2011) gracias a su carácter práctico y la inclusión del juego como recurso fundamental, puesto que estas dos circunstancias conectan directamente con sus intereses y estado psicoevolutivo.

Generalmente la educación física encuentra una de sus grandes bazas en la motivación que despierta entre el alumnado. Ahora bien, esta motivación puede estar sujeta a variaciones, como pueden ser la introducción de nuevos enfoques, estilos o actividades. En consonancia con Biddle (2003), la educación física debe velar por mantener los niveles de motivación del estudiantado altos a fin de favorecer su aprendizaje. Por este motivo, parece claro que cualquier alteración que quiera acometerse en la asignatura debería ser estudiada a fin de garantizar que la motivación de los alumnos y alumnas no se viera disminuida. 


\subsubsection{Finalidades de la educación física}

Toda asignatura presenta una serie de finalidades que de un modo explícito o implícito aspira a cumplir. De hecho, tal y como hemos descrito, desde un posicionamiento crítico, la educación debe preguntarse y tener claros cuáles son sus fines. La educación física ha perseguido diversas y cambiantes finalidades a lo largo de su historia, vinculadas siempre al contexto social circundante (McEvoy et al., 2017). Por ejemplo, Devís (2018) conviene que las finalidades de la educación física más tradicional radicaban en la salud, la ociosidad, la productividad, la disciplina o la defensa de la patria. Por su parte, Buscà (2005) afirma que en la educación física del siglo XIX pueden observarse unos marcados fines terapéuticos, físicos, morales o de higiene postural. Sin embargo, como se ha mencionado, la educación física actual no se rige por los mismos principios e ideas que antaño, por lo que parece lógico que sus finalidades hoy también sean diferentes. En este sentido, López-Pastor et al. (2016, p. 183) determinan tres grandes finalidades a las que la educación física actual debe atender: el desarrollo físico-motriz del alumnado, la creación y recreación de la cultura física del alumnado y su aportación al planteamiento global del desarrollo integral del alumnado.

La finalidad referente al desarrollo físico-motriz se encuentra vinculada a la función más tradicional y de corte racionalista de la educación física. En este sentido, queda demostrado que aún siguen vigentes ciertos aspectos de la educación de lo físico o a través de lo físico, así como la promoción de la salud desde el área. Sin embargo, y pese a que la educación física persigue también otras funciones, parece que en la actualidad las más tradicionales siguen teniendo cabida como consideraciones que la educación física debe atender.

La segunda finalidad de la educación física a la que aluden López-Pastor et al. (2016) radica en la creación y recreación de la cultura física de los discentes, es decir, en su función vinculada al desarrollo del componente cultural. En este sentido, siguiendo a Kirk (1988), el argumento cultural que da razón al deporte y al juego se ocupa tanto de transmitir estos tipos de actividades como, especialmente, de tratar de transformarlas con objeto de que los discentes generen nuevas concepciones a partir de ellas.

Por último, la tercera finalidad del área de educación física presentada por López-Pastor et al. (2016) concierne a la aportación que realiza esta área con respecto al desarrollo integral del alumnado desde, con y a través de la motricidad, cuestión que ya ha sido comentada 
anteriormente. Sin embargo, en este punto queremos aludir al desarrollo holístico de la persona recordando también la contribución de la educación física en lo que se refiere al disfrute y la diversión, ligados férreamente al carácter propio de esta asignatura (Reid, 1997). El disfrute y la diversión son elementos intrínsecamente valiosos para el desarrollo personal, se encuentran en todas las prácticas de educación física y también desempeñan su papel a la hora de formar al alumnado integralmente.

Por otro lado, Blázquez (2001) presenta cuatro finalidades generales de la educación física escolar. Basándose en la idea expuesta por Arnold (1991) que, como se ha expuesto, concebía la educación sobre el movimiento, a través del movimiento y en movimiento; Blázquez plantea cuatro ejes entorno a los cuales se articula la asignatura: eje funcional (educación del movimiento), eje cultural (educación a través del movimiento), eje utilitario (educación para el movimiento) y eje estratégico (educación acerca del movimiento).

El eje funcional, también denominado educación del movimiento, persigue favorecer las capacidades orgánicas y motrices de la persona, de forma que se vincula con especial ahínco con la práctica de actividades de tipo físico-deportivo. El eje cultural o educación a través del movimiento trata de forjar en el alumnado un carácter ligado a la educación social, de manera que pretende preparar al estudiantado para la vida cotidiana, así como promover la formación permanente. El eje utilitario es también conocido como educación para el movimiento y se centra en ofrecer al alumnado aquellos conocimientos que son necesarios para la autogestión en la práctica física propia, partiendo de diversas tendencias socioculturales. Por último, desde el eje estratégico o acerca del movimiento se pretende fomentar la reflexión y la toma de decisiones con respecto a la práctica de actividad física.

La última propuesta de definición de las finalidades que persigue la educación física a la que aludiremos es la realizada por Hardman (2011). Este autor propone que los fines de la educación física deberían ampararse en los tres siguientes aspectos: (1) el desarrollo motriz y las habilidades específicas del deporte, (2) el fomento de estilos de vida activos y saludables, y (3) el desarrollo personal, social y moral.

Como ha podido observarse, cada autor hace referencia a unas finalidades concretas, sin embargo, no es difícil percibir una cierta congruencia entre sus aportaciones. Cada uno toma los elementos nucleares de la educación física a los que aludíamos al comienzo del apartado 
relativo a esta asignatura y propone diferentes nomenclaturas para establecer los objetivos que guían a la educación física actual. La Tabla 4 muestra de forma sintética los fines propuestos por los autores comentados.

Tabla 4. Las finalidades de la educación física actual

\begin{tabular}{lll}
\hline López-Pastor et al. (2016) & Blázquez (2001) & Hardman (2011) \\
\hline -Desarrollo físico-motriz & -Educación del movimiento & -Desarrollo motriz y \\
-Creación y recreación de la & -Educación a través del & halidades deportivas \\
cultura física & movimiento & -Fomento de estilos de vida \\
-Desarrollo integral del & -Educación para el & activos y saludables \\
alumnado & movimiento & -Desarrollo personal, social y \\
& -Educación acerca del & moral \\
& movimiento &
\end{tabular}

\subsubsection{El proceso de enseñanza-aprendizaje en educación física}

El proceso de enseñanza-aprendizaje suele ser considerado un acto inherentemente complicado, también en el caso la educación física (Evans, Davies y Penney, 2003), en tanto en cuanto enseñanza y aprendizaje se construyen conjuntamente, adaptándose el uno al otro constantemente. En el marco concreto de la educación física dicho proceso se establece como un acto social y cultural influido por los contenidos establecidos en el currículum, por cómo se facilita el aprendizaje (modelos pedagógicos, estilos de enseñanza, etc.), así como por las necesidades propias del alumnado (Evans et al., 2003; Rink, 2003).

Con respecto a los contenidos propios de la educación física, conviene recordar que en dicha área se persiguen objetivos de índole piscomotriz, cognitivo y social (Byra, 2006). Con objeto de optimizar la praxis educativa, el proceso de enseñanza-aprendizaje debe ser abordado concienzudamente y estableciendo unos objetivos y estructura concretos a fin de proveer al educando con los mimbres necesarios que le permitan, desde el convencimiento y voluntad propios, optimizar sus posibilidades de desarrollo motor, intelectual, moral y emocional (Laws y Fisher, 2003).

Con esta premisa en mente y pasando a tratar cómo se aborda el proceso de enseñanzaaprendizaje, se observa que durante los últimos años el interés por los modelos pedagógicos en el área de educación física ha crecido exponencialmente (Peiró y Méndez, 2017). Estos 
modelos se basan en "la interdepenencia y la irreductibilidad de las relaciones entre el aprendizaje, la enseñanza, el contenido y el contexto" (Fernandez-Río et al., 2016, p. 57); y se caracterizan por aportar rigor y coherencia al proceso educativo. Así, los modelos pedagógicos garantizan la ubicación del alumnado en el centro de la praxis educativa, alejándose, por tanto, de un currículum centrado en el docente (Dyson et al., 2004). De este modo, los modelos pedagógicos ayudan al profesorado a poner en práctica esa idea de educación física actual a la que hemos ido haciendo referencia en los apartados precedentes, puesto que, entre otras cuestiones de calado, facilitan que el alumnado adquiera autonomía, responsabilidad y perciba la práctica de actividad física como un elemento más en su desarrollo integral. Pese a la pujanza que presentan en la actualidad los modelos pedagógicos, conviene ser cautos y recordar que en educación no existen soluciones inequívocas para que el alumnado aprenda mediante una experiencia educativa íntegra y eficaz; por lo que ningún modelo puede presentarse como la piedra filosofal de la educación física.

A continuación (Tabla 5), presentamos brevemente los que, atendiendo a Fernández-Río, Calderon, Hortigüela, Pérez-Pueyo y Aznar (2016) son los modelos pedagógicos más significativos y utilizados en educación física, diferenciándolos en tres grandes bloques: (1) modelos básicos, (2) modelos emergentes y (3) modelos híbridos.

Tabla 5. Bloques de modelos pedagógicos

\begin{tabular}{llll}
\hline Modelos básicos & Modelos emergentes & Modelos híbridos & \\
\hline -Aprendizaje cooperativo & -Educación aventura & $\begin{array}{l}\text {-Combinaciones de } \\
\text { modelos anteriores }\end{array}$ & \\
-Educación deportiva & -Alfabetización motora & & \\
-Comprensivo de iniciación & -Estilo actitudinal & & \\
deportiva & -Modelo ludotécnico & & \\
-Responsabilidad personal y & -Autoconstrucción de & & \\
social & materiales & & \\
& -Educación para la salud & & \\
& &
\end{tabular}

Fuente: Adaptado de Fernández-Río et al. (2016)

El conjunto de modelos pedagógicos básicos está conformado por aquellos que han tenido una primera y más amplia difusión. Brevemente puede decirse que el aprendizaje cooperativo se caracteriza por facilitar al estudiantado la oportunidad de aprender con, de y 
por otros compañeros de manera que el proceso de enseñanza-aprendizaje genera interacción e interdependencia positivas (Fernández-Río et al., 2016). La educación deportiva se cimienta sobre el trabajo en equipo y la cesión de responsabilidades al estudiantado a fin de crear experiencias de práctica deportiva auténticas. El modelo comprensivo de iniciación deportiva se enfoca en potenciar el resultado de aprendizaje que ofrecen los juegos deportivos, fomentando la experimentación, la toma de decisiones y el aprendizaje a partir del error (Hodges-Kulinna, 2008). Por su parte, el modelo responsabilidad personal y social se caracteriza por potenciar los valores implícitos en la sociedad, adquiriendo pautas de responsabilidad individual y grupal, como medio para desarrollar al máximo las capacidades del alumnado.

Por otro lado, Fernández-Río et al. (2016) presentan los modelos pedagógicos emergentes como aquellos que cumplen las exigencias marcadas por Metzler (2005) para poder ser considerados modelos como tales, pero aún no son tan recurrentes ni están tan reconocidos como los anteriores. La educación aventura es un modelo en el que el alumnado participa en actividades de aventura que requieren habilidades físicas, cognitivas y afectivas (Dort, Evaul y Gehris, 2005). El modelo de alfabetización motora persigue fomentar la motivación, la confianza, la competencia física, el conocimiento y la comprensión de la utilidad de la actividad física entre el estudiantado (Whitehead, 2010). El estilo actitudinal concibe que las actitudes constituyen el elemento vertebrador del aprendizaje y la motivación, por lo que se plantea lo motriz como un medio y no como un fin en sí mismo. El modelo ludotécnico establece las propuestas ludotécnicas como eje central y persigue la adquisición de habilidades técnicas desde la comprensión (Gómez-Mármol, Calderón-Luquin y ValeroValenzuela, 2014). La autoconstrucción de materiales potencia la creatividad del alumnado gracias a la creación de los materiales que se van utilizar en las actividades. La educación para la salud establece la salud como objetivo principal, de forma que fomenta que el alumnado valore la necesidad de vivir una vida físicamente activa.

Por último, se encuentran los modelos híbridos que consisten en la combinación de varios de los anteriores o tomar elementos significativos de varios modelos de forma conjunta. Son múltiples las hibridaciones posibles, entre las que Fernández-Río et al. (2016) destacan:

- Educación deportiva y modelo comprensivo. 
- Aprendizaje cooperativo y modelo comprensivo.

- Educación deportiva y responsabilidad personal y social.

- Aprendizaje cooperativo y educación aventura.

- Autoconstrucción y modelo comprensivo.

A pesar de que cada uno de los modelos pedagógicos posee una serie de características diferenciales, Dyson et al. (2004) encontraron seis analogías y establecieron una serie de consideraciones pedagógicas que el profesorado debía tomar en consideración para su adecuada aplicación. Ambas cuestiones quedan esbozadas en la Figura 8:

\begin{tabular}{|c|c|}
\hline \multirow{6}{*}{$\begin{array}{l}\text { Analogías entre } \\
\text { modelos } \\
\text { pedagógicos }\end{array}$} & El alumnado es el protagonista activo del proceso de enseñanza-aprendizaje. \\
\hline & $\begin{array}{l}\text { Se desarrollan objetivos a nivel físico, cognitivo, afectivo y social a fin de } \\
\text { promover el desarrollo integral de la persona. }\end{array}$ \\
\hline & $\begin{array}{l}\text { El estudiantado trabaja en pequeños grupos, de manera que los unos dependen de } \\
\text { los otros para completar las tareas. }\end{array}$ \\
\hline & El estudiantado ostenta gran parte de la responsabilidad en su aprendizaje. \\
\hline & $\begin{array}{l}\text { Se fomenta un aprendizaje activo incluyendo procesos de toma de decisiones, } \\
\text { interacción social y comprensión cognitiva. }\end{array}$ \\
\hline & Las actividades son auténticas y ajustadas al desarrollo de cada estudiante. \\
\hline \multirow{5}{*}{$\begin{array}{l}\text { Consideraciones } \\
\text { pedagógicas }\end{array}$} & El docente es un facilitador de aprendizajes. \\
\hline & El estudiantado está formado por aprendices activos. \\
\hline & El estudiantado trabaja en pequeños grupos y mediante juegos modificados. \\
\hline & $\begin{array}{l}\text { Las actividades de aprendizaje son auténticas y se ajustan al período de desarrollo } \\
\text { del alumnado. }\end{array}$ \\
\hline & Las actividades de aprendizaje son interesantes y estimulantes. \\
\hline
\end{tabular}

Figura 8. Analogías y consideraciones pedagógicas de los modelos pedagógicos

Fuente: Adaptado de Dyson et al. (2004)

Además de los modelos pedagógicos, otro de los aspectos definitorios de la pedagogía de la educación física radica en el espectro de estilos de enseñanza desarrollado por Muska 
Mosston. El espectro es, básicamente, una teoría de relaciones entre docente y discente, en el que se definen las diferentes opciones o estilos que pueden utilizarse (Mosston y Ashworth, 1993). Según Contreras, los estilos se caracterizan por "hacer hincapié en los elementos personales del proceso educativo (...) en la interacción profesor-alumno, en la adopción de decisiones y en el papel de cada uno de ellos en dicho proceso" (1993, p. 139). De este modo, estilos de enseñanza y modelos pedagógicos son elementos que no solo pueden coexistir sino que, de hecho, los estilos de aprendizaje pueden incorporarse eficazmente a las estructuras establecidas por los modelos pedagógicos (Fernández Río et al., 2016).

Los estilos de enseñanza supusieron un considerable avance en la didáctica de la educación física puesto que influyeron decisivamente a la hora de dotar al alumnado de mayor relevancia en el proceso de enseñanza-aprendizaje. De hecho, mediante los estilos se hizo patente que cada estudiante aprende de una forma diferente, posee un bagaje cultural diverso y tiene una experiencia motriz particular. Por lo tanto, dependiendo de las características del alumnado, el tipo objetivo que se persiga o el contexto que rodee las prácticas educativas, cada estilo puede ser más o menos apropiado (Byra, 2006; Mosston y Ashworth, 1993).

A continuación, se expone el espectro de los estilos de enseñanza planteado por Mosston y Ashworth (1993) que, tal y como se observa en la Figura 9, se compone por diez estilos. A medida que se va avanzando en el espectro, el alumnado va ganando relevancia y poder de decisión. Pueden diferenciarse dos grandes conjuntos de estilos separados por el umbral de descubrimiento. Por un lado, los cinco primeros (de mando directo a inclusión) se caracterizan por ser reproductivos, lo que significa que el estudiantado debe tratar de emular o reproducir un ejemplo dado. Por otro lado, los cinco últimos estilos (de descubrimiento guiado a autoenseñanza) se denominan productivos dado que persiguen que el alumnado produzca sus propias respuestas y no se presenta ningún modelo que deba seguirse. 


\begin{tabular}{|c|c|c|c|c|c|c|c|c|c|}
\hline \multicolumn{10}{|c|}{$\begin{array}{c}\text { Umbral de } \\
\text { descubrimiento }\end{array}$} \\
\hline$\leftarrow$ & \multicolumn{2}{|c|}{ Reproducción } & \multicolumn{2}{|c|}{$\rightarrow$} & \multicolumn{2}{|c|}{$\leftarrow$} & \multicolumn{2}{|c|}{ Producción } & $\rightarrow$ \\
\hline $\mathrm{A}$ & $\mathrm{B}$ & $\mathrm{C}$ & $\mathrm{D}$ & $\mathrm{E}$ & $\mathrm{F}$ & $\mathrm{G}$ & $\mathrm{H}$ & $\mathrm{I}$ & $\mathrm{J}$ \\
\hline Max & & & & & & & & $\rightarrow$ & Min \\
\hline Min & & & & & & & & $\rightarrow$ & Max \\
\hline
\end{tabular}

Figura 9. Espectro estilos de enseñanza

Fuente: Salvador-García (2015), adaptado de Mosston y Ashworth (1993)

En la Tabla 6 se sintetizan las características básicas de cada estilo, así como el rol de docente y discente. 
Tabla 6. Resumen de los estilos de enseñanza

\begin{tabular}{|c|c|c|c|}
\hline Estilo & Características básicas & Rol profesor & Rol estudiante \\
\hline $\begin{array}{l}\text { Mando Directo } \\
\text { (A) }\end{array}$ & $\begin{array}{l}\text { Todos hacen lo mismo al } \\
\text { mismo tiempo y cuando el } \\
\text { profesor lo indica. }\end{array}$ & $\begin{array}{l}\text { Tomar todas las } \\
\text { decisiones. }\end{array}$ & $\begin{array}{l}\text { Copiar y seguir las } \\
\text { instrucciones. }\end{array}$ \\
\hline $\begin{array}{l}\text { Asignación de } \\
\text { tareas (B) }\end{array}$ & $\begin{array}{l}\text { Práctica individualizada con } \\
\text { feedback. }\end{array}$ & $\begin{array}{c}\text { Tomar todas las } \\
\text { decisiones excepto } 9 \text { en } \\
\text { el impacto }{ }^{14} .\end{array}$ & $\begin{array}{c}\text { Realizar la tarea y } \\
\text { tomar } 9 \text { decisiones en el } \\
\text { impacto (lugar, ritmo, } \\
\text { etc.) }\end{array}$ \\
\hline $\begin{array}{l}\text { Estilo recíproco } \\
\text { (C) }\end{array}$ & $\begin{array}{l}\text { Trabajo por parejas recibiendo } \\
\text { feedback mutuo. }\end{array}$ & $\begin{array}{l}\text { Tomar decisiones del } \\
\text { preimpacto y dar } \\
\text { feedback a los } \\
\text { observadores. }\end{array}$ & $\begin{array}{l}\text { Ejecutante: igual que el } \\
\text { estilo anterior. } \\
\text { Observador: dar } \\
\text { feedback en base a unos } \\
\text { criterios dados. }\end{array}$ \\
\hline $\begin{array}{l}\text { Auto- } \\
\text { evaluación (D) }\end{array}$ & $\begin{array}{c}\text { Estudiantes trabajan } \\
\text { independientemente y } \\
\text { valorando sus propias } \\
\text { actuaciones. }\end{array}$ & $\begin{array}{l}\text { Tomar decisiones del } \\
\text { preimpacto y } \\
\text { comprobar que todo se } \\
\text { desarrolle como lo } \\
\text { había previsto. }\end{array}$ & $\begin{array}{c}\text { Comparar su ejecución } \\
\text { con los criterios que le } \\
\text { han dado. }\end{array}$ \\
\hline Inclusión (E) & $\begin{array}{l}\text { Los estudiantes deciden el } \\
\text { nivel en el que comienzan a } \\
\text { realizar la tarea. }\end{array}$ & $\begin{array}{l}\text { Tomar decisiones } \\
\text { preimpacto. }\end{array}$ & $\begin{array}{l}\text { Elegir el nivel de } \\
\text { dificultad de la tarea. }\end{array}$ \\
\hline $\begin{array}{l}\text { Descubrimiento } \\
\text { guiado }(\mathbf{F})\end{array}$ & $\begin{array}{l}\text { El profesor guía al estudiante } \\
\text { hacia el descubrimiento de una } \\
\text { respuesta determinada. }\end{array}$ & $\begin{array}{l}\text { Realizar las preguntas } \\
\text { oportunas que permitan } \\
\text { al alumno llegar a la } \\
\text { respuesta correcta. }\end{array}$ & $\begin{array}{l}\text { Descubrir la respuesta } \\
\text { correcta. }\end{array}$ \\
\hline Divergente (G) & $\begin{array}{l}\text { El alumno se encuentra ante un } \\
\text { problema que no tiene una } \\
\text { única solución correcta. }\end{array}$ & $\begin{array}{l}\text { Proponer un problema } \\
\text { que haga pensar, } \\
\text { razonar, indagar, etc. al } \\
\text { estudiante. }\end{array}$ & $\begin{array}{c}\text { Encontrar soluciones al } \\
\text { problema que le ha sido } \\
\text { planteado. }\end{array}$ \\
\hline $\begin{array}{c}\text { Programa } \\
\text { individual }(\mathrm{H})\end{array}$ & $\begin{array}{l}\text { Además de encontrar una de } \\
\text { las soluciones, los estudiantes } \\
\text { formulan la pregunta o } \\
\text { problema que van a resolver. }\end{array}$ & $\begin{array}{l}\text { Decide contenidos a } \\
\text { trabajar }\end{array}$ & $\begin{array}{c}\text { Propone el programa de } \\
\text { trabajo en función de } \\
\text { los contenidos que le da } \\
\text { el profesor. }\end{array}$ \\
\hline $\begin{array}{l}\text { Alumnos } \\
\text { iniciados (I) }\end{array}$ & $\begin{array}{l}\text { Los estudiantes deciden cómo } \\
\text { y qué van a hacer. }\end{array}$ & $\begin{array}{l}\text { Escuchar, observar y } \\
\text { hacer preguntas. }\end{array}$ & $\begin{array}{l}\text { Tomar el máximo } \\
\text { número de decisiones. }\end{array}$ \\
\hline $\begin{array}{l}\text { Autoenseñanza } \\
(\mathbf{J})\end{array}$ & $\begin{array}{l}\text { No puede desarrollarse en } \\
\text { clase. }\end{array}$ & \multicolumn{2}{|c|}{$\begin{array}{l}\text { No hay rol de profesor y alumno. Una misma } \\
\text { persona desempeña ambos papeles. }\end{array}$} \\
\hline
\end{tabular}

Fuente: Salvador-García (2015), adaptado de Mosston y Ashworth (1993) 
Conviene recordar que es complicado utilizar un estilo de enseñanza de manera pura (Delgado, 1991), ya que el profesorado debe ir adaptando la práctica a aquello que vaya aconteciendo a lo largo de la sesión. Cada estilo invita y desarrolla diferentes operaciones cognitivas además de crear ambientes sociales diversos, por los que cada uno puede ser útil para abordar unos objetivos concretos o para un colectivo de estudiantes particular. Por esto resulta conveniente recordar que no existen estilos mejores ni peores (Mosston y Ashworth, 1993), sino que cada uno de ellos resulta más adecuado dependiendo de la situación en que se desarrolle la práctica educativa.

Por último, tras haber presentado los modelos pedagógicos y los estilos de enseñanza propios de la educación física, las unidades funcionales concretas sobre las que se aplican dichos modelos y estilos son las tareas (entre las que se encuentran las formas jugadas) que se llevan a cabo en el proceso de enseñanza-aprendizaje. Las tareas motrices, desde la perspectiva de la educación física, conforman un campo temático ciertamente complejo. No es el objeto del presente trabajo realizar un análisis exhaustivo de esta cuestión, por lo que en las siguientes líneas únicamente realizaremos un esbozo a fin de anclar algunos aspectos básicos sobre los que retornaremos en pasajes posteriores.

Tradicionalmente, "las tareas motrices han ocupado un lugar preferente en la didáctica de la educación física" (Buscà, 2005, p. 74) y son diversas las definiciones que se ha dado de este término. Parlebas (2008), por ejemplo, concibe la tarea motriz como el conjunto de condiciones materiales y obligaciones que requieren de la realización de una serie de conductas motrices a fin de alcanzar un objetivo. Siedentop (1998), por su parte, concreta que una tarea se compone por el objetivo que la rige y las operaciones que deben realizarse para alcanzarlo; mientras que Famose (1992) estipula que son tres los parámetros que la definen: resultado que se espera lograr, condiciones que le acompañan e instrucciones que deben seguirse.

Siguiendo a Buscà (2005), pueden diferenciarse dos tipos de tareas. Por un lado, se encuentran aquellas de carácter eminentemente técnico y conductal, que podrían vincularse

\footnotetext{
${ }^{14}$ Mosston y Assworth (1993) utilizan preimpacto, impacto y postimpacto para referirse a los tres momentos en los que deben tomarle las decisiones.
} 
a los estilos de enseñanza reproductivos; mientras que por otro se presentan las tareas de cariz constructivista, que se hallarían ligadas a los estilos productivos. Además, este mismo autor propone cuatro criterios que el profesorado puede concretar en mayor o menor grado y cuya combinación puede generar tareas de diferentes naturalezas: (1) las consignas o informaciones sobre el objetivo a conseguir, (2) las acciones u operaciones a efectuar, (3) la evaluación de los resultados o criterios de éxito y (4) la disposición del espacio y del material. Por otra parte, dentro del complejo entramado que supone el análisis de las tareas en el campo de la educación física, es crucial subrayar la importancia del juego. Muchas veces, en educación física, la simple acción de jugar a un juego (tratando de mejorar en las diferentes facetas que este implica) puede llegar a convertirse en una tarea en sí. Además, conviene recordar que un juego puede presentarse de múltiples formas (grandes juegos, juegos populares, juegos modificados, juegos simples, formas jugadas, etc.), de forma que su organización puede diferir en cierta manera. Sin embargo, teniendo esto en cuenta, conviene tener claro que en función del enfoque por el que se opte, la opción elegida podrá ser considerada (o no) un juego.

\subsubsection{El futuro de la educación fisica}

Como se ha podido observar, la educación física ha podido ir evolucionando a lo largo del tiempo y ha pasado de una etapa inicial centrada en legitimar su valor educativo, a otra más cercana a un paradigma práctico y crítico (Kirk, 2010; Martos et al., 2016). Así, puede afirmarse que la educación física de hoy está deviniendo una poderosa herramienta no solo vinculada al conocimiento y la cultura, sino también a la justicia social y los valores democráticos (Devís, 2018). Sin embargo, la educación física no debería conformarse con lo que está consiguiendo. De hecho, de acuerdo con Kirk (2014), la educación física debe plantearse una serie de interrogantes pragmáticos y reflexionar sobre qué se puede hacer para mejorar la situación actual, qué podría hacerla ser mejor y cómo se podría abordar dicha tarea; teniendo en cuenta que no existe un "nirvana" al final del camino, sino una necesidad continua de enfrentarse a los obstáculos y retos que sean planteados por la realidad social.

La escuela tradicional se ha centrado en ofrecer estímulos lineales basados únicamente en elementos conceptuales y apostando por la acumulación de conocimientos sin demasiado significado para el alumnado (García-Sanz, 2014). Es evidente que este modelo no encaja 
con las necesidades del mundo actual, por este motivo, hoy en día se persigue favorecer el desarrollo íntegro del estudiantado a fin de formar personas críticas, reflexivas y concienciadas con la realidad social. Fruto de esta misión, el campo educativo está viviendo una clara emergencia de planteamientos globalizados.

Los enfoques globalizados se fundamentan en razones psicológicas, pedagógicas y sociológicas; y, según Martín (2010),

"se establecen como la solución más pertinente para organizar los contenidos educativos, a fin de que los alumnos y alumnas realicen aprendizajes significativos y funcionales. El carácter compensador de la acción educativa debe contribuir a evitar que los contenidos curriculares de los distintos ámbitos o áreas adquieran posiciones de jerarquía o independencia entre ellos, para respetar la forma en que los niños y niñas perciben la realidad o se plantean el conocimiento en ella.” (p. 112).

Por lo tanto, los enfoques globalizados apuestan por ofrecer al estudiantado formas de aprendizaje que emulen, al máximo de sus posibilidades, la vida diaria fuera de la escuela a fin de garantizar una educación funcional y aplicable, capaz de dar respuesta a la formación integral del alumnado. Desde esta perspectiva, a menudo, se aboga por la interdisciplinariedad y por abordar la enseñanza como un conjunto, huyendo de materias curriculares tratadas de forma inconexa. En esta línea, en el campo educativo actual se observa que ganan fuerza los métodos pedagógicos basados en proyectos o que favorecen la integración de dos o más materias curriculares (Chiva-Bartoll, 2016), puesto que estos establecen los mimbres necesarios para emprender la educación de manera global.

Con objeto de plantear y promocionar esta concepción de educación conviene tener presente que "la educación física tiene un potencial globalizador y aglutinador importante en el ámbito educativo" (Julián, Ibor, Aibar y Aguareles, 2017, p. 8) y, por tanto, puede contribuir enormemente en esta dirección. Desde la multidisciplinariedad se establecen los cimientos para una educación que forme personas capaces de saber, saber hacer, saber ser y saber estar (Delors, 1996), es decir, personas en toda su esencia. En esta empresa de formar ciudadanos y ciudadanas preparados para afrontar y participar plenamente del mundo en el que viven, la educación física, gracias a su idiosincrasia y elementos propios, puede jugar un 
papel de relevancia al promocionar propuestas interdisciplinares entre las que, en conexión con la presente investigación, emerge con fuerza la aplicación del enfoque AICLE.

En definitiva, la globalización actual hace aflorar nuevas y viejas formas de desigualdad y discriminación ante las que la educación física deberá ser capaz de responder, quizás compartiendo o incorporando contenidos, o incluso combinándose con otras materias del currículo a fin de proporcionar al alumnado prácticas globales en las que el proceso educativo se acometa como un todo. Sin embargo, es importante que en este todo educativo las raíces de la educación física, esas características que se han expuesto en los apartados precedentes, se mantengan firmes y mantengan intacto su potencial. En este sentido, parece deseable articular procedimientos de revisión que permitan adaptar y mejorar las prácticas educativas sustentados en evidencias científicas y de la didáctica de la educación física (Julián et al., 2016; Mawer, 2003). Solo así, apoyando fundadamente cada uno de los pasos que vayan realizándose, estaremos en disposición de poder afirmar que caminamos hacia una educación (física) mejor.

\subsection{Educación física y AICLE}

La educación física de hoy ostenta un papel de relevancia en la educación debido a la idiosincrasia que le es propia y el potencial educativo que ostenta, tal y como se ha expuesto en el apartado previo. No obstante, aún existen sectores que denuestan esta asignatura y opinan que posee menor valor educativo que otras (Kirk et al., 2006). Desde un paradigma liberal como el que dominaba en el siglo XX, la educación debía responder a la racionalidad, se consideraba que la educación física no era relevante en el desarrollo intelectual del alumnado y, por tanto, se relegaba esta asignatura a un rol secundario en el currículo (Conant, 1963; Hirst, 1974; Hirst y Peters 1970; Lawson, 1984; Peters, 1966). Fruto de esta equivocada visión, ante la tesitura de tener que elegir entre diferentes materias para desarrollar programas educativos experimentales, no sorprendería a nadie que la educación física fuese la opción elegida. De este modo, la educación física podría establecerse como el banco de pruebas de numerosos centros educativos. Si la iniciativa se resolviera favorablemente, esta podría ser incorporada en otras materias. Si, por el contrario, la iniciativa no fuera exitosa, el mal habría sido menor. 
Como se ha visto, AICLE, con las dudas e incerteza que le acompañan, está siendo incorporado en una gran cantidad de centros educativos españoles y la educación física es una de las asignaturas que más recurrentemente está acogiendo dicho enfoque metodológico (Coral y Lleixà, 2018; Baena-Extremera y Granero-Gallegos, 2015). Sin embargo, lejos de amedrentarse, los docentes y el alumnado de educación física afrontan dicha empresa como un reto y una responsabilidad. Aceptan que AICLE es una propuesta innovadora que pretende hacer frente a los retos presentes y futuros de un mundo globalizado, y que la educación física puede contribuir en su respuesta (Coral, 2012).

AICLE está rodeado de un halo de incertidumbre y la educación física puede contribuir a despejar las dudas al respecto de su validez, puesto que "para la toma de una decisión justificada, se hace necesaria una reflexión sobre cuáles son las características, beneficios y limitaciones de cada área dentro del enfoque AICLE" (Barrionuevo, 2017, p. 64). Por este motivo, es importante reflexionar acerca de cómo la educación física y AICLE pueden complementarse y llevarse a la práctica de manera conjunta y eficaz (Coral y Lleixà, 2013, 2014; Hernando, 2015).

\subsubsection{Definiendo la educación física mediante AICLE}

Según Coyle et al. (2010), AICLE puede ser aplicado en cualquier asignatura no lingüística del currículo. Si bien es cierto que todas las asignaturas no lingüísticas comparten algunas características, también lo es que cada una de ellas es diferente del resto, por los particulares contenidos, metodologías, casuísticas y perspectivas que les subsumen (Zindler, 2013). Estas particularidades de cada materia no deberían verse constreñidas a causa de la incorporación de AICLE. Por este motivo, parece razonable formular una definición de AICLE referida a cada una de las diferentes materias que acojan dicho enfoque metodológico.

En el caso de la educación física, Coral (2012) propone la siguiente:

"L'aprenentatge integrat de l'educació física i la llengua anglesa és un plantejament didàctic on l'activitat motriu i l'esport s'aprenen, s'ensenyen i es practiquen utilitzant una llengua estrangera. És una proposta educativa holística, que parteix dels principis de l'aprenentatge fent, que incideix en l'aprenentatge motor i la salut, que impulsa les habilitats cognitives i desenvolupa les relacions interpersonals i socials.” (p. 27) 
Pese a que tomando la concepción de este autor se incide en el aprendizaje mediante la experiencia del cuerpo y del movimiento, cuestión fundamental de la educación física; se echa en falta el aporte de la perspectiva cultural, tan relevante tanto en el campo de la educación física (Kirk, 1988; López Pastor et al., 2016) como en el de AICLE (Coyle, 2015; Coyle et al., 2010). Incorporando este elemento, más recientemente García-Calvo y Saliberri (2018) establecen que desde el área de educación física

"CLIL is a link between Physical Education and linguistics that starts from Bloom's taxonomy to develop educational competencies and the achievement of skills in a hierarchical manner. The cognitive scope sequenced in Bloom's methodology will be complemented with the communicative aspect in the teaching of a second language, all bearing in mind the subject matter contents (PE) and culture (essential context in a globalized world).” (p.369)

A partir de esta definición, puede observarse la relevancia que otorgan estos autores al elemento cognitivo y al cultural, a la par que mencionan tanto los contenidos propios de la educación física como la adopción del enfoque comunicativo de la didáctica de las lenguas, característica natural de AICLE.

\subsubsection{Convergencias entre educación física y AICLE}

Incorporar el enfoque AICLE no es empresa fácil para ninguna asignatura (Mehisto et al., 2008), sin embargo, esta tarea puede clarificarse y, por ende, devenir más sencilla si se concretan los elementos compartidos entre materia y enfoque metodológico. Partir de las similitudes y puntos convergentes resulta básico en la incorporación de cualquier tipo de innovación educativa con objeto de evitar un giro de trescientos sesenta grados en la praxis de enseñanza-aprendizaje que dificulte su desarrollo. En el caso de la educación física y AICLE, existen diversos aspectos comunes en los que conviene reparar (Figura 10). Un adecuado tratamiento de estos elementos podría generar una serie de sinergias que, en última instancia, podrían facilitar una adecuada y más eficaz imbricación de la educación física con dicho enfoque. 


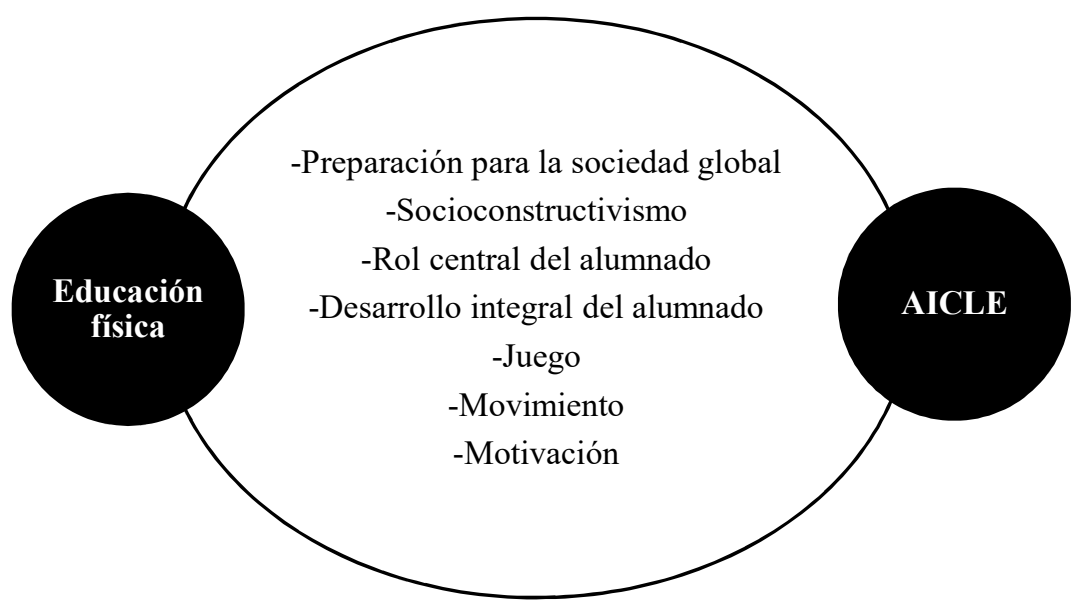

Figura 10. Aspectos coincidentes entre educación física y AICLE

Preparación para la sociedad global

La educación física muestra una firme voluntad por adaptarse a los retos y necesidades características del siglo XXI (Kirk, 2014; Lleixà, 2017). En particular, su aportación en este sentido adopta una doble vía, puesto que la formación que genera se vincula tanto al conocimiento teórico como al práctico, que emana de la experiencia del movimiento. Por lo que concierne a AICLE, tal y como se ha comentado anteriormente, su nacimiento fue fruto de diversos factores, y uno de ellos fue, precisamente, la voluntad de responder ante las necesidades de la sociedad global de hoy (Coyle et al., 2010). Parece clara pues, la convergencia establecida en torno al eje que constituye la formación de alumnado capacitado para vivir en la sociedad del presente y del futuro contribuyendo en áreas vinculadas al cuerpo, la socialización, el conocimiento cultural, el movimiento o las lenguas. Por tanto, la combinación de la educación física y AICLE puede contribuir a formar alumnado suficientemente preparado para vivir plenamente en el mundo que le rodea.

\section{Desarrollo integral del alumnado}

Vinculado a la preparación del alumnado para una sociedad global, otra de las convergencias que presentan la educación física y AICLE radica en su firme voluntad por fomentar un 
desarrollo integral del alumnado. Poder ser participante activo de la sociedad requiere, necesariamente, que la persona esté capacitada, conozca y pueda usar el raciocinio en muy diversas situaciones. Por esta razón la educación física trata de proporcionar experiencias prácticas que favorezcan aprendizajes tanto físicos como sociales, personales o cognitivos; contribuyendo así a la formación holística del estudiantado (Dyson et al., 2004; Kirk y MacDonald, 1998). De forma similar, AICLE, también persigue el desarrollo integral del alumnado. Por ejemplo, el marco metodológico de las 5Cs (Attard et al., 2015) según el cual se rige permite observar claramente la multiplicidad de aspectos que AICLE trata de desarrollar en los discentes. Además, otro punto a tomar en consideración reside en su voluntad de vincular contenidos que tradicionalmente pertenecían a materias curriculares diferentes e inconexas. Ahora, gracias a la aplicación de este enfoque, contenidos de diversa índole se ven integrados de forma natural con la lengua (Coyle, 2015).

Una educación física desarrollada mediante AICLE puede contribuir desde múltiples flancos en el desarrollo integral del estudiantado, creándose una sinergia clara entre las aportaciones de la asignatura y las del enfoque pedagógico. De hecho, haciendo referencia a prácticas de educación física mediante AICLE, Coral y Lleixà (2014) afirman que "su carácter holístico encaja perfectamente en la idea de una enseñanza interdisciplinar en la cual dos o más asignaturas se presentan integradas con el objetivo de avanzar en el conocimiento de cada una de ellas" (p. 1450). Esta cuestión ostenta gran relevancia hoy en día puesto que la legislación educativa actual incide en la promoción de este tipo de iniciativas. A modo de ejemplo puede mencionarse el Decreto 88/2017, de 7 de julio que atañe a la Comunidad Valenciana que alude específicamente al fomento de iniciativas de carácter interdisciplinario.

\section{Principios socio-constructivistas del aprendizaje}

En la actualidad los principios socio-constructivistas del aprendizaje como medio para favorecer el aprendizaje significativo del alumnado ostentan cada vez más valor en el campo de la didáctica (Buscà, 2005). Estos principios, lejanos a los posicionamientos conductistas, beben de las teorías propuestas por autores como Vygotsky, Ausubel o Piaget, entre otros, y se rigen por ideas como partir del conocimiento previo del alumnado, favorecer la construcción de aprendizajes significativos, promover que los discentes integren los nuevos conocimientos sobre sus esquemas previos o fomentar que el estudiantado sea autónomo y 
pueda aprender a aprender (Coll, 1996). En este sentido, Dyson et al. (2004) afirman que la educación física actual se apuntala sobre los cimientos de las teorías socio-constructivistas del aprendizaje, ubicando al alumnado en el centro del proceso de enseñanza-aprendizaje y guiándolo hacia la construcción de conocimientos significativos. De manera similar, Coyle et al. (2010) esgrimen que AICLE se muestra en clara consonancia con estos principios, de modo que dicho enfoque genera incluso una cierta repercusión en el profesorado, que, entre otras cuestiones, se ve abocado a optar por métodos y actividades más centradas en el alumnado (Kashiwagi y Tomecsek, 2015; Ting, 2011). En palabras de Ramos y RuizOmeñaca (2011),

“el aprendizaje integrado de lenguas y contenidos en y a través de una segunda lengua (...) requiere la participación activa de los alumnos y un enfoque diferente en la forma de enseñar del profesor, que debe alejarse de la tradicional lección magistral”. (p.154) Tomando en consideración que tanto la educación física como AICLE se construyen atendiendo a los principios socio-constructivistas del aprendizaje, parece razonable que las prácticas que combinen la asignatura con el enfoque pedagógico se ensamblen fácilmente en lo concerniente a la aproximación adoptada hacia el aprendizaje del alumnado. De hecho, circunscritos en entornos de educación física mediante AICLE, autores como García-Calvo y Saliberri (2018) o González, Hernández, Pastor y Villar (2013) sugieren que la utilización de enfoques constructivistas genera una mayor satisfacción del alumnado, tanto sobre la lengua de aprendizaje como sobre la educación física.

\section{La motricidad en el aprendizaje}

Parece claro que la educación física se vertebra en torno a la experiencia del cuerpo y el movimiento. Sin ir más lejos, únicamente hay que recordar que Blázquez (2001), basándose en las ideas de Kirk (1988), por ejemplo, articula las finalidades de la educación física proponiendo cuatro ejes centrados en el movimiento (educación del movimiento, educación a través del movimiento, educación para el movimiento y educación acerca del movimiento). Pese a que este elemento no se instaura como rotor fundamental de la didáctica de las lenguas, no resulta difícil observar el papel relevante que también juega en este campo. A modo de ejemplo, puede aludirse la metodología Total Physical Response planteada por Asher (1977). Esta se caracteriza por asociar lenguaje y acción, y se basa en el principio de que vincular el 
movimiento con oraciones sencillas en un ambiente relajado y agradable favorece su aprendizaje. De hecho, investigaciones como la desarrollada por Mavilidi, Okely, Chandler, Cliff y Paas (2015) sugieren que añadir la gesticulación a las actividades de aprendizaje de una lengua es una forma de aprendizaje eficaz porque favorece que el alumnado otorgue mayor significatividad a aquello que está aprendiendo.

De este modo, una educación física mediante AICLE puede proveer al alumnado con numerosas situaciones en las que converjan movimiento y gesticulación con aprendizaje cognitivo. Así, gracias al movimiento propio de la educación física, los aprendizajes relativos a la lengua que se den en este ambiente pueden ser incorporados más sencillamente a los conocimientos o experiencias previas del alumnado, convirtiéndose, por tanto, en aprendizajes significativos.

\section{El aprendizaje mediante el juego}

El juego es considerado uno de los elementos más definitorios de la educación física, puesto que se erige como un recurso prácticamente indispensable para esta asignatura. De hecho, como se ha expuesto anteriormente, su pertinencia dentro del marco de la educación física responde a cuatro justificaciones (García-Puchades y Chiva-Bartoll, 2018): socializadora, funcional, vivencial y vitalista. En lo concerniente a la didáctica de las lenguas, el juego también atesora un gran potencial. Bruner (1984), por ejemplo, explica que este desempeña un importante papel en el proceso de desarrollo de los niños y niñas señalando que el juego “proporciona (...) la primera y más importante oportunidad de pensar y hablar” (p. 219). Además, se defiende que podría ser uno de los recursos más propicios para facilitar el aprendizaje del inglés como lengua extranjera (Baena-Extremera y Granero-Gallegos, 2015; Baena-Extremera, Gómez-López y Granero-Gallegos, 2017) porque ofrece al alumnado un contexto que le es familiar, en el que se utiliza una lengua que le es habitual y esta tiene un sentido concreto. En esta línea se posicionan Tomlinson y Mashuara (2009), quienes afirman que, con respecto al aprendizaje de lenguas, el juego motriz, entre otros aspectos, puede:

- Motivar al alumnado y al profesorado.

- Proveer al alumnado con un aprendizaje experimental.

- Ofrecer oportunidades ricas y significativas de utilizar la lengua de aprendizaje.

- Estimular la implicación cognitiva y afectiva. 
- Aumentar la autoestima.

- Ofrecer oportunidades de aprender mediante el descubrimiento.

Teniendo en cuenta que el juego es un recurso ampliamente aceptado tanto en el campo de la educación física como en el de la didáctica de las lenguas, parece que en un ambiente de educación física mediante AICLE se erigirá como una herramienta a tener en consideración (Coral, 2012). En este sentido, Alías (2011) presenta una propuesta educativa centrada en el uso del juego para favorecer el aprendizaje de la lengua inglesa, considerando que los juegos "constituyen la máxima expresión de lo que los alumnos ya dominan en su propia lengua y de cómo lo representan” (p. 24). Además, expone que

“pretendemos que el cuerpo y el movimiento se constituyan en ejes básicos de nuestra acción educativa en la enseñanza del Inglés, considerando al juego como el elemento facilitador que posibilite al alumno en la activación de mecanismos no sólo motores, sino también cognitivos, afectivos y sociales.” (p. 26)

De este modo, siguiendo a este autor, parece que el juego se erige como un recurso de lo más apropiado para las prácticas de educación física a través de AICLE. Teniendo esto en consideración, las cuatro justificaciones establecidas para este recurso podrían ser reformuladas para los contextos de educación física a través de AICLE:

- Función socializadora: el juego incorpora la lengua real, de fuera de la escuela, a clase de una manera natural y que es familiar al estudiantado (Chroinin, Ní Mhurchú y Ceallaigh, 2016). Además, incorpora elementos culturales.

- Función funcional: la implicación y participación del alumnado en el juego, independientemente del orden social establecido fuera de la escuela, favorece que todo el alumnado se sienta fuertemente vinculado al mismo, incluyendo las reglas, organización o lengua que le son propias. De este modo, el estudiantado percibe que la lengua del juego también es la suya, de forma que esta lengua se incorpora significativamente a sus esquemas de conocimiento.

- Función vivencial: el juego debe estar por derecho propio en la escuela y, por tanto, también en la educación física mediante AICLE. 
- Función vitalista: más allá de estudiantes de lengua o de educación física los discentes son niños y niñas que necesitan jugar.

De este modo, puede observarse que el uso del juego en educación física mediante AICLE puede dar respuesta a las cuatro finalidades del juego propuestas por García-Puchades y Chiva-Bartoll (2018) y erigirse como un recurso básico.

\section{La motivación}

La motivación constituye un elemento de suma relevancia en cualquier proceso de enseñanza-aprendizaje, de hecho,

"los investigadores creen que es una variable importante y que preocupa a los docentes de EF e idiomas, ya que uno de los objetivos de la enseñanza es que a la vez que el alumno aprende, se divierta y esté satisfecho con los conocimientos que adquiere" (Baena-Extremera y Granero-Gallegos, 2015, p. 64).

Por lo general, diferentes estudios demuestran que el área de educación física despierta una motivación positiva entre el alumnado (Biddle, 2003; Carlson, 1995; Chedzoy y Burden, 2009; Dismore y Bailey, 2004; Groves y Laws, 2000; Rikard y Banville, 2006; Subramaniam y Silverman, 2007), por lo que es importante velar por mantener dichos niveles de motivación a fin de favorecer su aprendizaje (Biddle, 2003). Por su parte, a tenor de los resultados expuestos por diversas investigaciones, AICLE también podría repercutir favorablemente sobre los niveles de motivación del alumnado, incrementando tanto el deseo por entender y usar el contenido estudiado como por el aprendizaje de la lengua (Lasagabaster y Doiz, 2016a; Mehisto et al., 2008; Navarro y García, 2018; Scott y Beadle, 2014).

A tenor de estas observaciones, la hipótesis que, a priori, podría inferirse sería que combinar educación física y AICLE podría generar un aumento en la motivación del alumnado tanto por la asignatura como hacia el aprendizaje de la lengua (Ceallaigh, Mhurchú y Chróinín, 2017). Con objeto de esclarecer estas ideas ya han sido realizadas diversas investigaciones. Por ejemplo, Fernández-Barrionuevo y Baena-Extremera (2018) concluyen que los factores propios de la educación física y de AICLE por separado podrían afectar al otro. Según sus resultados, las chicas mostraban mayor motivación por el aprendizaje de lenguas y los chicos por la educación física. Así, estos autores sugieren que gracias a la integración de AICLE en 
la educación física, por un lado, dicha asignatura podría volverse más motivante para ellas al incorporársele el elemento lingüístico; y por otro, el aprendizaje de lengua podría resultar más motivante para ellos por producirse en la clase de educación física. En una línea similar, McCall (2011) desarrolló un estudio en el que analizó los niveles motivacionales del alumnado que realizó un proyecto para aprender francés basado en el futbol, concluyendo que la actitud de los chicos hacia el aprendizaje de la lengua se veía fuertemente influenciada gracias a vincular su aprendizaje a un tema que les interesaba y formaba parte de su vida diaria.

También Christopher, Dzakiria y Mohamed (2012) llevaron a cabo una investigación sobre una iniciativa que utilizaba actividades deportivas como medio para enseñar inglés como segunda lengua. En su caso el estudiantado también se mostró más motivado e incluso aumentó su nivel de seguridad hacia la lengua inglesa en comparación con las clases desarrolladas en el aula. Por último, el estudio desarrollado por Baena-Extremera et al. (2017) también se perfila en la línea de los anteriores. Según los resultados de dicha investigación, el alumnado mostraba altos niveles de satisfacción/diversión en las actividades realizadas en clase de educación física bilingüe, mientras que los valores de aburrimiento se mantenían bajos. De este modo, estos autores concluyen que los resultados obtenidos pueden calificarse de positivos porque evidencian que el alumnado que disfruta en las clases de educación física aumenta su compromiso con el aprendizaje de un nuevo idioma. En suma, diferentes investigaciones realizadas sugieren que vincular el aprendizaje de una lengua y las actividades propias de la educación física constituye una buena forma de mantener niveles de motivación que favorezcan el aprendizaje del alumnado.

A tenor de los múltiples elementos que comparten la educación física y AICLE, tal y como ha podido observarse a lo largo de los párrafos precedentes, parece que, al menos sobre el papel, "la educación física es un camino excelente para desarrollar la motricidad, mejorar la lengua extranjera, las habilidades cognitivas y favorecer el desarrollo personal y social de los estudiantes" (Coral y Lleixà, 2013, p. 80).

\subsubsection{Redefiniendo las funciones de la educación física}

Tal y como hemos expuesto con anterioridad, toda asignatura debe atender, ineludiblemente, una serie de finalidades que han debido adaptarse a la realidad propia de cada momento y 
situación, así como los retos que estos le han planteado. Por este motivo los fines de la educación física han ido modificándose y moldeándose a lo largo del tiempo hasta llegar a los objetivos propios a la educación física actual (Devís, 2018; McEvoy et al., 2017). Poniendo el punto de mira no solo en el presente, sino también en el futuro, López-Pastor et al., (2016) exponen que

"durante las últimas décadas se han ido planteando diferentes retos para conformar un modelo más completo de educación física: la adherencia a la actividad física en el tiempo, la condición física orientada a la salud, la recreación, la iniciación deportiva, la educación en valores, el bilingüismo, etc.” (p. 182).

Como puede observarse, estos autores ya apuntan hacia una posible incursión del aprendizaje de lenguas en la educación física; sin embargo, también inciden en que, desde su "perspectiva, el principal reto de la educación actual se relaciona con tener claras sus finalidades" (p. 182). Parece claro, pues, que una educación física que acoja al enfoque AICLE debe mantenerse fiel a sus propios fines.

Mirando ahora desde el ángulo opuesto, el de AICLE, resulta interesante recordar que dicho enfoque metodológico trae consigo un nuevo objetivo: aprender una lengua. La envergadura de este puede variar dependiendo de cada docente, cada clase, cada centro, o incluso cada día o cada sesión. No obstante, conviene recordar que la incorporación de AICLE en ningún caso significa diluir la asignatura que lo acoge (Dalton-Puffer, 2007), más bien al contrario. La materia que adopta AICLE debe sustentarse firmemente en sus principios y naturaleza con objeto de que AICLE pueda abrazarla y amoldarse a la misma sin desfigurarla ni asfixiarla, puesto que en ningún caso debería verse desvirtuada.

Si recordamos, la educación física actual debe responder a una serie de finalidades que, pese a la incorporación de AICLE deben seguir siendo el alma mater de la asignatura. Sin embargo, dichos fines pueden verse sutilmente ampliados a fin de incluir también la aportación de AICLE al área. Además, una nueva finalidad, seguramente no tan relevante pero indudablemente una posibilidad de enriquecer las propias de la educación física puede incorporarse: el aprendizaje de una lengua. A continuación, comentaremos cómo las finalidades inherentes a la materia se ven ligeramente ampliadas para darle cabida a AICLE y cómo se incorpora este nuevo fin a la educación física. 
Tal y como se ha expuesto en el apartado 3.5.4., diferentes autores han tratado de hacer explícitas las finalidades propias de la educación física actual. Aunque cada uno aportaba su particular perspectiva, puede observarse una cierta convergencia entre todas las propuestas que hemos expuesto. Por ser la referencia más actual, tratarse de una propuesta realizada en el ámbito de nuestro país y ser un posicionamiento con el que coincidimos; seguidamente nos servimos del planteamiento de López-Pastor et al. (2016), quienes sugieren que la educación física actual debe atender tres grandes finalidades: el desarrollo físico-motriz del alumnado, la creación y recreación de la cultura física del alumnado y su aportación al planteamiento global del desarrollo integral del alumnado.

El objetivo relativo al desarrollo físico-motriz está ligado a la concepción más tradicional de la educación física, la que concebía dicha asignatura como medio para la mejora de lo motriz. Desde esta perspectiva tan cerrada y de corte racionalista, la incorporación de AICLE no conlleva excesivas matizaciones puesto que lengua y desarrollo motriz son dos campos considerablemente alejados el uno del otro.

En cambio, la segunda finalidad de la educación física se encuentra más próxima al campo de la lengua porque hace referencia a la creación y recreación de la cultura física. Es ampliamente reconocido que la cultura se erige como elemento de relevancia en la didáctica de las lenguas puesto que constituye un factor clave a la hora de acceder al sentido de la comunicación (Villanueva, 2002). En una educación física desarrollada mediante AICLE, la dimensión cultural deberá verse redefinida, puesto que no solo implicará la cultura física, sino también la cultura relativa a la lengua. A modo de ejemplo, puede mencionarse la jerga propia de deportes o juegos. Este tipo de vocabulario propio a alguna actividad deportiva concreta puede ser incomprensible incluso para aquella gente nativa del idioma, pero ajena a su contexto de uso. De este modo, la educación física a través de AICLE debe acercar al alumnado a los constructos culturales que se erigen alrededor de la educación física incorporando también la perspectiva relativa a la lengua de uso típica en los mismos.

El tercer fin de la educación física radica en el desarrollo integral del alumnado que, además, constituye una característica propia de AICLE. De este modo, la adopción de dicho enfoque metodológico implicará una cierta matización del objetivo propio de la asignatura. Cómo el binomio educación física y AICLE afronta el reto de favorecer el desarrollo integral del 
estudiantado de manera conjunta ha sido comentado en el apartado 3.6.2., por lo que no reincidiremos en las mismas cuestiones, y simplemente recordamos que una educación física desarrollada mediante AICLE es capaz de contribuir en el desarrollo integral del alumnado desde nuevos flancos, especialmente los vinculados a la lengua y todo lo que la rodea.

\subsubsection{El proceso de enseñanza-aprendizaje en educación física mediante AICLE}

Parece claro que "la aplicación de los principios CLIL a la educación física implica una adaptación didáctica" (Coral y Lleixà, 2014, p. 1448). Si bien la educación física sigue rigiéndose por su idiosincrasia propia, incluyendo las estrategias y aproximaciones metodológicas del proceso de enseñanza-aprendizaje que le son inherentes, es necesario reflexionar sobre cómo se afronta dicho proceso incorporando AICLE de la manera más eficaz posible. En este sentido, una elección adecuada de la metodología deviene un factor de vital importancia a la hora de favorecer una apropiada incorporación del enfoque metodológico AICLE (Clancy y Hruska, 2005; Coral y Lleixà, 2014; Hernando, 2015).

Antes de adentrarnos en cómo se afronta el proceso de enseñanza-aprendizaje en una educación física mediante AICLE, conviene reparar en tres cuestiones esenciales relativas a este enfoque pedagógico, y concernientes a cualquier asignatura que pretenda aplicarlo:

- Incorporar el enfoque AICLE no es sinónimo de traducir las sesiones al inglés (Coyle et al., 2010). De hecho, la lengua utilizada debe ser adaptada a fin de poder asumir la enseñanza integrada del contenido de la asignatura y la lengua, garantizando que la utilización de dicha lengua sea relevante y favoreciendo, por tanto, el aprendizaje lingüístico.

- Programar mediante AICLE implica asegurar una presencia equilibrada de demandas lingüísticas de menor nivel (LOTS) y demandas lingüísticas de mayor calado (HOTS) (Coral, 2012), de modo que las actividades deben secuenciarse teniendo en consideración tanto el ámbito motriz como el cognitivo, haciendo este último también referencia a la lengua de uso.

- La incorporación de AICLE va ligada, a menudo, a una cierta ralentización del proceso de enseñanza-aprendizaje (Fernández-Barrionuevo, 2017). 
Tener en cuenta estas tres consideraciones es relevante para poder afrontar conscientemente el proceso de enseñanza-aprendizaje mediante AICLE, sea cual sea la asignatura desde la que se adopte. Una percepción equivocada sobre qué implica la incorporación de dicho enfoque pedagógico puede derivar en una praxis educativa ineficaz por lo que parece lógico que, previa incorporación de AICLE, el profesorado reflexione pausadamente sobre las implicaciones que van ligadas a este. En esta dirección se dirige el presente apartado, que pretende ayudar a reconceptualizar el proceso de enseñanza-aprendizaje en una educación física desarrollada mediante AICLE.

El enfoque metodológico AICLE puede ser utilizado a través de diferentes metodologías (Coral y Lleixà, 2014). Dado que los modelos pedagógicos están emergiendo con fuerza en el campo de la educación física (Fernández-Río et al., 2016; Peiró y Méndez, 2017), parece pertinente valorar cómo se conciben cuando se incorpora AICLE en dicha asignatura. Los modelos pedagógicos se establecen como un marco conceptual que determina el plan de acción de la docencia en la educación física, focalizando el proceso de enseñanza-aprendizaje en el alumnado (Casey, 2016; Metzler, 2005). De este modo y siguiendo esta filosofía, parece lógico que el profesorado que utilice AICLE deba adoptar una mayor sensibilidad lingüística a fin de adaptar los contenidos a la lengua de aprendizaje y a las características del estudiantado (Lorenzo, Hengst, Hernández y Pavón, 2005). Eso sí, siendo consciente de que la lengua no suponga un impedimento para la implementación de las estrategias propias de la educación física (Chroinin et al., 2016).

Como se ha comentado en apartados previos, existen diferentes modelos pedagógicos y cada uno está sujeto a una serie de consideraciones teórico-prácticas de naturalezas diversas (Fernández-Río et al., 2016).

“Aunque la investigación por separado de cada uno de estos modelos pedagógicos ha permitido contrastar su eficacia en el logro de los objetivos pretendidos, la cercanía entre sus diferentes aproximaciones teóricas (constructivismo, participación activa, aprendizaje significativo y social) y la relación entre los aspectos pedagógicos han justificado la creación de hibridaciones que optimicen los efectos desde un planteamiento más holístico.” (Peiró y Méndez, 2017, p.5) 
En otras palabras, todos los modelos pedagógicos comparten una serie de principios básicos que son los que justifican la creación de hibridaciones, siempre con el objetivo de optimizar el proceso de enseñanza-aprendizaje. Por lo tanto, la incorporación de AICLE debería verse sujeta, en primer lugar, a su cercanía a dichas analogías y, en segundo, a favorecer un desarrollo más holístico del alumnado.

Pasamos pues, primeramente, a comentar el encaje de AICLE en la asignatura de educación física con respecto a los principios comunes de los modelos pedagógicos expuestos por Dyson et al. (2004):

- El alumnado es el protagonista activo del proceso de enseñanza-aprendizaje. Con respecto a este precepto, una característica básica del enfoque AICLE reside en otorgar al alumnado el rol de actor principal de la praxis educativa, abogando por actividades centradas en sus características particulares (Kashiwagi y Tomecsek, 2015; Van Kampen et al., 2017). Además, uno de los elementos fundamentales de AICLE propuesto por Mehisto et al. (2008) es precisamente el aprendizaje activo, por lo que parece claro el posicionamiento de este enfoque pedagógico con respecto al rol del alumnado.

- Se desarrollan objetivos a nivel fisico, cognitivo, afectivo y social a fin de promover el desarrollo integral de la persona. El aprendizaje de una lengua requiere del uso de demandas cognitivas de múltiples complejidades. Por este motivo, desde AICLE se propone un enfoque múltiple (Mehisto et al., 2008) y se hace hincapié en garantizar una correcta secuenciación en las demandas cognitivas presentadas al estudiantado (Cenoz et al., 2013; Fortanet, 2013; Marsh, 2012). Como consecuencia, ha sido asiduamente vinculado a la Taxonomía de Bloom (Coyle et al., 2010; Meyer, 2010) y se ha enfatizado que debe proveer al estudiantado oportunidades para desarrollar los BICS y los CALP (Dalton-Puffer, 2007). Asimismo, AICLE pretende como fin último favorecer un desarrollo holístico del alumnado (Coyle, 2015).

- El estudiantado trabaja en pequeños grupos, de manera que los unos dependen de los otros para completar las tareas. De acuerdo con Casal (2016), AICLE y el marco de las 4C's constituyen un contexto más que indicado para favorecer que el alumnado trabaje conjuntamente y en cooperación. Además, según los elementos fundamentales 
de AICLE propuestos por Mehisto et al. (2008), desde este enfoque metodológico debería promocionarse el aprendizaje cooperativo, que lleva implícito el trabajo en pequeños grupos y el establecimiento de relaciones de interdependencia positiva entre el alumnado.

- El estudiantado ostenta gran parte de la responsabilidad en su aprendizaje. AICLE se rige por los principios del aprendizaje desde un punto de vista socioconstructivista, por lo tanto, el alumnado se erige como eje central del proceso de enseñanza-aprendizaje. Este posicionamiento conlleva facilitar que el estudiantado tome una mayor conciencia (Coyle et al., 2010), así como responsabilidad sobre su aprendizaje (Marsh, Mehisto, Wolff y Frigols, 2012; Mehisto et al., 2008).

- Se fomenta un aprendizaje activo incluyendo procesos de toma de decisiones, interacción social y comprensión cognitiva. Tal y como se ha mencionado unas líneas más arriba, uno de los elementos fundamentales de AICLE radica en el aprendizaje activo (Mehisto et al., 2008) aludiendo concretamente a la negociación de los significados de la lengua y el contenido con el estudiantado. Además, conviene recordar que AICLE se rige en base a la premisa de "aprender mientras se utiliza y utilizar mientras se aprende" (Coyle et al., 2010), bebiendo claramente del aprendizaje experiencial propuesto por Dewey (1944) y que, necesariamente, implica la toma de decisiones por parte del alumnado. El aprendizaje activo de AICLE también hace referencia a la interacción social. Sin ir más lejos, una de las C's que componen el marco conceptual de este enfoque pedagógico alude a la comunicación, elemento fundamental en cualquier iniciativa AICLE. De forma que, siguiendo a Meyer (2010), la interacción deviene un componente básico a fin de facilitar el aprendizaje. Por último, AICLE también promueve que el alumnado se implique cognitivamente en el proceso de enseñanza aprendizaje (Marsh, 2012) y, de hecho, autores como Coyle et al. (2010) subrayan que para que el aprendizaje mediante AICLE sea efectivo no solo deben tenerse en cuenta los conocimientos conceptuales y las habilidades a trabajar, sino también la demanda cognitiva a la que los discentes deben enfrentarse.

- Las actividades son auténticas y ajustadas al desarrollo de cada estudiante. Aludiendo de nuevo a los elementos fundamentales de AICLE, puede observarse que 
la autenticidad es uno de ellos (Mehisto et al., 2008), puesto que AICLE persigue el uso de la lengua de una manera real, cercana al alumnado y utilizada con un propósito. Por lo que respecta a la utilización de actividades ajustadas a las características del estudiantado, Kashiwagi y Tomecsek (2015) indican que la adopción de AICLE implica que el profesorado deba optar por actividades más centradas en el alumnado. Además, autores como Coyle et al. (2010), sugieren la utilización de la matriz de Cummins (2000) a fin de garantizar que las actividades seleccionadas se ajustan a los y las discentes.

En la Tabla 7, se aprecia de manera sintética cuáles de los elementos fundamentales de AICLE (Mehisto et al., 2008) dan respuesta a cada una de las analogías de los modelos pedagógicos de la educación física (Dyson et al., 2004):

Tabla 7. Elementos de AICLE que dan respuesta a las analogías de los modelos

\begin{tabular}{|c|c|}
\hline Analogías modelos pedagógicos & $\begin{array}{c}\text { Elementos } \\
\text { fundamentales } \\
\text { AICLE }\end{array}$ \\
\hline $\begin{array}{l}\text { El alumnado es el protagonista activo del proceso de } \\
\text { enseñanza-aprendizaje. }\end{array}$ & Aprendizaje activo \\
\hline
\end{tabular}

Se desarrollan objetivos a nivel físico, cognitivo, afectivo y social a fin de promover el desarrollo integral de la Enfoque múltiple persona.

El estudiantado trabaja en pequeños grupos, de manera que los unos dependen de los otros para completar las tareas.

Aprendizaje activo

Cooperación

El estudiantado ostenta gran parte de la responsabilidad en su aprendizaje.

Aprendizaje activo

Andamiaje

Aprendizaje activo

Se fomenta un aprendizaje activo incluyendo procesos de toma de decisiones, interacción social y comprensión cognitiva.

Las actividades son auténticas y ajustadas al desarrollo de cada estudiante.

Autenticidad

Andamiaje

Tal y como ha podido observarse, AICLE se adapta sin aparentes problemas a las diferentes analogías propias a los modelos pedagógicos de la educación física, que era la primera 
premisa a cumplir para poder incorporar dicho enfoque metodológico en los modelos. La segunda premisa para poder proceder a su imbricación incide en que la combinación de ambos elementos debe favorecer el desarrollo holístico del alumnado, aspecto que AICLE también parece cumplir, tal y como se ha expuesto en el apartado 3.6.2.

Aludiendo específicamente a los modelos pedagógicos, Peiró y Méndez (2017) señalan que

"El interés por los modelos pedagógicos ha crecido exponencialmente. Docentes e investigadores han experimentado la aplicación pura de cada uno de ellos por separado y diseñado determinadas hibridaciones de dos o más modelos con el objetivo de potenciar sus efectos educativos (por ejemplo, Méndez-Giménez, 2009). Dado que los objetivos de la EF son múltiples y afectan a distintos ámbitos de la persona, esta perspectiva mixta parece no solo loable, sino necesaria." (p.5)

Por lo tanto, si la combinación de modelos pedagógicos es una acción loable y necesaria como medio para potenciar los efectos educativos generados, cabe preguntarse cuál podría ser el efecto de implementar un modelo pedagógico mediante AICLE. Este enfoque puede aportar una nueva dimensión a los beneficios inherentes a los diferentes modelos, por lo que podría dotar de mayor envergadura a las acciones desarrolladas desde la asignatura de educación física. En suma, parece que, al menos en teoría, la combinación de AICLE con alguno de los modelos pedagógicos también podría ser conveniente o, como mínimo, capaz aportar algún beneficio.

Cada modelo pedagógico es diferente y, por lo tanto, no puede generalizarse que AICLE vaya a concordar del mismo modo con todos. Pueden encontrarse ejemplos de varias combinaciones. Por ejemplo, García-Calvo y Saliberri (2018) desarrollaron una iniciativa en educación física mediante AICLE utilizando el modelo comprensivo de iniciación deportiva, y concluyeron que el alumnado mostraba una alta satisfacción con respecto a la propuesta. Además, también subrayan que el modelo comprensivo de iniciación deportiva y AICLE tienen muchos vínculos gracias a sus raíces constructivistas, cuestión que también comparten el resto de modelos pedagógicos. Por su parte, también respecto al modelo comprensivo de iniciación deportiva, Cobo, Estevan y Warburton (2018) concluyen que la sociomotricidad presente en este modelo potencia las habilidades lingüísticas y no merma la adquisición de los elementos fundamentales del juego. Conviene señalar que una de las publicaciones que 
constituyen esta tesis doctoral se apoya en el modelo comprensivo como planteamiento pedagógico desarrollado en las clases de educación física mediante AICLE (Salvador-García, Chiva-Bartoll y Vergaz, 2018), aunque en última instancia el objetivo del estudio no se centró en valorar su adecuación o no.

Por su parte, la hibridación del aprendizaje cooperativo con AICLE se ha resuelto positivamente en otras materias (Karimi et al., 2017; Pastor, 2011, Pistorio, 2010) y diferentes autores han propuesto la aplicación conjunta de dicho modelo pedagógico y la educación física mediante AICLE (Chiva-Bartoll, Salvador-García y Capella-Peris, 2018; Coral, 2016) o incluso la combinación de aprendizaje cooperativo y estilo actitudinal con AICLE (Hortigüela et al., 2016).

Otro de los elementos característicos del proceso de enseñanza-aprendizaje de la educación física radica en los estilos de enseñanza (Byra, 2006; Mosston y Ashworth, 1993). Dado que los estilos de enseñanza aluden a la interacción entre docente y discente, la toma de decisiones y el rol de cada uno en el proceso de enseñanza-aprendizaje; el estilo por el que se opte puede "condicionar los patrones comunicativos que se den dentro del aula." (Fernandez-Barrionuevo, 2017, p. 69). De este modo, en una educación física mediante AICLE, la decisión sobre el estilo de enseñanza que se vaya a utilizar resulta ciertamente influyente no solo a la hora de promover en el alumnado un tipo de demanda cognitiva u otro, sino también el tipo de demanda lingüística a la que deba enfrentarse.

El espectro de estilos de enseñanza propuesto por Mosston y Ashworth (1993) presenta dos grandes conjuntos, los reproductivos y los productivos. Cada uno de estos conjuntos puede verse más relacionado con un tipo de demandas cognitivas y lingüísticas. Mientras que los estilos reproductivos, por perseguir la emulación de un modelo, pueden vincularse con demandas menos exigentes en ambos campos; los estilos productivos requieren que el alumnado cree sus propias respuestas a nivel cognitivo y que tenga mayor libertad a la hora de utilizar la lengua. Las dos agrupaciones de estilos tienen sus ventajas e inconvenientes con respecto al aprendizaje de una lengua, por este motivo parece no haber un consenso claro con respecto a qué conjunto es más apropiado en la introducción de AICLE.

Por un lado, se esgrime que los estilos de enseñanza más tradicionales, es decir, los reproductivos, son los más adecuados en estadios iniciales (Fernández-Barrionuevo, 2009) 
porque evitan el error y favorecen que el alumnado se sienta más seguro al utilizar la lengua. En este sentido se podría también mencionar a aquellos que, como Alías (2011) o Devos (2016), abogan por utilizar la Total Physical Response en educación física con estudiantes jóvenes, dado que este método es considerablemente directivo.

Desde el lado opuesto de la balanza se defiende que "los enfoques metodológicos de la educación física escolar orientados hacia el aprendizaje y la participación se complementan de manera más satisfactoria con la forma de trabajo CLIL y el desarrollo de las destrezas implícitas del idioma" (Hernando, 2015, p.135). Por lo tanto, parece que un uso más real de la lengua estaría vinculado con una orientación de la educación física hacia la práctica (Tinning, 1996), así como con los estilos productivos (Mosston y Ashworth, 1993). En esta línea, autores como Chiva-Bartoll, Isidori y Fazio (2015) indican que para poder implementar AICLE en conjunción con los postulados de la pedagogía crítica, la educación física "debe incorporar estilos de enseñanza que fomenten la participación del alumnado y, ante todo, que lo impliquen cognitivamente" (p. 112).

Por lo tanto, parece que ambos conjuntos de estilos podrían tener cabida en una educación física mediante AICLE. La primera parte del espectro de los estilos, los denominados reproductivos, puede ayudar a acercar una lengua sencilla al alumnado. De este modo se crean situaciones de aprendizaje aludiendo al primer cuadrante de la matriz de Cummins (2000), puesto que tanto la demanda cognitiva como la lingüística son bajas. Por el contrario, los estilos productivos pueden asociarse con los cuadrantes dos y tres de dicha matriz (Figura 6), puesto que aluden a demandas cognitivas superiores.

A tenor de lo expuesto, la elección del estilo de enseñanza queda sujeta al contexto concreto en el que se desarrolle la praxis, condicionada a las características del alumnado y los objetivos, tanto cognitivos como lingüísticos, que se persigan. Así, "diferentes estilos de enseñanza (...) de la educación física pueden ser utilizados en distintas situaciones con una gran variedad de finalidades enfocadas a la mejora de la lengua extranjera en educación física AICLE” (Fernández-Barrionuevo, 2017, p. 69), y cada uno de ellos puede ser más apropiado en una ocasión u otra.

Respecto al tratamiento concreto de las tareas, conviene recordar que en un marco puro de educación física estas se conciben como el conjunto de condiciones materiales y obligaciones 
que implican la realización de conductas motrices con objeto de lograr un objetivo (Parlebas, 2008). Sin embargo, como venimos diciendo, la incorporación del enfoque AICLE trae consigo la matización de los diferentes elementos inherentes al proceso de enseñanzaaprendizaje propios de la educación física, puesto que las conductas no se ven ligadas únicamente al ámbito motriz, sino que la vertiente lingüística también puede verse adherida. Esto implica, por tanto, que el concepto de tarea motriz debe verse reajustado. Con este fin, Coral (2012), ofrece su particular visión de lo que constituye una tarea motriz en el marco de la educación física mediante AICLE, definiéndola como la "unidad básica de actividades, ejercicios y situaciones-problema con un objetivo, procesos y pasos establecidos mediante los cuales el aprendiz ha de utilizar diversos procedimientos motrices, comunicativos/lingüísticos, cognitivos y volitivos que tienen como resultado un producto final definido" (p. 84). Una definición que, sin duda, abre la puerta a la incorporación de procedimientos relativos a la lengua.

Siguiendo a este mismo autor, la cuestión elemental ante la cual debe enfrentarse el profesorado se refiere a cómo incorporar la vertiente lingüística a las tareas motrices evitando que las actividades se compliquen en demasía y/o devengan menos motivantes para el estudiantado. En este sentido, Coral y Lleixà (2013) apuntan que

"la tipología de las tareas pertinentes para el aprendizaje integrado de educación física y lengua inglesa es la de una tarea realizada a través de grupos con estructura cooperativa y que incorpora, de forma intencional, el lenguaje. Es una tarea en la cual el alumnado adopta un papel activo en la verbalización de informaciones clave relacionadas directamente con la actividad física realizada." (p. 83)

Por lo tanto, parece que una adecuada selección y enfoque de las tareas constituye una decisión en absoluto trivial a fin de favorecer que la praxis educativa pueda ser exitosa. En este sentido, atendiendo a los tres parámetros que definen una tarea motriz según Famose (1992), el profesorado debe:

- Ser capaz de presentar tareas cuyo resultado sea asequible para el alumnado, tanto en lo concerniente a la vertiente motriz como a la lingüística. 
- Seleccionar unas condiciones de acompañamiento adecuadas, pudiendo estas tomar forma de grupos de trabajo cooperativo o estrategias de andamiaje (Bruner, 1984; Chroinin et al., 2016; Ramos y Ruiz-Omeñaca, 2011)

- Presentar las instrucciones de manera clara y entendible para el estudiantado, pudiendo, también en este caso, servirse de estrategias de andamiaje.

En esta toma de estas decisiones el profesorado debe, ineludiblemente, basarse en las características de su alumnado a fin de mantener los niveles de motivación altos (Biddle, 2003). En este sentido, Coral y Lleixà (2013) sugieren que "las tareas de aprendizaje integrado de educación física y lengua inglesa que suscitan mayor interés en el alumnado son aquellos juegos que, a pesar de incorporar exigencias lingüísticas, no distorsionan su esencia" (p. 84). Además, indican que a la hora de diseñar una actividad para educación física mediante AICLE, los niveles de exigencia motriz, lingüística, cognitiva y de desarrollo social y/o personal deben estar equilibrados. Con objeto de favorecer que el diseño de tareas equilibradas por parte del profesorado sea adecuado, Coral y Lleixà (2014) presentan un cuadro (Tabla 8) a modo de guía. En este se indica el nivel de dificultad de la tarea, las habilidades cognitivas implicadas y los actos cognitivos que comprende. Al mismo tiempo, hemos incorporado el tipo de tarea (Buscà, 2005) a la que se vincula, pudiendo ser tareas predominantemente conductales o de cariz predominantemente constructivista. De este modo puede vincularse cada tarea, en función del tipo, con uno de los conjuntos de estilos de enseñanza (Mosston y Ashworth, 1993), estando las conductales más ligadas con los estilos reproductivos y las constructivistas con los productivos. 
Tabla 8. Guía para el diseño de tareas equilibradas en educación física mediante AICLE

\begin{tabular}{|c|c|c|c|}
\hline Nivel & $\begin{array}{l}\text { Habilidades } \\
\text { cognitivas }\end{array}$ & Actos comunicativos & Tipo de tarea \\
\hline I & Recordar y comprender & Escuchar y comprender & $\begin{array}{l}\text { Predominantemente } \\
\text { conductales }\end{array}$ \\
\hline II & Aplicar & $\begin{array}{l}\text { Preguntar y responder, describir, } \\
\text { explicar, leer frases, escribir palabras }\end{array}$ & $\begin{array}{l}\text { Predominantemente } \\
\text { conductales }\end{array}$ \\
\hline III & Analizar & Comparar, escribir frases & $\begin{array}{l}\text { Predominantemente } \\
\text { conductales }\end{array}$ \\
\hline IV & Evaluar & $\begin{array}{l}\text { Hacer predicciones, dar opiniones, } \\
\text { leer y escribir frases compuestas, } \\
\text { emitir juicios }\end{array}$ & $\begin{array}{l}\text { Predominantemente } \\
\text { constructivistas }\end{array}$ \\
\hline V & Crear & $\begin{array}{l}\text { Dar argumentos, justificar } \\
\text { decisiones, leer y escribir textos } \\
\text { sencillos }\end{array}$ & $\begin{array}{l}\text { Predominantemente } \\
\text { constructivistas }\end{array}$ \\
\hline
\end{tabular}

Fuente: Adaptado de Coral y Lleixà (2014)

En definitiva, siguiendo a Coral (2012), las tareas en educación física mediante AICLE deben ser equilibradas y eficientes, para lo que deben cumplir los siguientes requisitos:

- Ser motivantes.

- Incorporar actividad física.

- Fomentar la interacción verbal.

- Desarrollar el razonamiento.

- Ser socializadoras.

Dentro del complicado constructo que constituyen las tipologías de tareas en educación física, el juego puede erigirse como una entidad per se. Este recurso, al que ya se le han dedicado unas líneas con anterioridad, puede establecerse como una herramienta de gran valor en una educación física mediante AICLE gracias a su capacidad de proporcionar no solo situaciones comunicativas relevantes, sino también fomentar un ambiente relajado y desinhibido (Alías, 2011; Alonso, Cachón, Castro y Zagalaz, 2015). Estos factores en absoluto son triviales, puesto que favorecen una integración natural de la lengua extranjera $\mathrm{y}$, consecuentemente, que los aprendizajes devengan significativos para el alumnado. Siguiendo a Alías (2011) los juegos se erigen como uno de los principales centros de interés 
en edades tempranas, por lo que parecen un punto de partida idóneo para tomar contacto y utilizar una nueva lengua. Sin embargo, conviene ser conscientes de que, si el alumnado está demasiado absorto en el juego, es posible que deje de presar atención al apartado lingüístico, por lo que parece necesario reparar en cómo se plantean las actividades jugadas (Bell y Lorenzi, 2004; Tomlinson y Masuhara, 2009).

A fin de extraer todas las posibilidades que los juegos pueden aportar a la educación física mediante AICLE, Coral y Lleixà (2013) puntualizan que "las estructuras lingüísticas objeto de desarrollo tienen que estar incrustadas en el juego proporcionando un contexto comunicativo significativo y real" (p. 83). De este modo, parece necesario que el profesorado reflexione concienzudamente sobre cómo presenta los juegos en clase, apreciando sus características como tarea, pudiendo servirse de la Tabla 8, pero sin olvidar que las características naturales de los juegos deben seguir siendo el pivote sobre el que gira toda la actividad.

En suma, todo parece indicar que el juego constituye un elemento básico de la educación física a través de AICLE gracias a su naturaleza. Por este motivo, autores como Alonso et al. (2015) o Ramos y Ruiz-Omeñaca (2011) no dudan en señalar que combinar la actividad física, el juego y el aprendizaje de una lengua puede constituir un recurso pedagógico de gran valor a fin de favorecer que el alumnado crezca y se desarrolle íntegramente.

La última cuestión referente a la enseñanza-aprendizaje de una educación física mediante AICLE que abordamos son las estrategias docentes. De hecho, una de las tareas del profesorado consiste en adaptar el contenido de la asignatura a fin de hacerlo comprensible y asequible para el estudiantado (Chroinin et al, 2016). Con este cometido en mente y atendiendo específicamente al apartado lingüístico (aunque este mismo procedimiento también debe realizarse con respecto al apartado motriz) resulta necesario prestar atención a la diversidad de niveles y conocimientos con respecto a la lengua que pueda tener el alumnado. Además, paralelamente es aconsejable incorporar estrategias de andamiaje que adecuen la exigencia lingüística y faciliten que el proceso de enseñanza-aprendizaje sea exitoso, de modo que estas estrategias faciliten tanto la comprensión como la expresión del estudiantado (Bruner, 1984; Ramos y Ruiz-Omeñaca, 2011). En este sentido, "una propuesta didáctica de educación física en CLIL tendrá una exigencia lingüística adecuada cuando, 
además de adaptar el discurso al contexto, incorpora los andamios lingüísticos necesarios para atender la diversidad lingüística del aula" (Coral y Lleixà, 2013, p. 84).

Además de garantizar que la exigencia lingüística es la apropiada, otro aspecto de relevancia radica en favorecer que el alumnado mantenga sus niveles de motivación y satisfacción altos con respecto a la asignatura pese a la incorporación de AICLE (Biddle, 2003). En relación a esta premisa, Baena-Extremera et al. (2017) enfatizan la necesidad de pasar de la enseñanza del idioma a la enseñanza en el idioma, puesto que desde esta segunda perspectiva se mantiene el acento sobre la educación física. De este modo, el profesorado de dicha asignatura debe optar por mantener las estrategias metodológicas propias de su materia, tales como el juego motriz, a fin de garantizar que la asignatura no se ve constreñida por el uso de la lengua y de excesivas actividades propias de las áreas lingüísticas (Chroinin et al., 2016).

Pese a que la premisa es enseñar en el idioma (Baena-Extremera et al., 2017), conviene ser conscientes de que la faceta relativa a la lengua debe incorporarse en clase. Ahora bien, esta no debe degenerar en la desinhibición del alumnado hacia el uso de la lengua y la participación en clase. Por este motivo, con objeto de mantener los niveles de participación y satisfacción elevados, García-Calvo y Saliberri (2018) indican que el profesorado debe adoptar una actitud positiva hacia el error. De este modo, el profesorado debe optar por estrategias que garanticen un buen ambiente en clase, donde prime la colaboración, la cooperación y el respeto, y donde el alumnado sea consciente de que errar es el primer paso para aprender.

Diferentes autores han tratado de aglutinar estrategias que favorecieran un aprendizaje exitoso tanto en educación física (Delgado y Tercedor, 2002; López-Pastor, Barba y González, 2005), como en clase de lengua (Celce-Murcia, 2001). En el caso particular de la educación física mediante AICLE, tanto, Coral y Lleixà (2018) como Hernando (2015) presentan una serie de estrategias que persiguen facilitar al profesorado su tarea docente. En la Figura 11 presentamos sucintamente las estrategias propuestas por estos autores. 


\begin{tabular}{|c|c|}
\hline \multirow{6}{*}{$\begin{array}{l}\text { Estrategias según } \\
\text { Coral y Lleixà } \\
\text { (2018) }\end{array}$} & $\begin{array}{l}\text { Animar al alumnado a explicar juegos en grupo, pero mediante una secuencia } \\
\text { ordenada. }\end{array}$ \\
\hline & $\begin{array}{l}\text { Traducir los conocimientos prácticos al inglés durante los períodos de descanso de } \\
\text { las actividades motrices más demandantes. }\end{array}$ \\
\hline & $\begin{array}{l}\text { Evitar explicaciones largas que reduzcan el tiempo de actividad motriz del } \\
\text { alumnado dividiendo los juegos complejos en dos o tres secuencias más sencillas. }\end{array}$ \\
\hline & $\begin{array}{l}\text { Cuando se trabajen deportes, incluir equipos de árbitros que deban justificar sus } \\
\text { decisiones premiando el uso correcto de la lengua. }\end{array}$ \\
\hline & $\begin{array}{l}\text { Incluir la lengua en las tareas evitando actividades que reduzcan la práctica del } \\
\text { juego. }\end{array}$ \\
\hline & $\begin{array}{l}\text { Incorporar herramientas de andamiaje que faciliten la comunicación y la } \\
\text { integración de contenidos motrices y lingüísticos. }\end{array}$ \\
\hline \multirow{6}{*}{$\begin{array}{l}\text { Estrategias según } \\
\text { Hernando (2015) }\end{array}$} & Equilibrar demandas cognitivas y lingüísticas. \\
\hline & Incorporar rutinas. \\
\hline & Trabajar vocabulario específico y estructuras del lenguaje. \\
\hline & Utilizar estrategias de comunicación. \\
\hline & Emplear herramientas de andamiaje. \\
\hline & Integrar las tecnologías de la información. \\
\hline
\end{tabular}

Figura 11. Estrategias didácticas para la educación física mediante AICLE

En definitiva, la elección de un determinado modelo pedagógico, estilo de enseñanza, tarea o juego, así como las estrategias didácticas utilizadas en el desarrollo de la educación física, constituyen decisiones determinantes para favorecer la efectividad de la aplicación del enfoque AICLE (Clancy y Hruska, 2005; Coral y Lleixà, 2014; Hernando, 2015). Por lo tanto, es recomendable reparar reflexivamente sobre la naturaleza del proceso de enseñanzaaprendizaje de la educación física mediante AICLE a fin de favorecer que la praxis se acometa con un cierto rigor y sentido y puedan optimizarse sus resultados, respondiendo efectivamente a los objetivos planteados.

\subsubsection{El rol docente en la educación física mediante AICLE}

El profesorado se erige como el más valioso de los recursos con que cuentan los centros educativos, puesto que es una pieza clave a la hora de condicionar los procesos cognitivos y 
emocionales del alumnado (Warbuton, 2016). Este punto se centra en el papel desarrollado por el docente de educación física mediante AICLE, puesto que su propia identidad docente puede verse afectada a causa de la incorporación de dicho enfoque metodológico (Breidbach y Medina-Suárez, 2016), así como la forma en que desarrolle su docencia y disponga las diferentes actividades para el estudiantado.

La aparición de situaciones de enseñanza-aprendizaje novedosas, como pueden ser las generadas por la incorporación de AICLE, pueden conllevar una serie de problemáticas o retos a los que debe hacer frente el profesorado (Coral y Lleixà, 2014). Es apropiado, pues, ser conscientes de qué implica la incorporación de AICLE a nivel docente. De forma general, resulta evidente la trilogía de tareas que debe afrontar: (1) enseñar educación física, (2) enseñar lengua e (3) integrar ambos tipos de enseñanza. Como consecuencia de estos, Valdés (2016) propone una serie de retos que deben ser asumidos por el profesorado que incorpora el enfoque AICLE, quedando estos detallados en la Figura 12:

\begin{tabular}{|c|c|}
\hline \multirow{9}{*}{$\begin{array}{l}\text { Retos del } \\
\text { profesorado } \\
\text { AICLE }\end{array}$} & $\begin{array}{l}\text { Dominar los conocimientos, la lengua y la didáctica propios de las dos disciplinas } \\
\text { (lengua y asignatura) que debe enseñar. }\end{array}$ \\
\hline & Conocer los fundamentos de AICLE y desarrollar estrategias de integración. \\
\hline & Ser capaz de desarrollar una reflexión personal sobre su docencia AICLE. \\
\hline & Mostrar conciencia del contenido y de la lengua. \\
\hline & Utilizar una buena metodología de aula, incluyendo la evaluación. \\
\hline & Participar en los prcesos de investigación y evaluación de los proyectos AICLE. \\
\hline & Encontrar y desarrollar recursos y contextos de aprendizaje AICLE. \\
\hline & Gestionar un aula plurilingüe y participativa. \\
\hline & Gestionar el proyecto AICLE en relación con otros actores. \\
\hline
\end{tabular}

Figura 12. Retos del profesorado AICLE según Valdés (2016)

Para poder asumir con eficacia estos retos, la preparación del docente de educación física deviene fundamental (Hernando, 2015, Ramos y Ruiz-Omeñaca, 2011). Con la incorporación de AICLE el docente no solo debe dominar las razones que guíen su actuación metodológica con respecto a su asignatura, sino que también debe atesorar una serie de conocimientos 
relativos a la incorporación fundada de la lengua. A fin de facilitar que el profesorado pueda ser consciente de su adecuación al enfoque AICLE, Mehisto et al. (2008) han desarrollado un checklist con diversas de las competencias que cualquier docente que implemente AICLE debería cumplir:

- Integrar contenido y lengua. Como se acaba de exponer, uno de los retos que debe afrontar un docente que utilice AICLE es ser capaz de integrar efectivamente el contenido y la lengua en clase (Chroinin et al, 2016; Valdés, 2016). De este modo, siguiendo a Lorenzo et al. (2005), el profesorado debe mostrar una cierta sensibilidad hacia la lengua que le permita adaptar los contenidos a la misma mientras pone en juego una serie de estrategias didácticas que posibilitan el aprendizaje del estudiantado. En otras palabras, el profesorado debe ser capaz de mostrar una competencia a nivel metodológico (Hernando, 2015).

- Crear un ambiente de aprendizaje rico. El profesorado debería ser capaz de conseguir que el clima de las sesiones fuera seguro y motivante, tal y como proponen Ryan y Deci (2000), pero con el factor extra de la incorporación explícita de la lengua. De este modo, el docente debe ser capaz de dar al alumnado posibilidades de mejora de su competencia comunicativa sin dejar de proveerlo con abundantes y valiosos aprendizajes de educación física en un ambiente adecuado.

- Utilizar una lengua comprensible para el alumnado. Al igual que el resto de asignaturas, la educación física posee un vocabulario especializado, una terminología particular y unas estructuras sintácticas concretas. Todos estos elementos lingüísticos deben ser utilizados en cualquier sesión mediante AICLE de una forma que el alumnado sea capaz de comprender. Por ello, "gran parte del trabajo que deben hacer los docentes es identificar cuál es el lenguaje necesario" (Hernando, 2015, p. 130) e incorporarlo fundadamente en clase.

- Usar el discurso docente efectivamente. El docente de educación física mediante AICLE debe tener un buen dominio de la lengua oral (Emmanouilidou y Laskaridou, 2017) y una buena competencia lingüística en general (Hernando, 2015). Sin embargo, este conocimiento no es suficiente. Además, el profesorado debe ser capaz de simplificar su lenguaje y evitar discursos y explicaciones excesivamente largos. 
- Favorecer que el estudiantado pueda expresarse. A fin de facilitar el aprendizaje lingüístico, el docente de educación física debe ser capaz de planificar actividades que incorporen el lenguaje de manera intencional (Coral y Lleixà, 2013) y favorezcan el planteamiento de cuestiones en el alumnado, construyendo entornos que impliquen procesos cognitivos incorporando tanto LOTS como HOTS (Coyle et al., 2010).

- Atender a las diversas necesidades del alumnado. El profesorado de educación física debe ser consciente de que cada estudiante es diferente y, por tanto, puede tener unas necesidades distintas. Por este motivo, resulta necesario adecuar el proceso de enseñanza-aprendizaje a sus características motrices, cognitivas y lingüísticas a fin de optimizar su aprendizaje en las múltiples vertientes que se trabajan. Además, pueden utilizarse diferentes recursos didácticos como ahora las estrategias de andamiaje o la evaluación a lo largo de todo el proceso, dando voz también al estudiantado (Casal, 2016; Ramos y Ruiz-Omeñaca, 2011).

- Facilitar la mejora continua en la corrección en el uso de la lengua. Pese a primar la comunicación sobre la corrección, el profesorado de educación física también debería tratar de facilitar la mejora de la segunda en su alumnado. Para ello, en determinados momentos, puede ser adecuado el uso de diferentes técnicas de feedback (De Graaff et al., 2007) o incluir en posibles procesos de coevaluación y autoevaluación, además de aquellos aspectos propios de la educación física, alguna cuestión referente al uso de la lengua.

En suma, la incorporación del enfoque AICLE no será tarea fácil para el profesorado, quien, como se ha descrito, debe hacer frente a diversos retos y adquirir una serie de competencias. Sin embargo, si se pretende optimizar los procesos de enseñanza-aprendizaje (incluyan o no AICLE), la formación permanente es una oportunidad de generar una evolución del proceso a fin de proporcionar el mejor aprendizaje posible al alumnado; lo que en última instancia constituye uno de los fines de la educación (Pallarés et al., 2018).

\subsubsection{El rol del alumnado en educación fisica mediante AICLE}

En contraposición a la tradicional concepción del binomio enseñanza-aprendizaje, en una educación física mediante AICLE el aprendizaje adquiere un rol preponderante, de forma que el alumnado se ubica en el centro del proceso. Por este motivo, el presente punto afronta 
concretamente el papel que el estudiantado desempeña, puesto que esta innovación conlleva un cambio sustancial en el proceso educativo que debe ser atendido reflexivamente. Como ya se ha adelantado, la incorporación de AICLE otorga relevancia al papel de la lengua en la materia que lo adopta, situación que no sucede sin dicho enfoque. Esta introducción de la lengua puede generar diversidad de posicionamientos en el alumnado. Por ejemplo, siguiendo a Fernández-Barrionuevo (2017), aquellos discentes que menos atraídos estén por la educación física, podrían ver incrementada su motivación hacia dicha asignatura como consecuencia de la incorporación de AICLE. Sin embargo, también puede darse el caso contrario, tal y como exponen Ramos y Ruiz-Omeñaca (2011), quienes señalan que el nuevo "idioma puede transformarse involuntariamente en un elemento extraño que afecte negativamente al interés de los alumnos por la Educación Física" (p. 158).

El cambio metodológico que comporta la implementación de AICLE lleva a los equipos docentes, necesariamente, a generar e incrementar oportunidades de exposición comunicativa por parte del alumnado (Clancy y Hruska, 2005; Coral y Lleixà, 2014; Zagalaz, Molero, Cachón y Gutiérrez, 2012). En este sentido, Clancy y Hruska (2005) exponen diferentes escenarios que pueden darse en las sesiones de educación física a fin de generar situaciones comunicativas diferenciándolas de acuerdo a las cuatro habilidades lingüísticas (Figura 13). 


\section{Comprensión oral}

- Escuchar al docente o a los compañeros explicaciones relacionadas con una actividad en concreto antes de su realización.

-Escuchar las aportaciones, sensaciones, opiniones de los compañeros antes, durante y/o al final de la clase.

- Escuchar fragmentos de videos, documentales y/o películas relacionados con el contenido que se aborde.

\section{Expresión oral}

- Expresar opiniones, experiencias, conocimientos acerca del contenido que se esté tratando.

- Explicar actividades.

- Aportar variantes y nuevas ideas relacionado con lo que se esté haciendo.

- Verbalizar y repetir términos específicos al tiempo que se está llevando a cabo la ejecución.

- Utilizar el lenguaje funcional de cortesía para saludar, despedirse, pedir algo, animar a los compañeros...

\section{Comprensión escrita}

- Leer fichas/tarjetas y ejecutar lo que se pide en las mismas.

-Leer pequeños artículos, textos, documentos...

\section{Expresión escrita}

- Describir y explicar diferentes actividades.

- Observar la ejecución de los compañeros y describirla con detalle.

-Escribir las sensaciones tras la realización de actividades.

Figura 13. Situaciones comunicativas en educación física mediante AICLE

Fuente: Adaptado de Clancy y Hruska (2005).

\subsubsection{Investigación en educación física mediante AICLE}

A pesar de que actualmente un considerable número de centros educativos españoles está desarrollando la educación física en una lengua adicional (Baena-Extremera y GraneroGallegos, 2015; Coral y Lleixà, 2018), la investigación en este campo aún se encuentra en una fase incipiente (Devos, 2016). Tal y como puede percibirse a través de la revisión bibliográfica que hemos desarrollado y que presentamos más adelante como una de las publicaciones que conforman el compendio del presente trabajo, durante los últimos años el estudio empírico de la educación física mediante AICLE se ha visto incrementado tanto en España como en otros países. Teniendo en cuenta que nuestro marco de acción es el contexto 
español, el presente punto complementa el trabajo publicado a través de un sucinto recorrido sobre tres de las tesis doctorales presentadas en este país en los últimos años.

Una tesis pionera en el campo de estudio de la educación física mediante AICLE fue la de Coral (2012), titulada "Aprenentatge integrat de continguts d'educació física i llengua anglesa: Educació física al cicle superior de primària". Esta investigación trata de mostrar un planteamiento holístico de la educación, focalizada, eso sí, en la educación física, aportando soluciones a los retos que en aquel momento comenzaban a vislumbrarse y que hoy día no han hecho más que acrecentarse, tal y como se ha comentado con anterioridad. Este autor formula cuatro objetivos:

- Determinar las características de las tareas de educación física que favorecen el aprendizaje integrado.

- Identificar las estrategias didácticas específicas del programa de educación física AICLE que mejoran la comunicación oral.

- Comprobar que con la aplicación del programa de educación física AICLE se produce una mejora significativa en la comprensión y expresión oral en lengua inglesa.

- Identificar las tareas integradas de educación física y lengua inglesa con más interés para el alumnado.

Para tratar de alcanzar estos objetivos desarrolla un proceso de investigación-acción compuesto por tres ciclos en el cual implementa un programa de educación física mediante AICLE con un curso de quinto de primaria. Tras desarrollar tres niveles de análisis de los datos obtenidos, el autor señala que ha podido mejorar el programa, la acción docente y dar respuesta a los objetivos planteados. Con respecto al primer objetivo indica que las tareas en educación física mediante AICLE deben ser equilibradas y eficientes cumpliendo cinco requisitos: ser motivantes, incorporar actividad física, fomentar la interacción verbal, desarrollar el razonamiento y ser socializadoras. En lo concerniente al segundo objetivo, asevera que las agrupaciones de estructura cooperativa combinadas con la técnica de los líderes es la estrategia organizativa que más favorece la comunicación oral. En relación al tercer objetivo señala que su investigación ha aportado evidencias de una mejora significativa en la comprensión y la expresión oral. Por último, con respecto al cuarto objetivo, determina que las tareas que más gustan al alumnado son aquellas equilibradas que incorporan la lengua 
y la acción motriz sin ralentizar la dinámica del juego o actividad. Además, a tenor de todos sus resultados concluye que la educación física es una forma excelente de mejorar la motricidad, la lengua, la salud y la convivencia al mismo tiempo.

Por orden cronológico, otra tesis de referencia fue la de Hernando (2015), cuyo título es “Caracterización de los aspectos metodológicos empleados en la enseñanza de la materia de educación física en los centros públicos de secundaria con sección bilingüe en inglés de Castilla y León". Este trabajo tenía por objetivo caracterizar la metodología empleada en la enseñanza integrada de educación física e inglés en la Comunidad de Castilla y León. La autora empleó una metodología mixta, desarrollando una primera fase cuantitativa consistente en analizar la percepción de los coordinadores de los programas bilingües y el profesorado de educación física bilingüe con respecto a la implantación del bilingüismo y la metodología aplicada, y una segunda cualitativa, en la que llevó a cabo el estudio de un caso.

De los resultados de este estudio se desprende que a pesar de que el nivel de implantación del bilingüismo difiere entre centros, en general el profesorado de educación física tiene una percepción positiva sobre las posibilidades que la asignatura puede ofrecer al aprendizaje de una lengua adicional. Sin embargo, se observa que la motivación e implicación hacia la materia no se manifiesta del mismo modo en todos los cursos. Por otro lado, se observa que existe relación entre la formación en idiomas y la metodología de los docentes. Asimismo, se señala que las habilidades orales son las destrezas lingüísticas más utilizadas en educación física bilingüe.

Por último, Fernández-Barrionuevo (2017) presentó la tesis titulada “Generación de la motivación en AICLE entre los dominios de educación física y aprendizaje en lengua extranjera en centros bilingües andaluces", cuyo objetivo principal era, en un contexto de educación física mediante AICLE, analizar la generalización de la motivación y satisfacción intrínseca entre la educación física y el aprendizaje en lengua extranjera, así como estudiar cómo esta generalización era predicha por la percepción del clima de apoyo a la autonomía, y cómo predecía la disposición a comunicarse en lengua extranjera y las calificaciones en lengua extranjera.

Así, primero, el autor tradujo, adaptó y validó los instrumentos de medida LLOS-IEA, ISCLE y WTC que, posteriormente, empleó para afrontar el objetivo del estudio mediante 
análisis de correlaciones, modelos lineales de regresión multinivel y modelos de ecuaciones estructurales teniendo en cuenta factores como el sexo o la edad. A partir de los resultados obtenidos el autor concluye, por un lado, que los instrumentos traducidos y adaptados son válidos y fiables y, por otro, que existe cierto grado de generalización de la motivación en los dominios de la educación física y el aprendizaje en una lengua extranjera. En este sentido señala (1) que el apoyo de la autonomía es un predictor de la motivación autodeterminada en lengua extranjera y en educación física, (2) que la motivación autodeterminada en el aprendizaje en lengua extranjera se establece como predictor de la disposición a comunicarse en lengua extranjera en las habilidades de expresión oral y escrita, así como en la comprensión oral; y (3) que la disposición a comunicarse en lengua extranjera para la comprensión lectora y expresión escrita predicen la nota en el área de lengua extranjera.

De este modo, puede observarse cómo estos estudios han aportado valiosa información al campo de la educación física mediante AICLE en nuestro país. Sin embargo, aún quedan numerosos cabos sueltos que conviene investigar a fin de aportar nuevos conocimientos empíricos sobre la temática. Hoy en día, parece necesario continuar investigando para comprender las situaciones que subyacen a la incorporación del enfoque AICLE en la asignatura de educación física. Así, el trabajo que aquí se presenta pretende contribuir aportando nuevos enfoques y respuestas. 



\section{El proyecto de investigación}

El presente apartado aborda el proyecto de investigación llevado a cabo en base al marco teórico expuesto hasta el momento. De este modo, tras justificar brevemente la necesidad de realizar esta investigación, se presentan los diferentes manuscritos que conforman el compendio de publicaciones de la tesis.

La introducción de AICLE en los centros educativos puede considerarse como una acción de innovación educativa. Sin embargo, dicha innovación no debería ser equiparable a la socorrida metáfora de los fuegos artificiales. A menudo, la innovación llega a las escuelas con gran poder y esplendor para irse diluyendo poco a poco hasta volver a la misma situación de partida. Así, el cambio en educación no debería ser efímero (Pallarés et al., 2018), bien al contrario. Aunque a menudo sea considerado caótico, intenso y laborioso (Fullan, 1999), es necesario consolidarlo, para lo que resulta necesario articular procedimientos de revisión, sustentados en la evidencia científica educativa y de la didáctica, que permitan ir adaptando y mejorando constantemente las prácticas educativas (Julián et al., 2016). De este modo, la racionalidad que rige el presente trabajo se sustenta en la idea de que la investigación educativa debe ser práctica, es decir, basada en y dirigida a la praxis educativa (Escámez, 2003), dado que "el reto que debe orientar todo trabajo de investigación empírica en el campo de la educación es mejorar la práctica educativa” (De Miguel, 2015, p. 282).

Como se ha expuesto en el marco teórico, AICLE es una realidad en el panorama educativo español (Fortanet, 2013; Pérez-Cañado, 2018). Sin embargo, su irrupción en las aulas ha sido fruto de una imposición normativa, sin haber sido su uso refutado empíricamente, invirtiendo el habitual procedimiento en cuestiones relativas a la innovación educativa, según el cual la revisión empírica debería preceder a la exigencia legal (Pallarés et al., 2018). Por este motivo, es necesario articular investigaciones encaminadas a estudiar la pertinencia o no del uso de AICLE. Es cierto que, de acuerdo con buena parte de la literatura, todo parece indicar que los programas AICLE en España se dirigen en la dirección adecuada, no obstante, queda mucho camino por recorrer (Ruiz de Zarobe y Lagasabaster, 2010).

La investigación sobre el enfoque AICLE se ha visto incrementada considerablemente durante los últimos años, sin embargo, la mayoría de estos estudios se centran en aspectos lingüísticos (Doiz, Lasagabaster y Sierra, 2014; Evnitskaya y Morton, 2011; Heras y 
Lagasabaster, 2015; Méndez-García, 2013; Moliner, 2014; Moliner y Fernández, 2013). Las investigaciones desarrolladas hasta el momento se han focalizado en aspectos como la adquisición de la lengua extranjera y la lengua madre o la evaluación de los programas llevados a cabo (Pérez-Cañado, 2018), dejando las cuestiones relativas al área de contenido que acoge dicho enfoque pedagógico ciertamente desatendido. Además, en lo relativo a las asignaturas de contenido, Pérez-Cañado (2018) indica que las tres áreas que más investigaciones han aglutinado son las matemáticas, la geografía y las ciencias naturales. De este modo, parece pertinente abordar el uso de AICLE en otras materias, como ahora la educación física.

En esta dirección se dirige el presente trabajo, que tiene como finalidad tratar de dar respuesta a un objetivo general que se concreta en: comprender cómo se desarrolla una práctica AICLE en educación física y reconocer las percepciones de los agentes implicados a fin de conocer posibles flancos de mejora y analizar sus efectos sobre la asignatura. Para abordar dicho objetivo pueden diferenciarse tres fases:

- Fase 1. Establecimiento del marco teórico sobre educación física vehiculada mediante un idioma extranjero.

- Fase 2. Estudio de las percepciones sobre la aplicación de AICLE en educación física por parte de los agentes implicados: profesorado y alumnado.

- Fase 3. Análisis del efecto generado por AICLE sobre los niveles de actividad física desempeñados en el área de educación física.

Cada una de las fases se corresponde con uno de los objetivos de investigación expuestos en el segundo capítulo, y cada uno de dichos objetivos se ve desarrollado mediante dos de las publicaciones que conforman el compendio que se presenta. A continuación, pasamos a justificar brevemente cada uno de estos objetivos para, seguidamente, mostrar los textos que tratan de darles respuesta.

\subsection{Establecimiento del marco teórico}

Este primer subapartado se corresponde con la primera fase del proyecto y se encamina a dar respuesta al primer objetivo de investigación: 
- O.1. "Averiguar cuál es el estado de la cuestión en el campo de la educación física mediante el enfoque AICLE”

De este modo, se pretende realizar un primer acercamiento a la realidad del contexto en el que se desarrolla el estudio que permitirá abordar las siguientes fases de la investigación con un mayor conocimiento de causa sobre la situación concreta de la educación física mediante AICLE. En primer lugar, se describen las características propias del enfoque pedagógico aplicado, a modo de ejemplo, desde la educación física y, posteriormente, se presenta una propuesta de innovación metodológica concreta mostrando los pasos seguidos a partir una experiencia práctica; respondiendo así a la primera de las dos vertientes del Objetivo 1:

- O.1.1. "Determinar cuál es el marco teórico particular de la educación física mediante AICLE y concretar sus posibilidades de aplicación.”

Con este manuscrito se presenta la utilización de AICLE desde el área de educación física como una posible fórmula de innovación educativa que ayude a adaptar las prácticas escolares a la realidad social circundante a la vez que se apuesta por un aprendizaje más global e integrado. Para ello, tras presentar la conceptualización del enfoque pedagógico y concretar algunos de sus conceptos básicos, se aborda su implementación concreta desde el área de educación física. Seguidamente se detallan los objetivos perseguidos a través de dicha innovación y finalmente se exponen los diferentes pasos a seguir para poder desarrollarla. Mediante este texto se pretende explorar la conexión entre teoría y práctica, con objeto de acercar el uso de AICLE al profesorado en activo para facilitar su puesta en práctica de manera coherente. 


\section{MANUSCRITO 1}

TÍTUlo:

Aprendizaje integrado de contenidos y lengua extranjera. Educación Física y Lengua

Inglesa

AUTORES:

Celina Salvador García, Òscar Chiva Bartoll y María Noelia Ruiz Madrid

FUENTE:

En O. Chiva y M. Martí (Coord.), Métodos pedagógicos activos y globalizadores.

Editorial Graó. 


\section{Aprendizaje integrado de contenidos y lengua extranjera Educación Física y Lengua Inglesa}

Celina Salvador García, Òscar Chiva Bartoll y María Noelia Ruiz Madrid

\section{Introducción}

El presente capítulo muestra una propuesta de innovación metodológica a través de la metodología del Aprendizaje Integrado de Contenidos y Lengua Extranjera (AICLE). En particular se toma como ejemplo el caso de la educación física (EF) y el inglés, mostrando los pasos seguidos a partir una experiencia práctica llevada a cabo en quinto curso de primaria. Los rasgos genéricos que la constituyen, sin embargo, podrían ser extrapolados perfectamente a cualquier otra etapa del sistema educativo u otras materias del currículo. La simbiosis generada de la unión entre EF y el aprendizaje de una lengua queda patente a lo largo de este capítulo, y es que las características de una y otra encajan perfectamente y crean un escenario en el que el alumnado puede, además, desarrollar múltiples competencias, así como su pensamiento crítico.

La globalización y los avances en las nuevas tecnologías permiten que hoy en día la comunicación entre dos personas que se encuentren en cualquier lugar del planeta sea factible e incluso sencilla. Sin embargo, aunque disponemos de las herramientas para poder comunicarnos, para posibilitar un proceso de comunicación eficaz es también necesario que los interlocutores compartan un sistema comunicativo común. Es aquí donde se cimienta la relevancia que ha adquirido hoy en día el aprendizaje de lenguas.

Mediante el desarrollo de AICLE en EF queremos adaptarnos a la situación actual, en la que ser competente en diversos idiomas es esencial para comprender y ser partícipes de la riqueza e incesante intercambio de conocimientos entre culturas. Aunque la aplicación de este método pedagógico puede aplicarse en otras áreas del currículo, desde aquí apostamos por el ejemplo de la EF por las características propias de dicha materia, ya que estas la convierten en un escenario idóneo para el desarrollo lingüístico (Coral, 2013; Ramos y Ruiz-Omeñaca, 2011; Zagalaz, Molero y Cachón, 2012). 
A través del uso de la metodología AICLE en EF se pretende dejar atrás la concepción tradicionalista de escuela en la que cada materia es un compartimiento estanco y no se ve relacionada con el resto, puesto que mediante esta propuesta lengua y EF van de la mano. De hecho, sería idóneo que los docentes de lengua extranjera colaboraran con los de EF (o el área concreta de aplicación en cada caso) en la preparación de este tipo de experiencias, para ayudarse mutuamente y trabajar en coherencia desde ambas materias. Además, mediante esta innovación se aspira a aumentar el tiempo que los alumnos y alumnas están expuestos a otro idioma, habitualmente extranjero, ya que para aprender una lengua cuanto más tiempo y práctica mejor. Asimismo, queremos aprovechar las peculiaridades de la EF, que la hacen idónea para el aprendizaje lingüístico, ya que durante nuestras sesiones se generan situaciones de comunicación reales, alejadas del aula y más cercanas a la vida de los alumnos fuera de la escuela. En este sentido, la EF posee una idiosincrasia propia y posibilita una gran variedad de organizaciones que la diferencian del resto de las materias a la hora de facilitar el desarrollo lingüístico.

Del mismo modo, en la innovación que planteamos apostamos por formar alumnos competentes y críticos, es decir, ciudadanos preparados para afrontar el mañana con autonomía, que sean capaces de comunicarse en una lengua adicional en situaciones diversas. Por esta razón otorgamos un planteamiento crítico a nuestra experiencia sirviéndonos de determinados principios afines a la pedagogía crítica. Así se pretende dar respuesta a las necesidades del mundo del siglo XXI, un mundo globalizado en el que las lenguas son indispensables a la hora de formar ciudadanos críticos, preparados para el futuro, así como capaces de pensar y entender otras realidades y puntos de vista.

\section{Conceptualización del AICLE}

Para aquellos que no hayan tenido ningún contacto previo con el enfoque pedagógico AICLE, a continuación se recogen algunas consideraciones básicas sobre la teoría elemental que lo sustenta. AICLE es una metodología que ha ido ganando seguidores en diferentes países especialmente a lo largo de los últimos años (Meyer, 2010). Esto no es algo que deba extrañarnos, puesto que concuerda perfectamente con los enfoques educativos innovadores y que facilitan el aprendizaje de lenguas propuestos desde el Consejo de Europa; que quedan plasmados, por ejemplo, en el Marco Común Europeo de Referencia para las Lenguas. 
AICLE hace referencia a acciones educativas en las que se parte del contenido de una materia no lingüística para promover y desarrollar no solo esta área, sino también la lengua, que en pocas ocasiones será la lengua madre de los estudiantes. En palabras de Marsh (2012), uno de los creadores de este concepto, AICLE queda definido como «un enfoque educativo dual a través del cual se hace uso de una lengua adicional para el aprendizaje y enseñanza de contenidos, y que tiene como objetivo promover el dominio tanto de la lengua como del contenido» (p.425).

Tradicionalmente la enseñanza-aprendizaje de lenguas se ha basado en la gramática, en torno a la cual giraba todo el aprendizaje. Sin embargo, desde una perspectiva AICLE todo el aprendizaje se centra en el contenido no lingüístico, que en nuestro caso es el propio de la EF. Aunque la EF es lo que le da sentido a todo y lo que prima en estas prácticas educativas, deben llevarse a cabo actividades que permitan desarrollar las cuatro habilidades lingüísticas (comprensión oral y escrita, y expresión oral y escrita) y el vocabulario. Por lo tanto la lengua adquiere una mayor relevancia y los docentes debemos ser muy conscientes de cómo la introducimos en las sesiones. Teniendo esto en cuenta, se puede afirmar que AICLE concuerda con las teorías sobre el aprendizaje de lenguas actuales, puesto que se apoya en una perspectiva ecléctica que otorga relevancia tanto al significado como a la forma (Villanueva, 2002). Esta es una de las potencialidades que además facilita la EF, ya que genera situaciones en las que la comunicación es real y los alumnos quieren comunicarse y entenderse.

Coyle, Hood y Marsh (2010) exponen que para poder sacar el máximo provecho de las prácticas AICLE los docentes deben ser capaces de adaptar el nivel lingüístico a las capacidades de los estudiantes, por lo que la planificación se convierte en una fase esencial. Asimismo, determinan que las prácticas AICLE deben poder integrar de forma natural los aspectos lingüísticos dentro del contenido del área. De este modo, una propuesta basada en AICLE deberá tener objetivos referentes tanto a la materia en cuestión como a la lengua objeto. Lo que se pretende mediante la lengua es acceder al contenido de la materia, es decir, favorecer la comunicación que dé acceso al aprendizaje. De esta manera, los objetivos lingüísticos deberán estar más relacionados con las competencias lingüísticas que con la gramática o el léxico. 
La puesta en marcha de una práctica AICLE debe tener en cuenta cuatro principios básicos (Marsh, 2006) que son Contenido, Comunicación, Cognición y Cultura; o las 4Cs. Mediante ellas los docentes encuentran un marco teórico que les ayuda a planificar sus propuestas educativas y a diseñar sus materiales (Meyer, 2010). Por otro lado, autores como Coyle, Hood y Marsh (2010) han vinculado la Taxonomía revisada de Bloom (Anderson et al., 2001) a AICLE, ya que también es una herramienta muy útil. Al respecto conviene apuntar brevemente que esta nos ayuda a determinar el nivel de exigencia cognitiva a la que los alumnos deben enfrentarse. Dicha taxonomía divide sus niveles en LOTS y HOTS de manera que resulta más sencillo adaptar el nivel de demanda cognitiva a las características de nuestros estudiantes (Coral, 2012).

En suma, AICLE implica utilizar un área no lingüística para, al mismo tiempo que se trabaja esta, promover el desarrollo de la lengua. Para ello, debemos adaptar nuestras sesiones con el fin de otorgar la relevancia pertinente al lenguaje, generar situaciones comunicativas significativas y lo más reales posible en las que aparezcan las $4 C s \mathrm{y}$, además, adaptar el nivel de demanda cognitiva y lingüística a nuestros alumnos.

Debido a su doble objetivo de aprendizaje, el de la materia particular y el lingüístico, AICLE no se considera como algo específico de la enseñanza de lenguas ni como algo específico de un área no lingüística, puesto que se trata de una combinación de ambos. En ningún caso implica traducir las sesiones al idioma objeto de aprendizaje. De hecho, para poder optimizar su uso, el material del área no lingüística debe ser adaptado otorgándole una mayor relevancia a la lengua, favoreciendo el aprendizaje de la misma sin olvidar los contenidos propios de la EF. En esta adaptación, dependiendo del nivel lingüístico de los estudiantes y el contexto de la práctica, el uso de la lengua objeto puede aumentar o disminuir con el objetivo de optimizar el aprendizaje del alumnado, pero esto debe hacerse de manera consciente (Lasagabaster, 2013).

\section{Conceptos básicos}

Las 4 Cs

Un concepto de considerable relevancia en AICLE es el de las 4Cs. En el marco de la metodología AICLE las 4Cs son los cuatro pilares básicos sobre los que esta se sustenta 
(Marsh, 2006). Cada “c" se corresponde con: contenido, comunicación, cognición y cultura. De hecho, autores como Kilmova (2012) afirman que cada uno de estos cuatro elementos debería verse incluido en cualquier programación basada en AICLE. Asimismo, gracias a ellos los docentes que implementan AICLE encuentran un marco teórico y metodológico mediante el cual pueden guiarse a la hora de planificar sus propuestas educativas y preparar sus materiales didácticos.

El contenido hace referencia al área no lingüística puesto que será su currículo el eje sobre el que girará toda la acción educativa. La comunicación es el hecho de aprender una lengua a la vez que esta misma se utiliza para aprender un contenido en particular, es decir, aprender un idioma mientras este se está usando. La cognición está vinculada con la formación de conceptos, la comprensión y el lenguaje, por ello desde la perspectiva AICLE se expone que se debe facilitar al alumnado el poder crear sus propias interpretaciones sobre el contenido. Por último, la cultura saca a relucir la importancia de este aspecto en el aprendizaje de lenguas, puesto que resulta un factor clave a la hora de ser capaces de comunicarnos. En conclusión, cada una de las $4 C s$ debe aparecer en una programación basada en AICLE para favorecer el aprendizaje lingüístico además del de la propia materia, en nuestro caso, la EF.

Lots y Hots

De acuerdo con la Taxonomía Revisada de Bloom (Anderson et al., 2001), que propone seis procesos de pensamiento diferentes, los LOTS (lower order thinking skills) son los tres primeros niveles, que requieren una demanda cognitiva menor; y los HOTS (higher order thinking skills) son los otros tres, que implican unas habilidades cognitivas de orden más elevado. En la Figura 1 se muestran los diferentes procesos propuestos por esta taxonomía y cómo quedan estos divididos en LOTS y HOTS. 


\begin{tabular}{|c|}
\hline CREAR \\
\hline EVALUAR \\
\hline ANALIZAR \\
\hline APLICAR \\
\hline ENTENDER \\
\hline RECORDAR \\
\hline
\end{tabular}

Figura 1. Taxonomía revisada de Bloom. Fuente: Adaptada de Ahmed, Anwar, Wajahat, Edriss y Abdurahen, 2014, p. 12.

Los conceptos de LOTS y HOTS son relevantes en el campo de AICLE puesto que no conlleva la misma dificultad cognitiva pedir a los estudiantes que recuerden o entiendan un diálogo o una serie de palabras de vocabulario, que pedirles que sean ellos los que creen este diálogo. Como docentes debemos adaptarnos a los diferentes niveles, características y posibilidades de nuestros alumnos y alumnas y, por ello, resulta esencial hacer una buena elección del tipo de demandas al que se van a ver expuestos.

\section{Andamiaje lingüístico}

Un último concepto esencial en AICLE que abordamos antes de continuar con el capítulo es el de "andamiaje lingüístico". El término andamiaje, en educación, alude a una metáfora utilizada por Jerome Bruner en diversas de sus obras. Con ella se hace referencia a las ayudas recibidas por un aprendiz durante un proceso de enseñanza-aprendizaje. El maestro debe ofrecer las ayudas necesarias (andamio) para que dicho aprendiz pueda ir progresando en su aprendizaje. A la vez que el alumnado va mejorando y aprendiendo, estas ayudas van retirándose paulatinamente hasta que es capaz de desarrollar la actividad o resolver el problema de forma autónoma.

Cuando nos referimos a un andamiaje lingüístico simplemente hay que aplicar esto a la lengua. Por lo tanto, el andamiaje lingüístico son las diferentes ayudas a nivel de lengua que un discente recibe durante su aprendizaje y que facilitarán el uso de un idioma hasta que sea capaz de comprenderlo y/o expresarse por sí mismo. Algunos ejemplos de estrategias de andamiaje lingüístico son las repeticiones, la simplificación de la lengua, la construcción de esquemas, la utilización de claves visuales, el aporte de expresiones o ideas, la utilización de 
reformulaciones, etc. Mediante ellas lo que se pretende es que los estudiantes se sientan cómodos y capaces de utilizar una lengua que no dominan inicialmente, favoreciendo un clima óptimo para el desarrollo lingüístico.

\section{AICLE en educación física}

El método pedagógico de AICLE está en proceso de expansión y, tanto en España como en otros lugares del mundo, cada vez son más los centros educativos que apuestan por él. En cuanto a AICLE en el área de EF, su difusión está viéndose aumentada y en los últimos años son diversos los artículos y propuestas publicadas en un intento de fomentar su desarrollo. Pese a que los estudios e investigaciones sobre los efectos de llevar a cabo una práctica de AICLE en el área de EF aún no son demasiado cuantiosos, sí queremos hacer mención a aquellos que por sus características o contenidos más nos han ayudado a fundamentar nuestra experiencia.

En España, uno de los estudios de mayor relevancia en el campo de la EF mediante AICLE es el realizado por Coral (2012), que dirigió su tesis doctoral hacia el análisis y puesta en marcha de este método pedagógico. Englobada dentro de dicho estudio se encuentra una línea de investigación en la que los autores tratan de identificar, por un lado, las características de las tareas que resultan más adecuadas en un marco de AICLE; y por otro, qué tareas resultan más interesantes para el alumnado (Coral y Lleixà, 2013). En cuanto al tipo de tareas más pertinentes en un contexto de AICLE, los autores concluyen que son aquellas de tipo cooperativo y en las que el lenguaje es incorporado de manera intencional dentro del juego. Asimismo, señalan la necesidad de incorporar andamios lingüísticos que faciliten el uso de la lengua extranjera.

Todo ello es sido tenido en cuenta a la hora de planificar nuestra experiencia y, de hecho, la incorporación de andamios lingüísticos en forma de ayudas visuales es uno de sus puntos fuertes, ya que facilita en gran medida el uso del inglés por parte del alumnado. También nos servimos de este estudio para tratar de evitar tareas con una excesiva exigencia lingüística o en las que el lenguaje esté descontextualizado, puesto que siguiendo lo expuesto, la exigencia motriz, lingüística, cognitiva y el desarrollo personal y/o social deben ser equilibrados (Coral y Lleixà, 2013). 
Otro trabajo del que bebe esta aportación es el de Chiva, Isidori y Fazio (2015), en el que se propone el uso de la metodología AICLE en el área de EF sustentándose en los principios de la pedagogía crítica. Estos autores defienden el valor de involucrar la perspectiva crítica y señalan que al fomentar el uso de la capacidad cognitiva del alumnado se le está proponiendo el uso de la lengua en contextos reales, similares a los que podría encontrarse fuera de la escuela. Con el objetivo de proponer situaciones lo más reales posibles y que favorezcan la formación de ciudadanos críticos, nuestra propuesta trata también de aprovechar los beneficios que se extraen de la simbiosis entre AICLE y pedagogía crítica en EF.

Conviene recordar que la metodología AICLE implica activamente la cognición, por lo que nos parece de sumo interés aprovecharnos de este hecho para trabajar aspectos que favorecen la emancipación de los estudiantes, fomentando así su autonomía y sentido crítico. Al mismo tiempo tenemos muy en cuenta que, tanto en el marco de AICLE como en el de la pedagogía crítica, el proceso es tanto o más importante que el resultado (Chiva, Isidori y Fazio, 2015). De esta manera, la experiencia que explicamos da relevancia a los diferentes momentos del proceso de enseñanza-aprendizaje.

Por su parte, González, Hernández, Pastor y Villar (2013) llevaron a cabo una experiencia que, al igual que la que aquí se ejemplifica, se desarrolló a nivel de primaria. En su caso, han trabajado con dos grupos diferentes unos mismos contenidos. Mientras que con el grupo control se utilizó una metodología más tradicional y reproductiva, el grupo experimental se benefició de un aprendizaje sustentado en el constructivismo y que perseguía ser más significativo para el alumnado. Tras llevar a cabo una unidad didáctica de floorball con ambos grupos, los autores señalan una mejora en el grupo experimental, tanto en lo referido a los resultados académicos obtenidos, como en la motivación de los estudiantes hacia las materias de EF e Inglés. Por este motivo concluyen que, teniendo en cuenta el rendimiento de los alumnos y alumnas, su experiencia fue positiva y satisfactoria.

Esta experiencia se erigió como una guía sobre la que orientar nuestra acción. A tenor de los resultados expuestos por González, Hernández, Pastor et al, (2013), nosotros procuramos en todo momento programar las sesiones de manera que el aprendizaje sea significativo y se sustente en las bases del socioconstructivismo. Además, también percibimos con gran interés 
la propuesta de involucrar simultáneamente la competencia comunicativa con todas las demás, algo que procuramos incorporar nuestra experiencia.

En el marco universitario, Figueras, Flores y González-Davíes (2011) explican su experiencia con alumnado de magisterio, en la que dos asignaturas de EF fueron las escogidas para implementar el método pedagógico AICLE. Los autores señalan que desde un principio tuvieron claro que el uso de AICLE iba a comportar un cambio en la metodología utilizada y optaron por la utilización de estrategias de trabajo cooperativo en las que los alumnos fueran los protagonistas. A partir de los resultados obtenidos mediante grupos de discusión y un diario de clase, Figueras, Flores y González-Davíes señalan que tanto la seguridad con respecto al uso de la lengua inglesa como su aprendizaje se vieron beneficiados. Pese a observar una inseguridad inicial con respecto al uso de este idioma, las diferentes opciones metodológicas utilizadas, así como el hecho de que la lengua no iba a ser evaluada, contribuyeron a la desaparición paulatina de ese miedo. Además, destacan que gracias a tener que utilizar el inglés para comunicarse los estudiantes tenían una mayor necesidad de cooperar entre ellos.

Estos autores también comentan que según la apreciación de los participantes el contenido de la asignatura no se vio afectado. Sin embargo, exponen que deberían haber sido utilizadas más estrategias para favorecer la lengua escrita y la producción oral, puesto que en su mayoría se dirigían a facilitar la comprensión. Estas cuestiones fueron tenidas en cuenta a la hora de orientar nuestros propios planteamientos, ya que nosotros pretendemos trabajar las cuatro destrezas lingüísticas. Por ello creamos múltiples ayudas visuales cuyo objetivo radica tanto en ayudar en la comprensión como en la producción, y además proponemos incorporar actividades que involucran la escritura mediante un blog de clase.

En suma, sustrayendo lo más significativo de estas aportaciones, el presente capítulo subraya algunas orientaciones prácticas con las que facilitar una aproximación plausible al método AICLE. En particular destacamos la necesidad de utilizar un lenguaje contextualizado y significativo para los estudiantes, de manera que vean facilitado su aprendizaje mediante diferentes tipos de andamios lingüísticos. Asimismo, la práctica debería estar impregnada por un cariz socioconstructivista y crítico que favoreciera la autonomía y emancipación del alumnado. Además, ponemos énfasis en el desarrollo de las diferentes competencias clave 
prestando una especial atención a la comunicativa, a la vez que conviene favorecer situaciones implicando las cuatro destrezas lingüísticas.

\section{Objetivos de la innovación}

Los objetivos de esta propuesta quedan definidos de la siguiente manera:

- Aplicar y optimizar el uso de AICLE en el área de EF.

- Aumentar el tiempo de exposición y práctica del inglés por parte del alumnado.

- Favorecer el aprendizaje de una lengua extranjera como el inglés de manera inherente al proceso de enseñanza-aprendizaje de la EF.

- Formar alumnos competentes a nivel lingüístico y críticos a nivel social.

- Plantear situaciones en las que el uso de la lengua sea contextualizado y significativo.

- Aportar andamios lingüísticos a los alumnos para favorecer su aprendizaje.

- Involucrar características de la pedagogía critica en la propuesta.

- Fomentar el desarrollo de competencias, en especial la comunicativa.

- Proponer situaciones en las que las cuatro destrezas lingüísticas se vean implicadas.

\section{Descripción de la innovación}

En este apartado procedemos a la explicación y esbozo de la innovación propuesta. A partir de nuestra experiencia queremos compartir con los lectores todos aquellos elementos relevantes que permitan mejorar o iniciarse en el uso de AICLE, bien en EF o bien en cualquier otra materia. En primer lugar se ofrece una breve descripción de la innovación, seguidamente se detalla una guía con los pasos necesarios para aplicarla con éxito, recogiendo algunas limitaciones a ser tenidas en cuenta, y, por último, se expondrá en detalle la ejemplificación de nuestra propia experiencia.

La propuesta presentada incumbe al área de EF y, ante todo, debe quedar claro (a riesgo de ser reiterativos) que relacionar EF con inglés no significa traducir las habituales sesiones, sino que la lengua tiene que ser adaptada y tenida en cuenta durante todo el proceso de planificación, desarrollo y evaluación. Mediante el uso de AICLE en EF, a través de la 
propuesta que aquí exponemos, estamos innovando en diferentes sentidos. El primero y principal es la conjunción de dos materias que en el currículo aparecen de manera separada. Al llevar esto a cabo estamos rompiendo con la concepción más tradicionalista de la escuela, en la que cada área es una parcela que no se relaciona con el resto. De este modo facilitamos que los estudiantes perciban el aprendizaje como un todo unificado, favoreciendo una formación integral del individuo.

Además, con la propuesta AICLE también nos estamos adaptando a la situación actual que nos encontramos fuera de las escuelas. Son muchos los docentes que aún reciclan año tras año sus programaciones, cuestión que debería verse modificada. La educación hoy en día no puede ser la misma que hace veinte años, porque si el contexto varía, nuestras prácticas educativas también deben hacerlo con el objetivo de adaptarse y preparar a los estudiantes para su vida fuera de las aulas. De este modo, en un mundo globalizado como el actual, en el que ser capaces de comunicarse en diferentes idiomas ha adquirido tanta relevancia, una propuesta como la que realizamos parece ser una buena forma de proceder.

Asimismo, nuestra propuesta no se conforma con utilizar la metodología AICLE en EF, sino que aspira a ir un poco más lejos. Creemos que preparar a los alumnos para sus vidas fuera de la escuela no es solo ayudarles a conseguir los diferentes objetivos propuestos desde el área de EF o conseguir un cierto dominio de otra lengua. En nuestra opinión, debemos tratar de formar ciudadanos racionales y capaces de reflexionar sobre los diversos temas que conciernen a la sociedad. Por este motivo proponemos insertar a nuestra propuesta AICLE el uso de los principios de la pedagogía crítica con el objetivo de desarrollar sus personalidades, ayudarlos a convertirse en seres autónomos y competentes y promover el uso de valores democráticos (Fraile, 1999; Freire, 1995).

Dar el paso de aplicar prácticas AICLE en EF no es una decisión que pueda tomarse a la ligera. Hay que ser conscientes de que para poder rentabilizar y favorecer el aprendizaje de los alumnos y alumnas se requiere un cierto esfuerzo e inversión de tiempo que, eso sí, muy probablemente se verá recompensado con el resultado final del proceso. Somos conscientes de que en educación no existen recetas mágicas. Sin embargo, a partir de nuestra experiencia queremos compartir una serie de pasos a seguir a la hora de preparar una Unidad Didáctica AICLE para EF. 
A continuación exponemos los pasos que seguimos para programar y llevar a cabo nuestra propia propuesta. Partiendo de los principios de AICLE expuestos por Coyle, Hood y Marsh (2010), los adaptamos al interés particular de optar por una pedagogía lo más crítica posible y los aplicamos al campo de la EF, atendiendo a la situación particular en la que se lleva a cabo la experiencia. Por lo tanto, es de recibo reiterar que lo descrito a continuación no son unas directrices rígidas e inamovibles, sino más bien unas pautas que deben ser adaptadas a cada contexto en particular. Este hecho, a su vez, justifica la posibilidad de extrapolar esta propuesta a otras áreas y niveles educativos.

\section{A. Elección del tema y enfoque del trabajo}

Tal y como el propio nombre indica, AICLE comienza con el contenido propio de la materia a desarrollar, la EF en nuestro caso. Por lo tanto, determinar este contenido es el que nos proponemos como primer paso. Pese a lo sencilla que pueda parecer esta decisión, conviene pensar bien antes de tomarla puesto que no todos los contenidos y enfoques facilitan de igual manera el uso de la lengua por parte de los estudiantes. Por ejemplo, no es lo mismo una sesión en la que se trabaje un contenido desde un enfoque puramente técnico, que otra en la que se aborde ese mismo contenido desde un modelo de diseño curricular deliberativo, ya que presumiblemente en la segunda opción la lengua va a estar mucho más presente.

Una vez elegido el modelo de diseño curricular y el contenido, es momento de determinar los objetivos de la Unidad Didáctica. No debemos olvidar que además de los propios de EF deberíamos proponer también alguno que haga referencia al apartado lingüístico, de manera que tengamos una primera idea de qué queremos que los alumnos hayan trabajado una vez llegados al final del proceso. En este sentido es muy aconsejable llevar a cabo un trabajo conjunto con el docente de lengua extranjera. Asimismo, también este es el momento para seleccionar cómo vamos a involucrar las diferentes competencias y el pensamiento crítico en la propuesta.

\section{B. Preparación de la Unidad Didáctica prestando atención a la lengua}

A continuación seguiremos con la preparación habitual de la Unidad Didáctica y la selección de las actividades, aunque prestando especial atención a la aparición y uso de la lengua. Debemos tener en cuenta que a través del lenguaje es como los discentes deben acceder al 
contenido propio de EF, así que es nuestro cometido como docentes facilitarles esta tarea. Otro aspecto relevante también a la hora de diseñar las actividades es que estas deben proponer situaciones de interacción en las que la participación del alumnado sea primordial, de forma que se fomente la cooperación, colaboración, el trabajo en equipo, el respeto al grupo y a las normas y el compañerismo. Una vez escogidas las actividades echaremos la vista atrás y comprobaremos que lo propuesto es acorde con los objetivos lingüísticos planteados. En caso de que algo no cuadre este es el momento de modificarlo y hacer que todo tenga coherencia y sentido.

\section{Secuenciar la lengua a utilizar}

Seguidamente debemos centrarnos en cómo vamos a realizar la progresión en cuanto al contenido lingüístico. Para ello nos serviremos de la ayuda de las $4 C s$. Del mismo modo que secuenciamos los contenidos de EF para que su aparición sea lógica y coherente, con la lengua debe realizarse el mismo procedimiento, yendo de lo más sencillo a lo más complicado, de estructuras más rígidas a producciones en las que los alumnos tengan mayor libertad para expresarse, o de mayor a menor número de ayudas.

Tras este primer paso en la secuenciación lingüística referida a la "c" de contenido, deberíamos continuar centrándonos en la comunicación. En este caso debemos prestar especial atención y determinar el vocabulario y las estructuras clave que queremos que aparezcan a lo largo de la Unidad Didáctica. Será conveniente reparar en el estilo de enseñanza a utilizar, puesto que cada opción crea un escenario en el que las relaciones sociales entre alumnos y entre alumnos y docente son diversas y, por tanto, también lo será el uso de la lengua (Salvador, Chiva y Fazio, 2016). El maestro debe ser consciente de que en función del estilo de enseñanza empleado las posibilidades, tipos y formas de comunicación presentes pueden variar en gran medida. Por ejemplo, utilizando el estilo del mando directo (propio de los planteamientos técnicos de diseño y programación del currículum) la práctica comunicativa del alumno va a estar muy coartada, ya que prácticamente no se provocarán situaciones en las que tenga la necesidad de expresarse y, por tanto, él sea el emisor. Mediante este estilo, los estudiantes básicamente se dedicarán a reproducir lo que el docente les diga y serán meros receptores de información. Por otra parte, estilos como el divergente (en la línea de los modelos de diseño curricular deliberativos) 
llevados a cabo mediante grupos, promueven considerablemente la comunicación entre los alumnos, viéndose abocados a expresarse, argumentar y elegir para poder interaccionar con el grupo.

De manera simultánea a la anterior "c" hay que poner el punto de mira en la de cognición. Debemos tratar de que nuestras propuestas supongan un reto para los alumnos, y que este, además, esté ligeramente por encima de su nivel inicial, de manera que ni lo superen demasiado fácil ni les resulte excesivamente difícil de alcanzar. De este modo los estudiantes se encontrarán ante un doble desafío, el relacionado con la actividad física o motriz y el afín al lenguaje. Estos dos retos deberían verse vinculados y presentarse como un todo y en una situación lo más real posible.

Además deberemos clarificar qué andamios vamos a necesitar para facilitar el proceso de aprendizaje al alumnado, también en ambos campos. Una posibilidad es apoyarnos en ayudas visuales que sirvan a los estudiantes para poder desenvolverse más sencillamente con la lengua inglesa, puesto que debemos pasar de LOTS a HOTS de manera progresiva (Coyle, Hood y Marsh, 2010). En nuestro caso, en la primera sesión prevalecen acciones como entender o identificar, mientras que en las últimas, comportamientos como dar razones o resolver problemas, adquieren mayor relevancia.

Por último, no podemos olvidar que las cuestiones relacionadas con la "c" de cultura también deben aparecer necesariamente en la Unidad Didáctica. Con cada “ $c$ ", la primera propuesta de actividades puede ir viéndose variada y es que estas deben estar adecuadamente adaptadas a la lengua que pretendemos que aparezca. No debemos tener miedo a modificar nuestras propuestas iniciales si con ello reforzamos la coherencia final de la Unidad Didáctica.

Por otra parte, una opción muy socorrida para facilitar nuestra introducción al AICLE es la de adaptar una Unidad Didáctica que ya tengamos, reformulándola a partir de las premisas de esta nueva metodología. En tal caso deberemos añadir los objetivos lingüísticos y el resto de aspectos referentes a la lengua y las 4Cs que acabamos de comentar, modificar aquello que fuera necesario y pensar y crear los recursos que faciliten el andamiaje lingüístico al alumnado.

\section{Evaluación de la innovación}


Llevar a cabo una propuesta propia de AICLE es todo un logro de por sí, sin embargo no podemos conformarnos con su simple puesta en práctica. En el campo educativo debemos tratar de mejorar siempre, analizar lo sucedido con el objetivo de aprender de lo desarrollado y poder incluso mejorar la acción docente la próxima vez. En este sentido, la evaluación se convierte en un elemento esencial puesto que nos servirá para poder ahondar en nuestra propuesta innovadora y darnos cuenta de qué ha sucedido y cómo podemos optimizar el proceso y sus resultados. Además, debemos cerciorarnos de que ha habido en nuestra experiencia cierta complementariedad y coherencia entre su desarrollo y el diseño inicial planteado.

Puesto que evaluar el proceso es algo que ya hacemos o deberíamos hacer en nuestras prácticas habituales, vamos a enfatizar un poco más en lo concerniente a la lengua. Conviene recordar que la evaluación debe realizarse durante todo el proceso. Además, es necesario ser conscientes en todo momento de las condiciones en que se está llevando a cabo la práctica, las dificultades u obstáculos que nos vamos encontrando en el camino y cómo los afrontamos, así como el grado de satisfacción con lo realizado. Basándonos en Mauri, Coll y Onrubia (2007) exponemos a continuación cuatro aspectos a tener en cuenta para llevar a cabo la evaluación de AICLE en EF.

-Analizar si el diseño y la organización han sido adecuados, es decir, si nos hemos adaptado al contexto educativo en el que nos encontramos.

-Valorar el diseño y desarrollo del mismo teniendo en cuenta si nos hemos adaptado a los conocimientos previos de los estudiantes, si hemos creado retos abordables, si los estudiantes han podido conectar conocimientos previos con los nuevos, y si han dado un uso real a la lengua gracias a haber propuesto actividades en situaciones significativas.

-Percatarnos de si las ayudas que hemos ido ofreciendo han sido adecuadas, es decir, si han sido útiles para facilitar el aprendizaje de todos los alumnos.

-Comprobar si se ha producido un aprendizaje colaborativo y sustentado en el socioconstructivismo que haya servido para que se aprendan los contenidos y que haya favorecido el desarrollo de competencias. 
En nuestro caso nos servimos de un cuestionario que debe ser cumplimentado por el docente al final de la propuesta, otro que completan los estudiantes y un diario de clase redactado por el docente para poder hacer una valoración general del desarrollo de la innovación. Entre otras cuestiones, estos instrumentos nos permiten identificar y conocer las diferencias entre diseño y propuesta. Del mismo modo, también ayudan a valorar los elementos fundamentales de la misma identificando los aspectos susceptibles de modificación y en qué sentido deberían llevarse a cabo los cambios.

\section{Atención a la diversidad}

Cada estudiante es diferente del resto, y ello puede propiciar la modificación de alguna de las actividades, tareas o juegos planteados o de cuestiones relacionadas con el andamiaje lingüístico, por ejemplo. Cada grupo de alumnos es único y es nuestra responsabilidad como docentes permitir que todos los estudiantes puedan participar de la práctica y del aprendizaje, obteniendo el máximo provecho de estos.

Reconociendo la diversidad de niveles presentes en un mismo grupo, y teniendo en cuenta que siguiendo la teoría de las inteligencias múltiples de Gardner (1983) cada alumno puede tener un tipo de inteligencia diferente; creemos conveniente proponer el mayor número posible de actividades grupales basándonos en las teorías de aprendizaje desde un punto de vista socioconstructivista. De esta manera, procuraremos siempre que haya una heterogeneidad dentro del grupo para que los equipos sean los más homogéneos entre sí. Así, alumnos con capacidades diversas podrán colaborar juntos, todos se sentirán incluidos en los juegos y los unos podrán aprender de los otros.

Atendiendo a esta teoría de Gardner, nuestra experiencia nos lleva a proponer escenarios diversos con la finalidad de que todos los tipos de inteligencias tengan su momento de protagonismo. De esta forma, considerando que todos los estudiantes deben beneficiarse de las prácticas propuestas, se procura que existan momentos en los que cada una de las ocho inteligencias sea necesaria.

\section{Posibles limitaciones y dificultades}

Como se ha dicho a lo largo de la presente obra, en educación siempre debemos tratar de ir a mejor. Nosotros, a partir de la experiencia que llevamos a cabo, nos percatamos de una 
serie de limitaciones surgidas en su aplicación. En este apartado detallamos aquellas limitaciones que consideramos más relevantes, así como otras cuestiones orientativas para que los docentes interesados en llevar a cabo una propuesta AICLE puedan adelantarse a las dificultades más previsibles.

En un marco idóneo, una práctica AICLE en EF (o en cualquier otra materia) se desarrollaría con una programación integrada y conjunta con el área de lengua extranjera, de manera que todo el aprendizaje tuviera una mayor significatividad y las dos materias fueran vistas por los estudiantes de una forma aún más interrelacionada. Sin embargo, esto es algo con lo que no siempre se puede contar. Pese a que quizá no toda la programación de una y otra área estén integradas, sí sería conveniente, al menos, tratar de introducir en nuestras sesiones vocabulario que los discentes hayan estado trabajando y conozcan, puesto que ello facilita que se sientan más seguros y motivados.

Otro aspecto a tener en cuenta a la hora de programar es que quizá el ritmo de las sesiones no sea el mismo que en una práctica de EF al uso, especialmente al principio. Con el método AICLE las sesiones suelen ser un poco más lentas de lo habitual puesto que la estructura organizacional es nueva tanto para los estudiantes como para los docentes. Sin embargo, no percibimos esto como algo negativo, simplemente como algo a tener en cuenta y que puede variar dependiendo del grupo ante el que nos encontremos. A nuestro juicio, el resultado de una propuesta será positivo en tanto que los contenidos y objetivos propios de la materia no se vean afectados.

Por otra parte, pese a estar acostumbrados a secuenciar los contenidos de nuestra área, en las sesiones mediante AICLE también deberemos preparar una progresión adecuada de lo lingüístico pasando de LOTS a HOTS adaptándonos a los alumnos y sus diferentes características. Programar dicha cuestión siempre resultará más sencillo si se cuenta con la colaboración del docente de lengua extranjera, puesto que su experiencia en este campo puede resultar de gran ayuda. Además, debemos estar preparados ante una más que posible inhibición inicial de los estudiantes hacia el uso de una lengua extranjera. En este sentido, resulta esencial crear un clima de confianza y respeto.

\section{Ejemplificación}


La experiencia que aquí recogemos como ejemplo para describir la aplicación del AICLE ha sido aplicada en el nivel de quinto curso de primaria. Al tratarse de la primera experiencia AICLE en EF llevada a cabo en ese centro en concreto, planteamos unos objetivos lingüísticos asequibles y no desmesurados puesto que éramos conscientes de las limitaciones ante las que podíamos encontrarnos. El inglés no era la lengua materna de ninguno de los discentes y no podíamos pretender una gran mejora o progreso de la misma gracias a la aplicación de una sola Unidad Didáctica.

A la hora de diseñar la propuesta nos decantamos por trabajar el contenido de la orientación espacial a través de una Unidad Didáctica de Iniciación a la orientación deportiva. Consideramos que este es un contenido que propicia y facilita el uso de la lengua, fomentando que los alumnos y alumnas tengan la necesidad de comunicarse e interactuar entre sí. Asimismo, la orientación incita al uso de diferentes agrupaciones y prácticas en las que el diálogo y la comprensión oral y escrita son esenciales.

Para nuestra experiencia de innovación creamos además un blog que los estudiantes deben ir visitando tras cada sesión. Con esto se pretende no solo consolidar los aprendizajes llevados a cabo en clase, sino también reforzar cuestiones como el uso del pensamiento crítico o las competencias clave (competencia digital, competencia básica en ciencia y tecnología, etc.), haciendo hincapié en las dos habilidades lingüísticas que menos suelen verse involucradas en las sesiones: la comprensión y la expresión escrita.

Los principales estilos de enseñanza empleados conforme al sistema de Mosston y Ashworth (1993), son el estilo recíproco, la microenseñanza y el estilo divergente (en la mayoría de ocasiones); aunque en determinados momentos también se utilizan otros. En definitiva, aplicando la clasificación propuesta por Delgado (1991), los estilos más recurridos son aquellos que posibilitan la participación y los que implican cognitivamente al alumno, de forma que se fomenta el uso de la lengua durante las actividades y se favorece el aprendizaje lingüístico.

Conviene destacar que dependiendo de las situaciones particulares ante las que se encuentra el profesor, el enfoque de diseño curricular deliberativo aconseja ir modificando actividades, normas, organización, agrupamientos, etc. Porque, como dice Delgado (1991), el docente de EF debe ser capaz de combinar y transformar estilos para adaptarse a los objetivos 
perseguidos, a los alumnos con sus estilos de aprendizaje propios y a su contexto educativo concreto. Por este motivo, durante toda la experiencia el maestro adquiere un rol de analista de necesidades y facilitador del aprendizaje.

Gracias a los instrumentos de evaluación utilizados hemos podido obtener información sobre el proceso llevado a cabo, tanto por parte de los alumnos y alumnas como por parte del docente. A partir de lo extraído mediante estas herramientas podemos indicar que la experiencia de innovación es satisfactoria y además los resultados suelen ser muy positivos, puesto que los objetivos propuestos inicialmente se acaban alcanzando. Por ejemplo, a partir de los cuestionarios que los estudiantes cumplimentaron al finalizar la Unidad Didáctica descrita encontramos citas como «me encanta la EF en inglés. Los juegos son chulísimos, me gustaría repetirlo» o «me ha gustado aprender palabras nuevas en inglés»; valorando no solo el ámbito de la EF, sino también la vertiente lingüística. Asimismo, mediante el diario del docente tenemos constancia de lo atentos que se muestran los alumnos al tratar de entender lo que él explica; o que las ayudas visuales que preparamos como andamiaje lingüístico son percibidas como una «maravillosa ayuda».

En definitiva, la puesta en práctica de esta innovación es muy satisfactoria en nuestro contexto, pero conviene ser conscientes de que podemos seguir mejorando. Además, aunque innovaciones de este tipo son positivas, destacamos que lo relevante es aprender de la experiencia desarrollada y continuar implementando y mejorando cada innovación para fomentar el máximo aprendizaje de los estudiantes. Por ello, que más y más docentes se lancen a leer sobre otras experiencias y tratar de replicarlas o tomar aquello que más les interese es la razón de ser de propuestas como la que aquí se presenta.

\section{Conclusiones}

Gracias a la experiencia personal podemos defender que utilizar la metodología AICLE en el área de EF permite el desarrollo de los alumnos y alumnas no solo en el campo vinculado a dicha materia, sino también en el lingüístico. Mediante el uso de este método pedagógico el tiempo de exposición de los discentes a otra lengua se ve incrementado, siendo este un hecho esencial para su aprendizaje. Por lo tanto, su implementación resulta francamente deseable en el mundo actual, puesto que ser competente en más de una lengua, además de 
ser imprescindible para desenvolverse con autonomía, es una riqueza de la que nuestro alumnado no debiera ser privado.

Mediante la implementación de AICLE los estudiantes se sitúan como eje central del proceso aprendizaje, siendo los protagonistas de todo aquello que sucede en la sesiones. Para ello, concebir el aprendizaje desde una perspectiva socioconstructivista resulta altamente aconsejable. Además, el hecho de proponer situaciones lo más reales posible en las que la actividad motriz y la lengua se ven interconectadas favorece el desarrollo de diversas competencias. Al mismo tiempo, conviene insistir en que AICLE está abierto a otorgar un cariz crítico a toda la práctica educativa, permitiendo plantear escenarios en los que el estudiantado tiene que poner en juego su capacidad de tomar decisiones y razonar de forma crítica.

En definitiva, aunque la experiencia expuesta se centra en una Unidad Didáctica de EF para primaria, el método AICLE puede ser aplicado en cualquier área de conocimiento y nivel educativo. Por lo que, desde aquí, animamos a los lectores a desarrollar sus propias prácticas AICLE. El mundo del siglo XXI no es el mismo que conocíamos hace unos años, y tal como dijo Roger Van Oech (1983, p.5), no es posible resolver los problemas de hoy con las soluciones de ayer. Por este motivo somos promotores de la innovación en el campo educativo reconociendo que innovar es una acción de riesgo, pero cuyo mayor riesgo no es otro que el hecho de no practicarla.

\section{Referencias bibliográficas}

AHMED, N. y otros (2014): «Bloom's taxonomy based proportionate curriculum development model», Journal of Education and Practice, 5(26), pp. 12-17.

ANDERSON, L.W. y otros (eds.) (2001): A Taxonomy for Learning, Teaching, and Assessing: A Revision of Bloom's Taxonomy of Educational Objectives, New York, Addison Wesley Longman.

CHIVA, O. y otros (2015): «Educación Física bilingüe y pedagogía crítica: una aplicación basada en el Judo», Retos: nuevas tendencias en educación física, deporte y recreación, 28, pp. 110-115. 
CORAL, J. (2012): Aprenentatge integrat de continguts d'educació fisica i llengua anglesa: educació física en AICLE al cicle superior de primària. (Tesis doctoral). Universitat de Barcelona, Barcelona.

CORAL, J. (2013): «Physical Education and English integrated learning: How school teachers can develop PE-in-CLIL programmes», Temps d'educació, 45, pp. 41-64.

CORAL, J. y LLEIXÀ, T. (2013): «Las tareas en el aprendizaje integrado de educación física y lengua extranjera (AICLE). Determinación de las características de las tareas mediante el análisis del diario de clase», Retos: Nuevas tendencias en Educación Física, Deporte y Recreación, 24, pp. 79-84.

COYLE, D. y otros (2010): CLIL, Cambridge, CUP.

DELGADO-NOGUERA, M. A. (1991): Los estilos de enseñanza en Educación Física, Granada, Universidad de Granada.

FIGUERAS, S. y otros (2011): «Educació Física en anglès: Percepcions dels estudiants entorn d'una experiència metodològica en el marc universitari», Aloma Revista de Psicologia, Ciències de l'Educació i de l'Esport, 29, pp. 61-80.

FRAILE, F. (1999): «La didáctica de la educación física desde una visión crítica», Revista electrónica interuniversitaria de formación del profesorado, 2(1), pp. 689-698.

FREIRE, P. (1995): Pedagogía: diálogo y conflicto, Sao Paulo, Editora Cortez.

GARDNER, H. (1983): Inteligencias múltiples, Barcelona, Paidos.

GONZÁLEZ, F. y otros (2013): «Educación Física e inglés, asociación eficaz para adquirir competencias», Tàndem: didáctica de la Educación Física, 43, pp. 97-105.

KILMOVA, B. (2012): «CLIL and the teaching of foreign languages», Procedia - Social and Behavioural Sciences, 47, pp. 572-576.

LASAGABASTER, D. (2013): «The use of the L1 in CLIL classes: The teachers' perspective», Latin American Journal of Content \& Language Integrated Learning, 6(2), pp. 1-21. 
MARSH, D. (2006): «English as a medium of instruction in the new global linguistic order: Global characteristics, Local consequences». Second Annual Conference for Middle East Teachers of Science, Mathematics and Computing, SM Stewart, JE Olearski and D. Thompson, eds., METSMaC, Abu Dhabi, Citeseer. Recuperado el 27 de noviembre de 2015

de https://archive.org/details/ProceedingsOfTheSecondAnnualConferenceForMiddleEa $\underline{\text { stTeachersOf }}$

MARSH, D. (2012): Content and language integrated (CLIL) A development trajectory, Córdoba, Servicio de publicaciones de la Universidad de Córdoba.

MAURI, T. y otros (2007): «La evaluación de la calidad de los procesos de innovación docente universitaria. Una perspectiva constructivista», RedU. Revista de Docencia Universitaria, 5(1), pp. 1-11.

MEYER, O. (2010): «Towards quality CLIL: successful planning and teaching strategies», Pulso, 33, pp. 11-29.

MOSSTON, M. y ASHWORT, S. (1993): La enseñanza de la Educación Física. La reforma de los estilos de enseñanza, Barcelona, Hispano Europea.

RAMOS, F. y RUIZ-OMEÑACA, J. V. (2011): «La Educación Física en centros bilingües de primaria inglés-español: de las singularidades propias del área a la elaboración de propuestas didácticas prácticas con AIBLE», RESLA, 24, pp. 153-170.

SALVADOR, C. y otros (2016 en prensa): «Características del aprendizaje integrado de contenidos de educación física y lengua extranjera», Retos: nuevas tendencias en educación física, deporte y recreación, 29.

VILLANUEVA, M. L. (2002): «Los estilos de aprendizaje ante los retos de la Europa multilingüe» en MIQUEL, L. y SANS, N. (coord.) (2002): Didáctica del español como lengua extranjera, Ed. Actilibre, col. "Cuadernos de tiempo libre, colección Expolingua”.

VON OECH, R. (1983): A Whack on the Side of the Head, New York, Warner Books. 
ZAGALAZ, M. L. y otros (2012): «Diseño de un cuestionario para medir la formación bilingüe del profesorado de Educación Física», Revista iberoamericana de Ciencias del Deporte, 1(1), pp. 7-12. 
Tras este primer manuscrito se presenta una revisión sistemática supeditada a la segunda vertiente del primer objetivo, que consiste en:

- O.1.2. "Examinar cuáles son y qué analizan los artículos de mayor impacto que vinculan educación física y enseñanza de lenguas extranjeras.”

Esta revisión sistemática analiza las investigaciones realizadas hasta la fecha, relativas a la educación física como contexto para el aprendizaje de un idioma extranjero. Tras comprobar inicialmente que existían relativamente pocos trabajos que estudiaran la temática abordada en esta investigación tal y como la planteamos, es decir, adoptando específicamente el enfoque AICLE; decidimos partir de aquellos estudios que relacionaran no solo dicho enfoque particular, sino la enseñanza de lenguas extranjeras en general. La motivación de realizar esta revisión ha radicado en recopilar aquellos textos de mayor calidad científica que permitieran establecer las bases de las siguientes fases de nuestra propia investigación. Este hecho nos ha permitido obtener una visión más cercana del campo de estudio en el cual se circunscribe la presente tesis. 


\section{MANUSCRITO 2}

TÍTULO:

Aprendizaje de un idioma extranjero a través de la Educación Física: una revisión sistemática

AUTORES:

Celina Salvador García, Òscar Chiva Bartoll y Emanuele Isidori

FUENTE:

Revista Movimento

(Publicado)

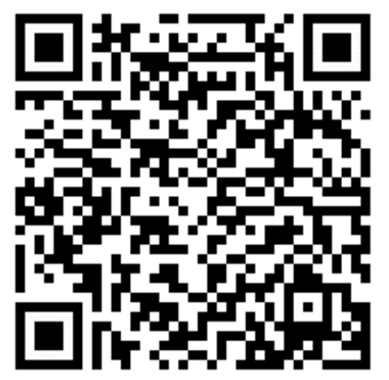




\title{
Aprendizaje de un idioma extranjero a través de la Educación Física: una revisión sistemática
}

\author{
Aprender uma língua estrangeira através da Educação Física: \\ uma revisão sistemática
}

\section{Learning a foreign language through Physical Education: a systematic review}

Celina Salvador-García *, Oscar Chiva-Bartoll *, Emanuele Isidori **

Palabras clave: Educación Física. Aprendizaje. Lengua Extranjera. Revisión.

\section{Resumen:}

Esta revisión sistemática tiene por objetivo ofrecer un análisis sobre la investigación en Educación Física como marco para el aprendizaje de un idioma extranjero en contextos de educación formal. El procedimiento de la investigación se circunscribió a los artículos publicados en la base de datos de la Isi Web of Knowledge y de la Scopus. Los artículos se sometieron a una serie de criterios de inclusión y exclusión que aseguraran la relevancia, la calidad y el ajuste temático, siguiendo el método propuesto por Gomes y Caminha (2014). En la investigación se combinaron varios términos de los dos campos de estudio en cuestión: (1) Educación Física y (2) aprendizaje de idiomas. Tras aplicar los criterios de selección, se analizaron las 18 publicaciones resultantes. De la discusión de los resultados se concluye que la Educación Física, como medio para aprender una lengua extranjera, constituye un tema de estudio de plena actualidad y capaz de aportar beneficios a distintos niveles.

Palavras chave: Educação Física. Aprendizagem. Língua estrangeira. Revisão.

\section{Resumo:}

Esta revisão sistemática tem como objetivo fornecer uma análise da pesquisa em Educação Física como marco para a aprendizagem de uma língua estrangeira em contexto de educação 
formal. O procedimento da pesquisa circunscreveu-se aos artigos publicados na base de dados da Isi Web of Knowledge e da Scopus. Os artigos foram submetidos a uma série de critérios de inclusão e exclusão, que asseguraram a relevância, a qualidade e o ajuste temático, sendo seguido o método proposto por Gomes e Caminha (2014). Na pesquisa, foram combinados vários termos dos dois campos de estudo em questão: (1) educação física e (2) aprendizagem de línguas. Depois de aplicados os critérios de seleção, o artigo analisa as 18 publicações daí resultantes. Da discussão dos resultados conclui-se que a Educação Física, como meio de aprendizagem de uma língua estrangeira, constitui-se um tema de estudo bastante atual e revelador de benefícios aos mais distintos níveis.

Keywords: Physical Education. Foreign Language Learning. Review.

\section{Abstract:}

This systematic review aims to provide an analysis of Physical Education research as a framework for learning a foreign language in formal education contexts. Isi Web of Knowledge and Scopus were the two databases employed to conduct the study. The papers gathered were subjected to a series of inclusion and exclusion criteria to ensure their relevance, quality and agreement with the topic according to the method proposed by Gomes and Caminha (2014). The research combined terms from two fields: 1) Physical Education and (2) language learning. Once the selection criteria were applied, the essay analyzes the resulting 18 papers. After the discussion, the results reveal that Physical Education as a means for learning a foreign language has become an issue of relevance which is able to provide advantages at different levels.

* Universitat Jaume I. Castellón. España. E-mail: salvadoc@uji.es; oscar.chiva@uv.es; oscar.chiva@uv.es.

** Università degli studi di Roma "Foro Italico". Roma. Italia. E-mail: labopedagogia@gmail.com

Recebido em: 22-03-2017

Aprovado em: 28-04-2017

\section{Introducción}


La comunidad educativa apuesta cada vez más por integrar el aprendizaje lingüístico con el de contenidos específicos de cualquier materia curricular (Finardi; Leão, 2016; Lasagabaster; Sierra, 2010; Tilio, 2014). Existen múltiples opciones metodológicas por las que se puede optar: Content and Language Integrated Learning (Clil), Content Based Instruction (CBI), programas bilingües, lengua X como Medio de Instrucción, game-based projects, programas de inmersión, etc. (Dalton-Puffer; Smit, 2007). Cada método implica unas particularidades, pero todos coinciden en promover simultáneamente el aprendizaje lingüístico y el de otro contenido específico. La lengua objeto de aprendizaje puede variar entre lengua materna, segunda lengua o lengua extranjera, cada una con sus peculiaridades de enseñanza (Manga, 2008; Trujillo, 2007).

El uso de contenidos diversos para fomentar el aprendizaje lingüístico ha sido revisado, por ejemplo, por Lailiyah (2016) o Williams (2015) en relación a las metodologías Clil y EMI respectivamente. Tradicionalmente la Educación Física (EF) ha sido un campo concurrido para integrar este tipo de aprendizaje lingüístico. En el contexto de la actividad física, las relaciones entre el alumnado y el docente son muy diferentes a las que se suceden en otras áreas del currículo (Ramos; Ruiz, 2011). Además, el hecho de desarrollarse fuera del aula ofrece carices sociales y vivenciales únicos. Del mismo modo, el estrecho vínculo que une estas prácticas con el movimiento, la acción y el juego, convierten a la EF en un escenario extraordinario (Lavega, 2007).

Dada la eclosión de aplicaciones e investigación dedicada a este ámbito es más que necesario un trabajo de revisión sistemática que, siguiendo las indicaciones de Gomes y Caminha (2014), capte los elementos y cuestiones constitutivas de este fenómeno: ¿Qué ocurre al ensamblar ejercicio físico y lengua? ¿Cómo se han llevado a cabo prácticas en este sentido? ¿Dónde han sido desarrolladas? Así, con la intención de promover esta práctica educativa y acercarla a docentes e investigadores, esta revisión tiene como objetivo presentar un análisis del estado de la cuestión sobre la EF como marco para el aprendizaje de una lengua extranjera en la educación formal.

\section{Método}

Estrategia de búsqueda 
La extracción de datos, el análisis y la redacción del presente texto ha sido desarrollada por un equipo experimentado de tres investigadores, cuya línea de estudio se halla en el ámbito de la EF bilingüe, contando con expertos tanto en el área de EF como en el aprendizaje lingüístico.

Para llevar a cabo este estudio de manera sistemática y rigurosa se han seguido los pasos propuestos por Gomes y Caminha (2014). Una vez identificada la necesidad de efectuar la presente revisión bibliográfica, se optó por llevar a cabo una búsqueda en dos de las bases de datos de mayor relevancia acreditada en el campo de las ciencias sociales en general y el educativo, en particular: ISI Web of Knowledge de Social Sciences-Thomson Reuters y Scopus- Elsevier. Dicha búsqueda se desarrolló entre los meses de junio y octubre de 2016. Se tomaron aquellas publicaciones que relacionaban la EF y el aprendizaje de una lengua extranjera. Para ello se desarrolló de manera sistemática una búsqueda que combinara términos de los dos campos sobre los que se conforma el ámbito de estudio: la EF y el aprendizaje de lenguas. Para el primer conjunto se utilizaron los términos physical education, physical activity, play y physical exercise; mientras que para el segundo se optó por language, bilingual, Clil, foreign language, teaching, integrated y multilingual. Estos debían aparecer en el título, en las palabras clave o en el abstract, cuando la búsqueda se realizaba con ISI Web of Knowledge o pertenecer al tema del artículo en Scopus, puesto que cada base de datos determina diferentes posibilidades de búsqueda.

Muchos de los artículos obtenidos diferían considerablemente del tema de estudio, que vincula la EF con el aprendizaje lingüístico, por lo que se optó por concretar la exploración estipulando una serie de criterios de inclusión y exclusión descritos a continuación.

\section{Criterios de inclusión y exclusión}

Tres fueron los principales criterios de selección establecidos: relevancia, calidad y temática. La utilización de las dos de las bases de datos referidas reafirma el criterio de relevancia de la selección, ya que todos los textos han sido publicados en revistas de trascendencia internacional. El conjunto de publicaciones de la muestra ha sido revisado por pares, emplea cuestionarios validados y presenta objetivos claros así como un diseño adecuado, cuestiones que avalan su calidad. 
Por otro lado, la temática debía hacer referencia a la utilización de la EF con el fin de aprender una lengua extranjera en un ambiente educativo. No se pretendía restringir la búsqueda a ninguna metodología particular de enseñanza de lenguas, por lo que se utilizaron diversos descriptores que pudieran englobar dicho objeto de estudio. Sin embargo, sí se desecharon aquellos artículos que entendían la actividad física como el uso de la metodología Total Physical Response (Asher, 1966) o la audio-motor unit (Kalivoda; Morain; Elkins, 1971) o la técnica del role-play. Pese a que estos métodos se vinculan al movimiento, los textos que se pretendía encontrar debían darle más relevancia al componente físico. Además, también se determinó que los estudiantes trabajaran las habilidades de expresión lingüística y no fueran meros receptores de lenguaje.

Finalmente, se descartaron aquellos textos que no estaban disponibles en inglés o español, por ser ininteligibles para el equipo investigador, por ejemplo uno que se halló en coreano.

\section{Criterios de análisis}

Los textos que superaron la criba se trataron en función de las siguientes variables de estudio: tipo de artículo (investigación, experiencia o propuesta), año de publicación, nivel educativo, descripción de la muestra y duración del estudio, instrumentos de recogida de información, localización geográfica, lengua meta, metodología docente aplicada, contenido específico de EF trabajado, aspectos adicionales trabajados y principales hallazgos de la investigación.

\section{Resultados}

Con la búsqueda inicial se accedió a un total 146 publicaciones, número que se redujo al aplicar los criterios de inclusión y exclusión enunciados. En concreto, 113 artículos no pasaron la selección por no cumplir todos los criterios de inclusión, dos fueron desestimados por utilizar las metodologías de Total Physical Response o la audio-motor unit, dos más fueron excluidos por considerar el uso del role-play como actividad física, y uno no fue seleccionado por estar escrito en coreano. Tras esta primera criba, el total de artículos se vio reducido a 34, entre los que figuraban artículos repetidos que, como muestra la tabla 1, se desecharon para conformar una muestra final de 18 publicaciones. El anexo 1 ofrece, a modo de cuadro, una síntesis de los principales resultados descritos a continuación. 
Tabla 1. Artículos encontrados en función de los descriptores

\begin{tabular}{|c|c|c|c|}
\hline Descriptores & Base de datos & $\begin{array}{l}\mathbf{N}^{0} \text { de } \\
\text { resultados }\end{array}$ & $\begin{array}{l}\text { Textos } \\
\text { seleccionados }\end{array}$ \\
\hline \multirow{2}{*}{$\begin{array}{l}\text { Physical education, language, } \\
\text { bilingual }\end{array}$} & ISI Web of knowledge & 28 & 5 \\
\hline & Scopus & 38 & 5 \\
\hline \multirow{2}{*}{$\begin{array}{l}\text { Physical education, Clil, } \\
\text { foreign language }\end{array}$} & ISI_Web_of_knowledge & 4 & 4 \\
\hline & Scopus & 4 & 4 \\
\hline \multirow{2}{*}{$\begin{array}{l}\text { Physical education, foreign } \\
\text { language, language learning }\end{array}$} & ISI_Web_of_knowledge & 16 & 2 \\
\hline & Scopus & 23 & 4 \\
\hline \multirow{2}{*}{$\begin{array}{l}\text { Play, foreign } \begin{array}{l}\text { language, } \\
\text { language } \\
\text { multilingual }\end{array} \\
\end{array}$} & ISI_Web_of_knowledge & 6 & 1 \\
\hline & Scopus & 5 & 0 \\
\hline \multirow{2}{*}{$\begin{array}{l}\text { Physical education, bilingual, } \\
\text { teaching }\end{array}$} & ISI_Web_of_knowledge & 11 & 4 \\
\hline & Scopus & 7 & 3 \\
\hline \multirow{2}{*}{$\begin{array}{l}\text { Physical exercise, integrated, } \\
\text { foreign language }\end{array}$} & ISI_Web_of_knowledge & 3 & 1 \\
\hline & Scopus & 1 & 1 \\
\hline Artículos totales: & & 146 & 34 \\
\hline Sin artículos repetidos: & & & 18 \\
\hline
\end{tabular}

Fuente: elaboración propia

Tipología de las publicaciones y fecha

De entrada, conviene apuntar que todos los textos incluidos en la presente revisión son investigaciones o experiencias narradas, a excepción del de Ramos y Ruiz (2011), cuya aportación es meramente teórica en forma de guía práctica.

Los 17 documentos restantes pueden dividirse en función de su tipología. Por un lado, aparecen cuatro textos con la descripción de experiencias llevadas a cabo y, por otro, 13 que se circunscriben al ámbito de estudios o investigaciones.

Otro aspecto relevante es la vigencia y actualidad de los textos. Aún sin haber adoptado ningún criterio de inclusión relativo a su fecha de publicación, un único artículo fue publicado antes de 2010 (Harris; Stockton, 1973). Además, 12 de los 18 artículos han aparecido a lo largo de los últimos dos años (2015-2016), suponiendo el 66,66\% de la muestra.

\section{Nivel educativo de aplicación}

El aprendizaje de una lengua extranjera mediante un contenido puede darse en diferentes etapas o niveles educativos (Llinares; Pastrana, 2013; Mehisto, 2012). En este sentido, como refleja la figura 1 , los artículos seleccionados se dirigen a una variedad amplia de etapas 
educativas. La mayoría, en concreto un $61,11 \%$ de la muestra, hace referencia a estudios en el nivel de educación primaria. Le siguen los niveles de educación infantil y secundaria con un $22,22 \%$ y un $16,66 \%$ respectivamente, relegando a la etapa universitaria a cifras más discretas, con solo una referencia (Sherin; Sherina, 2015).

Figura 1. Número de estudios por etapa educativa

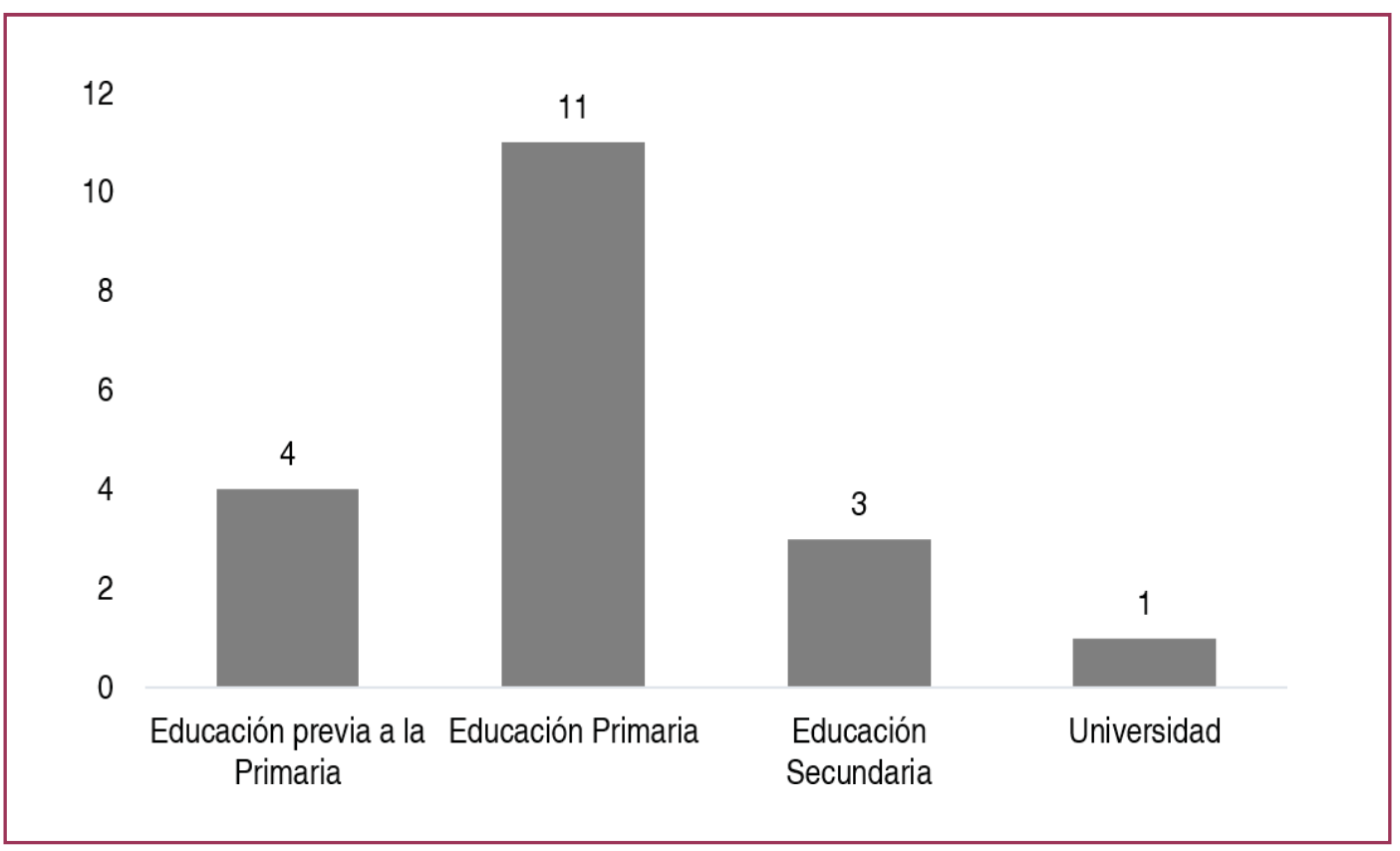

Fuente: elaboración propia

\section{Muestra y duración de las intervenciones}

Respecto a la muestra de los diferentes estudios, existe una gran variedad que fluctúa entre los 10 y los 23 estudiantes de Mulia (2015) o Cepero, García, López (2013) respectivamente, hasta los 328 de Baena y Granero (2015) o los 1.175 colegios de Coral, Lleixà, Ventura (2016). También existe gran heterogeneidad en la duración de las propuestas de intervención. Tres de los cuatro artículos que narran experiencias coinciden en la aplicación de una única unidad didáctica, que en todos los casos consta de seis sesiones; mientras que la restante (Griva; Chostelidou, 2015) describe un proyecto de 16 semanas. Sin embargo, en los artículos de investigación, la duración de las intervenciones difiere enormemente, moviéndose entre las cuatro semanas de la aplicación de Toumpaniari, et al. (2015) y Mavilidi et al. (2015), un curso escolar completo en los estudios de Coral y Lleixà (2014) o Cepero, García y López 
(2013), llegando incluso a los tres cursos académicos de Coral, Lleixà, y Ventura (2016).

Instrumentos de recogida de información

Entre los artículos de investigación aparecen en igual medida estudios que emplean métodos cualitativos, cuantitativos y aproximaciones mixtas. Asimismo, tres estudios han optado por seguir el método de investigación-acción (Cepero; García; López, 2013; Coral; Lleixà, 2016; Mulia, 2015), mientras que en el estudio de Moore y Lorenzo (2015) no se ha podido identificar la metodología.

De la diversidad de procedimientos metodológicos seguidos emana una gran variedad de instrumentos, sintetizados en la tabla 2. De índole cuantitativa destacan los cuestionarios y los tests. Su uso se centra en indagar el tipo de vocabulario practicado, el logro alcanzado, la mejora de la destreza oral o el conjunto de habilidades lingüísiticas en general. Por otra parte, el rango de instrumentos cualitativos es considerablemente mayor. Entre estos se encuentran la observación externa, el portfolio del alumnado, las entrevistas y las observaciones a través de grabaciones; aunque el instrumento más empleado es el diario del profesor. 
Tabla 2. Aparición de instrumentos según carácter cuantitativo o cualitativo

\begin{tabular}{lll}
\hline $\begin{array}{l}\text { Instrumentos } \\
\text { dearácter } \\
\text { cualitativo }\end{array}$ & $\begin{array}{l}\text { Frecuencia } \\
\text { de uso }\end{array}$ & Estudios que los utilizan \\
\hline $\begin{array}{l}\text { Observación } \\
\text { externa }\end{array}$ & 3 & $\begin{array}{l}\text { Coral; Lleixa (2014), Griva; Semoglou; Geladari } \\
\text { (2010), Mulia (2015) }\end{array}$ \\
\hline Portfolio & 1 & Cepero; García; López (2013) \\
\hline $\begin{array}{l}\text { Diario } \\
\text { docente }\end{array}$ & 6 & $\begin{array}{l}\text { Cepero; García; López (2013), Coral; Lleixà } \\
\text { (2014), Coral; Lleixà (2016), Griva; Semoglou; } \\
\text { Geladari (2010), Griva; Semoglou (2012); Mulia } \\
\text { (2015) }\end{array}$ \\
\hline $\begin{array}{l}\text { Grabaciones } \\
\text { Entrevistas }\end{array}$ & 2 & $\begin{array}{l}\text { Coral; Lleixa (2014), Coral; Lleixa (2016), Mulia } \\
\text { (2015) }\end{array}$ \\
\hline $\begin{array}{l}\text { Instrumentos } \\
\text { de carácter } \\
\text { cuantitativo }\end{array}$ & $\begin{array}{l}\text { Frecuencia } \\
\text { de uso }\end{array}$ & $\begin{array}{l}\text { Griva; Semoglou; Geladari (2010), Sherin; Sherina } \\
\text { (2015) }\end{array}$ \\
\hline $\begin{array}{l}\text { Estudios que los utilizan } \\
\text { Tests }\end{array}$ & 6 & $\begin{array}{l}\text { Coral; Lleixa; Ventura (2016), Griva; Semoglou; } \\
\text { Geladari (2010), Griva; Semoglou (2012), Harris; } \\
\text { Stockton (1973), Mavilidi et al. (2015), } \\
\text { Toumpaniari et al. (2015) }\end{array}$ \\
\hline Cuestionarios & 2 & $\begin{array}{l}\text { Cepero; García; López (2013), Harris; Stockton } \\
\text { (1973) }\end{array}$ \\
\hline
\end{tabular}

Fuente: elaboración propia

\section{Localización geográfica y lengua meta}

Por lo que respecta a la distribución geográfica de los artículos recopilados, resulta interesante observar que el 55,55\% de los mismos han sido escritos en España. En cuanto al resto, en Grecia se ubican 4 trabajos publicados, mientras que Indonesia, USA y Rusia únicamente aparecen en una ocasión. Del resto de países no se han encontrado estudios en las bases de datos analizadas. Por otra parte, destaca el inglés como lengua meta de la mayoría de los textos, siendo este el idioma estudiado en el $88,89 \%$ de las ocasiones.

\section{Metodología para la enseñanza de lengua}

El método pedagógico Clil es el más empleado. En concreto, siete de los 18 textos seleccionados aluden a esta metodología coincidiendo que todos estos son desarrollados en España. Otro de los métodos empleados es el game based project (Griva; Semoglou; Geladari, 2010; Griva; Semoglou, 2012). Por lo que respecta al resto de publicaciones, no 
explicitan una metodología en particular, simplemente exponen el aprendizaje de vocabulario bien mediante actividad física y gestos (Mavilidi et al., 2015; Mulia, 2015; Toumpaniari et al., 2015), bien a través de actividades vinculadas con el moviento (Griva; Chostelidou, 2015) o bien mediante programas de EF bilingüe (Alonso et al., 2015; Baena; Granero, 2015; Cepero; García; López, 2013; Harris; Stockton, 1973; Sherin; Sherina, 2015).

\section{Contenido específico de Educación Física y elementos transversales trabajados}

Si bien todos los artículos coinciden en el hecho de incidir en el aprendizaje lingüístico a través de la actividad física, la forma en que esta cuestión se aborda difiere considerablemente. 12 de los artículos utilizan la asignatura de EF para trabajar aspectos lingüísticos. Por ello, al desarrollarse las propuestas o estudios en el marco de dicha asignatura, resulta necesario trabajar, también, contenidos propios de la misma. Los contenidos seleccionados pasan por la orientación (Salvador; Chiva; Fazio, 2016), los juegos tradicionales (Alonso et al., 2015), el judo (Chiva; Isidori; Fazio, 2015), el kickball (Harris; Stockton, 1973) y los saltos (Ramos; Ruiz, 2011). Además, dos de las propuestas plantean el desarrollo de sus programas durante todo un curso académico (Cepero; García; López, 2013; Coral; Lleixà, 2014), o incluso durante más tiempo (Coral; Lleixà; Ventura, 2016), por lo que en estos casos se ha trabajado más de un contenido.

Por otro lado, existen estudios realizados en otras asignaturas que emplean contenidos próximos a la EF. Por ejemplo, Toumpaniari et al. (2015) y Mavilidi et al., (2015) apuestan por sustentar sus propuestas en el uso de gestos y movimientos; mientras que Mulia (2015) se decanta por utilizar la dramatización. En sus textos, Griva, Semoglou y Geladari (2010), Griva y Semoglou (2012) y Griva y Chostelidou (2015) abogaron por trasladar las clases de lengua extranjera al gimnasio del centro educativo, aunque allí no trabajaran contenidos directamente relacionados con la EF.

Destaca también que varios de los trabajos no optan por el simple aprendizaje ligado a la lengua y la EF, sino que además apuestan por desarrollar temas transversales u otros contenidos concretos. En este sentido sobresalen el desarrollo del pensamiento crítico trabajado por Chiva, Isidori y Fazio (2015), las competencias clave en general (Coral; Lleixà; Ventura, 2016), o de manera particular la digital (Cepero; García; López, 2013) y la cultural (Alonso et al., 2015; Sherin; Sherina, 2015). Por su parte, Griva y Semoglou (2012) abogan 
por el fomento de la creatividad.

\section{Principales hallazgos}

Haciéndose eco de los principales resultados y conclusiones a los que han llegado los artículos revisados, uno de los puntos principales recae en la idoneidad de la integración entre el aprendizaje de una lengua y la EF (Alonso et al., 2015; Coral; Lleixà, 2016; Griva; Semoglou; Geladari, 2010; Mavildi et al., 2015; Ramos; Ruiz, 2011; Salvador; Chiva; Fazio, 2016; Toumpaniari et al. 2015).

Esta idoneidad propiciada por la combinación de actividad física y aprendizaje lingüístico se explicita en trabajos como los de Chiva, Isidori y Fazio (2015), Griva, Semoglou y Geladari (2010) y Salvador, Chiva y Fazio (2016), quienes defienden el favorecimiento especial de las habilidades comunicativas. Del mismo modo, encontramos trabajos que enfatizan tanto el desarrollo de la comunicación oral (Coral; Lleixà, 2016), como la comprensión (Cepero; García; López, 2013).

Además, para asegurar un óptimo desarrollo de las propuestas, son diversos los autores que subrayan la relevancia de llevar a cabo una aplicación meticulosa y reflexiva (Ramos; Ruiz, 2011; Salvador; Chiva; Fazio, 2016). En este sentido, trabajos como los de Coral y Lleixà (2014), Moore y Lorenzo (2015) o Ramos y Ruiz (2011) exponen taxonomías y/o consideraciones para facilitar una óptima integración entre lengua y actividad física (Mulia, 2015).

Otro aspecto tratado en muchos de los textos alude a la motivación generada por las propuestas llevadas a cabo, tal y como se desprende de los estudios de Alonso et al. (2015), Cepero, García y López (2013), Chiva, Isidori y Fazio (2015), Griva y Semoglou (2012), y Griva, Semoglou y Geladari (2010). En esta línea merecen especial mención el trabajo de Baena y Granero (2015) que se focaliza en la validación de un instrumento de evaluación de las dimensiones diversión/aburrimiento, y el de Coral y Lleixà (2014), que trata el equilibrio entre motivación y efectividad de las tareas.

Por su parte, Toumpaniari et al. (2015) y Mulia (2015) defienden la gran oportunidad generada para potenciar el desarrollo físico, social y cognitivo del estudiantado, así como la promoción de hábitos saludables y su competencia profesional multicultural (Sherin; 
Sherina, 2015)

Por último, también es reseñable el beneficio que implica el uso del movimiento y los gestos para el aprendizaje lingüístico como justificación de algunas propuestas (Mulia, 2015; Ramos; Ruiz, 2011); fundamentalmente por la posibilidad de observar el movimiento del resto de alumnado (Mavilidi et al., 2015).

\section{Discusión y conclusiones}

La presente revisión sistemática demuestra la creciente tendencia que está viviendo el uso de la EF como contexto en el que desarrollar el aprendizaje de una lengua extranjera. A partir del texto aquí presentado, la comunidad científica puede encontrar una aproximación al estado de la cuestión sustentado por publicaciones con acreditada validez, vigencia y relevancia.

En este marco, diversas de las más notorias innovaciones metodológicas emplean el aprendizaje lingüístico a través de un contenido. Y, como se ha dicho, diversos autores subrayan la posibilidad de desarrollar dicho aprendizaje lingüístico haciendo uso de la actividad física (Chiva; Isidori; Fazio, 2015; Coral; Lleixà, 2016; García; García; Yuste, 2012; Ramos; Ruiz, 2011). Este hecho gana vigencia en tanto que prácticamente todos los textos han sido divulgados en los últimos años; hecho indicativo de que estamos viviendo un momento de emergencia importante.

Resulta interesante advertir la divergencia existente en las características de las diferentes investigaciones: objetivos, metodología, tipos de intervención, etc. Pese a converger todas en una misma temática (actividad física y aprendizaje lingüístico), existe un gran abanico de enfoques y aproximaciones. Diferentes focos de atención requieren diferentes propiedades para su estudio. Entre la gran variedad de objetivos de investigación destacan cuestiones como: determinación de estrategias de comunicación, identificación de dilemas que suceden, dificultades percibidas por los docentes, efectos de esta metodología de aprendizaje, etc., abriendo nuevos caminos a futuras líneas de investigación.

Más de la mitad de los textos que conforman la muestra han sido realizados en España. Esta cuestión podría indicar la gran importancia que ha adquirido el aprendizaje de lenguas en dicho país (Cepero; García; López, 2013; Guillamón; Renau, 2015), así como la apuesta por 
las innovaciones metodológicas en este campo. Por otra parte, que el inglés sea la lengua estudiada en la mayoría de ocasiones no hace más que refrendar la relevancia que este idioma ha adquirido en los últimos años (Lewis; Simmons; Fenning, 2016).

Por lo que se refiere al tipo de metodología utilizado, Clil es aquella que más se repite. Conviene comentar en este sentido que todos los textos que se sirven de dicho método son aplicados en España. De este modo, parece evidente que en dicho país el método Clil se ha convertido en la vía más recurrente en el campo del aprendizaje de lenguas (Llinares; Pastrana, 2013; Guillamón; Renau, 2015). En particular, puede señalarse que las publicaciones que se basan en esta metodología coinciden en proponer el trabajo de contenidos íntimamente ligados a la cultura como, por ejemplo, deportes típicos (Chiva; Isidori; Fazio, 2015; Salvador; Chiva; Fazio, 2016) o juegos tradicionales (Alonso

et al., 2015). Este hecho es razonable dado que uno de los pilares básicos sobre los que se cimienta la metodología Clil es la cultura (Coyle; Hood; Marsh, 2010), puesto que esta resulta de gran relevancia en lo que al aprendizaje lingüístico se refiere, ya que lengua y cultura son elementos indisociables (Abbaspour; Rajaee; Zare, 2012; Villanueva, 2002).

Entre las propuestas que no se desarrollan de manera reglada a través de la materia de EF, destaca que tres de los estudios utilizan la expresión corporal (Mavilidi et al., 2015; Mulia, 2015; Toumpaniari et al., 2015). Este hecho resulta coherente puesto que la expresión corporal y el lenguaje no verbal no solo se vinculan con la cultura (Fleet, 2006), sino que forman parte fundamental del acto comunicativo (Canale; Swain, 1980; Cestero, 2014) y, por lo tanto, son elementos clave en el desarrollo de la competencia comunicativa. Por este motivo, no es extraño que las propuestas de Alonso et al. (2015) y Sherin y Sherina, (2015) se decanten por enfatizar la cultura, que además se ve íntimamente vinculada con la EF (Figueras et al., 2016; Lleixà, 2007), como aspecto adicional a trabajar durante el desarrollo de su propuesta.

Por otra parte, gracias a las experiencias llevadas a cabo y a las reflexiones sobre las mismas, así como a las taxonomías y/o apreciaciones expresadas por diversos autores (Coral; Lleixà, 2014; Moore; Lorenzo, 2015; Ramos; Ruiz, 2011), el uso de la actividad física para aprender una lengua está más cerca que nunca de la realidad escolar, puesto que todos los escritos convergen en perseguir una mejora en la calidad y facilitación de la enseñanza lingüística. 
No en vano la lengua y la comunicación no pueden desvincularse en ningún momento del lenguaje no verbal y del movimiento (Fleet, 2006). En este sentido, lo expuesto en las publicaciones seleccionadas parece seguir la línea marcada por Castro, Piéron y González (2006), Granero y Baena (2014) y Moreno y Cervelló (2003), quienes exponen que la EF genera una alta motivación en el alumnado. Así, parece que la apreciación y el interés generados por la actividad física y el deporte se ven transferidos también hacia el aprendizaje lingüístico cuando ambos elementos se vinculan.

Según autores como Renzi (2009) o Vicente (2016), la EF, la actividad física y el deporte generan un contexto ideal en el que poder facilitar un crecimiento global del estudiantado. Siguiendo estas ideas y confrontándolas con los artículos analizados, parece que el hecho de vincular el aprendizaje lingüístico no hace más que incrementar estas posibilidades de mejora. El movimiento se torna en una cuestión clave para favorecer el aprendizaje (Griva; Chostelidou, 2015; Ramos; Ruiz, 2011). De manera que lo expuesto por Mavilidi et al. (2015) está en consonancia con el aprendizaje constructivista; los estudiantes aprenden mediante su propio movimiento, pero también aprenden gracias al de los otros, que pueden ver y vincular con el lenguaje utilizado; permitiendo que estos nuevos aprendizajes sean realmente significativos para ellos.

Finalmente, la posibilidad propuesta en varios de los artículos analizados, relativa a desarrollar otros aprendizajes más allá de los lingüísticos o propios de EF (Cepero; García; López, 2013; Chiva; Isidori; Fazio, 2015), acapara gran interés. Tres de los estudios analizados se inclinan hacia el desarrollo de las competencias como contenido adicional de sus propuestas, en concordancia con lo expuesto por Figueras et al. (2016), que llevaron a cabo una revisión crítica de diversos trabajos en los que se demostraba la potencialidad del área de EF para contribuir y promover el desarrollo de diferentes competencias.

En definitiva, aunque la validez, relevancia y vigencia de los artículos revisados es fiable, la cantidad de estudios publicados hasta la fecha es todavía limitada, por lo que cabe interpretar los resultados expuestos con cautela. En todo caso, no deja de ser interesante la confrontación de los hallazgos de diversos investigadores, puesto que del fruto de su trabajo se han podido extraer conclusiones sugerentes y de gran interés para la comunidad académica.

\section{Referencias}


Abbaspour, Ehsan; Rajaee, Mahdi; Zare, Javad. How to integrate culture in second language education. Journal of Education and Practice, v.3, n.10, p.20-24, 2012.

Alonso, Jesús; Cachón, Javier; Castro, Rosario; Zagalaz, Maria Luisa. Propuesta didáctica bilingüe para educación física en educación primaria. Juegos populares y tradicionales ingleses. Retos. Nuevas tendencias en educación física, deporte y recreación, n.28, p. 116- $121,2^{\circ}$ sem. 2015.

Asher, James. The Learning Strategy of the Total Physical Response: a Review. The modern language journal, v.50, n. 10, p.79-84, feb. 1966.

Baena, Antonio; Granero, Antonio. Versión española del Sport Satisfaction Instrument (SSI) adaptado al aprendizaje de la Educación Física bilingüe en Inglés. Porta Linguarum: revista internacional de didáctica de las lenguas extranjeras, n.24, p.63-76, jun. 2015.

Canale, Michael; Swain, Merril. Theoretical basis of communicative approaches to second language teaching. Applied linguistics, v.1, n.1, p.1-47, 1980.

Castro, Maria José; Piéron, Maurice; González, Miguel. Actitudes y motivación en educación física escolar, Retos. Nuevas tendencias en educación física, deporte y recreación, n.10, p.5-22, 2006.

Cepero, Mar; García, Ana; López, Manuel. Diseño de un Programa de intervención bilingüe para el área de Educación Física basado en la competencia digital. Porta Linguarum: revista internacional de didáctica de las lenguas extranjeras, n.19, p.257-273, 2013.

Cestero, Ana. Comunicación no verbal y comunicación eficaz. Estudios de Lingüística de la Universidad de Alicante, n.28, p.125-150, 2014.

Chiva, Òscar; Isidori, Emanuele; Fazio, Alessandra. Educación Física bilingüe y pedagogía crítica: una aplicación basada en el Judo. Retos. Nuevas tendencias en educación fisica, deporte y recreación, n.28, p. 110-115, 2ºm. 2015.

Coral, Josep; Lleixà, Teresa. La enseñanza de la Educación Física mediante el enfoque educativo Clil: la resolución de los dilemas profesionales surgidos durante un proceso de investigación-acción. Movimento, v.20, n.4, p.1447-1472, 2014. 
Coral, Josep; Lleixà, Teresa. Physical education in content and language integrated learning: successful interaction between physical education and English as a foreign language. International journal of bilingual education and bilingualism, v.19, n.1, p.108-126, 2016.

Coral, Josep; Lleixà, Teresa; Ventura, Carles. Foreign language competence and content and language integrated learning in multilingual schools in Catalonia: an ex post facto study analysing the results of state key competences testing. International journal of bilingual education and bilingualism, p.1-12, feb. 2016.

Coyle, Do; Hood, Philip; Marsh, David. Clil Content and Language Integrated Learning. Cambridge: Cambridge University, 2010.

Dalton-Puffer, Christiane; Smit, Ute. Introduction. In: Dalton-Puffer, Christiane; Smit, Ute. Empirical Perspectives on Clil Classroom. Frankfurt: Peter Lang, 2007. p.7-23.

Figueras, Sara; Capllonch, Marta; Blázquez, Domingo; Monzonís, Núria. Competencias básicas y educación física: estudios e investigaciones. Apunts. Educación Física y Deportes, n.123, p.34-43, ene./mar. 2016.

Finardi, Kyria; Leão, Roberta. English in Brazil: Insights from the Analysis of Language Policies, Internationalizaton Programs and the Clil Approach. Education and linguistics research, v.2, n.1, p. 54-68, 2016.

Fleet, Marilyn. The role of culture in second or foreign language teaching: Moving beyond the classroom experience. 2006. Disponible en:

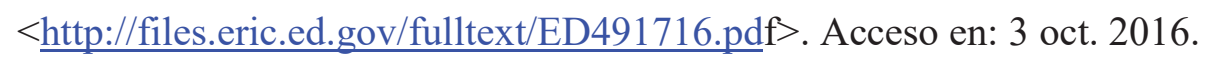

García, José; García, Juan; Yuste, Juan. Educación Física en inglés: una propuesta para trabajar la higiene postural en Educación Primaria. Retos. Nuevas tendencias en educación física, deporte y recreación, n.22, p. 70-75, 2ºm. 2012.

Gomes, Isabelle; Caminha, Iraquitan. Guia para estudos de revisão sistemática: uma opção metodológica para as Ciências do Movimento Humano. Movimento, v.20, n.1, p.395411, ene./ mar. 2014.

Granero, Antonio; Baena, Antonio. Predicción de la motivación autodeterminada según las 
orientaciones de meta y el clima motivacional en Educación Física. Retos. Nuevas tendencias en educación física, deporte y recreación, n.25, p. 23-27, 1 sem. 2014.

Griva, Eleni; Semoglou, Klio. Estimating the Effectiveness and Feasibility of a Game-based Project for Early Foreign Language Learning. English Language Teaching, v.3, n.9, p.33-44, sep. 2012.

Griva, Eleni; Semoglou, Klio; Geladari, Athina. Early foreign language learning: Implementation of a project in a game-based contex. Procedia: Social and Behavioral Sciences, v.2, n.2, p.3700-3705, 2010.

Guillamón, Francisco; Renau, Maria Luisa. A critical vision of the Clil approach in secondary education: a study in de Valencian Community in Spain. Latin American Journal of Content and Language integrated learning, v.8, n.1, p.1-12, 2015.

Harris, Mary; Stockton, Santiago. A comparison of bilingual and monolingual physical education instruction with elementary school students. The journal of educational research, v.62, n.2, p.53-56, oct. 1973.

Kalivoda, Theodore; Morain, Genelle; Elkins, Robert. The Audio-Motor Unit: a Listening Comprehension Strategy That Works. Foreign Language Annals, v.4, n.4, p.392-400, may 1971.

Lailiyah, Malikhatul. Content and language integrated learning in teaching English as second language: a systematic review of empirically based articles. EnJourMe: Journal of Culture, Language, and Teaching of English, v.1, n.1, jul. 2016. Disponívle en: $<\underline{\text { http://jurnal.unmer.ac.id/index.php/enjourme/article/view/278> }}$. Acceso en: 3 oct. 2016.

Lasagabaster, David; Sierra, Juean. Immersion and Clil in English: more differences than similarities. ELT Journal, v.64, n.4, p.367-375, oct. 2010.

Lavega, Pere. El juego motor y la pedagogía de las conductas motrices. Revista conexões, v.5, n.1, p.27-41, 2007.

Lewis, M. Paul; Simmons, Gary; Fenning, Charles (Eds.). Ethnologue: Languages of the world. 19. ed. Dallas: SIL International, 2016. 
Lleixà, Teresa. Educación física y competencias básicas. Contribución del área a la adquisición de las competencias básicas del currículo. Revista Tándem, v.7, n.23, p.31-37, 2007.

Llinares, Ana; Pastrana, Amanda. Clil students' communicative functions across activities and educational levels. Journal of pragmatics, v.59, p.81-92, dic. 2013.

Manga, André. Lengua Segunda (L2) Lengua extranjera (LE): Factores e incidencias de enseñanza/aprendizaje. Tonos Digital, n.16, 2008. Disponible en: $<$ http://www.tonosdigital.com/ojs/index.php/tonos/article/view/249/190>. Acceso en: 3 oct. 2016.

Mavildi, Myrto; Okely, Anthony; Chandler, Paul; Cliff, Dylan; Paas, Fred. Effects of integrated physical exercises and gestures on preschool children's foreign language vocabulary learning. Educational Psychology Review, v.7, n.3, p.413-426, 2015.

Mehisto, Peter. Excellence in bilingual education: a guide for school principals. Cambridge: Cambridge University, 2012.

Moore, Pat; Lorenzo, Francisco. Task-based learning and content and language integrated learning materials design: process and product. The Language Learning Journal, v.43, n.3, p.334-357, 2015.

Moreno, Juan; Cervelló, Eduardo. Pensamiento del alumnado hacia la educación física: su relación con la práctica deportiva y el carácter del educador. Enseñanza \& Teaching: Revista interuniversitaria de didáctica, n.21, p.345-362, 2003.

Mulia, Dewi. The use of first language scaffolding to teach English as a foreign language to pre- school children during dramatic play in West Sumatera, Indonesia. SHS Web of Conferences, v.16, p.1-10, 2015.

Ramos Francisco, Ruiz, Jesús. La Educación Física en centros bilingües de primaria inglésespañol: de las singularidades propias del área a la elaboración de propuestas didácticas con AIBLE. RESLA, n.24, p.153-170, 2011.

Renzi, Gladys. Educación Física y su contribución al desarrollo integral de los niños en la primera infancia. Revista iberoamericana de educación, v.7, n.50, p.1-14, nov. 2009. 
Salvador, Celina; Chiva, Òscar, Fazio, Alessandra. Características del Aprendizaje Integrado de Contenidos de Educación Física y Lengua Extranjera. Retos. Nuevas tendencias en educación fisica, deporte y recreación, n.29, p. 120-125, $1^{\circ}$ sem. 2014.

Sherin, V.; Sherina, A. Improvement of university educational activity in terms of formation of bilingual environment in sphere of physical culture and sport. Teorija i praktika fiziceskoj kultury, v.7, 2015. Disponible em: $<$ http://www.teoriya.ru/en/node/3854>. Acceso em: 3 oct. 2016.

Tilio, Rogério. Língua Estrangeira Moderna na Escola Pública: possibilidades e desafios. Educação e realidade, v. 39, n.3, p. 925-944, jul./set. 2014.

Toumpaniari, Konstantina; Loyens, Sofie; Mavildi, Myrto; Paas, Fred. Preschool children's foreign language vocabulary learning by embodying words through physical activity and gesturing. Education psychological review, v.27, n.3, p.445-456, sep. 2015.

Trujillo, Fernando. Enseñar nuevas lenguas en la escuela: L1, L2, LE...NL. Revista de Educación, n.343, p.71-91, may/ago. 2007.

Vicente, Miguel. Bases para una didáctica crítica de la Educación Física. Apunts. Educació Física y deportes, n.123, p.76-85, ene./mar. 2016.

Villanueva, Marisa. Los estilos de aprendizaje ante los retos de la Europa multilíngue. In: MIQUEL, Lourdes; SANS, Neus. Didáctica del español como lengua extranjera. Madrid: Actilibre, 2002. p. 243-263.

Williams, Dylan. A Systematic Review of English Medium Instruction (EMI) and implications for the South Korean education context. English Language Teaching World Online, abr. $2015 . \quad$ Disponible en: $<\underline{\text { https://blog.nus.edu.sg/eltwo/files/2015/04/EMI-in-South-Korea editforpdf- }}$ 1gmsyy5. pdf>. Acceso en: 3 oct. 2016.

\section{Apoyo:}

Seminario Permanente de Intercambio de Experiencias de Docencia en Inglés (SPIEDA). Referencia: 2523/12. Centro: Facultat Ciències Humanes i Socials. Departament: Estudis Anglesos. 


\begin{tabular}{|c|c|c|c|c|c|}
\hline Publicación & Nivel & $\begin{array}{l}\text { Localización } \\
\text { geográfica }\end{array}$ & $\begin{array}{l}\text { Muestra - } \\
\text { duración }\end{array}$ & Tipología & Metodología \\
\hline $\begin{array}{l}\text { Coral; Lleixà } \\
(2016)\end{array}$ & Educación Primaria & España & 26 estudiantes & Estudio & $\begin{array}{l}\text { Cualitativa e } \\
\text { investigación- } \\
\text { acción }\end{array}$ \\
\hline $\begin{array}{l}\text { Salvador; Chiva; } \\
\text { Fazio (2016) }\end{array}$ & Educación Primaria & España & $\begin{array}{l}\text { xxx -1 Unidad } \\
\text { Didáctica (6 } \\
\text { sesiones) }\end{array}$ & Experiencia & $\begin{array}{l}\text { Revisión y } \\
\text { experiencia }\end{array}$ \\
\hline $\begin{array}{l}\text { Baena; Granero } \\
\text { (2015) }\end{array}$ & $\begin{array}{l}\text { Educación } \\
\text { Secundaria }\end{array}$ & España & 328 estudiantes & Estudio & $\begin{array}{l}\text { Validación de un } \\
\text { instrumento de } \\
\text { evaluación }\end{array}$ \\
\hline $\begin{array}{l}\text { Chiva; Isidori; } \\
\text { Fazio (2015) }\end{array}$ & $\begin{array}{l}\text { Educación } \\
\text { Secundaria }\end{array}$ & España & $\begin{array}{l}\text { xxx - 1 Unidad } \\
\text { Didáctica (6 } \\
\text { sesiones) }\end{array}$ & Experiencia & $\begin{array}{l}\text { Revisión y } \\
\text { experiencia }\end{array}$ \\
\hline $\begin{array}{l}\text { Alonso, Cachón, } \\
\text { Castro; Zagalaz } \\
\text { (2015) }\end{array}$ & Educación Primaria & España & $\begin{array}{l}54 \text { estudiantes - } 1 \\
\text { Unidad Didáctica (6 } \\
\text { sesiones) }\end{array}$ & Experiencia & $\begin{array}{l}\text { Revisión y } \\
\text { experiencia }\end{array}$ \\
\hline $\begin{array}{l}\text { Cepero, García; } \\
\text { López (2013) }\end{array}$ & Educación Primaria & España & $\begin{array}{l}23 \text { estudiantes - } 1 \\
\text { curso escolar }\end{array}$ & Estudio & $\begin{array}{l}\text { Método mixto e } \\
\text { investigación } \\
\text { acción }\end{array}$ \\
\hline Ramos; Ruiz (2011) & Educación Primaria & España & & Propuesta & $\begin{array}{l}\text { Revisión y } \\
\text { experiencia }\end{array}$ \\
\hline $\begin{array}{l}\text { Coral; Lleixà } \\
\text { (2014) }\end{array}$ & Educación Primaria & España & $\begin{array}{l}27 \text { estudiantes - } 1 \\
\text { curso escolar }\end{array}$ & Estudio & Cualitativa \\
\hline $\begin{array}{l}\text { Coral, Lleixà; } \\
\text { Ventura (2016) }\end{array}$ & Educación Primaria & España & $\begin{array}{l}1175 \text { colegios de } \\
\text { Primaria }-3 \text { cursos } \\
\text { escolares }\end{array}$ & Estudio & Cuantitativa \\
\hline
\end{tabular}




\begin{tabular}{|c|c|c|c|c|c|}
\hline $\begin{array}{l}\text { Moore; Lorenzo } \\
\text { (2015) }\end{array}$ & $\begin{array}{l}\text { Educación Primaria } \\
\text { y Secundaria }\end{array}$ & España & & Estudio & \\
\hline Mulia (2015) & Educación Infantil & Indonesia & 10 estudiantes & Estudio & $\begin{array}{l}\text { Cualitativa e } \\
\text { investigación- } \\
\text { acción }\end{array}$ \\
\hline $\begin{array}{l}\text { Toumpaniari, } \\
\text { Loyens; Mavil- di } \\
(2015)\end{array}$ & Educación Intantil & Grecia & $\begin{array}{l}67 \text { estudiantes - } 4 \\
\text { semanas }\end{array}$ & Estudio & Cuasi-experimental \\
\hline $\begin{array}{l}\text { Griva; Semoglou } \\
\text { (2012) }\end{array}$ & Educación Primaria & Grecia & $\begin{array}{l}44 \text { estudiantes - } 16 \\
\text { semanas }\end{array}$ & Estudio & Mixta \\
\hline $\begin{array}{l}\text { Griva, Semoglou; } \\
\text { Geladari (2010) }\end{array}$ & Educación Primaria & Grecia & $\begin{array}{l}50 \text { estudiantes }-3 \\
\text { meses }\left(1^{\text {a }} \text { fase }\right)+16 \\
\text { semanas }\end{array}$ & Estudio & Mixta \\
\hline $\begin{array}{l}\text { Mavildi, Okely, } \\
\text { Chandler, Cliff; } \\
\text { Paas (2015) }\end{array}$ & Educación Intantil & & $\begin{array}{l}111 \text { estudiantes - } 4 \\
\text { semanas }\end{array}$ & Estudio & Cuantitativa \\
\hline $\begin{array}{l}\text { Griva; Chostelidou } \\
\text { (2015) }\end{array}$ & Educación Intantil & Grecia & 16 semanas & Estudio & \\
\hline $\begin{array}{l}\text { Harris; Stockton } \\
\text { (1973) }\end{array}$ & Educación Primaria & Estados Unidos & $\begin{array}{l}120 \text { estudiantes }-6 \\
\text { semanas }\end{array}$ & Experiencia & Cuantitativa \\
\hline $\begin{array}{l}\text { Sherin; Sherina } \\
\text { (2015) }\end{array}$ & Universidad & Rusia & & Estudio & Cualitativa \\
\hline
\end{tabular}




\subsection{Estudio de las percepciones de los principales agentes implicados}

El segundo subapartado concierne a la segunda fase del proyecto, es decir, el estudio interpretativo de las percepciones de docentes y discentes. De este modo, en este punto se pretende dar respuesta al segundo objetivo de investigación que queda establecido de la siguiente forma:

- "O.2. Investigar cuáles son las percepciones sobre la aplicación de AICLE en educación física de los agentes implicados directamente en su desarrollo.”

Con este objetivo se trata de ahondar en la visión sobre el uso de AICLE en educación física que tienen aquellos y aquellas docentes y discentes que han vivido en primera persona su aplicación. La perspectiva de cada una de estas poblaciones se aborda de manera separada, de modo que cada manuscrito hace referencia a una de las dos vertientes de este objetivo de investigación.

En primer lugar, el manuscrito 3 satisface el objetivo 2.1.:

- O.2.1. "Analizar cómo vive y qué opina sobre AICLE el profesorado de educación física que lo ha aplicado en sus clases."

La motivación de la que brota este texto radica en que, a menudo, el discurso docente dista considerablemente de la norma organizativa y del discurso científico (Pallarés et al., 2018). De hecho, siguiendo a Anderson et al. (2015), usualmente el profesorado es un agente carente de poder y sujeto a la voluntad de los legisladores. A pesar de esta exánime posición epistémica en el debate político, los y las docentes atesoran, gracias a su experiencia, conocimiento y habilidades, un gran potencial de colaboración en la investigación pro innovación y mejora en el campo educativo (Ellison, Anderson, Aronson y Clausen, 2018). Sin ir más lejos, Fullan (2007) asevera que el profesorado se erige como un agente clave a la hora de llevar a la práctica las reformas educativas impuestas por las instancias superiores. Por este motivo, es pertinente conocer su posicionamiento con respecto a la, en muchos casos, imposición de la enseñanza de lenguas a través, en nuestro caso, de la educación física.

El manuscrito 3 parte de esta idea y trata de desvelar cuáles son los posicionamientos a los que se adscriben los y las docentes de educación física que han utilizado AICLE con respecto 
a la introducción de dicho enfoque pedagógico en sus sesiones. A fin de ahondar en sus creencias, ideas y concepciones, optamos por emplear la metodología cualitativa decantándonos por un acercamiento interpretativo de la investigación (Flick, 2009). 
MANUSCRITO 3

Título:

CLIL in teaching physical education: views of the teachers in the Spanish context

AUTORES:

Celina Salvador García y Òscar Chiva Bartoll

FUENTE:

Journal of Physical Education and Sport

(Publicado)

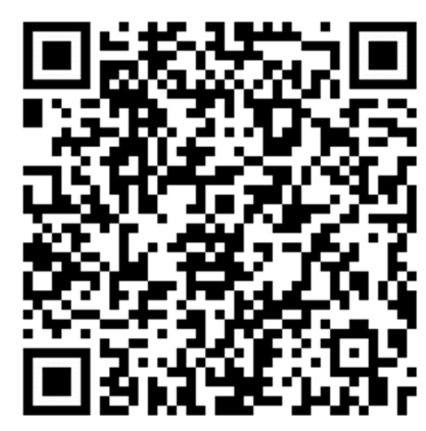




\title{
CLIL in teaching physical education: views of the teachers in the Spanish context
}

\author{
SALVADOR-GARCIA CELINA ${ }^{1}$; CHIVA-BARTOLL OSCAR ${ }^{2}$ \\ ${ }^{1,2}$ Department of Education, Universitat Jaume I, SPAIN
}

Published online: September 30, 2017

(Accepted for publication August 29, 2017)

DOI:10.7752/jpes.2017.03174

\begin{abstract}
:
Content and Language Integrated Learning (CLIL) provides students with enhanced opportunities to acquire competence in additional languages while learning different subjects. Due to its features one of the target subjects for the application of CLIL is Physical Education (PE). In this subject its application is widespread in countries such as Italy, Greece or Spain among others. The particular interest of this research focuses on the Spanish context. Spanish education is particularly sensitive to European initiatives regarding language policies. The aim of the study is to know, from the PE teachers' viewpoint, whether the essence of PE is subjected to so substantial modifications due to the introduction of CLIL that jeopardize its idiosyncrasy. We opt for a pure qualitative research method based on semistructured interviews. Particularly, an a priori theoretical orientation that influenced the development of our research questions, interview protocols, and subsequent data analysis was used. The results found were organized in five categories of analysis: Curricular effects, Language insertion, Teaching method, Motivation and Workload. Furthermore, each category was broken into several subcategories. The application of CLIL within the Secondary education in Spain does not endanger the essence of the PE according to the interviewees' perception. However, the study may conclude that there is a need to improve the amount of workload and the acknowledgement of teachers involved, since it could result
\end{abstract}


in an increase of burn- out and demotivation.

Key words: CLIL, physical education, teachers, qualitative research, bilingual education.

\section{Introduction}

The term Content and Language Integrated Learning (CLIL) was launched in Europe as a result of the growing interest in an active pursuit of improved foreign language teaching methods. This methodology is much welcomed at a time when the countries of the European Union are increasingly becoming integrated and, indeed, as nations around the world become globally connected. Since it was launched in the 1990s, the European Commission and the Council of Europe have funded many initiatives in support of CLIL because it responded to a need in Europe for enhancing second-language education and bilingualism (Marsh, 2002). In the Physical Education (PE) field it is easy to encounter examples of its application in countries such as Italy, Greece or Spain among others (Salvador et al., 2017) and even similar studies which use PE to teach a second language have been developed in the USA (Lieberman et al., 2010; Nguyen \& Watanabe, 2013; Santillan, Jacobs \& Wright; 2015; Sato \& Hodge; 2016; Sato, Walton \& Kim, 2017), even though these do not use CLIL methodology. Specifically, the focus setting of the current paper is the Spanish context, although some of the results presented may be interesting for the rest of countries using CLIL and/or those interested in using it or a similar method in the future.

There is little question that providing students with enhanced opportunities in school to acquire competence in additional languages will better prepare them for globalization. There are a variety of definitions and interpretations of CLIL (Cenoz et al., 2014; Mehisto et al., 2008), but Coyle et al., (2010: 1) present a succinct definition that refers to its specific features: 'Content and Language Integrated Learning (CLIL) is a dual-focused educational approach in which an additional language is used for the learning and teaching of both content and language'. According to this definition, CLIL can include a wide range of educational practices provided that these practices are conducted through the medium of an additional language. Particularly, it is important to recognize that in the European context, CLIL has mainly attracted practitioners of a number of specific subjects in the field of English as a foreign language. 
How does CLIL affect the subject matter?

CLIL has been gaining importance in recent years due to its introduction in many educational settings to enhance language learning. However, it is necessary to know whether the essence of each specific area is subjected to so substantial modifications that jeopardize its idiosyncrasy. With regard to this topic, previous research reports uncertain impact related to the implementation of CLIL in different subjects. On the one hand, in addition to benefit foreign language skills (Köller et al., 2012; Nold et al. 2008), several authors affirm that CLIL can transform the dynamics of the lessons towards a more student-centered, constructivist and motivational learning, since it allows the use of real language to access information and to understand and reformulate acquired knowledge (Pérez-Cañado, 2011). Besides, from the teacher's viewpoint, Pérez-Cañado (2011) states that CLIL also increases generic competence acquisition and does not water down contents, but increases their learning.

On the other hand, from the perspective of cognitive load theory (Sweller et al., 1994), it might be argued that students' working memory is overloaded by simultaneously processing new content and the foreign language. In this vein, it is very likely that CLIL students will often be struggling, with limited foreign language knowledge, lexically dense texts, and limited background knowledge of the subject matter (Bruton, 2015). Moreover, research conducted in actual CLIL classes also shows that it is difficult to achieve a strict balance of language and content (Mehisto et al., 2008; Salvador et al., 2016).

\section{Effects of CLIL on PE}

In order to contribute to a better understanding of the issue in the PE arena we should, therefore, inquire whether the goals of PE curriculum are achieved differently from the way they are achieved in L1, when the contents are taught through a CLIL approach (Coral and Lleixà, 2014). Focusing specifically on this field and according to literature, there are several key factors which underlie to its idiosyncrasy and essence that might be affected when applying CLIL such as (1) curricular effects, (2) insertion of the language, (3) teaching method, (4) motivation and (5) workload.

To begin with, many researchers of the PE field assume that the foreign language 
development means that activities will have both PE and language goals (Coral, 2013; Clancy and Hruska, 2005; Hernando, 2015; Salvador et al., 2016; Zindler, 2013), what necessarily involves modifying curricular elements of PE such as objectives, evaluation or contents (Chiva et al., 2015; Figueras et al., 2011; González et al., 2013; Glackas, 1995; Hortigüela et al., 2016b; Molero, 2011; Zagalaz et al., 2012). Even though PE goals are the priority, some objectives related to language should be included (Clancy and Hruska, 2005; Hernando, 2015; Salvador et al., 2016; Zindler, 2013). Focusing on evaluation, many teachers wonder whether they should assess language, content or both (Coyle et al., 2010). In this sense, Coral (2013) determines that language should be evaluated, although this process must be considered bearing in mind the CLIL practitioners' specific situation (Coyle et al., 2010).

Moving now to the contents, there are opposite conceptions and arguments about it. While Figueras et al. (2011) conclude that from the participants' perception the specific contents of PE do not suffer any damage, Martínez and García (2017) warn that incorporating the foreign language entails reducing the quantity of specific contents. In the same vein, Hernando (2015) and Hortigüela et al. (2016a) refer to a slowdown in the content approach. Specifically, Coral (2010) and Lynott (2008) refer to losses in motor learning as a consequence of the shorter physical activity time available.

When it comes to the insertion of the language, according to Coral (2012) it should be integrated with the motor skills development. In a like manner, the four linguistic skills should be practiced (Hernando, 2015; Hortigüela et al., 2016b) and opportunities to interact should be enhanced (Coral and Lleixà, 2014; Molero, 2011; Zagalaz et al., 2012). Even though, Molero (2011) and Zindler (2013) warn us because there is a risk of falling into a too theoretical approach that reduces the practical essence of PE.

Hence, PE teachers are increasingly expected to be familiar with language pedagogy that makes content comprehensible for students (Chiva and Salvador, 2016; Coral, 2013; Gómez and Jiménez, 2012). Consequently, in order to allow a balance between the motor, linguistic and cognitive demands, PE teaching methods should be redefined to increase cooperation and verbal interaction among students (Coral and Lleixà, 2014; Figueras et al., 2011; Molero, 2011; Zagalaz et al., 2012). This results in the promotion of social interaction (González et al., 2013). 
Another point worth underlining in PE with CLIL is the motivation. In this case, two approaches exist: some authors express that CLIL is a motivating input for students, while others argue that it can distort educational practices. On the one hand, Coral (2010) mentions that students' intrinsic motivation for the movement has a positive influence on English learning, which becomes a reinforcement to learn specific PE content (Figueras et al., 2011). On the other hand, there are investigations warning that the foreign language may be transformed into an element that negatively affects students' interest in PE (Hernando, 2015; Ramos and Ruiz, 2011). Specifically, Baena and Granero (2015) suggest that learning a foreign language could generate stress and anxiety, which is confirmed by Figueras et al., (2011).

Finally, regarding workload, we must highlight a lack of materials thought to develop language in PE tasks (Gómez and Jiménez, 2012; Mehisto et al, 2008). The truth is that there are few materials prepared and teachers have to choose between using those published or create their own (Coral, 2013). CLIL means a great challenge for teachers (Clancy and Hruska, 2005; Coral, 2012; Coral and Lleixà, 2014; González et al., 2013; Hernando, 2015; Molero, 2011), because it is necessary a linguistic and pedagogical formation whose lack would imply a handicap to make their messages understandable (Coral, 2013; Hortigüela et al., 2016a; Molero, 2011).

\section{CLIL in the Spanish context}

CLIL is extensively used in non-English-speaking countries since this is the target language in most of the cases, as the one presented here. This fact explains that a considerable amount of researches concerning this specific methodology have been developed and published in countries such as Greece, Spain or Italy (Salvador et al., 2017). The particular interest of our research focuses on the Spanish context, where due to the introduction of plurilingualism in the education system, the use of CLIL is very widespread. In particular, we attempt to obtain insights into educational PE processes and practices related to the application of CLIL using English language within the Secondary education in the Spanish context. In order to explore what 'happens' in CLIL PE lessons it is relevant to give voice to the teachers who have been implementing them. In fact, it has been well-documented in the literature that understanding teachers' views is significant when it comes to improving teaching practices (Tsangaridou, 
2006). Several studies have already been developed in this sense and concerning CLIL methodology (Bolarín, Porto \& García, 2012; Lova, Bolarín \& Porto, 2013; Pavón \& Rubio, 2010); however, they were not focused specifically on the PE subject and teachers. Therefore, this study will focus on considering and clarifying the PE teachers' perspectives and beliefs.

Currently, Spanish education is particularly sensitive to European initiatives regarding language policies. In fact, according to the national legal framework, it seems that plurilingualism has been enhanced progressively, particularly within the last decade. Nowadays, plurilingualism promotion is still increasing its relevance as can be perceived through the last educational decrees published. Generally, Spanish teachers who implement bilingual practices have to fulfil the following requirements: (1) at least B2 language level according to the CEFR (Common European Framework of Reference for the Languages), (2) official certificate or specific authorization that enables them to teach in the specific language. However, these may slightly differ depending on the autonomous region.

The general purpose of this study was to explore PE teachers' perspectives regarding the effects that CLIL methodology produces on their subject. This main aim was divided into more concrete research questions according with the literature review: (1) How does CLIL affect PE curricular elements? (2) How does CLIL affect the language used in the lessons? (3) How does CLIL affect the teaching method? (4) How does CLIL affect the motivation of the participants? and (5) How does CLIL affect the teachers' workload?

\section{Material \& methods}

Considering the research questions of this study, we opt for a pure qualitative research method. It focuses on the exploration of perceptions, meanings, beliefs, experiences, and feelings characteristic of the phenomenon under investigation (Halcomb and Davidson, 2006), which in this case is the specific insight into educational PE practices of CLIL within the Secondary education context in Spain. First, existing research helped to frame our approach. That is, the a priori theoretical orientation used influenced the development of our research questions, interview protocols, and subsequent data analysis (Creswell, 2012). In this way, the five categories introduced in the theoretical framework determined the research questions and the data analysis, which was divided in the following categories: (1) curricular effects, (2) insertion of the language, (3) teaching method, (4) motivation and (5) workload. 
After the data classification, these main categories were broken into several subcategories, some of them in accordance with the literature review, whereas others were emergent and were not expected (Renner and Taylor-Powell, 2003).

\section{Participants}

The sample was composed by eight PE teachers (four female and four male) from different Spanish Secondary schools who have been applying CLIL methodology at least during the last three academic years. Moreover, all of them have an official certificate that enables them to teach their subject in English through CLIL. This purposive sampling has been selected to attempt to achieve representativeness (Patton, 2002). The attributes for sample selection are displayed in Table 1. Their selection sought to approximate as much as possible the defining features of the study population.

Table 1. Configuration and main features of the participants involved.

\begin{tabular}{|c|c|c|c|c|}
\hline $\begin{array}{l}\text { CLIL students } \\
\text { age }\end{array}$ & $\begin{array}{l}\text { Age of the } \\
\text { teacher }\end{array}$ & $\begin{array}{l}\text { Experience } \\
\text { (years) using } \\
\text { CLIL }\end{array}$ & $\begin{array}{l}\text { Gender of the } \\
\text { teacher }\end{array}$ & $\begin{array}{l}\text { Number of inhabitants of } \\
\text { the city where the } \\
\text { Secondary school is } \\
\text { located }\end{array}$ \\
\hline $\begin{array}{l}12-14 \\
\text { years old }\end{array}$ & $30-40$ & $\mathrm{~N}=6$ & Mal. & $<20000$ \\
\hline \multirow{3}{*}{$\begin{array}{l}14-16 \\
\text { years old }\end{array}$} & $40-50$ & \multirow[t]{3}{*}{$\mathrm{N}=2$} & \multirow[t]{3}{*}{ Fem. } & $20000-150000$ \\
\hline & $50-60$ & & & $>150000$ \\
\hline & & & & \\
\hline
\end{tabular}

The participants of our study have been chosen because comprehending them will lead to better understanding, perhaps better theorizing, about a still larger collection of cases in the analyzed context (Stake, 2000). To make a proper selection of cases we opt for a parallel sampling design that will promote credible comparisons of them. This design implies comparing each case to all others in the sample, focusing mainly on perceptions and experiences referred to the theoretical nuclei determined. The teachers in this study had received thorough information about ethical considerations regarding informed approval and confidentiality, building on guidelines from our University ethics committee and had thereafter accepted to participate in the study.

\section{Instrument}

Semi-structured interviews were used in this study since they have found favor with many 
researchers as they permit the participants to describe detailed personal information, but at the same time the interviewer has good control over the information received (Creswell, 2012). Therefore, a list of key points was used to construct the interview guide, although other questions emerged from the dialogue between interviewer and interviewee to probe for more relevant data (DiCicco and Crabtree, 2006; Mackey and Gass, 2005). Each of these topic areas was introduced by, at least, an open question, ended by a confrontational one and in between several theory- driven questions were asked.

By following this procedure it is possible to reconstruct the interviewee's subjective theory without biasing it. In this sense, open-ended questions aim to get the knowledge that the interviewee has already got at hand, theory- driven questions are focused on trying to make this knowledge more explicit and the pursuit of confrontational questions is the reexamination of these notions (Flick, 2009). Examples of each type of these inquiries are the following ones: 'In your opinion, is CLIL suitable for the Secondary education level in PE? Why?' (open- ended), 'Have specific contents been lessened or reduced due to the use of CLIL?' (theory-driven), 'Do you feel more responsible for the development of communicative competence when you are using CLIL?' (confrontational). The interviews took between 55 and 70 minutes and were recorded with a SONY ICD-P530F recorder. Pseudonyms are used to protect the interviewees' identities.

\section{Data translation}

The interviews were developed in Spanish, therefore data were translated into English by the authors after its analysis took place. A professional translator assisted in the translation process of the quotes that appear in the results section.

\section{Data analysis and trustworthiness}

We have followed the steps proposed by Halcomb and Davidson (2006) to analyze the audiotape recordings, through which a series of categories and subcategories have been differentiated. In alignment with Creswell (2002), the subcategories can be classified as expected (those that had previously emerged from the literature review), and unexpected (those which were adventitious). First, the interviews were transcribed and then a preliminary content analysis was conducted. In the secondary content analysis each researcher 
individually analyzed recurrent topics across categories which were then shared. Subcategories agreement was reached by examining the data and discussing our interpretations. Finally, the recordings were relistened to make any necessary change and illustrative examples with which to demonstrate the participants' perspectives concerning each category and subcategory were selected.

We consider that our experience as researchers in CLIL has helped to strengthen the trustworthiness of the present study, in that we thereby have pre-understanding of the topic under investigation. With respect to the validity of the study, often referred to as authenticity in qualitative research, we claim that the ethical considerations concede a given degree of authenticity (Lincoln et al., 2011). Moreover, there is authenticity involved in the fact that we do not attempt to find general results about CLIL in PE, but merely for the Spanish context, which is supported by the sample selected. Finally, a member-check process was implemented.

\section{Results}

Below we present the main outcomes of the analysis according to the five research questions in which the results have been divided. Later on the five categories were broken into several subcategories.

\section{Curricular effects}

Developing CLIL may imply a modification of the PE curriculum (Pavón \& Rubio, 2010). However, when asked about this topic through an open-ended question, all the teachers agreed that from a general viewpoint there was not a significant change in their subject. 'Actually, I believe that nothing has changed, everything has been more or less the same' (Teresa) was one of the responses obtained, in line with the words of the other seven interviewees.

Nevertheless, when enquiring about the modification of more specific aspects of the curriculum, we found that some adjustments were made. In this line, three interrelated subcategories were set. The first one concerning the objectives, the second one focused on evaluation, and the third one related to content. Objectives showed clear consonance among the teachers because for them 'the most important are PE goals since we are doing PE' 
(Jaime). Despite this fact, the interviewees stated that linguistic goals were added with more or less relevance, depending on each case: 'You introduce English objectives such as the vocabulary and structures that you want them to learn, the fact that you want them to communicate in English, etc.' (Lidón).

On the contrary, the second subcategory, focused on evaluation, may be divided into two different approaches. On the one hand, there are some teachers who do not evaluate language because according to them 'language is assessed in the English subject' (Àngels). On the other hand, we find those who do introduce language on the evaluation, albeit they 'try it not to have too many consequences on the mark' (Iñaki). In fact, one of the teachers mentioned that 'basically I take into account their ability to communicate and express themselves' (Pablo) and another admitted that 'regarding English language, I think that PE should only assess the students' effort. I am not going to grade English more than PE content' (Iñaki). Therefore, those who do include English in the assessment do it in a very subtle way.

Regarding contents, the teachers agreed that specific PE contents were not diminished. In one of the interviewees' words, 'the idea was that the level of contents remained the same' (Ester). Moreover, in general, they did not believe that students had a shorter engagement physical activity time. Although in certain occasions, 'explanations could be longer' (Jaime); other times they were even 'more direct and dynamic' (Manuel) because students language level avoided its overuse. Therefore, 'the essence of sport and physical activity stayed the same, without stop' (Lidón).

\section{Language insertion}

A second category was established focusing on language insertion and divided into two subcategories: linguistic skills and attention to communication. 'The four linguistic skills were introduced in a way or another' (Pablo). Depending on each skill, they were given more or less emphasis in order not to disturb the usual development of the lesson. Although there were no relevant modifications in the communicative interaction, moving to the second subcategory, a thoroughly consideration regarding communication appeared as a general characteristic of PE teachers when using CLIL. Undoubtedly, 'PE content was the priority' (Ester), however, they bore more in mind communicative competence when following this methodology. 
I believe that English makes the teacher to pay more attention to communicative competence. Undoubtedly, in ordinary lessons we should pay it as much attention as possible, but as we have to develop our lessons in English, communicative competence concerns us even more. (Pablo).

Furthermore, there was an agreement on the fact that teachers want to make sure of the students' understanding. There was a general worry and they opted for different strategies to cope with possible comprehension problems and ensure effective communication. 'I wanted somebody else [student] to give the explanation to make sure whether they had understood or not. Besides, it means that students are receiving the message through different ways' (Manuel).

\section{Teaching method}

Related to the previous category, the methodology used by the teacher is another of the aspects which may be influenced by the introduction of English language in the PE subject. This category has been broken into three different subcategories. Teaching style and group work were in line with the literature review, but the third subcategory, major relevance of social constructivism, emerged after the data analysis. In relation to the first subcategory, as a consequence of the aforementioned increase of the attentiveness to communication during the lessons, teachers agreed that they tend to use more open and participative teaching styles. I think that [CLIL needs] the adoption of a more deliberative approach, by using teaching styles which are not directive and that do not have a concrete answer. I offer a problem, a challenge, and each group has to look for its own answer or possible answers. Later on, they have to share it with their classmates and justify their choices. (Àngels)

In this same line, appears the second subcategory. Cooperative and collaborative work was also highlighted as another possibility to favor communication and the use of the language because 'group work is important' (Iñaki). There was a harmony among the teachers' responses and all of them followed the same ideas. One of the ways to encourage the use of the language is proposing cooperative tasks. At the level of the structure of the session, it seems quite evident that we must search cooperative structures if we want to encourage the use of the language. (Ester) 
This methodological and organizational option was also conceived as an excellent possibility which enables students' understanding and learning. In words of one of the teachers 'to facilitate students' understanding, the fact that they worked in group was a key point to facilitate their learning' (Pablo). Closely linked with this regard, the third subcategory, major relevance of social constructivism, emerged. Teachers expressed that these changes helped to integrate all the pupils because through group work 'they can help each other more' (Lidón) and learn together.

Maybe in Spanish they do not have problems, but now there must be more cooperation among them. If they work in groups, they can correct each other and if someone does not know something, a classmate can help him or her. (Lidón)

\section{Motivation}

This category has been subdivided into two subcategories, maintenance or increase of motivation, which was set a priori; and the unexpected more attentiveness. All the teachers interviewed showed a congruity regarding students' motivation. According to them, 'in general, motivation was high and kept at a high level' (Pablo). Besides, some of them expressed that it was not only because of the PE subject, but language played a role too.

The fact of using English and see that the rest of the students are understanding them and that they can express themselves in English, although it is not through a perfect use of the language (...); I think it has got a direct connection with motivation. (Manuel)

However, they also express that there were exceptions because 'there is always a student who does not care about studies, is apathetic and disconnects' (Jaime).

Otherwise, according to the teachers' perceptions, an unexpected subcategory emerged, more attentiveness, since many students increased their level of attention during the lessons. In this way, 'even students who did not understand tried to get the information and, therefore, maybe they were more focused on the explanations' (Ester). In this sense, teachers agreed to say that the use of English implied an increase of students' attentiveness because they had to focus on both, understanding and performing the tasks of the class.

\section{Workload}


Albeit it cannot be conceived as a direct effect of the introduction of CLIL in the lessons, workload does have an impact on the teacher and his or her tasks; that is why it has been established as the fifth category of analysis. This category has also been broken into two different subcategories, the expected increase of planning and the emergent unacknowledged (hard)work. With respect to the former, every single one of the teachers interviewed agreed with the fact that 'in PE with English, there is a higher effort regarding planning' (Pablo). Maybe lessons do not significantly change in view of the tasks, nevertheless the amount of time that teachers have to spend to plan adequate lessons is considerably higher since they are paying more attention to language and communication.

There is a lot of vocabulary that I have to search prior to the lessons to be able to explain everything adequately. Besides, I have to explain it in a way in which they understand me. I cannot use just the translation of a word because they are not going to understand. I have to plan how I am going to make myself understood. (Teresa)

In addition, it is not only the time what teachers highlighted, but also the effort and the fact that anybody acknowledges their (hard)work. In this line, one of the teachers stated that introducing language implies 'a lot of work without any compensation' (Pablo). However, all of them agreed to say that it was a motivating work of which they were proud of. 'It has been a great effort, but it was not a sacrifice' (Manuel) were the words used by one of the teachers and another expressed that 'it was an effort, but it was worth it. It was an exciting task' (Pablo).

\section{Discussion}

The results obtained from the data analysis complement and reinforce the state of the art. By means of the interviews five categories were established which let us configure the PE teachers' perceptions on the effect of introducing CLIL methodology in their lessons.

Firstly, related to curricular effects, what they made clear is the fact that the most important aspect of the lessons is still PE despite the insertion of the language, which is completely in accordance with the words of Fernández-Barrionuevo (2009), who stated that the main goal was the teaching of PE content, and the L2 (second language) would only be the tool through which get the objectives. Regarding the subcategory of objectives modification, the 
interviewees recognized that PE goals remain similar but some linguistic ones are added, in accordance with Clancy and Hruska (2005), Hernando (2015), Salvador et al., (2016) and Zindler (2013); therefore, PE curriculum should be slightly re-adapted to fit with CLIL (Hortigüela et al., 2016b; Molero, 2011). The third subcategory deals with alterations and changes in the evaluation. In this sense, teachers' perceptions may be differentiated in two viewpoints. On the one hand, some teachers stated that language was not considered within the evaluation of their PE subject. On the other hand, we find those who do include some kind of linguistic issue in their evaluation process, although the majority of them introduces it in a quite subtle way intending the mark is not influenced, in line with Coral (2013). This divergence shows that there is not a clear discourse when a decision has to be made regarding the inclusion of language in evaluation (Coyle et al., 2010).

Focusing specifically on contents, teachers expressed that there was no loss on engagement physical activity time nor specific PE learning, in accordance with Figueras et al., (2011), although in specific situations or moments explanations could be longer or students could need more time to understand the activities. Therefore, in their opinion, generally there was not any delay on learning or a loss of time due to language, contrasting with Coral (2010), Hernando (2015) and Martínez and García (2017), who warned about a possible decrease of the motor learning time available.

Related to language insertion, according to Amade-Escot and O'sullivan (2007:197), 'particular knowledge has to be covered and explained in specific ways by the teacher [...]. This fact has an effect on the type of interactions in use in classrooms'. In this vein, the teachers interviewed coincided in their assertion that language was not a handicap in the development of the lessons. In fact, it was determined that they tried to integrate language and motor skills, which is in agreement with Coral (2012). Furthermore, the four linguistic skills were incorporated (Hernando, 2015; Hortigüela et al., 2016b), despite doing it with different emphasis depending on the skill; and there was a growing concern over communication. In this sense, Molero (2011) and Zagalaz et al. (2012) defended that opportunities to communicate and interact should be enhanced while Coral and Lleixà (2014) focused their study on different strategies to favor such communication.

Regarding the teaching method, the results evinced that more open and participative teaching 
styles were promoted over those that are more directive to favor communication. In this vein, Glakas (1993) suggested this modification to happen in order to enhance language learning. Moreover, according to the responses obtained, teachers attempted to create messages understandable for students, as reported by Coral (2013), to facilitate the communicative act (Molero, 2011; Zagalaz et al., 2012).

Cooperative and collaborative group work are also raised because they increase language use and better understanding. In this sense, through tasks which are not individual or require an opponent, social interaction is enhanced, which at the same time entails a more important role of the language (Bolarín et al., 2012; Coral and Lleixà, 2014; González et al., 2013). Furthermore, these changes in teaching style and tasks implied a growth of learning values and more integration among students, according to the teachers' answers. This may mean that PE in CLIL alludes to a learning based on social constructivist principles (Vygotsky, 1995), as reported by Figueras et al., (2011), who arrived at this same conclusion after their experience.

Motivation is a category that represents a key factor in the learning process (Shropshire et al., 1997; Subramaniam and Silverman, 2007). Perlman (2013) states that different forms of teacher instruction can influence students' motivational responses within Secondary physical education. In this sense, the interviewees mentioned that, in general, motivation in class was high and remained high when using CLIL. In this sense, the interviewees mentioned that, in general, motivation in class was high and remained high. However, there were specific cases in which language could affect negatively to some particular students, as previously reported by Ramos and Ruiz (2011). It is worth saying that this does not always happen and, in fact, in other cases language may become a positive element to increase motivation (Figueras et al., 2011; Zindler, 2013). Hence, it might be remarked that each learner is unique and, consequently, the introduction of another language can affect differently.

In this line, another effect that, according to the teachers, was caused by the language: an increase in some of the pupils' attentiveness. This fact is in accordance with Figueras et al. (2011), although in their study participants were at university and, therefore, they were supposed to be more mature and serious towards the learning process. According to Zindler (2013), PE with CLIL is cognitively more challenging and, consequently, pupils might have 
to be more focused on what is happening in the lesson if they want to follow properly the class, understand everything and avoid having to ask for more information.

Finally, workload was highlighted by the teachers as a relevant factor that affected their tasks. In this sense, planning becomes an essential aspect that must be considered (Martínez and García, 2017) because when introducing CLIL teachers not only have to plan PE lessons, but also integrate the language and prepare a proper discourse and the scaffolding that might be needed (Coral, 2013; Gómez and Jiménez, 2012; Ramos and Ruiz, 2011). Moreover, the lack of materials already prepared (Coral, 2013; Gómez and Jiménez, 2012; Mehisto et al., 2008) in the end means even greater effort (González et al., 2013; Lova et al., 2013). Teachers also remarked the fact that nobody acknowledged their work, which could turn into an increase of burn-out and, therefore, less teachers willing to continue with their CLIL practices.

\section{Conclusions}

The analysis applied encourages us to raise the following conclusions. Considering the interviewed teachers' perspectives and beliefs, the application of CLIL within the Secondary education in Spain does not endanger the essence of the PE. From a general viewpoint, there is not a significant change in the PE curriculum implementation despite subtle adjustments. Moreover, the use of the four linguistic skills is not a handicap to achieve the essential aims and contents of the subject. Indeed, to favor communication more participative teaching styles and cooperative work are developed. In addition, there is a maintenance or increase of students' motivation and attentiveness in the majority of the cases.

As a counterpart, the study highlights a need to improve the workload and acknowledgement of teachers involved in CLIL. This fact allows us to predict that in the medium and long term the good functioning of the educational process could be diminished due to teacher burn-out and demotivation. Therefore, given the importance of CLIL for the plurilingual model to which the Spanish educational system aspires, it is important that the administration takes action on this matter before it is too late.

All in all, these conclusions may be significant for other countries using CLIL since its implementation features are certainly shared. Thus, this is a first approach that, later on, may trigger further studies of CLIL practices in PE. For instance, one dimension that could 
complement this paper to cover the impact of CLIL on PE on a more comprehensive way could be to include the perceptions of the pupils.

Conflicts of interest: the authors declare that there are not conflicts of interest.

Funding: this work was supported by SPIEDA project of the University Jaume I (Reference number-3256).

\section{References:}

Amade-Escot, C., \& O'sullivan, M. (2007). Research on content in physical education: theoretical perspectives and current debates. Physical Education and Sport Pedagogy, 12(3), 185-204.

Baena, A., \& Granero, A. (2015). Versión española del Sport Satisfaction Instrument (SSI) adaptado al aprendizaje de la Educación Física bilingüe en Inglés. Porta Linguarum, 24, 63-76.

Bolarín, M. J., Porto, M., \& García, R. M. (2012). Los programas bilingües en la Región de Murcia: situación y valoraciones de profesores de disciplinas no lingüísticas. Educatio Siglo XXI, 30(2), 255-288.

Bruton, A. (2015). CLIL: Detail matters in the whole picture. More than a reply to J. Hüttner and U. Smit (2014). System, 53, 119-128.

Cenoz, J., Genesee, F., \& Gorter, D. (2014). Critical analysis of CLIL: Taking stock and looking forward. Applied Linguistics, 35(3), 243-262.

Chiva, O. \& Salvador, C. (2016). Aprendizaje integrado de Educación Física y lengua inglesa. Barcelona: INDE.

Chiva, O., Isidori, E., \& Fazio, A. (2015). Educación Física bilingüe y pedagogía crítica: una aplicación basada en el Judo. Retos, Nuevas Tendencias en Educación Física, Deporte y Recreación, 28, 110-115.

Clancy, M. E., \& Hruska, B. L. (2005). Developing language objectives for English language learners in physical education lessons. Journal of Physical Education, Recreation \& Dance, 76(4), 30-35. 
Coral, J. (2010). L'aprenentatge de l'anglès a través de l'educació física: el programa'Mou-te i aprèn'. Temps d'Educació, 39, 149-170.

Coral, J. (2012). Aprenentatge integrat de continguts d'educació física i llengua anglesa: educació fisica en AICLE al cicle superior de primària. $\mathrm{PhD}$ Thesis, Universitat de Barcelona, Spain.

Coral, J. (2013). Physical education and English integrated learning: How School Teachers can Develop PE-in- CLIL Programmes. Temps d'Educació, 45, 41-64.

Coral, J., \& Lleixà, T. (2016). Physical education in content and language integrated learning: successful interaction between physical education and English as a foreign language. International Journal of Bilingual Education and Bilingualism, 19(1), 108-126.

Coyle, D., Hood, P., \& Marsh, D. (2010). CLIL. Cambridge: CUP.

Creswell, J.W. (2002). Educational Research: Planning, Conducting, and Evaluating Quantitative. Upper Saddle River: Prentice Hall.

Creswell, J.W. (2012). Qualitative Inquiry and Research Design: Choosing among Five Approaches. London: Sage.

DiCicco, B., \& Crabtree, B. F. (2006). The qualitative research interview. Medical education, 40(4), 314-321.

Fernández-Barrionuevo, E. (2009). La secuenciación de contenidos lingüísticos dentro de la Educación Física Bilingüe. Revista Innovación y Experiencias Educativas, 23, 1-9.

Figueras, S., Flores, C., \& González- Davies, M. G. (2011). Educació Física en anglès: Percepcions dels estudiants entorn d'una experiència metodològica en el marc universitari. Aloma: revista de psicologia, ciències de l'educació i de l'esport Blanquerna, 29, 61-80.

Flick, U. (2009). An Introduction to Qualitative Research. London: SAGE.

Glakas, B. A. (1993). Teaching secondary physical education to ESL students. Journal of Physical Education, Recreation \& Dance, 64(7), 20-25.

Gomez, C. L., \& Jimenez-Silva, M. (2012). The physical educator as a language teacher for 
English language learners. Strategies, 25(4), 14-17.

González, S., Villar, L., Pastor, J. C, \& Gil, P. (2013). Propuesta didáctica interdisciplinar en educación primaria en España: la enseñanza de la educación física y el inglés. Paradigma, 34(2), 31-50.

Halcomb, E. J., \& Davidson, P. M. (2006). Is verbatim transcription of interview data always necessary? Applied Nursing Research, 19(1), 38-42.

Hernando, A. (2015). Caracterización de los aspectos metodológicos empleados en la enseñanza de la materia de Educación Física en los centros públicos de secundaria con sección bilingüe en inglés de Castilla y León. PhD Thesis, Universidad de Burgos, Spain.

Hortigüela, D., Hernando, A., \& Pérez-Pueyo, A. (2016a). ¿Qué estrategias metodológicas utiliza el profesorado de educación física bilingüe en el aula? In: M.I. Amor, J.L. Luengo \& M. Martínez (eds). Educación intercultural: metodología de aprendizaje en contextos bilingües. Granada: Atrio, pp. 103-106.

Hortigüela, D., Pérez-Pueyo, A., Casado, O., \& Herran, I. (2016b). Bilingüismo y cooperación en educación física a través de la dramatización ¿cómo integrarlo? In: Actes X Congrés internacional d'activitats fisiques cooperatives, Barcelona, Spain, 3-6 July 2016, pp.152-153. Barcelona: Institut de ciències de l'educació de l’UAB.

Köller, O., Leucht, M., \& Pant, H. (2012). Effekte bilingualen Unterrichts auf die Englischleistungen in der Sekundarstufe I. Unterrichtswissenschaft, 4(4), 334-350.

Lieberman, L. J., Columna, L., de la Vega Mansilla, P. M., \& Taylor, C. (2010). Infusing Sign Language and Spanish into Physical Education. Journal of Physical Education, Recreation \& Dance, 81(4), 45-49.

Lincoln, Y. S., Lynham, S. A., \& Guba, E. G. (2011). Paradigmatic controversies, contradictions, and emerging confluences, revisited. The Sage handbook of qualitative research, 4, 97-128.

Lova, M., Bolarín, M. J., \& Porto, M. (2013). Programas bilingües en Educación Primaria: valoraciones de docentes. Porta Linguarum, 20, 253-268. 
Lynott, F. J. (2008). Integrating other subject matter without jeopardizing physical education goals: The content linkage approach. Strategies, 22(1), 10-17.

Mackey, A. \& Gass, S.M. (2005). Second Language Research. Methodology and design. New Jersey: Lawrence Erlbaum.

Marsh, D. (2002). CLIL/EMILE the European Dimension. Finland: University of Jäyvskylä.

Martínez-Hita, F.J. \& García-Canto, E. (2017). Influence of Bilingualism on Engagement Motor Time in Physical Education. Retos, Nuevas tendencias en educación física, deporte y recreación, 32, 178-182.

Mehisto, P., Marsh, D., \& Frigols, M.J. (2008). Uncovering CLIL Content and Language Integrated Learning in Bilingual and Multilingual Education. Oxford: Macmillan.

Molero, J.J. (2011). De la Educación Física a la Educación Física bilingüe: un análisis desde el punto de vista metodológico. EmásF: revista digital de Educación Física, 2(10), 7-16.

Nguyen, H. T., \& Watanabe, M. F. (2013). Using visual supports to teach English language learners in physical education. Journal of Physical Education, Recreation \& Dance, 84(8), 46-53.

Nold, G., Hartig, J., Hinz, S. \& Rossa, H. (2008) Klassen mit bilingualem Sachfachunterricht. Englisch als Arbeitssprache. In: E. Klieme (ed). Unterricht und Kompetenzerwerb in Deutsch und Englisch. Weinheim: Belzt, pp. 451-457.

Pavón, V., \& Rubio, F. (2010). Teachers' concerns and uncertainties about the introduction of CLIL programmes. Porta Linguarum, 14, 45-58.

Patton, M.Q. (2002). Qualitative Research and Evaluation Methods. London: Sage.

Pérez-Cañado, M.L. (2011). The Effects of CLIL within the APPP: Lessons Learned and Ways Forward. Studies in honour of Ángeles Linde López, 13-30.

Perlman, D. J. (2015). Help motivate the amotivated by being a supportive teacher. Physical Education and Sport Pedagogy, 20(2), 204-214.

Ramos, F., \& Omeñaca, J. V. R. (2011). La educación física en centros bilingües de primaria 
inglés-español: de las singularidades propias del área a la elaboración de propuestas didácticas prácticas con AIBLE. Revista española de lingüística aplicada, 24, 153170.

Renner, M., \& Taylor-Powell, E. (2003). Analyzing Qualitative Data. Madison: University of Wisconsin.

Salvador, C., Chiva, Ò., \& Fazio, A. (2016). Características del Aprendizaje Integrado de Contenidos de Educación Física y Lengua Extranjera. Retos, Nuevas Tendencias en Educación Física, Deporte y Recreación, 29, 120-125.

Salvador, C., Chiva, Ò., \& Isidori, E. (2017). Aprendizaje de una lengua extranjera a través de la educación física: una revisión sistemática. Movimento. 23(2), 647-660.

Santillan, Y., Jacobs, J. M., \& Wright, P. M. (2015). Integrating Best Practices in ELL Classrooms with Quality Physical Education Instruction. Journal of Physical Education, Recreation and Dance, 86(3), 51-53.

Sato, T., \& Hodge, S. R. (2016). Elementary physical education teachers' experiences in teaching English language learners. Education and Urban Society, 48(3), 262-287.

Sato, T., Walton, J., \& Kim, I. (2017). Elementary physical educators' positioning in teaching English language learners. European Physical Education Review, 1-18.

Shropshire, J., Carroll, B., \& Yim, S. (1997). Primary school children's attitudes to physical education: gender differences. European Journal of Physical Education, 2(1), 23-38.

Stake, R.E. (2000). Case studies. In: N.K. Denzin \& Y.S. Lincoln (eds). Handbook of qualitative research. Thousand Oaks: Sage, pp. 435-454.

Subramaniam, P. R., \& Silverman, S. (2007). Middle school students' attitudes toward physical education. Teaching and teacher education, 23(5), 602-611.

Sweller, J. (1994). Cognitive load theory, learning difficulty, and instructional design. Learning and instruction, 4(4), 295-312.

Tsangaridou, N. (2006). Teachers' Beliefs. In: D. Kink, D. MacDonald \& M. O’Sullivan (eds). The handbook of Physical Education. London: Sage, pp. 486-501. 
Zagalaz, M.A., Molero, D., Cachón, J., et al. (2012). Diseño de un cuestionario para medir la formación bilingüe del profesorado de EF. Revista Iberoamericana de Ciencias del Deporte, $1(1), 7-12$.

Vygotsky, L.S. (1995). Pensamiento y lenguaje. Barcelona: Paidós.

Zindler, K. (2013). Content and Language Integrated Learning and PE in England. An Exploratory Study. PhD Thesis, University of Sheffield, UK. 
Siguiendo el enfoque anterior se presenta a continuación el manuscrito 4, centrado en esta ocasión en conocer la perspectiva del alumnado. Este trata de dar respuesta a la otra rama del Objetivo 2, que queda redactado de la siguiente manera:

- O.2.2. "Examinar cómo vive y qué opina el alumnado sobre el uso de AICLE en clase de educación física"

En el caso de este manuscrito optamos por estudiar la perspectiva del alumnado que ha vivido el uso de AICLE en las clases de educación física. Sin duda, sus experiencias e ideas son contribuciones influyentes a la hora de analizar el proceso de enseñanza-aprendizaje. Sin ir más lejos, autores como Smith (1991), ponen en duda que sea posible mejorar las clases de educación física sin tomar en consideración las ideas y opiniones de los discentes. Para ello, en este texto se aboga por desarrollar una investigación con el estudiantado, convirtiéndolo en agente activo y participante de la misma, huyendo de posicionamientos positivistas y optando, en su lugar, por acercamientos que ponen en valor los significados subjetivos de los y las participantes (Amis, 2005).

Escuchar detenidamente al estudiantado nos aportará nuevas ideas y perspectivas sobre las complejidades propias del proceso de enseñanza-aprendizaje de la educación física (Dyson, 2006). Por este motivo, abordamos en este manuscrito un enfoque metodológico cualitativo que nos permitirá conocer su visión relativa a su experiencia en las clases de educación física mediante AICLE. 
MANUSCRITO 4

TíTULO:

Percepción del alumnado sobre el uso del método AICLE en Educación Física: estudio de

caso

AUTORES:

Celina Salvador García, Òscar Chiva Bartoll y Juan José Vergaz Gallego

FUENTE:

Retos: nuevas tendencias en educación física, deporte y recreación

(Publicado)

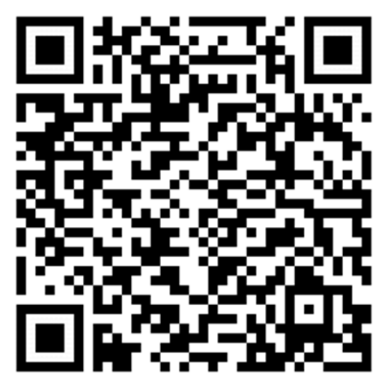




\title{
Percepción del alumnado sobre el uso del método AICLE en Educación Física: estudio de caso
}

\section{Perception of students on the use of CLIL method in Physical Education: A Case Study}

\author{
*Celina Salvador-García, *Óscar Chiva-Bartoll, **Juan JoséVergaz Gallego \\ *Universidad Jaume I (España), **Universidad de Valencia (España) \\ Fecha recepción: 30-11-16. Fecha de aceptación: 29-05-17 Oscar Chiva-Bartoll \\ ochiva@uji.es
}

\section{Resumen:}

El Aprendizaje Integrado de Contenidos y Lengua Extranjera (AICLE) está siendo cada vez más extendido e investigado en el panorama educativo español. Dada la importancia de la motivación y la predisposición del alumnado para que el proceso de enseñanza-aprendizaje sea efectivo, este estudio de caso analiza la percepción de un grupo de secundaria durante la aplicación del método AICLE en la asignatura de Educación Física. Se optó por un enfoque metodológico cualitativo apoyado en la triangulación de diarios de reflexión del alumnado, registro anecdótico del profesor-investigador y un focus group. Los resultados afianzan el actual estado de la cuestión, desvelando cinco categorías sobre las que se conforma la percepción del alumnado: temor a la lengua, motivación y participación en la asignatura, aprendizajes específicos de Educación Física, mejora de la expresión oral en inglés e importancia del inglés para el futuro académico-profesional. En conclusión, el estudio desvela cómo de la aprensión inicial hacia el AICLE, derivado del temor a la lengua, se pasó a un incremento progresivo de la participación del alumnado, ligado a una creciente percepción de mejora de la propia competencia comunicativa. 
Palabras clave: AICLE, Educación Física, Educación Secundaria, educación bilingüe, lengua inglesa.

\begin{abstract}
:
Content and Language Integrated Learning (CLIL) is becoming more widespread and studied in the Spanish educational panorama. Due to the importance of motivation and predisposition of students for an effective development of the teaching-learning process, the present case study analyses the perception of a secondary school group about their implementation of the CLIL method in Physical Education subject. A qualitative methodological approach was adopted, supported by the triangulation of students' reflection diaries, the teacherresearcher's anecdotal register and a focus group. The results reinforce the current status of the issue, uncovering five categories according to the students' beliefs: fear for the language, motivation and participation in the subject, specific Physical Education learnings, improvement of oral expression and magnitude of English language for their academicprofessional future. In conclusion, this research discloses how during the intervention an initial apprehension towards CLIL related to the fear for the language, turned into a progressive increase of the students' participation, linked to an improvement of the selfperception of communicative competence.
\end{abstract}

Keywords: CLIL, Physical Education, Secondary Education, bilingual education, English Language.

\title{
Introducción
}

AICLE (Aprendizaje Integrado de Contenidos y Lengua Extranje- ra) es un método pedagógico que empieza a ser cada vez más aplicado e investigado en el panorama educativo español (Salvador, Chiva \& Isidori, in press). El término AICLE (en inglés CLIL: Content and Language Integrated Learning) se define como un enfoque educativo dual en el que una lengua extranjera es utilizada para trabajar contenidos de una asignatura específica (Coyle, Hood \& Marsh, 2010). Su uso persigue un doble objetivo, la adquisición de la lengua utilizada y el aprendizaje de la materia en cuestión. Además, AICLE permite tratar el currículo como un todo en lugar de como diferentes asignaturas o áreas parceladas e inconexas. Aunque es un método utilizado en múltiples áreas del currículo, la Educación 
Física (EF) es una materia que por su propia idiosincrasia se ajusta especialmente a sus características (Alonso, Cachón, Castro \& Zagalaz, 2015; Chiva, Isidori \& Fazio, 2015; Chiva \& Salvador, 2016; Coral, 2012; Rio, Di Rubbo \& Gómez, 2014; Salva- dor, Chiva \& Ruiz-Madrid, 2016; Salvador, Chiva \& Fazio, 2016). En especial, es considerable el número de autores que enumeran ventajas de la utilización de AICLE en EF a raíz de la interacción y comunicación que la materia promueve a través del movimiento y el juego, resultando una vía para facilitar el aprendizaje de la lengua extranjera (Chiva et al., 2015; Coral, 2012; Coral \& Lleixà, 2016; García, García \& Yuste, 2012; Hernando, Hortigüela \& Pérez-Pueyo, 2018; Ramos \& Ruiz, 2011).

Pese al crecimiento actual de investigaciones sobre la aplicación del método AICLE (Lova \& Bolarín, 2015), en EF siguen existiendo terrenos por explorar. Uno de los puntos que requiere mayor atención radica en el conocimiento de la percepción del alumnado ante las clases de EF en inglés. Por ello, conociendo la importancia de la orientación motivacional y la predisposición del alumnado para que el proceso de enseñanza- aprendizaje sea efectivo (Sánchez-Alcaraz, Gómez-Mármol \& Más, 2016), es conveniente averiguar el grado de comprensión, motivación y miedo del estudiantado respecto a la introducción de las clases de EF en lengua inglesa. Este interés define el objetivo del presente artículo, basado en conocer la percepción del alumnado de secundaria sobre la aplicación del método AICLE en EF.

Existen diversos estudios centrados en el binomio EF y aprendizaje de inglés. Coral (2010) investigó en primaria los efectos de AICLE sobre el aprendizaje lingüístico, concluyendo que la EF constituye una posibilidad diferente de aprender una lengua extranjera. Por otra parte, Figueras, Flores y González (2011), en el contexto universitario, también destacan la mejora lingüística de los participantes, en línea con lo expuesto por Reyes (2014), que en particular resalta la mejora de la competencia oral. En la misma línea, Devos (2012) analizó el lenguaje utilizado en una intervención de AICLE y concluyó que se produjo un aprendizaje lingüístico gracias a la construcción de nuevos significados. Mientras que González, Villar, Pastor y Gil (2013) llevaron a cabo un estudio similar, destacando la relevancia del componente lúdico aportado por la EF para favorecer el aprendizaje y la motivación del alumnado. Asimismo, existen estudios que amplían el foco de interés y trascienden el análisis de la mera 
competencia lingüística. Por ejemplo, en Educación Primaria, Alonso et al., (2015) no solo aluden a esta mejora, sino también la idoneidad de trabajar la cultura inglesa. Rottmann (2007) sostiene que utilizar EF como contenido para desarrollar una lengua fomenta las interacciones de los alumnos. Por su parte, Alías (2011) defiende el progreso de las habilidades orales y expresivas pero, además, analiza en su estudio la percepción del alumnado, concluyendo que enseñar inglés a través del juego en EF resulta muy motivante.

El estado de la cuestión desvela que, tratándose de un campo de estudio tan reciente, quedan abiertas algunas líneas de investigación con las que mejorar las posibilidades de implementación del método AICLE. En particular, la etapa de educación secundaria representa un espacio de estudio al que contribuye la presente investigación. La intervención se llevó acabo en cuarto curso de Educación Secundaria Obligatoria (ESO), eligiendo como contenido el Touch-Rugby. Este contenido fue elegido por sus características como deporte promotor de conductas prosociales y de actitudes de cooperación y trabajo en equipo (Parise, Pagani, Cremascoli \& Iafrate, 2015). Además, con la intención de acentuar todavía más estas características, el Touch-Rugby se introdujo desde un enfoque metodológico comprensivo (Valera, Ureña, Ruiz \& Alarcón, 2010).

\section{Material y Métodos}

Situado en el paradigma investigador interpretativo, el presente estudio de caso analiza la percepción del alumnado ante prácticas de EF mediante el método AICLE. Esta cuestión se acomete cualitativamente tras una intervención didáctica que aspira, conforme a los planteamientos metodológicos de Halcomb \& Davidson (2006), a detectar y reconocer las posibles inquietudes, miedos y motivaciones que dicho proceso de enseñanza-aprendizaje supone para el estudiantado. La investigación planteada fue participativa, de manera que la explicación de «lo que sucede» se ha construido conjuntamente entre el profesor-investigador y el alumnado participante. Asimismo, en la línea marcada por Creswell (2002) respecto a la validez y fiabilidad en investigación cualitativa, consideramos que nuestra experiencia como investigadores en AICLE ha ayudado a fortalecer la fiabilidad del presente estudio, ya que con ello tenemos una comprensión previa del tema investigado. El resultado constituye una interpretación de los datos recopilados con la que se responde a la siguiente pregunta de investigación: ¿Cómo percibe el alumnado de secundaria la introducción del método AICLE 
en EF?

Programa de intervención

La unidad didáctica de Touch-Rugby se aplicó en cuarto curso de ESO y constó de siete sesiones. El Touch-Rugby es un deporte con un elevado componente cognitivo que ha facilitado la aplicación de un enfoque de enseñanza comprensivo (González, Cecchini, Fernández- Río \& Méndez, 2008). Este enfoque de enseñanza deportiva se basa, fundamentalmente, en plantear retos o problemas prácticos al alumnado, de forma que se vea favorecida su relación interpersonal mediante la utilización de actividades grupales y cooperativas (Sánchez-Gómez, Devís-Devís \& Navarro-Adelantado, 2014).

Por otra parte, el nivel de lengua inglesa empleado fue elemental o básico, habiéndose ajustado previamente con la profesora de inglés, con la que también se concretó el vocabulario y ciertas estructuras gramaticales a trabajar. A continuación, la tabla 1 describe los principales rasgos de la unidad didáctica aplicada desde el marco de las 4 «Cs» propuesto por el método AICLE. 
Tabla 1. Unidad didáctica aplicada desde el enfoque metodológico AICLE.tim

\section{Content}

-Touch-Rugby.

-Habilidades específicas: handballing, marking, feinting.

-Normas básicas del Touch-Rugby.

-Desarrollo de las habilidades motrices especificas aplicadas al Touch.

-Aplicación de estrategias colectivas ofensivas y defensivas.

-Resolución de situaciones en las que se haga uso de una deliberación crítica.

-Participación activa en las actividades tanto motrices como deliberativas.

\section{Communication}

\begin{tabular}{|c|c|}
\hline Language of learning & $\begin{array}{l}\text { Vocabulario: } \\
\text {-Touch: Game, rules, turn over, team } \\
\text {-Skills: Handballing, marking, passing, } \\
\text {-Verbs: To bend, to hit, to hold, to pass, to score, to run, to mark } \\
\text {-Body: thumb, knee, toe, chest, arm, elbow } \\
\text {-People: teammate, opponent, umpire, Player, wing, middle. } \\
\text {-Prepositions: Far, near, above, backwards, above, down } \\
\text {-Rules: cheating, fair play, shake hands, respect }\end{array}$ \\
\hline & $\begin{array}{l}\text { Estructuras: } \\
\text {-Modales: Should, can/could/must/have to } \\
\text {-Allowed/forbidden } \\
\text {-In my opinion: I think, I believe, I would... }\end{array}$ \\
\hline Language for learning & $\begin{array}{l}\text {-Dar opinión y razone } \\
\text {-Proponer tareas } \\
\text {-Dar consejos } \\
\text {-Generar normas }\end{array}$ \\
\hline Language through & $\begin{array}{l}\text {-Resolver conflictos } \\
\text {-Evitar trampas y respeto a las normas }\end{array}$ \\
\hline \multicolumn{2}{|l|}{ Culture } \\
\hline \multicolumn{2}{|c|}{$\begin{array}{l}\text {-Reconocer la relevancia cultural de deportes como el rugby } \\
\text {-Comprender la importancia y el significado de las tradiciones vincl } \\
\text {-Interpretar el papel que desempeñan los árbitros en la sociedad } \\
\text {-Comprender la importancia del respeto y los valores en el deporte }\end{array}$} \\
\hline \multicolumn{2}{|l|}{ Cognition } \\
\hline LOTS & $\begin{array}{l}\text { Comparar, nombrar, asociar, explicar, describit, seleccionar, elegir, } \\
\text { utilizar, observar, organizar }\end{array}$ \\
\hline HOTS & $\begin{array}{l}\text { Distinguir, propponer, adaptar, opinar, analizar, crear, diseñar, } \\
\text { diferenciar, concluir... }\end{array}$ \\
\hline
\end{tabular}




\section{Participantes y contexto}

Los participantes del estudio fueron el alumnado de un grupo de cuarto curso de ESO formado por 20 alumnos de entre 15-17 años de edad (nueve alumnos y 11 alumnas). El nivel de dominio de la lengua inglesa promedio de este grupo era medio-alto y su conocimiento del Touch-Rugby prácticamente nulo. Además, era la primera vez que el estudiantado experimentaba el método AICLE, por lo que el planteamiento de la investigación se centró en conocer, desde un paradigma interpretativo, las percepciones que genera el primer contacto con el método AICLE en EF.

\section{Técnicas de recogida de datos}

Se utilizaron varios instrumentos de recogida de datos a partir de los cuales se realizó una triangulación y comparación de los resultados, siguiendo el modelo del trabajo de Coral (2010).

-Focus group. Se realizó al finalizar la propuesta. Participaron 4 alumnos (dos chicos y dos chicas), elegidos mediante la técnica de muestreo de expertos (Patton, 2002), basada en la elección por parte del investigador de acuerdo a su criterio y conocimiento del grupo. La elección de esta técnica de muestreo vino determinada por las características de la población adolescente objeto de investigación. En particular, dado que el estudiantado de secundaria presenta rasgos muy dispares en términos de maduración psicológica y social, se valoraron parámetros como la locuacidad, la implicación en el proceso de enseñanza-aprendizaje, el sexo (paridad), la predisposición e interés por participar en el estudio y la capacidad crítica demostrada a lo largo del proceso. En definitiva, se seleccionaron aquellos participantes susceptibles de aportar información de calidad con la que responder a la pregunta de investigación. La premisa del grupo de discusión era desvelar el significado que tuvo para el alumnado la introducción del método AICLE en EF.

-Registro anecdótico. En él el profesor-investigador reflejó, en base a un proceso de observación participante, evidencias sobre las interacciones del alumnado en situaciones cotidianas vividas durante la intervención. Para su redacción se registró la actuación observada tras finalizar cada sesión, de forma inmediata y de manera breve y lo más clara posible, tratando de no distorsionar los incidentes descritos. Su redacción se estructuraba en 
dos columnas paralelas en las que se escribía, por una parte, la descripción fehaciente del incidente observado y, por otra, la apreciación e interpretación del docente-investigador. Este instrumento permitió reflejar evidencias constatables sobre las que fundamentar la interpretación posterior de los datos.

-Diarios de reflexión. Los diarios analizados provenían del total de los 20 componentes de la clase. Este instrumento es una técnica de recogida de información muy habitual en contextos educativos (Elliot, 1991; Latorre, 2003; Mcniff \& Whitehead, 2006) por su prestigio y tradición, dado que permite recoger información significativa sobre el proceso de enseñanzaaprendizaje (Zabalza, 2004). En este caso se ha optado por la modalidad de Analytical writing, de modo que se pautaron en torno a diferentes dimensiones como: el nivel y uso percibido de inglés, la nueva forma de vivir la EF en inglés, expectativas y experiencias ante el AICLE, participación e implicación en las tareas, aprendizaje sobre aspectos específicos de la materia (táctica y técnica del Tough-Rugby y sus procesos de aprendizaje). Su utilización permitió disponer de información proveniente de todos los participantes, incrementando de este modo la validez del estudio, en tanto que pudo emplearse como elemento de triangulación.

\section{Análisis de datos}

El estudio de la información obtenida se llevó a cabo mediante un análisis conjunto de contenido, entendido como una técnica sistemática y cualitativa que trabaja con materiales representativos (Porta \& Silva, 2003). Para el análisis completo de los datos se llevaron a cabo estrategias de codificación, fragmentación y categorización. Antes de llegar a las categorías o núcleos de contenido definitivos se identificaron las unidades de significado y los temas emergentes en el discurso, procediendo a su posterior fragmentación $\mathrm{y}$ categorización en base a cadenas textuales diferenciadas. Los resultados obtenidos fueron sometidos a un proceso de member checking, consistente en verificar la conformidad de los informantes con la interpretación final de los resultados.

\section{Resultados}

Los resultados obtenidos del análisis permiten conformar cinco categorías o núcleos de contenido: temor a la lengua, motivación y participación en la asignatura, aprendizajes 
específicos de EF, mejora de la expresión oral en inglés e importancia del inglés para el futuro académico-profesional.

\section{Temor a la lengua}

Al inicio de la experiencia muchos alumnos exponían que temían no poder comunicarse en inglés debido a su bajo nivel. A ello cabe añadir que antes de la realización de la unidad didáctica desconocían tanto el contenido (Touch-Rugby) como el método AICLE. Esto les llevó a reflejar un discurso dubitativo a la hora de mostrar su predisposición para realizar las clases de EF en inglés.

A mí no me gusta ya que prefiero darlas o en lengua española (castellano) [...], pero si proponéis darla en inglés yo no puedo hacer nada. Creo que dificultará la comunicación con los compañeros y será más difícil jugar.

En esta línea fueron constantes las referencias a inquietudes y miedos acerca de las dificultades de comprensión, tanto del contenido teórico como de las explicaciones de las tareas de la práctica.

Me va a costar bastante, ya que me cuesta bastante hablar en inglés ya la hora de las explicaciones en inglés, me va a costar entenderlo y comunicarme en inglés. Espero que el vocabulario sea sencillo. Además, me preocupa no acabar de entender lo que haya que hacer en el juego, las explicaciones en inglés y por tanto no enterarme de la clase, además, al ser el examen de contenidos en inglés también me da miedo de cara a la nota.

Este miedo era patente ya que, en las clases iniciales, principalmente en las dos primeras, los alumnos trataban de inhibirse del uso oral de la lengua, intentando evitar tener que comunicarse verbalmente al realizar las tareas. Era palpable que no estaban acostumbrados/as a realizar las clases de EF en inglés y mucho menos a comunicarse en él mientras practicaban deporte.

Bueno, al principio la verdad es que éramos todos bastante tímidos a la hora de hablar en inglés, pero ya en las últimas sesiones, nos hemos esforzado más.

Como es normal, no se comunicaban en todo momento en lengua inglesa; pero la evolución 
de las primeras sesiones a las últimas fue notable.

\section{Motivación y participación en la asignatura}

Muchos de los alumnos admiten que al interactuar desde un planteamiento que les obligaba a comunicarse constantemente se han sentido más participativos de lo habitual a la hora de realizar las clases de EF. Me ha parecido diferente, no ha sido igual que otras clases, hemos tenido que tener estrategias, y la verdad es que todos han participado bastante.

Esto facilitó, en consecuencia, que los alumnos que generalmente no eran muy participativos se sintieran más integrados y motivados.

Siempre me suelo cansar rápido de los juegos porque no participo mucho, pero al ser necesaria la comunicación para decidir la táctica me he sentido mucho más partícipe.

De hecho, este planteamiento fue respaldado en varias ocasiones por el alumnado participante en el grupo de discusión.

Yo, al igual que mi compañera, no suelo participar mucho en deportes como el futbol, o el baloncesto, y la verdad es que de esta manera, con muchos más juegos y teniendo que pensar y decidir la estrategia, me he sentido más partícipe del juego, ya que es un juego en equipo y se necesita a todos los compañeros.

Asimismo, además de la preminencia del componente comunicativo del nuevo enfoque, que sin duda cambió la lógica de relaciones y las dinámicas habituales de la clase de EF (dando protagonismo a alumnado más retraído), la propia introducción de la lengua inglesa también actuó en algunos casos como agente motivador per se.

A mí de normal la educación física no es que me guste mucho, pero al hacerlo en inglés y mediante más juegos, he participado más y me he sentido más a gusto dentro del juego normal.

\section{Aprendizajes específicos de Educación Física}

Los aprendizajes específicos de EF fueron otro núcleo común en las narrativas analizadas. En particular, a pesar del hándicap lingüístico para comunicarse de forma fluida, todo indica 
que el planteamiento no se vio afectado negativamente por la lengua inglesa. Es decir, el inglés no supuso una barrera infranqueable para la adquisición de nuevos aprendizajes específicos.

Yo personalmente juego a fútbol, pero [el Touch-Rugby] me ha parecido un deporte donde se trabaja mucho la inteligencia, incluso más que en fútbol, y por eso creo que he aprendido tanto, porque para poder llegar al objetivo, debes de hablar y jugar en equipo con una idea clara.

Dado que gran parte de las tareas estaban centradas en la táctica y la estrategia, el alumnado evolucionó de manera notable a la hora de pensar y comunicarse durante la práctica. Ello les proporcionó un mayor conocimiento del espacio de juego, así como una mayor amplitud del espectro táctico en su capacidad cognitiva.

Nos ha hecho pensar mucho, es un deporte donde tienes que pensar en equipo y utilizar la inteligencia mucho. [...] A mí me gustaría que todos los años pudiéramos jugar y además de la manera que lo hemos hecho, con muchos juegos donde participábamos todos.

A destacar en este punto que muchos de ellos, en el día a día, se mostraban satisfechos de haber podido adquirir ese tipo conocimientos a través de tareas eminentemente participativas.

\section{Mejora de la expresión oral}

Con el paso de las sesiones el alumnado fue plenamente consciente de que la EF a través del método AICLE les permitía potenciar su dominio de la lengua inglesa, haciendo especial mención a la comunicación oral.

Bueno, al principio la verdad es que éramos todos bastante tímidos a la hora de hablar en inglés, pero ya en las últimas sesiones, lo hemos hecho mucho más.

Este hecho se palpa también en el análisis del registro anecdótico del profesor-investigador, evidenciando que día a día la gran mayoría de alumnos se esforzaba por comunicarse oralmente a través del uso de palabras específicas, frases cortas y estructuras ordenadas; en coincidencia con las demás fuentes de información.

Me he dado cuenta que en solo siete clases he podido mejorar mi comunicación 
oral, me he esforzado mucho por mejorar y me he visto más progreso que en la asignatura de inglés.

Algunos compañeros sí que hemos intentado hablar en inglés porque pensamos que es muy beneficioso para nosotros, creo que ha estado bien, ya que hemos ido poco a poco introduciendo la lengua. También es destacable el aprecio del alumnado por el uso real y significativo de la lengua que propone el método AICLE, en contraposición con la asignatura específica de inglés, más centrada en la adquisición de estructuras gramaticales y vocabulario.

Este año [en clase de inglés] solo hacemos que redacciones y gramática, y el nivel hablado es muy pobre, creo que habría que mejorarlo. En educación física es diferente, ya que cuando estás jugando no te acuerdas.

Yo creo que es una buena manera de practicar la lengua oral, ya que en clase [de inglés] se trabaja toda la gramática, el vocabulario, la escucha, pero el oral es lo que menos se practica.

Con todo, existen voces que confiesan no haberse comunicado con tanta soltura y solvencia. No obstante, ello no ha sido óbice para no valorar positivamente la mejora en su nivel de comprensión.

Hay gente que tiene un nivel bastante bajo de inglés y que le cuesta mucho, pero también les sirve para esforzarse y entender mejor a los demás.

Para mí ha sido complicado y prácticamente no me he comunicado en inglés con mis compañeros, ya que me resulta bastante difícil, aun así he podido comprender todo y mejorarlo con las sesiones.

\section{Importancia del inglés para el futuro académico-profesional}

Esta última categoría reconoce el sentir del alumnado de querer mejorar la destreza lingüística y la capacidad comunicativa en inglés, pensando tanto en el próximo futuro académico, como en el desarrollo profesional posterior Esta realidad parece tener una relación clara con la predisposición hacia la experiencia AICLE.

Yo quiero ser fisioterapeuta enfocado al deporte, y sé que necesitaré un buen nivel 
de inglés para serlo, por eso [introducir el AICLE en EF] me parece una buena idea.

La importancia del inglés para el futuro académico-profesional, además, no es solo reconocida por aquellos que tienen decidida la opción profesional a seguir, sino que se percibe como un sentir generalizado. Es decir, independientemente del futuro académico o laboral por el que se decida optar, el alumnado es consciente de la importancia del inglés en todos los casos.

Yo no sé qué quiero ser de mayor, pero sé que tengo que mejorar mi nivel de inglés porque prácticamente en todas las carreras te piden algo de inglés y todos los trabajos también.

En definitiva, a pesar de reflejar una motivación extrínseca basada en un uso instrumental del aprendizaje lingüístico, esta creencia actúa como un importante leitmotiv a la hora de asumir la clase de EF en inglés. Como se ve, incluso el alumnado que no necesariamente siente un especial interés por la EF, ni por la lengua inglesa, ve en esta cuestión un argumento de peso para afrontar la experiencia con determinación.

\section{Discusión}

Los resultados complementan y refuerzan el actual estado de la cuestión, perfilando una serie de categorías en torno a las que se configura la concepción del alumnado sobre el método AICLE y su empleo en EF. En primer lugar, el alumnado hace explícito un sentimiento de aprensión y temor ante la propuesta de trabajar por primera vez una unidad didáctica de EF mediante el método AICLE. En coincidencia con Montávez, Mariscal y López (2002), todo apunta a que la causa de este reparo puede hallarse en el miedo al ridículo o a bajos niveles de autoestima. Esta inseguridad, previa a la aplicación de la unidad didáctica, se muestra también en línea con lo expuesto por Figueras et al. (2011). Asimismo, tras este escenario inicial, los resultados del análisis muestran un comportamiento paralelo a lo descrito por Christopher, Dzakiria y Mohamed (2012), coincidiendo en que según pasaban las sesiones, las primeras reticencias fueron diluyéndose y dando paso a sentimientos de mayor seguridad y confianza en el uso del inglés. De hecho, incluso el alumnado menos participativo, ya fuera por inseguridad, timidez o introversión, también acabó adquiriendo mayores niveles de 
confianza, en la línea de lo expuesto por Reyes (2014), asegurando que en cualquier caso comprendieron las tareas propuestas sin problema.

La motivación e implicación relativa a la asignatura de EF ha sido otra manifestación relevante, en sintonía con lo apuntado por Alías (2011), Coral y Lleixà (2013) y Chiva et al., (2015), quienes en sus respectivos análisis ya determinaron que el tipo de actividades que promueve el método AICLE despiertan y promueven una mayor participación e implicación del estudiantado. Además, dado que las actividades propuestas por el método AICLE favorecen la interacción y participación constante del alumnado, en aras de una construcción significativa de los nuevos aprendizajes (González, et al., 2013), los participantes podrían haber visto incrementado su nivel de motivación y participación al sentirse plenamente protagonistas de su propio proceso de aprendizaje. Otra cuestión que ha podido influir en este sentido es la motivación intrínseca generada por la propia asignatura de EF (Alonso, et al., 2015; Coral, 2010); o incluso por el propio uso de la lengua inglesa, tal y como expuso algún alumno/a en el grupo de discusión. De este modo, el incremento progresivo de la implicación y participación a lo largo de la propuesta se muestra en consonancia con los hallazgos de Coral (2010), Montávez et al. (2002) y Christopher et al., (2012).

Respecto a la categoría referida a los aprendizajes específicos de EF, conviene recordar que la mejora lingüística en una propuesta basada en AICLE comparte relevancia con la mejora del contenido que se está trabajando (Coyle, etal., 2010). En este sentido, del discurso del alumnado puede extraerse que la lengua inglesa no supuso ningún impedimento en el correcto desarrollo de las sesiones, ni tampoco en el aprendizaje del contenido (Touch-Rugby); algo ya analizado también por Dalton-Puffer (2011) con resultados similares. En general, el grupo se mostró satisfecho y destacó su aprendizaje a nivel de táctica, de estrategia y de conocimiento del Touch-Rugby como modalidad deportiva, en armonía con lo advertido por Figueras et al. (2011).

Por otra parte, coincidiendo plenamente con lo planteado por Montávez et al. (2002), del análisis se deriva otra cuestión a tener en consideración: la mejora de las capacidades comunicativo-expresivas del alumnado. Esto podría explicarse debido al vínculo de la lengua con el movimiento (Alías, 2011), hecho que favorece su uso real y significativo. Asimismo, las tareas participativas y de carácter crítico y deliberativo propician que el alumnado sea 
participante activo de su aprendizaje (Coral \& Lleixà, 2016), de manera que se incrementa el Student Talking Time (tiempo de habla del estudiantado) en detrimento del Teacher Talking Time (tiempo de habla del profesorado) (Bentley, 2007). Al propiciar tantas situaciones comunicativas, incluso aquellos más reticentes a utilizar el inglés se han visto imbuidos a ello (Salvador, Chiva \& Fazio, 2016) y, aunque se expresaran en menor medida, sí han señalado la mejora en sus habilidades de comprensión, en consonancia con lo indicado por Figueras et al. (2011).

Por último, la última categoría surgida hace referencia a la predisposición por el aprendizaje de la lengua inglesa en relación a sus futuras expectativas académicas y laborales. Las motivaciones expuestas en este sentido se dividen en dos vertientes. Por un lado, el alumnado relaciona el aprendizaje de la lengua inglesa con unas mejores perspectivas laborales en su futuro, algo que ya se percibió en los trabajos de Christopher et al. (2012) y Figueras et al. (2011). Por otro lado, muchos alumnos también manifiestan, de forma explícita, un abanico más am plio de posibilidades en lo referente a su futuro académico. Este hallazgo, aun siendo lógico, no deja de ser novedoso en tanto que se trata de estudiantes de secundaria, en contraposición con la mayoría de los estudios referidos al método AICLE realizados hasta la fecha.

\section{Conclusiones}

El presente estudio de caso interpreta la percepción de un grupo de secundaria al experimentar una aplicación del método AICLE en EF. Los resultados obtenidos afianzan el actual estado de la cuestión para esta área de conocimiento, desvelando cinco categorías o núcleos fundamentales de contenido: Temor a la lengua, Motivación y participación en la asignatura, Aprendizajes específicos de Educación Física, Mejora de la expresión oral en inglés, e Importancia del inglés para el futuro académico-profesional.

En lo referente al Temor a la lengua el estudio desvela cómo, al inicio, un sector del alumnado se mostraba reticente al uso del método AICLE, ya que en su mayoría consideraban que su (in)capacidad comunicativa en inglés podría dificultar el adecuado seguimiento de las clases. Sin embargo, a medida que se fueron sucediendo las sesiones, se dio una progresión que provocó cambios sustanciales en sus perspectivas y actitudes iniciales. 
La Motivación y participación en la asignatura fue otro de los núcleos de contenido sobre los que se configura este análisis. El trabajo pone en evidencia, tanto desde las narrativas del alumnado como desde la observación del profesor-investigador, un alto grado de interés y participación en las clases. Además, dada la nueva dinámica de las clases (más comunicativa e interactiva) facilitada por el método AICLE, se advierte que el alumnado que anteriormente se mostraba poco participativo, se implicó más e incluso lideró algunas tareas con gran determinación.

Por otra parte, destacar que los Aprendizajes especificos de EF no solo no se vieron disminuidos con la propuesta AICLE, sino que además de haberse producido nuevos aprendizajes específicos del área se dio un vuelco en el que emergieron aprendizajes menos comunes hasta la fecha, como la táctica o la estrategia. Esta nueva concepción, además de concebirse igual de importante que el tradicional aprendizaje basado en la técnica, dio pie a un modelo de aprendizaje mucho más inclusivo; ya fuera para alumnos con menor nivel técnico o de habilidad motriz, como entre participantes de ambos sexos.

Respecto a la Mejora de la expresión oral en inglés, es claramente visible que la percepción generalizada del alumnado apunta a una valoración muy positiva. Esta percepción se apoya en la enorme cantidad de situaciones comunicativas facilitadas por la propuesta didáctica implementada. En especial, en momentos de la práctica de EF en los que el uso de la lengua fue significativo y real.

Del análisis emerge finalmente como núcleo de significado la Importancia del inglés para el futuro académico-profesional. En este sentido, el alumnado manifestó ser consciente de la necesidad de mejorar su nivel de inglés para estar a la altura de sus propias expectativas académicas y profesionales. Este hecho podría haber actuado como un aliciente o motivación extrínseca que, en cualquier caso, pareció facilitar el beneplácito del alumnado hacia el método AICLE.

En definitiva, si bien es cierto que a través de una única aplicación didáctica resulta complicado descifrar de manera categórica el sentir del alumnado respecto al método AICLE, el estudio ha aportado conclusiones de interés. Además, como aportaciones generales para mejorar la introducción del AICLE en EF, el artículo sugiere que este método se optimiza en EF cuando se emplean contenidos y estilos de enseñanza que promueven trabajo cooperativo, 
propuestas de superación de retos y resolución de problemas en grupo. Por otra parte, también es importante resaltar la importancia de ser perseverantes en la aplicación del método AICLE, ya que de los resultados también se desprende que ante el primer contacto es normal que surjan actitudes y conductas de inseguridad, temor e incluso repulsión; pero si se superan las dificultades de esta fase inicial, la situación mejora considerablemente, llegando a generar sensaciones muy satisfactorias en consonancia con los hallazgos de Coral (2010), Montávez et al. (2002) y Christopher et al., (2012). En este sentido, conviene decir que una sola experiencia AICLE ha sido suficiente para modificar positivamente las perspectivas iniciales del alumnado, mostrando un interés explícito por repetir la experiencia. De cara al futuro, para profundizar y complementar este estudio, podrían ser de gran interés nuevas investigaciones relativas al sentir y percepción del profesorado.

\section{Agradecimientos}

El presente trabajo se llevó a cabo gracias al apoyo del Proyecto de Innovación Educativa SPIEDA de la Universitat Jaume I (número de referencia 3256).

\section{Referencias}

Alías, D. (2011). El valor didáctico del juego y del movimiento en la enseñanza del inglés en el primer ciclo de Primaria. Campo abierto, 30(2), 23-41.

Alonso, J. A., Cachón, J., Castro, R., \& Zagalaz, M. L. (2015). Propuesta didáctica bilingüe para educación física en educación primaria. Juegos populares tradicionales ingleses. Retos: Nuevas tendencias en Educación Física, Deporte y Recreación, (28), 116-121.

Bentley, K. (2007). Student talking time. How can teachers develop learners communication skills in a secondary school CLIL programme? Revista Española de Lingüistica Aplicada. (1), 129-140.

Chiva, O, Isidori, E., \& Fazio, A. (2015). Educación Física bilingüe y pedagogía crítica: una aplicación basada en el judo. Retos: Nuevas tendencias en Educación Física, Deporte y Recreación, (28), 110-115.

Chiva, O., \& Salvador, C. (2016). Aprendizaje integrado de Educación Física y Lengua Inglesa. Barcelona: Inde. 
Christopher, A., Dzakiria, H., \& Mohamed, A. (2012). Teaching English through sport: a case study. Asian EFL Journal. Professional Teaching Articles. 59(4), 20-29.

Coral, J. (2010). L'aprenentatge de l'anglès a través de l'educació física: el programa «moute i aprèn». Temps d'educació, (39), 149-170.

Coral, J. (2012). Aprenentatge integrat de continguts d'educació fisica i llengua anglesa: educació fisica en AICLE al cicle superior de primaria. Barcelona: Facultat de Formació del professorat.

Coral, J., \& Lleixà, T. (2013). Las tareas en el aprendizaje integrado de educación física y lengua extranjera (AICLE). Determinación de las características de las tareas mediante el análisis del diario de clase. Retos: Nuevas tendencias en Educación Física, Deporte y Recreación, (24), 79-84.

Coral, J., \& Lleixà, T. (2016). Physical education in content and language integrated learning: successful interaction between physical education and English as a foreign language. International Journal of Bilingual Education and Bilingualism, 19(1), 108-126.

Coyle, D., Hood, P. \& Marsh, D. (2010). CLIL. Cambridge: CUP.

Creswell, J.W. (2002). Educational Research: Planning, Conducting, and Evaluating Quantitative. Upper Saddle River: Prentice Hall.

Dalton-Puffer, C. (2011). Content-and-Language Integrated Learning: From Practice to Principles?. Annual Review of Applied Linguistics, 31, 182-204.

Devos, N. (2012). CLIL in Physical Education: Evidence for Language and Content Scaffolding during Peer Interaction. En P. Lennon (Ed.) Learner Autonomy in the English Classroom: Empirical Studies and Ideas for Teachers (pp. 359- 381). Frankfurt: Peter Lang.

Elliot, J. (2007). Reflecting where the action is. London: Routledge.

Figueras, S., Flores, C., \& González, M. (2011). Educació Física en anglès: percepcions dels estudiants entorn d'una experiència metodològica en el marc universitari. 
Aloma: Revista de Psicologia, Ciències de l'Educació i de l'Esport, (29), 61-80.

García, J.V., García, J.J., \& Yuste, J.L. (2012). Educación Física en inglés. Una propuesta para trabajar la higiene postural en Educación Primaria. Retos: Nuevas tendencias en Educación Física, deporte y recreación, (22), 70-75.

González, C., Cecchini, J. A., Fernández-Río, J. \& Méndez, A. (2008). Posibilida- des del modelo comprensivo del aprendizaje cooperativo para la enseñanza deportiva en el contexto educativo, Aula Abierta, $36(1,2), 27-38$.

González, S., Villar, L., Pastor, J.C., \& Gil, P. (2013). Propuesta didáctica interdisciplinar en educación primaria en España: la enseñanza de la educación física y el inglés. Paradigma, 34(2), 31-50.

Halcomb, E.J., \& Davidson, P. M. (2006). Is Verbatim Transcription of Interview Data always Necessary? Applied Nursing Research, 19(1), 38-42.

Hernando, A., Hortigüela, D. \& Pérez-Pueyo, A. (2018). Percepción de coordinado- res de programas bilingües y docentes de educación física en inglés en secunda- ria sobre el proceso de implantación y desarrollo del bilingüismo en la Comu- nidad de Castilla y León, Retos: Nuevas tendencias en Educación Física, Deporte y Recreación, (33), 63-68.

Latorre, A. (2003). La investigación-acción. Conocer y cambiar la práctica educa- tiva. Barcelona: Graó.

Lova, M., \& Bolarín, M. J. (2015). La coordinación en programas bilingües: las voces del profesorado, Aula Abierta, 43(2), 102-109.

McNiff, J., \& Whitehead, J. (2006). All you need to know about action research. Sage Publications.

Montávez, M., Mariscal, A., \& López-Díaz, I. (2002). Desdramaticemos el inglés. Propuesta interdisciplinar: Educación Física (expresión corporal) y Lengua extranjera. Retos. Nuevas tendencias en Educación Física, Deporte y Recreación, (1), 29-36. 
Parise, M., Pagani, A. F., Cremascoli, V. \& Iafrate, R. (2015). Rugby, self- perception and prosocial behaviour: evidence from the italian «rugby project for schools», Revista Iberoamericana de Psicología del ejercicio y el Deporte, 10(1), 57-61.

Patton, M.Q. (2002). Qualitative Research and Evaluation Methods. London: Sage.

Porta, L., \& Silva, M. (2003). La investigación cualitativa: El Análisis de Conteni- do en la investigación educativa. Red Nacional Argentina de Documentación e Información Educativa. Recuperado de: http://www. uccor. edu. ar/paginas/ REDUC/porta. pdf.

Ramos, F., \& Ruiz, J.V. (2011). La Educación Física en centros bilingües de primaria inglés-español. RESLA, 24, 153-170.

Reyes, A. (2014). Una propuesta didáctica para favorecer la comunicación oral en inglés en el área de educación física en ciclo inicial de educación primaria. Phonica, (910), 213-221.

Rio, L., Di Rubbo, N., \& Gómez-Paloma, F. (2014). Natural acquisition of the second language (12) through routine movements in children, Journal of Human Sport \& Exercise, (9), 355-358.

Rottmann, B. (2007). Sports in English. Learning opportunities through CLIL in Physical Education. En C. Dalton-Puffer \& U. Smit (Eds.), Empirical Perspectives on CLIL Discourse (pp. 205-227). Frankfurt: Peter Lang.

Salvador, C., Chiva, O., \& Fazio, A. (2016). Características del Aprendizaje Integra- do de Contenidos de Educación Física y Lengua Extranjera. Retos. Nuevas Tendencias en Educ. Física, Deporte y Recreación. (29), 120-125.

Salvador, C., Chiva, O., \& Ruiz, N. (2016). Aprendizaje integrado de contenidos y lengua extranjera. Educación física e inglés. En O. Chiva \& M. Martí (Coord.), Métodos pedagógicos activos y globalizadores (pp. 45-64). Barcelona: Graó. Salvador, C., Chiva, O., \& Isidori, E. (in press). Aprendizaje de una lengua extranjera a través de la educación física: una revisión sistemática. Movimento. 0(0),00-00.

Sánchez-Alcaraz, B. J., Gómez-Marmol, A., \& Más, M., (2016). Estudi de la motivació 
d'assoliment i orientació motivacional en estudiants d'educació física. Apunts. Educació Física i Esports. (124), 35-40.

Sánchez-Gómez, R., Devís-Devís, J., \& Navarro-Adelantado, V. (2014). El modelo teaching games for understanding en el contexto internacional y español: una perspectiva histórica, Ágora para la Educación Física y el Deporte, 16(3), 1972013.

Valera, S., Ureña, N., Ruiz, E., \& Alarcón, F. (2010). La enseñanza de los deportes colectivos en educación física en la E.S.O., Revista Internacional de Medicina y Ciencias de la Actividad Física y el Deporte, 10(40), 502-520. 


\subsection{Investigación empírica del efecto de AICLE sobre la actividad física del alumando}

Por último, el tercer subapartado se vincula con la tercera fase del proyecto, es decir, el análisis del efecto generado por AICLE sobre la actividad física realizada en educación física. Así, mediante esta sección se pretende abordar el tercer objetivo de investigación que se concreta de la siguiente forma:

- O.3. "Analizar cómo afecta el uso del enfoque AICLE en las sesiones de educación física."

Este tercer objetivo queda subdividido en dos que, a diferencia de los anteriores, han sido planteados secuencialmente. Esto significa que primero se planteó la necesidad de afrontar el primero de ellos $\mathrm{y}$, fruto de los inesperados resultados obtenidos, optamos por establecer el segundo, aportando una nueva visión, más profunda, sobre el estudio realizado.

El primer objetivo de la tercera fase del proyecto de investigación queda concretado de la siguiente forma:

- O.3.1. "Examinar si la utilización de AICLE en educación implica que se vean alterados los niveles de actividad física del alumnado durante las sesiones en comparación con las sesiones ordinarias de esta asignatura."

La motivación de la que emana el manuscrito 5, que trata de abordar este cometido, reside en la necesidad establecida de investigar cuestiones relativas al área de contenido que acoge AICLE (Fernández-Sanjurjo et al., 2017; Pérez-Cañado, 2018). La educación física, al igual que el resto de materias curriculares que pueden acoger AICLE, atesora una serie de particularidades que conforman su esencia. Estas características, básicas para el desarrollo de su didáctica, no deberían verse alteradas como consecuencia de la introducción de AICLE. Sin embargo, autores como Coral, et al. (en prensa) o Martínez y García (2017) plantean que la incursión de dicho enfoque pedagógico podría poner en peligro un correcto desarrollo de la materia de educación física.

En el caso de esta asignatura en concreto, sus contenidos engloban habilidades de carácter competencial, cognitivo, social y motriz (Ayuso, Rivero y Izquierdo, 2018; Gill et al., 2016), erigiéndose el movimiento en una de sus mayores singularidades (Larsson y Nyberg, 2017). 
De hecho, múltiples autores indican que, entendiendo el movimiento desde su sentido más amplio e inclusivo (Svennberg, 2017), su promoción debería ser una de las finalidades básicas de la asignatura (Dodd, 2015; Heikinaro-Johansson, Hasanen, McEvoy y Lyyra, 2018; Molina, Queralt, Estevan y Sallis, 2016; Viciana, Mayorga y Mompeán, 2016). Sin embargo, cuando la educación física se imbrica con el enfoque AICLE, se pone en duda que la actividad física de las sesiones no se vea sujeta a una disminución significativa (Coral et al., en prensa; Martínez y García, 2017). Por este motivo, resulta apropiado analizar objetivamente cómo varían los niveles de actividad física del alumnado durante las sesiones. El manuscrito 5 pretende dar respuesta a esta circunstancia, midiendo objetivamente los niveles de actividad alcanzados por el estudiantado que desarrolla prácticas en AICLE y comparándolos con otro grupo de discentes que llevan a cabo las mismas sesiones pero utilizando su lengua materna. 


\section{MANUSCRITO 5}

TÍTULO:

The effect of bilingual Physical Education on students' Physical Activity. Things are not always as they seem

AUTORES:

Celina Salvador García, Òscar Chiva Bartoll y Carla Colomer

FUENTE:

Cultura, Ciencia y Deporte

(Aceptado para publicación) 


\title{
The effect of bilingual Physical Education on students' Physical Activity. Things are not always as they seem.
}

\section{El efecto de la Educación Física bilingüe sobre la actividad física del alumnado. No todo es lo que parece.}

Celina Salvador García, Òscar Chiva Bartoll y Carla Colomer

\begin{abstract}
One of the priorities of ET2020 is to increase the efficiency of teaching through the Content and Language Integrated Learning (CLIL) approach. In Physical Education (PE), it is still not crystal clear whether sessions that involve CLIL undergo such substantial modifications that the amount of physical activity in the lessons is jeopardized when compared with ordinary Physical Education lessons. The objectives of this study were: (1) to determine the difference in Moderate to Vigorous Physical Activity (MVPA) between a CLIL and a nonCLIL group; (2) to analyse the progression of MVPA during a PE unit; (3) to analyse the possible differences in MVPA between males and females. A quasi-experimental design was implemented. The sample consisted of 48 from a Spanish secondary school, divided into a CLIL group and a non-CLIL group. GENEActiv Accelerometers were used to objectively measure their MVPA. The results showed significant differences in favour of the CLIL group, whose average MVPA was higher than that of the non-CLIL group. In conclusion, the results suggest that CLIL may be a valid approach to use in PE without compromising students' physical activity.
\end{abstract}

Keywords: Physical Education, CLIL, Physical Activity, Accelerometers, Approach.

\section{Resumen}

Una prioridad del ET2020 es incrementar la eficiencia de la enseñanza mediante el Aprendizaje Integrado de Contenidos y Lengua (AICLE). En Educación Física (EF) aún no parece claro si la sesiones mediante AICLE se ven tan modificadas como para alterar 
significativamente la cantidad de actividad física del alumnado en comparación con clases ordinarias. Los objetivos de este estudio fueron: (1) determinar la diferencia de Actividad Física Moderada-Vigorosa (AFMV) entre un grupo AICLE y otro no-AICLE; (2) analizar la progresión de AFMV durante una unidad de EF; (3) analizar las posibles diferencias en AFMV entre chicos y chicas. Se utilizó un diseño cuasi-experimental. La muestra estaba compuesta por 48 estudiantes de un insitituto de educación secundaria español, divididos en un grupo AICLE y otro no-AICLE. Para medir objetivamente los niveles de AFMV se utilizaron acelerómetros GENEActiv. Los resultados indicaron diferencias significativas a favor del grupo AICLE, cuya media de AFMV fue mayor que la del grupo no-AICLE. En conclusión, los resultados apuntan a que AICLE podría ser un enfoque válido en EF puesto que no necesariamente pone en riesgo la actividad física del alumnado.

Palabras clave: Educación Física, AICLE, actividad física, acelerómetros, enfoque pedagógico.

\section{Introduction}

Changing trends require adjustments of educative models, which usually come together with shifts in legal frameworks. One of the priorities of ET2020 is to increase the efficiency of teaching through the Content and Language Integrated Learning (CLIL) approach. According to Coyle, Hood, and Marsh (2010, 1), CLIL is defined as a 'dual focused educational approach in which an additional language is used for the learning and teaching of both content and language', and linguistic contents should be naturally integrated within the specific subject matter. Therefore, CLIL has three different goals, which are learning content, language, and skills, all of which have to fit into the context where it is implemented (Mehisto, Marsh, \& Frigols, 2008).

Since CLIL was launched in the 1990s, the European Commission and the Council of Europe have funded many initiatives to support it, in response to a need in Europe to enhance secondlanguage education and multilingualism (Marsh, 2002). Therefore, CLIL is one of the trendier methodological options in the Foreign Language teaching setting. For example, the Netherlands and Spain have invested a lot in CLIL or similar methodologies that also encourage language learning through content (Coral, Lleixà, \& Ventura, 2016; DaltonPuffer, 2011; van Kampen, Admiraal, \& Berry, 2018) and it is also being trialled in non- 
european countries such as Australia, Taiwan or Thailand among many others (Cross, 2014; Kewara, 2017; Turner, 2013; Yang, 2015).

CLIL is not only a trend in education in general, but also in the Physical Education (PE) field (Baena \& Granero, 2015; Brooke, 2015; Ceallaigh, Mhurchú, \& Chróinín, 2017; Gruber, 2015). This tendency can be perceived at a scientific level, considering the growing body of research on this topic (see Salvador, Chiva, \& Isidori, 2017, for review). Moreover, at a practical level, the European award for languages in 2007 was obtained by a project entitled 'A CLIL Experience in Primary School: Teaching French through a games strand of the PE Curriculum'.

A number of researchers have reported both advantages and disadvantages of using CLIL, which Pérez-Cañado (2016) has called the 'pendulum effect'. Specifically in the case of the subject of PE, Martínez and García (2017) wondered if this area would be distorted and its sessions misused due to the incorporation of CLIL. Similarly, Coral and Lleixà $(2016,16)$ wondered whether the goals of the PE curriculum would be achieved differently if taught in the first language or through the CLIL approach. In this regard, some authors have mentioned that this approach might cause learning delays (Coral, 2010, 2012) related to acquiring less knowledge linked to the subject (Hernando, 2015). In this case, if the PE program is not applied properly, it may negatively affect learners' physical activity time (Lynott, 2008), which is a key factor in the acquisition of the contents of this particular subject (Martínez \& García, 2017; Sánchez-Bañuelos, 1992).

In light of these questions, research is needed that examines how teaching content in a second language affects the non-linguistic area (Cenoz, Genesee, \& Gorter, 2014; Coral \& Lleixà, 2016). In the case of PE, the contents involve motor, cognitive, and social skills as well as competences (Ayuso, Rivero \& Izquierdo, 2018; Gill et al., 2016) taking into account that movement is one of its key features (Larsson \& Nyberg, 2017). Moreover, promoting physical activity is one of its primary goals (Dodd, 2015; Heikinaro-Johansson, Hasanen, McEvoy, \& Lyyra, 2018; Molina, Queralt, Estevan, \& Sallis, 2016; Viciana, Mayorga, \& Mompeán, 2016), being movement understood in its wide and inclusive sense (Svennberg, 2017). In this regard, Coral et al. (2017) conducted a pilot study that aimed to measure the time that students were physically active in PE with CLIL through an observation tool. They 
conclude that motor-engaged time is lower than what is recommended by educational authorities and suggest that the shortfall in the amount of physical activity time may be accounted for by the excessive use of language support materials or the types of physical activity involved in the lessons.

Several studies have concluded that PE lessons currently play a decisive role in the amount of physical activity children and teenagers do because these classes may be their only opportunity to engage in a minimal amount of physical activity (Gill et al., 2016; Martínez et al., 2012; Meyer et al., 2011; Molina et al., 2016). Therefore, PE has been highlighted as an important way to promote a healthy and active lifestyle among young people (Hall-López et al., 2017; Lonsdale et al., 2013, Rivera-Sosa \& Arras-Vota, 2015). Particularly, previous research states that students should spend $50 \%$ of their time in PE lessons engaged in moderate to vigorous physical activity (MVPA) (Fröberg, Raustorp, Pagels, Larsson, \& Boldemann, 2017; Ha, Londsdale, Ng, \& Lubans, 2017; Murillo, Julián, García, Abarca, \& Zaragoza, 2014) because this is the level associated to health benefits (Martínez et al., 2012). Nevertheless, a review paper concluded that few schools meet international recommendations about the minimum MVPA time per session (Fairclough \& Stratton, 2005). In the same vein, in their recent systematic review and meta-analysis of MVPA levels in secondary school PE lessons, Hollis et al. (2017) concluded that students spend $40.5 \%$ of the time in MVPA, which is below the 50\% recommended by the US Centre for Disease Control and Prevention and the UK Associations for Physical Education.

Because the PE class is said to be crucial for performing and promoting physical activity, and CLIL approach is currently gaining relevance in many countries (Salvador et al., 2017), researchers should question whether the sessions involved in PE through CLIL undergo such substantial modifications that the amount of physical activity performed in the lessons is jeopardized. The literature has already focused on some factors that may affect the MVPA in PE such as sex, motivation, structure, or content, among others (Mesa, Guzmán, \& Vázquez, 2011; Molina et al., 2016). In addition, the use of CLIL may involve some other modifications, such as giving extra instructions (Chiva \& Salvador, 2016; Coral, 2013; Gómez \& Jiménez, 2012), including the four linguistic skills (Coral, 2012; Hernando, 2015, 
Salvador \& Chiva, 2017) or using language support materials to facilitate communication (Coral et al., 2017), which might alter the time students are engaged in MVPA.

The main aim of this study is to analyse the influence of CLIL on the physical activity of students in PE lessons objectively. To do so, three specific objectives have been established: (1) to study the differences in the MVPA between a CLIL group and a non-CLIL group when learning the same curricular content; (2) to analyse and compare the progression of the amount of MVPA in CLIL and non-CLIL groups during the six lessons of one unit; and (3) to analyse the differences between males and females in their MVPA.

We utilized MVPA levels in our study because they have been used in many studies focused on examining physical activity in the PE field. Measuring MVPA levels through accelerometry makes it possible to arrange objective data in order to compare the results of the two groups in the present study (CLIL vs non-CLIL), and compare these results to those from previous studies on physical activity in PE lessons. Particularly, this research is focused on Secondary education in the Spanish context, where, due to the introduction of multilingualism in the educational system, the use of CLIL to learn English as a second language is widespread and even legally required in several regions. Currently, Spanish education is particularly sensitive to European initiatives about language policies. In fact, in the last decade, countries such as Finland, Germany or Sweden, seem to have progressively enhanced multilingualism. Therefore, there is a need to understand how the introduction of CLIL approach might affect the essence of PE.

\section{Method}

\section{Research Design}

A quasi-experimental approach was used to objectively test (through accelerometer measures) the intensity of physical activity using a non-equivalent control group design (Campbell \& Stanley, 1963). Intact classes were used for assignment to the CLIL and nonCLIL groups. However, classes were randomly assigned to each group by the secondary school. Moreover, similar conditions were established in order to compare them; that is, two intact groups in a public secondary school were taught the same athletic contents by the same PE teacher. 


\section{Participants and Settings}

This study was conducted in a Spanish public secondary school located in an average socioeconomic area during the 2016/2017 academic year. A convenience sample was used, consisting of 48 13-14-year-old students (born in 2003) divided into the CLIL group (13 females and 9 males) and the non-CLIL group (19 females and 7 males). There were no differences in sex between the two groups, $\chi^{2}(\mathrm{~N}=48)=1.05, p=.306$. The CLIL group had never been taught PE through CLIL before. Regarding English language level, students of both groups have the same educational background. One of the students in the CLIL group had a visual impairment, and so his data were excluded from the statistical analyses. However, the results did not change when this student's data were included.

Each group had two PE periods per week; classes were 50 min long, and all of them were held in the morning. Data recruitment took place from January to February 2017. Accelerometer-based outcome measures were taken from all the students in the class. PE classes in both groups were taught by a PE teacher with 12 years of experience who had been teaching through CLIL for several academic years. She has an official certificate that enables her to teach PE through the English language.

Study approval was obtained from the human research ethics committee of the University and the school district. The principal and the PE teacher agreed to participate through the establishment of a memorandum of understanding. Informed written consent was obtained from the adolescents' parents or guardians.

\section{Procedure}

Prior to the beginning of the study, the PE teacher attended a 120-minute meeting with the researchers to clarify all the instructional and experimental procedures related to the study. The teacher was responsible for both the CLIL intervention group and the non-CLIL control group in an attempt to control for potential 'teacher-related' confounds. She was told to teach the same content to both groups, but one of them would be taught through CLIL approach. An experienced external observer conducted practice observations of the lessons of both groups to verify that they were carried out as planned. Moreover, through this observation, the 'planning and observation checklist' for CLIL (Mehisto et al., 2008) was completed to 
ensure that the hard CLIL approach applied was accurate (Ball, 2009; Griva \& Kasvikis, 2015). The students and teacher were aware of the different methodologies used, but they were blind to the specific objectives of this study. The idea was that they were to act as naturally as possible in order to gather authentic data.

To control for differing durations of PE lessons, physical activity data were collected during the entire 50-minute lesson because the English language was used with the CLIL group during this period of time. Prior to starting each PE session, accelerometers were distributed to students and worn for the entire class time.

\section{The unit}

Both the CLIL and non-CLIL units were focused on athletics combining discovery teaching, self-check teaching and direct teaching styles (Kirk, McDonald, \& O'Sullivan, 2006). This content has been implemented before through CLIL approach (Griva \& Kasvikis, 2015; Hortigüela \& Hernando, 2015), and it was selected in this study because it is considered one of the most common and widespread contents in PE curricula around the world (Ginciene \& Matthiesen, 2017), therefore it enables the replicability of the investigation. Each unit consisted of six lessons presented in the same order and in the same setting (indoors/outdoors). The specific content of each session was the following: session 1 (S1) race and race walking techniques, (S2) relays, (S3) hurdles, (S4) long jump and triple jump, (S5) triple jump and shot put, (S6) review of all the events practiced. Each lesson consisted of a 10-min warm-up, followed by skill-related practice, and ending with a 5-min selfassessment task in both groups. Nevertheless, the CLIL group usually added a couple of tasks focused on communication and language use that were often performed during waiting time periods. Lessons were developmentally appropriate for the designated grade level, and their scope and order were arranged to build skills and abilities sequentially. Evaluation was based on effort, improvement, and performance scores. All the lessons were taught independently by the class teacher while a researcher acted as observer. All the sessions were held in the morning.

\section{Instrument}

Accelerometers have been found to be one of the most objective tools to measure the amount 
of physical activity (Calahorro et al., 2015), and they have been increasingly used to measure the physical activity of school children (Rowlands et al., 2014). In fact, there has recently been an increased use of wrist-worn devices to measure physical activity in different settings (Fairclough et al., 2016). We assessed physical activity using the GENEActiv Original triaxial accelerometer worn on the left wrist. Accelerometers are easy to move, very accurate, and do not interfere with the lessons (Calahorro et al., 2015), and they are valid and reliable tools (Molina et al., 2016). In fact, accelerometers have been validated for both children and teenagers, and they are considered the most appropriate tool to measure physical activity (Martínez et al., 2012). A number of studies have already used them for this purpose (Calahorro et al., 2015; Lopes, Santos, Mota, Pereira, \& Lopes, 2017; Martínez et al., 2012; Molina et al., 2016; Murillo et al., 2014). In this particular study, the GENEActiv accelerometers were configured with a sampling frequency of $100 \mathrm{~Hz}$, data uploaded, and the .bin files converted to 1s epoch .csv files using GENEActiv PC software version 3.1. The 1s epoch files were imported into custom-built spreadsheets in Excel. Laboratory-based studies have developed cut-off points (sedentary, light, moderate, and vigorous) for the wristworn GENEActiv, and supported its validity for estimating energy expenditure and time spent at different activity intensities in adults (Esliger et al., 2011; Pavey, Gomersall, Clark, $\&$ Brown, 2016) and children (Phillips, Parfitt, \& Rowlands, 2013). The time spent on MVPA was calculated applying previously calibrated and validated cut-off points from Phillips et al. (2013).

\section{Data analysis}

In accordance with the literature, the analyses were conducted by unifying the moderate and vigorous categories into one variable called Moderate Vigorous Physical Activity (MVPA). A Mixed-model Analysis of Variance (mixed ANOVA) was conducted to examine whether the time spent in MVPA differed between groups (first objective) and sessions (second objective), with group as between-subject factor (2 levels: CLIL and non-CLIL) and sessions as within-subject factor (6 levels: sessions 1-6), followed by Bonferroni-adjusted pairwise comparisons. Finally, sex effects were analysed with a Factorial 2x2 ANOVA, using group and sex as independent variables, and time spent in MVPA as dependent variable. 
Results with $\mathrm{p}$ values $<.05$ were considered statistically significant. Partial eta squared effect sizes $\left(\eta^{2}\right)$ were reported. The data analyses were performed using IBM SPSS Statistics, Version 23 (SPSS Inc., Chicago, IL).

\section{Results}

The mixed ANOVA conducted to evaluate the effect of group and sessions on MVPA showed a statistically significant main effect for Group $(F(1,46)=24.58, \mathrm{p}<.001, \eta 2=.348)$, Session (Wilk's Lambda $(\Lambda)=.038, F(5,42)=211.46, p<.001, \eta 2=.962)$, and the Group $\mathrm{x}$ Session interaction (Wilk's Lambda $(\Lambda)=.211, \mathrm{~F}(5,42)=31.32, \mathrm{p}<.001, \eta 2=.789$ ).

Regarding the first objective, the significant effect for Group indicates that adolescents in the CLIL group $(\mathrm{M}=1034.29, \mathrm{SD}=138.28)$ spent significantly more time in MVPA than those on the non-CLIL group $(\mathrm{M}=816.12, \mathrm{SD}=128.52)$.

The second objective focused on the session effect and the group $\mathrm{x}$ session interaction. Regarding the session effect, post-hoc analyses showed statistically significant differences between all the sessions $(p<.001)$, except the last two (S5 and S6), which were also the sessions where more time was spent on MVPA. For the interaction effect, post-hoc analyses showed statistically significant differences between the CLIL and non-CLIL groups in the last three sessions: S4 $(p<.001)$, S5 $(p<.001)$, and S6 $(p<.001)$, whereas there were nonsignificant differences in S1 $(p=.431), \mathrm{S} 2(p=.257)$ and S3 $(p=.053)$. The CLIL group had higher mean scores than the non-CLIL group on the significant variables, which means that the CLIL group spent significantly more time in MVPA than the non-CLIL group in the last three sessions (see Figure 1). 


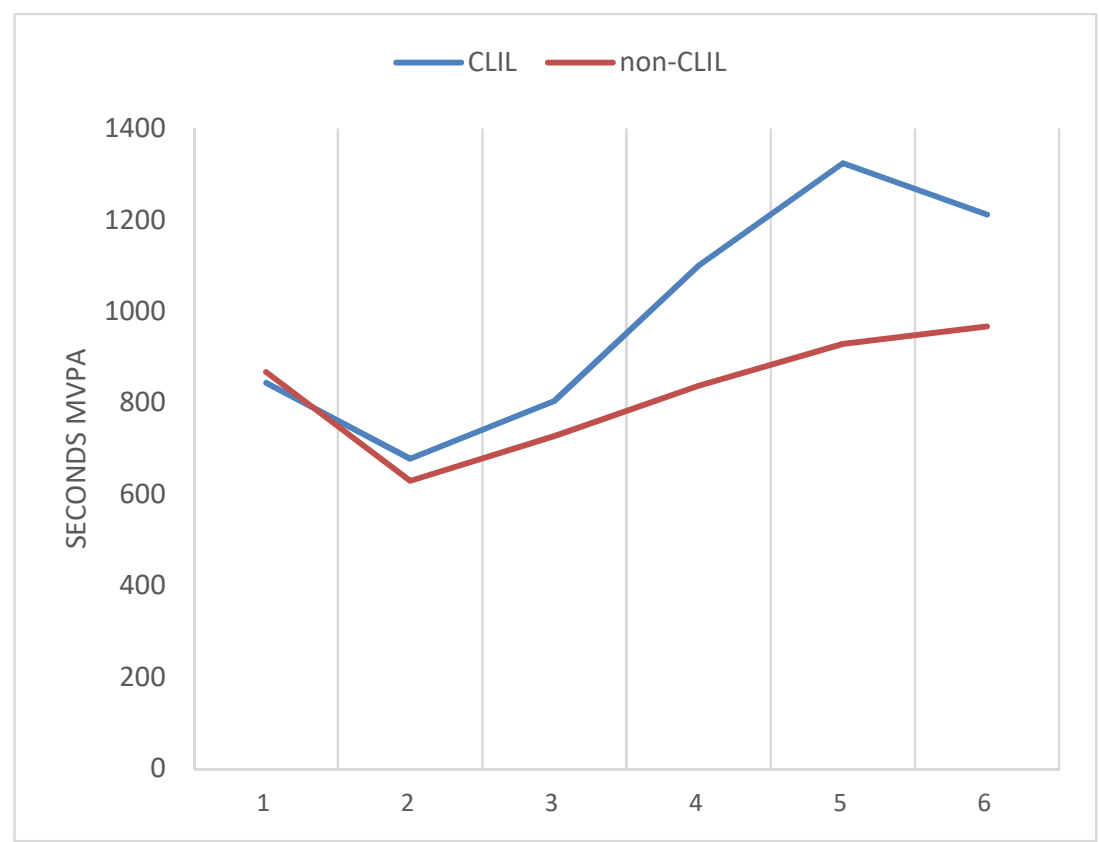

Figure 1. Time (seconds) spent in MVPA by CLIL and non-CLIL groups during the six lessons of the Unit.

Finally, the Factorial ANOVA conducted to test the third objective showed that there was a sex effect $\left(\mathrm{F}(1,44)=13.31, p=.001, \eta^{2}=.232\right)$. As expected, MVPA was higher in males $(\mathrm{M}=1025.11, \mathrm{SD}=203.32)$ than in females $(\mathrm{M}=861.62 ; \mathrm{SD}=123.98)$. The Group $\mathrm{x}$ Sex interaction for MVPA did not reach statistical significance $\left(\mathrm{F}(1,44)=2.93, p=.094, \eta^{2}=\right.$ .062). It is worth noting that the MVPA mean of CLIL females ( $M=955.50 ; \mathrm{SD}=62.16)$, was higher than the MVPA of non-CLIL males $(\mathrm{M}=866.95, \mathrm{SD}=158.63)$.

\section{Discussion}

The current study was designed to determine the effect of the implementation of CLIL approach on the amount of MVPA performed by the students during PE lessons. The results are discussed, taking into account the three specific objectives established.

The first research objective, focused on analysing the difference in the time spent in MVPA between the CLIL and non-CLIL groups, and its discussion will be divided into two main parts. First, we will focus on the direct comparison of the two groups analysed in the present research; and second, our findings will be compared to those from other studies that also measured MVPA in PE lessons. 
The overall amount of MVPA time of the CLIL and non-CLIL groups presented a significant difference. More specifically, the CLIL group presented higher levels of physical activity than the non-CLIL group. It is interesting to understand and discuss this result because some authors have argued that CLIL would negatively affect learners' physical activity time (Coral, 2013; Coral et al., 2017; Lynott, 2008). Some of the explanations for our results are related to linguistic adjustments by the teacher, such as using shorter and less complex utterances (Gruber, 2015, Salvador \& Chiva, 2017) or giving clear and simple instructions (Gómez \& Jiménez, 2012). Moreover, according to Zindler (2013), the use of a foreign language may force the teacher to limit him/herself to the essential message, and at the same time, students have to listen more carefully. Another possible explanation for this result is the fact that because students are more motivated by participating in CLIL programs (Doiz, Lasagabaster, \& Sierra, 2014; Salvador \& Chiva, 2017), they might be more willing to participate in their PE lessons.

Independently from the non-CLIL group, the current study found that the group that attended PE classes with CLIL approach devoted 17.24 minutes of the lesson $(34.48 \%)$ to MVPA on average. This finding is consistent with other studies that have also measured the levels of physical activity in PE lessons; for example, primary school children in Switzerland spent 16.7 minutes on MVPA (Meyer et al., 2011), primary and secondary school students in Brazil spent 12.3 minutes (Kremer, Reichert, \& Hallal, 2012), and secondary school students in Spain spent 11.8 minutes (Molina et al., 2016). All of them measured MVPA in non-CLIL lessons with similar durations to ours (50 minutes). Moreover, the meta-analysis conducted by Hollis et al. (2017) concluded that secondary school students spend $34.7 \%$ of the lesson in MVPA. Although there are subtle differences, it can be perceived that the amount of MVPA time spent by the CLIL group in PE seems to agree with previous research that studied regular PE lessons. Thus, it can be suggested that CLIL approach does not notably alter students' MVPA time.

However, we should be cautious about our results because physical activity levels during PE sessions might depend on a range factors. Several studies have been carried out to measure the amount of physical activity in different settings (Molina et al., 2016). For example, in a PE with CLIL setting, Coral et al. (2017) found that, on average, students spent $41,8 \%$ of the 
class physically engaged in the fifteen lessons analysed. Nevertheless, they conducted the study using an observation tool and, although they provide very interesting results, their study did not identify the intensity level. Taking into account non-CLIL settings and focusing on a specific content, Harvey et al. (2016) developed TGM basketball sessions of 50 minutes each and concluded that they provided between 25-35 minutes of MVPA over the course of a week. This finding agrees with our results because the two sessions implemented every week involve up to 32.77 minutes of MVPA for CLIL students. Moreover, Murillo et al. (2014) found that in the lessons devoted to athletics, the average MVPA time was 14.2 minutes for a secondary school group. Therefore, this study may serve as a mirror for our analysis, and CLIL approach does not seem to have decreased the amount of MVPA.

Another factor that might influence physical activity levels is class size. Whereas Molina et al. (2016) mentioned that groups with more than 25 pupils are related to more time spent in MVPA, McKenzie et al. (2000) stated that large class size negatively affects MVPA time. Our study included only two classes with similar sizes: CLIL group ( $\mathrm{n}=23)$, non-CLIL group $(n=26)$. Studies with more groups should be conducted to analyse the influence of class size on CLIL. When comparing groups in general, class-level factors such as the sex distribution might enhance or diminish activity levels during PE class (Aelterman et al., 2012). However, these explanations cannot be used in our case because the sex distribution does not differ significantly, and the class topic was exactly the same.

The second objective consisted of analysing the progression of the amount of MVPA during the six lessons of the PE unit in the CLIL and non-CLIL groups. Both groups progressively increased the amount of MVPA during the six lessons; however, the CLIL group's progression was significantly different from the non-CLIL group. More specifically, in the first three lessons, both groups had a similar MVPA, whereas in the last three lessons, the CLIL group spent more time than the non-CLIL group in MVPA. The difference in the evolution of the MVPA of the CLIL and non-CLIL groups during the sessions of the unit might be explained by the fact that the experimental group was not familiar with CLIL approach in the beginning. Ha et al. (2017) determined that their experimental group was not familiar with teaching rope skipping activities (a new content) initially. Moreover, these authors mentioned that 'teachers had to spend more time to manage students while 
implementing rope skipping activities' (p. 192), which might provide some possible explanations for our findings. In this regard, our CLIL group might have been unfamiliar with CLIL approach during the first sessions; as they became used to it, the physical activity time could have been optimized. In the same vein, Emmanouilidou and Laskaridou (2017) found that after a few weeks of using CLIL approach, students began to feel safer, more confident, and more used to using language for and through learning, which in our case might be related to having the chance to spend more time engaged in MVPA.

Regarding the third objective, related to the differences in MVPA between males and females, this research found that boys spent more time engaged in MVPA. These results corroborate the findings of a large amount of previous work in this field because it seems that boys tend to be more active than girls on average (Harvey et al., 2016; How, Whipp, Dimmock, \& Jackson, 2013; Kremer, et al., 2012; Meyer et al., 2011; Molina et al., 2016). However, some studies did not find such clear differences (Fröberg et al., 2017; Ha et al., 2017). Ha et al. (2017) perceived that females increased their physical activity more than males, although they concluded that it was due to the content (rope skipping). Moreover, it is interesting to point out that girls in the CLIL group presented a higher MVPA-level mean than the boys in the non-CLIL group.

Generally, girls and boys tend to show a discrepancy in their attitudes and motivation when learning a foreign language (Clark, 1995; Doiz, et al., 2014). Girls usually show more motivation and involvement in learning tasks requiring verbal interaction. Therefore, as CLIL seems to present a more motivating challenge for girls (Fernández-Barrionuevo, 2017; López Rúa, 2006), its implementation in PE could have positively influenced their commitment to the subject and, consequently, increased their levels of MVPA. However, this hypothesis needs to be studied more in depth.

All these assumptions should be interpreted taking into account certain limitations to overcome in future investigations. First, the results should be interpreted with caution because the sample size was small, and only two groups were included. The findings refer to a specific unit within a specific context, and so they might not be transferable to every group and/or school using CLIL. Second, our study obtained the data by measuring a short period of time (six lessons). However, this limitation is common in studies that measure levels of 
physical activity. Nevertheless, to minimize these limitations, our research objectively measured all the students in both groups (which few studies do).

\section{Conclusion}

Educational research must guarantee that new educative models, especially the ones included in legal frameworks, are coherently introduced and developed. Sometimes, some changes which have not been deeply examined are established in order to follow the last educational trends. Regarding the topic that concerns us, language learning, and particularly the use of CLIL approach, has achieved an undeniable relevance.

One of the main concerns that has received the use of this approach in PE subject is related to the reduction of physical activity levels. Although PE subject can not be reduced to the levels of physical activity developed in class, it is clear that movement, in its wide sense, is one of the key features of the subject. In this regard, we have studied the effects of CLIL on physical activity during PE classes.

The results show promising preliminary evidence for the use of the CLIL approach in PE classes. The use of a second language in PE classes through CLIL does not necessarily entail a decrease in the physical activity level; indeed, in our results it is increased. Nevertheless,

further research might explore some issues that remain unclear, such as MVPA measured with different curricular contents and its evolution over longer periods of time. Another possible progression in this line of research could focus on complementing its design with observational methodology.

\section{References}

Aelterman, N., Vansteenkiste, M., Van Keer, H., Van den Berghe, L., De Meyer, J., \& Haerens, L. (2012). Students' objectively measured physical activity levels and engagement as a function of between-class and between-student differences in motivation toward physical education. Journal of Sport and Exercise Psychology, 34(4), 457-480.

Ayuso, J. A. Z., Rivero, M. D. G., \& Izquierdo, A. C. (2018). El modelo competencial en educación física: Contribución, evaluación y vinculación con sus contenidos. Cultura, Ciencia y Deporte, 13(37), 17-30. doi: 10.12800/ccd 
Baena, A., \& Granero, A. (2015). Versión española del sport satisfaction instrument (SSI) adaptado al aprendizaje de la educación física bilingüe en inglés [Spanish version of the sport satisfaction instrument (SSI) adapted to learning bilinligual in English physical ducation]. Porta Linguarum: Revista Internacional de Didáctica de las Lenguas Extranjeras, 24, 63-76.

Ball, P. (2009). Does CLIL work?. In D. Hill \& A. Pulverness (Eds.), The best of both worlds (pp. 32-43). Norwich: Norwich Institute for Language Education.

Brooke, M. (2015). A completely different ball game: Content and language integrated learning through the sociology of sport. ELTWorldOnline.com, 1-23.

Calahorro, F., Torres-Luque, G., López-Fernández, I., Santos-Lozano, A., Garatachea, N., \& Álvarez, E. (2015). Actividad física y acelerometría; orientaciones metodológicas, recomendaciones y patrones [Physical activity and accelerometer: Methodological training, recommendations and movement patterns in school]. Nutrición Hospitalaria, 31(1), 115-128. doi:10.3305/nh.2015.31.1.7450

Campbell, D.T., \& Stanley, J.C. (1963). Experimental and quasi-experimental designs for research. Reprinted from N.L. Gage (Ed.), Handbook of research on teaching. Boston: Rand McNally.

Ceallaigh, T. Ó., Mhurchú, S. N., \& Chróinín, D. N. (2017). Balancing content and language in CLIL. Journal of Immersion and Content-Based Language Education, 5(1), 5886. doi:10.1075/jicb.5.1.03oce

Cenoz, J., Genesee, F., \& Gorter, D. (2014). Critical analysis of CLIL: Taking stock and looking forward. Applied Linguistics, 35(3), 243-262. doi:10.1093/applin/amt011

Chiva, O., \& Salvador, C. (2016). Aprendizaje integrado de educación física y lengua inglesa. Aplicación crítico-deliberativa del método AICLE. Barcelona: INDE.

Clark, A. (1995). Boys into modern languages: An investigation of the discrepancy in attitudes and performance between boys and girls in modern languages. Gender and Education, 7(3), 315-326. 
Coral, J. (2010). L'aprenetatge de l'anglès a través de l'educació física: El programa “moute i aprèn. Temps d'educació, 39, 149-170.

Coral, J. (2012). Aprenentatge integrat de continguts d'educació física i llengua anglesa: educació física en AICLE al cicle superior de primària. (Tesis doctoral). Universitat de Barcelona: Barcelona.

Coral, J. (2013). Physical education and English integrated learning: How school teachers can develop PE-in-CLIL Programmes. Temps d'Educació 45, 41-64.

Coral, J., \& Lleixà, T. (2016). Physical education in content and language integrated learning: successful interaction between physical education and English as a foreign language. International Journal of Bilingual Education and Bilingualism, 19(1), 108-126. doi.org/10.1080/13670050.2016.1143445

Coral, J., Lleixà, T., \& Ventura. C. (2016). Foreign language competence and content and language integrated learning in multilingual schools in Catalonia: an ex post facto study analysing the results of state key competences testing. International Journal of Bilingual Education and Bilingualism. Advance online publication. doi: 10.1080/13670050.2016.1143445.

Coral, J., Urbiola, M., Sabaté, E., Bofill, J., Lleixà, T., \& Vilà Baños, R. (2017). Does the teaching of physical education in a foreign language jeopardise children's physical activity time? A pilot study. International Journal of Bilingual Education and Bilingualism. Advance online publication. doi:10.1080/13670050.2017.1407289

Coyle, D., Hood, P., \& Marsh, D. (2010). CLIL. Cambridge: CUP.

Cross, R. (2014). Defining content and language integrated learning for languages education in Australia. Babel, 49(2), 4-15.

Dalton-Puffer, C. (2011). Content-and-language integrated learning: From practice to principles?. Annual Review of Applied Linguistics, 31, 182-204.

Dodd, G. D. (2015). The unrealised value of human motion-'moving back to movement!'. Asia-Pacific Journal of Health, Sport and Physical Education, 6(2), 191-213. 
Doiz, A., Lasagabaster, D., \& Sierra, M. (2014). CLIL and motivation: The effect of individual and contextual variables. The Language Learning Journal, 42(2), 209-224. doi.org/10.1080/09571736.2014.889508

Emmanouilidou, K., \& Laskaridou, C. (2017). Physical education through CLIL: Teaching movement vocabulary to young learners. Research Papers in Language Teaching and Learning, 8(1), 51-62.

Esliger, D. W., Rowlands, A. V., Hurst, T. L., Catt, M., Murray, P., \& Eston, R. G. (2011). Validation of the GENEA Accelerometer. Medicine \& Science in Sports \& Exercise, 43(6), 1085-1093.

Fairclough, S., \& Stratton, G. (2005). Physical activity levels in middle and high school physical education: A review. Pediatric Exercise Science, 17(3), 217-236.

Fairclough, S., Noonan, R., Rowlands, A., Van Hees, V., Knowles, Z., \& Boddy, L. (2016). Wear compliance and activity in children wearing wrist and hip mounted accelerometers. Medicine \& Science in Sports \& Exercise, 48(2), 245-253.

Fernández-Barrionuevo, E. (2017). Generalización de la motivación en aicle entre los dominios de educación física y aprendizaje en lengua extranjera en centros bilingües andaluces (Doctoral dissertation). Universidad de Granada: Granada.

Fröberg, A., Raustorp, A., Pagels, P., Larsson, C., \& Boldemann, C. (2017). Levels of physical activity during physical education lessons in Sweden. Acta Paediatrica, 106(1), 135-141. doi:10.1111/apa.13551

Gill, M., Chan-Golston, A. M., Rice, L. N., Cole, B. L., Koniak-Griffin, D., \& Prelip, M. L. (2016). Consistency of moderate to vigorous physical activity in middle school physical education. Family \& Community Health, 39(4), 283-292. doi:10.1097/FCH.0000000000000115

Ginciene, G., \& Matthiesen, S. Q. (2017). The sport education model on the teaching of track and field in school. Movimento, 23(2), 729-742.

Gómez, C.L., \& Jimenez, M. (2012). The physical educator as a language teacher for English language learners. Strategies, 25(4), 14-17. 
Griva, E., \& Kasvikis, K. (2015). CLIL in primary education: Possibilities and challenges for developing L2/FL skills, history understanding and cultural awareness. In N. BakićMirić \& D. Erkinovich Gaipov (Eds.) Current trends and issues in higher education: an international dialogue. Cambridge, UK: Cambridge Scholars.

Gruber, K. (2015). Improving students' foreign language competence through Content and Language Integrated Learning (CLIL) in Physical Education (Doctoral dissertation). Wien University: Vienna.

Ha, A. S., Lonsdale, C., Ng, J. Y., \& Lubans, D. R. (2017). A school-based rope skipping program for adolescents: Results of a randomized trial. Preventive Medicine, 101, 188-194. doi.org/10.1016/j.ypmed.2017.06.001

Hall-López, J. A., Ochoa-Martínez, P. Y., Burruel, R. Z., Meza, E. I. A., Castro, R. A. M., \& Buñuel, P. S. L. (2017) Moderate-to-vigorous physical activity during recess and physical education among mexican elementary school students. Retos. Nuevas Tendencias en Educación Física, Deporte y Recreación, (31), 137-139.

Harvey, S., Smith, M. L., Song, Y., Robertson, D., Brown, R., \& Smith, L. R. (2016). Gender and school-level differences in students' moderate and vigorous physical activity levels when taught basketball through the tactical games model. Journal of Teaching in Physical Education, 35(4), 349-357. doi:10.1123/jtpe.2016-0089

Heikinaro-Johansson, P., Hasanen, E., McEvoy, E., \& Lyyra, N. (2018). Preparing physical and health education pre-service teachers to support students' physical activity and wellbeing during the school day. Curriculum Studies in Health and Physical Education, 9(1), 43-57. doi.org/10.1080/18377122.2017.1418181

Hernando, A. (2015). Caracterización de los aspectos metodológicos empleados en la enseñanza de la materia de Educación Física en los centros públicos de secundaria con sección bilingüe en inglés de Castilla y León (Doctoral dissertation) Universidad de Burgos: Burgos.

Hollis, J. L., Sutherland, R., Williams, A. J., Campbell, E., Nathan, N., Wolfenden, L., ... \& Wiggers, J. (2017). A systematic review and meta-analysis of moderate-to-vigorous physical activity levels in secondary school physical education lessons. International 
Journal of Behavioral Nutrition and Physical Activity, 14(1), 52. doi:10.1186/s12966-017-0504-0

Hortigüela, D., \& Hernando, A. (2015). El atletismo bajo el enfoque metodológico CLIL en la educación física bilingüe. [Athletics using CLIL approach in bilingual physical education]. Tándem: Didáctica de la Educación Física, (50), 54-58.

How, Y. M., Whipp, P., Dimmock, J., \& Jackson, B. (2013). The effects of choice on autonomous motivation, perceived autonomy support, and physical activity levels in high school physical education. Journal of Teaching in Physical Education, 32(2), 131-148.

Kewara, P. (2017). Phrasebook: A way out for CLIL teachers in Thailand. Latin American Journal of Content \& Language Integrated Learning, 10(1), 49-73.

Kirk, D., MacDonald, D., \& O'Sullivan, M. (Eds.). (2006). Handbook of physical education. London: Sage.

Kremer, M. M., Reichert, F. F., \& Hallal, P. C. (2012). Intensity and duration of physical efforts in physical education classes. Revista de Saúde Pública, 46(2), 320-326.

Larsson, H., \& Nyberg, G. (2017). It doesn't matter how they move really, as long as they move. Physical education teachers on developing their students' movement capabilities. Physical Education and Sport Pedagogy, 22(2), 137-149. doi.org/10.1080/17408989.2016.1157573

Lonsdale, C., Rosenkranz, R. R., Peralta, L. R., Bennie, A., Fahey, P., \& Lubans, D. R. (2013). A systematic review and meta-analysis of interventions designed to increase moderate-to-vigorous physical activity in school physical education lessons. Preventive Medicine, 56(2), 152-161.

Lopes, L., Santos, R., Mota, J., Pereira, B., \& Lopes, V. (2017). Objectively measured sedentary time and academic achievement in schoolchildren. Journal of Sports Sciences, 35(5), 463-469. doi:10.1080/02640414.2016.117272

López Rúa, P. (2006). The sex variable in foreign language learning: an integrative approach. Porta Linguarum, 6, 99-114. 
Lynott, F. J. (2008). Integrating other subject matter without jeopardizing physical education goals: The content linkage approach. Strategies, 22(1), 10-17.

Marsh, D. (2002). CLIL/EMILE the European dimension. Finland: University of Jäyvskylä.

Martínez, F. J., \& García, E. (2017). Influence of bilingualism on engagement motor time in physical education. Retos. Nuevas Tendencias en Educación Física, Deporte y Recreación (32), 178-182.

Martínez, J. M., Jordán, O. R. C., Navarro, Á. L., \& Laín, S. A. (2012). Niveles de actividad física medido con acelerómetro en alumnos de $3^{\circ}$ ciclo de educación primaria: actividad física diaria y sesiones de educación física [Children's physical activity levels measured by accelerometer: All day physical activity vs physical education classes]. Revista de Psicología del Deporte, 21(1), 117-123.

McKenzie, T. L., Marshall, S. J., Sallis, J. F., \& Conway, T. L. (2000). Student activity levels, lesson context, and teacher behavior during middle school physical education. Research Quarterly for Exercise and Sport, 71(3), 249-259.

Mehisto, P., Marsh, D., \& Frigols, M. J. (2008). Uncovering CLIL content and language integrated learning in bilingual and multilingual education. Oxford: Macmillan.

Mesa, M. D. C. C., Guzmán, M. E. G., \& Vázquez, C. C. (2011). El estilo de enseñanza como determinante del tiempo de compromiso motor en educación física. Scientia: revista multidisciplinar de ciencias de la salud, 16(1), 40-51.

Meyer, U., Roth, R., Zahner, L., Gerber, M., Puder, J. J., Hebestreit, H., \& Kriemler, S. (2011). Contribution of physical education to overall physical activity. Scandinavian Journal of Medicine \& Science in Sports, 23(5), 600-606.

Molina-García, J., Queralt, A., Estevan, I., \& Sallis, J. F. (2016). Ecological correlates of Spanish adolescents' physical activity during physical education classes. European Physical Education Review, 22(4), 479-489. doi:10.1177/1356336X15623494

Murillo, B., Julián, J. A., García-González, L., Abarca-Sos, A., \& Zaragoza, J. (2014). Effect of gender and contents on physical activity and perceived competence in physical 
education. RICYDE. Revista Internacional de Ciencias del Deporte, 10(36), 131-143. doi: $10.5232 /$ ricyde

Pavey, T. G., Gomersall, S. R., Clark, B. K., \& Brown, W. J. (2016). The validity of the GENEActiv wrist-worn accelerometer for measuring adult sedentary time in free living. Journal of Science and Medicine in Sport, 19(5), 395-399. doi.org/10.1016/j.jsams.2015.04.007

Pérez-Cañado, M. L. (2016). Stopping the "pendulum effect" in CLIL research: Finding the balance between Pollyanna and Scrooge. Applied Linguistics Review, 8(1), 79-99. doi.org/10.1515/applirev-2016-2001

Phillips, L. R., Parfitt, G., \& Rowlands, A. V. (2013). Calibration of the GENEA accelerometer for assessment of physical activity intensity in children. Journal of Science and Medicine in Sport, 16(2), 124-128.

Rivera-Sosa, J.M., \& Arras-Vota, A. M. (2015). Educación física y la «alfabetización física». (1st. Ed.). In J. Tarango, G. Mendoza Meraz, L.A. Fierro Ramírez, \& G.A. Baca (Eds.), Aproximaciones teórico-conceptuales y metodológicas en investigación educativa (pp. 40-48). Chihuahua: Universidad Autónoma de Chihuahua.

Rowlands, A. V., Rennie, K., Kozarski, R., Stanley, R. M., Eston, R.G., \& Olds, T.S. (2014). Children's physical activity assessed with wrist- and hip-worn accelerometers. Medicine and Science in Sports and Exercise, 46(12), pp.2308-2316.

Salvador, C., Chiva, Ò., \& Isidori, E. (2017). Aprendizaje de una lengua extranjera a través de la educación física: Una revisión sistemática. Movimento, 23(2), 647-660.

Salvador, C., \& Chiva, Ò. (2017). CLIL in teaching physical education: views of the teachers in the Spanish context. Journal of Physical Education and Sport, 17(3), 1130 - 1138.

Sánchez-Bañuelos, F. (1992). Bases para una didáctica de la educación física y el deporte. Gymnos: Madrid

Svennberg, L. (2017). Swedish PE teachers' understandings of legitimate movement in a criterion-referenced grading system. Physical Education and Sport Pedagogy, 22(3), 257-269. 
Turner, M. (2013). CLIL in Australia: The importance of context. International Journal of Bilingual Education and Bilingualism, 16(4), 395-410.

van Kampen, E., Admiraal, W., \& Berry, A. (2018). Content and language integrated learning in the Netherlands: Teachers' self-reported pedagogical practices. International Journal of Bilingual Education and Bilingualism, 21(2), 222-236. doi.org/10.1080/13670050.2016.1154004

Viciana Ramírez, J., Mayorga-Vega, D., \& Mompeán Campillo, M. (2016). Cumplimiento de los estándares curriculares de condición física-salud en educación física. Estudio de la planificación en la formación inicial. Cultura, Ciencia y Deporte, 11(32), 8795.

Yang, W. (2015). Content and language integrated learning next in Asia: Evidence of learners' achievement in CLIL education from a Taiwan tertiary degree programme. International Journal of Bilingual Education and Bilingualism, 18(4), 361-382.

Zindler, K. (2013). Content and language integrated learning (CLIL) and PE in England. An Exploratory Study (Doctoral dissertation). University of Sheffield: Sheffield.

\section{Funding}

This work was supported by SPIEDA project of the University Jaume-I (Reference number3256); and UJI-PRE-DOC Grant FPI-UJI (Programa 541-A). 
Dados los inesperados resultados obtenidos en el manuscrito anterior, en contraste con muchos de los estudios planteados por la literatura, sobrevino la necesidad de plantear un nuevo sub-objetivo circunscrito a la tercera fase del proyecto de investigación:

- O.3.2. "Conocer si el enfoque AICLE repercute sobre el nivel de actividad física moderada-vigorosa del alumnado y, en caso afirmativo, comprender cómo y por qué."

Como bien señalan Coral et al., (en prensa), aún queda mucha investigación por realizar relativa a la asociación entre actividad física y aprendizaje de una segunda lengua en actividad física. Por ello, mediante el manuscrito 6 tratamos de incorporar un acercamiento cualitativo que permita conocer las razones subyacentes de los resultados obtenidos previamente. De este modo, con objeto de comprender cómo y por qué los niveles de actividad física del alumnado AICLE eran superiores, optamos por realizar este estudio desde un enfoque mixto que combinara el apartado cuantitativo con otro cualitativo basado en las entrevistas realizadas a la docente y discentes implicados. 


\section{MANUSCRITO 6}

TÍTUlO:

Educación física bilingüe: efectos de CLIL sobre los niveles de actividad física

AUTORES:

Celina Salvador García, Òscar Chiva Bartoll y Carlos Capella Peris

FUENTE:

(En revisión) 


\title{
Educación física bilingüe: efectos de CLIL sobre los niveles de actividad física
}

\section{Bilingual Physical Education: CLIL effects on the physical activity levels}

\section{Resumen:}

La Educación Física (EF) es seleccionada a menudo para la aplicación de iniciativas plurilingües basadas en CLIL. Algunos autores apuntan que esta asignatura podría perder su esencia si se pone demasiado acento en el aprendizaje lingüístico, pudiendo verse mermada la Actividad-Física-Moderada-Vigorosa (AFMV), directamente relacionada con estilos de vida saludables. Ante la necesidad de la EF de tener que aumentar la AFMV y, a la vez, satisfacer el aprendizaje de nuevas lenguas, el presente estudio tiene por objetivos conocer si el método CLIL repercute sobre el nivel de AFMV y, en caso afirmativo, comprender cómo y por qué. Desde un enfoque metodológico mixto de diseño explicativo secuencial con predominancia cuantitativa, se acomete una parte cuantitativa $(n=49)$, basada en un diseño cuasi-experimental en el que se aplicaron respectivamente un ANOVA Mixto y otro Factorial, y una parte cualitativa basada en un análisis emergente de entrevistas realizadas a 13 participantes. Los resultados apuntan a que los niveles de AFMV del grupo experimental (CLIL) aumentan debido al incremento de atención y al uso de determinadas estrategias didácticas comunicativas. Como conclusión, el estudio pone sobre la mesa evidencias que auguran un futuro optimista a la propagación del CLIL en EF.

Palabras clave: educación física, CLIL, actividad física moderada-vigorosa, método pedagógico, métodos mixtos.

\begin{abstract}
:
Physical Education (PE) is often selected to apply plurilingual proposals through CLIL aproach. A number of authors suggest that this subject might lose its essence if the centre of attention is too focused on language learning because it might entail lessening Moderate-to-
\end{abstract}


Vigorous-Physical-Activity (MVPA), necessary to keep healthy lifestyles. PE must provide students with opportunities to learn language but, at the same time, MVPA levels of the lessons have to be increased. Therefore, the objectives of this study were to uncover whether using CLIL affects students' MVPA levels in PE lessons and, in case the answer is affirmative, to understand the main underlying causes. A mixed method approach with a sequential explanatory design was selected giving priority to quantitative data. The quantitative approach $(n=49)$ responded to a quasi-experimental design in which a Mixed ANOVA and a Factorial ANOVA were applied. Qualitative data were collected from 13 interviews in which an emergent analysis of content was carried out. The findings appear to indicate that the AFMV levels of the experimental group (CLIL) were higher due to an increase of students' attention and the use of communicative strategies inherent to CLIL method. In conclusion, CLIL in PE seems to have an optimistic future.

Key words: physical education, CLIL, physical activity, pedagogical method, mixed methods.

\section{Introducción}

El proceso de globalización ha desencadenado en el escenario educativo europeo la aparición de numerosas iniciativas orientadas al aprendizaje lingüístico (Cenoz, Genesee \& Gorter, 2014). El presente estudio reflexiona sobre las consecuencias de esta apuesta educativa plurilingüe impulsada por la Comisión Europea (Marsh, 2012). El ET2020 tiene entre sus prioridades mejorar la eficiencia de uno de los métodos pedagógicos más empleados para la enseñanza de lenguas, el Content and Language Integrated Learning (CLIL) (Coyle, Hood \& Marsh, 2010); siendo España uno de los países en los que más fuerte han calado estas iniciativas.

La implantación de CLIL despierta opiniones que fluctúan entre su demonización y su idolatría (Pérez-Cañado, 2016). Por un lado, se expone que se infravaloran el resto de asignaturas del currículo priorizando el aprendizaje de idiomas; mientras que, por otro, se defiende CLIL como un método muy beneficioso para el aprendizaje lingüístico (Paran, 2013). Diversos estudios han analizado las consecuencias de aplicar CLIL sobre la motivación o la mejora de habilidades y competencias sociales del alumnado (FernándezRío, Hortigüela \& Pérez, 2017). A todas luces, un correcto uso de CLIL comporta 
ineludiblemente un cambio en el proceso de enseñanza-aprendizaje (Coyle, 2015), por lo que autores como Cenoz et al. (2014) o Pérez-Cañado (2016) señalan la necesidad de investigar, más allá del fenómeno lingüístico, qué sucede con las asignaturas en las que se aplica CLIL.

La Educación Física (EF) emerge como una de las materias más comúnmente seleccionadas para introducir CLIL (Baena \& Granero, 2015; Baena, López \& Granero, 2017; Ceallaigh, Mhurchú \& Chróinín, 2017; Gruber, 2015, Salvador, Chiva \& Isidori, 2017; Zindler, 2013), argumentándose que, por su naturaleza procedimental, presenta numerosas posibilidades que favorecen el aprendizaje lingüístico (Coral, 2013). Este hecho, sin embargo, no obsta para que comparta con el resto de las materias el temor a perder su identidad si se pone demasiado énfasis en la lengua (Merino, 2016). Uno de los argumentos más recurrentes sostiene que la incorporación de la nueva lengua podría mermar los diferentes contenidos y funciones de la EF (Martínez y García, 2017), con especial mención al aprendizaje motor, ya que para su consecución requiere mucho tiempo de práctica física (Coral, 2013; Lynott, 2008).

En particular, CLIL podría comprometer el tiempo de actividad física por motivos relacionados con la necesidad de extender las explicaciones (Chiva \& Salvador, 2016; Coral, et al., 2017; Gómez \& Jiménez 2012), así como por el hecho de tener que promover el empleo de las cuatro habilidades lingüísticas (escucha, habla, lectura y escritura) (Coral, 2013, Salvador \& Chiva, 2017). Sin ir más lejos, en un reciente estudio piloto, Coral et al. (2017) analizan la cantidad de actividad física desarrollada en clases de EF siguiendo CLIL. Los resultados, obtenidos a través de una herramienta de observación, apuntan hacia un porcentaje de tiempo dedicado a actividades motrices inferior al recomendado por las autoridades educativas.

Sin embargo, a la EF actual se le requiere la promoción de clases que incrementen los niveles de Actividad Física Moderada-Vigorosa (AFMV), dado que este es el tipo de intensidad más directamente asociada a efectos positivos en la salud (Martínez, Contreras, Aznar \& Lera, 2012). Según la OMS (2013), la AFMV es el nivel de intensidad que genera en el organismo una respuesta fisiológica comparable a actividades como caminar a paso ligero o andar en bicicleta. Asimismo, conviene señalar que las clases de EF representan para muchos jóvenes la única oportunidad de realizar un mínimo de actividad física semanal (Meyer et al., 2011). Un hecho que, a su vez, conlleva que esta asignatura sea crucial para promocionar estilos de 
vida saludables en poblaciones juveniles (Martínez et al., 2012), especialmente entre las chicas (Murillo, Julián, García-González, Abarca-Sos \& Zaragoza, 2014). Esta falta de actividad, a su vez, se asocia al riesgo de padecer enfermedades cardíacas, diabetes o cáncer (US Department of Health and Human Services, 2012). No en vano, la literatura especializada estipula que actualmente el alumnado de EF debería incrementar el tiempo dedicado a AFMV en las clases de EF, tal y como se desprende de la revisión de Fairclough y Stratton (2005) o del reciente meta análisis de Hollis et al. (2017),

Por tanto, la necesidad de asegurar unos niveles saludables de AFMV, unida a la preocupación de que la práctica de actividad física en las clases de EF podría verse afectada (Coral et al., 2017; Martínez \& García, 2017), demanda nuevos estudios encaminados a determinar si los niveles de actividad física alcanzados mediante CLIL se alejan de los niveles saludables de AFMV. En este sentido, dado el rigor y precisión que requiere esta comprobación, la presente investigación opta por emplear acelererometría, aprovechando que la literatura científica la describe como una de las formas de medición de la actividad física más fiable y objetiva (Murillo et al., 2014).

En definitiva, la EF se ve sumida en un aparente conflicto de intereses sobre el que conviene aportar luz. Por una parte, cobra cada vez más fuerza la exigencia de promover un modelo de EF que, con fines saludables, aumente la cantidad de AFMV; mientras que, por otra parte, no es menos enérgica la demanda de incorporar el método CLIL en EF para satisfacer el aprendizaje de nuevas lenguas. Por tanto, es pertinente analizar si CLIL influye sobre los niveles de AFMV del alumnado. Los objetivos del presente estudio son: (1) averiguar si la utilización de CLIL en EF repercute sobre el nivel de AFMV del alumnado y determinar en qué sentido, y (2) comprender las principales razones que pudieran subyacer a dicho fenómeno.

\section{Método}

El estudio sigue un método mixto de diseño explicativo secuencial de predominancia cuantitativa (Creswell, Plano Clark, Gutmann \& Hanson, 2003). A nivel cuantitativo se aplica un diseño cuasi-experimental que compara los niveles de AFMV de un grupo experimental (CLIL) con los de un grupo control (NO-CLIL). La AFMV se midió mediante acelerometría. Posteriormente, se realizaron entrevistas a la docente y a alumnado del grupo 
experimental, a fin de complementar los resultados cuantitativos y tratar de interpretarlos con mayor profundidad.

\section{Hipótesis}

La hipótesis del estudio cuantitativo mantiene que el grupo experimental (CLIL) obtendrá valores de AFMV significativamente inferiores a los del grupo control (NO-CLIL). También se espera que los niveles de AFMV de los chicos sean superiores a los de las chicas en ambos grupos.

\section{Pregunta de investigación}

La pregunta de investigación de la vertiente cualitativa del estudio fue: ¿Qué razones pueden subyacer a las modificaciones del nivel de AFMV cuando se aplica CLIL en EF?

\section{Diseño de investigación}

Desde la perspectiva cuantitativa se aplicó un diseño cuasi-experimental basado en grupos naturales no equivalentes para analizar objetivamente los niveles de AFMV en clase de EF, siendo uno de los diseños más recurrentes en investigación educativa (Tejedor, 2000). Dos grupos-clase fueron seleccionados aleatoriamente, de manera que uno desarrollaría las sesiones de EF utilizando el método CLIL y el otro no. En ambos grupos se establecieron condiciones idénticas en variables como el centro, el nivel educativo, la docente de EF y el contenido curricular. En una segunda fase, dicho diseño fue complementado con un enfoque cualitativo a fin de responder a la pregunta de investigación aproximándonos a las percepciones, experiencias y sensaciones reflejadas por los participantes (Creswell et al., 2003).

\section{Participantes}

La muestra del estudio cuantitativo la conformaron 49 estudiantes de educación secundaria nacidos en 2003. El grupo experimental (CLIL) lo formaban 13-chicas y 10-chicos, mientras que el grupo control (NO-CLIL) 19-chicas y 7-chicos. Previamente se comprobó que la muestra presentara una distribución estadísticamente proporcional en la variable sexo entre los dos grupos $\chi^{2}(\mathrm{~N}=49)=1.05, \mathrm{p}=.306$. 
En la vertiente cualitativa se optó por una muestra intencionada en la que participaron la docente y 12 estudiantes (Patton, 2002). El muestreo trató de acceder a cuotas de participantes representativos del grupo-clase en relación a criterios que, a juicio del equipo investigador, podían condicionar su experiencia: (1) el sexo, (2) las calificaciones de inglés del último curso académico y (3) las calificaciones de EF del último curso académico. De este modo, tres representantes de cada cuadrante conforman la muestra (Tabla 1).

Tabla 1. Configuración de las características del alumnado entrevistado.

\begin{tabular}{|l|rrc|}
\hline+ & & $\mathrm{N}=3$ & $\mathrm{~N}=3$ \\
Nota EF & $\mathrm{N}=3$ & & $\mathrm{~N}=3$ \\
\hline
\end{tabular}

\section{Procedimiento}

Cada grupo tenía dos clases semanales de 50 minutos por la mañana. La recogida de datos cuantitativos se efectuó durante una unidad didáctica realizada entre enero y febrero de 2017, mientras que las entrevistas se realizaron una vez finalizada la intervención. Los datos de acelerometría fueron tomados en ambos grupos. Cada participante tenía asignado un acelerómetro.

Un observador externo, que asistió a todas las sesiones para monitorizar la aplicación, anotó las horas de comienzo y finalización de cada sesión. Las mediciones de los acelerómetros se ajustaron al tiempo efectivo de clase (Ferreira, Mota \& Duarte, 2014), ya que siempre existe una parte del tiempo que no se dedica a los objetivos de la sesión (desplazamiento del aula al patio, preparación y recogida de material, aseo del alumnado, etc.) (McKenzie, Marshall, Sallis \& Conway, 2000). Dado que el interés del estudio se centraba en comparar los niveles de AFMV, consideramos incluir únicamente el tiempo efectivo de clase de las sesiones, tal y como realizan Ferreira et al. (2014), Harvey, et al. (2016) o Kremer, Reichert y Hallal (2012). Además, el observador completó el planning and observation checklist de CLIL (Mehisto, Marsh \& Frigols, 2008) para asegurar que dicho método se utilizaba adecuadamente.

El contenido curricular seleccionado fue el atletismo, dado que este ya ha sido utilizado en estudios previos sobre CLIL (Griva \& Kasvikis, 2015). Se trata de uno de los contenidos más 
extendidos en EF (Ginciene \& Matthiesen, 2017), lo que facilita la replicabilidad futura del estudio. La unidad didáctica consistió en ocho sesiones, de las cuales seis fueron prácticas y dos teóricas. Estas últimas no fueron consideradas para la toma de datos de acelerometría.

\section{Instrumentos}

Acelerómetros: Este instrumento es concebido como una de las formas más fiables para medir niveles de actividad física y no interfiere en la realización de las sesiones de EF (Calahorro, et al., 2015). Su uso con niños y adolescentes ha sido validado para medir objetivamente sus niveles de actividad física y, de hecho, son empleados en numerosas investigaciones con menores de edad (Calahorro et al., 2015; Hollis et al., 2017; Martínez et al., 2012; Rowlands, et al., 2014). El presente estudio calculó los niveles de actividad física utilizando el acelerómetro GENEActiv Original triaxial, colocado en la muñeca izquierda.

Entrevistas semiestructuradas: La docente y doce estudiantes pertenecientes al grupo experimental fueron entrevistados tras la intervención, siguiendo un formato semiestructurado que permitió indagar sobre lo acontecido en las sesiones. Cuatro estudiantes participaron en entrevistas individuales y el resto en una entrevista grupal. De este modo, las experiencias individuales pudieron complementarse con un discurso colectivo, contrastando diferentes perspectivas de una misma realidad y evitando así su distorsión. Para su desarrollo se fueron introduciendo preguntas de carácter más general y sucesivamente se fueron planteando otras más específicas, a fin de reconstruir las teorías subjetivas de los entrevistados sin que estas se vieran influenciadas por el investigador (Flick, 2009).

\section{Análisis}

En relación al análisis cuantitativo, los datos registrados por los acelerómetros fueron exportados al paquete estadístico SPSS-24. Para analizar el efecto de la variable Grupo sobre el tiempo de AFMV se realizó un análisis ANOVA Mixto. Seguidamente, para contrastar el impacto de la variable Sexo en el nivel de AFMV, se aplicó un test ANOVA Factorial.

Respecto al análisis cualitativo, las entrevistas fueron transcritas y exportadas al software NVivo-11. Con la identificación de las "categorías vivas" se construyó la codificación y desde la matriz se detectaron las categorías relevantes. Finalmente, para conferir validez 
intersubjetiva, se llevó a cabo un proceso de member checking consistente en la verificación y aprobación de los resultados por parte de los participantes (Johnson y Christensen, 2012).

Ética

El Comité deontológico de la universidad del equipo investigador y la administración educativa aprobaron la realización del estudio. Además, los padres, madres o tutores del alumnado firmaron un consentimiento informado.

\section{Resultados}

Este apartado se divide en dos secciones, una primera para exponer los resultados cuantitativos y una segunda para los cualitativos. Posteriormente, siguiendo las recomendaciones de los métodos mixtos, ambos tipos de resultados son abordados conjuntamente en la discusión (Creswell \& Plano Clark, 2007).

\section{Resultados del análisis cuantitativo}

La realización del test ANOVA mixto muestra efectos significativos para la variable Grupo $(\mathrm{F}(1,47)=23.38, \mathrm{p}<.001, \eta 2=.332)$. Así pues, se aprecia un efecto significativo sobre los adolescentes pertenecientes al Grupo CLIL $(\mathrm{M}=982.09$, $\mathrm{DS}=124.02)$, los cuales no cumplieron la hipótesis planteada y pasaron significativamente más tiempo en la zona de AFMV que los miembros del grupo NO-CLIL (M=815.80, DS=116.60).

Por otra parte, el test ANOVA Factorial refleja un efecto significativo sobre la variable Sexo ( $F(1,45)=6.48, p=.014, \eta 2=.126)$. Como se esperaba, el tiempo en la zona de AFMV fue mayor en chicos $(M=970.38, D S=169.13)$ que en chicas $(M=853.20, D S=114.39)$. La interacción Grupo x Sexo para la zona AFMV no alcanzó significatividad estadística ( $F$ $(1,45)=0.18, p=.672, \eta 2=.004)$. Sin embargo, vale la pena señalar que la media de AFMV para las chicas del Grupo CLIL $(\mathrm{M}=936.99, \mathrm{DS}=53.94)$ es superior a la de los chicos del Grupo NO-CLIL (M=869.89, DS=125.75). En la Tabla 2 se aprecian las medias del porcentaje que el estudiantado de ambos grupos pasó en niveles de AFMV a lo largo de la unidad didáctica. 
Tabla 2. Porcentaje por sesión del tiempo en AFMV

\begin{tabular}{lll} 
& \multicolumn{1}{c}{$\boldsymbol{L I L}$} & NO-CLIL \\
\hline General & $(\mathrm{M}=35.15, \mathrm{DS}=4.49)$ & $(\mathrm{M}=30.33, \mathrm{DS}=4.33)$ \\
\hline Chicos & $(\mathrm{M}=37.29, \mathrm{DS}=5.95)$ & $(\mathrm{M}=32.30, \mathrm{DS}=4.73)$ \\
\hline Chicas & $(\mathrm{M}=33.51, \mathrm{DS}=1.92)$ & $(\mathrm{M}=29.61, \mathrm{DS}=4.06)$. \\
\multicolumn{2}{c}{ Nota. $\mathrm{M}=$ media por sesión. } &
\end{tabular}

\section{Resultados del análisis cualitativo}

La matriz de codificación evidenció diversas categorías que, una vez identificadas, fueron evaluadas de forma crítica por el equipo investigador. Dicho proceso estaba destinado a analizar cuáles de ellas podían explicar los resultados obtenidos mediante el apartado cuantitativo del estudio. Es decir, el análisis crítico tenía por cometido estudiar las diferentes categorías para descubrir cuales podían ser las razones por las que el alumnado del grupo experimental (CLIL) tuviera unos niveles de AFMV más elevados durante las sesiones de EF. En este punto, la "atención del alumnado" y las "estrategias didácticas comunicativas" emergieron como categorías que daban respuesta a la pregunta de investigación.

\section{Atención del alumnado}

Por lo que respecta a la categoría "atención del alumnado", encontramos evidencias del discurso compartido por los distintos entrevistados. Por una parte, la docente percibió un incremento en la atención del alumnado, “creo que han prestado más atención”, aunque se mostró cauta por tratarse de su propia opinión. Sin embargo, esta idea se vio refrendada por el propio alumnado, "teníamos que prestar muchísima más atención que antes, que [si no lo entendías] te lo explicaba un amigo y ya lo sabías, pero en estos momentos no. Teníamos que estar atentos a ella [la docente]" (EI-1).

Dicho supuesto se refuerza a través de comentarios como "en castellano no hubiéramos atendido tanto y las explicaciones se nos hubieran ido completamente" (EI-1), así como a partir de testimonios que afirmaban que "cuando [la docente] explicaba atendíamos más que si hubiera sido en castellano, porque si no hubiéramos podido estar jugando, pero como se hace en inglés estabas centrado en lo que decía e intentabas comprenderlo" (EG-7). En definitiva, este planteamiento se evidencia en el relato del alumnado, para quienes el método 
CLIL únicamente había implicado "querer estar más atentos para enterarnos de todo. Lo demás ha seguido igual" (EI-4).

Por otra parte, del discurso de la docente se desprende, además, un incremento especial del interés por parte del alumnado femenino:

He tenido alumnas que, a la hora de dirigir el calentamiento, aun viendo que les costaba hablar, se han ofrecido voluntarias varias veces [...]. El otro día también voluntarias y eso es que tienen interés de aprender. [...] he notado que, pese a que les costaba, ellas ahí... Han querido participar. Ya no sé si es por interés por sacar más nota o porque les motivaba el aprendizaje (docente).

Comentarios como este indican que las chicas se involucraron mucho en este tipo de clases, apuntando que el método CLIL supuso un reto motivante para ellas en EF. Como hemos visto en el apartado anterior, esta situación se complementa plenamente con los resultados cuantitativos del estudio.

\section{Estrategias didácticas comunicativas}

En cuanto a la categoría "estrategias didácticas comunicativas", la profesora aseveró claramente que "en este grupo he tenido que utilizar otras estrategias". En esta línea, el alumnado señaló el uso de la comunicación no verbal como complemento de gran valor en el desarrollo de las explicaciones de la profesora "muchas veces [la docente] decía una cosa y nosotros nos quedábamos mirando porque no entendíamos. Después hacía el gesto y ahí sí lo hacíamos" (EG-4). De esta cuestión se desprende una relación muy clara con la categoría anterior, pues el hecho de tener que atender tanto a la comunicación verbal como a la no verbal, exigía al alumnado estar más atento para captar la información a través de los diferentes canales utilizados.

Otra estrategia detectada hace referencia a la adecuación del lenguaje de la docente en base a los conocimientos del alumnado. Es decir, en la medida de lo posible, la profesora adaptaba el nivel del lenguaje empleado en función de los conocimientos lingüísticos del alumnado. Este hecho queda reflejado en comentarios del tipo "la hemos entendido porque el vocabulario se adaptaba mucho a nosotros" (EI-3). Asimismo, la docente admite haber tenido que preparar con mayor atención y detalle su discurso para concretar bien "qué vocabulario 
iba a utilizar para que fuera comprensible el vocabulario en inglés, o las estructuras". Como ella misma señala, esta situación no se tenía en cuenta al mismo nivel cuando las clases eran en español, dado que la comprensión del mensaje no se veía comprometida en ese caso.

En definitiva, a tenor de los resultados cualitativos, la aplicación del método CLIL en la asignatura de EF provocó un aumento de la "atención del alumnado", especialmente entre las chicas, así como el uso de determinadas "estrategias didácticas comunicativas" como: (1) el refuerzo del mensaje a través de un canal complementario de comunicación no verbal, y (2) la adecuación del lenguaje empleado por la profesora para ajustarlo al nivel del alumnado.

\section{Discusión}

Los resultados proporcionados por el enfoque metodológico mixto se complementan para dar respuesta a los objetivos de investigación. Mediante la combinación de ambas perspectivas se evidencia el incumplimiento de la hipótesis principal y se responde la pregunta de investigación del estudio. Los resultados del estudio apuntan a que los niveles de AFMV del grupo experimental (CLIL) se ven aumentados debido al incremento de atención y al uso de estrategias didácticas comunicativas relacionadas con la aplicación de CLIL. Esta tesis se sustenta tanto desde la significatividad estadística de la comparación de los niveles de AFMV entre el grupo experimental y el control, como desde las percepciones expuestas a través de las entrevistas. Partiendo de que diferentes autores han mostrado preocupación por la posibilidad de que CLIL afectara negativamente sobre los niveles de actividad física del alumnado en las clases de EF (Coral, 2013; Lynott, 2008), no es atrevido afirmar que los resultados del estudio son, cuando menos, alentadores.

En un reciente estudio piloto, Coral et al. (2017) utilizaron una herramienta de observación para medir la cantidad de actividad física en las sesiones de EF mediante CLIL, concluyendo que los estudiantes pasaban menos tiempo del recomendado por las autoridades educativas realizando actividad motriz, aunque sin especificar su intensidad. Su estudio sugiere que las causas de esta falta de actividad pueden atribuirse al uso excesivo de materiales de apoyo lingüístico o al tipo de actividad física propuesta en las sesiones CLIL. Sin embargo, ciñéndonos a la intensidad moderada-vigorosa que centra el interés de nuestro estudio, el uso de acelerometría permite afirmar que el porcentaje de tiempo que el alumnado del grupo experimental se mantuvo en niveles de AFMV fue de del $35.15 \%$, una cifra similar a la de 
distintas investigaciones que emplean este mismo procedimiento de medida. Es decir, si se comparan los niveles de AFMV del grupo CLIL con los hallados en diferentes estudios del campo de la EF en grupos NO-CLIL, se aprecia que los porcentajes son muy parejos. Por ejemplo, Meyer et al. (2011) demostraron que alumnado de primaria disfrutaba de un $32,8 \%$ del tiempo de las sesiones de EF en niveles de AFMV. Ferreira et al. (2014), por su parte, hallaron que estudiantado adolescente permanecía en estos niveles de intensidad durante el $28,18 \%$ de las sesiones, mientras que la investigación de Kremer et al. (2012) concluyó que se mantenían niveles de AFMV durante el 32,7\% del tiempo de clase.

Del mismo modo, nuestros resultados pueden ser comparados con los obtenidos en el reciente meta-análisis de Hollis et al. (2017), en el que se concluye que aquellos estudios que utilizaron acelerómetros como instrumento de medición presentaban una media del 34,7\% del tiempo de la sesión de EF en niveles de AFMV, mientras que todos los estudios relativos al nivel de enseñanza secundaria, misma etapa que nuestros grupos, se mantenían en estos niveles durante el $35,9 \%$ de las clases.

Pasando ahora a la comparación entre los dos grupos participantes en el presente estudio, a fin de contrastar directamente el impacto del método CLIL, los resultados evidencian una diferencia estadísticamente significativa en los niveles de AFMV a favor del grupo experimental (CLIL). El incremento de la atención por parte del estudiantado de ese grupo, tal y como se desprende de las entrevistas, supone una posible explicación a estos inesperados resultados. Parece ser que la introducción de la lengua inglesa en las sesiones de EF ha favorecido que el alumnado incrementara su atención hacia las explicaciones, hecho que podría explicar el aumento en el tiempo dedicado a actividades físicas. Consecuentemente, si el tiempo de las explicaciones se optimiza y el de las actividades aumenta, parece razonable que el porcentaje de AFMV del grupo experimental haya sido superior al del grupo control debido al uso de CLIL. Este aumento en la atención está en consonancia con los hallazgos de Doiz et al. (2014) y Baena et al. (2017), quienes afirman que el alumnado participante en programas CLIL veía incrementada su motivación, o los de Fernández-Río et al. (2017), quienes hallaron que el estudiantado que formaba parte de grupos bilingües mostraba niveles mayores de responsabilidad. 
Por otro lado, la utilización de estrategias didácticas comunicativas (verbales y gestuales) por parte de la docente podría ser otra explicación al mayor tiempo de AFMV del alumnado del grupo CLIL. La adecuación del lenguaje (ajustado al nivel de inglés del alumnado) y la mayor comunicación gestual, son dos estrategias que provocan que las explicaciones puedan ser más breves y comprensibles, tal como indican Gómez y Jiménez (2012), Gruber (2015) y Salvador y Chiva (2017). Además, profundizando sobre esta cuestión, tanto Ting (2011) como Zindler (2013), determinan que los docentes que aplican CLIL cuidan el vocabulario y las estructuras lingüísticas utilizadas para asegurar que la comunicación sea efectiva, ciñéndose a mensajes comunicativos más básicos y provocando escuchas más atentas en el alumnado. Estas actuaciones, sin embargo, contrastan con el uso excesivo de materiales de apoyo lingüístico que, conforme al estudio de Coral et al. (2017), podrían ocasionar una merma de actividad física.

Por otra parte, considerando los niveles de AFMV en función del sexo, los chicos alcanzaron niveles más elevados que las chicas. Estos resultados convergen con los presentados por Harvey et al. (2016), Kremer, et al. (2012) y Meyer et al. (2011) en sus respectivas investigaciones sobre niveles de AFMV en EF. Conforme a estos estudios, por norma general, los chicos suelen ser más activos que las chicas en clase de EF. Sin embargo, resulta interesante destacar que, en nuestro diseño, si se comparan las medias del nivel de AFMV de chicos y chicas, diferenciando el grupo al que pertenecen, las chicas del grupo CLIL presentan niveles de AFMV muy homogéneos entre ellas y con una media superior que los chicos del grupo NO-CLIL, aunque sin alcanzar diferencias estadísticamente significativas. Esta posible tendencia, que convendría retomar en posteriores estudios, puede encontrar explicación en el hecho que las motivaciones y actitudes del alumnado hacia el aprendizaje de una lengua extranjera difieren en función del sexo (Clark, 1995; Doiz et al., 2014), siendo habitual que las chicas se involucren más. En este sentido, la incorporación de CLIL puede suponer un reto más motivante para ellas (López Rúa, 2006); por lo que, en el marco de la $\mathrm{EF}$, la incorporación del método CLIL podría motivar positivamente a las alumnas, pudiendo llevarlas indirectamente a incrementar la AFMV.

Finalmente, es de justicia expresar que el tamaño de la muestra dificulta la posibilidad de realizar generalizaciones contundentes. Sin embargo, para contrarrestar y/o minimizar los 
efectos de esta limitación, cabe decir que el estudio mide objetivamente los niveles de AFMV de todo el alumnado implicado, a diferencia de lo que hacen la mayoría de investigaciones que emplean acelerometría, en las que suele medirse una muestra menor.

\section{Conclusiones}

El presente artículo ha afrontado la encrucijada de la EF a la hora de cumplir con las exigencias de organismos e instituciones educativas de diversa índole. Por una parte, tal y como manifiesta la OMS, se requiere una EF que incremente la AFMV a fin de garantizar la promoción de estilos de vida saludables. Por otra, muchas administraciones educativas apuestan decididamente por esta asignatura a la hora de ejecutar planes plurilingües a través de CLIL. A priori todo hacía pensar que ambas exigencias podían ser contrapuestas, dado que poner el acento en el aprendizaje de una nueva lengua, con las alteraciones que ello implica para la asignatura, podría significar que el nivel de AFMV en las clases descendiera. No obstante, del estudio se desprenden una serie de resultados que indican que los niveles de AFMV no solo no descienden, sino que llegan a aumentar con la aplicación de CLIL. Una situación motivada, muy posiblemente, por el incremento de atención del alumnado y por el uso de estrategias docentes relacionadas con su puesta en práctica. Estos resultados, a pesar de augurar perspectivas favorables para la expansión del método CLIL en EF, no dejan de ser sorprendentes $\mathrm{y}$, por ende, necesitados de nuevas investigaciones que los contrasten y discutan.

\section{Referencias bibliográficas}

Baena, A., \& Granero, A. (2015). Versión española del Sport Satisfaction Instrument adaptado al aprendizaje de la Educación Física bilingüe en Inglés. Porta Linguarum, 24, 63-76.

Baena, A., Gómez, M., \& Granero, A. (2017). Aprendizaje de la Educación Física Bilingüe a partir de las Metas de Logro y el Clima de Aprendizaje. Porta Linguarum, 28, 8193.

Calahorro, F., Torres-Luque, G., López-Fernández, I., Santos-Lozano, A., Garatachea, N., \& Álvarez, E. (2015). Actividad física y acelerometría; orientaciones metodológicas, 
recomendaciones y patrones. Nutrición Hospitalaria, 31(1), 115-128. doi:10.3305/nh.2015.31.1.7450

Ceallaigh, T.Ó., Mhurchú, S.N., \& Chróinín, D.N. (2017). Balancing content and language in CLIL. Journal of Immersion and Content-Based Language Education, 5(1), 58-86. doi:10.1075/jicb.5.1.03oce

Cenoz, J., Genesee, F., \& Gorter, D. (2014). Critical analysis of CLIL: Taking stock and looking forward. Applied Linguistics, 35(3), 243-262. Doi:10.1093/applin/amt011

Chiva, Ò., \& Salvador, C. (2016). Aprendizaje integrado de Educación Física y lengua inglesa. Barcelona: INDE.

Clark, A. (1995). Boys into modern languages: An investigation of the discrepancy in attitudes and performance between boys and girls in modern languages. Gender and Education, 7(3), 315-326.

Coral, J. (2013). Physical Education and English Integrated Learning: How School Teachers can Develop PE-in-CLIL Programmes. Temps d'educació, 45, 41-64.

Coral, J., Urbiola, M., Sabaté, E., Bofill, J., Lleixà, T., \& Vilà, R. (2017). Does the teaching of physical education in a foreign language jeopardise children's physical activity time? A pilot study. International Journal of Bilingual Education and Bilingualism, 1-16. doi.org/10.1080/13670050.2017.1407289

Coyle, D. (2015). Strengthening integrated learning: Towards a new era for pluriliteracies and intercultural learning. Latin American Journal of Content \& Language Integrated Learning, 8(2), 84-103. doi:10. 5294/lacli1.2015.8.2 .2

Coyle, D., Hood, P., \& Marsh, D. (2010). CLIL. Cambridge: CUP.

Creswell, J.W., \& Plano Clark, V.L. (2007). Designing and Conducting Mixed Methods Research. Thousand Oaks, CA: Sage Publications.

Creswell, J.W., Plano Clark, V.L., Gutmann, M.L., \& Hanson, W.E. (2003). Advanced mixed methods research designs. En A. Tashakkori y C. Teddlie (Eds.), Handbook of mixed methods in social and behavioral research (209-240). Thousand Oaks, CA: Sage. 
Fairclough, S., \& Stratton, G. (2005). Physical activity levels in middle and high school physical education: a review. Pediatric Exercise Science, 17(3), 217-236.

Fernández-Río, J., Hortigüela Alcalá, D., \& Pérez Pueyo, Á. (2017). Educación bilingüe, streaming y metas sociales en estudiantes de secundaria. Revista de Educación, 377, 30-53. doi:10.4438/1988-592X-RE-2017-377-352

Ferreira, F.S., Mota, J., \& Duarte, J.A. (2014). Patterns of Physical Activity in Portuguese Adolescents. Evaluation during Physical Education Classes throught Accelerometry. Archives of Exercise in Health and Disease, 4(2), 280-285. doi: 10.5628/aehd.v4i2.135

Flick, U. (2009). An Introduction to Qualitative Research. London: SAGE.

Ginciene, G., \& Matthiesen, S.Q. (2017). The sport education model on the teaching of track and field in school. Movimento, 23(2), 729-742.

Gómez, C.L., \& Jiménez, M. (2012). The Physical Educator as a Language Teacher for $\begin{array}{llll}\text { English } \quad \text { Language } & \text { Learners. }\end{array}$ doi:10.1080/08924562.2012.10592157

Griva, E., \& Kasvikis, K. (2015). CLIL in Primary Education: Possibilities and challenges for developing L2/FL skills, history understanding and cultural awareness. En N. Bakić-Mirić y D. Erkinovich-Gaipov (Eds.), Current trends and issues in higher education: an international dialogue (101-124). Cambridge: Cambridge Scholars.

Gruber, K. (2015). Improving students' foreign language competence through Content and Language Integrated Learning (CLIL) in Physical Education. (Tesis doctoral). Wien University, Viena.

Harvey, S., Smith, M.L., Song, Y., Robertson, D., Brown, R., \& Smith, L.R. (2016). Gender and school-level differences in students' moderate and vigorous physical activity levels when taught basketball through the tactical games model. Journal of Teaching in Physical Education, 35(4), 349-357. doi:10.1123/jtpe.2016-0089

Hollis, J.L., Sutherland, R., Williams, A.J., Campbell, E., Nathan, N., “...” Wolfenden, L. (2017). A systematic review and meta-analysis of moderate-to-vigorous physical- 
activity levels in secondary school physical education lessons. International Journal of Behavioral Nutrition and Physical Activity, 14(1), 52. doi:10.1186/s12966-0170504-0

Johnson, B., \& Christensen, L. (2012). Educational research. Quantitative, Qualitative and Mixed approaches. Thousand Oaks: SAGE.

Kremer, M.M., Reichert, F.F., \& Hallal, P.C. (2011). Intensity and duration of physical efforts in physical education classes. Revista de Saúde Pública, 46(2), 320-326.

López Rúa, P. (2006). The sex variable in foreign language learning: an integrative approach. Porta Linguarum, 6, 99-114.

Lynott, F.J. (2008). Integrating other Subject Matter without Jeopardizing Physical Education Goals: The Content Linkage Approach. Strategies, 22(1), 10-17.

Marsh, D. (2012). Content and lenguaje integrated (CLIL): A development trajectory. Córdoba: Servicio de publicaciones de la Universidad de Córdoba.

Martínez, F.J., \& García, E. (2017). Influencia del bilingüismo en el tiempo de compromiso motor en Educación Física. Retos. Nuevas tendencias en educación física, deporte y recreación, 32, 178-182.

Martínez, J.M., Contreras, O.R., Aznar, S., \& Lera, A. (2012). Niveles de actividad física medido con acelerómetro en alumnos de $3^{\circ}$ ciclo de educación primaria: actividad física diaria y sesiones de educación física. Revista de Psicología del Deporte, 21(1), 117-123.

McKenzie, T.L., Marshall, S.J., Sallis, J.F., \& Conway, T.L. (2000). Student activity levels, lesson context, and teacher behavior during middle school physical education. Research Quarterly for Exercise and Sport, 71(3), 249-259.

Mehisto, P., Marsh, D., \& Frigols, M.J. (2008). Uncovering CLIL content and language integrated learning in bilingual and multilingual education. Oxford: Macmillan. 
Merino, J. (2016). Non-linguistic content in CLIL: is its learning diminished? En D. Lasagabaster y A. Doiz (Eds.). CLIL experiences in secondary and tertiary education: In search of good practices (17-43). Bern: Peter Lang.

Meyer, U., Roth, R., Zahner, L., Gerber, M., Puder, J.J., Hebestreit, H., \& Kriemler, S. (2013). Contribution of physical education to overall physical activity. Scandinavian journal of medicine \& science in sports, 23(5), 600-606. doi:10.1111/j.16000838.2011.01425.x

Murillo, B., Julián, J.A., García-González, L., Abarca-Sos, A., \& Zaragoza, J. (2014). Influencia del género y de los contenidos sobre la actividad física y la percepción de competencia en Educación Física. Revista Internacional de Ciencias del Deporte, 10(36), 131-143.

Organización Mundial de la Salud (2013). Global Action Plan for the Prevention and Control of Noncommunicable Diseases 2013-2020. Recuperado de http://www. who.int/mediacentre/factsheets/fs385/es/

Paran, A. (2013). Content and language integrated learning: Panacea or policy borrowing myth? Applied Linguistics Review, 4(2), 317-342.

Patton, M.Q. (2002). Qualitative Research and Evaluation Methods. London: Sage.

Pérez-Cañado, M.L. (2016). Stopping the "pendulum effect" in CLIL research: Finding the balance between Pollyanna and Scrooge. Applied Linguistics Review, 8(1), 79-99. doi.org/10.1515/applirev-2016-2001

Rowlands, A.V., Rennie, K., Kozarski, R., Stanley, R. M., Eston, R.G., \& Olds, T.S. (2014). Children's physical activity assessed with wrist- and hip-worn accelerometers. Medicine and Science in Sports and Exercise, 46(12), 2308-2316.

Salvador, C., \& Chiva, Ò. (2017). CLIL in teaching physical education: views of the teachers in the Spanish context. JPES, 17(3), 1130-1138. doi:10.7752/jpes.2017.03174

Salvador, C., Chiva, Ò., \& Isidori, E. (2017). Aprendizaje de una lengua extranjera a través de la educación física: una revisión sistemática. Movimento, 23(2), 647-660. 
Tejedor, F.J.T. (2000). El diseño en la evaluación de programas. Revista de investigación educativa, 18(2), 319-339.

Ting, Y.T. (2011). CLIL... not only not immersion but also more than the sum of its parts. ELT-journal, 65(3), 314-317.

US Department of Health and Human Services (2012). Physical activity guidelines for Americans midcourse report. Washington: US Department of Health and Human Services.

Zindler, K. (2013). Content and Language Integrated Learning (CLIL) and PE in England. An Exploratory Study. (Tesis doctoral). University of Sheffield, Sheffield. 


\section{Discusión}

La sociedad actual ha experimentado un profundo proceso de transformación en las últimas décadas, especialmente motivado por la globalización, propiciando un apremio generalizado hacia el aprendizaje de lenguas. Este escenario ha puesto de relieve la necesidad de replantear el sistema educativo a fin de dar respuesta a las nuevas necesidades de la ciudadanía, hecho que implica insólitas demandas y desafíos que conforman, necesariamente, una nueva forma de concebir el currículum. Tal y como hemos descrito en el presente trabajo, uno de los planteamientos más generalizados radica en la utilización de enfoques pedagógicos como AICLE desde diferentes asignaturas no lingüísticas.

Ante tal situación, a fin de guiar la implementación de esta tendencia hacia el aprendizaje integrado de lenguas y encauzarlo con garantías en la legislación educativa, resulta necesario analizar el qué, el cómo, el cuándo y el porqué de su puesta en práctica. Para ello se requieren estudios específicos que, desde cada una de las materias, aporten criterios y orientaciones de aplicación. En nuestro caso, hemos abordado la incorporación de AICLE a través del área de educación física.

El presente trabajo ha presentado un análisis conceptual y funcional inicial desde el que se han contextualizado y formulado con propiedad los objetivos de estudio. En base a dicho marco, se han concretado los siguientes objetivos que, en última instancia, son los que han guiado las diferentes fases que conforman la investigación realizada:

O.1. Averiguar cuál es el estado de la cuestión en el campo de la educación física mediante el enfoque AICLE.

- O.1.1. Determinar cuál es el marco teórico particular de la educación física mediante AICLE y concretar sus posibilidades de aplicación.

- O.1.2. Examinar cuáles son y qué analizan los artículos de mayor impacto que vinculan educación física y enseñanza de lenguas extranjeras.

O.2. Investigar cuáles son las percepciones sobre la aplicación de AICLE en educación física de los agentes implicados directamente en su desarrollo. 
- O.2.1. Analizar cómo vive y qué opina sobre AICLE el profesorado de educación física que lo ha aplicado en sus clases.

- O.2.2. Examinar cómo vive y qué opina el alumnado sobre el uso de AICLE en clase de educación física.

O.3. Analizar cómo afecta el uso del enfoque AICLE en las sesiones de educación física.

- O.3.1. Examinar si la utilización de AICLE en educación implica que se vean alterados los niveles de actividad física del alumnado durante las sesiones en comparación con las sesiones ordinarias de esta asignatura.

- O.3.2. Conocer si el enfoque AICLE repercute sobre el nivel de actividad física moderada-vigorosa del alumnado y, en caso afirmativo, comprender cómo y por qué.

Con objeto de abordar estos objetivos, se planteó un proceso de investigación por fases. Cada una de dichas fases se ha correspondido con uno de los objetivos y cada uno de estos objetivos ha sido tratado en dos de los manuscritos que conforman la presente tesis. A fin de aportar una visión global de la investigación, el presente apartado presenta y discute los resultados referentes a cada objetivo de manera conjunta.

\subsection{Discusión Objetivo 1}

Como puede apreciarse a través de los dos manuscritos que abordan el objetivo 1, existe una creciente tendencia en la utilización de la asignatura de educación física como área a través de la cual favorecer el aprendizaje de lenguas adicionales. De hecho, nuestros textos refrendan y actualizan el conocimiento de un hecho aseverado por múltiples autores (BaenaExtremera y Granero-Gallegos, 2015; Chiva-Bartoll et al., 2015; Coral y Lleixà, 2016; García-Jiménez, García-Pellicer y Yuste, 2012; Ramos y Ruiz-Omeñaca, 2011). Así, todo parece indicar que nos encontramos ante una recurrente innovación metodológica basada en el enfoque AICLE. A pesar de que los resultados presentados en la revisión sistemática evidencian una cantidad de estudios aún limitada, resulta interesante incidir en que tras la publicación de este texto el número de artículos ha continuado incrementándose. A modo de ejemplo podemos citar textos como los de Baena-Extremera et al. (2017), Ceallaigh et al. (2017), Coral, Esquerda y Benito (2017), Coral et al., (en prensa), Emmanouilidou y Laskaridou (2017), Fernández-Barrionuevo y Baena-Extremera (2018), García-Calvo y 
Salaberri (2018), Hernando, Hortigüela y Pérez (2018), Martínez y García (2017), Muszyńska, Urpí y Galazca (2017), Salvador-García y Chiva-Bartoll (2017) o SalvadorGarcía, Chiva-Bartoll y Vergaz (2018); todos ellos dirigidos al estudio y reflexión sobre la imbricación entre educación física y aprendizaje de lenguas.

En el caso de todos estos ejemplos la tendencia observada en nuestra revisión sistemática sigue cumpliéndose, dado que la mayoría de publicaciones continúan ubicándose en España, la lengua más recurrente sigue siendo el inglés y el enfoque metodológico más empleado es AICLE. Estas cuestiones son muestra clara de lo expuesto en el marco teórico de esta tesis, sugiriendo que el aprendizaje de lenguas está en auge en nuestro país, especialmente a través del enfoque AICLE; y que el inglés se ubica como la lengua extranjera más estudiada (Fortanet, 2013; Pérez-Cañado, 2016).

La utilización de AICLE en el área de educación física se erige como una clara puesta en práctica de innovación metodológica ajustada a la situación social. El campo educativo se encuentra - o debería encontrase - constantemente sujeto a un proceso de revisión pro mejora (Pallarés et al., 2018) y parece que el uso de AICLE en educación física es una forma de abordar dicho cometido. Atendiendo a la literatura, su uso puede favorecer el aumento del tiempo de exposición a la lengua extranjera por parte del alumnado (Mehisto et al., 2008), promoviendo así que aumente su competencia comunicativa. También estimula la capacidad de relacionarse socialmente con personas de cualquier punto del planeta y adquiriendo un rico bagaje de conocimiento al que todos y todas tienen derecho. Además, al ubicar a los discentes en el centro del proceso de enseñanza-aprendizaje y dar un uso real a la lengua (Coyle et al., 2010; Ting, 2011), satisface positivamente las corrientes didácticas y pedagógicas actuales. De este modo, la puesta en práctica de AICLE desde la materia de educación física puede contribuir al desarrollo integral del alumnado, potenciando la educación de ciudadanos libres, emancipados, capaces de comunicarse y relacionarse críticamente con el mundo que les rodea (Coyle et al., 2010; Dalton-Puffer, 2009; De Graaff et al., 2007).

No obstante, conviene ser cautos y, pese a promover la innovación metodológica, es necesario reparar en las posibles limitaciones que puedan acaecer. Un correcto desarrollo de AICLE requiere, ineludiblemente, de una adecuada coordinación entre el área de lengua 
extranjera y aquella que acoja dicho enfoque pedagógico, en nuestro caso la educación física (McDougald, 2015; Méndez y Pavón, 2012). Sin embargo, parece que esta coordinación y trabajo coherente entre áreas curriculares no siempre resulta sencilla ni factible a todos los niveles (Pavón, Ávila, Gallego y Espejo, 2014).

Además, conviene cuestionarse hasta qué punto puede la incorporación de AICLE afectar al área curricular que lo acoge, dado que parece que el ritmo, los contenidos o incluso la forma de preparar y secuenciar las sesiones podrían verse alteradas (Coral, 2012; Hernando, 2015; Martínez y García, 2017). A fin de analizar estas cuestiones planteamos los objetivos 2 y 3 de la presente tesis, centrados en analizar y comprender qué subyace a la utilización de AICLE.

Por esta razón, como cualquier elemento del ámbito educativo, el uso de AICLE es susceptible de ser evaluado con objeto de optimizar su desarrollo. En nuestro caso, esto significa reparar específicamente en cada materia que acoge dicho enfoque pedagógico, dado que cada una de ellas presenta características diferentes. Para seguir avanzando y mejorando en el uso de AICLE es imprescindible mejorar con cada aplicación y aprender del día a día a fin de analizar si existe coherencia entre diseño y puesta en práctica. En el caso de AICLE, la consecución de este primer objetivo de estudio consolida nuestro convencimiento de que su desarrollo implica formar alumnado preparado para vivir en sociedad de manera crítica y autónoma, y que sea por tanto capaz de comunicarse en una lengua adicional en múltiples situaciones. Por lo que, desde esta perspectiva, todo apunta a que AICLE debería involucrar el razonamiento real en otro idioma a la par que favorecer el aprendizaje de dicha lengua (Torres, 2018).

\subsection{Discusión Objetivo 2}

El incesante incremento de estudios sobre AICLE está dando lugar a una vasta multiplicidad de objetivos de estudio. Sin embargo, estos no están haciendo más que abrir nuevos flancos y posibles líneas de investigación ante los que este trabajo pretende, en la medida de lo posible, ayudar a dar respuesta. El uso de la actividad física como medio en el cual desarrollar el aprendizaje de una lengua se ha convertido ya en una realidad escolar y, por tanto, conviene preguntarse qué opinan los agentes directamente implicados en la misma y qué le sucede a 
la educación física cuando acoge el enfoque AICLE. En este terreno se enmarcan los objetivos que pasamos a discutir.

En primer lugar, abordamos el segundo objetivo de la tesis, desarrollado en los manuscritos 3 y 4. En concreto, estos textos ahondan en la percepción que ostenta tanto el profesorado como el alumnado de educación física que ha vivenciado la puesta en práctica del enfoque AICLE. Puede percibirse que, en numerosos puntos, las perspectivas de ambos colectivos son manifiestamente coincidentes. Por ejemplo, tanto docentes como discentes señalan que no han percibido que la incorporación de una lengua adicional haya supuesto impedimentos significativos a la hora de desarrollar las sesiones, destacando que la educación física continuaba siendo el elemento base de las clases y que los contenidos no se han visto afectados, en consonancia con lo señalado por autores como Coral (2012), Dalton-Puffer (2011) o Figueras, Flores y González (2011).

Pese a ello, el análisis llevado a cabo en los manuscritos desvela que las sesiones deben ser readaptadas para favorecer una adecuada introducción de la lengua, en la línea de lo indicado por Chroinin et al. (2016), implicando, en algunas ocasiones, explicaciones más largas y/o más tiempo para comprender el mensaje por parte del alumnado. No obstante, a tenor de lo expuesto por ambos agentes (profesorado y alumnado) ni el aprendizaje esperado se vio disminuido ni los contenidos programados fueron reducidos, cuestiones que autores como Coral (2010), Hernando (2015) o Martínez y García (2017) habían sugerido que podría ocurrir.

Asimismo, al aprendizaje usual de los contenidos propios de la educación física, tanto profesorado como alumnado coinciden en incorporar una mejora en la competencia comunicativa en lengua extranjera. Según indican, las cuatro habilidades comunicativas pueden verse desarrolladas en las sesiones de educación física gracias al uso real y significativo que se le da a la lengua, en la línea de lo esgrimido por Hernando (2015), Hortigüela et al. (2016) o Montávez, Mariscal y López (2002). De este modo, de los dos artículos se extrae que el favorecimiento del aprendizaje de otra lengua, uno de los objetivos básicos del uso de AICLE, parece conseguirse.

Además del cambio didáctico en aras de fomentar el uso consciente de la lengua por parte del alumnado, el empleo de AICLE en educación física induce a un cambio metodológico 
sustentado en el uso de planteamientos más participativos y abiertos, así como actividades cooperativas y colaborativas, señalado por el profesorado y percibido también por el alumnado. La utilización de dichos estilos y actividades converge mejor con la promoción del aprendizaje de una lengua (Casal, 2016; Glakas 1993; Mehisto et al., 2008), propiciando al mismo tiempo que el alumnado sea participante activo de su aprendizaje (Coral y Lleixà, 2016; Kashiwagi y Tomecsek, 2015; Van Kampen et al., 2017).

No obstante, conviene señalar que dichos cambios en las estrategias metodológicas de la asignatura implican, necesariamente, un relevante incremento de la labor de planificación docente. De este modo, el profesorado de educación física que utiliza AICLE se ve sometido a un considerable esfuerzo (González, Villar, Pastor y Gil, 2013; Lova, Bolarín y Porto, 2013; McDougald, 2015). Parece apropiado, pues, proporcionar un cierto soporte a los docentes que emplean AICLE, dado que una falta de apoyo a diferentes niveles podría desencadenar un efecto de burnout (Fernández-Costales y González-Riaño, 2015); lo que, a su vez, comprometería la aplicación exitosa de AICLE.

Otro aspecto de relevancia tratado en ambos manuscritos hace referencia a la motivación del alumnado puesto que, siguiendo a Biddle (2003), conviene favorecer que el estudiantado mantenga unos niveles de motivación altos hacia la asignatura de educación física. En este sentido, a tenor de lo expuesto por los docentes y los discentes, la incorporación de AICLE no ha suscitado la disminución de los niveles de motivación del alumnado. Además, el estudiantado expone que su participación e implicación se ha visto favorecida gracias a la tipología de actividades y la metodología empleada. Así, aunque la incorporación de la lengua podría devenir un elemento disuasorio de la motivación en determinados casos (Ramos y Ruiz-Omeñaca, 2011), estudios recientes también ponen de relieve que la integración de AICLE en la educación física puede generar no solo el mantenimiento de los niveles de motivación, sino su posible incremento (Christopher et al., 2012; FernándezBarrionuevo y Baena-Extremera, 2018).

Por último, resulta interesante reparar en que, según los docentes, el alumnado mostraba mayor atención en las clases mediante AICLE. Esta cuestión puede encontrar diferentes explicaciones. Por un lado, de acuerdo con Zindler (2013), la incorporación de AICLE propicia una mayor demanda cognitiva que podría generar que el alumnado debiera 
permanecer más atento a lo que ocurre en clase. Otro posible motivo puede encontrarse en el aumento de la motivación que parece generar la educación física desarrollada a través de AICLE (Baena-Extremera et al., 2017; Ceallaigh et al., 2017; Christopher et al., 2012; Fernández-Barrionuevo y Baena-Extremera, 2018). Por último, una tercera explicación potencial radica en el inicial sentimiento de aprensión y temor expuesto por el alumnado en el manuscrito 4. Pese a que estas reticencias iniciales fueron diluyéndose y dando paso a sentimientos de mayor seguridad y confianza en el uso de la lengua, podrían haber generado que desde el principio el estudiantado se mostrara más atento.

En suma, en referencia al segundo objetivo planteado en el presente trabajo, en la opinión de docentes y discentes de educación física, la incorporación de AICLE a las sesiones no pone el riesgo los elementos básicos de la asignatura. Sin embargo, estas visiones no dejan de fundamentarse sobre las percepciones e impresiones de cada entrevistado. Por este motivo, parece apropiado complementar estos resultados con información objetiva que desvele qué ocurre a los elementos nucleares que conforman la asignatura de educación física, como puede ser el tiempo e intensidad de la actividad física realizada.

\subsection{Discusión Objetivo 3}

El movimiento es uno de los elementos nucleares de la asignatura de educación física (Larsson y Nyberg, 2017), además, debido a las altas tasas de sedentarismo, la promoción de la actividad física desde esta asignatura se ha convertido en uno de sus objetivos primarios (Dodd, 2015; Heikinaro-Johansson, Hasanen, McEvoy y Lyyra, 2018; Molina et al., 2016; Viciana et al., 2016). Este hecho podría verse en contraposición con la introducción del enfoque AICLE en las sesiones de educación física, puesto que se ha señalado que estas pueden verse ralentizadas (Chroinin et al., 2016), implicando, consecuentemente, una disminución de la actividad física realizada por el alumnado (Coral et al., 2017; Martínez y García, 2017).

A fin de analizar qué sucedía a los niveles de intensidad de actividad física del alumnado de educación física que empleaba AICLE, establecimos el tercer objetivo de estudio, abordado, al igual que los dos anteriores, por dos manuscritos diferentes. El manuscrito 5 presenta los datos objetivos obtenidos en un diseño cuasi-experimental de investigación que, desde un enfoque metodológico cuantitativo, nos permitió comparar la actividad física realizada por 
dos grupos-clase (uno control y otro experimental) que realizaron seis sesiones prácticas del mismo contenido: una unidad didáctica completa de atletismo. Este planteamiento desveló, en contra de las hipótesis que la literatura revisada sugería, que el grupo que realizaba las sesiones mediante AICLE presentaba niveles de intensidad en la actividad física realizada en clase significativamente superiores a los niveles presentados por el grupo control (Coral et al., 2017; Lynott, 2008; Martínez y García, 2017).

Tras buscar en la literatura una explicación convincente para este hecho, son diversos los motivos potenciales que argüimos ante tales hallazgos. De entrada, podría darse el caso de que el profesorado ajustara su discurso a un mensaje más corto, claro y sencillo con objeto de facilitar una comunicación efectiva y lo más inteligible posible (Gómez y Jiménez, 2012; Gruber, 2015; Salvador-García y Chiva-Bartoll, 2017), yendo directamente al quid de la explicación (Zindler, 2013). Paralelamente, el uso de una lengua que no se domina al mismo nivel que la materna podría haber llevado al alumnado a escuchar con mayor atención en clase a fin de seguir mejor el hilo de las explicaciones (Zindler, 2013), o incluso a ver aumentados sus niveles motivacionales al verse expuesto a un nuevo planteamiento metodológico que, a todas luces, les insta a mostrarse más activos y centrados en las explicaciones y actividades propuestas (Doiz et al., 2014; Salvador-García y Chiva-Bartoll, 2017). No obstante, estas no dejaban de ser posibles hipótesis o especulaciones que, aun siendo plenamente coherentes con los resultados de nuestra investigación, abrían una interesante línea de investigación que convenía seguir explorando.

Con este cometido diseñamos el estudio presentado en el manuscrito 6; donde, para complementar los resultados obtenidos en el escrito anterior, incorporamos una vertiente cualitativa a la investigación. La meta era entender mejor el cómo y el porqué de los resultados cuantitativos obtenidos. Para ello se optó por el empleo de un método mixto de diseño explicativo secuencial (Creswell et al., 2003) en el cual, pese a seguir estableciendo una predominancia de los resultados cuantitativos, la perspectiva cualitativa podría ayudarnos a comprender e interpretar las razones que regían los resultados obtenidos inicialmente en la variable de estudio. De este modo, para entender qué podría haber llevado al alumnado a obtener unos niveles de actividad física superiores en el enfoque AICLE, se optó por triangular los datos cuantitativos con la información relevante extraída de las 
entrevistas realizadas a 12 discentes y a la docente que llevaron a cabo las sesiones de educación física mediante AICLE.

De dichas entrevistas se desprende que una explicación plausible radica en que el alumnado pudo haber aumentado su nivel de atención en clase de modo que el tiempo utilizado en las explicaciones se vio reducido, pudiendo este dedicarse en mayor medida a las actividades prácticas, en consonancia con lo expuesto por Doiz et al. (2014), Fernández-Río, Hortigüela y Pérez (2017) y Baena-Extremera et al. (2017). Además, a través del análisis de contenido de las entrevistas también se aprecia que la docente utilizó estrategias comunicativas de diversas naturalezas, lo cual pudo ayudar a que el alumnado fuera capaz de comprender mejor y más rápido las explicaciones, facilitando que estas fueran más breves y fáciles de asimilar (Gómez y Jiménez, 2012; Gruber, 2015; Salvador-García y Chiva-Bartoll, 2017).

En definitiva, esta línea del estudio permite apuntar, en base a las evidencias empíricas analizadas, la inesperada capacidad que tiene el enfoque AICLE para fomentar facetas tan esenciales en la asignatura de educación física como la cantidad e intensidad de actividad física realizada durante las sesiones prácticas. De modo que, en adelante, el temor generalizado a que la aplicación de AICLE pudiera llegar a comprometer uno de los elementos esenciales y más representativos de la materia (que en educación física es por excelencia la práctica motriz) queda firmemente cuestionado. Sin embargo, a pesar de tener un gran valor (reconocido por los revisores de los textos sometidos a evaluación), nuestros resultados no son totalmente concluyentes, dado que existen limitaciones que futuras investigaciones deberían tratar de superar, tales como el restringido tamaño de la muestra o la falta de variedad en los dominios de acción motriz analizados (únicamente el atletismo), pudiendo ampliarse en interacciones motrices con colaboración-oposición, actividades en el medio natural o planteamientos artístico-expresivos. En cualquier caso, los resultados presentados, en su conjunto, contribuyen a delimitar rigurosamente un problema de investigación que en los próximos tiempos seguirá estando en el centro de muchos debates educativos. 



\section{Conclusiones}

Mediante el presente trabajo doctoral se ha explorado la utilización del enfoque AICLE desde el área de educación física. Con tal de conseguir dicho objetivo, en primer lugar, comprobamos los estudios que se habían realizado en torno a esta temática para, después, abordar nuestra propia investigación al respecto. Como se ha podido comprobar en los resultados expuestos en los diferentes manuscritos que componen esta tesis, el empleo de dicho enfoque es una realidad ya asentada en el campo de la educación física. Sin embargo, siguen existiendo incertezas con respecto a las implicaciones que genera su aplicación. El trabajo que aquí presentamos trata de contribuir a desentramar de manera empírica las consecuencias que esta opción metodológica genera en el contexto educativo actual de la educación física. Además, respondiendo a las exigencias de la investigación educativa, conviene mencionar que este trabajo adquiere un valor añadido ya que presenta un análisis científico de un tema de creciente interés no solo pedagógico, sino también político; por lo que los resultados obtenidos y conclusiones a las que se llega podrán ser valorados y tomados en consideración para el futuro.

A continuación, se recogen las principales conclusiones de la tesis organizadas conforme a los objetivos de estudio planteados:

Objetivo 1. Averiguar cuál es el estado de la cuestión en el campo de la educación física mediante el enfoque AICLE.

- Objetivo 1.1. Determinar cuál es el marco teórico particular de la educación física mediante AICLE y concretar sus posibilidades de aplicación.

La educación física, por su idiosincrasia propia, requiere del desarrollo de un marco teórico concreto para su combinación efectiva con el enfoque AICLE. Son diversas las pautas y consideraciones sobre las cuales el profesorado de dicha materia debe reparar a la hora de abordar su implementación. Por ejemplo, resulta apropiado conocer el marco teórico relativo a AICLE para poder afrontar pasos elementales como la elección del tema y el enfoque del trabajo, la preparación de la unidad didáctica incorporando conscientemente el uso de la lengua, así como la evaluación de la práctica desarrollada. Esta base es necesaria para poder aplicar óptimamente el enfoque AICLE en educación física aprovechando las múltiples 
sinergias que se crean entre ellas, hecho que genera un marco idóneo para preparar al alumnado atendiendo a las demandas de la sociedad actual.

- Objetivo 1.2. Examinar cuáles son y qué analizan los artículos de mayor impacto que vinculan educación física y enseñanza de lenguas extranjeras.

Un número creciente de artículos científicos aborda el aprendizaje de una lengua desde el área de educación física, realizándose un considerable porcentaje en el marco del Estado español, hecho que indica la notoriedad que está adquiriendo en nuestro contexto el aprendizaje integrado de contenidos y lengua. Pese a la divergente naturaleza de los estudios analizados, puede observarse que el inglés se erige como el idioma por el que más se opta como lengua de aprendizaje, evidenciando también su hegemonía como lengua global. Además, pese a que existen diferentes opciones metodológicas a la hora de abordar el aprendizaje integrado de un contenido y una lengua, el enfoque AICLE emerge como el claro dominante. Por último, entre las aspiraciones que se plantean algunos de los estudios analizados destacan determinar las estrategias de comunicación, identificar dilemas, señalar las dificultades percibidas por el profesorado, o concretar los efectos de este enfoque pedagógico. Del análisis de todos ellos se evidencia que el uso del enfoque AICLE en el área de educación física es una realidad, quedando abierto un considerable abanico de líneas de exploración ante las que la investigación educativa debe hacer frente.

Objetivo 2. Investigar cuáles son las percepciones sobre la aplicación de AICLE en educación física de los agentes implicados directamente en su desarrollo.

- Objetivo 2.1. Analizar cómo vive y qué opina sobre AICLE el profesorado de educación física que lo ha aplicado en sus clases.

El profesorado ostenta un rol de suma relevancia en el quehacer educativo y, de hecho, conocer su visión de la implementación de AICLE en el área de educación física ha aportado diferentes ideas sobre las que conviene reparar a fin de garantizar una óptima práctica educativa. Por ejemplo, en lo concerniente a su experiencia, pese a los múltiples aspectos positivos señalados, la introducción de AICLE conlleva un aumento significativo de su carga de trabajo. Esta cuestión debe ser tomada en cuenta puesto que, si el profesorado no ve 
reconocida de alguna manera su labor, puede decaer su motivación $y$, por ende, dejar de aplicar AICLE o aplicarlo sin toda la planificación que conlleva.

Por lo que se refiere a las opiniones desprendidas por el profesorado, pese a los temores que puedan plantearse ante una posible desvirtuación de la educación física, los y las docentes consideran que el uso de AICLE no pone en riesgo la naturaleza de esta asignatura. De hecho, resulta ciertamente interesante reparar en que, desde su perspectiva, la implementación de dicho enfoque podría ser incluso un aliciente añadido hacia una educación física más participativa y cooperativa dada la necesidad de introducir la lengua de manera deliberada.

- Objetivo 2.2. Examinar cómo vive y qué opina el alumnado sobre el uso de AICLE en clase de educación física.

El alumnado tiene una visión propia de las prácticas educativas que puede contribuir en gran mesura a conocer cómo mejorarlas. Los y las discentes viven de manera diversa las sesiones de educación física mediante AICLE; sin embargo, parece haber consenso a la hora de percibir un cierto temor hacia la incorporación de dicho enfoque en clase. No obstante, este sentimiento desaparece con el paso del tiempo y da lugar a un aumento de su motivación y participación. Además, con respecto a su opinión sobre la combinación de AICLE y educación física, el alumnado resalta su mejora en la práctica de las destrezas orales sin disminuir el aprendizaje de contenidos propios de la asignatura. De este modo, a partir de su experiencia, el estudiantado es consciente de los beneficios que aporta el uso de AICLE a la par que expone que no existe necesidad de temer por una pérdida del aprendizaje relativo a la educación física.

Objetivo 3. Analizar cómo afecta el uso del enfoque AICLE en las sesiones de educación fisica.

- Objetivo 3.1. Examinar si la utilización de AICLE en educación implica que se vean alterados los niveles de actividad física del alumnado durante las sesiones en comparación con las sesiones ordinarias de esta asignatura.

Promover la realización de actividad fisca y proporcionar oportunidades para desarrollarla es uno objetivos de la educación física. Por este motivo, que AICLE pudiera repercutir negativamente sobre los niveles de actividad física del alumnado es una de las 
preocupaciones más recurrentes. Teniendo en cuenta la preocupación evidente plasmada en la literatura, los resultados obtenidos han sido ciertamente inesperados, mostrando una perspectiva alentadora de cara a la introducción del enfoque AICLE en la materia de educación física. En nuestro estudio el uso de dicho enfoque no ha disminuido los niveles de actividad física del estudiantado y, por tanto, puede afirmarse que AICLE se erige como una opción compatible con la promoción de actividad física desde la asignatura de educación física.

- Objetivo 3.2. Conocer si el enfoque AICLE repercute sobre el nivel de actividad física moderada-vigorosa del alumnado y, en caso afirmativo, comprender cómo y por qué.

Contrariamente a todo lo presupuesto, el enfoque AICLE no disminuye los niveles de actividad física del alumnado en las sesiones de educación física. Dada la relevancia de este hallazgo resulta apropiado tratar de entender las razones que originan los resultados obtenidos. Así, todo parece indicar que estos datos se deben al incremento de atención por parte del alumnado, así como al uso de estrategias docentes relacionadas con la puesta en práctica de AICLE. En suma, dicho enfoque genera cambios en las sesiones de educación física, pero sus efectos no contravienen la promoción de actividad física desde esta asignatura.

Mediante esta investigación se ha podido explorar, de entrada, el panorama relativo a la introducción del enfoque pedagógico AICLE en la asignatura de educación física. De los resultados obtenidos en los seis manuscritos que componen el presente trabajo se extrae que, pese a la aún incipiente cantidad de investigaciones realizadas sobre la temática, la imbricación de dichos enfoque y área se muestran en clara ascensión. Asimismo, los resultados demuestran que los elementos esenciales de la educación física no se ven diluidos necesariamente por el hecho de incorporar el enfoque AICLE en las sesiones. Este hecho es reconocido tanto en los manuscritos realizados desde una perspectiva cualitativa, incumbiendo a docentes y discentes, como en los realizados desde un posicionamiento cuantitativo, mediante el empleo de acelerometría. También resulta interesante subrayar la motivación generada por el empleo de este enfoque, puesto que, pese a las reticencias iniciales que pueden aparecer, este aumento del interés del alumnado podría ser uno de los desencadenantes del incremento de los niveles de actividad física en clase. 
Además, de los estudios se desprende que la incorporación de AICLE, y por ende una voluntad explícita de otorgar relevancia a la comunicación en clase, podría favorecer el empleo de estilos de enseñanza más participativos y cooperativos. Es decir, el uso de AICLE promueve abordar la educación física tal y como se la concibe en la actualidad, movilizando no solo a la dimensión más puramente física de la práctica, sino también poniendo en valor el desarrollo integral del alumnado desde, con y a través de la motricidad.

Por otro lado, esta investigación implica la necesidad de seguir replanteándonos cómo puede optimizarse un proceso de enseñanza-aprendizaje que combine la educación física y el aprendizaje de una lengua. Hoy en día este hecho queda estipulado legislativamente, por lo que los docentes lo ven como un imperativo. A esto hay que sumarle la cantidad de trabajo extra que conlleva su adecuada implementación. Por ello, parece necesario reflexionar sobre cómo continuar mejorando y facilitando la tarea docente a fin de garantizar que las prácticas de educación física mediante AICLE sean adecuadas.

Por otra parte, es de recibo comentar que la presente tesis y los diferentes manuscritos que la componen presentan una serie de limitaciones. A continuación, las analizamos con más detalle.

Como se ha comentado en algunos manuscritos, una de las limitaciones comunes es el tamaño de la muestra. En concreto, los manuscritos 5 y 6 presentan una muestra reducida dado que el empleo de acelerometría, tal como reflejan la mayoría de estudios de esta índole, dificulta disponer de un mayor número de participantes cuando se utiliza en situaciones de intervención directa. No obstante, dando respuesta a las necesidades del diseño cuasiexperimental empleado en esta vertiente, se ha podido contar con un grupo experimental y un grupo control entre los que poder hacer comparaciones. Finalmente, en estos artículos, la limitación temporal ha sido otro aspecto a tener en cuenta, puesto que únicamente se ha podido analizar una única unidad didáctica completa trabajando un contenido concreto.

Pese a las limitaciones mencionadas, este trabajo pretende velar por la educación física y contribuir en la mejora del aprendizaje de lenguas desde dicha materia, abriendo nuevas líneas de investigación y planteando nuevas propuestas. Por ello, seguidamente exponemos diversas posibilidades que se presentan como futuras líneas de investigación dentro de la temática abordada. 
- Seguir ahondando, desde nuevos enfoques y diseños, sobre las implicaciones que tiene AICLE en los diferentes agentes implicados.

- Analizar la percepción de las altas instancias educativas como entidad de relevancia dentro del sistema educativo.

- Incorporar en el análisis mediante acelerometría otro tipo de contenidos de educación física pertenecientes a diferentes bloques de contenidos, así como realizar el estudio en otros niveles educativos y ampliando el tiempo de estudio.

- Abordar el estudio a través de acelerometría de manera combinada con la metodología observacional.

- Investigar qué beneficios puede obtener la educación física de la incorporación del enfoque AICLE.

En definitiva, los resultados obtenidos, pese a sus limitaciones y a las cautelas necesarias por las características del estudio, nos ofrecen pistas para seguir mejorando la enseñanza y el aprendizaje de las futuras generaciones, lo cual, sin ninguna duda, es uno de los retos más importantes que debe afrontar la sociedad actual. Tratar de aportar un granito de arena en la mejora educativa a través de esta tesis doctoral ha sido mi gran objetivo de un tiempo a esta parte. Por ello, a título personal, el presente trabajo ha representado un camino que he disfrutado muchísimo hasta prácticamente el final, ayudándome a crecer, aportándome innumerables experiencias y contribuyendo asazmente en mi formación. Sin embargo, con su finalización me encuentro ante lo que George Bernard Shaw considera una desdicha, puesto que como escribió una vez: "hay dos tragedias en la vida, una es perder el deseo que tiene el corazón, y la otra es obtenerlo" (p. 277). Solo espero que nuevas tragedias estén por venir... 


\section{6bis. Conclusions}

This doctoral thesis has explored the use of the CLIL approach in the area of physical education. In order to achieve this objective, we first reviewed the previous studies (see previous chapters) that had been conducted on this subject and then carried out our own research on the matter. As can be seen from the results presented in the manuscripts that make up this thesis, the use of this approach is a reality that is already firmly established in the field of physical education. However, the implications of its application continue to generate uncertainty. The study presented here attempts to contribute to the empirical research being conducted to unravel the consequences that this methodological option produces in the present-day educational context of physical education. Furthermore, in response to the demands of educational research, it should be highlighted that this work has an added value as it presents a scientific analysis of a topic of increasing pedagogical as well as political interest. The results and conclusions obtained can therefore be valued and taken into consideration for the future.

The main conclusions of the thesis are set out below, ordered according to the study objectives that were initially proposed:

Objective 1. To find out what the current status of the issue is in the field of teaching physical education through the CLIL approach.

- Objective 1.1. To determine the particular theoretical framework of physical education through CLIL and to establish its applicability.

Due to its very idiosyncrasy, physical education requires the development of a particular theoretical framework for its effective combination with the CLIL approach. There are several guidelines and considerations that teachers of this subject must bear in mind when it comes to undertaking its implementation. For example, they should be familiar with the theoretical framework of CLIL in order to be able to address the elementary steps such as the choice of topic and the way the work is to be approached, the preparation of the didactic unit consciously incorporating the use of the language, and also the assessment of the practical work carried out. This groundwork is necessary for the optimal application of the CLIL approach in physical education taking advantage of the multiple synergies that are created 
between them, which generates an ideal framework for preparing students to meet the demands of today's society.

- Objective 1.2. To determine which high-impact articles link physical education and the teaching of foreign languages and what exactly they analyse.

A growing number of scientific papers address language learning from the area of physical education, with a considerable percentage of them coming from Spain, which reflects the relevance that content and language integrated learning is acquiring in our context. Despite the divergent nature of the studies analysed, it can be observed that English stands out as the most commonly chosen language to be learnt, which also evidences its hegemony as a global language. Furthermore, although there are different methodological options when it comes to the integrated learning of content and language, the CLIL approach clearly dominates the field. Lastly, the aims of some of the studies analysed include determining communication strategies, identifying dilemmas, pinpointing the difficulties perceived by teachers or specifying the effects of this pedagogical approach. The analysis of all of them shows that the use of the CLIL approach within the area of physical education is a reality, although a considerable range of lines of exploration remain open and must be addressed by educational research.

Objective 2. To investigate the way the application of CLIL in physical education is perceived by those directly involved in its development.

- Objective 2.1. To analyse the day-to-day experience of physical education teachers who have applied CLIL in their classes and what they think about it.

Teachers play an extremely important role in education and, in fact, knowing their vision of the implementation of CLIL in the area of physical education has provided different ideas that should be considered in order to guarantee optimal educational practice. For example, from their experience, despite the numerous positive aspects mentioned, the introduction of CLIL gives rise to a significant increase in their workload. This issue must be taken into account because if teachers do not see some kind of recognition for their efforts, their motivation may drop and they may stop applying CLIL or apply it without all the planning that it entails. 
With regard to the opinions expressed by teachers, despite the fears that may arise about a possible distortion of physical education, they consider that the use of CLIL does not jeopardise the nature of this subject. In fact, it is interesting to note that, from their perspective, the implementation of such an approach could even be an added incentive towards a more participatory and cooperative physical education, given the need to introduce the language deliberately.

- Objective 2.2. To examine students' day-to-day experience of the use of CLIL in their physical education classes and what they think about it.

Students have their own view of educational practices, which can make a valuable contribution to know how to improve them. Learners experience physical education sessions using CLIL in different ways; nevertheless, they seem to agree that there is a certain fear of incorporating this approach into the classroom. However, this feeling disappears over time and leads to an increase in their motivation and participation. Furthermore, with respect to their opinion on the combination of CLIL and physical education, students highlight their improvement in the practice of oral skills without diminishing the learning of the specific contents of the subject. Thus, based on their experience, students become aware of the benefits of using CLIL, while also stating that there is no need to fear a loss of learning about physical educational.

Objective 3. To analyse how the use of the CLIL approach affects the physical education sessions.

- Objective 3.1. To examine whether the use of CLIL in education implies that students' levels of physical activity are altered during the sessions in comparison to the ordinary sessions in this subject.

One of the goals of physical education is to encourage physical activity and provide opportunities to carry it out. For this reason, the fact that CLIL could have a negative impact on students' levels of physical activity is one of the most recurrent concerns. In view of the evident concern expressed in the literature, the results obtained were certainly unexpected, since they show an encouraging outlook for the introduction of the CLIL approach into physical education. In this study, the use of this approach has not diminished students' levels 
of physical activity and it can therefore be stated that CLIL stands as an option that is compatible with fostering physical activity through the subject of physical education.

- Objective 3.2. To know whether the CLIL approach affects the level of moderate to vigorous physical activity of students and, if so, to understand how and why it does so.

Contrary to expectations, the CLIL approach does not reduce students' levels of physical activity in physical education sessions. Given the relevance of this finding, efforts should be made to try to understand the reasons behind the results obtained. Hence, it seems that these data are due to an increase in students' attention, as well as to the use of teaching strategies related to the implementation of CLIL. In short, this approach gives rise to changes in the physical education sessions, but its effects do not go against the promotion of physical activity advocated by this subject.

This research has made it possible to explore, from the outset, the panorama regarding the introduction of the pedagogical approach known as CLIL into the subject of physical education. From the results obtained in the six manuscripts that make up this thesis, it can be deduced that, despite the scant research conducted on this subject, there is a clear growing tendency to interweave this approach and area of study. Likewise, the results also show that the essential elements of physical education are not necessarily becoming diluted by incorporating the CLIL approach into the sessions. This fact is acknowledged both in the articles based on a qualitative perspective, involving teachers and students, and in those that were developed following a quantitative stance, by using accelerometry. It is also interesting to highlight the motivation generated by the use of this approach, since, despite the initial reluctance that may appear, this increase in students' interest could be one of the factors that trigger the increased levels of physical activity in class.

In addition, the studies show that incorporating CLIL, and hence an explicit willingness to give relevance to classroom communication, could favour the use of more participatory and cooperative teaching styles. In other words, the use of CLIL fosters physical education being addressed as it is currently conceived, that is, by mobilising not only the purely physical dimension of the practice, but also enhancing the students' integral development from, with and through motor skills. 
Moreover, this research implies a need to continue to rethink how a teaching-learning process that combines physical education and language learning can be optimised. Today this fact is stipulated in legislation, and teachers therefore see it as an imperative. On top of all this, it is also necessary to take into account the amount of extra work required to implement it properly. It thus seems necessary to reflect upon how to continue to improve and facilitate the teaching task in order to ensure that the practices used in teaching physical education through CLIL are suitable.

Moreover, it must also be noted that this thesis and the different manuscripts contained within it present a series of limitations. These are analysed in more detail in the following.

As has been mentioned in some of the manuscripts, one of the common limitations is the sample size. Specifically, manuscripts 5 and 6 include a small sample since the use of accelerometry, as reflected in most studies of this kind, makes it difficult to have a greater number of participants when used in situations involving direct intervention. However, in response to the needs of the quasi-experimental design used in this aspect, it has been possible to have an experimental group and a control group with which comparisons can be performed. Finally, in these papers, the time restraint was another aspect to be taken into account, as it has only been possible to analyse a single complete didactic unit working on a specific item of the curriculum.

Despite the above-mentioned limitations, this work aims to uphold physical education and contribute to the improvement of language learning based on that subject by opening up new avenues of research and putting forward new proposals. For this reason, below we outline several possibilities that are presented as future lines of research within the topic addressed.

- Continue to explore, from new approaches and designs, the implications that CLIL has on the different stakeholders involved.

- Analyse the perception of the educational authorities as a significant entity within the educational system.

- Use accelerometry to incorporate other types of contents of physical education from different blocks of contents, as well as conduct studies at other educational levels and extend the time the study is to last. 
- Address the study through accelerometry in combination with an observation-based methodology.

- Explore what benefits physical education can gain from incorporating the CLIL approach.

In short, despite their limitations and the precautions required by the characteristics of the study, the results obtained offer us some clues on how to continue to improve the teaching and learning process of future generations, which is undoubtedly one of the most important challenges facing society today. Trying to make a small contribution to the improvement of education has been my main aim for some time now. Therefore, on a personal note, this work has represented a path that I have very much enjoyed treading until almost the end, as it has helped me to grow, has offered me countless experiences and has been a valuable addition to my training. Nevertheless, on its completion I find myself faced with what George Bernard Shaw considers a misfortune, for as he once wrote: "There are two tragedies in life: one is not to get your heart's desire. The other is to get it" (p. 277). I only hope that new tragedies are yet to come... 


\section{Referencias bibliográficas}

Admiraal, W., Westhoff, G., y de Bot, K. (2006). Evaluation of bilingual secondary education in The Netherlands: Students' language proficiency. English Educational Research and Evaluation, 12(1), 75-93.

Ahmed, N., Anwar, M. A., Wajahat, U., Edriss, A., y Abdurahen, M. (2014). Bloom's taxonomy based proportionate curriculum develoment model. Journal of Education and Practice, 5(26), 12-17.

Alcón, E. (2011). La universidad multilingüe. Revista de Docencia Universitaria, 9(3), 119-127.

Alías, D. (2011). El valor didáctico del juego y del movimiento en la enseñanza del inglés en el primer ciclo de Educación Primaria. Campo abierto, 30(2), 23-41.

Almond, L. (1989). The place of physical education in the curriculum. En L. Almond (ed.), The place of physical education in schools (pp.13-36). London: Kogan Page.

Alonso, J. A., Cachón, J., Castro, R., y Zagalaz, M. L. (2015). Propuesta didáctica bilingüe para educación física en educación primaria. Juegos populares y tradicionales ingleses. Retos: nuevas tendencias en educación física, deporte y recreación, (28), 116-121.

Altan, M. Z. (2017). Globalization, English Language Teaching and Turkey. International Journal of Languages' Education and Teaching, 5(4), 764-776.

Álvarez-Diez, V. (2010). El inglés mejor a edades tempranas. Pedagogía magna, (5), 251-256.

Amis, J. (2005). The art of interview for case study research. En D. Manson, D. Andrews y M. Silk (eds.), Qualitative methods in sports studies. Oxford \& New York: Berg.

Anderson, A., Aronson, B., Ellison, S., Fairchild-Keyes, S., Cuevas, J., Akkaymak, G., ... y Rodriguez, A. (2015). Pushing up against the limit-horizon of educational change: A critical discourse analysis of popular education reform texts. Journal for Critical Education Policy Studies, 12(3), 338-370.

Anderson, L. W., Krathwohl, D. L., Airasian, P. W., Cruikshank, K. A., Mayer, R. E., Pintrich, P. R., Raths, J., y Wittrock, M.C. (eds.). (2001). A Taxonomy for Learning, Teaching, and Assessing: A Revision of Bloom's Taxonomy of Educational Objectives. New York: Addison Wesley Longman.

Andúgar, A., y Cortina-Pérez, B. (2018). EFL Teachers' Reflections on Their Teaching Practice in Spanish Preschools: A Focus on Motivation. En M. Schwartz (ed.), Preschool Bilingual Education (pp. 219-244). Cham: Springer.

Arnold, P. (1979). Meaning in movement, sport and physical education. London: Heineman. Arnold, P. J. (1991). Educación física, movimiento y curriculum. Madrid: Morata-MEC. 
Asher, J. (1977). Learning another language through actions. Los Gatos, CA: Sky Oaks.

Attard-Montalto, S., Walter, L., Theodorou, M., y Chrysanthou, K. (2015). CLIL Book. Recuperado de http://www.languages.dk/archive/clil4u/book/CLIL\%20Book\%20ES.pdf

Ayuso, J. A. Z., Rivero, M. D. G., y Izquierdo, A. C. (2018). El modelo competencial en educación física: Contribución, evaluación y vinculación con sus contenidos. Cultura, Ciencia y Deporte, 13(37), 17-30. doi: 10.12800/ccd

Baena-Extremera, A., Gómez-López, M., y Granero-Gallegos, A. (2017). Aprendizaje de la Educación Física Bilingüe a partir de las metas de logro y el clima de aprendizaje. Porta Linguarum: revista internacional de didáctica de las lenguas extranjeras, (28), 81-93.

Baena-Extremera, A., y Granero-Gallegos, A. (2015). Versión española del Sport Satisfaction Instrument (SSI) adaptado al aprendizaje de la Educación Física bilingüe en Inglés. Porta Linguarum: revista internacional de didáctica de las lenguas extranjeras, (24), 63-76.

Banegas, D. L. (2012). CLIL teacher development: Challenges and experiences. Latin American Journal of Content \& Language Integrated Learning, 5(1), 46-56.

Bell, N. D., y Lorenzi, D. (2004). Facilitating second language acquisition in elementary and secondary physical education classes. Journal of Physical Education, Recreation y Dance, 75(6), 46-51.

Bergroth, M. (2006). Immersion students in the matriculation examination three years after immersion. In Exploring dual-focussed education. En S. Björklund, K. Mard- Miettinen, M. Bergström, y M. Södergard (eds.), Integrating language and content for individual and societal needs (pp. 123-134). Recuperado de http://www.uwasa.fi/materiaali/pdf/isbn_952476-149-1.pdf.

Bergroth, M., y Palviainen, Å. (2016). The early childhood education and care partnership for bilingualism in minority language schooling: collaboration between bilingual families and pedagogical practitioners. International Journal of Bilingual Education and Bilingualism, 19(6), 649-667.

Biddle, S. J. H. (2003). The Motivation of Pupils in Physical Education. En C. Hardy y M. Mawer (eds.), Learning and teaching in physical education (pp.105-125). London: Falmer Press.

Blázquez, Á. (2001). La educación física. Barcelona: inde.

Bondarenko, D. V., Nasonkin, V. V., Shagieva, R. V., Kiyanova, O. N., y Barabanova, S. V. (2018). Linguistic Diversity In Russia Is A Threat To Sovereignty Or A Condition Of Cohesion?. Modern Journal of Language Teaching Methods, 8(5), 196-214.

Breen, M. P., y Candlin, C. N. (2001). The essentials of a communicative curriculum in language teaching. En D. R. Hall y A. Hewings (eds.), Innovation in English language teaching: A reader (pp. 9-26). London: Routledge.

Breidbach, S., y Medina-Suárez, J. (2016). Teachers' Perspectives on CLIL and Classroom Innovation in a Method based on Drama Games. Estudios sobre Educación, 31, 97-116. 
Breivik, G. (2014). Sporting knowledge and the problem of knowing how. Journal of the Philosophy of Sport, 41(2), 143-162.

Brinton, D., Snow, M. A., y Wesche, M. (2003). Content-based Second Language Instruction. Ann Arbor: Michigan classics edition, University of Michigan Press.

Broca, Á. (2016). CLIL and non-CLIL: differences from the outset. Elt Journal, 70(3), 320-331.

Bruner, J. (1984). Acción, Pensamiento y Lenguaje. Madrid: Alianza Psicología.

Brunner, J. J. (2000). Globalización y el futuro de la educación: tendencias, desafíos, estrategias. Seminario sobre Prospectiva de la Educación en la Región de América Latina y el Caribe, 1-35. Recuperado de http://200.6.99.248/ bru487cl/files/Futuro_EDU\%2525UNESCO2000_JJB.pdf

Bruton, A. (2011). Is CLIL so beneficial, or just selective? Re-evaluating some of the Research. System, 39, 523-532.

Bruton, A. (2013). CLIL: Some of the reasons why ... and why not. System, 41, 587-597.

Bruton, A. (2015). CLIL: Detail matters in the whole picture. More than a reply to J. Hüttner and U. Smit (2014). System, 53, 119-128.

Bruton, A. (2017). Questions about CLIL which are unfortunately still not outdated: A reply to Pérez-Cañado. Applied Linguistics Review, xx(xx), xx-xx.

Buscà, F. (2005). Educación física escolar y transversalidad curricular. Un estudio de casos para el análisis y diseño de tareas motrices significativas (Tesis doctoral). Facultat de Formació del Professorat Universitat de Barcelona, Barcelona.

Byra, M. (2006). Teaching styles and inclusive pedagogies. En D. Kirk, D. MacDonald y M. O'Sullivan (eds.), The handbook of physical education (pp. 449-466). London: Sage.

Byrnes, H. (ed.) (2006) Perspectives. The Modern Language Journal, 90(2), 244-266.

Cambra, M. (2011). Plurilingüisme i ensenyament de llengües. Articles de didáctica de la llengua $i$ la literatura, 53, 77-84.

Campagna, S., y Pulcini, V. (2014). English as a medium of instruction in Italian universities: linguistic policies, pedagogical implications. Textus, 27(1), 173-190.

Canale, M., y Swain, M. (1980). Theoretical bases of com-municative approaches to second language teaching and testing. Applied linguistics, 1(1), 1-47.

Cañellas, C., y Torán, R. (1975). Escuela y sanidad: el movimiento higienista. Cuadernos de Pedagogía, 4, 35-37.

Capone, R., del Sorbo, M. R., y Fiore, O. (2017). A Flipped Experience in Physics Education Using CLIL Methodology. EURASIA Journal of Mathematics, Science and Technology Education, 10(13), 6579-6582. 
Carlson, T. (1995). We hate gym: Student alienation from physical education. Journal of Teaching in Physical Education, 14(4), 467-477.

Casal, S. (2016). Cooperative Assessment for Learning in CLIL Contexts/Evaluación formativa y cooperativa en contextos AICLE. Estudios sobre Educación, 31, 139-157.

Casey, A. (2016). Models-Based Practice. En C. D. Ennis (ed.), Handbook of Physical Education Pedagogy (pp. 54-67). London: Routledge.

Castells, M. (1999). La era de la información: Economía, sociedad y cultura. Vol. 1: La sociedad en red. Madrid: Alianza Editorial.

Çayak, S., y Eskici, M. (2018). Globalization: In Terms of Teachers' Opinion and Metaphorical Perceptions. World Journal of Education, 8(3), 44-55.

Ceallaigh, T. Ó., Mhurchú, S. N., y Chróinín, D. N. (2017). Balancing content and language in CLIL. Journal of Immersion and Content-Based Language Education, 5(1), 58-86.

Celce-Murcia, M. (ed.). (2001). Teaching English as a second or foreign language (3rd Edition). Boston: Heinle \& Heinle.

Celce-Murcia, M. (2008). Rethinking the role of communicative competence in language teaching. En E. Alcón y M. P. Safont (eds.), Intercultural language use and language learning (pp. 41-57). Dordrecht: Springer.

Cenoz, J. (2003). El aprendizaje del inglés desde educación infantil: efectos cognitivos, lingüísticos y afectivos. Eduling Revista-Forum sobre plurilingüismo y educación, 1, 1-11.

Cenoz, J. (2015). Content-based instruction and content and language integrated learning: the same or different? Language, Culture and Curriculum, 28(1), 8-24.

Cenoz, J., Genesee, F., y Gorter, D. (2013). Critical analysis of CLIL: Taking stock and looking forward. Applied Linguistics, 35(3), 243-262.

Chaplier, C. (2013). Des cours de sciences en anglais à l'EMILE: état des lieux, réflexion et recommandations. Cas de l'Université Paul Sabatier. Recherche et pratiques pédagogiques en langues de spécialité. Cahiers de l'Apliut, 32(3), 57-79.

Chedzoy, S., y Burden, R. (2009). Primary school children's reflections on physical education lessons: an attributional analysis and possible implications for teacher action. Thinking Skills and Creativity, 4(3), 185-193.

Chesterton, G. K. (1924, July 5). Selected quotes from G. K. Chesterton. Illustrated London News (no pagination). Recuperado de http://www.cse.dmu.ac.uk/ mward/gkc/books/quotes.html

Chiva-Bartoll, Ò. (2016). Introducción. En Ó. Chiva-Bartoll y M. Martí-Puig (eds.), Métodos pedagógicos activos y globalizadores: conceptualización y propuestas de aplicación (pp. 59). Barcelona: Graó.

Chiva-Bartoll, Ò., Isidori, E., y Fazio, A. (2015). Educación Física bilingüe y pedagogía crítica: una aplicación basada en el judo. Retos, (28), 110-115 
Chiva-Bartoll, Ò., Salvador-García, C., y Capella-Peris, C. (2018). Sinergias entre aprendizaje cooperativo y educación física con AICLE. En J. Fernández-Río, R. Sánchez-Gómez y A. Méndez-Giménez (coords.) Libro de actas del XI Congreso Internacional de Actividades Físicas Cooperativas (pp. 81-90). Oviedo: Ediciones Universidad de Oviedo.

Christopher, A. A., Dzakiria, H. B., y Mohamed, A. H. (2012). Teaching English through Sports: A Case Study. Asian EFL Journal, 59, 20-29.

Chroinin, D., Ní Mhurchú, S., y Ó Ceallaigh, T. J. (2016). Off-balance: the integration of physical education content learning and Irish language learning in English-medium primary schools in Ireland. Education 3-13, 44(5), 566-576.

Clancy, M. E., y Hruska, B. L. (2005) Developing Language Objectives for English Learners in Physical Education. Journal of Physical Education, Recreation y Dance, 76(4), 30-35.

Cobo, J., Estevan, I., y Warburton, S. (2018). Descripción de una experiencia basada en el enfoque CLIL en la enseñanza comprensiva de los juegos deportivos. Estudios de Lingüística Aplicada, 3, 93-102.

Coll, C. (1996). Constructivismo y educación escolar: ni hablamos siempre de lo mismo ni lo hacemos siempre desde la misma perspectiva epistemológica. Anuario de psicología/The UB Journal of psychology, (69), 153-178.

Comisión Europea (1995). Libro blanco sobre la educación y la formación. Enseñar y aprender. Hacia una sociedad cognitiva. Bruselas: Oficina de Publicaciones Oficiales de las Comunidades Europeas.

Comisión Europea (2005). European Council of the European Union, EDUC 69 Ressolution. Brussels: European Comission.

Conant, J. B. (1963). The education of American teachers. New York: McGraw-Hill.

Contreras, O. (1993). Formas de organización y estilos de enseñanza en la Educación Física y su didáctica. Madrid: Publicaciones ICCE.

Coral, J. (2010). L'aprenentatge de l'anglès a través de l'educació física: el programa 'Mou-te i aprèn'. Temps d'Educació, 39, 149-170.

Coral, J. (2012). Aprenentatge integrat de continguts d'educació física i llengua anglesa: Educació fisica al cicle superior de primària (Tesis doctoral). Universidad de Barcelona, Barcelona.

Coral, J. (2016). When cooperative learning makes the difference. Teaching Physical Education in CLIL from primary to higher education. En Actes 10è Congrés Internacional d'Activitats Físiques i Cooperatives (p. 142-153). Institut de Ciències de l'Educació de la Universitat Autònoma de Barcelona, Barcelona.

Coral, J., Esquerda, G., y Benito, J. (2017). Design and validation of a tool to evaluate Physical Education and Language integrated learning tasks. Didacticae, (2), 43-58. 
Coral, J., y Lleixà, T. (2013). Las tareas en el aprendizaje integrado de educación física y lengua extranjera (AICLE). Determinación de las características de las tareas mediante el análisis del diario de clase. Retos: Nuevas tendencias en Educación Física, Deporte y Recreación, 24, 79-84.

Coral, J., y Lleixà, T. (2014). La enseñanza de la EF mediante el enfoque educativo Clil: la resolución de los dilemas profesionales surgidos durante un proceso de investigaciónacción. Movimento, 20(4), 1447-1472.

Coral, J., y Lleixà, T. (2018). Physical education in content and language integrated learning: successful interaction between physical education and English as a foreign language. International Journal of Bilingual Education and Bilingualism, 19(1), 108-126.

Coral, J., Lleixà, T., y Ventura, C. (2018). Foreign language competence and content and language integrated learning in multilingual schools in Catalonia: an ex post facto study analysing the results of state key competences testing. International Journal of Bilingual Education and Bilingualism, 21(2), 139-150.

Coral, J., Urbiola, M., Sabaté, E., Bofill, J., Lleixà, T., y Vilà, R. (en prensa). Does the teaching of physical education in a foreign language jeopardise children's physical activity time? A pilot study. International Journal of Bilingual Education and Bilingualism, 1-16. doi.org/10.1080/13670050.2017.1407289

Corral, S., y González, G. (2018). Effect of CLIL and non-CLIL approaches on the written competence of upper-secondary students. International journal of pedagogy and curriculum, 25(2), 31-43.

Coulter, M., y Ní Chróinín, D. (2011). What is PE? Sport, education and society, 18(6), 825-841.

Coyle, D. (2007). Content and Language Integrated Learning: Towards a connected research agenda for CLIL pedagogies. International Journal of Bilingual Education and Bilingualism, 10(5), 543-562.

Coyle, D. (2015). Strengthening integrated learning: Towards a new era for pluriliteracies and intercultural learning. Latin American Journal of Content \& Language Integrated Learning, 8(2), 84-103.

Coyle, D., Holmes, B., y King, L. (2009). Towards an intergrated curriculum: CLIL National Statement and Guidelines. London: Languages Company. Recuperado de https://www.languagescompany.com/wpcontent/uploads/clil_national_statement_and_guidelines.pdf

Coyle, D., Hood, P. y Marsh, D. (2010). CLIL. Cambridge: CUP.

Creswell, J. W., Plano Clark, V. L., Gutmann, M. L., y Hanson, W. E. (2003). Advanced mixed methods research designs. En A. Tashakkori y C. Teddlie (eds.), Handbook of mixed methods in social and behavioral research (pp. 209-240). Thousand Oaks, CA: Sage.

Crystal, D. (1997). English as a global language. Cambridge: Cambridge University Press. 
Cummins, J. (2000). Language, power, and pedagogy: Bilingual children in the crossfire. Clevendon: Multilingual Matters.

Curdt-Christiansen, X. L., y Sun, B. (2016). Nurturing bilingual learners: challenges and concerns in Singapore. International Journal of Bilingual Education and Bilingualism, 19(6), 689705.

Dalton-Puffer, C. (2007). Discourse in content and language integrated learning (CLIL) classrooms (Vol. 20). John Benjamins Publishing.

Dalton-Puffer, C. (2009). Communicative Competence and the CLIL Lesson. En Y. Ruiz de Zarobe y R. M. Jiménez (eds.), Content and language integrated learning: evidence from research in Europe (pp. 197-214). Bristol: Multilingual Matters.

Dalton-Puffer, C. (2011). Content-and-language integrated learning: From practice to principles? Annual Review of applied linguistics, 31, 182-204.

Dam, M. (2014). Making educational reforms practical for teachers: using a modular, successoriented approach to make a context-based educational reform practical for implementation in Dutch biology education (Tesis doctoral). Leiden University Graduate School of Teaching, Leiden.

De Graaff, R., Jan Koopman, G., Anikina, Y., y Westhoff, G. (2007). An observation tool for effective L2 pedagogy in content and language integrated learning (CLIL). International Journal of Bilingual Education and Bilingualism, 10(5), 603-624.

De Miguel, M. (2015). Ideología y pedagogía empírica: cuestiones para un debate. Revista de investigación educativa, 33(2), 269-287.

Dearden, J. (2015). English as a Medium of Instruction - A Growing Global Phenomenon. Oxford: British Council/Oxford University Press.

Deci, E. L., Vallerand, R. J., Pelletier, L. G., y Ryan, R. M. (1991). Motivation and education: The self-determination perspective. Educational psychologist, 26(3-4), 325-346.

Deckert, G. (2004). The communicative approach: addressing frequent failure. English teaching Forum, 42(1), 12-17.

Decreto 127/2012, de 3 de agosto, del Consell, por el que se regula el plurilingüismo en la enseñanza no universitaria en la Comunidad Valenciana. Diari oficial de la Comunitat Valenciana, 6 de agosto de 2012, núm. 6834, pp. 23451-23459.

Decreto 108/2014, de 4 de julio, del Consell, por el que establece el currículo y desarrolla la ordenación general de la educación primaria en la Comunitat Valenciana. Diari oficial de la Comunitat Valenciana, 7 de julio de 2014, núm. 7311, pp. 16325-16694.

Decreto 87/2015, de 5 de junio, del Consell, por el que establece el currículo y desarrolla la ordenación general de la Educación Secundaria Obligatoria y del Bachillerato en la Comunitat Valenciana, 10 de junio de 2015, núm. 7544, pp. 17437-18582. 
Decreto 88/2017 de 7 de julio, del Consell, por el que se modifica el Decreto 108/2014, de 4 de julio, del Consell, por el que se establece el currículo y se desarrolla la ordenación general de la Educación Primaria en la Comunitat Valenciana, 14 de julio de 2017, núm. 8084, pp. 24839-24842.

Delgado-Noguera, M.A. (1991). Los estilos de enseñanza en Educación Física. Granada: ICE, Universidad de Granada.

Delgado, M., y Tercedor, P. (2002). Estrategias de intervención en educación para la salud desde la educación fisica (Vol. 27). Barcelona: Inde.

Delors, J. (1996). Informe delors. La educación encierra un tesoro. Madrid: UNESCO-Santillana.

Devís, J. (2018). Els discursos sobre les funcions de l'educació física escolar Continuïtats, discontinuïtats i reptes. Lliçó magistral llegida en el solemne acte d'obertura del curs 2018-2019. Valencia: Publicacions de la Universitat de València.

Devís, J., y Molina, J. P. (2004). Las funciones de la educación física escolar: de la modernidad a la postmodernidad. En F. Caparroz y N. F. de Andrade (eds.), Educaçao física escolar. Politica, investigaçao e intervençao, LESEF/UFFS y NEPECC/UFU (pp. 35-49). Vitória: Proteoria.

Devís, J., y Peiró, C. (2002). La salud en la educación física escolar: ¿qué es lo realmente importante? Tándem. Didáctica de la Educación Física, 8, 73-83.

Devos, N. J. (2016). Peer interactions in new content and language integrated settings. Switzerland: Springer International Publishing.

Dewey, J. (1944). Democracy and education. New York, NY: Macmillan

Dismore, H., y Bailey, R. (2004). How children and young people perceive their engagement and participation in Physical Education and school sport. En British Educational Research Association annual conference, Manchester.

Dodd, G. D. (2015). The unrealised value of human motion-'moving back to movement!'. AsiaPacific Journal of Health, Sport and Physical Education, 6(2), 191-213.

Doiz, A., Lasagabaster, D., y Sierra, J. M., (eds.). (2013). English-Medium Instruction at Universities: Global Challenges. Bristol: Multilingual Matters.

Doiz, A., Lasagabaster, D., y Sierra, J. M. (2014). CLIL and motivation: The effect of individual and contextual variables. The Language Learning Journal, 42(2), 209-224.

Dörnyei, Z. (2009). The 2010s Communicative language teaching in the 21 st century: The 'principled communicative approach'. Perspectives, 36(2), 33-43.

Dort, A., Evaul, T., y Gehris, J. (2005). The heart of adventure. Adventurer, winter-spring issue, 12. 
Duran-Martínez, R. (2018). A Comparative Analysis of Teachers' Perceptions of Bilingual Programmes in Primary and Secondary Education. Revista complutense de educación, 29(3), 865-880.

Dyson, B. (2006). Students' perspectives of physical education. Handbook of physical education. En D. Kirk, D. MacDonald, y M. O'Sullivan (eds.), The handbook of physical education (pp. 326-346). London: Sage.

Dyson, B., Griffin, L. L., y Hastie, P. (2004). Sport education, tactical games, and cooperative learning: Theoretical and pedagogical considerations. Quest, 56(2), 226-240.

Ellison, S., Anderson, A. B., Aronson, B., y Clausen, C. (2018). From objects to subjects: Repositioning teachers as policy actors doing policy work. Teaching and Teacher Education, 74, 157-169.

Emmanouilidou, K., y Laskaridou, C. (2017). Physical Education through CLIL: teaching movement vocabulary to young learners. Research Papers in Language Teaching and Learning, 8(2), 51-62.

Escámez, J. (2003). La filosofía de la educación como praxis educativa. En VVAA La filosofía de la educación en Europa (pp. 135-147). Madrid: Dykinson.

Eurydice (2002). Key Competences. A developing concept in general compulsory education. Bruselas. Recuperado de http://www.edmide.gr/KEIMENA\%20E.U/key\%20competences\%20Europe.pdf

Eurydice (2006). Content and Language Integrated Learning (CLIL) at School in Europe. Brussels: Eurydice. Recuperado de www.indire.it/lucabas/lkmw_file/eurydice/CLIL_EN.pdf (visto el 12/12/2014)

Evans, J., Davies, B., y Penney, D. (2003). The Social Construction of Teaching and Learning: The Politics of Pedagogy. En C. Hardy y M. Mawer (eds.), Learning and teaching in physical education (pp. 9-21). London: Falmer Press.

Evnitskaya, N., y Morton, T. (2011). Knowledge Construction, Meaning-Making and Interaction in CLIL Science Classroom Communities of Practice. Language and Education, 25(2), 109127.

Famose, J. P. (1992). Aprendizaje motor y dificultad de la tarea. Barcelona: Paidotribo

Felis-Anaya, M., Martos-Garcia, D., y Devís-Devís, J. (2018). Socio-critical research on teaching physical education and physical education teacher education: A systematic review. European Physical Education Review, 24(3), 314-329.

Fernández-Balboa, J. M. (1999). Pedagogía crítica y educación física en la escuela secundaria. Revista Conceptos de Educación, 6, 15-33.

Fernández-Barrionuevo, E. (2009). La secuenciación de contenidos lingüísticos dentro de la Educación Física Bilingüe. Revista Innovación y Experiencias Educativas, 23, 1-9. 
Fernández-Barrionuevo, E. (2017). Generación de la motivación en AICLE entre los dominios de educación física y aprendizaje en lengua extranjera en centros bilingües andaluces (Tesis doctoral). Universidad de Granada, Granada.

Fernández Barrionuevo, E., y Baena-Extremera, A. (2018). Motivation in Physical Education and Foreign Language Learning in CLIL Teaching: Gender Differences and Implications for Future Studies. Porta Linguarum: revista internacional de didáctica de las lenguas extranjeras, 30, 207-220.

Fernández-Costales, A., y González-Riaño, X. (2015). Teacher Satisfaction Concerning the Implementation of Bilingual Programmes' in a Spanish University. Porta Linguarum. 23, 93-108.

Fernández-Río, J., Calderon, A., Hortigüela, D., Pérez-Pueyo, Á., y Aznar, M. (2016). Modelos pedagógicos en educación física: consideraciones teórico-prácticas para docentes. Revista Española de Educación Física y Deportes, (413), 55-75.

Fernández-Río, J., Hortigüela-Alcalá, D., y Pérez-Pueyo, Á. (2017). Educación bilingüe, streaming y metas sociales en estudiantes de secundaria. Revista de Educación, 377, 30-53. doi:10.4438/1988-592X-RE-2017-377-352

Fernández-Sanjurjo, J., Fernández-Costales, A., y Arias-Blanco, J. M. (2017). Analysing students' content-learning in science in CLIL vs. non-CLIL programmes: Empirical evidence from Spain. International Journal of Bilingual Education and Bilingualism, 1-14 http://dx.doi.org/10.1080/13670050.2017.1294142.

Figueras, S., Flores, C., y González, M. (2011). Educació Física en anglès: percepcions dels estudiants entorn d'una experiència metodològica en el marc universitari. Aloma: Revista de Psicologia, Ciències de l'Educació i de l'Esport, (29), 61-80.

Fleta, M. T. (2016). Foreign language learning in the Early Years in the Madrid Region: teachers' profile, perceptions and methodologies. Didáctica, lengua y litratura, 28, 87-111.

Flick, U. (2009). An Introduction to Qualitative Research. London: SAGE.

Fortanet, I. (2013). CLIL in higher education: Towards a multilingual language policy (Vol. 92). Bristol: Multilingual matters.

Fraile, A. (1995). El maestro de educación fisica y su cambio profesional. Salamanca: Amarú.

Fraile, A. (2004). Didáctica de la Educación Física: una perspectiva crítica y transversal. Madrid: Biblioteca Nueva.

Fullan, M. (1999). Change forces-the sequel. London: Falmer Press.

Fullan, M. (2007). The new meaning of educational change (4th ed.). New York: Teachers College Press. 
Gallardo del Puerto, F., y Gómez-Lacabex, E. (2017). Oral production outcomes in CLIL: an attempt to manage amount of exposure. European Journal of Applied Linguistics, 5(1), 3154.

Gallardo del Puerto, F., y Martínez-Adrián, M. (2013). ¿Es más efectivo el aprendizaje de la lengua extranjera en un contexto AICLE? Resultados de la investigación en España. Padres y Madres, 349, 25-28.

García-Sanz, M. P. (2014). La evaluación de competencias en Educación Superior mediante rúbricas: un caso práctico. Revista electrónica interuniversitaria de formación del profesorado, 17(1), 106.

García-Puchades, W., y Chiva-Bartoll, O. (2018). El juego como proceso de subjetivación y su justificación en el currículum de educación física. Cultura, ciencia y deporte: revista de ciencias de la actividad física y del deporte de la Universidad Católica de San Antonio, $38(13), 147-156$.

García-Jiménez, J., García-Pellicer, J. J., y Yuste, J. (2012). Educación Física en inglés. Una propuesta para trabajar la higiene postural en Educación Primaria. Retos: nuevas tendencias en educación física, deporte y recreación, (22), 70-75.

García-Calvo, S., y Saliberri, M. (2018). Physical Education and English: constructivist vs traditional approaches in bilingual and non-bilingual education. Sportis, 4(2), 364-387.

Gil, F. J., y Aznar, M. (2016). Educación física de calidad en el sistema educativo español. Revista Española de Educación Física y Deportes, (414), 69-82.

Gil, J., y Chiva-Bartoll, O. (2014). Guía de juegos motrices. Una alternativa para el Young Athletes Program de Special Olymics. España: INDE.

Gill, M., Chan-Golston, A. M., Rice, L. N., Cole, B. L., Koniak-Griffin, D., y Prelip, M. L. (2016). Consistency of moderate to vigorous physical activity in middle school physical education. Family \& Community Health, 39(4), 283-292. doi:10.1097/FCH.0000000000000115

Glakas, B. A. (1993). Teaching secondary physical education to ESL students. Journal of Physical Education, Recreation \& Dance, 64(7), 20-25.

Gómez-Mármol, A., Calderón Luquin, A., y Valero Valenzuela, A. (2014). Análisis comparativo de diferentes modelos de enseñanza para la iniciación al atletismo. Ágora para la educación física y el deporte. 16(2), 104-121.

Gómez, C. L., y Jimenez, M. (2012). The physical educator as a language teacher for English language learners. Strategies, 25(4), 14-17.

González, F., Hernández, A., Pastor, J. C. y Villar, L. (2013). Educación Física e inglés, asociación eficaz para adquirir competencias. Tàndem: didáctica de la Educación Física, 43, 97-105.

González, S., Villar, L., Pastor, J., y Gil, P. (2013). Propuesta didáctica interdisciplinar en educación primaria en España. Paradígma. 34(2), 31-50. 
Goorhuis-Brouwer, S., y de Bot, K. (2010). Impact of early English language teaching on L1 and L2 development in children in Dutch schools. International Journal of Bilingualism, 14(3), 289-302

Greere, A., y Räsänen, A. (2008). Report on the LANQUA Subproject on Content and Language Integrated Learning: Redefining CLIL-Towards Multilingual Competence. Recuperado de http://www. lanqua. eu/files/Year1Report_CLIL_ForUpload_WithoutAppendices_0.pdf.

Grek, S. (2009). Governing by numbers: The PISA 'effect'in Europe. Journal of education policy, 24(1), 23-37.

Groves, S., y Laws, C. (2000). Children's experiences of physical education. European Journal of Physical Education, 5(1), 19-27.

Gruber, K. (2015). Improving students' foreign language competence through Content and Language Integrated Learning (CLIL) in Physical Education (Tesis Doctoral). Wien University, Viena.

Hardman, K. (2011). Global issues in the situation of physical education in schools. En K. Hardman, y K. Green (eds.), Contemporary issues in physical education (pp. 11-29). Maidenhead: Meyer \& Meyer Sport.

Hargreaves, A., y Fink, D. (2006). Sustainable leadership. San Francisco, CA: Jossey-Bass.

Harrop, E. (2012). Content and Language Integrated Learning (CLIL): Limitations and Possibilities. Encuentro, revista de investigación e innovación en la clase de idiomas, 21, 57-70.

Heikinaro-Johansson, P., Hasanen, E., McEvoy, E., y Lyyra, N. (2018). Preparing physical and health education pre-service teachers to support students' physical activity and wellbeing during the school day. Curriculum Studies in Health and Physical Education, 9(1), 43-57. doi.org/10.1080/18377122.2017.1418181

Hellison, D. R. (2011). Teaching Personal and Social Responsibility Trough Physical Activity. Champaign, IL: Human Kinetics.

Heras, A., y Lagasabaster, D. (2015). The Impact of CLIL on Affective Factors and Vocabulary Learning. Language Teaching Research, 19(1), 70-88.

Hernando, A. (2015). Caracterización de los aspectos metodológicos empleados en la enseñanza de la materia de Educación Física en los centros públicos de secundaria con sección bilingüe en inglés de Castilla y León (Tesis Doctoral). Universidad de Burgos, Burgos.

Hernando, A., Hortigüela, D., y Pérez, Á. (2018). Percepción de coordinadores de programas bilingües y docentes de Educación Física en inglés en secundaria sobre el proceso de implantación y desarrollo del bilingüismo en la Comunidad de Castilla y León. Retos: nuevas tendencias en educación física, deporte y recreación, (33), 63-68.

Hirst, P. H. (1974). Knowledge and the Curriculum. London: Routledge \& Kegan Paul. 
Hirst, P. H., y Peters, R. S. (1970). The Logic of Education. London: Routledge \& Kegan Paul.

Hodges-Kulinna, P. (2008). Models for Curriculum and Pedagogy in Elementary School Physical Education. Elementary School Journal, 108(3), 219-227.

Hortigüela, D., Hernando, A., Pérez, A., Casado, O., Herrán, I., Garrote, J., Centeno, L., Fernández, L., y Martínez, R. (2016). Bilingüismo y cooperación en Educación Física a través de la dramatización. ¿Cómo integrarlo? En Actes 10è Congrés Internacional d'Activitats Físiques i Cooperatives (p. 142-153). Institut de Ciències de l'Educació de la Universitat Autònoma de Barcelona, Barcelona.

Horwitz, E. K. (1987). Surveying student beliefs about language learning. En A. Wenden y J. Rubin (eds.), Learner strategies in language learning (pp. 119-129). Englewood Cliffs, NJ: Prentice Hall.

Horwitz, E. K. (1988). The beliefs about language learning of beginning university foreign language students. The modern language journal, 72(3), 283-294.

Huizinga, J. (1954). Homo ludens. Madrid: Alianza.

Hüttner, J., y Smit, U. (2014). CLIL (Content and Language Integrated Learning): The bigger picture. A response to: A. Bruton. 2013. CLIL: Some of the reasons why ... and why not. System 41 (2013): 587-597. System, 44, 160-167.

Hymes, D. (1974). Foundations in Sociolinguistics. An Ethnographic Approach. Philadelphia: University of Pennsylvania Press.

Jauregui, K., y Melchor-Couto, S. (2017). The TeCoLa project: pedagogical differentiation through telecollaboration and gaming for intercultural and content integrated language teaching. En K. Borthwick, L. Bradley, y S. Thouësny (eds.), CALL in a Climate of Change: Adapting to Turbulent Global Conditions. Short Papers from EUROCALL 2017 (pp. 163-169). Dublin: Research publishing.net.

Julián, J. A., Abarca-Sos, A. A., Zaragoza, J., y Aibar, A. (2016). Análisis crítico de la propuesta del currículum básico de la LOMCE para la asignatura de Educación Física. Acciones derivadas en la Comunidad Autónoma de Aragón y propuestas de futuro. Retos: nuevas tendencias en educación física, deporte y recreación, (29), 173-181.

Julián, J. A., Ibor, E, Aibar, A., y Aguareles, I. (2017). Educación física, motor de proyectos. Tándem: Didáctica de la educación física, (56), 7-15.

Karimi, P., Lotfi, A. R., y Biria, R. (2017). Efficacy of content and language integrated learning (CLIL) pedagogical techniques in improving aviation students' engagement in attaining the specified learning outcomes. Journal of Teaching English for Specific and Academic Purposes, 5(4), 781-791.

Kashiwagi, K., y Tomecsek, J. (2015). How CLIL classes exert a positive influence on teaching style in student centered language learning through overseas teacher training in Sweden and Finland. Procedia-Social and Behavioral Sciences, 173, 79-84. 
Kaur, P. (2014). Attitudes towards English as a Lingua Franca. Procedia - Social and Behavioral Sciences, 118, 214-221.

Kenning, M. M. (2006) Evolving concepts and moving targets: Communicative competence and the mediation of communication. International Journal of Applied Linguistics, 16, 363-388

Kirk, D. (1988). Physical education and curriculum study. A critical introduction. London: Coom Helm-Routledge.

Kirk, D. (2010). Physical education futures. Oxon: Routledge.

Kirk, D. (2014). A defining time for physical education futures? Exploring the legacy of Fritz Duras. Asia-Pacific Journal of Health, Sport and Physical Education, 5(2), 103-116.

Kirk, D., y Macdonald, D. (1998). Situated learning in physical education. Journal of Teaching in Physical education, 17(3), 376-387.

Kirk, D., MacDonald, D., y O'Sullivan, M. (eds.). (2006). Handbook of physical education. London: Sage.

Krashen, S. D. (1981). Second language acquisition and second language learning. Oxford: Oxford University Press.

Lamb, M. (2004). Integrative motivation in a globalizing world. System, 32(1), 3-19.

Lancaster, N. (2018). Extramural Exposure and Language Attainment: The Examination of InputRelated Variables in CLIL Programmes. Porta Linguarum: revista internacional de didáctica de las lenguas extranjeras, 29, 91-114.

Larsen-Freeman, D. (2018). Looking ahead: Future directions in, and future research into, second language acquisition. Foreign Language Annals, 51(1), 55-72.

Larsson, H., y Nyberg, G. (2017). It doesn't matter how they move really, as long as they move. Physical education teachers on developing their students' movement capabilities. Physical Education and Sport Pedagogy, 22(2), 137-149. doi.org/10.1080/17408989.2016.1157573

Lasagabaster, D., y Doiz, A. (2016a). CLIL students' perceptions of their language learning process: delving into self-perceived improvement and instructional preferences. Language Awareness, 25(1-2), 110-126.

Lasagabaster, D., y Doiz, A. (eds.). (2016b). CLIL experiences in secondary and tertiary education: In search of good practices. Bern: Peter Lang.

Lasagabaster, D., y Sierra, J. M. (2010). Immersion and CLIL in English: more differences than similarities. ELT Journal, 64(4), 367-375.

Laws, C. J., y Fisher, R. J. (2003). Pupils' Interpretations of Physical Education. En C. Hardy y M. Mawer (eds.), Learning and teaching in physical education (pp. 23-37). London: Falmer Press.

Lawson, H. A. (1984). Invitation to Physical Education. Champaign: Human Kinetics. 
Leader, H. S. T., Halat, R., Maayeh, R., Dabdoub, R., Rafidi, T., Shaaban, S. A., y Hamdy, H. (2017). Blended English Language Learning for Refugees: Challenges and Possibilities. Cambridge: Cambridge University Press. Recuperado de http://www.englishprofile.org/images/pdf/Final-report_TRP_CUP_2016-Simas-et-al.pdf

Leung, C. (2005). Convivial communication: Recontextualizing communicative competence. International Journal of Applied Linguistics, 15(2), 119-144.

Ley $4 / 2018$, de 21 de febrero, de la Generalitat, por la que se regula y promueve el plurilingüismo en el sistema educativo valenciano, 22 de febrero de 2018, núm. 8240, pp. 7860-7873.

Ley Orgánica 8/2013, de 9 de diciembre, para la mejora de la calidad educativa. Boletín Oficial del Estado, $\mathrm{n}^{\circ} 295$ de 10 de diciembre de 2013.

Lightbown, P. M., Spada, N., Ranta, L., y Rand, J. (1999). How languages are learned (Vol. 2). Oxford: Oxford university press.

Lleixà, T. (2017). Didáctica de la Educación Física: Nuevos temas, nuevos contextos. Didacticae: Revista de Investigación en Didácticas Específicas, (2), 2-5.

Llinares, A. M., y Whittaker, R. (2007). Talking and writing in a foreigner language in CLIL contexts: a linguistic analysis of secondary school learners of Geography and History. Revista española de lingüística aplicada, 20(1) 83-91.

Lo, Y. Y., y Lin, A. M. (2015). Special issue: Designing multilingual and multimodal CLIL frameworks for EFL students. International Journal of Bilingual Education and Bilingualism, 18(3), 261-269.

López-Pastor, V. (coord.). (2002). Algunas reflexiones sobre Educación Física y Pedagogía Crítica. Retos. Nuevas tendencias en Educación Física, Deportes y Recreación, 2, 30-35.

López-Pastor, V., Barba, J. J., y González, M. (2005). La participación del alumnado en la evaluación: la autoevaluación, la coevaluación y la evaluación compartida. Tándem Didáctica Educación Física, 17, 21-37.

López-Pastor, V. M., Brunicardi, D. P., Arribas, J. C. M., y Aguado, R. M. (2016). Los retos de la Educación Física en el Siglo XXI. Retos: nuevas tendencias en educación física, deporte y recreación, (29), 182-187.

Lorente, E., y Martos, D. (2018). Educación Física y pedagogía crítica: Propuestas para la transformación personal y social (Vol. 6). Lleida: Universitat de Lleida.

Lorenzo, F., Casal, S., y Moore, P. (2009). The effects of content and language integrated learning in European education: Key findings from the Andalusian bilingual sections evaluation project. Applied Linguistics, 31(3), 418-442.

Lorenzo, F, Hengst, H., Hernández, H., y Pavón, V. (2005). Borrador para la elaboración del Currículo Integrado, Plan to Promote Multlingualism, Junta de Andalucía. Recuperado de: www.juntadeandalucia.es/averroes/plurilinguismo/curriculo/borradorcil.pdf. 
Lova, M., Bolarín, M., y Porto, M. (2013). Programas bilingües en Educación Primaria: valoraciones de docentes. Porta Linguarum, 20, 253-268.

Luzón, A., y Torres, M. (2016). Apuntes sobre la internacionalización y la globalización en educación. De la internacionalización de los modelos educativos a un nuevo modelo de gobernanza. Journal of Supranational Policies of Education, (1), 53-66.

Lynott, F. J. (2008). Integrating other subject matter without jeopardizing physical education goals: The content linkage approach. Strategies, 22(1), 10-17.

Lyster, R., y Ballinger, S. (2011). Content-based Language Teaching: Convergent Concerns across Divergent Contexts. Language Teaching Research, 15(3), 279-288.

Marsh, D. (ed.) (2002). CLIL/EMILE the European Dimension. Finland: University of Jyvaskyla.

Marsh, D. (2006). English as a medium of instruction in the new global linguistic order: Global characteristics, Local consequences. En S. M. Stewart, J. E. Olearski y D. Thompson (eds.), Second Annual Conference for Middle East Teachers of Science, Mathematics and Computing (pp. 29-38). Abu Dhabi, Citeseer. Recuperado de https://archive.org/details/ProceedingsOfTheSecondAnnualConferenceForMiddleEastTeac hersOf (visto el 16/11/2014)

Marsh, D. (2012). Content and lenguaje integrated (CLIL) A development trajectory. Córdoba: Servicio de publicaciones de la Universidad de Córdoba.

Marsh, D., Mehisto, P., Wolff, D., y Frigols Martin, M. J. (2012). European framework for CLIL teacher education. Recuperado de:

https://ebuah.uah.es/dspace/bitstream/handle/10017/14881/CLIL-

Framework_Marsh.pdf? sequence $=1$

Marsh, D., Pérez-Cañado, M. L., y Ráez-Padilla, J. (eds.). (2015). CLIL in Action: Voices from the Classroom. Cambridge: Cambridge Scholars Publishing.

Martín, F. (2010). La importancia de globalizar para aprender. Publicaciones didácticas, 8, 112122.

Martínez, F. J., y García, E. (2017). Influencia del bilingüismo en el tiempo de compromiso motor en Educación Física. Retos. Nuevas tendencias en educación física, deporte y recreación, $32,178-182$.

Martos, D., Tamarit, E., y Torrent, G. (2016). Negociando el currículum en educación física. Una propuesta práctica de cogestión. Retos: nuevas tendencias en educación física, deporte y recreación, (29), 223-228.

Marzano, R. J., y Kendall, J. S. (eds.). (2007). The new taxonomy of educational objectives. Thousand Oaks: Corwin Press.

Mavilidi, M. F., Okely, A. D., Chandler, P., Cliff, D. P., y Paas, F. (2015). Effects of integrated physical exercises and gestures on preschool children's foreign language vocabulary learning. Educational Psychology Review, 27(3), 413-426. 
Mawer, M. (2003). Teaching Styles and Teaching Approaches in Physical Education. En C. Hardy y M. Mawer (eds.), Learning and teaching in physical education (pp. 83-104). London: Falmer Press.

McBride, R. E. (1991). Critical thinking: An overview with implications for Physical Education. Journal of Teaching in Physical Education, 11(2), 112-25.

McBride, R., Gabbard, C., y Miller, G. (1990). Teaching critical thinking skills in the psychomotor domain. The Clearing House, 63(5), 197-201.

McCall, I. (2011). Score in French: motivating boys with football in Key Stage 3. Language Learning Journal, 39(1), 5-18.

McDougald, J. (2015). Teachers' attitudes, perceptions and experiences in CLIL: A look at content and language. Colombian Applied Linguistics Journal, 17(1), 25-41.

McDougald, J. S. (2017). Language and Content in Higher Education. Latin American Journal of Content \& Language Integrated Learning, 10(1), 9-16.

McEvoy, E., Heikinaro-Johansson, P., y MacPhail, A. (2017). Physical education teacher educators' views regarding the purpose (s) of school physical education. Sport, Education and Society, 22(7), 812-824.

Mehisto, P., Marsh, D., y Frigols, M. J. (2008). Uncovering CLIL content and language integrated learning in bilingual and multilingual education. Oxford: Macmillan.

Mejía-Jiménez, M. R. (2011). Educación (es) en la (s) globalización (es): entre el pensamiento único y la nueva crítica. Lima: Ediciones desde abajo.

Méndez-García, M. C. (2013). The Intercultural Turn Brought about by the Implementation of CLIL Programmes in Spanish Monolingual Areas: A Case Study of Andalusian Primary and Secondary Schools. Language Learning Journal, 41(3), 268-283.

Méndez, M. y Pavón, V. (2012). Investigating the coexistence of the mother tongue and the foreign language through teacher collaboration in CLIL contexts: perceptions and practice of the teachers involved in the plurilingual programme in Andalusia. International Journal of Bilingual Education and Bilingualism. 15(5), 573-592.

Merino, J. (2016). Non-linguistic content in CLIL: is its learning diminished? En D. Lasagabaster y A. Doiz (eds.), CLIL experiences in secondary and tertiary education: In search of good practices (pp. 17-43). Bristol: Peter Lang.

Merino, J. A., y Lasagabaster, D. (2018a). CLIL as a way to multilingualism. International Journal of Bilingual Education and Bilingualism, 21(1), 79-92.

Merino, J. A., y Lasagabaster, D. (2018b). The effect of content and language integrated learning programmes' intensity on English proficiency: A longitudinal study. International Journal of Applied Linguistics, 28(1), 18-30. 
Merisuo-Storm, T. (2006). Development of boys' and girls' literacy skills and learning attitudes in CLIL education. En S. Björklund, K. Mard-Miettinen, M. Bergström, y M. Södergard (eds.), Integrating language and content for individual and societal needs (pp. 176-188). Recuperado de http://www.uwasa.fi/materiaali/pdf/isbn_952-476-149-1.pdf, Accessed date: 15 April 2017.

Metzler, M. W. (2005). Instructional models for physical education. Needham Heights, Massachusetts: Allyn \& Bacon.

Meyer, O. (2010). Towards quality CLIL: successful planning and teaching strategies. PULSO. Revista de Educación, (33), 11-29.

Molina, J., Queralt, A., Estevan, I., y Sallis, J. F. (2016). Ecological correlates of Spanish adolescents' physical activity during physical education classes. European Physical Education Review, 22(4), 479-489. doi:10.1177/1356336X15623494

Moliner, M. (2014). La influencia de la legislación de cada una de las CCAA en el desempeño de rol del profesor de metodología AICLE. Salamanca: Universidad Pontificia de Salamanca.

Moliner, M., y Fernández, L. M. (2013). The Effects of CLIL from the Perspective of In-service Teachers in Salamanca (Castilla y León, Spain). Exedra: Revista Científica, 8, 200-217.

Montávez, M., Mariscal, A., y López, I. (2002). Desdramaticemos el inglés. Propuesta interdisciplinar: Educación Física (expresión corporal) y Lengua extranjera. Retos. Nuevas tendencias en Educación Física, Deporte y Recreación, 1, 29-36.

Monzonís, N., y Capllonch, M. (2014). La educación física en la consecución de la competencia social y ciudadana. Retos. Nuevas tendencias en Educación Física, Deporte y Recreación, $25,180-185$.

Morilla-García, C. (2017). The Role of Emotional Intelligence in Bilingual Education: A Study on The Improvement of the Oral Language Skill. REMIE Multidisciplinary Journal of Educational Research, 7(1), 27-52.

Mosston, M., y Ashworth, S. (1993). La enseñanza de la Educación Física. La reforma de los estilos de enseñanza. Barcelona: Hispano Europea.

Muñoz, C. (2003). Variation in oral skills development and age of acquisition. En M. P. Garcia Mayo y M. Garcia Lecumberri (eds.), Age and the acquisition of English as a foreign language (pp. 161-181). Clevedon: Multilingual Matters.

Muszyńska, A., Urpí, C., y Galazca, A. (2017). Teacher Education through Drama. CLIL Practice in the Spanish Context. Estudios sobre educación, 32, 179-195. Doi: 10.15581/004.32.179195.

Nanclares, N. H., y Rodríguez, M. P. (2016). Students' Satisfaction with a Blended Instructional Design: The Potential of" Flipped Classroom" in Higher Education. Journal of Interactive Media in Education, 1(4), 1-12 
Navarro, M., y García, E. (2018). Are CLIL Students More Motivated? An Analysis of Affective Factors and their Relation to Language Attainment. Porta Linguarum, 29, 71-90.

Nieto, E. (2018). Acquisition of reading comprehension in L1 in bilingual programmes of Primary Education. A comparative study Adquisición de la lectura en L1 en programas bilingües de Educación Primaria. Un estudio comparativo. Ocnos, 17(1), 43-54.

Nikolov, M., y Djigunović, J. M. (2006). Recent research on age, second language acquisition, and early foreign language learning. Annual review of applied linguistics, 26, 234-260.

Ouazizi, K. (2016). The effects of CLIL education on the subject matter (mathematics) and the target language (English). Latin American Journal of Content \& Language Integrated Learning, 9(1), 110-137.

Pallarés-Piquer, M., y Chiva-Bartoll, Ó. (2017). La pedagogía de la presencia. Tecnologías digitales y aprendizaje-servicio. Barcelona: Editorioal UOC.

Pallarés-Piquer, M., Chiva-Bartoll, Ó., López-Martín, R., y Cabero-Fayos, I. (2018). La escuela que llega. Tendencias y nuevos enfoques metodológicos. Barcelona: Octaedro.

Palviainen, Å., y Mård-Miettinen, K. (2015). Creating a bilingual pre-school classroom: the multilayered discourses of a bilingual teacher. Language and education, 29(5), 381-399.

Palviainen, Å., Protassova, E., Mård-Miettinen, K., y Schwartz, M. (2016). Two languages in the air: A cross-cultural comparison of preschool teachers' reflections on their flexible bilingual practices. International Journal of Bilingual Education and Bilingualism, 19(6), 614-630.

Papadopoulos, I., y Theodoglou, E. (2017). Living together in a culturally diverse world: Designing and implementing a CLIL project in primary education. En E. Griva y V. Zorbas (eds.), Multicultural and Citizenship awareness through language: cross thematic practices in language pedagogy (p.295-311). New York: Nove science publishers.

Paran, A. (2013). Content and language integrated learning: Panacea or policy borrowing myth? Applied Linguistics Review, 4(2), 317-342.

Parlebas, P. (2008). Juegos, deporte y sociedad. Léxico de praxiología motriz. Barcelona: Paidotribo.

Pastor, M. R. (2011). CLIL and cooperative learning. Encuentro, 20, 109-118.

Pavón, V., Ávila, J., Gallego, A., y Espejo, R. (2014). Strategic and organisational considerations in planning content and language integrated learning: a study on the coordination between content and language teachers. International Journal of Bilingual Education and Bilingualism, 18(4), 409-425. Doi:10.1080/13670050.2014.909774

Pedrosa, B. (2016). New learning scenarios in a higher education clil setting. En D. Lasagabaster y A. Doiz (eds.), CLIL experiences in secondary and tertiary education: In search of good practices (pp. 197-232). Bern: Peter Lang. 
Peiró, C., y Méndez, A. (2017). Modelos pedagógicos en educación física. Tándem, didáctica de la educación física, 57, 4-6.

Pena-Díaz, C., y Porto-Requejo, M. D. (2008). Teacher beliefs in a CLIL education project. Porta Linguarum, 10, 151-161.

Pennington, T. R., Prusak., K. A., y Wilkinson, C. (2014). Succeed together or fail alone: Going from good to great in physical education. Journal of Teaching in Physical Education, $33(1), 28-52$.

Pennycook, A. (2017). The cultural politics of English as an international language. London: Routledge.

Pérez-Cañado, M. L. (2011). The effects of CLIL within the APPP: Lessons learned and ways forward. En R. Crespo y M. A. García de Sola (eds.), Studies in honour of Ángeles Linde López (pp. 13-30). Granada: Universidad de Granada.

Pérez-Cañado, M. L. (2012). CLIL research in Europe: Past, present, and future. International Journal of Bilingual Education and Bilingualism, 15(3), 315-341.

Pérez-Cañado, M. L. (2016). From the CLIL craze to the CLIL conundrum: Addressing the current CLIL controversy. Bellaterra Journal of Teaching \& Learning Language \& Literature, 9(1), 9-31.

Pérez-Cañado, M. L. (2017). Stopping the "pendulum effect" in CLIL research: Finding the balance between Pollyanna and Scrooge. Applied linguistics review, 8(1), 79-99.

Pérez-Cañado, M. L. (2018a). CLIL and Educational Level: A Longitudinal Study on the Impact of CLIL on Language Outcomes. Porta Linguarum, 29, 51-70.

Pérez-Cañado, M. L. (2018b). The effects of CLIL on L1 and content learning: Updated empirical evidence from monolingual contexts. Learning and Instruction, 57, 18-33.

Pérez Cañado, M. L., y Lancaster, N. K. (2017). The effects of CLIL on oral comprehension and production: a longitudinal case study. Language, Culture and Curriculum, 30(3), 300-316.

Pérez-Ramírez, C. (1993). Evolución histórica de la Educación Física. Educación Física y Deportes, 33, 24-38.

Pérez-Vidal, C. (2015). Languages for all in education: CLIL and ICLHE at the crossroads of multilingualism, mobility and internationalisation. En M. Juan-Garau y J. Salazar-Noguera (eds.), Content-based language learning in multilingual educational environments (pp. 31 50). Cham: Springer.

Peter, S. (1998). A cognitive approach to language learning. Oxford: Oxford University Press.

Peters, R.S. (1966). Ethics and Education. London: Allen \& Unwin.

Piernavieja, M. (1960). Francisco Amorós: el primer Gimnasiarca español. Citius, Altius, Fortius, 2, 277-313. 
Piesche, N., Jonkmann, K., Fiege, C., y Keßler, J. U. (2016). CLIL for all? A randomised controlled field experiment with sixth-grade students on the effects of content and language integrated science learning. Learning and Instruction, 44, 108-116.

Pistorio, M. I. (2010). A blend of CLIL and cooperative learning creates a socially constructed learning environment. Latin American Journal of Content \& Language Integrated Learning, 3(1), 1-10.

Pitura, J., y Chmielarz, D. (2017). Creating a Comic Strip Is Very Creative and Thanks to It We Learn and Remember: Student Perceptions of a Biology Challenge in a Gamified Extracurricular CLIL Project. Teaching English with Technology, 17(3), 77-95.

Pladevall-Ballester, E. (2016). CLIL subject selection and young learners' listening and reading comprehension skills. International Journal of Applied Linguistics, 26(1), 52-74.

Pladevall-Ballester, E., y Vallbona, A. (2016). CLIL in minimal input contexts: A longitudinal study of primary school learners' receptive skills. System, 58, 37-48.

Porto, M., Houghton, S. A., y Byram, M. (2017). Intercultural citizenship in the (foreign) language classroom. Language teaching research, 22(5), 484-498.

Prieto-Arranz, J. I., Fabra, L. R., Calafat-Ripoll, C., y Catrain-González, M. (2015). Testing progress on receptive skills in CLIL and non-CLIL contexts. En M. Juan-Garau y J. Salazar-Noguera (eds.), Content-based language learning in multilingual educational environments (pp. 123-137). Cham: Springer.

Rallo, L., y Jacob, K. (2015). Does CLIL enhance oral skills? Fluency and pronunciation errors by Spanish-Catalan learners of English. En En M. Juan-Garau y J. Salazar-Noguera (eds.), Content-based language learning in multilingual educational environments (pp. 163-177). Cham: Springer.

Ramos, F., y Ruiz-Omeñaca, J.V. (2011). La EF en centros bilingües de primaria inglés-español: de las singularidades propias del área a la elaboración de propuestas didácticas prácticas con AIBLE. Resla, 24, 153-170.

Rauschert, P., y Byram, M. (2018). Service learning and intercultural citizenship in foreignlanguage education. Cambridge Journal of Education, 48(3), 353-369.

Real Decreto 126/2014, de 28 de febrero, por el que se establece el currículo básico de educación primaria. Boletín oficial del Estado, 1 de marzo de 2014, núm 52, pp. 19349-19420.

Real Decreto 1105/2014, de 26 de diciembre, por el que se establece el currículo básico de la Educación Secundaria Obligatoria y del Bachillerato. Boletín oficial de Estado, 3 de enero de 2015, núm. 3, pp. 169-546.

Reid, A. (1997). Value pluralism and physical education. European Physical Education Review, $3(1), 7-18$.

Ricardo, C. P. (2017). Gamifying Content and Language Integrated Learning with Serious Videogames. Journal of Language and Education, 3(3), 107-114. 
Richards, J. C., y Rodgers, T. (2001). Approaches and methods in language teaching (2nd ed.). New York: Cambridge University Press

Rikard, G. L., y Banville, D. (2006). High school students attitudes about physical education. Sport, Education and Society, 4, 385-400.

Rink, J. (2003). Instruction from a Learning Perspective. En C. Hardy y M. Mawer (eds.), Learning and teaching in physical education (pp. 149-168). London: Falmer Press.

Ríos, I. M. (2005). Les llengües en una societat i una escola pluriculturals. En A. Sales, et al. (eds.), La diversitat cultural a l'escola: propostes pràctiques per a un currículum intercultural (pp. 13-27). Castelló de la Plana: Publicacions de la Universitat Jaume I.

Rodríguez-Rojo, M. (1997). Hacia una didáctica crítica. Madrid: La Muralla.

Rodríguez-Merayo, M. B., y Cebrián-Bernat, G. (2018). CLIL proposal by integration of ICTin the bilingual music classroom at secondary education. Encuentro-Revista de investigación e innovación en la clase de idiomas, (26), 69-82.

Roquet, H., Llopis, J., y Pérez-Vidal, C. (2016). Does gender have an impact on the potential benefits learners may achieve in two contexts compared: formal instruction and formal instruction+ content and language integrated learning?. International Journal of Bilingual Education and Bilingualism, 19(4), 370-386.

Roussel, S., Joulia, D., Tricot, A., y Sweller, J. (2017). Learning subject content through a foreign language should not ignore human cognitive architecture: A cognitive load theory approach. Learning and Instruction, 52, 69-79.

Ruiz de Zarobe, Y. (2011). La lectura en el aprendizaje integrado de contenidos en lengua extranjera. En Y. Ruiz de Zarobe y L. Ruiz de Zarobe (eds.), La lectura en lengua extranjera (p. 220-244). Londres: BM Portal Editions.

Ruiz de Zarobe, Y., y Lasagabaster, D. (2010). Introduction. The emergence of CLIL in Spain: An educational challenge. En D. Lasagabaster y Y. Ruiz de Zarobe (eds.), CLIL in Spain: Implementation, Results and Teacher Training (pp. ix-xvii). Newcastle upon Tyne: Cambridge Scholars Publishing.

Ryan, R. M., y Deci, E. L. (2000). Intrinsic and extrinsic motivations: Classic definitions and new directions. Contemporary educational psychology, 25(1), 54-67.

Salvador García, C. (2015). Aprendizaje integrado de contenidos y lengua: aprendizaje de inglés en el área de educación física (Trabajo de fin de Máster). Universitat Jaume I, Castellón de la Plana.

Salvador-García, C., y Chiva-Bartoll, O. (2017). CLIL in teaching physical education: views of the teachers in the Spanish context. Journal of Physical Education and Sport, 17(3), 11301138. Doi: 10.7752/jpes.2017.03174. 
Salvador-García, C., Chiva-Bartoll, O., y Vergaz, J. J. (2018). Percepción del alumnado sobre el uso del método AICLE en Educación Física: estudio de caso. Retos: nuevas tendencias en educación física, deporte y recreación, (33), 138-142.

Sánchez-Pérez, M. D. M., y Salaberri, M. S. (2017). Implementing Plurilingualism in Higher Education: Teacher Training Needs and Plan Evaluation. Porta Linguarum, monográfico II, 139-156.

Savignon, S. J. (2003). Teaching English as communication: A global perspective. World Englishes, 22(1), 55-66.

Schwartz, M., y Palviainen, Å. (2016). Twenty-first-century preschool bilingual education: facing advantages and challenges in cross-cultural contexts. International Journal of Bilingual Education and Bilingualism, 19(6), 603-613.

Scott, D., y Beadle, S. (2014). Improving the effectiveness of language learning: CLIL and computer assisted language learning. Brussels: European Comission.

Shaw, G. B. (2008). Man and superman. South Bend, Indiana, USA: Eve Sobol.

Siedentop, D. (1998). Aprender a enseñar la educación física. Barcelona: Inde

Smith, S. J. (1991). Where is the child in physical education research? Quest, 43, 37-54.

Sosaoga, A. (2017). Discurso y praxis de la Educación Física en el País Vasco en el contexto de la Escuela Primaria (Tesis doctoral). Universidad del País Vasco, Vitoria-Gasteiz.

Spada, N. (2007). Communicative language teaching. En J. Cummins y C. Davison (eds.), International handbook of English language teaching (pp. 271-288). Boston, MA: Springer.

Sparkes, A. C., Templin, T. J., y Schempp, P. G. (1993). Exploring dimensions of marginality: Reflecting on the life histories of physical education teachers. Journal of Teaching in Physical Education, 12(4), 386-398.

Spring, J. (2008). Research on globalization and education. Review of Educational Research, $78(2), 330-363$.

Stroot, S. A., y Ko, B. O. M. N. A. (2006). Induction of beginning physical educators into the school setting. En D. Kirk, D. MacDonald, y M. O'Sullivan (eds.), The handbook of physical education (pp. 425-448). London: Sage.

Subramaniam, P. R., y Silverman, S. (2007). Middle school students' attitudes towards physical education. Teaching and Teacher Education, 23, 602-611

Suits, B. (1967). What is a Game?. Philosophy of Science, 34(2), 148-156.

Surmont, J., Struys, E., Van Den Noort, M., y Van De Craen, P. (2016). The effects of CLIL on mathematical content learning: A longitudinal study. Studies in Second Language Learning and Teaching, 6(2), 319-337. 
Svennberg, L. (2017). Swedish PE teachers' understandings of legitimate movement in a criterionreferenced grading system. Physical Education and Sport Pedagogy, 22(3), 257-269.

Taillefer, G. (2013). CLIL in higher education: the (perfect?) crossroads of ESP and didactic reflection. ASp. La revue du GERAS, (63), 31-53.

Teck Koh, K., Wen Ong, S., y Camiré, M. (2016). Implementation of a values training programme in physical education and sport: Perspectives from teachers, coaches, students, and athletes. Physical Education and Sport Pedagogy, 21(3), 295-312. doi: 10.1080/17408989.2014.990369

Tenolahti, I. (2017). The same thing over and over again in many different ways: case study about bilingual teaching methods in the Family Centre Klubičko, Czech Republic. Finlandia: University of Jyväskylä.

Thoilliez, B. (2019). Vindicación de la escuela como espacio para el desarrollo de experiencias democráticas: aproximación conceptual a las prácticas morales de reconocimiento y respeto. Educación XX1, 22(1), 295-314.

Ting, Y. T. (2011). CLIL... not only not immersion but also more than the sum of its parts. ELT journal, 65(3), 314-317.

Tinning, R. (1996). Discursos que orientan el campo del movimiento humano y el problema de la formación del profesorado. Revista de Educación, 311, 123-134.

Tomlinson, B., y Masuhara, H. (2009). Playing to learn: A review of physical games in second language acquisition. Simulation \& Gaming, 40(5), 645-668.

Torres, A. (20 octubre, 2018). Entrevista a David Marsh, experto en bilingüismo. El País. Recuperado de: https://elpais.com/sociedad/2018/09/24/actualidad/1537811034_517768.html

Valdés, L. (2016). Estudi de la col•laboració discursiva en l'ensenyament integrat de les ciències $i$ l'anglès a l'aula d'educació primària: La docència compartida com a eina per promoure el diàleg disciplinar (Tesis Doctoral). Universidad Autónoma de Barcelona, Barcelona.

Van Kampen, E., Meirink, J., Admiraal, W., y Berry, A. (2017). Do we all share the same goals for content and language integrated learning (CLIL)? Specialist and practitioner perceptions of 'ideal'CLIL pedagogies in the Netherlands. International Journal of Bilingual Education and Bilingualism, 21(2), 1-17.

Viciana, J., Mayorga, D., y Mompeán, M. (2016). Cumplimiento de los estándares curriculares de condición física-salud en educación física. Estudio de la planificación en la formación inicial. Cultura, Ciencia y Deporte, 11(32), 87-95.

Villanueva, M. L. (2002). Los estilos de aprendizaje ante los retos de la Europa multilingüe. En L. Miquel y N. Sans (coord.), Didáctica del español como lengua extranjera (pp. 243-263). Barcelona: Ed. Actilibre. 
Villanueva, M. L. (2007). Eclecticism or complexity? Concepts of connections and differences between old and new language teaching-learning paradigms. En E. Usó y N. Ruiz-Madrid (eds), Pedagogical reflections on learning languages in instructed settings (pp. 2-27). Cambridge: Cambridge Scholars Press.

Vygotsky, L. S. (1989). El Desarrollo de los Procesos Psicológicos Superiores. Barcelona: Crítica.

Warbuton, S. (2016). Aprendizaje Integrado de Contenidos y Lenguas Extranjeras en Educación Secundaria: propuesta piloto para su implementación en la Comunidad Valenciana (Tesis Doctoral). Universidad politécnica de Valencia, Valencia.

Warschauer, M. (2000). The changing global economy and the future of English teaching. Tesol Quarterly, 34(3), 511-535.

Watanabe, Y., Ikeda, M., y Izumi, S. (2011). CLIL (content and language integrated learning) new challenges in foreign language education at Sophia university volume 1: Principles and methodologies. Tokyo, Japan: Sophia University Press.

Whitehead, M. E. (2010). Physical literacy: throughout the lifecourse. London: Routledge.

Whittaker, R., Llinares, A., y McCabe, A. (2011). Written discourse development in CLIL at secondary school. Language Teaching Research, 15(3), 343-362.

Zagalaz, M. L. (2001). Bases Teóricas de la Educación Física y el Deporte. Jaén: Universidad de Jaén.

Zagalaz, M. A., Molero, D., Cachón, J., y Gutiérrez, J. (2012). Diseño de un cuestionario para medir la formación bilingüe del profesorado de EF (FBPEF). Revista Iberoamericana de Ciencias del Deporte, 1(1), 7-12.

Zindler, K. (2013). Content and Language Integrated Learning (CLIL) and PE in England. An Exploratory Study (Tesis Doctoral). University of Sheffield, Sheffield. 

8. Anexos 


\section{UNIVERSITAT \\ JAUME}

Escola de Doctorat · ED

(Nombre).... Carla Colomer Diago

como coautor/ coautora doy mi autorización a (Nombre del doctorando/doctoranda)Celina Salvador.Garçiapara la presentación de las siguientes publicaciones como parte de su tesis doctoral.

Relación de publicaciones:

Salvador, C., Chiva, O., \& Colomer, C. (in press.). El efecto de la Educación Física bilingüe sobre la actividad fisica del alumnado. No todo es lo que parece. Cultura Ciencia Deporte.

Asimismo, renuncio a poder utilizar estas publicaciones como parte de otra tesis doctoral.

Y para que conste firmo el presente documento,

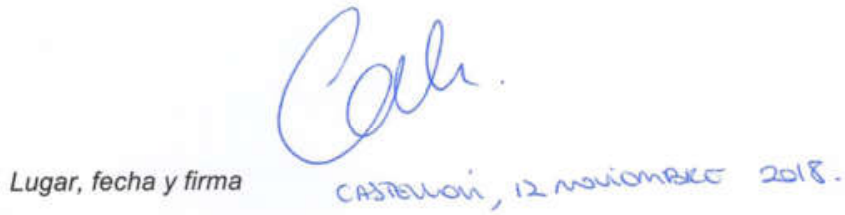

Todo ello, atendiendo al artículo 23 de la Normativa de los Estudios de Doctorado, regulados por el RD 99/2011, en la Universitat Jaume I (Aprobada por el Consejo de Gobierno núm. 19 de 26 de Enero de 2012, modificada por el Consejo de Gobierno núm. 29 de 27 de Noviembre de 2012 y con posterior modificación por el Consejo de Gobierno núm. 37 de 25 de Julio de 2013):

$$
\text { (....) }
$$

"Aquellas tesis doctorales que opten por la incorporación de articulos (compendio de publicaciones) deben de ajustarse, en la medida de lo posible, a la siguiente estructura: -Introducción/objetivos - Un capitulo por articulo incorporado - Discusión general de los resultados - Conclusiones. -Aceptación de los coautores de que el doctorando presente el trabajo como tesis y renuncia expresa de estos a presentarlo como parte de otra tesis doctoral." 
UNIVERSITAT

JAUME I

Escola de Doctorat · ED

(Nombre)......................................

como coautor/ coautora doy mi autorizaclón

a (Nombre del doctorando/doctoranda)................................para la presentación de las siguientes publicaciones como parte de su tesis doctoral.

Relación de publicaciones:

- Educación física bilingüe: efectos de CLIL sobre los niveles de actividad física. Porta Linguarum

Asimismo, renuncio a poder utilizar estas publicaciones como parte de otra tesis doctoral.

Y para que conste firmo el presente documento,

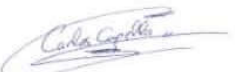

Castellón, 12 de Noviembre de 2018

Lugar, fecha y firma

Todo ello, atendiendo al artículo 23 de la Normativa de los Estudios de Doctorado, regulados por el RD 99/2011, en la Universitat Jaume I (Aprobada por el Consejo de Gobierno núm. 19 de 26 de Enero de 2012, modificada por el Consejo de Gobiemo núm. 29 de 27 de Noviembre de 2012 y con posterior modificación por el Consejo de Gobierno núm. 37 de 25 de Julio de 2013):

$$
\text { "(...) }
$$

"Aquellas tesis doctorales que opten por la incorporación de articulos (compendio de publicaciones) deben de ajustarse, en la medida de lo posible, a la siguiente estructura: -Introducción/objetivos - Un capltulo por articulo incorporado - Discusión general de los resultados - Conclusiones. -Aceptación de los coautores de que el doctorando presente el trabajo como tesis y renuncia expresa de estos a presentarlo como parte de otra tesis doctoral." 


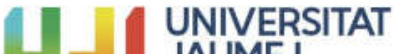

Escola de Doctorat · ED

......Emanuele Isidori....., como coautor/ coautora doy mi autorización

a...........Celina Salvador García...............para la presentación de las

siguientes publicaciones como parte de su tesis doctoral.

Relación de publicaciones:

Salvador-García, C.; Chiva-Bartoll,O y Isidori, E. (2017). Aprendizaje de un idioma extranjero a

través de la educación física: una revisión sistemática. Movimento, 23(2), 647-660.

Asimismo, renuncio a poder utilizar estas publicaciones como parte de otra tesis doctoral.

Y para que conste firmo el presente documento,

Lygar, fecha y firma

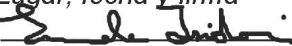

Rome, July 31, 2018

Todo ello, atendiendo al artículo 23 de la Normativa de los Estudios de Doctorado, regulados por el RD 99/2011, en la Universitat Jaume I (Aprobada por el Consejo de Gobierno núm. 19 de 26 de Enero de 2012, modificada por el Consejo de Gobierno núm. 29 de 27 de Noviembre de 2012 y con posterior modificación por el Consejo de Gobierno núm. 37 de 25 de Julio de 2013):

"Aquellas tesis doctorales que opten por la incorporación de articulos (compendio de publicaciones) deben de ajustarse, en la medida de lo posible, a la siguiente estructura: -Introducción/objetivos - Un capitulo por articulo incorporado - Discusión general de los resultados - Conclusiones. -Aceptación de los coautores de que el doctorando presente el trabajo como tesis y renuncia expresa de estos a presentarlo como parte de otra tesis doctoral." 


\section{In Inverstar \\ JAUME I}

Escola de Doctorat · ED

......Juan José Vergaz Gallego........, como coautor/ coautora doy mi autorización

a............Celina Salvador García................para la presentación de las

siguientes publicaciones como parte de su tesis doctoral.

Relación de publicaciones:

Salvador-Garcia, C; Chiva-Bartoll,O y Vergaz-Gallego J.J. (2018). Percepción del alumnado sobre el uso del método AICLE en educación física: estudio de caso. Retos, 33, 138-142.

Asimismo, renuncio a poder utilizar estas publicaciones como parte de otra tesis doctoral.

Y para que conste firmo el presente documento,

Lugar, fecha y firma

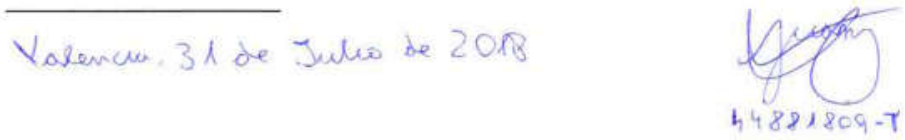

Todo ello, atendiendo al articulo 23 de la Normativa de los Estudios de Doctorado, regulados por el RD 99/2011, en la Universitat Jaume 1 (Aprobada por el Consejo de Gobierno núm. 19 de 26 de Enero de 2012, modificada por el Consejo de Gobierno núm. 29 de 27 de Noviembre de 2012 y con posterior modificación por el Consejo de Gobierno núm. 37 de 25 de Julio de 2013):

$$
\text { "(...) }
$$

"Aquellas tesis doctorales que opten por la incorporación de articulos (compendio de publicaciones) deben de ajustarse, en la medida de lo posible, a la siguiente estructura: -Introducción/objetivos - Un capitulo por artículo incorporado - Discusión general de los resultados - Conclusiones. Aceptación de los coautores de que el doctorando presente el trabajo como tesis y remuncia expresa de estos a presentarlo como parte de otra tesis doctoral. 


\section{Métodos pedagógicos activos}

y globalizadores

Conceptualización y propuestas de aplicación Óscar Chiva Bartoll, Manuel Marti Puig (coords.)

318$$
\text { . }
$$ 


\section{Métodos pedagógicos activos y globalizadores}

\section{Conceptualización y propuestas de aplicación}

Óscar Chiva Bartoll, Manuel Martí Puig (coords.)

Patricia Balaguer Rodríguez, Carlos Capella Peris, Raquel Corbatón Martínez, Jesús Gil Gómez, M. Ángeles Llopis Nebot, María Maravé Vivas, Noelia Ruiz Madrid, Celina Salvador García, Andreu Serret Segura, Lorena Zorrilla Silvestre 


\section{Serie Didáctica}

- Óscar Chiva Bartoll, Manuel Marti Puig (coords.), Patricia Balaguer Rodriguez, Carlos Capella Peris, Raquel Corbatón Martinez, Jesús Gil Gómez, M. Ángeles Llopis Nebot, Maria Maravé Vivas, Noelia Ruiz Madrid, Celina Salvador Garcia, Andreu Serret Segura, Lorena Zorrilla Silvestre

(๑) de esta edición: Editorial GRAÓ, de IRIF, S.L.

c/ Hurtado, 29. 08022 Barcelona

www.grao.com

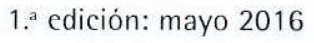

ISBN: 978-84-9980-676-1

D.L.: B 9643-2016

Diseño de cubierta: Xavier Aguiló Impresión: Service Point FMI, S.A.

Impreso en España

Quedan rigurosamente prohibidos y estarán sometidos a las sanciones establecidas por las leyes, la reproducción o total o parcial de la presente publicación, incluyendo el diseño de la portada, asi como la transmisión de ésta por cualquier medio, tanto si es eléctrico, como quimico, mecánico, óptico, de grabación o bien de fotocopia, sin la autorización escrita de los titulares del copyright. Dirijase a CEDRO (Centro Español de Derechos Reprográficos, www.cedro.org) si necesita fotocopiar o escanear algún fragmento de esta obra (www.conlicencia.com, 917021970 / 932720 447). 


\section{Índice}

Introducción, Ó. Chiva | 5

Referencias bibliográficas | 8

1. Flipped classroom (clase invertida), J. Gil, O. Chiva | 11

Introducción | 11

Marco conceptual | 12

Propuesta de aplicación | 16

Posibles limitaciones y dificultades | 20

Ejemplificación | 21

Conclusiones | 24

Referencias bibliográficas | 25

Bibliografia | 26

2. Aprendizaje cooperativo: la técnica juego-concurso de De Vries, A. Serret, M. Marti,

R. Corbatón | 27

Introducción | 27

Marco conceptual | 29

Propuesta de aplicación | 34

Posibles limitaciones y dificultades | 37

Ejemplificación | 37

Conclusiones | 41

Referencias bibliográficas | 43

3. Aprendizaje integrado de contenidos y lengua extranjera, C. Salvador, O. Chiva,

M. ${ }^{\mathrm{N}}$ N. Ruiz $\mid 45$

Introducción $\mid 45$

Marco conceptual | 47

Propuesta de aplicación | 54

Posibles limitaciones y dificultades | 60

Ejemplificación | 61

Conclusiones | 63

Referencias bibliográficas | 64

4. Aprendizaje-servicio, L. Zorrilla, C. Capella, J. Gil | 67

Introducción | 67 


\title{
Aprendizaje integrado de contenidos y lengua extranjera
}

\section{Educación física y lengua inglesa}

\author{
Celina Salvador García, Óscar Chiva Bartoll, M. ${ }^{a}$ Noelia Ruiz Madrid
}

\section{Introducción}

El presente capitulo muestra una propuesta de innovación metodológica a través del aprendizaje integrado de contenidos y lengua extranjera (AICLE). En particular, se toma como ejemplo el caso de la educación física (en adelante, EF) y el inglés, mostrando los pasos seguidos a partir de una experiencia práctica llevada a cabo en quinto curso de primaria. Los rasgos genéricos que la constituyen, sin embargo, podrian ser extrapolados perfectamente a cualquier otra etapa del sistema educativo $u$ otras materias del currículo. La simbiosis generada por la unión entre EF y el aprendizaje de una lengua queda patente a lo largo de este capitulo, y es que las caracteristicas de una y otra encajan perfectamente y crean un escenario en el que el alumnado puede, además, desarrollar múltiples competencias, asi como su pensamiento critico.

La globalización y los avances en las nuevas tecnologias permiten que hoy en dia la comunicación entre dos personas que se encuentren en cualquier lugar del planeta sea factible e incluso sencilla. Sin embargo, aunque 


\section{APRENDIZAJE DE UN IDIOMA EXTRANJERO A TRAVÉS DE LA EDUCACIÓN FÍSICA: UNA REVISIÓN SISTEMÁTICA}

\author{
APRENDER UMA LÍNGUA ESTRANGEIRA ATRAVÉS DA EDUCAÇÃO FÍSICA: \\ UMA REVISÃO SISTEMÁTICA
}

\author{
LEARNING A FOREIGN LANGUAGE THROUGH PHYSICAL EDUCATION: A \\ LEARNING A FOREIGN
SYSTEMATIC REVIEW
}

Celina Salvador-García *, Oscar Chiva-Bartoll *, Emanuele Isidori ** 


\section{INTRODUCCIÓN}

La comunidad educativa apuesta cada vez más por integrar el aprendizaje lingüístico con el de contenidos específicos de cualquier materia curricular (FINARDI; LEÃO, 2016; LASAGABASTER; SIERRA, 2010; TILIO, 2014). Existen múltiples opciones metodológicas por las que se puede optar: Content and Language Integrated Learning (CLIL), Content Based Instruction (CBI), programas bilingües, lengua $X$ como Medio de Instrucción, game-based projects, programas de inmersión, etc. (DALTON-PUFFER; SMIT, 2007). Cada método implica unas particularidades, pero todos coinciden en promover simultáneamente el aprendizaje lingüístico y el de otro contenido específico. La lengua objeto de aprendizaje puede variar entre lengua materna, segunda lengua o lengua extranjera, cada una con sus peculiaridades de enseñanza (MANGA, 2008; TRUJILLO, 2007).

El uso de contenidos diversos para fomentar el aprendizaje lingüístico ha sido revisado, por ejemplo, por Lailiyah (2016) o Williams (2015) en relación a las metodologías CLIL y EMI respectivamente. Tradicionalmente la Educación Física (EF) ha sido un campo concurrido para integrar este tipo de aprendizaje lingüístico. En el contexto de la actividad física, las relaciones entre el alumnado y el docente son muy diferentes a las que se suceden en otras áreas del currículo (RAMOS; RUIZ, 2011). Además, el hecho de desarrollarse fuera del aula ofrece carices sociales y vivenciales únicos. Del mismo modo, el estrecho vínculo que une estas prácticas con el movimiento, la acción y el juego, convierten a la EF en un escenario extraordinario (LAVEGA, 2007).

Dada la eclosión de aplicaciones e investigación dedicada a este ámbito es más que necesario un trabajo de revisión sistemática que, siguiendo las indicaciones de Gomes y Caminha (2014), capte los elementos y cuestiones constitutivas de este fenómeno: ¿Qué ocurre al ensamblar ejercicio físico y lengua? ¿Cómo se han llevado a cabo prácticas en este sentido? ¿Dónde han sido desarrolladas? Así, con la intención de promover esta práctica educativa y acercarla a docentes e investigadores, esta revisión tiene como objetivo presentar un análisis del estado de la cuestión sobre la EF como marco para el aprendizaje de una lengua extranjera en la educación formal.

\section{MÉTODO}

\subsection{Estrategia de búsqueda}

La extracción de datos, el análisis y la redacción del presente texto ha sido desarrollada por un equipo experimentado de tres investigadores, cuya línea de estudio se halla en el ámbito de la EF bilingüe, contando con expertos tanto en el área de EF como en el aprendizaje lingüístico.

Para llevar a cabo este estudio de manera sistemática y rigurosa se han seguido los pasos propuestos por Gomes y Caminha (2014). Una vez identificada la necesidad de efectuar la presente revisión bibliográfica, se optó por llevar a cabo una búsqueda en dos de las bases de datos de mayor relevancia acreditada en el campo de las ciencias sociales en general y el educativo, en particular: ISI Web of Knowledge de Social Sciences-Thomson Reuters y ScopusElsevier. Dicha búsqueda se desarrolló entre los meses de junio y octubre de 2016. Se tomaron 
aquellas publicaciones que relacionaban la EF y el aprendizaje de una lengua extranjera. Para ello se desarrolló de manera sistemática una búsqueda que combinara términos de los dos campos sobre los que se conforma el ámbito de estudio: la EF y el aprendizaje de lenguas. Para el primer conjunto se utilizaron los términos physical education, physical activity, play y physical exercise; mientras que para el segundo se optó por language, bilingual, CLIL, foreign language, teaching, integrated y multilingual. Estos debían aparecer en el título, en las palabras clave o en el abstract, cuando la búsqueda se realizaba con ISI Web of Knowledge o pertenecer al tema del artículo en Scopus, puesto que cada base de datos determina diferentes posibilidades de búsqueda.

Muchos de los artículos obtenidos diferían considerablemente del tema de estudio, que vincula la EF con el aprendizaje lingüístico, por lo que se optó por concretar la exploración estipulando una serie de criterios de inclusión y exclusión descritos a continuación.

\subsection{Criterios de inclusión y exclusión}

Tres fueron los principales criterios de selección establecidos: relevancia, calidad y temática. La utilización de las dos de las bases de datos referidas reafirma el criterio de relevancia de la selección, ya que todos los textos han sido publicados en revistas de trascendencia internacional. El conjunto de publicaciones de la muestra ha sido revisado por pares, emplea cuestionarios validados y presenta objetivos claros así como un diseño adecuado, cuestiones que avalan su calidad.

Por otro lado, la temática debía hacer referencia a la utilización de la EF con el fin de aprender una lengua extranjera en un ambiente educativo. No se pretendía restringir la búsqueda a ninguna metodología particular de enseñanza de lenguas, por lo que se utilizaron diversos descriptores que pudieran englobar dicho objeto de estudio. Sin embargo, sí se desecharon aquellos artículos que entendían la actividad física como el uso de la metodología Total Physical Response (ASHER, 1966) o la audio-motor unit (KALIVODA; MORAIN; ELKINS, 1971) o la técnica del role-play. Pese a que estos métodos se vinculan al movimiento, los textos que se pretendía encontrar debían darle más relevancia al componente físico. Además, también se determinó que los estudiantes trabajaran las habilidades de expresión lingüística y no fueran meros receptores de lenguaje.

Finalmente, se descartaron aquellos textos que no estaban disponibles en inglés 0 español, por ser ininteligibles para el equipo investigador, por ejemplo uno que se halló en coreano.

\subsection{Criterios de análisis}

Los textos que superaron la criba se trataron en función de las siguientes variables de estudio: tipo de artículo (investigación, experiencia o propuesta), año de publicación, nivel educativo, descripción de la muestra y duración del estudio, instrumentos de recogida de información, localización geográfica, lengua meta, metodología docente aplicada, contenido específico de EF trabajado, aspectos adicionales trabajados y principales hallazgos de la investigación. 


\section{RESULTADOS}

Con la búsqueda inicial se accedió a un total 146 publicaciones, número que se redujo al aplicar los criterios de inclusión y exclusión enunciados. En concreto, 113 artículos no pasaron la selección por no cumplir todos los criterios de inclusión, dos fueron desestimados por utilizar las metodologías de Total Physical Response o la audio-motor unit, dos más fueron excluidos por considerar el uso del role-play como actividad física, y uno no fue seleccionado por estar escrito en coreano. Tras esta primera criba, el total de artículos se vio reducido a 34, entre los que figuraban artículos repetidos que, como muestra la tabla 1, se desecharon para conformar una muestra final de 18 publicaciones. El anexo 1 ofrece, a modo de cuadro, una síntesis de los principales resultados descritos a continuación.

Tabla 1 - Artículos encontrados en función de los descriptores

\begin{tabular}{llcc}
\hline Descriptores & Base de datos & $\begin{array}{c}\text { № de } \\
\text { resultados }\end{array}$ & $\begin{array}{c}\text { Textos } \\
\text { seleccionados }\end{array}$ \\
\hline Physical education, language, bilingual & ISI_Web_of_knowledge & 28 & 5 \\
& Scopus & 38 & 5 \\
\hline Physical education, CLIL, foreign language & ISI_Web_of_knowledge & 4 & 4 \\
& Scopus & 4 & 4 \\
\hline Physical activity, foreign language, language & ISI_Web_of_knowledge & 16 & 2 \\
learning & Scopus & 23 & 4 \\
\hline Play, foreign language, language teaching, & ISI_Web_of_knowledge & 6 & 1 \\
multilingual & Scopus & 5 & 0 \\
\hline \multirow{2}{*}{ Physical education, bilingual, teaching } & ISI_Web_of_knowledge & 11 & 4 \\
\hline \multirow{2}{*}{ Physical exercise, integrated, foreign language } & Scopus & 7 & 3 \\
\hline Artículos totales: & SSI_Web_of_knowledge & 3 & 1 \\
\hline Sin artículos repetidos: & & 1 & 1 \\
\hline
\end{tabular}

Fuente: elaboración propia

\subsection{Tipología de las publicaciones y fecha}

De entrada, conviene apuntar que todos los textos incluidos en la presente revisión son investigaciones o experiencias narradas, a excepción del de Ramos y Ruiz (2011), cuya aportación es meramente teórica en forma de guía práctica.

Los 17 documentos restantes pueden dividirse en función de su tipología. Por un lado, aparecen cuatro textos con la descripción de experiencias llevadas a cabo y, por otro, 13 que se circunscriben al ámbito de estudios o investigaciones.

Otro aspecto relevante es la vigencia y actualidad de los textos. Aún sin haber adoptado ningún criterio de inclusión relativo a su fecha de publicación, un único artículo fue publicado antes de 2010 (HARRIS; STOCKTON, 1973). Además, 12 de los 18 artículos han aparecido a lo largo de los últimos dos años (2015-2016), suponiendo el 66,66\% de la muestra. 


\subsection{Nivel educativo de aplicación}

El aprendizaje de una lengua extranjera mediante un contenido puede darse en diferentes etapas o niveles educativos (LLINARES; PASTRANA, 2013; MEHISTO, 2012). En este sentido, como refleja la figura 1, los artículos seleccionados se dirigen a una variedad amplia de etapas educativas. La mayoría, en concreto un $61,11 \%$ de la muestra, hace referencia a estudios en el nivel de educación primaria. Le siguen los niveles de educación infantil y secundaria con un $22,22 \%$ y un $16,66 \%$ respectivamente, relegando a la etapa universitaria a cifras más discretas, con solo una referencia (SHERIN; SHERINA, 2015).

Figura 1 - Número de estudios por etapa educativa

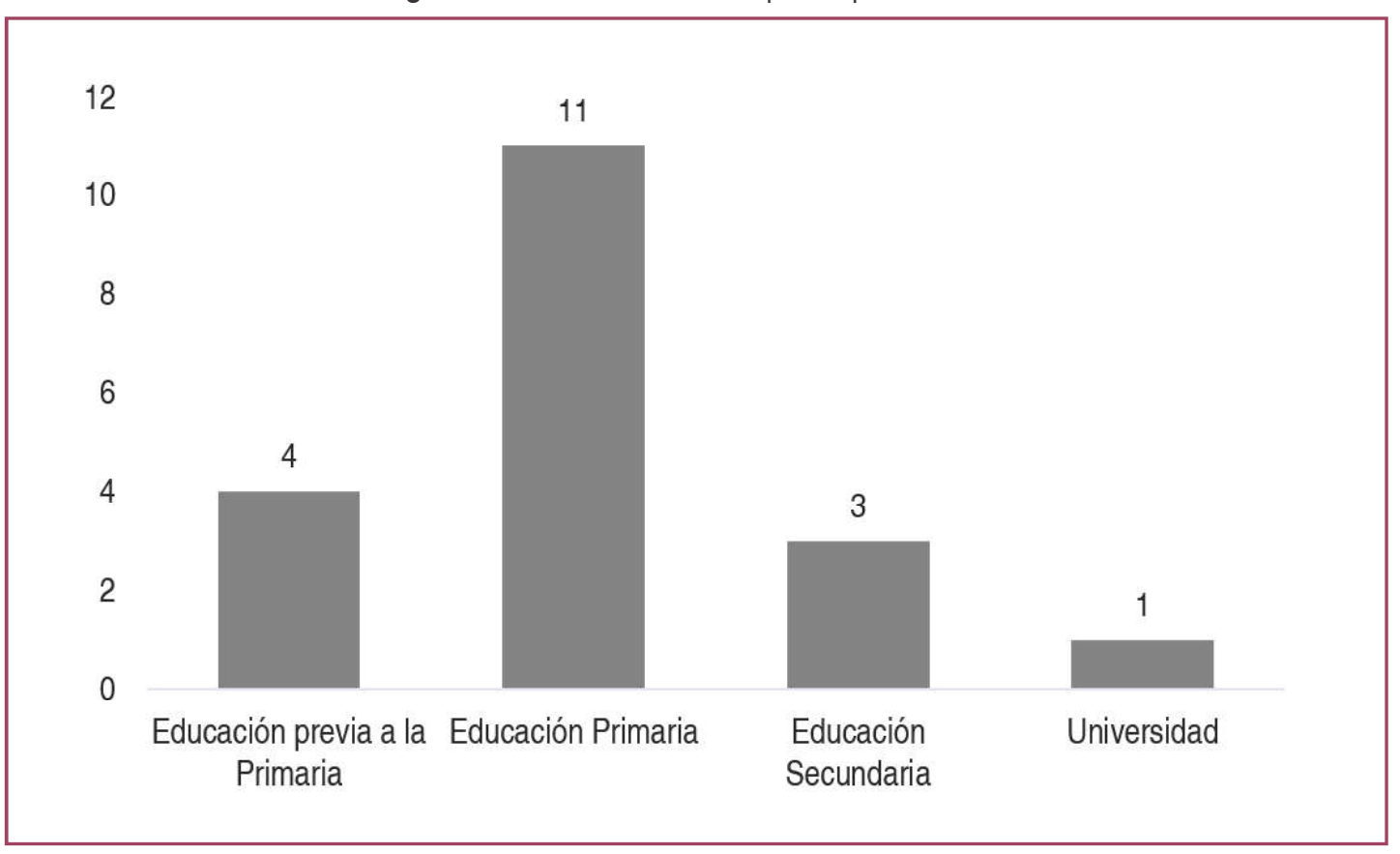

Fuente: elaboración propia

\subsection{Muestra y duración de las intervenciones}

Respecto a la muestra de los diferentes estudios, existe una gran variedad que fluctúa entre los 10 y los 23 estudiantes de Mulia (2015) o Cepero, García, López (2013) respectivamente, hasta los 328 de Baena y Granero (2015) o los 1.175 colegios de Coral, Lleixà, Ventura (2016). También existe gran heterogeneidad en la duración de las propuestas de intervención. Tres de los cuatro artículos que narran experiencias coinciden en la aplicación de una única unidad didáctica, que en todos los casos consta de seis sesiones; mientras que la restante (GRIVA; CHOSTELIDOU, 2015) describe un proyecto de 16 semanas. Sin embargo, en los artículos de investigación, la duración de las intervenciones difiere enormemente, moviéndose entre las cuatro semanas de la aplicación de Toumpaniari, et al. (2015) y Mavilidi et al. (2015), un curso escolar completo en los estudios de Coral y Lleixà (2014) o Cepero, García y López (2013), llegando incluso a los tres cursos académicos de Coral, Lleixà, y Ventura (2016). 


\subsection{Instrumentos de recogida de información}

Entre los artículos de investigación aparecen en igual medida estudios que emplean métodos cualitativos, cuantitativos y aproximaciones mixtas. Asimismo, tres estudios han optado por seguir el método de investigación-acción (CEPERO; GARCÍA; LÓPEZ, 2013; CORAL; LLEIXÀ, 2016; MULIA, 2015), mientras que en el estudio de Moore y Lorenzo (2015) no se ha podido identificar la metodología.

De la diversidad de procedimientos metodológicos seguidos emana una gran variedad de instrumentos, sintetizados en la tabla 2. De índole cuantitativa destacan los cuestionarios y los tests. Su uso se centra en indagar el tipo de vocabulario practicado, el logro alcanzado, la mejora de la destreza oral o el conjunto de habilidades lingüísiticas en general. Por otra parte, el rango de instrumentos cualitativos es considerablemente mayor. Entre estos se encuentran la observación externa, el portfolio del alumnado, las entrevistas y las observaciones a través de grabaciones; aunque el instrumento más empleado es el diario del profesor.

Tabla 2 - Aparición de instrumentos según carácter cuantitativo o cualitativo

\begin{tabular}{|c|c|c|}
\hline $\begin{array}{l}\text { Instrumentos de carácter } \\
\text { cualitativo }\end{array}$ & $\begin{array}{l}\text { Frecuencia } \\
\text { de uso }\end{array}$ & Estudios que los utilizan \\
\hline Observación externa & 3 & Coral; Lleixà (2014), Griva; Semoglou; Geladari (2010), Mulia (2015) \\
\hline Portfolio & 1 & Cepero; García; López (2013) \\
\hline Diario del docente & 6 & $\begin{array}{c}\text { Cepero; García; López (2013), Coral; Lleixà (2014), Coral;Lleixà } \\
\text { (2016), Griva; Semoglou; Geladari (2010); Griva; Semoglou, (2012), } \\
\text { Mulia (2015) }\end{array}$ \\
\hline Grabaciones & 3 & Coral; Lleixà (2014), Coral;Lleixà (2016), Mulia (2015) \\
\hline Entrevistas & 2 & Griva; Semoglou; Geladari (2010),Sherin; Sherina (2015) \\
\hline $\begin{array}{l}\text { Instrumentos de carácter } \\
\text { cuantitativo }\end{array}$ & $\begin{array}{l}\text { Frecuencia } \\
\text { de uso }\end{array}$ & Estudios que los utilizan \\
\hline Tests & 6 & $\begin{array}{l}\text { Coral; Lleixà; Ventura (2016); Griva; Semoglou; Geladari (2010); } \\
\text { Griva; Semoglou, (2012), Harris; Stockton (1973), Mavilidi et al., } \\
\text { (2015), Toumpaniari et al. (2015) }\end{array}$ \\
\hline Cuestionarios & 2 & Cepero; García; López (2013), Harris; Stockton (1973) \\
\hline
\end{tabular}

\subsection{Localización geográfica y lengua meta}

Por lo que respecta a la distribución geográfica de los artículos recopilados, resulta interesante observar que el 55,55\% de los mismos han sido escritos en España. En cuanto al resto, en Grecia se ubican 4 trabajos publicados, mientras que Indonesia, USA y Rusia únicamente aparecen en una ocasión. Del resto de países no se han encontrado estudios en las bases de datos analizadas. Por otra parte, destaca el inglés como lengua meta de la mayoría de los textos, siendo este el idioma estudiado en el $88,89 \%$ de las ocasiones.

\subsection{Metodología para la enseñanza de lengua}

El método pedagógico CLIL es el más empleado. En concreto, siete de los 18 textos seleccionados aluden a esta metodología coincidiendo que todos estos son desarrollados en 
España. Otro de los métodos empleados es el game based project (GRIVA; SEMOGLOU; GELADARI, 2010; GRIVA; SEMOGLOU, 2012). Por lo que respecta al resto de publicaciones, no explicitan una metodología en particular, simplemente exponen el aprendizaje de vocabulario bien mediante actividad física y gestos (MAVILIDI et al., 2015; MULIA, 2015; TOUMPANIARI et al., 2015), bien a través de actividades vinculadas con el moviento (GRIVA; CHOSTELIDOU, 2015) o bien mediante programas de EF bilingüe (ALONSO et al., 2015; BAENA; GRANERO, 2015; CEPERO; GARCÍA; LÓPEZ, 2013; HARRIS; STOCKTON, 1973; SHERIN; SHERINA, 2015).

\subsection{Contenido específico de Educación Física y elementos transversales trabajados}

Si bien todos los artículos coinciden en el hecho de incidir en el aprendizaje lingüístico a través de la actividad física, la forma en que esta cuestión se aborda difiere considerablemente. 12 de los artículos utilizan la asignatura de EF para trabajar aspectos lingüísticos. Por ello, al desarrollarse las propuestas o estudios en el marco de dicha asignatura, resulta necesario trabajar, también, contenidos propios de la misma. Los contenidos seleccionados pasan por la orientación (SALVADOR; CHIVA; FAZIO, 2016), los juegos tradicionales (ALONSO et al., 2015), el judo (CHIVA; ISIDORI; FAZIO, 2015), el kickball (HARRIS; STOCKTON, 1973) y los saltos (RAMOS; RUIZ, 2011). Además, dos de las propuestas plantean el desarrollo de sus programas durante todo un curso académico (CEPERO; GARCÍA; LÓPEZ, 2013; CORAL; LLEIXÀ, 2014), o incluso durante más tiempo (CORAL; LLEIXÀ; VENTURA, 2016), por lo que en estos casos se ha trabajado más de un contenido.

Por otro lado, existen estudios realizados en otras asignaturas que emplean contenidos próximos a la EF. Por ejemplo, Toumpaniari et al. (2015) y Mavilidi et al., (2015) apuestan por sustentar sus propuestas en el uso de gestos y movimientos; mientras que Mulia (2015) se decanta por utilizar la dramatización. En sus textos, Griva, Semoglou y Geladari (2010), Griva y Semoglou (2012) y Griva y Chostelidou (2015) abogaron por trasladar las clases de lengua extranjera al gimnasio del centro educativo, aunque allí no trabajaran contenidos directamente relacionados con la EF.

Destaca también que varios de los trabajos no optan por el simple aprendizaje ligado a la lengua y la $E F$, sino que además apuestan por desarrollar temas transversales $u$ otros contenidos concretos. En este sentido sobresalen el desarrollo del pensamiento crítico trabajado por Chiva, Isidori y Fazio (2015), las competencias clave en general (CORAL; LLEIXÀ; VENTURA, 2016), o de manera particular la digital (CEPERO; GARCÍA; LÓPEZ, 2013) y la cultural (ALONSO et al., 2015; SHERIN; SHERINA, 2015). Por su parte, Griva y Semoglou (2012) abogan por el fomento de la creatividad.

\subsection{Principales hallazgos}

Haciéndose eco de los principales resultados y conclusiones a los que han llegado los artículos revisados, uno de los puntos principales recae en la idoneidad de la integración entre el aprendizaje de una lengua y la EF (ALONSO et al., 2015; CORAL; LLEIXÀ, 2016; GRIVA; SEMOGLOU; GELADARI, 2010; MAVILDI et al., 2015; RAMOS; RUIZ, 2011; SALVADOR; CHIVA; FAZIO, 2016; TOUMPANIARI et al. 2015). 
Esta idoneidad propiciada por la combinación de actividad física y aprendizaje lingüístico se explicita en trabajos como los de Chiva, Isidori y Fazio (2015), Griva, Semoglou y Geladari (2010) y Salvador, Chiva y Fazio (2016), quienes defienden el favorecimiento especial de las habilidades comunicativas. Del mismo modo, encontramos trabajos que enfatizan tanto el desarrollo de la comunicación oral (CORAL; LLEIXÀ, 2016), como la comprensión (CEPERO; GARCÍA; LÓPEZ, 2013).

Además, para asegurar un óptimo desarrollo de las propuestas, son diversos los autores que subrayan la relevancia de llevar a cabo una aplicación meticulosa y reflexiva (RAMOS; RUIZ, 2011; SALVADOR; CHIVA; FAZIO, 2016). En este sentido, trabajos como los de Coral y Lleixà (2014), Moore y Lorenzo (2015) o Ramos y Ruiz (2011) exponen taxonomías y/o consideraciones para facilitar una óptima integración entre lengua y actividad física (MULIA, 2015).

Otro aspecto tratado en muchos de los textos alude a la motivación generada por las propuestas llevadas a cabo, tal y como se desprende de los estudios de Alonso et al. (2015), Cepero, García y López (2013), Chiva, Isidori y Fazio (2015), Griva y Semoglou (2012), y Griva, Semoglou y Geladari (2010). En esta línea merecen especial mención el trabajo de Baena y Granero (2015) que se focaliza en la validación de un instrumento de evaluación de las dimensiones diversión/aburrimiento, y el de Coral y Lleixà (2014), que trata el equilibrio entre motivación y efectividad de las tareas.

Por su parte, Toumpaniari et al. (2015) y Mulia (2015) defienden la gran oportunidad generada para potenciar el desarrollo físico, social y cognitivo del estudiantado, así como la promoción de hábitos saludables y su competencia profesional multicultural (SHERIN; SHERINA, 2015)

Por último, también es reseñable el beneficio que implica el uso del movimiento y los gestos para el aprendizaje lingüístico como justificación de algunas propuestas (Mulia, 2015; Ramos; Ruiz, 2011); fundamentalmente por la posibilidad de observar el movimiento del resto de alumnado (MAVILIDI et al., 2015).

\section{DISCUSIÓN Y CONCLUSIONES}

La presente revisión sistemática demuestra la creciente tendencia que está viviendo el uso de la EF como contexto en el que desarrollar el aprendizaje de una lengua extranjera. A partir del texto aquí presentado, la comunidad científica puede encontrar una aproximación al estado de la cuestión sustentado por publicaciones con acreditada validez, vigencia y relevancia.

En este marco, diversas de las más notorias innovaciones metodológicas emplean el aprendizaje lingüístico a través de un contenido. Y, como se ha dicho, diversos autores subrayan la posibilidad de desarrollar dicho aprendizaje lingüístico haciendo uso de la actividad física (CHIVA; ISIDORI; FAZIO, 2015; CORAL; LLEIXÀ, 2016; GARCÍA; GARCÍA; YUSTE, 2012; RAMOS; RUIZ, 2011). Este hecho gana vigencia en tanto que prácticamente todos los textos han sido divulgados en los últimos años; hecho indicativo de que estamos viviendo un momento de emergencia importante.

Resulta interesante advertir la divergencia existente en las características de las diferentes investigaciones: objetivos, metodología, tipos de intervención, etc. Pese a converger 
todas en una misma temática (actividad física y aprendizaje lingüístico), existe un gran abanico de enfoques y aproximaciones. Diferentes focos de atención requieren diferentes propiedades para su estudio. Entre la gran variedad de objetivos de investigación destacan cuestiones como: determinación de estrategias de comunicación, identificación de dilemas que suceden, dificultades percibidas por los docentes, efectos de esta metodología de aprendizaje, etc., abriendo nuevos caminos a futuras líneas de investigación.

Más de la mitad de los textos que conforman la muestra han sido realizados en España. Esta cuestión podría indicar la gran importancia que ha adquirido el aprendizaje de lenguas en dicho país (CEPERO; GARCÍA; LÓPEZ, 2013; GUILLAMÓN; RENAU, 2015), así como la apuesta por las innovaciones metodológicas en este campo. Por otra parte, que el inglés sea la lengua estudiada en la mayoría de ocasiones no hace más que refrendar la relevancia que este idioma ha adquirido en los últimos años (LEWIS; SIMMONS; FENNING, 2016).

Por lo que se refiere al tipo de metodología utilizado, CLIL es aquella que más se repite. Conviene comentar en este sentido que todos los textos que se sirven de dicho método son aplicados en España. De este modo, parece evidente que en dicho país el método CLIL se ha convertido en la vía más recurrente en el campo del aprendizaje de lenguas (LLINARES; PASTRANA, 2013; GUILLAMÓN; RENAU, 2015). En particular, puede señalarse que las publicaciones que se basan en esta metodología coinciden en proponer el trabajo de contenidos íntimamente ligados a la cultura como, por ejemplo, deportes típicos (CHIVA; ISIDORI; FAZIO, 2015; SALVADOR; CHIVA; FAZIO, 2016) o juegos tradicionales (ALONSO et al., 2015). Este hecho es razonable dado que uno de los pilares básicos sobre los que se cimienta la metodología CLIL es la cultura (COYLE; HOOD; MARSH, 2010), puesto que esta resulta de gran relevancia en lo que al aprendizaje lingüístico se refiere, ya que lengua y cultura son elementos indisociables (ABBASPOUR; RAJAEE; ZARE, 2012; VILLANUEVA, 2002).

Entre las propuestas que no se desarrollan de manera reglada a través de la materia de EF, destaca que tres de los estudios utilizan la expresión corporal (MAVILIDI et al., 2015; MULIA, 2015; TOUMPANIARI et al., 2015). Este hecho resulta coherente puesto que la expresión corporal y el lenguaje no verbal no solo se vinculan con la cultura (FLEET, 2006), sino que forman parte fundamental del acto comunicativo (CANALE; SWAIN, 1980; CESTERO, 2014) y, por lo tanto, son elementos clave en el desarrollo de la competencia comunicativa. Por este motivo, no es extraño que las propuestas de Alonso et al. (2015) y Sherin y Sherina, (2015) se decanten por enfatizar la cultura, que además se ve íntimamente vinculada con la EF (FIGUERAS et al., 2016; LLEIXÀ, 2007), como aspecto adicional a trabajar durante el desarrollo de su propuesta.

Por otra parte, gracias a las experiencias llevadas a cabo y a las reflexiones sobre las mismas, así como a las taxonomías y/o apreciaciones expresadas por diversos autores (CORAL; LLEIXÀ, 2014; MOORE; LORENZO, 2015; RAMOS; RUIZ, 2011), el uso de la actividad física para aprender una lengua está más cerca que nunca de la realidad escolar, puesto que todos los escritos convergen en perseguir una mejora en la calidad y facilitación de la enseñanza lingüística. No en vano la lengua y la comunicación no pueden desvincularse en ningún momento del lenguaje no verbal y del movimiento (FLEET, 2006). En este sentido, lo expuesto en las publicaciones seleccionadas parece seguir la línea marcada por Castro, Piéron y González (2006), Granero y Baena (2014) y Moreno y Cervelló (2003), quienes exponen que la EF genera una alta motivación en el alumnado. Así, parece que la apreciación y el interés 
generados por la actividad física y el deporte se ven transferidos también hacia el aprendizaje lingüístico cuando ambos elementos se vinculan.

Según autores como Renzi (2009) o Vicente (2016), la EF, la actividad física y el deporte generan un contexto ideal en el que poder facilitar un crecimiento global del estudiantado. Siguiendo estas ideas y confrontándolas con los artículos analizados, parece que el hecho de vincular el aprendizaje lingüístico no hace más que incrementar estas posibilidades de mejora. El movimiento se torna en una cuestión clave para favorecer el aprendizaje (GRIVA; CHOSTELIDOU, 2015; RAMOS; RUIZ, 2011). De manera que lo expuesto por Mavilidi et al. (2015) está en consonancia con el aprendizaje constructivista; los estudiantes aprenden mediante su propio movimiento, pero también aprenden gracias al de los otros, que pueden ver y vincular con el lenguaje utilizado; permitiendo que estos nuevos aprendizajes sean realmente significativos para ellos.

Finalmente, la posibilidad propuesta en varios de los artículos analizados, relativa a desarrollar otros aprendizajes más allá de los lingüísticos o propios de EF (CEPERO; GARCÍA; LÓPEZ, 2013; CHIVA; ISIDORI; FAZIO, 2015), acapara gran interés. Tres de los estudios analizados se inclinan hacia el desarrollo de las competencias como contenido adicional de sus propuestas, en concordancia con lo expuesto por Figueras et al. (2016), que llevaron a cabo una revisión crítica de diversos trabajos en los que se demostraba la potencialidad del área de EF para contribuir y promover el desarrollo de diferentes competencias.

En definitiva, aunque la validez, relevancia y vigencia de los artículos revisados es fiable, la cantidad de estudios publicados hasta la fecha es todavía limitada, por lo que cabe interpretar los resultados expuestos con cautela. En todo caso, no deja de ser interesante la confrontación de los hallazgos de diversos investigadores, puesto que del fruto de su trabajo se han podido extraer conclusiones sugerentes y de gran interés para la comunidad académica.

\section{REFERENCIAS}

ABBASPOUR, Ehsan; RAJAEE, Mahdi; ZARE, Javad. How to integrate culture in second language education. Journal of Education and Practice, v.3, n.10, p.20-24, 2012.

ALONSO, Jesús; Cachón, Javier; CASTRO, Rosario; ZAGALAZ, Maria Luisa. Propuesta didáctica bilingüe para educación física en educación primaria. Juegos populares y tradicionales ingleses. Retos. Nuevas tendencias en educación física, deporte y recreación, n.28, p. 116121, 2ํㅗ. sem. 2015.

ASHER, James. The Learning Strategy of the Total Physical Response: a Review. The modern language journal, v.50, n. 10, p.79-84, feb. 1966.

BAENA, Antonio; GRANERO, Antonio. Versión española del Sport Satisfaction Instrument (SSI) adaptado al aprendizaje de la Educación Física bilingüe en Inglés. Porta Linguarum: revista internacional de didáctica de las lenguas extranjeras, n.24, p.63-76, jun. 2015.

CANALE, Michael; SWAIN, Merril. Theoretical basis of communicative approaches to second language teaching. Applied linguistics, v.1, n.1, p.1-47, 1980. 
CASTRO, Maria José; PIÉRON, Maurice; GONZÁLEZ, Miguel. Actitudes y motivación en educación física escolar, Retos. Nuevas tendencias en educación física, deporte y recreación, n.10, p.5-22, 2006.

CEPERO, Mar; GARCÍA, Ana; LÓPEZ, Manuel. Diseño de un Programa de intervención bilingüe para el área de Educación Física basado en la competencia digital. Porta Linguarum: revista internacional de didáctica de las lenguas extranjeras, n.19, p.257-273, 2013.

CESTERO, Ana. Comunicación no verbal y comunicación eficaz. Estudios de Lingüística de la Universidad de Alicante, n.28, p.125-150, 2014.

CHIVA, Òscar; ISIDORI, Emanuele; FAZIO, Alessandra. Educación Física bilingüe y pedagogía crítica: una aplicación basada en el Judo. Retos. Nuevas tendencias en educación física, deporte y recreación, n.28, p. 110-115, 2º sem. 2015.

CORAL, Josep; LLEIXÀ, Teresa. La enseñanza de la Educación Física mediante el enfoque educativo Clil: la resolución de los dilemas profesionales surgidos durante un proceso de investigación-acción. Movimento, v.20, n.4, p.1447-1472, 2014.

CORAL, Josep; LLEIXÀ, Teresa. Physical education in content and language integrated learning: successful interaction between physical education and English as a foreign language. International journal of bilingual education and bilingualism, v.19, n.1, p.108-126, 2016.

CORAL, Josep; LLEIXÀ, Teresa; VENTURA, Carles. Foreign language competence and content and language integrated learning in multilingual schools in Catalonia: an ex post facto study analysing the results of state key competences testing. International journal of bilingual education and bilingualism, p.1-12, feb. 2016.

COYLE, Do; HOOD, Philip; MARSH, David. CLIL Content and Language Integrated Learning. Cambridge: Cambridge University, 2010.

DALTON-PUFFER, Christiane; SMIT, Ute. Introduction. In: DALTON-PUFFER, Christiane; SMIT, Ute. Empirical Perspectives on CLIL Classroom. Frankfurt: Peter Lang, 2007. p.7-23.

FIGUERAS, Sara; CAPLLONCH, Marta; BLÁZQUEZ, Domingo; MONZONÍS, Núria. Competencias básicas y educación física: estudios e investigaciones. Apunts. Educación Física y Deportes, n.123, p.34-43, ene./mar. 2016.

FINARDI, Kyria; LEÃO, Roberta. English in Brazil: Insights from the Analysis of Language Policies, Internationalizaton Programs and the Clil Approach. Education and linguistics research, v.2, n.1, p. 54-68, 2016.

FLEET, Marilyn. The role of culture in second or foreign language teaching: Moving beyond the classroom experience. 2006. Disponible en: <http://files.eric.ed.gov/fulltext/ED491716.pdf >. Acceso en: 3 oct. 2016.

GARCÍA, José; GARCÍA, Juan; YUSTE, Juan. Educación Física en inglés: una propuesta para trabajar la higiene postural en Educación Primaria. Retos. Nuevas tendencias en educación física, deporte y recreación, n.22, p. 70-75, 2ํㅗ sem. 2012.

GOMES, Isabelle; CAMINHA, Iraquitan. Guia para estudos de revisão sistemática: uma opção metodológica para as Ciências do Movimento Humano. Movimento, v.20, n.1, p.395-411, ene./ mar. 2014. 
GRANERO, Antonio; BAENA, Antonio. Predicción de la motivación autodeterminada según las orientaciones de meta y el clima motivacional en Educación Física. Retos. Nuevas tendencias en educación física, deporte y recreación, n.25, p. 23-27, 1ํㅗ sem. 2014.

GRIVA, Eleni; SEMOGLOU, Klio. Estimating the Effectiveness and Feasibility of a Game-based Project for Early Foreign Language Learning. English Language Teaching, v.3, n.9, p.33-44, sep. 2012.

GRIVA, Eleni; SEMOGLOU, Klio; GELADARI, Athina. Early foreign language learning: Implementation of a project in a game-based contex. Procedia: Social and Behavioral Sciences, v.2, n.2, p.3700-3705, 2010.

GUILLAMÓN, Francisco; RENAU, Maria Luisa. A critical vision of the CLIL approach in secondary education: a study in de Valencian Community in Spain. Latin American Journal of Content and Language integrated learning, v.8, n.1, p.1-12, 2015.

HARRIS, Mary; STOCKTON, Santiago. A comparison of bilingual and monolingual physical education instruction with elementary school students. The journal of educational research, v.62, n.2, p.53-56, oct. 1973.

KALIVODA, Theodore; MORAIN, Genelle; ELKINS, Robert. The Audio-Motor Unit: a Listening Comprehension Strategy That Works. Foreign Language Annals, v.4, n.4, p.392-400, may 1971.

LAILIYAH, Malikhatul. Content and language integrated learning in teaching English as second language: a systematic review of empirically based articles. EnJourMe: Journal of Culture, Language, and Teaching of English, v.1, n.1, jul. 2016. Disponível em: <http://jurnal.unmer. ac.id/index.php/enjourme/article/view/278>. Acceso en: 3 oct. 2016.

LASAGABASTER, David; SIERRA, Juean. Immersion and CLIL in English: more differences than similarities. ELT Journal, v.64, n.4, p.367-375, oct. 2010.

LAVEGA, Pere. El juego motor y la pedagogía de las conductas motrices. Revista conexões, v.5, n.1, p.27-41, 2007.

LEWIS, M. Paul; SIMMONS, Gary; FENNING, Charles (Eds.). Ethnologue: Languages of the world. 19. ed. Dallas: SIL International, 2016.

LLEIXÀ, Teresa. Educación física y competencias básicas. Contribución del área a la adquisición de las competencias básicas del currículo. Revista Tándem, v.7, n.23, p.31-37, 2007.

LLINARES, Ana; PASTRANA, Amanda. CLIL students' communicative functions across activities and educational levels. Journal of pragmatics, v.59, p.81-92, dic. 2013.

MANGA, André. Lengua Segunda (L2) Lengua extranjera (LE): Factores e incidencias de enseñanza/aprendizaje. Tonos Digital, n.16, 2008. Disponible en: <http://www.tonosdigital.com/ ojs/index.php/tonos/article/view/249/190>. Acceso en: 3 oct. 2016.

MAVILDI, Myrto; OKELY, Anthony; CHANDLER, Paul; CLIFF, Dylan; PAAS, Fred. Effects of integrated physical exercises and gestures on preschool children's foreign language vocabulary learning. Educational Psychology Review, v.7, n.3, p.413-426, 2015.

MEHISTO, Peter. Excellence in bilingual education: a guide for school principals. Cambridge: 
MOORE, Pat; LORENZO, Francisco. Task-based learning and content and language integrated learning materials design: process and product. The Language Learning Journal, v.43, n.3, p.334-357, 2015.

MORENO, Juan; CERVELLÓ, Eduardo. Pensamiento del alumnado hacia la educación física: su relación con la práctica deportiva y el carácter del educador. Enseñanza \& Teaching: Revista interuniversitaria de didáctica, n.21, p.345-362, 2003.

MULIA, Dewi. The use of first language scaffolding to teach English as a foreign language to preschool children during dramatic play in West Sumatera, Indonesia. SHS Web of Conferences, v.16, p.1-10, 2015.

RAMOS Francisco, RUIZ, Jesús. La Educación Física en centros bilingües de primaria inglésespañol: de las singularidades propias del área a la elaboración de propuestas didácticas con AIBLE. RESLA, n.24, p.153-170, 2011.

RENZI, Gladys. Educación Física y su contribución al desarrollo integral de los niños en la primera infancia. Revista iberoamericana de educación, v.7, n.50, p.1-14, nov. 2009.

SALVADOR, Celina; CHIVA, Òscar, FAZIO, Alessandra. Características del Aprendizaje Integrado de Contenidos de Educación Física y Lengua Extranjera. Retos. Nuevas tendencias en educación física, deporte y recreación, n.29, p. 120-125, 1ํ sem. 2014.

SHERIN, V.; SHERINA, A. Improvement of university educational activity in terms of formation of bilingual environment in sphere of physical culture and sport. Teorija i praktika fiziceskoj kultury, v.7, 2015. Disponible em:<http://www.teoriya.ru/en/node/3854>. Acceso em: 3 oct. 2016.

TILIO, Rogério. Língua Estrangeira Moderna na Escola Pública: possibilidades e desafios. Educação e realidade, v. 39, n.3, p. 925-944, jul./set. 2014.

TOUMPANIARI, Konstantina; LOYENS, Sofie; MAVILDI, Myrto; PAAS, Fred. Preschool children's foreign language vocabulary learning by embodying words through physical activity and gesturing. Education psychological review, v.27, n.3, p.445-456, sep. 2015.

TRUJILLO, Fernando. Enseñar nuevas lenguas en la escuela: L1, L2, LE...NL. Revista de Educación, n.343, p.71-91, may/ago. 2007.

VICENTE, Miguel. Bases para una didáctica crítica de la Educación Física. Apunts. Educació Física y deportes, n.123, p.76-85, ene./mar. 2016.

VILLANUEVA, Marisa. Los estilos de aprendizaje ante los retos de la Europa multilíngue. In: MIQUEL, Lourdes; SANS, Neus. Didáctica del español como lengua extranjera. Madrid: Actilibre, 2002. p. 243-263.

WILLIAMS, Dylan. A Systematic Review of English Medium Instruction (EMI) and implications for the South Korean education context. English Language Teaching World Online, abr. 2015. Disponible en: <https://blog.nus.edu.sg/eltwo/files/2015/04/EMI-in-South-Korea editforpdf-1gmsyy5. pdf>. Acceso en: 3 oct. 2016.

\section{Apoyo:}

Seminario Permanente de Intercambio de Experiencias de Docencia en Inglés (SPIEDA). Referencia: 2523/12. Centro: Facultat Ciències Humanes i Socials. Departament: Estudis Anglesos. 


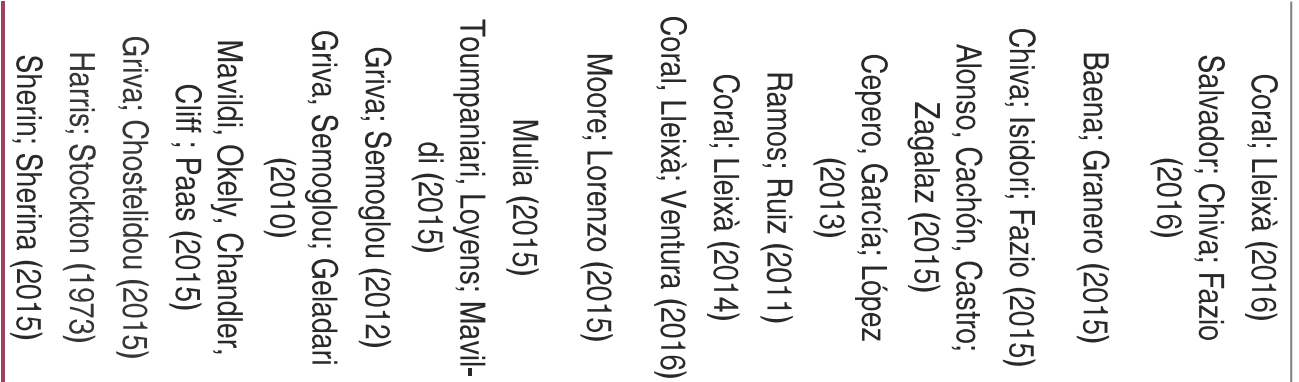

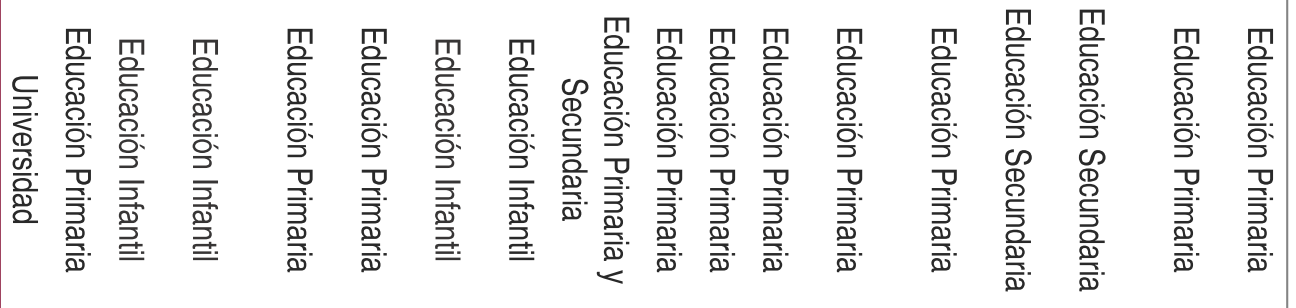

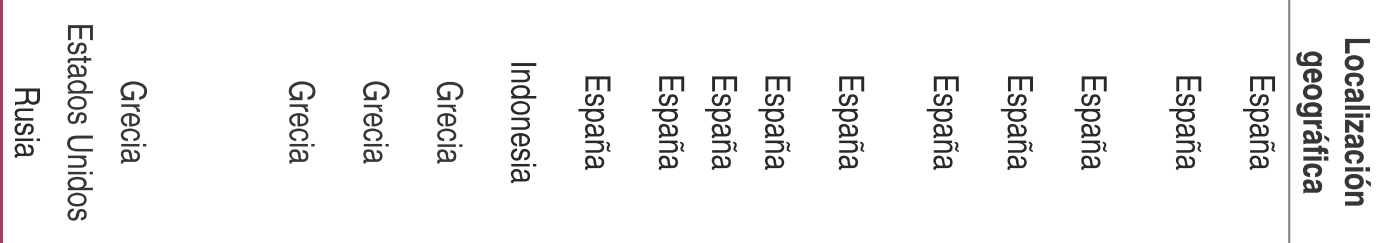

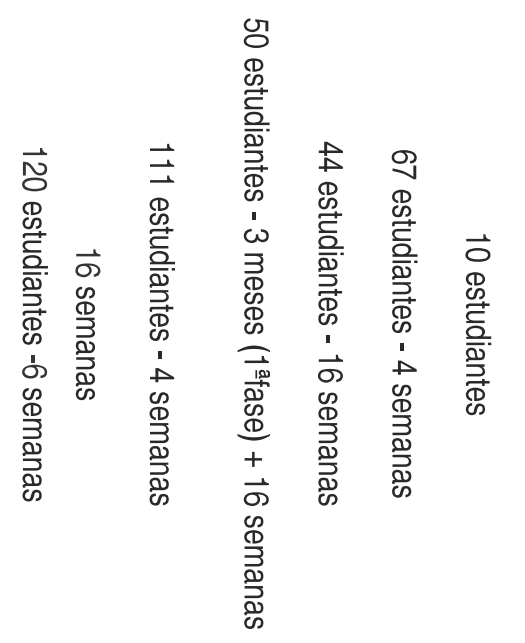

$\overrightarrow{\vec{ज}}$<smiles>[CH]C1CCC1</smiles>

ind

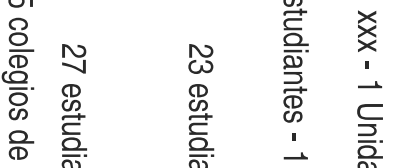

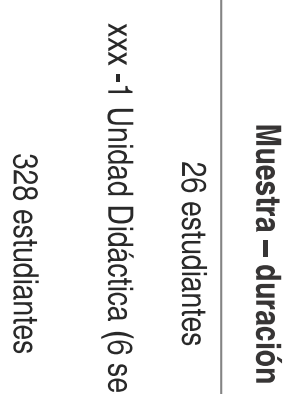

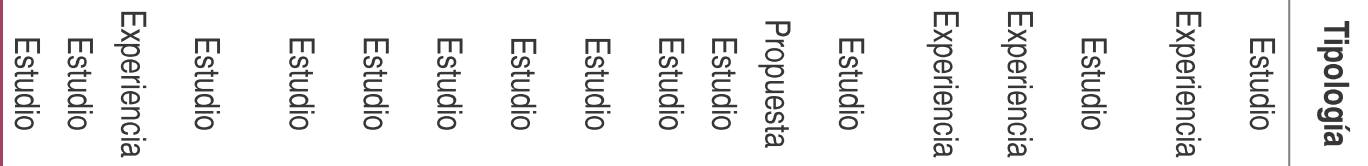

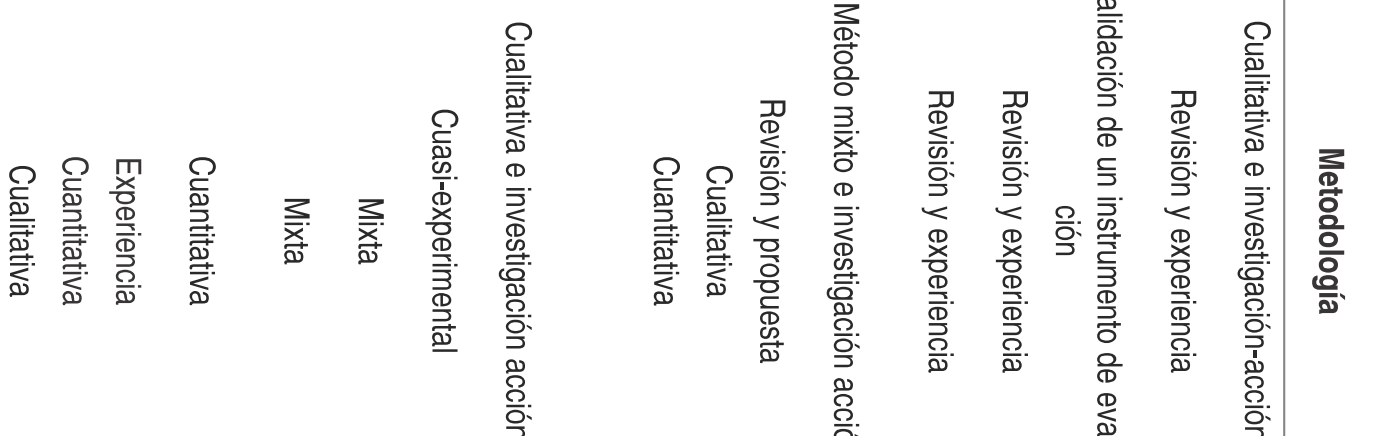




\title{
CLIL in teaching physical education: views of the teachers in the Spanish context
}

\author{
SALVADOR-GARCIA CELINA ${ }^{1}$; CHIVA-BARTOLL OSCAR ${ }^{2}$ \\ ${ }^{1,2}$ Department of Education, Universitat Jaume I, SPAIN
}

Published online: September 30, 2017

(Accepted for publication August 29, 2017

DOI:10.7752/jpes.2017.03174

\begin{abstract}
:
Content and Language Integrated Learning (CLIL) provides students with enhanced opportunities to acquire competence in additional languages while learning different subjects. Due to its features one of the target subjects for the application of CLIL is Physical Education (PE). In this subject its application is widespread in countries such as Italy, Greece or Spain among others. The particular interest of this research focuses on the Spanish context. Spanish education is particularly sensitive to European initiatives regarding language policies. The aim of the study is to know, from the PE teachers' viewpoint, whether the essence of PE is subjected to so substantial modifications due to the introduction of CLIL that jeopardize its idiosyncrasy. We opt for a pure qualitative research method based on semi-structured interviews. Particularly, an a priori theoretical orientation that influenced the development of our research questions, interview protocols, and subsequent data analysis was used. The results found were organized in five categories of analysis: Curricular effects, Language insertion, Teaching method, Motivation and Workload. Furthermore, each category was broken into several subcategories. The application of CLIL within the Secondary education in Spain does not endanger the essence of the PE according to the interviewees' perception. However, the study may conclude that there is a need to improve the amount of workload and the acknowledgement of teachers involved, since it could result in an increase of burnout and demotivation.

Key words: CLIL, physical education, teachers, qualitative research, bilingual education.
\end{abstract}

\section{Introduction}

The term Content and Language Integrated Learning (CLIL) was launched in Europe as a result of the growing interest in an active pursuit of improved foreign language teaching methods. This methodology is much welcomed at a time when the countries of the European Union are increasingly becoming integrated and, indeed, as nations around the world become globally connected. Since it was launched in the 1990s, the European Commission and the Council of Europe have funded many initiatives in support of CLIL because it responded to a need in Europe for enhancing second-language education and bilingualism (Marsh, 2002). In the Physical Education (PE) field it is easy to encounter examples of its application in countries such as Italy, Greece or Spain among others (Salvador et al., 2017) and even similar studies which use PE to teach a second language have been developed in the USA (Lieberman et al., 2010; Nguyen \& Watanabe, 2013; Santillan, Jacobs \& Wright; 2015; Sato \& Hodge; 2016; Sato, Walton \& Kim, 2017), even though these do not use CLIL methodology. Specifically, the focus setting of the current paper is the Spanish context, although some of the results presented may be interesting for the rest of countries using CLIL and/or those interested in using it or a similar method in the future.

There is little question that providing students with enhanced opportunities in school to acquire competence in additional languages will better prepare them for globalization. There are a variety of definitions and interpretations of CLIL (Cenoz et al., 2014; Mehisto et al., 2008), but Coyle et al., (2010: 1) present a succinct definition that refers to its specific features: 'Content and Language Integrated Learning (CLIL) is a dual-focused educational approach in which an additional language is used for the learning and teaching of both content and language'. According to this definition, CLIL can include a wide range of educational practices provided that these practices are conducted through the medium of an additional language. Particularly, it is important to recognize that in the European context, CLIL has mainly attracted practitioners of a number of specific subjects in the field of English as a foreign language.

\section{How does CLIL affect the subject matter?}

CLIL has been gaining importance in recent years due to its introduction in many educational settings to enhance language learning. However, it is necessary to know whether the essence of each specific area is subjected to so substantial modifications that jeopardize its idiosyncrasy. With regard to this topic, previous research reports uncertain impact related to the implementation of CLIL in different subjects. On the one hand, in addition to benefit foreign language skills (Köller et al., 2012; Nold et al. 2008), several authors affirm that 
CLIL can transform the dynamics of the lessons towards a more student-centered, constructivist and motivational learning, since it allows the use of real language to access information and to understand and reformulate acquired knowledge (Pérez-Cañado, 2011). Besides, from the teacher's viewpoint, Pérez-Cañado (2011) states that CLIL also increases generic competence acquisition and does not water down contents, but increases their learning.

On the other hand, from the perspective of cognitive load theory (Sweller et al., 1994), it might be argued that students' working memory is overloaded by simultaneously processing new content and the foreign language. In this vein, it is very likely that CLIL students will often be struggling, with limited foreign language knowledge, lexically dense texts, and limited background knowledge of the subject matter (Bruton, 2015). Moreover, research conducted in actual CLIL classes also shows that it is difficult to achieve a strict balance of language and content (Mehisto et al., 2008; Salvador et al., 2016).

\section{Effects of CLIL on PE}

In order to contribute to a better understanding of the issue in the PE arena we should, therefore, inquire whether the goals of PE curriculum are achieved differently from the way they are achieved in L1, when the contents are taught through a CLIL approach (Coral and Lleixà, 2014). Focusing specifically on this field and according to literature, there are several key factors which underlie to its idiosyncrasy and essence that might be affected when applying CLIL such as (1) curricular effects, (2) insertion of the language, (3) teaching method, (4) motivation and (5) workload.

To begin with, many researchers of the PE field assume that the foreign language development means that activities will have both PE and language goals (Coral, 2013; Clancy and Hruska, 2005; Hernando, 2015; Salvador et al., 2016; Zindler, 2013), what necessarily involves modifying curricular elements of PE such as objectives, evaluation or contents (Chiva et al., 2015; Figueras et al., 2011; González et al., 2013; Glackas, 1995; Hortigüela et al., 2016b; Molero, 2011; Zagalaz et al., 2012). Even though PE goals are the priority, some objectives related to language should be included (Clancy and Hruska, 2005; Hernando, 2015; Salvador et al., 2016; Zindler, 2013). Focusing on evaluation, many teachers wonder whether they should assess language, content or both (Coyle et al., 2010). In this sense, Coral (2013) determines that language should be evaluated, although this process must be considered bearing in mind the CLIL practitioners' specific situation (Coyle et al., 2010).

Moving now to the contents, there are opposite conceptions and arguments about it. While Figueras et al. (2011) conclude that from the participants' perception the specific contents of PE do not suffer any damage, Martínez and García (2017) warn that incorporating the foreign language entails reducing the quantity of specific contents. In the same vein, Hernando (2015) and Hortigüela et al. (2016a) refer to a slowdown in the content approach. Specifically, Coral (2010) and Lynott (2008) refer to losses in motor learning as a consequence of the shorter physical activity time available.

When it comes to the insertion of the language, according to Coral (2012) it should be integrated with the motor skills development. In a like manner, the four linguistic skills should be practiced (Hernando, 2015; Hortigüela et al., 2016b) and opportunities to interact should be enhanced (Coral and Lleixà, 2014; Molero, 2011; Zagalaz et al., 2012). Even though, Molero (2011) and Zindler (2013) warn us because there is a risk of falling into a too theoretical approach that reduces the practical essence of PE.

Hence, PE teachers are increasingly expected to be familiar with language pedagogy that makes content comprehensible for students (Chiva and Salvador, 2016; Coral, 2013; Gómez and Jiménez, 2012). Consequently, in order to allow a balance between the motor, linguistic and cognitive demands, PE teaching methods should be redefined to increase cooperation and verbal interaction among students (Coral and Lleixà, 2014; Figueras et al., 2011; Molero, 2011; Zagalaz et al., 2012). This results in the promotion of social interaction (González et al., 2013).

Another point worth underlining in PE with CLIL is the motivation. In this case, two approaches exist: some authors express that CLIL is a motivating input for students, while others argue that it can distort educational practices. On the one hand, Coral (2010) mentions that students' intrinsic motivation for the movement has a positive influence on English learning, which becomes a reinforcement to learn specific $\mathrm{PE}$ content (Figueras et al., 2011). On the other hand, there are investigations warning that the foreign language may be transformed into an element that negatively affects students' interest in PE (Hernando, 2015; Ramos and Ruiz, 2011). Specifically, Baena and Granero (2015) suggest that learning a foreign language could generate stress and anxiety, which is confirmed by Figueras et al., (2011).

Finally, regarding workload, we must highlight a lack of materials thought to develop language in PE tasks (Gómez and Jiménez, 2012; Mehisto et al, 2008). The truth is that there are few materials prepared and teachers have to choose between using those published or create their own (Coral, 2013). CLIL means a great challenge for teachers (Clancy and Hruska, 2005; Coral, 2012; Coral and Lleixà, 2014; González et al., 2013; Hernando, 2015; Molero, 2011), because it is necessary a linguistic and pedagogical formation whose lack would imply a handicap to make their messages understandable (Coral, 2013; Hortigüela et al., 2016a; Molero, 2011). 
CLIL in the Spanish context

CLIL is extensively used in non-English-speaking countries since this is the target language in most of the cases, as the one presented here. This fact explains that a considerable amount of researches concerning this specific methodology have been developed and published in countries such as Greece, Spain or Italy (Salvador et al., 2017). The particular interest of our research focuses on the Spanish context, where due to the introduction of plurilingualism in the education system, the use of CLIL is very widespread. In particular, we attempt to obtain insights into educational PE processes and practices related to the application of CLIL using English language within the Secondary education in the Spanish context. In order to explore what 'happens' in CLIL PE lessons it is relevant to give voice to the teachers who have been implementing them. In fact, it has been well-documented in the literature that understanding teachers' views is significant when it comes to improving teaching practices (Tsangaridou, 2006). Several studies have already been developed in this sense and concerning CLIL methodology (Bolarín, Porto \& García, 2012; Lova, Bolarín \& Porto, 2013; Pavón \& Rubio, 2010); however, they were not focused specifically on the PE subject and teachers. Therefore, this study will focus on considering and clarifying the PE teachers' perspectives and beliefs.

Currently, Spanish education is particularly sensitive to European initiatives regarding language policies. In fact, according to the national legal framework, it seems that plurilingualism has been enhanced progressively, particularly within the last decade. Nowadays, plurilingualism promotion is still increasing its relevance as can be perceived through the last educational decrees published. Generally, Spanish teachers who implement bilingual practices have to fulfil the following requirements: (1) at least B2 language level according to the CEFR (Common European Framework of Reference for the Languages), (2) official certificate or specific authorization that enables them to teach in the specific language. However, these may slightly differ depending on the autonomous region.

The general purpose of this study was to explore PE teachers' perspectives regarding the effects that CLIL methodology produces on their subject. This main aim was divided into more concrete research questions according with the literature review: (1) How does CLIL affect PE curricular elements? (2) How does CLIL affect the language used in the lessons? (3) How does CLIL affect the teaching method? (4) How does CLIL affect the motivation of the participants? and (5) How does CLIL affect the teachers' workload?

\section{Material \& methods}

Considering the research questions of this study, we opt for a pure qualitative research method. It focuses on the exploration of perceptions, meanings, beliefs, experiences, and feelings characteristic of the phenomenon under investigation (Halcomb and Davidson, 2006), which in this case is the specific insight into educational PE practices of CLIL within the Secondary education context in Spain. First, existing research helped to frame our approach. That is, the a priori theoretical orientation used influenced the development of our research questions, interview protocols, and subsequent data analysis (Creswell, 2012). In this way, the five categories introduced in the theoretical framework determined the research questions and the data analysis, which was divided in the following categories: (1) curricular effects, (2) insertion of the language, (3) teaching method, (4) motivation and (5) workload. After the data classification, these main categories were broken into several subcategories, some of them in accordance with the literature review, whereas others were emergent and were not expected (Renner and Taylor-Powell, 2003).

\section{Participants}

The sample was composed by eight PE teachers (four female and four male) from different Spanish Secondary schools who have been applying CLIL methodology at least during the last three academic years. Moreover, all of them have an official certificate that enables them to teach their subject in English through CLIL. This purposive sampling has been selected to attempt to achieve representativeness (Patton, 2002). The attributes for sample selection are displayed in Table 1. Their selection sought to approximate as much as possible the defining features of the study population.

Table 1. Configuration and main features of the participants involved.

\begin{tabular}{|c|c|c|c|c|c|c|c|c|c|}
\hline CLIL stuc & nts age & $\begin{array}{l}\text { Age o } \\
\text { teacher }\end{array}$ & the & $\begin{array}{l}\text { Experien } \\
\text { (years) } \\
\text { CLIL }\end{array}$ & using & $\begin{array}{l}\text { Gender } \\
\text { teacher }\end{array}$ & of the & $\begin{array}{l}\text { Number of inhabitan } \\
\text { city where the S } \\
\text { school is located }\end{array}$ & $\begin{array}{l}\text { nts of the } \\
\text { Secondary }\end{array}$ \\
\hline $\begin{array}{l}12-14 \\
\text { years old }\end{array}$ & $\mathrm{N}=4$ & $30-40$ & $\mathrm{~N}=4$ & $3-5$ & $\mathrm{~N}=6$ & Mal. & $\mathrm{N}=4$ & $<20000$ & $\mathrm{~N}=2$ \\
\hline \multirow{2}{*}{$\begin{array}{l}14-16 \\
\text { years old }\end{array}$} & \multirow{2}{*}{$\mathrm{N}=4$} & $40-50$ & $\mathrm{~N}=3$ & \multirow{2}{*}{$>5$} & \multirow{2}{*}{$\mathrm{N}=2$} & \multirow{2}{*}{ Fem. } & \multirow{2}{*}{$\mathrm{N}=4$} & $20000-150000$ & $\mathrm{~N}=3$ \\
\hline & & $50-60$ & $\mathrm{~N}=1$ & & & & & $>150000$ & $\mathrm{~N}=3$ \\
\hline
\end{tabular}

Total $\mathbf{N}=\mathbf{8}$ 
The participants of our study have been chosen because comprehending them will lead to better understanding, perhaps better theorizing, about a still larger collection of cases in the analyzed context (Stake, 2000). To make a proper selection of cases we opt for a parallel sampling design that will promote credible comparisons of them. This design implies comparing each case to all others in the sample, focusing mainly on perceptions and experiences referred to the theoretical nuclei determined. The teachers in this study had received thorough information about ethical considerations regarding informed approval and confidentiality, building on guidelines from our University ethics committee and had thereafter accepted to participate in the study.

\section{Instrument}

Semi-structured interviews were used in this study since they have found favor with many researchers as they permit the participants to describe detailed personal information, but at the same time the interviewer has good control over the information received (Creswell, 2012). Therefore, a list of key points was used to construct the interview guide, although other questions emerged from the dialogue between interviewer and interviewee to probe for more relevant data (DiCicco and Crabtree, 2006; Mackey and Gass, 2005). Each of these topic areas was introduced by, at least, an open question, ended by a confrontational one and in between several theorydriven questions were asked.

By following this procedure it is possible to reconstruct the interviewee's subjective theory without biasing it. In this sense, open-ended questions aim to get the knowledge that the interviewee has already got at hand, theorydriven questions are focused on trying to make this knowledge more explicit and the pursuit of confrontational questions is the re-examination of these notions (Flick, 2009). Examples of each type of these inquiries are the following ones: 'In your opinion, is CLIL suitable for the Secondary education level in PE? Why?' (openended), 'Have specific contents been lessened or reduced due to the use of CLIL?' (theory-driven), 'Do you feel more responsible for the development of communicative competence when you are using CLIL?' (confrontational). The interviews took between 55 and 70 minutes and were recorded with a SONY ICD-P530F recorder. Pseudonyms are used to protect the interviewees' identities.

\section{Data translation}

The interviews were developed in Spanish, therefore data were translated into English by the authors after its analysis took place. A professional translator assisted in the translation process of the quotes that appear in the results section.

\section{Data analysis and trustworthiness}

We have followed the steps proposed by Halcomb and Davidson (2006) to analyze the audiotape recordings, through which a series of categories and subcategories have been differentiated. In alignment with Creswell (2002), the subcategories can be classified as expected (those that had previously emerged from the literature review), and unexpected (those which were adventitious). First, the interviews were transcribed and then a preliminary content analysis was conducted. In the secondary content analysis each researcher individually analyzed recurrent topics across categories which were then shared. Subcategories agreement was reached by examining the data and discussing our interpretations. Finally, the recordings were relistened to make any necessary change and illustrative examples with which to demonstrate the participants' perspectives concerning each category and subcategory were selected.

We consider that our experience as researchers in CLIL has helped to strengthen the trustworthiness of the present study, in that we thereby have pre-understanding of the topic under investigation. With respect to the validity of the study, often referred to as authenticity in qualitative research, we claim that the ethical considerations concede a given degree of authenticity (Lincoln et al., 2011). Moreover, there is authenticity involved in the fact that we do not attempt to find general results about CLIL in PE, but merely for the Spanish context, which is supported by the sample selected. Finally, a member-check process was implemented.

\section{Results}

Below we present the main outcomes of the analysis according to the five research questions in which the results have been divided. Later on the five categories were broken into several subcategories.

\section{Curricular effects}

Developing CLIL may imply a modification of the PE curriculum (Pavón \& Rubio, 2010). However, when asked about this topic through an open-ended question, all the teachers agreed that from a general viewpoint there was not a significant change in their subject. 'Actually, I believe that nothing has changed, everything has been more or less the same' (Teresa) was one of the responses obtained, in line with the words of the other seven interviewees.

Nevertheless, when enquiring about the modification of more specific aspects of the curriculum, we found that some adjustments were made. In this line, three interrelated subcategories were set. The first one concerning the objectives, the second one focused on evaluation, and the third one related to content. Objectives showed clear consonance among the teachers because for them 'the most important are PE goals since we are 
doing PE' (Jaime). Despite this fact, the interviewees stated that linguistic goals were added with more or less relevance, depending on each case: 'You introduce English objectives such as the vocabulary and structures that you want them to learn, the fact that you want them to communicate in English, etc.' (Lidón).

On the contrary, the second subcategory, focused on evaluation, may be divided into two different approaches. On the one hand, there are some teachers who do not evaluate language because according to them 'language is assessed in the English subject' (Àngels). On the other hand, we find those who do introduce language on the evaluation, albeit they 'try it not to have too many consequences on the mark' (Iñaki). In fact, one of the teachers mentioned that 'basically I take into account their ability to communicate and express themselves' (Pablo) and another admitted that 'regarding English language, I think that PE should only assess the students' effort. I am not going to grade English more than PE content' (Iñaki). Therefore, those who do include English in the assessment do it in a very subtle way.

Regarding contents, the teachers agreed that specific PE contents were not diminished. In one of the interviewees' words, 'the idea was that the level of contents remained the same' (Ester). Moreover, in general, they did not believe that students had a shorter engagement physical activity time. Although in certain occasions, 'explanations could be longer' (Jaime); other times they were even 'more direct and dynamic' (Manuel) because students language level avoided its overuse. Therefore, 'the essence of sport and physical activity stayed the same, without stop' (Lidón).

\section{Language insertion}

A second category was established focusing on language insertion and divided into two subcategories: linguistic skills and attention to communication. 'The four linguistic skills were introduced in a way or another' (Pablo). Depending on each skill, they were given more or less emphasis in order not to disturb the usual development of the lesson. Although there were no relevant modifications in the communicative interaction, moving to the second subcategory, a thoroughly consideration regarding communication appeared as a general characteristic of PE teachers when using CLIL. Undoubtedly, 'PE content was the priority' (Ester), however, they bore more in mind communicative competence when following this methodology.

I believe that English makes the teacher to pay more attention to communicative competence. Undoubtedly, in ordinary lessons we should pay it as much attention as possible, but as we have to develop our lessons in English, communicative competence concerns us even more. (Pablo).

Furthermore, there was an agreement on the fact that teachers want to make sure of the students' understanding. There was a general worry and they opted for different strategies to cope with possible comprehension problems and ensure effective communication. 'I wanted somebody else [student] to give the explanation to make sure whether they had understood or not. Besides, it means that students are receiving the message through different ways' (Manuel).

\section{Teaching method}

Related to the previous category, the methodology used by the teacher is another of the aspects which may be influenced by the introduction of English language in the PE subject. This category has been broken into three different subcategories. Teaching style and group work were in line with the literature review, but the third subcategory, major relevance of social constructivism, emerged after the data analysis. In relation to the first subcategory, as a consequence of the aforementioned increase of the attentiveness to communication during the lessons, teachers agreed that they tend to use more open and participative teaching styles.

I think that [CLIL needs] the adoption of a more deliberative approach, by using teaching styles which are not directive and that do not have a concrete answer. I offer a problem, a challenge, and each group has to look for its own answer or possible answers. Later on, they have to share it with their classmates and justify their choices. (Àngels)

In this same line, appears the second subcategory. Cooperative and collaborative work was also highlighted as another possibility to favor communication and the use of the language because 'group work is important' (Iñaki). There was a harmony among the teachers' responses and all of them followed the same ideas.

One of the ways to encourage the use of the language is proposing cooperative tasks. At the level of the structure of the session, it seems quite evident that we must search cooperative structures if we want to encourage the use of the language. (Ester)

This methodological and organizational option was also conceived as an excellent possibility which enables students' understanding and learning. In words of one of the teachers 'to facilitate students' understanding, the fact that they worked in group was a key point to facilitate their learning' (Pablo). Closely linked with this regard, the third subcategory, major relevance of social constructivism, emerged. Teachers expressed that these changes helped to integrate all the pupils because through group work 'they can help each other more' (Lidón) and learn together.

Maybe in Spanish they do not have problems, but now there must be more cooperation among them. If they work in groups, they can correct each other and if someone does not know something, a classmate can help him or her. (Lidón) 
Motivation

This category has been subdivided into two subcategories, maintenance or increase of motivation, which was set a priori; and the unexpected more attentiveness. All the teachers interviewed showed a congruity regarding students' motivation. According to them, 'in general, motivation was high and kept at a high level' (Pablo). Besides, some of them expressed that it was not only because of the PE subject, but language played a role too.

The fact of using English and see that the rest of the students are understanding them and that they can express themselves in English, although it is not through a perfect use of the language (...); I think it has got a direct connection with motivation. (Manuel)

However, they also express that there were exceptions because 'there is always a student who does not care about studies, is apathetic and disconnects' (Jaime).

Otherwise, according to the teachers' perceptions, an unexpected subcategory emerged, more attentiveness, since many students increased their level of attention during the lessons. In this way, 'even students who did not understand tried to get the information and, therefore, maybe they were more focused on the explanations' (Ester). In this sense, teachers agreed to say that the use of English implied an increase of students' attentiveness because they had to focus on both, understanding and performing the tasks of the class.

\section{Workload}

Albeit it cannot be conceived as a direct effect of the introduction of CLIL in the lessons, workload does have an impact on the teacher and his or her tasks; that is why it has been established as the fifth category of analysis. This category has also been broken into two different subcategories, the expected increase of planning and the emergent unacknowledged (hard)work. With respect to the former, every single one of the teachers interviewed agreed with the fact that 'in PE with English, there is a higher effort regarding planning' (Pablo). Maybe lessons do not significantly change in view of the tasks, nevertheless the amount of time that teachers have to spend to plan adequate lessons is considerably higher since they are paying more attention to language and communication.

There is a lot of vocabulary that I have to search prior to the lessons to be able to explain everything adequately. Besides, I have to explain it in a way in which they understand me. I cannot use just the translation of a word because they are not going to understand. I have to plan how I am going to make myself understood. (Teresa)

In addition, it is not only the time what teachers highlighted, but also the effort and the fact that anybody acknowledges their (hard)work. In this line, one of the teachers stated that introducing language implies 'a lot of work without any compensation' (Pablo). However, all of them agreed to say that it was a motivating work of which they were proud of. 'It has been a great effort, but it was not a sacrifice' (Manuel) were the words used by one of the teachers and another expressed that 'it was an effort, but it was worth it. It was an exciting task' (Pablo).

\section{Dicussion}

The results obtained from the data analysis complement and reinforce the state of the art. By means of the interviews five categories were established which let us configure the PE teachers' perceptions on the effect of introducing CLIL methodology in their lessons.

Firstly, related to curricular effects, what they made clear is the fact that the most important aspect of the lessons is still PE despite the insertion of the language, which is completely in accordance with the words of Fernández-Barrionuevo (2009), who stated that the main goal was the teaching of PE content, and the L2 (second language) would only be the tool through which get the objectives. Regarding the subcategory of objectives modification, the interviewees recognized that PE goals remain similar but some linguistic ones are added, in accordance with Clancy and Hruska (2005), Hernando (2015), Salvador et al., (2016) and Zindler (2013); therefore, PE curriculum should be slightly re-adapted to fit with CLIL (Hortigüela et al., 2016b; Molero, 2011). The third subcategory deals with alterations and changes in the evaluation. In this sense, teachers' perceptions may be differentiated in two viewpoints. On the one hand, some teachers stated that language was not considered within the evaluation of their PE subject. On the other hand, we find those who do include some kind of linguistic issue in their evaluation process, although the majority of them introduces it in a quite subtle way intending the mark is not influenced, in line with Coral (2013). This divergence shows that there is not a clear discourse when a decision has to be made regarding the inclusion of language in evaluation (Coyle et al., 2010).

Focusing specifically on contents, teachers expressed that there was no loss on engagement physical activity time nor specific PE learning, in accordance with Figueras et al., (2011), although in specific situations or moments explanations could be longer or students could need more time to understand the activities. Therefore, in their opinion, generally there was not any delay on learning or a loss of time due to language, contrasting with Coral (2010), Hernando (2015) and Martínez and García (2017), who warned about a possible decrease of the motor learning time available.

Related to language insertion, according to Amade-Escot and O'sullivan (2007:197), 'particular knowledge has to be covered and explained in specific ways by the teacher [...]. This fact has an effect on the 
type of interactions in use in classrooms'. In this vein, the teachers interviewed coincided in their assertion that language was not a handicap in the development of the lessons. In fact, it was determined that they tried to integrate language and motor skills, which is in agreement with Coral (2012). Furthermore, the four linguistic skills were incorporated (Hernando, 2015; Hortigüela et al., 2016b), despite doing it with different emphasis depending on the skill; and there was a growing concern over communication. In this sense, Molero (2011) and Zagalaz et al. (2012) defended that opportunities to communicate and interact should be enhanced while Coral and Lleixà (2014) focused their study on different strategies to favor such communication.

Regarding the teaching method, the results evinced that more open and participative teaching styles were promoted over those that are more directive to favor communication. In this vein, Glakas (1993) suggested this modification to happen in order to enhance language learning. Moreover, according to the responses obtained, teachers attempted to create messages understandable for students, as reported by Coral (2013), to facilitate the communicative act (Molero, 2011; Zagalaz et al., 2012).

Cooperative and collaborative group work are also raised because they increase language use and better understanding. In this sense, through tasks which are not individual or require an opponent, social interaction is enhanced, which at the same time entails a more important role of the language (Bolarín et al., 2012; Coral and Lleixà, 2014; González et al., 2013). Furthermore, these changes in teaching style and tasks implied a growth of learning values and more integration among students, according to the teachers' answers. This may mean that PE in CLIL alludes to a learning based on social constructivist principles (Vygotsky, 1995), as reported by Figueras et al., (2011), who arrived at this same conclusion after their experience.

Motivation is a category that represents a key factor in the learning process (Shropshire et al., 1997; Subramaniam and Silverman, 2007). Perlman (2013) states that different forms of teacher instruction can influence students' motivational responses within Secondary physical education. In this sense, the interviewees mentioned that, in general, motivation in class was high and remained high when using CLIL. In this sense, the interviewees mentioned that, in general, motivation in class was high and remained high. However, there were specific cases in which language could affect negatively to some particular students, as previously reported by Ramos and Ruiz (2011). It is worth saying that this does not always happen and, in fact, in other cases language may become a positive element to increase motivation (Figueras et al., 2011; Zindler, 2013). Hence, it might be remarked that each learner is unique and, consequently, the introduction of another language can affect differently.

In this line, another effect that, according to the teachers, was caused by the language: an increase in some of the pupils' attentiveness. This fact is in accordance with Figueras et al. (2011), although in their study participants were at university and, therefore, they were supposed to be more mature and serious towards the learning process. According to Zindler (2013), PE with CLIL is cognitively more challenging and, consequently, pupils might have to be more focused on what is happening in the lesson if they want to follow properly the class, understand everything and avoid having to ask for more information.

Finally, workload was highlighted by the teachers as a relevant factor that affected their tasks. In this sense, planning becomes an essential aspect that must be considered (Martínez and García, 2017) because when introducing CLIL teachers not only have to plan PE lessons, but also integrate the language and prepare a proper discourse and the scaffolding that might be needed (Coral, 2013; Gómez and Jiménez, 2012; Ramos and Ruiz, 2011). Moreover, the lack of materials already prepared (Coral, 2013; Gómez and Jiménez, 2012; Mehisto et al., 2008) in the end means even greater effort (González et al., 2013; Lova et al., 2013). Teachers also remarked the fact that nobody acknowledged their work, which could turn into an increase of burn-out and, therefore, less teachers willing to continue with their CLIL practices.

\section{Conclusions}

The analysis applied encourages us to raise the following conclusions. Considering the interviewed teachers' perspectives and beliefs, the application of CLIL within the Secondary education in Spain does not endanger the essence of the PE. From a general viewpoint, there is not a significant change in the PE curriculum implementation despite subtle adjustments. Moreover, the use of the four linguistic skills is not a handicap to achieve the essential aims and contents of the subject. Indeed, to favor communication more participative teaching styles and cooperative work are developed. In addition, there is a maintenance or increase of students' motivation and attentiveness in the majority of the cases.

As a counterpart, the study highlights a need to improve the workload and acknowledgement of teachers involved in CLIL. This fact allows us to predict that in the medium and long term the good functioning of the educational process could be diminished due to teacher burn-out and demotivation. Therefore, given the importance of CLIL for the plurilingual model to which the Spanish educational system aspires, it is important that the administration takes action on this matter before it is too late.

All in all, these conclusions may be significant for other countries using CLIL since its implementation features are certainly shared. Thus, this is a first approach that, later on, may trigger further studies of CLIL practices in PE. For instance, one dimension that could complement this paper to cover the impact of CLIL on PE on a more comprehensive way could be to include the perceptions of the pupils. 
Conflicts of interest: the authors declare that there are not conflicts of interest.

Funding: this work was supported by SPIEDA project of the University Jaume I (Reference number-3256).

\section{References:}

Amade-Escot, C., \& O'sullivan, M. (2007). Research on content in physical education: theoretical perspectives and current debates. Physical Education and Sport Pedagogy, 12(3), 185-204.

Baena, A., \& Granero, A. (2015). Versión española del Sport Satisfaction Instrument (SSI) adaptado al aprendizaje de la Educación Física bilingüe en Inglés. Porta Linguarum, 24, 63-76.

Bolarín, M. J., Porto, M., \& García, R. M. (2012). Los programas bilingües en la Región de Murcia: situación y valoraciones de profesores de disciplinas no lingüísticas. Educatio Siglo XXI, 30(2), 255-288.

Bruton, A. (2015). CLIL: Detail matters in the whole picture. More than a reply to J. Hüttner and U. Smit (2014). System, 53, 119-128.

Cenoz, J., Genesee, F., \& Gorter, D. (2014). Critical analysis of CLIL: Taking stock and looking forward. Applied Linguistics, 35(3), 243-262.

Chiva, O. \& Salvador, C. (2016). Aprendizaje integrado de Educación Física y lengua inglesa. Barcelona: INDE.

Chiva, O., Isidori, E., \& Fazio, A. (2015). Educación Física bilingüe y pedagogía crítica: una aplicación basada en el Judo. Retos, Nuevas Tendencias en Educación Física, Deporte y Recreación, 28, 110-115.

Clancy, M. E., \& Hruska, B. L. (2005). Developing language objectives for English language learners in physical education lessons. Journal of Physical Education, Recreation \& Dance, 76(4), 30-35.

Coral, J. (2010). L'aprenentatge de l'anglès a través de l'educació física: el programa'Mou-te i aprèn'. Temps $d_{i}$ Educació, 39, 149-170.

Coral, J. (2012). Aprenentatge integrat de continguts d'educació física i llengua anglesa: educació física en AICLE al cicle superior de primària. $\mathrm{PhD}$ Thesis, Universitat de Barcelona, Spain.

Coral, J. (2013). Physical education and English integrated learning: How School Teachers can Develop PE-inCLIL Programmes. Temps d'Educació, 45, 41-64.

Coral, J., \& Lleixà, T. (2016). Physical education in content and language integrated learning: successful interaction between physical education and English as a foreign language. International Journal of Bilingual Education and Bilingualism, 19(1), 108-126.

Coyle, D., Hood, P., \& Marsh, D. (2010). CLIL. Cambridge: CUP.

Creswell, J.W. (2002). Educational Research: Planning, Conducting, and Evaluating Quantitative. Upper Saddle River: Prentice Hall.

Creswell, J.W. (2012). Qualitative Inquiry and Research Design: Choosing among Five Approaches. London: Sage.

DiCicco, B., \& Crabtree, B. F. (2006). The qualitative research interview. Medical education, 40(4), 314-321.

Fernández-Barrionuevo, E. (2009). La secuenciación de contenidos lingüísticos dentro de la Educación Física Bilingüe. Revista Innovación y Experiencias Educativas, 23, 1-9.

Figueras, S., Flores, C., \& González- Davies, M. G. (2011). Educació Física en anglès: Percepcions dels estudiants entorn d'una experiència metodològica en el marc universitari. Aloma: revista de psicologia, ciències de l'educació $i$ de l'esport Blanquerna, 29, 61-80.

Flick, U. (2009). An Introduction to Qualitative Research. London: SAGE.

Glakas, B. A. (1993). Teaching secondary physical education to ESL students. Journal of Physical Education, Recreation \& Dance, 64(7), 20-25.

Gomez, C. L., \& Jimenez-Silva, M. (2012). The physical educator as a language teacher for English language learners. Strategies, 25(4), 14-17.

González, S., Villar, L., Pastor, J. C, \& Gil, P. (2013). Propuesta didáctica interdisciplinar en educación primaria en España: la enseñanza de la educación física y el inglés. Paradígma, 34(2), 31-50.

Halcomb, E. J., \& Davidson, P. M. (2006). Is verbatim transcription of interview data always necessary? Applied Nursing Research, 19(1), 38-42.

Hernando, A. (2015). Caracterización de los aspectos metodológicos empleados en la enseñanza de la materia de Educación Física en los centros públicos de secundaria con sección bilingüe en inglés de Castilla y León. PhD Thesis, Universidad de Burgos, Spain.

Hortigüela, D., Hernando, A., \& Pérez-Pueyo, A. (2016a). ¿Qué estrategias metodológicas utiliza el profesorado de educación física bilingüe en el aula? In: M.I. Amor, J.L. Luengo \& M. Martínez (eds). Educación intercultural: metodología de aprendizaje en contextos bilingües. Granada: Atrio, pp. 103-106.

Hortigüela, D., Pérez-Pueyo, A., Casado, O., \& Herran, I. (2016b). Bilingüismo y cooperación en educación física a través de la dramatización ¿cómo integrarlo? In: Actes X Congrés internacional d'activitats fisiques cooperatives, Barcelona, Spain, 3-6 July 2016, pp.152-153. Barcelona: Institut de ciències de l'educació de l'UAB.

Köller, O., Leucht, M., \& Pant, H. (2012). Effekte bilingualen Unterrichts auf die Englischleistungen in der Sekundarstufe I. Unterrichtswissenschaft, 4(4), 334-350. 
Lieberman, L. J., Columna, L., de la Vega Mansilla, P. M., \& Taylor, C. (2010). Infusing Sign Language and Spanish into Physical Education. Journal of Physical Education, Recreation \& Dance, 81(4), 45-49.

Lincoln, Y. S., Lynham, S. A., \& Guba, E. G. (2011). Paradigmatic controversies, contradictions, and emerging confluences, revisited. The Sage handbook of qualitative research, 4, 97-128.

Lova, M., Bolarín, M. J., \& Porto, M. (2013). Programas bilingües en Educación Primaria: valoraciones de docentes. Porta Linguarum, 20, 253-268.

Lynott, F. J. (2008). Integrating other subject matter without jeopardizing physical education goals: The content linkage approach. Strategies, 22(1), 10-17.

Mackey, A. \& Gass, S.M. (2005). Second Language Research. Methodology and design. New Jersey: Lawrence Erlbaum.

Marsh, D. (2002). CLIL/EMILE the European Dimension. Finland: University of Jäyvskylä.

Martínez-Hita, F.J. \& García-Canto, E. (2017). Influence of Bilingualism on Engagement Motor Time in Physical Education. Retos, Nuevas tendencias en educación física, deporte y recreación, 32, 178-182.

Mehisto, P., Marsh, D., \& Frigols, M.J. (2008). Uncovering CLIL Content and Language Integrated Learning in Bilingual and Multilingual Education. Oxford: Macmillan.

Molero, J.J. (2011). De la Educación Física a la Educación Física bilingüe: un análisis desde el punto de vista metodológico. EmásF: revista digital de Educación Física, 2(10), 7-16.

Nguyen, H. T., \& Watanabe, M. F. (2013). Using visual supports to teach English language learners in physical education. Journal of Physical Education, Recreation \& Dance, 84(8), 46-53.

Nold, G., Hartig, J., Hinz, S. \& Rossa, H. (2008) Klassen mit bilingualem Sachfachunterricht. Englisch als Arbeitssprache. In: E. Klieme (ed). Unterricht und Kompetenzerwerb in Deutsch und Englisch. Weinheim: Belzt, pp. 451-457.

Pavón, V., \& Rubio, F. (2010). Teachers' concerns and uncertainties about the introduction of CLIL programmes. Porta Linguarum, 14, 45-58.

Patton, M.Q. (2002). Qualitative Research and Evaluation Methods. London: Sage.

Pérez-Cañado, M.L. (2011). The Effects of CLIL within the APPP: Lessons Learned and Ways Forward. Studies in honour of Ángeles Linde López, 13-30.

Perlman, D. J. (2015). Help motivate the amotivated by being a supportive teacher. Physical Education and Sport Pedagogy, 20(2), 204-214.

Ramos, F., \& Omeñaca, J. V. R. (2011). La educación física en centros bilingües de primaria inglés-español: de las singularidades propias del área a la elaboración de propuestas didácticas prácticas con AIBLE. Revista española de lingüística aplicada, 24, 153-170.

Renner M and Taylor-Powell E (2003) Analyzing Qualitative Data. Madison: University of Wisconsin.

Salvador, C., Chiva, Ò., \& Fazio, A. (2016). Características del Aprendizaje Integrado de Contenidos de Educación Física y Lengua Extranjera. Retos, Nuevas Tendencias en Educación Física, Deporte y Recreación, 29, 120-125.

Salvador, C., Chiva, Ò., \& Isidori, E. (2017). Aprendizaje de una lengua extranjera a través de la educación física: una revisión sistemática. Movimento. 23(2), 647-660.

Santillan, Y., Jacobs, J. M., \& Wright, P. M. (2015). Integrating Best Practices in ELL Classrooms with Quality Physical Education Instruction. Journal of Physical Education, Recreation and Dance, 86(3), 51-53.

Sato, T., \& Hodge, S. R. (2016). Elementary physical education teachers' experiences in teaching English language learners. Education and Urban Society, 48(3), 262-287.

Sato, T., Walton, J., \& Kim, I. (2017). Elementary physical educators' positioning in teaching English language learners. European Physical Education Review, 1-18.

Shropshire, J., Carroll, B., \& Yim, S. (1997). Primary school children's attitudes to physical education: gender differences. European Journal of Physical Education, 2(1), 23-38.

Stake, R.E. (2000). Case studies. In: N.K. Denzin \& Y.S. Lincoln (eds). Handbook of qualitative research. Thousand Oaks: Sage, pp. 435-454.

Subramaniam, P. R., \& Silverman, S. (2007). Middle school students' attitudes toward physical education. Teaching and teacher education, 23(5), 602-611.

Sweller, J. (1994). Cognitive load theory, learning difficulty, and instructional design. Learning and instruction, 4(4), 295-312.

Tsangaridou, N. (2006). Teachers' Beliefs. In: D. Kink, D. MacDonald \& M. O'Sullivan (eds). The handbook of Physical Education. London: Sage, pp. 486-501.

Zagalaz, M.A., Molero, D., Cachón, J., et al. (2012). Diseño de un cuestionario para medir la formación bilingüe del profesorado de EF. Revista Iberoamericana de Ciencias del Deporte 1(1), 7-12.

Vygotsky, L.S. (1995). Pensamiento y lenguaje. Barcelona: Paidós.

Zindler, K. (2013). Content and Language Integrated Learning and PE in England. An Exploratory Study. PhD Thesis, University of Sheffield, UK. 


\title{
Percepción del alumnado sobre el uso del métodoAICLE en Educación Física: estudio de caso Perception of students on the use of CLIL method in Physical Education: A Case Study \\ *Celina Salvador-García, *Óscar Chiva-Bartoll, **Juan José Vergaz Gallego Universidad Jaume I (España), **Universidad de Valencia (España)
}

\begin{abstract}
Resumen. El Aprendizaje Integrado de Contenidos y Lengua Extranjera (AICLE) está siendo cada vez más extendido e investigado en el panorama educativo español. Dada la importancia de la motivación y la predisposición del alumnado para que el proceso de enseñanza-aprendizaje sea efectivo, este estudio de caso analiza la percepción de un grupo de secundaria durante la aplicación del método AICLE en la asignatura de Educación Física. Se optó por un enfoque metodológico cualitativo apoyado en la triangulación de diarios de reflexión del alumnado, registro anecdótico del profesor-investigador y un focus group. Los resultados afianzan el actual estado de la cuestión, desvelando cinco categorías sobre las que se conforma la percepción del alumnado: temor a la lengua, motivación y participación en la asignatura, aprendizajes específicos de Educación Física, mejora de la expresión oral en inglés e importancia del inglés para el futuro académico-profesional. En conclusión, el estudio desvela cómo de la aprensión inicial hacia el AICLE, derivado del temor a la lengua, se pasó a un incremento progresivo de la participación del alumnado, ligado a una creciente percepción de mejora de la propia competencia comunicativa.
\end{abstract}

Palabras clave: AICLE, Educación Física, Educación Secundaria, educación bilingüe, lengua inglesa.

Abstract. Content and Language Integrated Learning (CLIL) is becoming more widespread and studied in the Spanish educational panorama. Due to the importance of motivation and predisposition of students for an effective development of the teaching-learning process, the present case study analyses the perception of a secondary school group about their implementation of the CLIL method in Physical Education subject. A qualitative methodological approach was adopted, supported by the triangulation of students' reflection diaries, the teacher-researcher's anecdotal register and a focus group. The results reinforce the current status of the issue, uncovering five categories according to the students' beliefs: fear for the language, motivation and participation in the subject, specific Physical Education learnings, improvement of oral expression and magnitude of English language for their academic-professional future. In conclusion, this research discloses how during the intervention an initial apprehension towards CLIL related to the fear for the language, turned into a progressive increase of the students' participation, linked to an improvement of the self-perception of communicative competence.

Keywords: CLIL, Physical Education, Secondary Education, bilingual education, English Language.

\section{Introducción}

AICLE (Aprendizaje Integrado de Contenidos y Lengua Extranjera) es un método pedagógico que empieza a ser cada vez más aplicado e investigado en el panorama educativo español (Salvador, Chiva \& Isidori, in press). El término AICLE (en inglés CLIL: Content and Language Integrated Learning) se define como un enfoque educativo dual en el que una lengua extranjera es utilizada para trabajar contenidos de una asignatura específica (Coyle, Hood \& Marsh, 2010). Su uso persigue un doble objetivo, la adquisición de la lengua utilizada y el aprendizaje de la materia en cuestión. Además, AICLE permite tratar el currículo como un todo en lugar de como diferentes asignaturas o áreas parceladas e inconexas. Aunque es un método utilizado en múltiples áreas del currículo, la Educación Física (EF) es una materia que por su propia idiosincrasia se ajusta especialmente a sus características (Alonso, Cachón, Castro \& Zagalaz, 2015; Chiva, Isidori \& Fazio, 2015; Chiva \& Salvador, 2016; Coral, 2012; Rio, Di Rubbo \& Gómez, 2014; Salvador, Chiva \& Ruiz-Madrid, 2016; Salvador, Chiva \& Fazio, 2016). En especial, es considerable el número de autores que enumeran ventajas de la utilización de AICLE en EF a raíz de la interacción y comunicación que la materia promueve a través del movimiento y el juego, resultando una vía para facilitar el aprendizaje de la lengua extranjera (Chiva et al., 2015; Coral, 2012; Coral \& Lleixà, 2016; García, García \& Yuste, 2012; Hernando, Hortigüela \& Pérez-Pueyo, 2018; Ramos \& Ruiz, 2011).

Pese al crecimiento actual de investigaciones sobre la aplicación del método AICLE (Lova \& Bolarín, 2015), en EF siguen existiendo terrenos por explorar. Uno de los puntos que requiere mayor atención radica en el conocimiento de la percepción del alumnado ante las clases de EF en inglés. Por ello, conociendo la importancia de la orientaciónmotivacional y la predisposición del alumnado para que el proceso de enseñanzaaprendizaje sea efectivo (Sánchez-Alcaraz, Gómez-Mármol \& Más, 2016), es conveniente averiguar el grado de comprensión, motivación y miedo del estudiantado respecto a la introducción de las clases de EF en lengua inglesa. Este interés define el objetivo del presente artículo, basa-

Fecha recepción: 30-11-16. Fecha de aceptación: 29-05-17 Osccar Chiva-Bartol

ochiva@uji.es do en conocer la percepción del alumnado de secundaria sobre la aplicación del método AICLE en EF.

Existen diversos estudios centrados en el binomio EF y aprendizaje de inglés. Coral (2010) investigó en primaria los efectos de AICLE sobre el aprendizaje lingüístico, concluyendo que la EF constituye una posibilidad diferente de aprender una lengua extranjera. Por otra parte, Figueras, Flores y González (2011), en el contexto universitario, también destacan la mejora lingüística de los participantes, en línea con lo expuesto por Reyes (2014), que en particular resalta la mejora de la competencia oral. En la misma línea, Devos (2012) analizó el lenguaje utilizado en una intervención de AICLE y concluyó que se produjo un aprendizaje lingüístico gracias a la construcción de nuevos significados. Mientras que González, Villar, Pastor y Gil (2013) llevaron a cabo un estudio similar, destacando la relevancia del componente lúdico aportado por la EF para favorecer el aprendizajey la motivación del alumnado.

Asimismo, existen estudios que amplían el foco de interés y trascienden el análisis de la mera competencia lingüística. Por ejemplo, en Educación Primaria,Alonso et al., (2015) no solo aluden a esta mejora, sino también la idoneidad de trabajar la cultura inglesa. Rottmann (2007) sostiene que utilizar EF como contenido para desarrollar una lengua fomenta las interacciones de los alumnos. Por su parte, Alías (2011) defiende el progreso de las habilidades orales y expresivas pero, además, analiza en su estudio la percepción del alumnado, concluyendo que enseñar inglés a través del juego en EF resulta muy motivante.

El estado de la cuestión desvela que, tratándose de un campo de estudio tan reciente, quedan abiertas algunas líneas de investigación con las que mejorar las posibilidades de implementación del método AICLE. En particular, la etapa de educación secundaria representa un espacio de estudio al que contribuye la presente investigación. La intervención se llevó a cabo en cuarto curso de Educación Secundaria Obligatoria(ESO), eligiendo como contenido el Touch-Rugby. Este contenido fue elegido por sus características como deporte promotor de conductas prosociales y de actitudes de cooperación y trabajo en equipo (Parise, Pagani, Cremascoli \& Iafrate, 2015). Además, con la intención de acentuar todavía más estas características, el Touch-Rugby se introdujo desde un enfoque metodológico comprensivo (Valera, Ureña, Ruiz \& Alarcón, 2010). 


\section{Material y Métodos}

Situado en el paradigma investigador interpretativo, el presente estudio de caso analiza la percepción del alumnado ante prácticas de EF mediante el métodoAICLE. Esta cuestión se acomete cualitativamente tras una intervención didáctica que aspira, conforme a los planteamientos metodológicos de Halcomb \& Davidson (2006), a detectar y reconocer las posibles inquietudes, miedos y motivaciones que dicho proceso de enseñanza-aprendizaje supone para el estudiantado. La investigación planteada fue participativa, de manera que la explicación de «lo que sucede» se ha construido conjuntamente entre el profesor-investigador y el alumnado participante. Asimismo, en la línea marcada por Creswell (2002) respecto a la validez y fiabilidad en investigación cualitativa, consideramos que nuestra experiencia como investigadores en AICLE ha ayudado a fortalecer la fiabilidad del presente estudio, ya que con ello tenemos una comprensión previa del tema investigado. El resultado constituye una interpretación de los datos recopilados con la que se responde a la siguiente pregunta de investigación: ¿Cómo percibe el alumnado de secundaria la introducción del método AICLE en EF?

\section{Programa de intervención}

La unidad didáctica de Touch-Rugby se aplicó en cuarto curso de ESO y constó de siete sesiones. El Touch-Rugby es un deporte con un elevado componente cognitivo que ha facilitado la aplicación de un enfoque de enseñanza comprensivo (González, Cecchini, FernándezRío \& Méndez, 2008). Este enfoque de enseñanza deportiva se basa, fundamentalmente, en plantear retos o problemas prácticos al alumnado, de forma que se vea favorecida su relación interpersonal mediante la utilización de actividades grupales y cooperativas (Sánchez-Gómez, Devís-Devís \& Navarro-Adelantado, 2014).

Por otra parte, el nivel de lengua inglesa empleado fue elemental o básico, habiéndose ajustado previamente con la profesora de inglés, con la que también se concretó el vocabulario y ciertas estructuras gramaticales a trabajar. A continuación, la tabla 1 describe los principales rasgos de la unidad didáctica aplicada desde el marco de las 4 «Cs» propuesto por el método AICLE.

\begin{tabular}{|c|c|}
\hline \multicolumn{2}{|c|}{ Unidad didáctica aplicada desde el enfoque metodológico AICLE.tim } \\
\hline \\
\hline \multirow{2}{*}{\multicolumn{2}{|c|}{$\begin{array}{l}\text {-Habilidades específicas: handballing, marking, feinting. } \\
\text {-Normas básicas del Touch-Rugby. }\end{array}$}} \\
\hline & \\
\hline \multicolumn{2}{|c|}{-Desarrollo de las habilidades motrices especificas aplicadas a } \\
\hline \multicolumn{2}{|c|}{$\begin{array}{l}\text {-Desarrollo de las habilidades motrices especiticas aplicadas al louch. } \\
\text {-Aplicación de estrategias colectivas ofensivas y defensivas. }\end{array}$} \\
\hline \multirow{2}{*}{\multicolumn{2}{|c|}{$\begin{array}{l}\text {-Aplicacion de estrategras colectlvas ofensivas y detensivas. } \\
\text {-Resolución de situaciones en las que se haga uso de una deliberación crítica. }\end{array}$}} \\
\hline & \\
\hline \multicolumn{2}{|c|}{ Comunication } \\
\hline \multirow{11}{*}{ Language of learning } & Vocab \\
\hline & -Touch: Game, rules, turn over, team \\
\hline & -Skills: Handballing, marking, passing, \\
\hline & -Verbs: To bend, to hit, to hold, to pass, to score, to run, to mark \\
\hline & \\
\hline & \\
\hline & $\begin{array}{l}\text {-Prepositions: Far, near, above, backwards, above, down } \\
\text {-Rules: cheating, fair play, shake hands, respect }\end{array}$ \\
\hline & Estructuras: \\
\hline & -Modales: Should, can/could/must/have to \\
\hline & -Allowed/forbidden \\
\hline & -In my opinion: I think, I believe, I would... \\
\hline \multirow{4}{*}{ Language for learning } & -Dar opinión y razones \\
\hline & -Proponer ideas \\
\hline & -Dar consejos \\
\hline & -Generar normas \\
\hline Language through & \\
\hline \multirow{2}{*}{\multicolumn{2}{|c|}{ Culture }} \\
\hline & \\
\hline \multirow{4}{*}{\multicolumn{2}{|c|}{$\begin{array}{l}\text {-Reconocer la relevancia cultural de deportes como el rugby } \\
\text {-Comprender la importancia y el significado de las tradiciones vinculados con el Touch-Rugby } \\
\text {-Interpretar el papel que desempeñan los árbitros en la sociedad } \\
\text {-Comprender la importancia del respeto y los valores en el deporte } \\
\text { Cognition }\end{array}$}} \\
\hline & \\
\hline & \\
\hline & \\
\hline LOTS & $\begin{array}{l}\text { Comparar, nombrar, asociar, explicar, describir, seleccionar, } \\
\text { elegir, utilizar, observar, organizar }\end{array}$ \\
\hline HOTS & $\begin{array}{l}\text { Distinguir, proponer, adaptar, opinar, analizar, crear, diseñar, } \\
\text { diferenciar, concluir... }\end{array}$ \\
\hline
\end{tabular}

\section{Participantes y contexto}

Los participantes del estudio fueron el alumnado de un grupo de cuarto curso de ESO formado por 20 alumnos de entre 15-17 años de edad (nueve alumnos y 11 alumnas). El nivel de dominio de la lengua inglesa promedio de este grupo era medio-alto y su conocimiento del Touch-Rugby prácticamente nulo. Además, era la primera vez que el estudiantado experimentaba el método AICLE, por lo que el planteamiento de la investigación se centró en conocer, desde un paradigma interpretativo, las percepciones que genera el primer contacto con el método AICLE en EF.

\section{Técnicas de recogida de datos}

Se utilizaron varios instrumentos de recogida de datos a partir de los cuales se realizó una triangulación y comparación de los resultados, siguiendo el modelo del trabajo de Coral (2010).

-Focus group. Se realizó al finalizar la propuesta. Participaron 4 alumnos (dos chicos y dos chicas), elegidos mediante la técnica de muestreo de expertos (Patton, 2002), basada en la elección por parte del investigador de acuerdo a su criterio y conocimiento del grupo. La elección de esta técnica de muestreo vino determinada por las características de la población adolescente objeto de investigación. En particular, dado que el estudiantado de secundaria presenta rasgos muy dispares en términos de maduración psicológica y social, se valoraron parámetros como la locuacidad, la implicación en el proceso de enseñanza-aprendizaje, el sexo (paridad), la predisposición e interés por participar en el estudio y la capacidad crítica demostrada a lo largo del proceso. En definitiva, se seleccionaron aquellos participantes susceptibles de aportar información de calidad con la que responder a la pregunta de investigación. La premisa del grupo de discusión era desvelar el significado que tuvo para el alumnado la introducción del método AICLE en EF.

-Registro anecdótico. Enél el profesor-investigador reflejó, en base a un proceso de observación participante, evidencias sobre las interacciones del alumnado en situaciones cotidianas vividas durante la intervención. Para su redacción se registró la actuación observada tras finalizar cada sesión, de forma inmediata y de manera breve y lo más clara posible, tratando de no distorsionar los incidentes descritos. Su redacción se estructuraba en dos columnas paralelas en las que se escribía, por una parte, la descripción fehaciente del incidente observado y, por otra, la apreciación e interpretación del docente-investigador. Este instrumento permitió reflejar evidencias constatables sobre las que fundamentar la interpretación posterior de los datos.

-Diarios de reflexión. Los diarios analizados provenían del total de los 20 componentes de la clase. Este instrumento es una técnica de recogida de información muy habitual en contextos educativos (Elliot, 1991; Latorre, 2003; Mcniff \& Whitehead, 2006) por su prestigio y tradición, dado que permite recoger información significativa sobre el proceso de enseñanza-aprendizaje (Zabalza, 2004). En este caso se ha optado por la modalidad de Analytical writing, de modo que se pautaron en torno a diferentes dimensiones como: el nivel y uso percibido de inglés, la nueva forma de vivir la EF en inglés, expectativas y experiencias ante elAICLE, participación e implicación en las tareas, aprendizaje sobre aspectos específicos de la materia (táctica y técnica del ToughRugby y sus procesos de aprendizaje). Su utilización permitió disponerdeinformación proveniente de todos los participantes, incrementando de este modo la validez del estudio, en tanto que pudo emplearse como elemento de triangulación.

\section{Análisis de datos}

El estudio de la información obtenida se llevó a cabo mediante un análisis conjunto de contenido, entendido como una técnica sistemática y cualitativa que trabaja con materiales representativos (Porta \& Silva, 2003). Para el análisis completo de los datos se llevaron a cabo estrategias de codificación, fragmentación y categorización. Antes de llegar a las categorías o núcleos de contenido definitivos se identificaron las unidades de significado y los temas emergentes en el discurso, procediendo a su posterior fragmentación y categorización en base a cadenas textuales diferenciadas. Los resultados obtenidos fueron sometidos a un proceso de member checking, consistente en verificar la conformidad de los informantes con la interpretación final de los resultados. 


\section{Resultados}

Los resultados obtenidos del análisis permiten conformar cinco categorías o núcleos de contenido: temor a la lengua, motivación y participación en la asignatura, aprendizajes específicos de EF, mejora de la expresión oral en inglés e importancia del inglés para el futuro académico-profesional.

\section{Temor a la lengua}

Al inicio de la experiencia muchos alumnos exponían que temían no poder comunicarse en inglés debido a su bajo nivel. A ello cabe añadir que antes de la realización de la unidad didáctica desconocían tanto el contenido (Touch rugby) como el método AICLE. Esto les llevó a reflejar un discurso dubitativo a la hora de mostrar su predisposición para realizar las clases de $\mathrm{EF}$ en inglés.

A mí no me gusta ya que prefiero darlas o en lengua española (castellano) [...], pero si proponéis darla en inglés yo no puedo hacernada. Creo que dificultará la comunicación con los compañeros y será más difícil jugar.

En esta línea fueron constantes las referencias a inquietudes y miedos acerca de las dificultades de comprensión, tanto del contenido teórico como de las explicaciones de las tareas de la práctica.

Me va a costar bastante, ya que me cuesta bastante hablar en inglés y a la hora de las explicaciones en inglés, me va a costar entenderlo y comunicarme en inglés. Espero que el vocabulario sea sencillo.

Además, me preocupa no acabar de entender lo que haya que hacer en el juego, las explicaciones en inglés y por tanto no enterarme de la clase, además, al ser el examen de contenidos en inglés tambiénme da miedo de cara a la nota.

Este miedo era patente ya que, en las clases iniciales, principalmente en las dos primeras, los alumnos trataban de inhibirse del uso oral de la lengua, intentando evitar tener que comunicarse verbalmente al realizar las tareas. Era palpable que no estaban acostumbrados/as a realizar las clases de EF en inglés y mucho menos a comunicarse en él mientras practicaban deporte.

Bueno, al principio la verdad es que éramos todos bastante tímidos

a la hora de hablar en inglés, pero ya en las últimas sesiones, nos hemos esforzado más.

Como es normal, no se comunicaban en todo momento en lengua inglesa; pero la evolución de las primeras sesiones a las últimas fue notable.

\section{Motivación y participación en la asignatura}

Muchos de los alumnos admiten que al interactuar desde un planteamiento que les obligaba a comunicarse constantemente se han sentido más participativos de lo habitual a la hora de realizar las clases de EF.

Me ha parecido diferente, no ha sido igual que otras clases, hemos tenido que tener estrategias, y la verdad es que todos han participado bastante.

Esto facilitó, en consecuencia, que los alumnos que generalmente no eran muy participativos se sintieran más integrados y motivados.

Siempre me suelo cansar rápido de los juegos porque no participo mucho, pero al ser necesaria la comunicación para decidir la táctica me he sentido mucho más partícipe.

De hecho, este planteamiento fue respaldado en varias ocasiones por el alumnado participante en el grupo de discusión.

Yo, al igual que mi compañera, no suelo participar mucho en deportes como el futbol, o el baloncesto, y la verdad es que de esta manera, con muchos más juegos y teniendo que pensar y decidir la estrategia, me he sentido más partícipe del juego, ya que es un juego en equipo y se necesita a todos los compañeros.

Asimismo, además de la preminencia del componente comunicativo del nuevo enfoque, que sin duda cambió la lógica de relaciones y las dinámicas habituales de la clase de EF (dando protagonismo a alumnado más retraído), la propia introducción de la lengua inglesa también actuó en algunos casos como agente motivador per se.

A mí de normal la educación física no es que me guste mucho, pero al hacerlo en inglés y mediante más juegos, he participado más y me he sentido más a gusto dentro del juego normal.

\section{Aprendizajes específicos de Educación Física}

Los aprendizajes específicos de EF fueron otro núcleo común en las narrativas analizadas. En particular, a pesar del hándicap lingüístico para comunicarse de forma fluida, todo indica que el planteamiento no se vio afectado negativamente por la lengua inglesa. Es decir, el inglés no supuso una barrera infranqueable para la adquisición de nuevos aprendizajes específicos.

Yo personalmente juego a fútbol, pero [el Touch-Rugby] me ha parecido un deporte donde se trabaja mucho la inteligencia, incluso más que en fútbol, y por eso creo que he aprendido tanto, porque para poder llegar al objetivo, debes de hablar y jugar en equipo con una idea clara

Dado que gran parte de las tareas estaban centradas en la táctica y la estrategia, el alumnado evolucionó de manera notable a la hora de pensar y comunicarse durante la práctica. Ello les proporcionó un mayor conocimiento del espacio de juego, así como una mayor amplitud del espectro táctico en su capacidad cognitiva.

Nos ha hecho pensar mucho, es un deporte donde tienes que pensar en equipo y utilizar la inteligencia mucho. [...]A mí me gustaría que todos los años pudiéramos jugar y además de la manera que lo hemos hecho, con muchos juegos donde participábamos todos.

A destacar en este punto que muchos de ellos, en el día a día, se mostraban satisfechos de haber podido adquirir ese tipo conocimientos a través de tareas eminentemente participativas.

\section{Mejora de la expresión oral}

Con el paso de las sesiones el alumnado fue plenamente consciente de que la EF a través del método AICLE les permitía potenciar su dominio de la lengua inglesa, haciendo especial mención a la comunicación oral.

Bueno, al principio la verdad es que éramos todos bastante tímidos a la hora de hablar en inglés, pero ya en las últimas sesiones, lo hemos hecho mucho más.

Este hecho se palpa también en el análisis del registro anecdótico del profesor-investigador, evidenciando que día a día la gran mayoría de alumnos se esforzaba por comunicarse oralmente a través del uso de palabras específicas, frases cortas y estructuras ordenadas; en coincidencia con las demás fuentes de información.

Me he dado cuenta que en solo siete clases he podido mejorar mi comunicación oral, me he esforzado mucho por mejorar y me he visto más progreso que en la asignatura de inglés.

Algunos compañeros sí que hemos intentado hablar en inglés porque pensamos que es muy beneficioso para nosotros, creo que ha estado bien, ya que hemos ido poco a poco introduciendo la lengua.

También es destacable el aprecio del alumnado por el uso real y significativo de la lengua que propone el método AICLE, en contraposición con la asignatura específica de inglés, más centrada en la adquisición de estructuras gramaticales y vocabulario.

Este año [en clase de inglés] solo hacemos que redacciones y gramática, y el nivel hablado es muy pobre, creo que habría que mejorarlo. En educación física es diferente, ya que cuando estás jugando no te acuerdas.

Yo creo que es una buena manera de practicar la lengua oral, ya que en clase [de inglés] se trabaja toda la gramática, el vocabulario, la escucha, pero el oral es lo que menos se practica.

Con todo, existen voces que confiesan no haberse comunicado con tanta soltura y solvencia. No obstante, ello no ha sido óbice para no valorar positivamente la mejora en su nivel de comprensión.

Hay gente que tiene un nivel bastante bajo de inglés y que le cuesta mucho, pero también les sirve para esforzarse y entender mejor a los demás.

Para mí ha sido complicado y prácticamente no me he comunicado en inglés con mis compañeros, ya que me resulta bastante difícil, aun así he podido comprender todo y mejorarlo con las sesiones. 
Importancia del inglés para el futuro académico-profesional

Esta última categoría reconoce el sentir del alumnado de querer mejorar la destreza lingüística y la capacidad comunicativa en inglés, pensando tanto en el próximo futuro académico, como en el desarrollo profesional posterior Esta realidad parece tener una relación clara con la predisposición hacia la experienciaAICLE.

Yo quiero ser fisioterapeuta enfocado al deporte, y sé que necesitaré un buen nivel de inglés para serlo, por eso [introducir el AICLE en $\mathrm{EF}]$ me parece una buena idea.

La importancia del inglés para el futuro académico-profesional, además, no es solo reconocida por aquellos que tienen decidida la opción profesional a seguir, sino que se percibe como un sentir generalizado. Es decir, independientemente del futuro académico o laboral por el que se decida optar, el alumnado es consciente de la importancia del inglés en todos los casos.

Yo no sé qué quiero ser de mayor, pero sé que tengo que mejorar mi nivel de inglés porque prácticamente en todas las carreras te piden algo de inglés y todos los trabajos también.

En definitiva, a pesar de reflejar una motivación extrínseca basada en un uso instrumental del aprendizaje lingüístico, esta creencia actúa como un importante leitmotiv a la hora de asumir la clase de EF en inglés. Como se ve, incluso el alumnado que no necesariamente siente un especial interés por la $\mathrm{EF}$, ni por la lengua inglesa, ve en esta cuestión un argumento de peso para afrontar la experiencia con determinación.

\section{Discusión}

Los resultados complementan y refuerzan el actual estado de la cuestión, perfilando una serie de categorías en torno a las que se configura la concepción del alumnado sobre el método AICLE y su empleo en EF. En primer lugar, el alumnado hace explícito un sentimiento de aprensión y temor ante la propuesta de trabajar por primera vez una unidad didáctica de EF mediante el método AICLE. En coincidencia con Montávez, Mariscal y López (2002), todo apunta a que la causa de este reparo puede hallarse en el miedo al ridículo o a bajos niveles de autoestima. Esta inseguridad, previa a la aplicación de la unidad didáctica, se muestra también en línea con lo expuesto por Figueras et al. (2011). Asimismo, tras este escenario inicial, los resultados del análisis muestran un comportamiento paralelo a lo descrito por Christopher, Dzakiria y Mohamed (2012), coincidiendo en que según pasaban las sesiones, las primeras reticencias fueron diluyéndose y dando paso a sentimientos de mayor seguridad y confianza en el uso del inglés. De hecho, incluso el alumnado menos participativo, ya fuera por inseguridad, timidezo introversión, también acabó adquiriendo mayores niveles de confianza, en la línea de lo expuesto por Reyes (2014), asegurando que en cualquier caso comprendieron las tareas propuestas sin problema.

La motivación e implicación relativa a la asignatura de EF ha sido otra manifestación relevante, en sintonía con lo apuntado por Alías (2011), Coral y Lleixà (2013) y Chiva et al., (2015), quienes en sus respectivos análisis ya determinaron que el tipo de actividades que promueve el método AICLE despiertan y promueven una mayor participación e implicación del estudiantado. Además, dado que las actividades propuestas por el método AICLE favorecen la interacción y participación constante del alumnado, en aras de una construcción significativa de los nuevos aprendizajes (González, et al., 2013), los participantes podrían haber visto incrementado su nivel de motivación y participación al sentirse plenamente protagonistas de su propio proceso de aprendizaje. Otra cuestión que ha podido influir en este sentido es la motivación intrínseca generada por la propia asignatura de EF (Alonso, et al., 2015; Coral, 2010); o incluso por el propio uso de la lengua inglesa, tal y como expuso algún alumno/a en el grupo de discusión. De este modo, el incremento progresivo de la implicación y participación a lo largo de la propuesta se muestra en consonancia con los hallazgos de Coral (2010), Montávez et al. (2002) y Christopher et al., (2012).

Respecto a la categoría referida a los aprendizajes específicos de $\mathrm{EF}$, conviene recordar que la mejora lingüística en una propuesta basada
enAICLE comparte relevancia con la mejora del contenido que se está trabajando(Coyle, etal., 2010). En este sentido, del discurso del alumnado puede extraerse que la lengua inglesa no supuso ningún impedimento en el correcto desarrollo de las sesiones, ni tampoco en el aprendizaje del contenido(Touch-Rugby); algo ya analizado también por Dalton-Puffer (2011) con resultados similares. En general, el grupo se mostró satisfecho y destacó su aprendizaje a nivel de táctica, de estrategia y de conocimiento del Touch-Rugby como modalidad deportiva, en armonía con lo advertido por Figueras et al. (2011).

Por otra parte, coincidiendo plenamente con lo planteado por Montávez et al. (2002), del análisis se deriva otra cuestión a tener en consideración: la mejora de las capacidades comunicativo-expresivas del alumnado. Esto podría explicarse debido al vínculo de la lengua con el movimiento (Alías, 2011), hecho que favorece su uso real y significativo. Asimismo, las tareas participativas y de carácter crítico y deliberativo propician que el alumnado sea participante activo de su aprendizaje (Coral \& Lleixà, 2016), de manera que se incrementa el Student Talking Time (tiempo de habla del estudiantado) en detrimento del Teacher Talking Time (tiempo de habla del profesorado) (Bentley, 2007). Al propiciar tantas situaciones comunicativas, incluso aquellos más reticentes a utilizar el inglés se han visto imbuidos a ello(Salvador, Chiva \& Fazio, 2016) y, aunque se expresaran en menor medida, sí han señalado la mejora en sus habilidades de comprensión, en consonancia con lo indicado por Figueras et al. (2011).

Por último, la última categoría surgida hace referencia a la predisposición por el aprendizaje de la lengua inglesa en relación a sus futuras expectativas académicas y laborales. Las motivaciones expuestas en este sentido se dividen en dos vertientes. Por un lado, el alumnado relaciona el aprendizaje de la lengua inglesa con unas mejores perspectivas laborales en su futuro, algo que ya se percibió en los trabajos de Christopher et al. (2012) y Figueras et al. (2011). Por otro lado, muchos alumnos también manifiestan, de forma explícita, un abanico más amplio de posibilidades en lo referente a su futuro académico. Este hallazgo, aun siendo lógico, no deja de ser novedoso en tanto que se trata de estudiantes de secundaria, en contraposición con la mayoría de los estudios referidos al método AICLE realizados hasta la fecha.

\section{Conclusiones}

El presente estudio de caso interpreta la percepción de un grupo de secundaria al experimentar una aplicación del método AICLE en EF. Los resultados obtenidos afianzan el actual estado de la cuestión para esta área de conocimiento, desvelando cinco categorías o núcleos fundamentales de contenido: Temor a la lengua, Motivación y participación en la asignatura, Aprendizajes específicos de Educación Física, Mejora de la expresión oral en inglés, e Importancia del inglés para el futuro académico-profesional.

En lo referente al Temor a la lengua el estudio desvela cómo, al inicio, un sector del alumnado se mostraba reticente al uso del método AICLE, ya que en su mayoría consideraban que su (in)capacidad comunicativa en inglés podría dificultar el adecuado seguimiento de las clases. Sin embargo, a medida que se fueron sucediendo las sesiones, se dio una progresión que provocó cambios sustanciales en sus perspectivas $\mathrm{y}$ actitudes iniciales.

La Motivación y participación en la asignatura fue otro de los núcleos de contenido sobre los que se configura este análisis. El trabajo pone en evidencia, tanto desde las narrativas del alumnado como desde la observación del profesor-investigador, un alto grado de interés y participación en las clases. Además, dada la nueva dinámica de las clases (más comunicativa e interactiva) facilitada por el método AICLE, se advierte que el alumnado que anteriormente se mostraba poco participativo, se implicó más e incluso lideró algunas tareas con gran determinación.

Por otra parte, destacar que los Aprendizajes específicos de EF no solo no se vieron disminuidos con la propuesta AICLE, sino que además de haberse producido nuevos aprendizajes específicos del área se dio un vuelco en el que emergieron aprendizajes menos comunes hasta 
la fecha, como la táctica o la estrategia. Esta nueva concepción, además de concebirse igual de importante que el tradicional aprendizaje basado en la técnica, dio pie a un modelo de aprendizaje mucho más inclusivo; ya fuera para alumnos con menor nivel técnico o de habilidad motriz, como entre participantes de ambos sexos.

Respecto a la Mejora de la expresión oral en inglés, es claramente visible que la percepción generalizada del alumnado apunta a una valoración muy positiva. Esta percepción se apoya en la enorme cantidad de situaciones comunicativas facilitadas por la propuesta didáctica implementada. En especial, en momentos de la práctica de EF en los que el uso de la lengua fue significativo y real.

Del análisis emerge finalmente como núcleo de significado la Importancia del inglés para el futuro académico-profesional. En este sentido, el alumnado manifestó ser consciente de la necesidad de mejorar su nivel de inglés para estar a la altura de sus propias expectativas académicas y profesionales. Este hecho podría haber actuado como un aliciente o motivación extrínseca que, en cualquier caso, pareció facilitar el beneplácito del alumnado hacia el método AICLE.

En definitiva, si bien es cierto que a través de una única aplicación didáctica resulta complicado descifrar de manera categórica el sentir del alumnado respecto al método AICLE, el estudio ha aportado conclusiones de interés. Además, como aportaciones generales para mejorar la introducción del AICLE en EF, el artículo sugiere que este método se optimiza en EF cuando se emplean contenidos y estilos de enseñanza que promueven trabajo cooperativo, propuestas de superación de retos y resolución de problemas en grupo. Por otra parte, también es importante resaltar la importancia de ser perseverantes en la aplicación del métodoAICLE, ya que de los resultados también se desprende que ante el primer contacto es normal que surjan actitudes y conductas de inseguridad, temor e incluso repulsión; pero si se superan las dificultades de esta fase inicial, la situación mejora considerablemente, llegando a generar sensaciones muy satisfactorias en consonancia con los hallazgos de Coral (2010), Montávez et al. (2002) y Christopher et al., (2012). En este sentido, conviene decir que una sola experiencia AICLE ha sido suficiente para modificar positivamente las perspectivas iniciales del alumnado, mostrando un interés explícito por repetir la experiencia. De cara al futuro, para profundizar y complementar este estudio, podrían ser de gran interés nuevas investigaciones relativas al sentir y percepción del profesorado.

\section{Agradecimientos}

El presente trabajo se llevó a cabo gracias al apoyo del Proyecto de Innovación Educativa SPIEDA de la Universitat Jaume I (número de referencia 3256).

\section{Referencias}

Alías, D. (2011). El valor didáctico del juego y del movimiento en la enseñanza del inglés en el primer ciclo de Primaria. Campo abierto, 30(2), 23-41.

Alonso, J. A., Cachón, J., Castro, R., \& Zagalaz, M. L. (2015). Propuesta didáctica bilingüe para educación física en educación primaria. Juegos populares tradicionales ingleses. Retos: Nuevas tendencias en Educación Física, Deporte y Recreación, (28), 116-121.

Bentley, K. (2007). Student talking time. How can teachers develop learners communication skills in a secondary school CLIL programme? Revista Española de Lingüistica Aplicada. (1), 129-140.

Chiva, O, Isidori, E., \& Fazio, A. (2015). Educación Física bilingüe y pedagogía crítica: una aplicación basada en el judo. Retos: Nuevas tendencias en Educación Física, Deporte y Recreación, (28), 110-115.

Chiva, O., \& Salvador, C. (2016). Aprendizaje integrado de Educación Física y Lengua Inglesa. Barcelona: Inde.

Christopher, A., Dzakiria, H., \& Mohamed, A. (2012). Teaching English through sport: a case study. Asian EFL Journal. Professional Teaching Articles. 59(4), 20-29.

Coral, J. (2010). L'aprenentatge de l'anglès a través de l'educació física: el programa «mou-te i aprèn». Temps d'educació, (39), 149-170.

Coral, J. (2012). Aprenentatge integrat de continguts d'educació fisica i llengua anglesa: educació fisica en AICLE al cicle superior de primaria. Barcelona: Facultat de Formació del professorat.

Coral, J., \& Lleixà, T. (2013). Las tareas en el aprendizaje integrado de educación física y lengua extranjera (AICLE). Determinación de las características de las tareas mediante el análisis del diario de clase. Retos: Nuevas tendencias en
Educación Física, Deporte y Recreación, (24), 79-84.

Coral, J., \& Lleixà, T. (2016). Physical education in content and language integrated learning: successful interaction between physical education and English as a foreign language. International Journal of Bilingual Education and Bilingualism, 19(1), 108-126.

Coyle, D., Hood, P. \& Marsh, D. (2010). CLIL. Cambridge: CUP.

Creswell, J.W. (2002). Educational Research: Planning, Conducting, and Evaluating Quantitative. Upper Saddle River: Prentice Hall.

Dalton-Puffer, C. (2011). Content-and-Language Integrated Learning: From Practice to Principles?. Annual Review of Applied Linguistics, 31, 182-204.

Devos, N. (2012). CLIL in Physical Education: Evidence for Language and Content Scaffolding during Peer Interaction. En P. Lennon (Ed.) Learner Autonomy in the English Classroom: Empirical Studies and Ideas for Teachers (pp. 359381). Frankfurt: Peter Lang.

Elliot, J. (2007). Reflecting where the action is. London: Routledge.

Figueras, S., Flores, C., \& González, M. (2011). Educació Física en anglès: percepcions dels estudiants entorn d'una experiència metodològica en el marc universitari. Aloma: Revista de Psicologia, Ciències de l'Educació i de l'Esport, (29), 61-80.

García, J.V., García, J.J., \& Yuste, J.L. (2012). Educación Física en inglés. Una propuesta para trabajar la higiene postural en Educación Primaria. Retos: Nuevas tendencias en Educación Física, deporte y recreación, (22), 70-75.

González, C., Cecchini, J. A., Fernández-Río, J. \& Méndez, A. (2008). Posibilidades del modelo comprensivo del aprendizaje cooperativo para la enseñanza deportiva en el contexto educativo, Aula Abierta, $36(1,2), 27-38$.

González, S., Villar, L., Pastor, J.C., \& Gil, P. (2013). Propuesta didáctica interdisciplinar en educación primaria en España: la enseñanza de la educación física y el inglés. Paradigma, 34(2), 31-50.

Halcomb, E.J., \& Davidson, P. M. (2006). Is Verbatim Transcription of Interview Data always Necessary? Applied Nursing Research, 19(1), 38-42.

Hernando, A., Hortigüela, D. \& Pérez-Pueyo, A. (2018). Percepción de coordinadores de programas bilingües y docentes de educación física en inglés en secundaria sobre el proceso de implantación y desarrollo del bilingüismo en la Comunidad de Castilla y León, Retos: Nuevas tendencias en Educación Física, Deporte y Recreación, (33), 63-68.

Latorre, A. (2003). La investigación-acción. Conocer y cambiar la práctica educativa. Barcelona: Graó.

Lova, M., \& Bolarín, M. J. (2015). La coordinación en programas bilingües: las voces del profesorado, Aula Abierta, 43(2), 102-109.

McNiff, J., \& Whitehead, J. (2006). All you need to know about action research. Sage Publications.

Montávez, M., Mariscal, A., \& López-Díaz, I. (2002). Desdramaticemos el inglés. Propuesta interdisciplinar: Educación Física (expresión corporal) y Lengua extranjera. Retos. Nuevas tendencias en Educación Física, Deporte y Recreación, (1), 29-36.

Parise, M., Pagani, A. F., Cremascoli, V. \& Iafrate, R. (2015). Rugby, selfperception and prosocial behaviour: evidence from the italian «rugby project for schools», Revista Iberoamericana de Psicología del ejercicio y el Deporte, 10(1), 57-61.

Patton, M.Q. (2002). Qualitative Research and Evaluation Methods. London: Sage.

Porta, L., \& Silva, M. (2003). La investigación cualitativa: El Análisis de Contenido en la investigación educativa. Red Nacional Argentina de Documentación e Información Educativa. Recuperado de: http://www. uccor. edu. ar/paginas/ REDUC/porta. pdf.

Ramos, F., \& Ruiz, J.V. (2011). La Educación Física en centros bilingües de primaria inglés-español. RESLA, 24, 153-170.

Reyes, A. (2014). Una propuesta didáctica para favorecer la comunicación oral en inglés en el área de educación física en ciclo inicial de educación primaria. Phonica, (9-10), 213-221.

Rio, L., Di Rubbo, N., \& Gómez-Paloma, F. (2014). Natural acquisition of the second language (12) through routine movements in children, Journal of Human Sport \& Exercise, (9), 355-358.

Rottmann, B. (2007). Sports in English. Learning opportunities through CLIL in Physical Education. En C. Dalton-Puffer \& U. Smit (Eds.), Empirical Perspectives on CLIL Discourse (pp. 205-227). Frankfurt: Peter Lang.

Salvador, C., Chiva, O., \& Fazio, A. (2016). Características del Aprendizaje Integrado de Contenidos de Educación Física y Lengua Extranjera. Retos. Nuevas Tendencias en Educ. Física, Deporte y Recreación. (29), 120-125.

Salvador, C., Chiva, O., \& Ruiz, N. (2016). Aprendizaje integrado de contenidos y lengua extranjera. Educación física e inglés. En O. Chiva \& M. Martí (Coord.), Métodos pedagógicos activos y globalizadores (pp. 45-64). Barcelona: Graó.

Salvador, C., Chiva, O., \& Isidori, E. (in press). Aprendizaje de una lengua extranjera a través de la educación fisica: una revisión sistemática. Movimento. $0(0), 00-00$

Sánchez-Alcaraz, B. J., Gómez-Marmol, A., \& Más, M., (2016). Estudi de la motivació d'assoliment i orientació motivacional en estudiants d'educació física. Apunts. Educació Física i Esports. (124) , 35-40.

Sánchez-Gómez, R., Devís-Devís, J., \& Navarro-Adelantado, V. (2014). El modelo teaching games for understanding en el contexto internacional y español: una perspectiva histórica, Ágora para la Educación Física y el Deporte, 16(3), 1972013.

Valera, S., Ureña, N., Ruiz, E., \& Alarcón, F. (2010). La enseñanza de los deportes colectivos en educación física en la E.S.O., Revista Internacional de Medicina y Ciencias de la Actividad Física y el Deporte, 10(40), 502-520. 


\section{CULTURA, CIENCIA Y DEPORTE}

REVISTA DE CIENCIAS DE LA ACTIVIDAD FÍSICAY DEL DEPORTE

UNIVERSIDAD CATÓLICA SAN ANTONIO DE MURCIA

Departamento de Ciencias de la Actividad Física y del Deporte.

Universidad Católica

San Antonio de Murcia.

Campus de Los Jerónimos, $\mathrm{s} / \mathrm{n}, 30107$

Guadalupe (Murcia) España

Tel: +34968278824

Fax: +34968278658

Murcia, 18 de diciembre 2018

\section{Autor \\ Dña. Celina Salvador-García \\ D. Oscar Chiva-Bartoll \\ Dña. Carla Colomer.}

Estimados investigadores,

Le comunicamos que su manuscrito con título "The effect of bilingual Physical Educatión students physical activity. This are not always as they seen" ha sido ACEPTADO para su publicación en la revista CULTURA_CIENCIA_DEPORTE (ISSN: 1696-5043). Sin otro particular, y esperando nuevas contribuciones por su parte, reciba un cordial saludo.

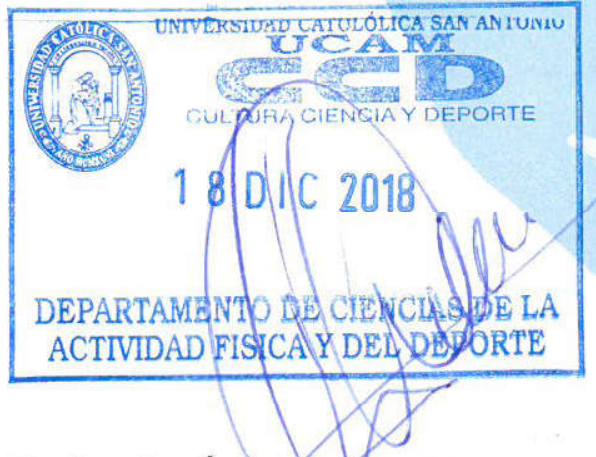

Fdo.: D. Jacobo Ánger Rubio Arias

Director de la revista CULTURA_CIENCIA_DEPORTE (1696-5043)

Universidad Católica San Antonio
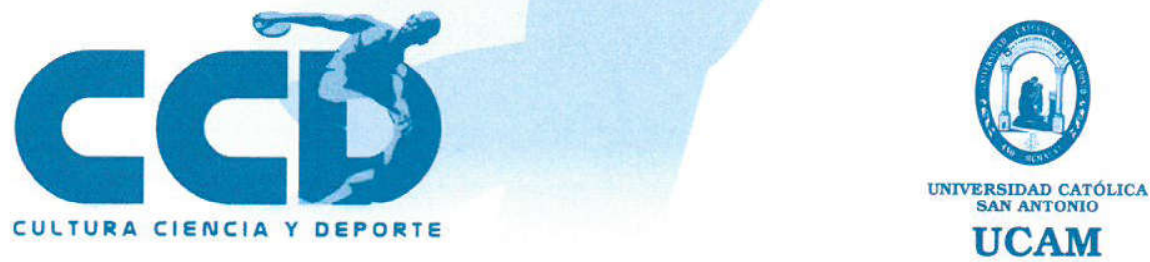